Monatsschr Kinderheilkd 2010 [Suppl. 1] 158:1-164

DOI 10.1007/s00112-010-2273-6

๑) Springer Medizin Verlag 2010

\title{
Abstracts der 106. Jahrestagung der Deutschen Gesellschaft für Kinder- und Jugendmedizin (DGKJ)
}

\author{
Potsdam-Babelsberg, 16.-19. September 2010
}

\section{Donnerstag, 16. September 2010}

\author{
Ärztliche Gesprächsführung mit Eltern kranker \\ Kinder \\ DGKJ-WS-01 \\ „Ärztliche Gesprächsführung mit Eltern kranker Kinder" \\ W. Kölfen \\ Elisabeth-Krankenhaus Rheydt
}

Sie machen sich auf den Weg zu gestressten und überforderten Eltern kranker Kinder mit einer ernsten Diagnose. Haben Sie einen Plan um die Eltern zu gewinnen? Vorwürfe und Ängste blockieren das Gespräch. Der Vater wird aggressiv und die Mutter reagiert nicht mehr. Macht es Sinn weiter zu sprechen oder sollten Sie abbrechen? Was werden die Eltern von dem was Sie sagen verstehen? Wie erreichen Sie eine vertrauensvolle Zusammenarbeit?

Kinderärzte müssen Sprachärzte sein. Nur eine zielgerichtete Gesprächsführung, die sich an der Situation und am Elterntyp orientiert, ist erfolgversprechend. Machen Sie sich die verschiedenen Techniken der Kommunikation zu Nutze, bleiben Sie der Chef im Ring und helfen Sie den Eltern weiter durch Ihre Professionalität im Umgang mit der Sprache. Zahllose Beispiele und Situationen aus dem täglichen Alltag werden besprochen und mit Hilfe des Riemann-Thoman-Modell werden Übungen durchgeführt.

Schlechte Nachrichten, Umgang mit Stress, schwierige Eltern, zielgerichtete Gesprächsführung, Elterntypen, Fragearten, Rieman-ThomanModell.

Zielgruppen: Assistenzärzte/Kinderärzte (Klinik/Praxis)

\section{Rationale Diagnostik, Therapie und Beratung: Das Handwerkszeug der Evidenzbasierten Medizin}

\section{DGKJ-WS-09}

Bewertung diagnostischer Tests

U. Mansmann

Institut für Medizinsiche Informatik, Biometrie und Epidemiologie, Pettenkofer School of Public Health, LMU München

Die Diagnose ist eine zentrale ärztliche Tätigkeit. Kombiniert mit einer Prognose ergibt sich hieraus die notwendigen ärztlichen und therapeutischen Maßnahmen zur Behandlung eines Patienten. Die richtige Diagnose ist zentral für eine gute und kosteneffektive Versorgung, sie schützt vor Unter- oder Überversorgung und erlaubt die angemessene Allokation der Ressourcen. Eine gute Diagnose ist nicht nur eine ärztliche Kunst, sie ist auch eine methodische Herausforderung. Ihre Methodik birgt Fallstricke, die ungewollt zu einer Fehlinterpretation von Ergebnissen diagnostischer Tests führen können.
Der Beitrag zum Workshop präsentiert einleitend die Grundlagen zur quantitativen Bewertung der Qualität diagnostischer Tests. Er zeigt, dass die in der Literatur oft eingeführten Begriffe der Sensitivität und Spezifität nur indirekt für die Interpretation von Testergebnissen hilfreich sind. Der Fokus liegt auf den prädiktiven Wert, die in der ärztlichen Praxis die Interpretation eines Testergebnisses (Das Stellen der Diagnose) ermöglichen.

Im zweiten Teil des Vortrages werden Testergebnisse in eine umfassendere ärztliche Strategie integriert. Es wird verdeutlicht, wie Nutzenüberlegungen gekoppelt mit der Qualität eines diagnostischen Testes - abhängig von der Prävalenz der Erkrankung - zu konträren Strategien führen können: Abhängig von der Prävalenz der Erkrankung ist es sinnvoll einen Test durchzuführen und darauf aufbauend eine Therapieentscheidung zu treffen. Andererseits gibt es Situationen, bei denen auf einen Test verzichtet werden muss und alle Patienten mit einer einheitlichen therapeutischen Strategie behandelt werden.

Der dritte Teil des Vortrages erläutert wie Labortests, die auf stetigen Messmerkmalen aufbauen, in ein positives oder negatives Ergebnis umgesetzt werden können. Es erfolgt eine kurze Einführung in die Technologie der ROC-Kurven und der Wahl idealer diagnostischer Schwellenwerte.

Der vierte Teil beschreibt die kontrollierte Überprüfung der Qualität diagnostischer Tests durch Diagnosestudien. Hier ist die Verifizierung des individuellen Krankheitszustandes oft aufgrund ethischer Aspekte nicht möglich. Die in der Regel hierzu notwendigen invasiven Verifizierungsverfahren lassen sich nicht für alle Studienteilnehmer rechtfertigen. Es werden einige Designs aufgezeigt, die trotz unvollständiger Verifikation des Gesundheitszustandes eine exakte Quantifizierung der Qualität erlauben.

In diesem Beitrag werden auch statistische Grundkonzepte zum Schätzen und Testen eingeführt und angewendet. Hierbei spielt das Konfidenzintervall eine zentrale Rolle. Es erlaubt einerseits die klassische Möglichkeit einer Signifikanzaussage, andererseits über diese qualitative Aussage hinaus gibt es relevante quantitative Information über die klinische Relevanz der erhobenen Daten erschlossen.

Der Beitrag schließt mit einem Ausblick auf die individualisierte Medizin, die als neues Paradigma diagnostische und therapeutische Strategien eng verbindet.

\section{Zeckenassoziierte Erkrankungen}

\section{DGKJ-WS-11}

\section{Epidemiologie zeckenübertragener Erkrankungen}

Der Überträger der Erreger von Lyme-Borreliose (LB) und Frühsommer-Meningoenzephalitis (FSME) ist die Schildzecke Ixodes ricinus. In sog. Naturherden zirkulieren die Erreger zwischen den Zecken und deren Wirten (insbesondere Nagetiere, Rot- und Rehwild). Der Entwicklungszyklus der Zecke dauert ein bis drei Jahre; sie durchläuft dabei drei Entwicklungstadien (Larve, Nymphe, adulte Zecke), für die jeweils eine Blutmahlzeit am Wirt notwendig ist. Voraussetzung für den Bestand des Erregers im Naturherd ist eine hohe Zeckendichte und 
eine hohe Populationsdichte der natürlichen Wirte. Zecken beginnen mit der Wirtssuche bei Temperaturen von 7 bis 10 Grad und ausreichend hoher Luftfeuchtigkeit. Typische Lebensräume für Zecken sind hohes Gras, Laubbäume und Büsche.

Die LB und die FSME sind die beiden häufigsten durch Zecken übertragenen Erkrankungen in Europa. Beiden Erkrankungen gemeinsam sind der Übertragungsmodus und die Verursachung von Krankheitssymptomen, die im schlimmsten Falle zu schweren neurologischen Folgeschäden führen können. Im Unterschied zur FSME kann sich eine Infektion mit Borrelia burgdorferi sensu lato jedoch auch an anderen Organen, insbesondere der Haut und den Gelenken manifestieren und zu entsprechenden Beschwerden führen. Die Diagnostik der FSME ist (serologisch) einfach; es besteht eine Meldepflicht nach Infektionsschutzgesetz. Die Diagnostik der Borreliose dagegen macht häufig Schwierigkeiten; somit ist auch die Epidemiologie unzuverlässiger als bei der FSME.

Die LB ist insgesamt wesentlich häufiger als die FSME, was u. a. auf eine höhere Durchseuchung der Zecken und einer weiteren regionalen Verbreitung des Erregers B. burgdorferi s. $l$. in Deutschland zurückzuführen ist. Für die LB sind nach einem Zeckenstich Serokonversionsraten von 20 bis $30 \%$ beschreiben worden; die Infektionswahrscheinlichkeit steigt mit der Dauer des Saugakts der Zecke. Das Risiko einer manifesten Erkrankung liegt zwischen o,4 und 4\%.

Die Risikogebiete für die FSME liegen in Deutschland vor allem in Bayern, Baden-Württemberg und Südhessen. Betroffen sind auch einzelne Landkreise in Rheinland-Pfalz und Thüringen. Bei über 90\% der Erkrankungen der letzten Jahre, bei denen der Infektionsort in Deutschland angegeben wurde, lag dieser in den jeweils aktuellen Risikogebieten. Das Risiko, in einem FSME-Risikogebiet nach einem Zeckenstich zu erkranken, liegt schätzungsweise zwischen 1: 10. ooo (bei einer angenommenen Zeckendurchseuchung von ca. 0,1\%) und 1: 300 (bei einer angenommenen Zeckendurchseuchung von ca. 3,5\%). Die Durchseuchung der Zecken ist nicht nur geographisch-regional unterschiedlich, sondern variiert auch erheblich innerhalb kleinster geographischer Einheiten (Naturherde).

Zecken können die verschiedensten Erreger beherbergen und entsprechend groß ist die Zahl der von ihnen übertragenen Erkrankungen. Neben der FSME und Borreliose sind dies u. a. (in alphabetischer Reihenfolge): humane granulozytäre Anaplasmose (Ehrlichiose), Babesiose, Fleckfieber (Rickettsiose), Krim-Kongo-Fieber, Q-Fieber, Rocky Mountain Fleckfieber, Südafrikanisches Fleckfieber, Tularämie, Zecken-Rückfallfieber. Diese Erkrankungen kommen allerdings in Deutschland nicht oder nur extrem selten vor.

\section{DGKJ-WS-14}

Therapie und Prävention der Lyme-Borreliose

F. Dressler

Kinderklinik der Medizinischen Hochschule Hannover

Die Lyme-Borreliose ist eine durch Zeckenstich übertragene Infektion mit Borrelia burgdorferi, bei der es vor allem zu Krankheitserscheinungen an der Haut, dem Nervensystem und an den Gelenken kommt. Prinzipiell ist die Prävention einer Lyme-Borreliose einer Therapie vorzuziehen, aber nur begrenzt möglich. Insbesondere ist der einzige in den USA zugelassene Impfstoff aus kommerziellen Gründen wieder vom Markt genommen worden und ein neuer Impfstoff nicht absehbar. Die Wahrscheinlichkeit eines Zeckenstichs lässt sich durch zweckmäßige Kleidung, gärtnerische Maßnahmen, Insektizide wie DEET und Permethrin sowie andere Maßnahmen zur Reduktion der Zeckenzahl senken. Rasche Entfernung von Zecken reduziert zudem das Borrelienübertragungsrisiko. Eine prophylaktische antibiotische Therapie nach jedem Zeckenstich wird in Europa nicht empfohlen. Der Wert der Untersuchung einer vom Patienten entfernten Zecke auf Borrelien ist zweifelhaft. Leider besteht auch bei hohen borrelienspezifischen Antikörpertitern kein sicherer Schutz vor einer Zweitinfektion nach erneutem Zeckenstich.
Für die Therapie der Lyme-Borreliose sind Antibiotika die Mittel der Wahl. Meist kann mit oralen Therapien mit Amoxicillin, Doxycyclin, Cephalosporin oder als Reservemittel Makroliden erfolgreich behandelt werden. Für die frühen Hautmanifestationen des Erythema migrans ist eine 10-tägige, beim Borrelienlymphozytom eine 20-tägige Therapie meist ausreichend. Bei der Lyme-Arthritis oder der im Kindesalter extrem seltenen Acrodermatitis chronica atrophicans ist eine 28-tägige orale Behandlung zu empfehlen. Neue Richtlinien der European Federation of Neurological Societies sehen auch bei unkomplizierter früher Neuroborreliose eine 14-tägige orale Doxycyclintherapie als ausreichend an. Kompliziertere Neuroborreliosen oder Lyme-Carditis sowie therapierefraktäre Lyme-Arthritis nach einer oralen Therapie sollten mit intravenösen Antibiotika wie Ceftriaxon, Cefotaxim oder Penicillin behandelt werden, wobei meist eine Therapie über 14 Tage erfolgen sollte.

Insgesamt ist die Prognose einer Lyme-Borreliose günstig, da die genannten Antibiotika ein Fortschreiten der Erkrankung verhindern können und meist zu einer vollständigen Ausheilung führen. Bei antibiotikarefraktären Beschwerden sollte die Diagnose überprüft werden, und bei bleibender Indikation eine zweite Antibiotikagabe erfolgen. Es gibt keine Evidenz zugunsten von sehr häufigen antibiotischen Therapien oder längerer Therapiedauer als 28 Tage. Bei der Lyme-Arthritis ist eine zusätzliche Therapie mit einem nichtsteroidalen Entzündungshemmer für die Dauer der Beschwerden indiziert. Haben auch 2 antibiotische Therapien nicht zur Besserung der Arthritis geführt, sollte eine Therapie analog zur juvenilen idiopathischen Arthritis mit intraartikulären Steroidgaben oder einem Basistherapeutikum wie Methotrexat erfolgen.

\section{Sinnvolle und aktuelle Diagnostik in der Kinder- und Jugendgastroenterologie}

DGKJ-WS-19

Sinnvoller Einsatz von MRT und CT

B. Kammer

Ludwigs Maximilians-Universität, Kinderpoliklinik

Ziel: Darstellung des sinnvollen Einsatzes der Computertomographie (CT) und der Magnetresonanztomographie (MRT) in der Kinder- und Jugendgastroenterologie.

Material und Methoden: Anhand von klinischen Fällen werden die Stufendiagnostik und die Indikationen zur CT bzw. der MRT aufgezeigt. Besonderes Augenmerk wird auf die Einschätzung und Größenordnung der Strahlenexposition durch die CT gelegt.

Ergebnisse: Die CT stellt eine überall und jederzeit verfügbare sehr effektive Methode dar, die eine schnelle und vollständige Abklärung ermöglicht. Die Indikationen zur CT ist vor allem in der Notfalldiagnostik beim schweren Bauchtrauma, zur Darstellung der Gefäße (z. B. prä-OP oder bei Durchblutungsstörungen des Darms), bei postoperativen oder posttherapeutischen Komplikationen (z. B. Abszess, Pankreatitis u. a. m.) gegeben. Abdominelle Tumoren, Erkrankungen der Leber und der Gallenwege, angeborene Fehlbildungen wie z. B. die Darmduplikaturen sollten eher mit der MRT abgeklärt werden. Die chronisch entzündlichen Darmerkrankungen sind eine Domäne der MRT.

Schlussfolgerung: Immer dann, wenn die diagnostische Aussagekraft von CT und MRT gleich gut ist, sollte der MRT aufgrund der fehlenden Strahlenbelastung im Kindesalter der Vorzug gegeben werden. Posttraumatische und postoperative Komplikationen sowie spezielle Probleme stellen eine Indikation zur CT dar. 


\section{Fehler- und Risikomanagement in der ambulanten und stationären Pädiatrie}

DGKJ-WS-20

Was ist CIRS und wie kann es sinnvoll im Fehler- und Risikomanagement integriert werden?

C. Thomeczek, J. Rohe, A. Sanguino Heinrich

Ärztliches Zentrum für Qualität in der Medizin (ÄZQ)

Patientensicherheit ist ist kein technisches Instrument, das einfach durch Verordnung umgesetzt werden kann. Essentielle Voraussetzung ist eine Änderung der Fehlerkultur im beruflichen Umfeld und damit eine kritische Auseinandersetzung mit dem eigenen Tun und der eigenen Fehlerhaftigkeit. Der Vortrag fokussiert auf die notwendigen professionellen Änderungen und auf die in den letzten Jahren stattgefundene Auseinandersetzung der medizinischen Profession bis zur Entwicklung von geeigneten Instrumenten für das Fehler- und Risikomanagement und der Veränderung der Fehlerkultur bis hin zum CIRSPädiatrie.

\section{DGKJ-WS-21}

Fehler- und Risikomanagementsysteme in pädiatrisch neonatologischen Intensivstationen

G. Selzer

Klinikum Bremen Mitte, Klinik für Neonatologie und pädiatrische Intensivmedizin

Seit über 10 Jahren haben wir Erfahrung mit den verschiedenen Phasen nach Einführung eines „Beinah-Fehler-Meldesystems" heute meist als "Critical incidents Reporting" (CIRS) bezeichnet. Es werden die Implementierung dieses Systems auf den beiden Intensivstationen unserer Klinik beschrieben. Im weiteren Verlauf das Pilotprojekt der Bremer Kinderkliniken unter wissenschaftlicher Leitung des Instituts für Gesundheits- und Medizinrechts.

Im Anschluss das „Verbundprojekt norddeutscher Kinderkliniken: Risiken verringern Sicherheit steigern. Kinderkliniken für Patientensicherheit" jeweils begleitet von der Universität Bremen und dem Institut für Gesundheit und Medizinrecht aus Sicht dieser Intensivbereiche. Mittlerweile ist dieses Risikomanagementtool in den 4 Kliniken der Gesundheit Nord Bremen in allen klinischen Bereichen eingeführt. Die Veränderung der „Fehlerkultur“, die zu einem neuen Umgang mit diesen „Incidents“ oder Beinahe Fehlern in dem „nonputitiven System“ führte und die sich daraus ergebenden Chancen werden aufgezeigt und mit Beispielen aus dem Stationsalltag dargestellt.

Die Grenzen und Schwächen werden ebenfalls genannt. Aus der Zahl der Berichte lassen sich keine Rückschlüsse über die Anzahl der „Incidents“ ziehen, CIRS ist nicht quantitativ nutzbar - die Anzahl der Meldungen ist eher positiv korreliert mit der momentanen Akzeptanz. Diese wiederum ist auch nach langer Zeit von den Rückmeldungen an die Mitarbeiter abhängig.

CIRS scheint aufgrund seines nonpunitiven Ansatzes zur „Delegation" der Verantwortung zu verleiten, dies ist nicht sinnvoll und nicht gewollt, persönliche Verantwortung ist Grundvoraussetzung für ein Qualitätsmanagementsystem.

CIRS ist nur einer von mehreren Bausteinen eines Qualitätmanagementsystems einer Station oder einer Klinik. Weitere sind notwendig (z. B. MoMo-Konferenzen, Hygienemanagement inklusive Hygienesurveillance (z. B. Neokiss), Standards, Training + Simulation usw.) können aber durch CIRS unterstützt und begleitet werden.

Mit der Veränderung der „Fehlerkultur“ besteht die Möglichkeit auch gemeinsame Strategien zur Prävention von „Critical Incidents“ zu entwickeln und damit die Sicherheit für die Patienten und die Mitarbeiter erhöhen. Dies wird bei entsprechender Transparenz und Rückmeldung zumindest in unseren „High-Risk-Bereichen“ von den MitarbeiterInnen trotz des zusätzlichen Aufwandes auch oder gerade in Zeiten zunehmender Arbeitsverdichtung akzeptiert.
DGKJ-WS-22

CIRS-Pädiatrie - Erfahrungen aus einem Jahr Online-CIRS für Kinderund Jugendärzte

D. Ewald

Klinikum der Johann Wolfgang Goethe-Universität

Critical Incident Reporting Systeme, CIRS und Fehlermanagementsysteme sind im Gegensatz zu deren Implementierung in KrankenhausEinrichtungen im ambulanten Bereich erst seit Ende 2008 aufgrund einer Initiative des Ärztlichen Zentrums für Qualität in der Medizin (ÄZQ), dessen Träger die Bundesärztekammer (BÄK) und die Kassenärztliche Bundesvereinigung (KBV) sind, bundesweit verbreitet. Anders als einrichtungsinterne Systeme besteht so die Möglichkeit über das Internet einrichtungsübergreifend und bundesweit Fehlerberichtsund Lernsysteme anzubieten.

Fehlerstatistiken zeigen, dass sich bestimmte kritische Ereignisse und Fehler in Arztpraxen, Ambulanzen oder stationären Einrichtungen gleichen und wiederholen. Werden CIRS als Lernsysteme genutzt, ermöglichen sie den Nutzern auf einer webbasierten Plattform solche Ereignisse anonym mit anderen zu teilen und Erfahrungen und Lösungen auszutauschen. Ziel ist der bewußte Umgang mit Fehlern - losgelöst von der Schuldfrage, hin zur Problemlösung und Fehler-Vermeidung.

CIRS-Paediatrie.de ist ein Angebot des Berufsverbands der Kinderund Jugendärzte $(\mathrm{BVKJ})$ für niedergelassene und stationär arbeitende Kinder- und Jugendärzte, Medizinische Fachangestellte, Kinderkrankenschwestern und anderes medizinisches Personal. Im Frühjahr 2009 startete das CIRS im Internet über die benutzergeschützte Plattform Paedinform. de, dem internetbasierten Intranet des BVKJ.

Wir stellen dar, wie das Angebot von niedergelassenen und in Krankenhäusern arbeitenden Kinder- und Jugendärzten angenommen wurde, welche kritischen Fehlermuster und Lösungsansätze zu deren Vermeidung berichtet wurden. Wir wollen im Workshop den Umgang und die Nutzung mit CIRS intern wie auch über das Internet mit den Teilnehmern schulen und kritisch hinterfragen.

\section{DGKJ-WS-23}

Beispiele gelungener Risikomanagement-Maßnahmen im stationären Bereich

M. Claßen

Klinik für Kinder- und Jugendmedizin, Klinikum Links der Weser

Jede Behandlung von Patienten beinhaltet das Risiko von Fehlern, die potenziell eine Gefahr für deren Gesundheit darstellen. Ein zentrales Instrument der Fehlererkennung und -vermeidung sind anonyme Meldesysteme für kritische Ereignisse: Beinahe-Schäden und Fehler (CIRS, Critical Incident Reporting System).

In einer multizentrischen Studie mehrerer norddeutscher Kinderkliniken wurde ein CIRS in den klinischen Alltag von 12 norddeutschen Kinderkliniken implementiert und über 24 Monate zentral eine Sammlung und Analyse aller eingehender Fehlerberichte vorgenommen.

Aus den 1299 Berichten wurden 1829 Risikokonstellationen extrahiert. Die häufigsten Konstellationen waren Medikationsfehler mit 35\%, Verfehlung von Standards mit 24\% und Risiken durch Dokumentationsfehler mit $15 \%$.

Die Daten zeigen repräsentativ für die stationäre Pädiatrie typische Risiken, ohne die Inzidenz solcher Fehler messen zu können. Aus den Berichten wurden Präventionsmaßnahmen für die beteiligten Kliniken abgeleitet und Empfehlungen für die Fehlervermeidung formuliert. In den Workshop werden neben den Daten der multizentrischen Studie anhand von Beispielen das Vorgehen bei Eingang einer Meldung und die sich daraus ergebenden Maßnahmen.

Die Ergebnisse der Studie, aber auch die Erfahrungen in der eigenen Klinik zeigen, dass ein Fehlermeldesystem mit signifikantem Benefit für die Sicherheit der Patienten eingeführt und erfolgreich in den Alltag einer Klinik integriert werden kann. 
DGKJ-WS-24

Beispiele gelungener Risikomanagement-Maßnahmen im niedergelassenen Bereich, Fragebogen und Benchmarking

N. Weissenrieder

Praxiszentrum Saarstrasse

In der Praxis des niedergelassenen Kinder- und Jugendarztes gibt es viele Bereiche, in denen Risiken auftreten können, die die Gesundheit von Patienten und Mitarbeitern beeinträchtigen können. Die Einführung eines Risikomanagements ist dabei hilfreich Prozesse zu identifizieren, bei denen das Auftreten von Fehlern in der Behandlung von Patienten oder Fehlern in der Organisation vorhersehbar ist. Risikomanagement leistet damit einen praktischen Beitrag zur Prävention.

Die Erhebung der Patientenzufriedenheit ist ein Instrument des praxisinternen Qualitätsmanagement. In Zusammenarbeit mit Frau Prof. Dierks $(\mathrm{MHH})$ wurde ein für die kinder- und jugendärztliche Praxis evaluiertes Instrument entwickelt, mit der die Zufriedenheit der ambulanten Versorgung aus Patientensicht (Kinder, Jugendliche und Bezugspersonen) ermittelt werden kann.

Das Zussammenführen dieser Daten ermöglicht erstmals in der ambulanten Pädiatrie ein Benchmarking der teilnehmenden Praxen.

\section{Zertifizierte (GNPI) Fortbildungsreihe zum Erwerb der Bezeichnung „Neugeborenen- Notzarzt"}

\section{DGKJ-WS-27}

Wärmehaushalt nach der Geburt

R. Schlößer

Kliniken der Johann Wolfgang Goethe-Universität, Zentrum für Kinder- und Jugendmedizin

Das Bemühen, Neugeborene, insbesondere Frühgeborene in einer optimalen Umgebungstemperatur zu halten, war immer schon Bestand der intuitiven als auch der Evidenz-basierten Medizin. Eine der ersten kontrollierten Studien in der Neonatologie hatte die Wärmetherapie zum Thema (W. Silverman 1958). Es ist anzunehmen, dass der Regelkreis der Temperaturregulation auch beim sehr unreifen Frühgeborenen funktioniert. Die Neutraltemperatur ist diejenige, in der der Energieverbrauch des Kindes am geringsten ist. Ziel jeder guten Erstversorgung ist es, dazu die Voraussetzungen zu schaffen und den Kältestress mit seinen Folgen zu verhüten. Die Maßnahmen, die dazu im Kreißsaal getroffen werden, müssen natürlich auch die jeweilige kritische Situation des Patienten berücksichtigen. So wird die effektivste von ihnen, der sofortige Hautkontakt mit der Mutter, nicht immer möglich sein. Auch die für den Wärmeschutz bei Erstversorgung von Frühgeborenen empfohlenen Polyethylenfolien müssen unter praktischen Erwägungen kritisch bewertet werden.

\section{DGKJ-WS-29}

Neuroprotektion nach schwerer Asphyxie und Therapie zerebraler Anfälle

F. Pillekamp

Universität Düsseldorf, Zentrum für Kinder- und Jugendmedizin

Ziel der Versorgung von Neugeborenen, insbesondere von Neugeborenen nach schwerer Asphyxie ist nicht allein deren Überleben zu gewährleisten, sondern auch die Chance auf eine normale zerebrale Entwicklung zu optimieren.

Da man weiß, dass Hirngewebe nach einem akuten hypoxisch-ischämischen Ereignis besonders vulnerabel ist und über verschiedene Mechanismen Stunden, Tage und sogar Wochen später noch regelhaft sekundäre Schäden drohen, ergibt sich die Chance, auch nach der Erstversorgung die langfristige Prognose zu verbessern:
$\mathrm{Zu}$ vermeiden ist eine Hyperventilation, die durch eine Vasokonstriktion insbesondere bei Frühgeborenen zu einer Ischämie und so zu einer periventrikulären Leukomalazie führen kann. Ebenso kann neben einer Hypoxie auch die schwere Hyperoxie Hirnschäden aggravieren. Die Beurteilung der Kreislaufsituation ist besonders dann von entscheidender Bedeutung, wenn von einer Störung der vaskulären Autoregulation auszugehen ist. Eine adäquate Glukoseversorgung sollte beachtet werden, da bekannt ist, dass auch milde Hypoglykämien in Langzeitschäden resultieren und Hyperglykämien wiederum die Osmolarität empfindlich stören. Hirnorganische Anfälle sollten medikamentös antikonvulsiv therapiert werden, das wann und wie bleibt jedoch umstritten. Hinsichtlich der anzustrebenden Temperatur gilt, dass die schädliche Hyperthermie vermieden werden sollte. Die Wirksamkeit einer moderaten Hypothermie über mehrere Tage konnte in mehreren Studien inzwischen für Reifgeborene gezeigt werden.

Ziel des Referates ist es, entsprechend dem aktuellen Wissensstand Empfehlungen zu geben. Die anzustrebenden Zielbereiche sollen jedoch auch begründet werden und die Evidenz der Empfehlungen hinterfragt werden.

\section{DGKJ-WS-31}

Gefäßzugänge und Volumentherapie im Kreißsaal

R. Schlößer

Kliniken der Johann Wolfgang Goethe-Universität, Zentrum für Kinder- und Jugendmedizin

In der Reihenfolge der wichtigen Maßnahmen in der Reanimation von Neugeborenen spielen der Gefäßzugang und die Verabreichung von Medikamenten und/oder Volumen erst eine Rolle, wenn Beatmung und mechanische Kreislaufetablierung durchgeführt worden sind. Wenn eine periphere Vene nicht oder nur schwer für einen Zugang erreichbar ist, ist die Katheterisierung der Nabelvene Mittel der ersten Wahl. Die Gabe von Volumen als kristalline Lösung ist vor allem bei vorangegangenem Volumenverlust indiziert, wobei dieser anamnestisch oder auch klinisch nicht immer eindeutig diagnostiziert werden kann. Eine wiederholte Gabe von Flüssigkeit ist bei Frühgeborenen kritisch zu betrachten.

\section{DGKJ-WS-33}

Besonderheiten in der Versorgung II: Kinderchirurgie und schwere Fehlbildungen: Gastroschisis, Omphalozele, Zwerchfellhernie, Spina bifida, obstruktive Uropathie

U. Rolle

Klinik für Kinderchirurgie, Klinikum der Johann Wolfgang-Goethe-Universität Frankfurt/M.

Die Prognose kritisch kranker Neugeborener ist besser, wenn diese Kinder in speziellen Zentren geboren und anschließend interdisziplinär versorgt werden. Das gilt insbesondere auch für Kinder mit angeborenen Fehlbildungen. Auf der anderen Seite kann nicht jeder Patient bereits antenatal in ein entsprechendes Zentrum verlegt werden. Patienten mit angeborenen Fehlbildungen, die einer zeitgemäßen kinderchirurgischen Versorgung bedürfen, müssen deshalb regelmäßig in entsprechende Perinatalzentren verlegt werden. Die initiale Versorgung der Neugeborenen obliegt den lokalen Ärzten und Pflegekräften. Die sich anschließende Stabilisierung zur Verlegung muss vom Neugeborenen-Notarzt durchgeführt bzw. koordiniert werden. Zunächst gelten dabei die allgemeinen Grundsätze der Versorgung eines kritisch kranken Neugeborenen (Atemwege, Kreislauf, Temperatur, Blutzucker, Infektion?, Information der Eltern, Information der Zieleinrichtung). Des Weiteren ist hervorzuheben, dass angeborene Fehlbildungen wie Gastroschisis, Omphalozele, Zwerchfellhernie, Spina bifida, Ösophagusatresie, Kloakenexstrophie, Blasenexstrophie oder obstruktiver Uropathie in der Regel keine Notfallindikationen zur Operation darstellen. Die Operationen erfolgen nach dem Prinzip der aufgeschobenen Dringlichkeit. 
Besonderheiten der Erstversorgung ergeben sich bei den Kindern mit Zwerchfellhernie, Gastroschisis, Omphalozele und Ösophagusatresie, da hier eine Maskenbeatmung bzw. CPAP-Atemhilfe vermieden werden sollte. Bei erforderlicher Intubation eines Kindes mit Ösophagusatresie sollte die Tubusspitze möglichst unterhalb der zu vermutenden ösophagotrachealen Fistel liegen. Eine in den oberen Ösophagusblindsack plazierte Magensonde erlaubt das intermittierende Absaugen von Speichel bei diesen Kindern. Die anderen Kinder dieser Gruppe bedürfen regelhaft einer Magensonde zur Dekompression des MagenDarmtraktes. Bei Patienten mit Gastroschisis, Omphalozele, Blasenexstrophie, Kloakenexstrophie und Spina bifida muss der lokale Befund mit steriler Folie abgedeckt und die Austrocknung vermieden werden. Das Darmpaket bei Gastroschisis und Omphalocele sollte dabei zentriert und etwas fixiert werden, um Torsionen oder venöse Stauungen zu vermeiden. Diese Patienten weisen einen zusätzlich erhöhten Flüssigkeitsbedarf auf. Bei Patienten mit erhöhtem Infektionsrisiko sollte eine Antibiotika-Therapie begonnen werden. Patienten, die einer baldigen Operation bedürfen, erhalten Vitamin K. Falls die Eltern des Kindes, den Transport nicht begleiten können, ist möglichst das Einverständnis zur Narkose und Operation einzuholen und zu protokollieren.

Zusammenfassend sind eine koordinierte Erstversorgung und Stabilisierung kritisch kranker Neugeborener mit angeborenen Fehlbildungen erforderlich, um einen sicheren Transport in ein Perinatalzentrum zu gewährleisten.

\section{DGKJ-WS-35}

\section{Besonderheiten in der Versorgung III: Frühgeborene, Mehrlings- schwangerschaften}

E. Mildenberger

Klinikum der Johannes-Gutenberg-Universität, Kinderklinik

Rund $10 \%$ aller Neugeborenen sind Frühgeborene. Hauptursachen der Frühgeburtlichkeit sind vorzeitige Wehen und vorzeitiger Blasensprung, denen sehr oft eine Chorioamnionitis zugrunde liegt. Dann folgt die Mehrlingsgravidität. Umgekehrt sind Mehrlinge 6-mal so häufig Frühgeborene wie Einlinge.

Frühgeborene und Mehrlinge sind Risiko-Neugeborene. Daher hat der gemeinsame Bundesausschuß mit Wirkung zum 1. Januar 2006 Versorgungsstrategien entsprechend Gestationsalter, Geburtsgewicht und Mehrlingsstatus festgelegt. Kinder, die die jeweiligen Kriterien erfüllen, sollen pränatal in geeignete Einrichtungen verlegt werden. Die Geburt eines Frühgeborenen ist oftmals kalkulierbar. Man hat also Gelegenheit, sich vorzubereiten.

Ist das Kind geboren, beginnt das ABC der Reanimation des Neugeborenen. Unter A werden initiale Maßnahmen und Sicherung des Atemweges subsummiert. Für sehr kleine Frühgeborene bedeutet dies die Lagerung des Kindes, so daß die Atemwege geöffnet werden (Schnüffelposition), ggf. nasales und orales Absaugen und die Applikation von Wärme (erhöhte Raumtemperatur, Heizstrahler, Wärmematratze, Mütze). Es besteht ein - wenngleich geringes - Risiko einer Hyperthermie. Daher muß die Temperatur gemessen werden!

Im ABC der Neugeborenen-Reanimation folgt jetzt - sofern das Frühgeborene nicht selbst anfängt zu atmen - die Beatmung. Die Empirie lehrt, daß bei Frühgeborenen die Ventilation mit initialen Blähdrücken von $20-25 \mathrm{~cm} \mathrm{H}_{2} \mathrm{O}$ erreicht werden kann. Hebt sich der Thorax nicht, oder steigt die Herzfrequenz nicht über 10o/min, kann der Blähdruck höher eingestellt werden. Um Barotraumata zu vermeiden ist es günstig, Vorrichtungen mit Druckbegrenzung zu verwenden. Es sollte nur so viel Druck aufgewendet werden, daß sich der Thorax gerade hebt. Die Anwendung von PEEP ist möglicherweise protektiv gegenüber einem Volutrauma. Eine große Zahl auch sehr kleiner Frühgeborener kann mit Maskenbeatmung stabilisiert werden. Möglicherweise kann durch die frühe Anwendung von Nasen-CPAP bereits im Kreißsaal spätere Beatmung vermieden werden. Bleibt das Frühgeborene nach den initialen Blähmanövern bradycard oder weist im Weiteren Zeichen der Ateminsuffizienz auf, sollte es intubiert werden. (Richtzahlen: $1 \mathrm{~kg}$ Körpergewicht: Tubus 2,5 mm, Einführlänge $8 \mathrm{~cm}$ ab Naseneingang, 2 kg Körpergewicht: Tubus $3 \mathrm{~mm}$, Einführlänge von $10 \mathrm{~cm}$ ab Naseneingang).

Aus den Ergebnissen mehrerer Metanalysen der Cochrane Collaboration läßt sich ableiten, daß postnatal intubierte Frühgeborene $<1500 \mathrm{~g}$ innerhalb von 2 Stunden nach der Geburt Surfactant erhalten sollten. Es bleibt offen, ob diese Gabe bereits im Kreißsaal oder nach radiologischer Kontrolle der Tubuslage erfolgen sollte.

Im ABC der Reanimation des Neugeborenen folgen nun die Punkte $\mathrm{C}$ für Kreislauf und D für Drugs, Medikamente. Auch für das sehr kleine Frühgeborene gilt: Beatmung ist der effektivste Schritt der Reanimation! Falls nach 30 Sekunden effektiver Ventilation - d. h. bei optimaler Lagerung, ausreichender Blähung der Lunge und adäquater Beatmung über Maske oder intratrachealen Tubus, sprich einer Beatmung die erreicht, daß sich der Thorax hebt - die Herzfrequenz $<60 / \mathrm{min}$ bleibt, sind Thoraxkompressionen anzuwenden. Medikamente, das heißt im Wesentlichen Adrenalin, sind zur Reanimation des Frühgeborenen außerordentlich selten nötig. Da die Energiereserven des Frühgeborenen spärlich sind, sollte immer eine intravenöse Glukosezufuhr von $2-3 \mathrm{ml}$ Glukose $10 \% / \mathrm{kg}$ * h etabliert werden.

Mehrlinge sind ein Kollektiv von Neugeborenen mit besonderen Risiken. Schwangerschaftskomplikationen, wie Plazentainsuffizienz, vorzeitige Wehen oder Blasensprung kommen bei Zwillingen 3-mal häufiger vor als bei Einlingen. Zwillinge werden 3 Wochen früher geboren als Einlinge. Zwillinge weisen gegenüber Einlingen ein 4 fach erhöhtes Fehlbildungsrisiko auf, haben häufiger Nabelschnurkomplikationen, regelwidrige Geburtslagen und Geburtstraumata. Diese Kombination bringt es mit sich, daß die perinatale Mortalität von Zwillingen um ein Vielfaches höher ist als bei Einlingen. Ein besonderes Risiko droht den monochorialen Zwillingen durch das fetofetale Transfusionsyndrom, dessen Häufigkeit in dieser Gruppe mit 4-40\% angegeben wird. Beim hämodynamisch relevanten fetofetalen Transfusionssyndrom beträgt die perinatale Mortalität beider Zwillinge bis zu 90\%!

Mehrlinge und insbesondere frühgeborene Mehrlinge sind Höchstrisikoneugeborene, für die besondere Versorgungsstrukturen vorgehalten werden müssen. Für die Erstversorgung von frühgeborenen Mehrlingen sollte für jedes Kind eine neonatologische Ärztin oder Arzt und eine neonatologisch erfahrene Kinderkrankenschwester oder -pfleger bereitstehen. Das kann im Einzelnen bedeuten, daß für höhergradige Mehrlingsgeburten besondere Rufdienste eingerichtet werden müssen. Neben der Vorhaltung von Personal gehört zu den logistischen Vorbereitungen die Bereitstellung eigener jeweils komplett ausgerüsteter Erstversorgungsplätze - möglichst in warmer Umgebung.

\section{DGKJ-WS-38}

\section{Dokumentation und Verantwortlichkeit bei Erstversorgung und Transport}

F. Jochum

Ev. Waldkrankenhaus Spandau, Klinik für Kinder- und Jugendmedizin

Die Erstversorgung in fremder Umgebung und / oder der Transport eines schwer kranken Neugeborenen stellt eine Extremsituation und besondere Herausforderung für das Neugeborenennotarztteam dar. Neben der häufig schwierigen medizinischen Versorgung unter möglicherweise ungünstigen Einsatzbedingungen ist der Neugeborenennotarztdienst zusätzlich und zunehmend häufig Gegenstand juristischer Auseinandersetzungen. Darum ist es für alle im Neugeborenennotarztdienst handelnden Personen wichtig, die juristischen Rahmenbedingungen zu kennen und zu beachten. Hierbei nimmt die Dokumentation des Einsatzablaufes, der Monitoring- und Therapiemaßnahmen eine Schlüsselposition ein. Zusätzlich sind durch das Neugeborenennotarztteam eine Vielzahl von praktischen Fragen, die unterschiedliche Rechtsgebiete berühren, oft ohne lange Bedenkzeit zu entscheiden; zum Beispiel: Ist das Fahren mit Sondersignal in der spezifischen Situation zulässig? Ist es erlaubt, ein Beatmungsgerät zu verwenden, für das kein Mitglied des Notffallteams eine Einweisung erhalten hat?

Ziel des Vortrages ist es, unter Hinweis auf juristische und ethische Gesichtspunkte eine möglichst praxisnahe Orientierungshilfe für Not- 
falleinsätze zu bieten. Der Inhalt ist darauf ausgerichtet, häufige Entscheidungsfindungen zu erleichtern und gleichzeitig zur juristischen Absicherung beizutragen

\section{Sonographie-Auffrischungskurs (DEGUM zertifiziert)}

\section{DGKJ-WS-39}

Niere und ableitende Harnwege. Normalbefunde und Pathologie B. Kranz

Kindernephrologie, UKM

Die Sonographie ist ein wesentlicher Baustein in der Diagnostik des kranken Kindes. Die Wiederholbarkeit ohne zwingende Indikation zur Sedierung/Narkose, die fehlende Strahlenbelastung verbunden mit der detaillierten Darstellbarkeit verschiedener Organsysteme mit ihren Pathologien macht sie zum unverzichtbaren Element in der Diagnostik der Pädiatrie.

Die Nierensonographie beinhaltet die Darstellung der Nieren und der ableitenden Harnwege, d. h. der Ureteren, der Blase, gelegentlich auch der Urethra und ggf. der Mitbeurteilung angrenzender Nachbarorgane des kleinen Beckens. Zur Beurteilung der Pathologien ist die exakte Kenntnis der Normalbefunde in verschiedenen Entwicklungsstufen des Kindes unverzichtbar. In der Pathologie finden sich angeborene und erworbene parenchymatöse Veränderungen, entzündliche Erkrankungen, angeborene und seltener auch erworbene Urinabflußstörungen, vaskuläre Erkrankungen, Stein- und Tumorerkrankungen.

\section{Ernährung chronisch-kranker, dystropher Kinder - Ernährungsintervention bei untergewichtigen Kindern}

\section{DGKJ-WS-44}

\section{Stufenprogramm der Ernährungsinterventionen: K. Schlüter}

Diätassistentin, Ernährungsberaterin/DGE, Kinderklinik der Med. Hochschule Hannover

Bei verschiedenen, chronischen Erkrankungen im Kindesalter hat der Ernährungsstatus einen großen Einfluss auf den Verlauf der Erkrankung. Genannt seien hier z. B. pulmonale-, kardiologische-, Leber- und entzündliche Darmerkrankungen. Der Bedarf an Energie ist bei den Kindern durch erhöhten Verbrauch und/oder eingeschränkte Resorptionsmöglichkeiten der Energieliefernden Nährstoffe bedingt.

Dass Klientel der vom Untergewicht gefährdeten Kinder muss erkannt werden und frühzeitig in eine diätetische Versorgung eingebunden werden.

Am Beispiel der Leitlinien zur Ernährungsintervention bei Mukoviszidose nach dem Consensus Report, Journal of Cystic Fibrosis (1) werden die drei Interventionsstufen vorgestellt:

1. jährliche, präventive Ernährungsberatung

2. Intensivierung der Ernährungsberatung bei Gedeihstörungen 3. invasiver Ernährungssupport bei anhaltenden Gedeihstörungen Der Berater muss innerhalb der Interventionsstufen das richtige Maß an informativer, motivierender Gesprächsführung anwenden, damit keinen Druck auf das Thema „Essen“ in der Familie ausübt wird.

Die Aufgabe der Ernährungsberatung ist u. a., von Anfang an eine positive Esskultur in der Familie zu fördern. Des Weiteren muss erkannt werden, wann negativ besetzte Interaktionen während der Mahlzeiten zwischen Eltern und Kind zu einem Problem werden und wann psychologisches Fachpersonal zusätzlich eingeschaltet werden muss. Erfolgversprechend können diese Interventionsstufen nur sein, wenn sie kontinuierlich und anhaltend bei dem einzelnen Patienten angewendet werden. Diätassistenten/innen, die diese Interventionsstufen am Patienten durchführen, müssen in das interdisziplinäre Behandlerteam chronisch kranker Kinder einbezogen sein.

Der Prozess „Ernährungsberatung im interdisziplinären Behandlungsansatz" und der Prozess "Stufenprogramm der Ernährungsinterventionen“ kann nach dem PDCA-Zyklus nach dem Qualitätsexperten Deming geplant werden.

Der PDCA-Zyklus besteht aus folgenden Schritten:

Planen einer Verbesserung,

Do-Phase in der die Verbesserung durchgeführt wird,

Check-Phase in der die durchgeführten Maßnahmen auf ihren Erfolg überprüft werden Act-Phase, in der die Ergebnisse auf Grund der Erfahrungen weiter verbessert werden

Für beide Prozesse werden kurze Erläuterungen der Umsetzung gegeben.

Literatur: (1) Consensus Report, Nutrition in patients with cystic fibrosis, a European Consensus, Journal of Cysic fibrosis 1 (2002) 51-75

\section{DGKJ-WS-45}

Kindgerechte Sondenernährung - Marktübersicht und Anwendungsmöglichkeiten

U. Och

Westf. Wilhelms-Universität, Kinderklinik

Die Indikationen zur enteralen Ernährung in der Pädiatrie sind vielfältig. Immer dann, wenn ein Patient auf oralem Weg über längere Zeit nicht ausreichend Nahrung aufnimmt, ist eine enterale Ernährung erforderlich. Eine Mangelernährung führt bei Kindern schnell zu verzögertem Längen- und Gewichtswachstum, das Immunsystem wird geschwächt, das Infektionsrisiko steigt. Wunden heilen schlechter und die Kinder wirken insgesamt teilnahmslos und müde.

Häufig eingesetzt wird die enterale Ernährung bei Frühgeborenen und Säuglingen mit Trinkschwäche und Schluckstörungen, bei Kindern mit neurologischen Erkrankungen und bei onkologischen Patienten.

Die Beurteilung des Ernährungszustandes bei Kindern erfolgt meistens über die geschlechts-spezifischen Perzentilen. Wenn die Gewichtszunahme eines Kindes stagniert oder es sogar zu Gewichtsverlust kommt und sich die Ernährung auch in Zukunft voraussichtlich nicht verbessern lässt, sollte mit den Eltern über die Möglichkeit einer enteralen Ernährung gesprochen werden.

Für die Eltern ist es häufig ein schwerer Schritt, der enteralen Ernährung zuzustimmen, da sie es als persönliches Versagen empfinden, ihr Kind nicht ausreichend ernähren zu können.

Die enterale Ernährung kann über eine transnasale oder über eine perkutane (durch die Haut) Sonde erfolgen. Die perkutane Sonde bietet gegenüber der transnasalen Sonde einige Vorteile. Die Patienten haben kein Fremdkörpergefühl durch die Sonde im Nasen-Rachenraum und sie haben keine Behinderung beim Sprechen und Schlucken. Außerdem kann die Sonde nicht vom Patienten selbst gezogen werden. Nachteil der perkutanen Sonde ist, dass sie in einem kleinen operativen Eingriff gelegt werden muss.

Nach dem Legen der Sonde beginnt man einschleichend mit dem Nahrungsaufbau, entweder als Bolusgabe oder kontinuierlich über Nahrungspumpe. Die Dosierung richtet sich nach dem Alter des Kindes, nach seinem Gewicht und nach der individuellen Verträglichkeit.

Die Sondierung erfolgt entweder in den Magen (gastrale Sondenlage), in den Zwölffingerdarm (duodenale Sondenlage) oder in den Dünndarm (jejunale Sondenlage). Bei der duodenalen und jejunalen Sondenlage sollte die Nahrung immer kontinuierlich über eine Nahrungspumpe appliziert werden, da hier die Reservoirfunktion des Magens umgangen wird.

Die duodenale/jejunale Lage wird bei Kindern gewählt, die häufig erbrechen, um das Aspirieren der Nahrung zu verhindern.

Säuglinge können Muttermilch oder Säuglingsanfangsnahrungen über die Sonde erhalten. Kinder nach dem 1. Lebensjahr mit uneingeschränkter Verdauungsfunktion bekommen als Standardnahrung eine normokalorische (100 kcal/10o ml) nährstoffdefinierte Sondennahrung 
mit Ballaststoffen, da die Ballststoffe das Auftreten von Diarrhöen und Obstipation vermindern.

Kinder mit eingeschränkter Verdauungsfunktion erhalten eine chemisch-definierte Sondennahrung, in der die Nähstoffe bereits „vorverdaut“ sind, z. B. liegen bei dieser Nahrung die Proteine in Form von Oligopeptiden oder Aminosäuren vor.

Die Energiezufuhr orientiert sich an den Empfehlungen der DGE, muss aber für jeden Patienten entsprechend seiner Erkrankung und seiner Lebensumstände individuell festgelegt werden. Immobile Patienten bleiben in ihrem Energiebedarf teilweise deutlich unter den Empfehlungen während Patienten mit epileptischen Anfällen oder konsumierenden Erkrankungen einen wesentlich höheren Energiebedarf haben. Ziel der Ernährungsbehandlung ist ein möglichst perzentilengerechtes Wachstum. Um das zu erreichen, muss die Ernährung bei Säuglingen ca. alle 1-2 Monate, bei Kleinkindern alle ca. 3-4 Monate und bei Schulkindern alle 6 Monate angepasst werden.

Auch die Flüssigkeitszufuhr orientiert sich an den Empfehlungen der DGE. Für viele Patienten ist die empfohlene Menge jedoch zu groß und es kommt zu Unwohlsein und Erbrechen. Wenn keine Symptome eines Flüssigkeitsmangels wie dunkler Urin, Verstopfung und trockene Schleimhäute vorliegen, kann die Zufuhr dann auch unter der empfohlenen Menge bleiben.

Die Zahl der Kinder, die mit enteraler Ernährung versorgt werden, ist in den letzten Jahren kontinuierlich gestiegen. Bei vielen Kindern hat sich durch die verbesserte Nährstoffzufuhr der Gesundheitszustand stabilisiert. Einige Eltern berichteten auch, dass sich ihre Kinder wohler fühlen und wieder mehr Kraft zum Spielen haben.

\section{Pädiatrisch praktische Psychosomatik - Verstehen was (auch) gesagt wird}

\section{DGKJ-WS-51}

Leitfaden für komplexe Gesprächssituationen

D. Kunert

Gesundheit Nordhessen - Kinderkrankenhaus Park Schönfeld

Wie kann ich komplexe Gesprächssituationen mit Patienten und ihren Angehörigen so gestalten, dass sie dem Patienten helfen, seine Entwicklung fördern?

Diese Frage ist eng verknüpft mit der Frage: wie schafft man eine hilfreiche Beziehung?

Der amerikanische Psychologe Carl Rogers hat sich eingehend mit dieser Frage beschäftigt und Bedingungen herausgearbeitet, die notwendig sind, damit eine Beziehung hilfreich bzw. entwicklungsfördernd sein kann und so zwischen Patient/Angehörigen und Helfer gegenseitiger Respekt und Vertrauen entstehen.

Diese Thesen werden dargestellt und anhand eines Modells auf die Ebene praktischen Alltagshandeln gebracht, auf die Ebene des konkreten Gesprächs zwischen Helfer und Patient/Angehöriger.

\section{DGKJ-WS-52}

\section{Erstgespräch in der psychosomatischen Praxis}

M. von Stauffenberg

Clementine Kinderhospital, Klinik für Kinder- und Jugendmedizin

Jedes 5. Kind hat nach der KIGGS-Studie 2008 psychische Probleme und jedes 10. Kind braucht eine Behandlung. Ein Drittel von 1000 untersuchten Kindern zwischen 9 und 14 zeigten sich überfordert durch Erwartungen ihrer Eltern oder der Schule; viele zeigen körperliche Symptome wie Kopf- oder Bauchschmerzen ohne erkennbare organische Ursache. Jeder Arzt, insbesondere jeder Pädiater sollte deshalb befähigt sein, psychosomatische Zusammenhänge zu erkennen und entsprechende diagnostische Gespräche zu führen. Voraussetzungen dafür sind die Einstellungen des Arztes zur Psychosomatik, ein von Empathie getragenes Interesse am Kind bzw. Jugendlichen selbst und dessen persönlicher Geschichte und aktuellen Problemen sowie der Vorgeschichte der Eltern und den psychosozialen Gegebenheiten. Zudem sollte er Erkenntnisse über häufig, psychisch bedingte Symptome und psychiatrische Komorbiditäten haben sowie über Therapiemöglichkeiten.

Das Erstgespräch in der Psychosomatischen Praxis dient der Diagnosestellung und der Aufklärung des Kindes und der Eltern über die Wechselwirkungen zwischen Körper und Seele sowie der Klärung des weiteren Vorgehens. Erste diagnostische Hinweise ergeben sich oft schon durch die Art der Anmeldung und der Beobachtung der Familie im Wartezimmer sowie der Wahrnehmung der eigenen spontanen Gefühle im Erstkontakt.

Im Erstgespräch mit dem Patienten alleine und dessen Familie wird das aktuelle Befinden erfragt sowie die aktuellen Symptome und Beschwerden erfasst. Auch die Vorstellungen zur Ursache der Erkrankung und die Auswirkungen auf Patient und Familie sind Themen. Der Umgang mit den Symptomen, der Leidensdruck, Ideen zur Wechselwirkung von Körper und Seele, das Erkennen von psychosozialen Belastungen und von Ressourcen sowie die Erwartungen an den Untersucher sind weitere wichtige Inhalte des Gesprächs.

\section{DGKJ-WS-53}

Diagnostikum Team - vom Nutzen der Übertragungsphänomene M. Martens

Städt. Krankenanstalten, Kinderkrankenhaus

Der Begriff der Übertragung stammt aus der Psychoanalyse und bezeichnet die Verlagerung eines Affektbezuges ( positiv oder negativ) von einem Ding, einer Person auf eine andere. Übertragung stellt sich immer her wo Beziehungen eingegangen werden. Im Beziehungsgeschehen der Übertragung des Patienten auf die verschiedenen Personen eines Behandlungsteams wird ein neues Verständnis im Umgang mit dem Patienten und es tun sich Bedeutungszusammenhänge auf, die bei der Diagnostik und Therapie erleichtern.

Der Vortrag gibt Einblick in die Nutzung der Übertragungsphänomäne bei der Diagnostik und Therapie von Kindern und Jugendlichen mit chronischen Schmerzen

\section{Aktuelle Forschung in den Zentren für Pädiatrische Infektiologie}

\section{DGKJ-WS-67}

Vorstellung der infektiologischen Weiterbildung in Bonn und Darstellung ausgewählter Forschungsprojekte

J. Prusseit, A. Müller, T. Dresbach, J. Schneider, E. Mühlenborn, B. Strahl,

A. Simon

Universitätsklinik Zentrum f. Kinderheilkunde

Im Jahr 2009 wurde der Ausbildungsgang Spezielle Pädiatrische Infektiologie am Zentrum für Kinder- und Jugendmedizin der Universitätsklinik Bonn durch PD Dr. Arne Simon und PD Dr. Andreas Müller etabliert. Die 2-jährige Ausbildung nach den Vorgaben des DGPI Curriculums umfasst ein 6-monatiges Modul Labor mit Mitarbeit im Institut für Mikrobiologie und Parasitologie sowie im Institut für Virologie. Im Vordergrund steht die Identifikation von infektiösen Erregern, der richtigen Interpretation von Labortests und Ergebnissen sowie Kenntnisse über wichtige mikrobiologische und immunologische Techniken einschließlich deren Sensitivität und Spezifität und möglichen Interpretationsfehlern. Im anschließenden einmonatigen Modul Krankenhaushygiene werden wichtige Prinzipien der Prävention und Kontrolle Gesundheitssystem-assoziierter Infektionen nach Evidenz-basierten Standards vermittelt. Ein Hauptaugenmerk liegt in diesem Modul auf multiresistenten Infektionserregern (Bedeutung, Prävention, Kontrolle). Im Modul Klinik durchläuft die Fachärztin für Kinderheilkunde noch einmal alle Hochrisikobereiche der Kinderklinik mit den Spezial- 
ambulanzen, in denen infektiologische Schwerpunktthemen zum Alltag gehören (z. B. Mukoviszidose, Immunsupprimierte) sowie gegen Ende der Ausbildung auch die internistische Infektiologie und Immunologie. Die Fachärztin in der Weiterbildung nimmt an infektiologischen Konsilen teil, insbesondere auch mit dem Ziel einer verbesserten Kosteneffizienz von Diagnostik und Therapie. Das assoziierte Modul Forschung, Lehre und interne Leitlinienentwicklung beinhaltet bisher die Koordinierung folgender Forschungsprojekte: 1. Eine prospektive Beobachtungsstudie zur Überprüfung der Aussagekraft einer täglichen Bestimmung des Oberflächenantigen CD64 auf neutrophilen Granulozyten im Rahmen von Routineblutentnahmen als Screeningparameter der Sepsis bei Frühgeborenen im Vergleich zu a) der klinischen Beobachtung der behandelnden Ärzte und b) zu der etablierten, durch klinische Zeichen getriggerten Bestimmung von C-reaktivem Protein und IL-6 2. Influenza A H1N1 o9 Surveillance: Systematischen Erfassung und Analyse der klinisch relevanten Aspekte der stationären Behandlung von Kindern mit nachgewiesener $\mathrm{H}_{1} \mathrm{~N}_{1}$ o9-Infektion 3. Überprüfung der humoralen Immunantwort nach $\mathrm{H}_{1} \mathrm{~N}_{1}$ o9 Impfung onkologischer Risikopatienten am Zentrum für Kinderheilkunde des Universitätsklinikums Bonn 4. Retrospektive, anonymisierte, multizentrische Umfrage zum Einsatz von Linezolid in der Kinder- und Jugendmedizin mit Ziel der Generierung strukturierter und auswertbarer Daten in Bezug auf die praktische Anwendung von Linezolid in deutschen Zentren für Kinder- und Jugendmedizin Langfristig werden sich solche speziellen Ausbildungsgänge nur etablieren lassen, wenn es den pädiatrischen Infektiologen gelingt, ihren wichtigen Beitrag zu einer systematischen Verbesserung der Prävention, Diagnostik und Therapie von Infektionen in Klinik und Forschung für alle sichtbar zu machen.

\section{DGKJ-WS-68}

Blut-Hirnschranken in der Pathogenese der akuten bakteriellen

Meningitis

T. Tenenbaum

Universitätsklinikum Mannheim, Klinik für Kinder- und Jugendmedizin,

Pädiatrische Infektiologie

Ein entscheidender Schritt während der Pathogenese der bakteriellen Meningitis ist das Eindringen von Erregern in das zentrale Nervensystem (ZNS). Als Eintrittspforte in das ZNS wird neben der bereits gut untersuchten Blut-Hirn-Schranke (BHS) ebenso die Blut-LiquorSchranke (BLS) diskutiert. An humanen mikrovaskulären Endothelzellen (HBMEC), welche ein Modell für die BHS darstellen, konnte gezeigt werden, dass Virulenzfaktoren von Streptococcus agalactiae (S. agalactiae) sowohl die Adhäsion, am Beispiel des Fibrinogen-bindenden Proteins FbsA, als auch die Invasion mit Hilfe des Laminin-bindenden Proteins Lmb fördern. Wie Bakterien und Phagozyten mit den Epithelzellen des Plexus choroideus, der strukturellen Basis der BLS, interagieren, ist dagegen bisher nicht näher wissenschaftlich bearbeit worden. In eigenen Untersuchungen konnte erstmalig in einem in vitro-BHS-Modell gezeigt werden, dass der schweine- und humanpathogene Erreger Streptococcus suis (S. suis) die Barrierefunktion von porcinen choroidalen Plexusepithelzellen (PCPEC) beeinträchtigen kann. Dabei wird die Barrierefunktion der PCPEC aufgrund von Veränderungen der zellulären Integrität kompromittiert, die einerseits durch Zelltodmechanismen (Nekrose oder Apoptose), anderseits durch Affektion von Tight junctions herbeigeführt werden. In diesem Zusammenhang konnte für Dexamethason, welches bereits klinisch während der Behandlung der bakteriellen Meningitis eingesetzt wird, eine protektive Wirkung am Plexusepithel demonstriert werden. Welche bakteriellen Komponenten und Wirtsfaktoren die Invasion und Translokation von S. suis durch die BLS begünstigen, konnte mit Hilfe eines neu etablierten „Umkehrkultur"-Modells im Transwell-Filtersystem gezeigt werden. In diesem Modell wurde erstmalig die Keim-Wirt-Interaktion von der pathogenetisch besonders relevanten basolateralen Seite des Plexusepithels („Blutseite“) analysiert. Es konnte gezeigt werden, dass Invasion und Translokation von S. suis durch das Plexusepithel bevorzugt von der basolateralen Seite und abhängig von dem Virulenzfaktor Kapsel erfolgt. Die Inhibition des $\mathrm{PI}_{3} \mathrm{~K}$-Signalweges, welcher die Zytoskelettveränderungen im Rahmen des bakteriellen Internalisierungsprozesses reguliert, verhinderte dabei die Invasions- und Translokationsrate signifikant. Diese Untersuchungen ermöglichen zum einen neue grundsätzliche Einblicke in die Pathogenese der Meningitis, eröffnen zum anderen aber auch Perspektiven für therapeutische, diagnostische und präventive Strategien.

\section{DGKJ-WS-69}

Vorstellung des Infektiologischen Zentrums Mannheim

H. Schroten

Universitätsklinikum Mannheim, Klinik für Kinder- und Jugendmedizin

Die Universitätskinderklinik Mannheim ist ein anerkanntes Schwerpunktzentrum der DGPI. Unter der Leitung von Herrn Prof. Schroten und Herrn Priv. Doz. Tenenbaum ist hier die Ausbildung zum pädiatrischen Infektiologen nach europäischem Curriculum möglich. Mannheim hat als eines von drei deutschen DGPI-Schwerpunktzentren das DGPI-Fellowship zuerkannt bekommen. Zur Zeit befindet sich Herr Dr. Stefan Weichert in Mannheim in der Ausbildung. Das ausführliche Mannheimer Ausbildungscurriculum, in das Aufenthalte in der Tropenmedizin Heidelberg sowie dem Department für Infektiologie Heidelberg integriert sind, finden Sie auf der DGPI-Homepage (auf www. dgpi. de).

Neben der curriculären klinischen Ausbildung zum Infektiologen werden in Mannheim klinisch-infektiologische Studien durchgeführt. Schwerpunkt infektiologischer Grundlagenforschung stellt die Pathogeneseforschung dar, d. h. die Untersuchung der Erreger-Wirt-Beziehung insbesonders auf dem Gebiet der bakteriellen Meningitis.

\section{Leitsymptome von Immundefekten und Interpretation immunologischer Laborbefunde}

\section{DGKJ-WS-72}

\section{Interpretation molekulargenetischer Ergebnisse: Ist eine Mutation} krankmachend oder nicht?

M. Hönig

Universitätsklinikum Ulm, Klinik für Kinder- und Jugendmedizin

Der Begriff Mutation bezeichnet eine Veränderung des Erbgutes, die in einer Veränderung des Phänotyps resultiert. Mit der rasanten Entwicklung neuer Technologien wird die Detektion von Veränderungen im menschlichen Genom eine voraussichtlich häufig durchgeführte Maßnahme werden. Die Interpretation dieser Veränderungen ist jedoch nicht trivial und stellt die eigentlich diagnostisch relavante Tätigkeit dar. Der Weg von der Veränderung der Basensequenz in der genomischen DNA über die Transkription in mRNA bis zur Translation in Protein muss zunächst verfolgt und bewertet werden. Weitere Schritte sind die funktionelle Testung der Relevanz des Fehlens oder der Veränderung eines Proteinproduktes und ggf. der Beweis der krankmachenden Wirkung in der Zellkultur oder im Tierversuch.

Dieser Weg vom Genotyp zum Phänotyp wird an Beispielen aus der Immundefektdiagnostik erläutert. 


\section{Hypothermie}

\section{DGKJ-WS-73}

Asphyxie und Hypoxisch Ischämische Enzephalopathie: Ursachen, Symptome und Konsequenzen

M. Rüdiger

Neonatologie \&amp; Pädiatrische Intensivmedizin, Universitätsklinikum Dresden

Die perinatale Aspyhxie führt zu einer unzureichenden Sauerstoffversorgung der Gewebe unter der Geburt. Es sind ungefähr 9 von 1000 Neugeborenen betroffen. Die Gewebehypoxie führt zu einem primären Energiemangel. Bei rechtzeitiger und adäquater Wiederherstellung des plazentaren bzw. pulmonalen Gasaustausches kommt es zu einer Verbesserung der Gewebeoxygenierung. In Abhängigkeit von der Schwere und Dauer des primären Energiemangels ergeben sich drei verschiedene zelluläre Reaktionsmuster: (A) Ein zu starker primärer Energiemangel führt zu einer sofortigen Schädigung des Gewebes mit zellulärer Nekrose. (B) Nach einem milden primären Energiemangel erholt sich das Gewebe ohne weitere Schädigung. (C) Bei moderatem primärem Energiemangel kommt es zunächst zu einer Erholung, dieser folgt jedoch eine Phase des sekundären Energiemangels, welche mit z. T. massiven Schädigungen einhergeht. Während im ersten Fall keine Therapie verfügbar und die Schädigung derzeit irreversibel ist und im zweiten Fall keine Therapie notwendig ist, kann die Schädigung durch einen sekundären Energiemangel teilweise verhindert werden.

Besonders betroffen von der Gewebehypoxie ist das zentrale Nervensystem, die Schädigung manifestiert sich als Enzephalopathie mit hypoxisch-ischämischer (HIE) Genese, von der ca. 3 von 1000 Neugeborenen betroffen sind. Klinisch manifestieren sich diese Kinder mit einer typischen Symptomatik, welche eine Einteilung in eine milde, moderate oder schwere Form erlaubt. Das aEEG ermöglicht eine weiterführende Beurteilung des Schädigungszustandes und damit in gewissem Umfang auch prognostische Aussagen. Insbesondere Kinder mit einer moderaten Enzephalopathie profitieren von einer Hypothermiebehandlung.

\section{DGKJ-WS-76}

Wann sollten welche Patienten gekühlt werden?

T. Höhn

Neonatologie und pädiatrische Intensivmedizin, Universitätsklinikum Düsseldorf, Heinrich -Heine-Universität

Der Wirksamkeitsnachweis von therapeutischer Hypothermie nach Zuständen eingeschränkter Perfusion ist im Tiermodell seit langem erbracht. Die Umsetzung in klinische Szenarien beim Menschen ist bisher lediglich bei reifen Neugeborenen nach Asphyxie und bei Erwachsenen nach Reanimation evidenzbasiert erfolgt. Die derzeitige Datenlage bei Neugeborenen legt nahe die Eintrittskriterien der großen Studien zur Hypothermie zu verwenden.

Die klinische Wirksamkeit von therapeutischer Hypothermie ist für einen Zeitraum von bis zu 6 Stunden gezeigt. Tierexperimentell lässt sich der protektive Effekt der Hypothermie vergrößern indem die Zeitlatenz bis zum Beginn der Therapie verringert wird. Für die klinische Anwendung bedeutet dies: Beginn der Hypothermie sobald die Eintrittskriterien zweifelsfrei erfüllt sind.

\begin{tabular}{|c|c|c|c|}
\hline \multirow[t]{4}{*}{$\begin{array}{l}\text { Eintrittskrite- } \\
\text { rien }\end{array}$} & $\begin{array}{l}\text { Coolcap-Stu- } \\
\text { die }\end{array}$ & NICHD & TOBY \\
\hline & $\begin{array}{l}\mathrm{pH}<7.0 \text { oder } \\
\mathrm{BE}^{3} 16 \text { oder } \\
\mathrm{APGAR}=5\left(10^{\prime}\right) \\
\text { oder Reanima- } \\
\text { tion mit } 10^{\prime}\end{array}$ & $\begin{array}{l}\mathrm{pH}<7.0 \text { oder } \\
\mathrm{BE}^{3} 16 ; \text { falls kein } \\
\text { Blutgas vor- } \\
\text { handen oder } \mathrm{pH} \\
\text { 7.01-7. } 15 \text { bzW. } \\
\text { BE 10-15. 9: Not- } \\
\text { wendigkeit eines } \\
\text { akuten perina- } \\
\text { talen Ereignisses } \\
\text { und APGAR=5 } \\
\left(10^{\prime}\right) \text { oder Re- } \\
\text { animation seit } \\
\text { Geburt und fort- } \\
\text { gesetzt für } 10^{\prime}\end{array}$ & $\begin{array}{l}\mathrm{pH}<7.0 \text { oder } \mathrm{BE}^{3} 16 \\
\text { oder } \mathrm{APGAR}=5\left(10^{\prime}\right) \\
\text { oder Reanimation } \\
\text { mit } 10^{\prime}\end{array}$ \\
\hline & $\begin{array}{l}\text { Moderate bis } \\
\text { schwere klini- } \\
\text { sche Enzepha- } \\
\text { lopathie }\end{array}$ & $\begin{array}{l}\text { Moderate bis } \\
\text { schwere klini- } \\
\text { sche Enzepha- } \\
\text { lopathie oder } \\
\text { Krampfanfälle }\end{array}$ & $\begin{array}{l}\text { Moderate bis } \\
\text { schwere klinische } \\
\text { Enzephalopathie } \\
\text { (wie Lethargie, } \\
\text { Stupor oder Koma) } \\
\text { oder entweder } \\
\text { Hypotonie, ab- } \\
\text { normale Reflexe, } \\
\text { fehlender oder } \\
\text { schwacher Saugre- } \\
\text { flex oder klinische } \\
\text { Krampfanfälle }\end{array}$ \\
\hline & $\begin{array}{l}\text { Abnormales } \\
\text { aEEG oder } \\
\text { Krampfanfälle }\end{array}$ & Fetaler Stress & $\begin{array}{l}\text { Abnormales aEEG } \\
\text { oder Krampfanfälle }\end{array}$ \\
\hline
\end{tabular}

\section{Beratung von Familien mit adipösen Kindern und} Jugendlichen

\section{DGKJ-WS-83}

Beratung von Familien mit adipösen Kindern und Jugendlichen - Die medizinische Perspektive

T. Reinehr

Vestische Kinder- und Jugendklinik Datteln, Universität Witten-Herdecke

Kinder- und Jugendärzte werden zunehmend mit adipösen Kinderund Jugendlichen konfrontiert. Der Pädiater sollte keinesfalls aufgrund der häufigen Schwierigkeiten eine Lifestyle Veränderung zu erzielen resignieren, sondern adipöse Kinder und ihre Familien empathisch behandeln. Der Kinder- und Jugendarzt sollte zunächst das Ausmaßes der Adipositas erfassen und dies dem Kind und seinen Eltern darstellen. Dazu eignet sich in der Praxis am besten der Body Mass Index $\left(\mathrm{BMI}=\right.$ Gewicht in $\left.\mathrm{kg} /(\mathrm{Größe} \text { in } \mathrm{m})^{2}\right)$ eingetragen in altersund geschlechtsbezogene BMI- Percentilen. Danach sollten Primärerkrankungen sicher ausgeschlossen werden, die mit Adipositas einhergehen: Bei einer verminderten Wachstumsgeschwindigkeit (Adipositas geht im Kindesalter in der Regel mit einem relativen Großwuchs einher) sollte eine Hypothyreose, ein Cushing- Syndrom und Wachstumshormonmangel ausgeschlossen werden. Wegweisende Hinweise auf eine syndromale Genese sind neben dem Kleinwuchs, die Entwicklungsverzögerung und Dysmorphiestigmata. Bei Vorliegen von Symptomen, die auf eine psychiatrische Genese hinweisen sollte ein Kinder- und Jugendpsychiater hinzugezogen werden. Der sichere Ausschluss von Primärerkrankung ermöglicht den Familien eine Veränderung des Bewegungs- und Ernährungsverhaltens anzustreben vor allem unter dem Hinweis auf eine nicht abänderbare genetische Veran- 
lagung. Dies nimmt die „Schuld“ von den Familien. Die wichtige Aufgabe des Pädiaters besteht dann darin geeignete Therapieverfahren zu vermitteln, zu begleiten und ggf. die Komorbidität der Adipositas zu behandeln. Die Leitlinien der Arbeitsgemeinschaft für Adipositas im Kindes- und Jugendalter (AGA) sehen als Screening für die Komorbidität der Adipositas eine Bestimmung des Blutdrucks, von Triglyceriden, HDL- und LDL-Cholesterin vor. Rund ein Drittel der adipösen Kinder haben bereits eine arterielle Hypertonie oder Dyslipidämie. Bei pubertären adipösen Kindern mit Verwandten mit Typ 2 Diabetes (DM2) sollte ein DM2 ausgeschlossen werden, der im Kindesalter meist zunächst asymptomatisch verläuft (geschätzte Häufigkeit $\mathrm{DM}_{2}$ bei adipösen Kindern 1\%). Zyklusstörungen und Hirsutismus weisen bei adipösen Mädchen auf ein polyzystisches Ovarsyndrom hin. Eine gegenüber der AST erhöhte ALT stellt einen Hinweis auf eine nichtalkoholische Steatohepatitis dar. Schnarchen und Tagesmüdigkeit bei extrem Adipösen sind Zeichen eines Schlaf- Apnoe- Syndroms.

\section{DGKJ-WS-84}

Ernährungsberatung: Grenzen und Möglichkeiten

A. Schaefer, K. Winkel, M. Dobe, M. Kleber, T. Reinehr

Vestische Kinder- und Jugendklinik, Universität Witten / Herdecke

Hintergrund: Adipositas im Kindes- und Jugendalter ist heutzutage weit verbreitet. Etwa jedes 6 . Kind ist davon betroffen und die Zahlen steigen weiter an. Die Weltgesundheitsorganisation (WHO) spricht von einer Epidemie.

Neben den Folgeerkrankungen spielen für die Kinder und Jugendlichen der Kontakt mit Mitschülern \& Freunden, die Hänseleien in der Schule oder beim Sport, sowie die Nachverfolgung der modischen Trends eine weitaus wichtigere Rolle. Neben der Bewegungstherapie ist die Ernährungsberatung eine wichtige Säule in der Behandlung.

Methoden: Ziel der Ernährungsberatung ist zunächst die Motivation zu einer langfristigen Ernährungs- und Verhaltensänderung aufzubauen. Eine Ernährungsumstellung wird erleichtert mit dem einfachen, praktischen Ampelsystem, Spiele, Sinnesschulungen und praktisches Einüben beim gemeinsamen Kochen. In der Beratung der betroffenen Kinder und Familien sollen Bestrafung und Verbote minimiert werden und Motivation durch Belohnung und Lob in den Vordergrund gestellt werden.

Beispiele für Sinnesschulungen und praktische Übungen sind z. B. die Schokoladenphantasiereise. Diese übt das Genießen ein und ermöglicht den Genuss von z. B. fett- und kalorienreichen Lebensmitteln wie z. B. Schokolade auf eine andere Art und Weise.

Der Vollkorn-Brot-Geschmackstest verdeutlicht die Unterschiede von VK-Brot zu Mischbrot mit Körnern und klärt die Hintergründe auf. Das Zuckerwürfelratespiel zeigt die Zuckergehalte von typischen Kinderlebensmitteln in Form von Zuckerwürfeln auf und nimmt bei den Kindern viele Illusionen, die durch die Werbung und deren Werbeslogans hervorgerufen werden.

Diese und weitere Übungen werden vorgestellt, die auch in der Kinderarztpraxis angeboten werden können.

Zusammenfassung: Der Workshop soll die theoretischen und praktischen Inhalte im Bereich der Ernährungsberatung vermitteln und Tipps bzw. Schulungsmethoden vorstellen, die eine Motivation zur langfristigen Ernährungs- und Verhaltensänderung ermöglichen.

\section{DGKJ-WS-86}

\section{Gesprächsführung in schwierigen Situationen}

M. Dobe

Vestische Kinder- und Jugendklinik Datteln, Universität Witten/Herdecke

Gerade bei der Behandlung von Kinder und Jugendlichen (im Folgenden: Kinder) spielen Gespräche, welche auf eine Veränderung des Ernährungs-, Bewegungs- und Essverhalten abzielen eine große Rolle. Häufig machen Ärzte allerdings die Erfahrung, dass die Vermittlung von Empfehlungen in einem Arzt-Eltern-Kind-Gespräch zu keiner (ausreichenden) Änderung des Problemverhaltens des Kindes und der Eltern führen. Ein bekanntes Phänomen. Speziell diese Patientengruppe birgt eine hohe Frustrations- und auf Dauer auch Burnoutgefahr für die Behandelnden. Deswegen werden als erstes speziell für diese Patientengruppe hilfreiche therapeutische Haltungen vermittelt sowie wichtige Aspekte in der Arzt-Eltern-Kind Gesprächsführung aufgezeigt, deren Beachtung die Umsetzung von Empfehlungen erheblich wahrscheinlicher macht. Da in einem ärztlichen Gespräch in der Regel nur wenig Zeit zur Verfügung steht, wird eine besonders strukturierte Form der Gesprächsführung vorgestellt („Ein Akt in drei Schritten") und anhand von zwei Fallbeispielen erläutert.

\section{Freitag, 17. September 2010}

\section{Fast am Termin ist immer noch zu früh - spezifische Risiken bei späten Frühgeborenen}

\author{
DGKJ-IS-14 \\ Späte Frühgeborene als Risikogruppe wahrnehmen
}

DGKJ-IS-15

RS-Virusinfektionen: Welche Kinder sind gefährdet?

DGKJ-IS-16

Rechtliche Aspekte einer patientengerechten Therapie

\section{Asthma im Kindesalter - was ist wichtig für die tägliche Praxis?}

\section{DGKJ-IS-17}

Asthmatherapie im Kindesalter - wann Leukotrienantagonist, wann inhalatives Steroid?

DGKJ-IS-18

Zeitlicher Verlauf unterschiedlicher Asthmaphänotypen im Kindesalter

\section{DGKJ-IS-19}

Nationale Versorgungsleitlinie Asthma - Umsetzung im Praxisalltag

\section{Probiotika und Präbiotika in Forschung und Klinik}

DGKJ-PL-2

Probiotika zur Prävention der nekrotisierenden Enterokolitis: aktuelle Forschungsergebnisse

H. Lin

School of Chinese Medicine, China Medical University and School of Chinese Medicine, China Medical University

NEC is one of the most catastrophic G-I emergencies in preterm VLBW infants. The pathogenesis of NEC is likely to be multifactorial, involving immaturity of intestinal host defenses and abnormal bacterial colonization. Dysbiotic flora with predominant of pathologic microorganism plays a fundamental role in the pathogenesis of NEC. Several animal studies suggest a strong relationship between the delayed and low-colonization of probiotics flora and the proliferation of pathogenic flora in the immature gut that predisposes preterm infants to NEC. Caplan and Butel showed that Bifidobacter supplementation in neo/natal rat and quail models result in intestinal colonization and subsequent reduction in NEC-like lesions. 
According to the clinical observations and animal studies, we hypothesized that oral probiotics in the forms of Bifidobacter and Lactobacil fed to PVLBW infants will reduce the incidence and severity of NEC. From 1999 to 2003 we conducted a mask / randomized control trial in our institution. The results showed that the incidence of NEC, death and sepsis were significant lower in the study group. We further hypothesized that oral probiotics in the forms of Bifidobacterium and Lactobacterium fed to PVLBW infants for 6 weeks will reduce the incidence and severity of NEC. From 2005 to 2007 , a prospective multi-center randomized control trial was conducted in Taiwan. Preterm VLBW infants below 34 weeks and birth weight below 1500 gm who survived to feed enterally were eligible for the trial. The protocol was the same with our previous study except that the probiotics has been altered by changing the Bifidobacterial infantis to Bifidobacterial bifidum and given with first feeding and duration was shorter as 6 weeks. We further indicated the exclusion criterias. The incidence of death or NEC beyond stage 2 was significantly lower in the study group compare to the control group. ( $4 / 217$ vs $20 / 217 \mathrm{p}=0.002)$. There was no difference between the study group and control group on the incidence of death due to NEC. The incidence of death unrelated to NEC (o/217 vs 6/217 $\mathrm{p}=0$. o4) was significantly lower in the study group compare to the control group. Our follow up study at 3 years of corrected age showed that oral probiotics given to PVLBW infants after one week of age to reduce the incidence of NEC did not affect the growth and neurodevelopmental and sensory outcomes. Our follow up study showed that use of probiotics to PVLBW infants is relative safe on short term and long term effects. We did a meta-analysis of 11 papers that tried to investigate the efficacy of different probiotics on death or NEC for PVLBW infants. Because the heterogeneity of the different protocols was not significant, the fixed model showed that mixture flora was more effective in prevention of death and NEC with a P value approaching zero. Lactobacillus alone was not effective in prevention of death and NEC. Due to inadequate papers, we couldn't conduct the meatanalys of the efficacy of Bifidobacte on death or NEC. Our animal model of NEC demonstrated that mixed flora was effective in prevention of death. Bifidobacterial longus with Bifidobacterial bifidus were most effective in prevention of death. Mixed flora was effective in prevention of NEC with $\mathrm{P}$ value approaching zero. Bifidobacterial longus and Bifidobacterial Bifidus were most effective in prevention of NEC and death.

Although probiotics sepsis had been concerned in patients who are immuncompromised or who have underlying medical conditions. The number accumulated from all the clinical trials are power to state that it is relatively safe comparing the probiotics sepsis from probiotics microorganisms to the higher incidence and disaster of NEC for VLBW infants.

Based on all the clinical trials and in vitro studies, we suggest that mixture of probiotics contains Bifidobacterium might be the most appropriate strain for the prevention of NEC. It is a simple, safe, and noninvasive method that attempts an early-establish of probiotics flora to inhibit pathogenic flora and inflammatory response. Although careful evaluation of the dosage and other factors as their effect in ELBW and breastfed infants are still arouse with critism. However, history may not judge us kindly if we ignore in adopting effective treatment. We believe it is about time to use probiotics as a routine care for PVLBW infants.

\section{Ernährungsmedizin und Zahnheilkunde}

\section{DGKJ-PV-001}

Protektiver Einfluss von Bifidobakterium longum AH1206 auf die allergische Immunantwort

S. Diemer', I. Rosner', T. Eiwegger', D. Gianelli', K. von Burg' ', G. Menz', R. Lauener', L. O'Mahony'2, A. Jung ${ }^{3}$

${ }^{1}$ Hochgebirgsklinik Davos, ${ }^{2}$ Swiss Institute of Allergy and Asthma Research (SIAF), ${ }^{3}$ Christine Kühne - Center for Allergy Research and Education (CK(ARE)

Einleitung: Die Frage, ob bestimmte Probiotika eine Induktion von regulatorischen T-Zellen (Treg) hervorrufen und damit allergische Symptome verhindern oder abschwächen können, ist Gegenstand kontroverser Diskussion.

Ziele: Im Mausmodell sollen probiotische Bakterienstämme identifiziert werden, welche eine protektive Wirkung auf allergische Mechanismen besitzen. Es soll geprüft werden, ob die Induktion von spezifischen Treg mit einer Verminderung der allergischen Entzündung assoziiert ist.

Methoden: Bifidobacterium breve $\mathrm{AH} 1205$, Bifidobacterium longum AH1206 und Lactobacillus salivarius $\mathrm{AH}_{102}$ wurden Balb/c-Mäusen täglich oral für 3 bis 8 Wochen verabreicht und die Induktion von $\mathrm{FOXP}_{3}+$ Treg in Milz und Peyerschen Plaques ermittelt. Die Stämme wurden zudem im Hinblick auf ihre protektiven Eigenschaften im Ovalbumin (OVA) Allergie-Modell und OVA-Choleratoxin (CT) Allergie-Modell untersucht.

Ergebnisse: Die Einnahme von B. longum AH1206 führte zu einer deutlichen Induktion von $\mathrm{FOXP}_{3}+$ Treg. B. longum $\mathrm{AH}_{12} \mathrm{O} 6$ reduzierte die Eosinophilenzahl und Zytokinproduktion in den Atemwegen und im Serum bzw. in stimulierten Milzzellen und wirkte sich so protektiv auf die Atemwegsentzündung bei OVA-sensibilisierten Mäusen aus. Zudem wurde die spezifische IgE-Ausschüttung auf oral verabreichtes OVA bei OVA-CT-senibilisierten Mäusen blockiert.

B. breve $\mathrm{AH} 1205$ und L. salivarius AH102 zeigten eine deutlich geringere Treg-Induktion und weniger protektive Eigenschaften.

Schlussfolgerung und Ausblick: Die Induktion von spezifischen $\mathrm{FOXP}_{3}+$ Treg durch B. longum AH1206 ist im Tiermodel mit einer deutlichen Verringerung des Schweregrades von allergischen Reaktionen in den Atemwegen und im Gastrointestinaltrakt assoziiert. Eine prospektive placebokontrollierte Interventionsstudie soll nun die Wirkung von B. longum AH1206 auf den Schweregrad der allergischen Symptome und die Lebensqualität bei Jugendlichen und Erwachsenen mit oralem Allergiesyndrom und Birkenpollenallergie untersuchen. Hierzu wird vor und nach der Intervention die Induktion, Funktion und Anzahl von allergen-spezifischen Treg und das induzierte Zytokinprofil nach Provokation mit bet v1-assoziierten Nahrungsmitteln beurteilt und mit den klinischen Symptomen korreliert. Eine gezielte Ernährungstherapie mit B. longum AH1206 könnte künftig bei Menschen mit allergischen Erkrankungen zur Immunmodulation und Symptomlinderung eingesetzt werden.

\section{DGKJ-PV-002}

Ernährung und Wachstum bei angeborenen Herzfehlern: Malnutrition und Wachstumsretardierung sowie Adipositas

R. Eyermann

Dr. Richard Eyermann

Problemstellung: Malnutrition und Wachstumsretardierung sind große Besorgnisse bei Kindern mit angeborenen Herzfehlern.

Ergebnisse: Die Ursachen abnormen Wachstums sind multifaktoriell. Hindernisse für die Sicherung einer adäquaten enteralen Ernährung inkludieren individuelle Gegebenheiten in praxi, Unterversorgung mit enteralen Nährstoffen und frequente Unterbrechungen der Zuführung der Nährstoffe. So belegen Studien, dass kritisch kranke Patienten nur die Hälfte bis zwei Drittel ihres kalorischen Bedarfs erhalten. Trotz unterschiedlicher Methoden und Endpunkte kommt die Mehrzahl der 
Studien zu dem Schluss, dass die energetische Imbalance ein großer Risikofaktor für die Wachstumsretardierung von Kindern mit angeborenen Herzfehlern ist: Das Alter des Kindes und der Zeitpunkt der korrektiven Chirurgie beeinflussen das Potenzial der nutritiven Erholung. Kinder mit zyanotischen Herzfehlern und pulmonaler Hypertension erleiden am häufigsten signifikante Wachstumsretardierung. Die Population von Kindern mit funktionell univentrikulärer Zirkulation hat dabei das höchste Risiko: Das somatisches Wachstum ist signifikant verzögert vor der Konversion zur FONTAN-Zirkulation, zu Aufholwachstum kommt es aber im Langzeitverlauf.

Diskussion: Das Erkennen verzögerten Wachstums ist der erste Schritt in der Optimierung des Outcomes von Kindern mit kardiovaskulären Erkrankungen. Es ist die Verantwortung des interdisziplinären Teams dem Ernährungsmanagement hohe Priorität im Behandlungsmanagement von Säuglingen und Kindern mit angeborenen Herzfehlern beizumessen. Medizinische und nutritive Risikofaktoren müssen für jedes Kind indiduell identifiziert werden. Evidence-basierte Protokolle fokusieren darauf, dass frühe enterale Ernährung das klinische Outcome verbessern und die Hindernisse reduzieren kann, kritisch kranke Kinder optimal zu ernähren (u. a. hypermetabolische Response, getriggert durch kardiopulmonalen Bypass und Energieerfordernisse nach chirurgischer Korrektur). RCT bei beatmeten Kindern mit Vergleich von Nahrungstuben in Magen und Dünndarm zeigen signifikant höhere mögliche Ernährungsmengen im Dünndarm ohne Differenz in Nahrungstoleranz und -aspiration. Aber auch die Krankenhausverweildauer von Säuglingen nach offener Herzchirugie kann die enterale Ernährung beeinflussen: Probleme der oralen Nahrungsaufnahme bestehen v. a. bei Stimmbandläsionen, bei prolongierter Intubation, bei komplexen Vitien und bei niedrigem Gewicht zum Op-Zeitpunkt. Im Gegensatz dazu können angeborene Herzfehler mit Fettsucht assoziiert sein. Kinder mit Herzerkrankungen haben dann ein höheres Risiko für adipositasassoziierte kardiovaskuläre Komplikationen.

Konklusion: Entsprechend den Risikofaktoren für eine inadäquate andererseits aber auch exzessive Ernährung (Malnutrition aber auch Übergewicht/Adipositas) in dieser Population sollten nutritive Evaluationen in jede ambulante Visite einbezogen werden. Anthropometrische Messungen erlauben das nutritive Management zu steuern. Strategien sollten darauf abzielen, die kalorischen Bedürfnisse für Basisbedarf, weitere metabolische Erfordernisse und Aufhol-Wachstumssicherung festzulegen. Die Erreichung adäquater Nutrition wird optimale Outcomes von physischer, kognitiver und motorischer Entwicklung sichern helfen.

\section{DGKJ-PV-003}

Adipositasepidemie: Ist Körperfett gleich Körperfett ? Waist-toHeight-Ratio (WHtR) als neues Maß für die Messung des Körperfetts und neuer Prädiktor für Kardiovaskuläres Risiko (Events und Mortalität)

R. Eyermann

Dr. Richard Eyermann

Problem: Kardiovaskuläre Erkrankungen führende Ursache für Morbidität $u$. vorzeitige Mortalität in Industriestaaten u. vielen Entwicklungsländern. Nach jüngsten Daten $75 \%$ aller deutschen Männer u. fast $60 \%$ aller Frauen übergewichtig, mehr als 50\% der Männer u. 23\% der Frauen adipös. Medizinische Bedeutung dieser Daten kontrovers diskutiert.

Frage: Statistiken basieren auf dem BMI (WHO-Empfehlung). Eignet sich BMI als gesundheitlicher Risikoprädiktor?

Ergebnis: BMI seit einiger Zeit in der Expertenkritik, eignet sich nicht als Prädiktor für Schlaganfall-, Herzinfarkt- oder Mortalitätsrisiko. Für Risikoaussagen eignet sich nach neuesten Multizenter-Studien viel besser die Waist-to-Height-Ratio (WHtR). Korrekte Messung in Taillenhöhe im Stehen zwischen Beckenkamm und Rippenbogen in Atemmittellage.

Nicht die Menge, sondern die Verteilung des Körperfetts ist entscheidend. Abdominale Adipositas, weist auf deletäre kardiometabole
Effekte von intraabdominalem Bauchfett hin, mit mehr als 4x erhöhtem Risiko eines Myokardinfarktes: OR 4,5 für Westeuropa, u. a. Deutschland, in der INTERHEART-Study 2004.

Bauchfett, Vermehrung von viszeralem Fettgewebe: führt zur gesteigerten Expression von Botenstoffen u. Entzündungsmarkern wie TNF-alpha, Interleukin-6 oder Leptin sowie zu CRP-Erhöhung, bei verminderter Freisetzung von Adiponektin aus s. c. Fettdepots; fördert die subklinische Inflammation u. Atherogenese; produziert Plasminogen-Aktivator Inhibitor-1 (PAI-1), mit Einfluss auf die Blutgerinnung u. ebenfalls Assoziation mit gesteigertem kardiovaskulären Risiko. bildet Angiotensin u. darüber Verbindung zur arteriellen Hypertonie; in gesteigerter Mobilisation von FFS Entstehung von Lipidstoffwechselstörungen.

Hüft-, Oberschenkel- u. Gesäßfett haben nach jüngsten Daten nichts mit dem Risiko für Herz-Kreislauf-Erkrankungen zu tun u. wirken mitunter protektiv.

Multizenter-Studiendaten an 11. ooo Probanden mit Erfassung von WHR, WHtR u. BMI u. Gesundheitsentwicklung über einen Verlauf bis zu 8 Jahren belegen die Überlegenheit von WHtR als Prädiktor für das Herzinfarkt-, Apoplexie- und Mortalitätsrisiko: Je höher die WHtR , desto größer das Risiko. Die beiden anderen getesteten Maße, die WHR war weitaus weniger u. der BMI gar nicht aussagekräftig.

Diskussion: Immer mehr Studien belegen, dass der bislang von der WHO empfohlene BMI zur Messung des Körperfetts kein zuverlässiger Risikoprädiktor für kardiovaskuläres Risiko u. Mortalität (Event u. Tod von Herzinfarkt u. Schlaganfall) darstellt. Besonders die hohe Fettverteilung am Bauch begünstigt Krankheiten wie Hypertonie, Diabetes mellitus u. Arteriosklerose u. ist mit gesteigertem KHK-Risiko assoziiert. In jüngster Vergangenheit wurde daher bereits der WHR ein höherer prädiktiver Stellenwert für das kardiovaskuläre Risiko zuerkannt als dem BMI.

Konklusion: Es gilt abdominale Adipositas mit ihren deletären kardiometabolen Effekten von intraabdominalem Bauchfett noch besser mit einfachen Methoden nichtinvasiv zu erfassen u. so die Hochrisikopatienten für kardiovaskuläre Ereignisse zu ermitteln. Die WHtR zeigt sich in jüngsten Studien als bislang bester Parameter für die klinische Beurteilung der Körperfettverteilung u. ist der WHR überlegen, dem BMI weit überlegen. Die Übernahme der WHtR als Empfehlung für die Messung des Körperfetts und zur Prädiktion des kardiovaskulären Risikos durch die Medizinischen Fachgesellschaften u. die WHO steht aber noch aus.

\section{Verteilung des Körperfetts}

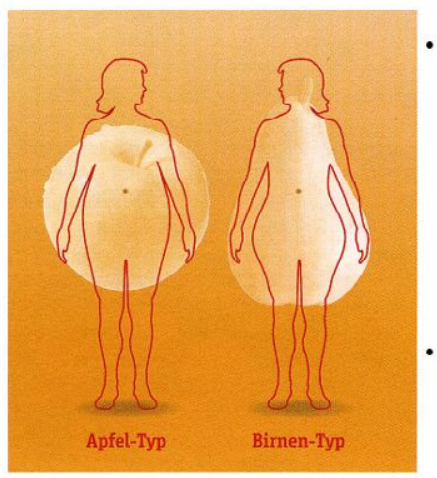

- Bei jungeren Frauen lagert sich das Körperfett bevorzugt um die Hüften ab (Birnen-Typ), bei älteren Frauen eher am Bauch (Apfcl-Typ). Dcr Apfcl-Typ ist mit einem besonders hohen kardiovaskulären Risiko assoziiert.

- Adipöse Männer disponieren primär zur Fettverteilung vom Apfel-Typ. 
DGKJ-PV-004

Mütterliche Steuerung und kindliche Ernährung

K. Kröller, P. Warschburger

Universität Potsdam

Fragestellung:Empirische Untersuchungen haben gezeigt, dass elterliche Einflüsse für die Ausbildung von kindlichen Nahrungspräferenzen ausschlaggebend sind. Das Ziel der Untersuchung war die Analyse eines Strukturgleichungsmodells zum Zusammenhang zwischen mütterlicher Steuerung in der Essenssituation und der kindlichen Ernährung unter Berücksichtigung demographischer und gewichtsbezogener Faktoren.

Methodik: 556 Mütter mit 1-10-jährigen Kindern wurden zu ihren soziodemographischen und gewichtsbezogenen Daten sowie der mütterlichen Steuerung (ISS) und der kindlichen Ernährung (FFQ) befragt. Ergebnisse: Generell zeigt das getestete Model einen guten Fit. Es konnten $73 \%$ der Varianz gesunder und 34\% problematischer Nahrungsmittel erklärt werden, wobei sich vor allem die mütterliche Steuerung durch Belohnung und Vorbildwirkung als signifikante Prädiktoren erwiesen.

Schlussfolgerung: Die Ergebnisse unterstreichen die Relevanz mütterlicher Steuerungsstrategien für die kindliche Ernährung. Zur Vermeidung von ess- oder gewichtsbedingten Problemen sollten Eltern vermehrt in der Anwendung eines expliziten Vorbildverhaltens und der Vermeidung eines belohnenden Steuerungsverhaltens geschult werden.

\section{DGKJ-PV-005}

Verzehr von Milch und Milchprodukten bei Kleinkindern im Alter von 10-36 Monaten in einer bundesweiten Verzehrsstudie

A. Hilbig, S. Klein, C. Drossard, U. Alexy, M. Kersting

Forschungsinstitut für Kinderernährung

Hintergrund: Längsschnittuntersuchungen in der DONALD Studie (Dortmund Nutritional and Anthropometric Longitudinally Designed Study) zeigten einen zunehmenden Trend beim Verzehr von Säuglingsund „Kinder"milch (Fertigmilch) auf Kosten von Kuhmilch(produkten) im Kleinkindalter. Jetzt wurden neue bundesweite Verzehrsdaten entsprechend aufgeschlüsselt.

Probanden und Methode: Im Rahmen der German Representative Study of Toddler Alimentation (GRETA) wurde im Jahr 2008 eine Stichprobe von Eltern von 10-36 Monate alten Kleinkindern nach kombinierten Quotenvorgaben (TNS Access-Panel) gezogen. Erhoben wurden 7-Tage-Ernährungsprotokolle von 526 Kindern. Die Verzehrsmengen wurden von den Eltern anhand der Häufigkeit altersadaptierter Portionsgrößen, die großteils anhand gewogener Verzehrsmengen bei Kleinkindern der DONALD Studie ermittelt worden waren, erfasst. Hier wurden Verzehrsmengen (g/Tag) und -muster von Milch(produkten) insgesamt sowie aufgeschlüsselt in Fertigmilch und Kuhmilch(produkten) und deren Beiträge zur Zufuhr von Energie und ausgewählten Nährstoffen in Abhängigkeit vom Alter und der sozio-ökonomischen Schicht ausgewertet.

Ergebnisse: Der mittlere Verzehr von Milch(produkten) insgesamt lag bei ca. 322 g/Tag. Ein Alterstrend oder Unterschiede zwischen den sozialen Schichten wurden nicht beobachtet. Der Anteil der Fertigmilch am Verzehr von Milch(produkten) sank von $62 \%$ (10-12 Monate) über 25\% (18-24 Monate) auf $12 \%$ (25-36 Monate). Folgemilch machte in allen Altersgruppen den größten Anteil der Fertigmilch (60-73\%) aus, während „Kinder"milch nur eine untergeordnete Rolle spielte. Mit zunehmendem Alter sank der Anteil von Milch(produkten) insgesamt an der Zufuhr von Energie bzw. Fett von 28 auf $20 \%$ bzw. von 38 auf 22\%. Der Anteil an Milch(produkten) an der Zufuhr von Protein bzw. Calcium lag weitgehend unabhängig vom Alter bei ca. $32 \%$ bzw. $58 \%$.

Schlussfolgerung: Die mittleren Verzehrsmengen von Milch(produkten) entsprachen den Empfehlungen der Optimierten Mischkost für das Kleinkindalter. Folgemilch wurde nach dem ersten Lebensjahr rasch durch herkömmliche Milch(produkte) ersetzt. Spezielle
„Kinder"milch konnte sich gegenüber einer Fortführung der Folgemilch nach dem ersten Lebensjahr nicht durchsetzen. Mit finanzieller Förderung durch die Nestlé Nutrition $\mathrm{GmbH}$

\section{DGKJ-PV-006}

Ist die Prävention der atopischen Dermatitis mit Hydrolysatnahrung kosteneffektiv? Eine gesundheitsökonomische Analyse der GINI-Studie

J. Mertens' ', S. Stock', M. Lüngen', A. von Berg², U. Krämer ${ }^{3}$, B. Filipiak-Pittroff $^{2}$, J. Heinrich', S. Koletzko ${ }^{5}$, A. Grübl ${ }^{6}$, H. Wichmann ${ }^{5}$, C. Bauer ${ }^{6}$, D. Reinhardt ${ }^{5}$, D. Berdel ${ }^{2}$, A. Gerber ${ }^{7}$

'Institut für Gesundheitsökonomie und Klinische Epidemiologie (IGKE), ${ }^{2}$ Marien-Hospital Wesel, ${ }^{3}$ UUF-Institut für Umweltmedizinische Forschung, ${ }^{4}$ Helmholtz Zentrum München, ${ }^{5}$ Ludwig-Maximilians University, ${ }^{6}$ Technical University of Munich, ${ }^{7}$ Institut für Qualität und Wirtschaftlichkeit im Gesundheitswesen (IGQiG)

Hintergrund und Ziele: Die atopische Dermatitis verursacht jährlich Kosten von 1,2 bis 3,5 Mrd. $€$ in Deutschland. Diese sollten möglichst präventiv reduziert werden. So konnte die randomisiert doppelblind angelegte GINI-Studie, in die zwischen 1995 und 1998 2. 252 Neugeborene eingeschlossen wurden, die genetisch über Eltern oder Geschwister atopiegefährdet waren, je nach Hydrolysatnahrung, wenn mindestens vier Monate eingesetzt, eine Reduktion des relativen Risikos für atopische Dermatitis um 26 bis $45 \%$ gegenüber regulärer kuhmilchbasierter Nahrung nachweisen. Auf dieser Grundlage wurde die vorliegende gesundheitsökonomische Analyse durchgeführt.

Methoden: Grundlage der Kosten-Effektivitäts-Analyse ist ein Entscheidungsbaum, der im Programm TreeAge erstellt wurde. Die Kinder werden über den bisher ausgewerteten Sechs-Jahres-Zeitraum verfolgt. Die Analyse wurde aus der Perspektive der Gesetzlichen Krankenversicherung und aus der gesellschaftlichen Perspektive durchgeführt Ergebnisse: Schon für das erste Jahr sind sowohl die partiell hydrolysierte Nahrung auf Molkebasis und die stark hydrolysierte Nahrung auf Kaseinbasis kosteneffektiv. Im sechsten Jahr ergeben sich sogar Kosteneinsparungen. Die dritte eingeschlossene Hydrolysatnahrung, eine stark hydrolysierte Nahrung auf Molkebasis, wurde zu beiden Zeitpunkten in der Kosten-Effektivitäts-Analyse dominiert.

Schlussfolgerung: Die Ergebnisse zeigen, dass zwei der drei Hydrolysatnahrungen je nach Szenario kosteneffektiv oder sogar kostensparend sein können über einen Zeitraum von sechs Jahren.

\section{DGKJ-PV-007}

Adipositas bei Kindern und Jugendlichen: Einfluss sozialer Risikofaktoren auf den Therapieerfolg ambulanter und stationärer AdipositasTherapien anhand der multizentrischen APV-Daten.

M. Röbl' ', S. Wiegand ${ }^{2}$, R. Schiel ${ }^{3}$, I. Gellhaus ${ }^{4}$, K. Zwiauer ${ }^{5}$, M. de Souza ${ }^{6}$, R. Holl ${ }^{6}$

${ }^{1}$ Universitätsmedizin Göttingen, ${ }^{2}$ Universitätsmedizin Berlin, ${ }^{3}$ Medigreif Inselklinik Heringsdorf, ${ }^{4}$ Universität Paderborn, ${ }^{5}$ Landesklinikum, ${ }^{6}$ Universität Ulm

Fragestellung: In der Untersuchung soll der Einfluss sozialer Risikofaktoren auf den Therapieerfolg von Adipositas-Therapien untersucht werden.

Methodik: Die APV-Dokumentation wurde in Kooperation mit der AG Adipositas bei Kindern und Jugendlichen an der Universität Ulm entwickelt und erlaubt eine EDV-basierte, standardisierte, prospektive Erfassung von relevanten Parametern der Anthropometrie, Komorbidität, Einflussfaktoren und Therapie von Patienten in spezialisierten Therapieprogrammen. 104 Zentren aus Deutschland, Österreich und der Schweiz setzen dieses Programm ein. Bis Juni 2009 wurden 57390 Patienten erfasst. In die Untersuchung gingen Daten von 8720 Patienten ein, bei denen Angaben zur kulturellen Herkunft, zur Erwerbstätigkeit der Eltern und zur Schulbildung der Patienten vorlagen und deren BMI-SDS $\geq 1,28$ (Übergewicht) war. Anhand eines Risiko-Score teilten 
wir in Abhängigkeit der sozialen Risikofaktoren die Patienten in drei Risiko-Gruppen (keine, moderate und hohe soziale Risikogruppe) ein. Ergebnisse: Zu Beginn der Therapie betrug das mittlere Alter 11,6 2 , 7 Jahre. $15 \%(\mathrm{n}=1310)$ waren übergewichtig, 48,4\% $(\mathrm{n}=4221)$ adipös und $36,6 \%(n=3189)$ extrem adipös. Der mittlere BMI-SDS betrug 2,38 $\pm 0,74$. Weiblich waren 54,7\% der Kinder und Jugendlichen. 86,6\% $(n=7552)$ der Kinder und Jugendlichen wiesen keine der von uns untersuchten Risikofaktoren auf. Bei $11,7 \%(n=1016)$ stellten wir eine moderate Anzahl sozialer Risikofaktoren fest und bei $1,7 \%(n=150)$ eine hohe Anzahl sozialer Risikofaktoren. Mit Hilfe eines Regressionsmodells zur Adjustierung der Patientenheterogenität (soziale Risikofaktoren, Geschlecht, Alter, BMI-SDS, Therapiedauer) konnten wir signifikante Unterschiede $(\mathrm{p}<$. ooo1) in der BMI-Reduktion zwischen den einzelnen Risikogruppen feststellen. Die größte BMI-SDS Reduktion zeigte die Gruppe ohne soziale Risikofaktoren mit -0,21, in der Gruppe mit einer moderaten Anzahl sozialer Risikofaktoren betrug sie -0,16 und in der Gruppe mit einer hohen Anzahl sozialer Risikofaktoren nur -0,14. Hierbei unterschieden sich die einzelnen Risiko-Gruppen nicht in der Therapieintensität (Anzahl der Therapieeinheiten à 45 Minuten).

Schlussfolgerung: Kinder und Jugendliche mit einer hohen Anzahl sozialer Risikofaktoren (Migrationshintergrund, Erwerbslosigkeit der Eltern und geringe Schulbildung) zeigen einen signifikant schlechteren Therapie-Erfolg als Kinder ohne entsprechende soziale Risikofaktoren. Scheinbar werden die bisherigen Adipositas-Schulungsprogramme den besonderen Bedürfnissen dieser Subgruppe nicht gerecht. Um den Therapieerfolg auch bei Kindern und Jugendlichen mit einer hohen Anzahl sozialer Risikofaktoren zu verbessern, müssen spezielle Adipositas-Schulungsprogramme entwickelt werden.

\section{DGKJ-PV-008}

Multiple Mangelzustände eines vollgestillten Säuglings bei veganer Ernährung der Mutter

J. Dörner, M. Eulitz, I. Eckart, S. Voigt, K. Milbredt, J. Seidel

SRH Wald-Klinikum Gera

Einleitung: Eine vegane Lebensweise der Mutter verhindert bereits intrauterin die Anlage eines Vitamin-B12-Speichers in der kindlichen Leber. Erfolgt postnatal die Ernährung des Neugeborenen und Säuglings ausschließlich über Muttermilch, droht ein schwerer symptomatischer VitaminB12-Mangel bereits im frühen Säuglingsalter. Weitere relevante Unterversorgungen können bezüglich VitaminD und Eisen auftreten.

Zielstellung: Es soll im Rahmen der Abklärung einer Säuglingsanämie auf die dringende Notwendigkeit einer Ernährungsanamnese von Mutter und Kind und die DD Betrachtung eines Vitamin-B12-Mangels und weiterer möglicher Mangelzustände hingewiesen werden.

Methode: Wir stellen die Kasuistik eines zum Zeitpunkt der stationären Aufnahme 11 Wochen alten voll gestillten Säuglings mit ausgeprägter Anämie, Mangelgedeihen und Adynamie vor, dessen Mutter Veganerin ist. Der weitere Verlauf bis zum 10. Lebensmonat wird verfolgt.

Ergebnisse: Die stationäre Einweisung erfolgte wegen schwerer Anämie $(\mathrm{Hb} 3,8 \mathrm{mmol} / \mathrm{l}, \mathrm{Hk}$ 0,18) und Mangelgedeihen. In der Diagnostik fanden sich eine megaloblastäre Anämie ( $\mathrm{MCV}, \mathrm{MCH}$ erhöht) mit Nachweis eines deutlich erniedrigten Vitamin B12-Wertes (36 pmol/l, NB 140-49o; bei hochnormalen Eisen- und Folsäurewerten) sowie eine Homocysteinämie ( $188 \mu \mathrm{mol} / \mathrm{l}, \mathrm{NB} 5-15)$ und Methylmalonazidurie als Zeichen des B12-Mangels.

Unter Therapie (Bluttransfusion und i. V. Injektion von Vitamin B12) verbesserten sich die Vigilanz und das Trinkverhalten des Kindes rasch und normalisem B12-Wert nach 4 Wochen (169 pmol/l).

Im weiteren Verlauf, unter monatlicher i. m. Injektion von Vitamin B12 (100-150 $\mu \mathrm{g})$ normalisierte sich der Homocysteinstoffwechsel (Abnahme der Methylmalonsäure-Ausscheidung im Urin, Homocysteinspiegel $<15 \mu \mathrm{mol} / \mathrm{l})$. Im Alter von 5 Monaten wurde ein VitaminDMangel (25-OHD < $10 \mathrm{nmol} / \mathrm{l}, \mathrm{NB} 27,7-107)$, mit AP- und PTH-Erhöhung (AP 4,8 $\mu \mathrm{mol} / 1 /$; iPTH 8,o pmol/1; NB 1,6-6,9) diagnostiziert und eine VitaminD-Substitution (1. ooo IE /d für 4 Wochen, anschließend weiter mit $500 \mathrm{IE} / \mathrm{d})$ durchgeführt, die zur PTH-Normalisierung $(1,9$ pmol/l) führte.

Mit 5 Monaten fand sich bei im unteren NB befindlichen VitaminB12Wert (149 pmol/l) eine beginnende mikrozytäre Anämie ( $\mathrm{Hb}$ 6,9 $\mathrm{mmol} / \mathrm{l}$, HK o,33; MCV mit $72 \mathrm{fl}$ vermindert) bei nachweisbarem Eisenmangel (Fe mit 5,3 $\mu \mathrm{mol} / \mathrm{l}$ erniedrigt; Ferritin-Abfall von 227 -> 65,9 ng/ $\mathrm{ml}$; NB 30-400), so dass zusätzlich auch eine Eisensubstitution mit Ferrosanol Gtt. eingeleitet werden musste. Von den Eltern wurden keinerlei prophylaktischen Behandlungen akzeptiert und Impfungen vor Vollendung des 1. LJ abgelehnt.

Diskussion und Schlussfolgerung: Da zukünftig trotz mehrfacher medizinischer und Ernährungs-Beratungen auch mit veganer bzw. vegetarischer Ernährung des Kindes durch die Mutter bei Brei-Zufütterung und in der Kleinkindkost gerechnet werden muss, ist es erforderlich, das Kind auch zukünftig engmaschig bezüglich drohender Mangelerscheinungen zu überwachen.

\section{DGKJ-PV-009}

Essen leberkranke Kinder anders?

M. Bohn, K. Wimmer, L. Schwadtke, M. Niemeyer, E. Pfister, U. Baumann Kinderklinik der Med. Hochschule

Einleitung: Bereits Kinder und Jugendliche mit leichter bis mäßiger Lebererkrankung weisen eine veränderte Stoffwechsellage auf. Es ist bislang unklar, ob dies allein durch eine gestörte Leberfunktion ausgelöst wird oder auch durch eine veränderte Nahrungszufuhr. Durch einen Vergleich von leberkranken Patienten mit einem lebergesunden Kontrollkollektiv soll geprüft werden, ob und wie sich biometrische Daten und Ernährungsprofile in beiden Gruppen unterscheiden. Patienten und Methoden: Anonymisierte retrospektive Fragebogen-gestützte Erhebung: Leberkranke $(n=43)$ versus lebergesunde Patienten $(n=43)$, dabei Betrachtung der Altersgruppen o-6 Jahre (leberkrank n=19, Alter 6-83, Median 49 Monate, vs. lebergesund $n=22$, Alter 5-77, Median 40,5 Monate) und 7-18 Jahre (leberkrank $n=24$, Alter 7-18, Median 11 Jahre, vs. lebergesund $\mathrm{n}=21$, Alter 7-17, Median 10,5 Jahre). Ergebnisse: Leberkranke Patienten hatten im Mittel ein niedrigeres Geburtsgewicht (3119 g vs. 3434 g, t-Test; $p=0,0029)$, waren insgesamt seltener gestillt $(69,8 \%$ vs. 95,3\%, Chi-Quadrat; $\mathrm{p}=0,0034$ ) und in der jüngeren Altersgruppe häufiger auf ärztlichen Rat abgestillt worden (52,6 \% vs. O \%, Chi-Quadat; $\mathrm{p}=0,0002)$. Zwischen den betrachteten Gruppen bestand kein signifikanter Unterschied beim BMI (o-6 Jahre: $15,5 \mathrm{~kg} / \mathrm{m} 2$ vs. $15,8 \mathrm{~kg}$ / m2; 7-18 Jahre: $16,45 \mathrm{~kg} / \mathrm{m} 2$ vs. $17,4 \mathrm{~kg} / \mathrm{m} 2)$ und bei der Flüssigkeitszufuhr pro Tag (o-6 Jahre: 947 vs. $861 \mathrm{ml}$; 7-18 Jahre: 1540 vs. $1468 \mathrm{ml}$ ). In Bezug auf einzelne Lebensmittel scheinen leberkranke Kinder mehr Kohlenhydrate (Wilcoxon-Test, $\mathrm{p}=0,0127$ ), mehr Fett ( Wilcoxon-Test, $\mathrm{p}=\mathrm{o}, \mathrm{0426}$ ) sowie tendenziell eher salzig (Wilcoxon-Test, $\mathrm{p}=\mathrm{o}, 0082$ ) zu essen. Zusammenfassung: Schon bei leicht bis mäßig leberkranken Kindern finden sich Ernährungsunterschiede, die zu den bekannten assoziierten Stoffwechselstörungen beitragen. Schlussfolgerung: Die Kenntnis der besonderen Ernährungspräferenzen sollte zur optimierten Diätberatung und Ernährungstherapie berücksichtigt werden. Eine frühzeitige Intervention erscheint indiziert, weitere prospektive Untersuchungen sind aber erforderlich.

\section{DGKJ-PV-010}

Dystrophie und psychomotorische Entwicklungsverzögerung sowie Tremor bei vollgestilltem Kleinkind

B. Leidl, A. Thürigen, G. Leineweber, S. Eichholz, M. Kabus

Klinik für Kinder- und Jugendmedizin, Städtisches Krankenhaus DresdenNeustadt

Hintergrund: Ein Vitamin B12-Mangel (Mangel an Cobalamin) kann zu Gedeihstörung mit schwerer psychomotorischer Entwicklungsretardierung und neurologischen Symptomen führen. Hämatologisch kommt es zur makrozytären Anämie. Häufigste Ursache dieses in Mitteleuropa seltenen Vitaminmangels ist meist eine unsachgemäße und 
nicht altersadäquate Ernährung, bei ersten Symptomen im Kleinkindalter muss jedoch auch an Vitamin B12-Stoffwechseldefekte gedacht werden.

Kasuistik: 23 Monate altes weibliches Kleinkind mit anhaltendem Tremor des rechten Armes und der rechten Gesichtshälfte sowie auffälliger Agitation und Unruhe seit 2-3 Tagen. Unauffällige Entwicklung im ersten Lebensjahr, danach Stagnation der motorischen und mentalen Entwicklung. Kein Vorsorgeheft, keine U-Untersuchungen durchgeführt. Bislang ausschließlich gestillt, da die Versuche der Beikosteinführung stets an der Kostverweigerung des Kindes (starke Abwehr, Würgen und Erbrechen) gescheitert sind.

Aufnahmestatus: Deutlich reduzierter AZ, kachektischer EZ, unleidlich, Gewicht 7,18 kg (-3,92 SDS), Länge 70 cm (-4. 72 SDS), BMI 14,69 $\mathrm{kg} / \mathrm{m} 2$ (-1,03 SDS), KU $47 \mathrm{~cm}$ ( $\left.\mathrm{P}_{25}\right)$, rechtsbetonte nicht unterbrechbare Kloni der oberen Extremität und M. sternocleido-mastoideus, rechtsbetontes Grimmasieren, deutlicher motorischer und sprachlicher Entwicklungsrückstand.

Labor: makrozytäre Anämie, Vit. K-, A- und E-Mangel, Vit. B12-Spiegel nicht messbar, Metabolite Homocystein und Methylmalonsäure erhöht und damit hinweisend auf nutritiven Vit. B12-Mangel.

cMRT: frontale Atrophie.

Diagnose: Die kombinierte Entwicklungsstörung mit makrozytärer Anämie und die neurologische Symptomatik einer funikulären Myelose sowie die o. g. Laborbefunde beweisen einen Vit. B12-Mangel in Kombination mit weiteren nutritiven Mangelerscheinungen.

Verlauf: Unter Vit. B12-Substitution rasche Normalisierung des Blutbildes und Rückläufigkeit der neurologischen Symptomatik, insbesondere des Tremors. Im weiteren Verlauf deutliche Entwicklungsfortschritte, jedoch noch lange Zeit Sondenernährung erforderlich bei beginnendem, aber noch nicht ausreichendem oralen Kostaufbau.

Schlussfolgerung: Häufigste Ursache eines Vit. B12-Mangels im Säuglings- und Kindesalter ist die vegane Ernährung der stillenden Mutter bzw. die zu späte Beikosteinführung bei vollgestillten Kleinkindern. Eine Vit. B12-Substitution ist dringend erforderlich und kann zu einer Regredienz der neurologischen Entwicklung führen. Wichtig zur Vermeidung einer frühkindlichen Malnutrition durch Diätfehler ist die Teilnahme an engmaschigen kinderärztlichen Vorsorgeuntersuchungen bzw. regelmäßige Gewichtskontrollen in den ersten Lebensjahren.

\section{DGKJ-PV-011}

\section{Generalisierte Dentitio praecox - eine Fallpräsentation}

R. Schilke', J. Berten', C. Eulzer², A. Dini ${ }^{3}$, C. Kayser ${ }^{4}$

${ }^{1}$ Medizinische Hochschule Hannover, ${ }^{2}$ PraxisKlinik RosenQuartier, ${ }^{3}$ Ernst von Bergmann Poliklinik, ${ }^{4}$ Praxis für Kinderheilkunde und Jugendmedizin

Einleitung: Der Zeitpunkt der Dentition der einzelnen Zähnen ist interindividuell variabel. Er folgt jedoch einer parametrischen Verteilung. Innerhalb der $95 \%$-Grenze liegt die physiologische Dentition, unterhalb davon die Dentitio praecox. Andere sprechen von einer Dentitio praecox, wenn die doppelte Standardabweichung der Durchbruchszeit des jeweiligen Zahns unterschritten wird oder das Zahnalter mehr als 2 Jahre vom Durchschnittswert abweicht.

Fallberichte über einen verfrühten Zahndurchbruch einzelner Zähne oder Zahngruppen sind in der Literatur zahlreich zu finden, während generalisierte Formen äußerst selten beschrieben sind.

Falldarstellung: Nach kinderärztlicher Überweisung stellte sich ein $2^{1 / 2}$ jähriges Mädchen vor. Die Zähne 31 und 41 befanden sich nach physiologischer Exfoliation der Zähne 71, 81 und 82 im Durchbruch. Radiologisch entsprach der Entwicklungsstand der übrigen Zahnkeime einem dentalen Alter von etwa 5 Jahren. Anamnestisch konnte eruiert werden, dass die ersten Zähne der 1 . Dentition mit $2^{1 / 2}$ Monaten durchgebrochen waren und mit 6 Monaten das Gebiss der 1. Dentition vollständig vorhanden war. Die Schwangerschaft sowie die statomotorische und psychomentale Entwicklung des Kindes verliefen unauffällig. Nach einer Handwurzelaufnahme entsprach das skelettale Alter dem chronologischen. Genetische oder endokrinologische Erkrankungen konnte nicht verifiziert werden.
Der Zahnwechsel ist wie folgt dokumentiert (Alter der Patientin in Jahren (J.) und Monaten (M.)):

\begin{tabular}{|lll|}
\hline Tab. & Oberkiefer & Unterkiefer \\
\hline mittlerer Schneidezahn & $4 \mathrm{~J} .11 \mathrm{M}$. (nach OP) & 2 J.5 M. \\
\hline seitlicher Schneidezahn & $4 \mathrm{~J} .8 \mathrm{M}$. & $3 \mathrm{~J} .0 \mathrm{M}$. \\
\hline Eckzahn & $5 \mathrm{~J} .1 \mathrm{M} / 6 \mathrm{~J} .2 \mathrm{M}$. & $5 \mathrm{~J} .5 \mathrm{M}$. \\
\hline 1. Prämolar & $5 \mathrm{~J} .1 \mathrm{M} / 6 \mathrm{~J} .0 \mathrm{M}$. & $4 \mathrm{~J} .9 \mathrm{M} . / 5 \mathrm{~J} .5 \mathrm{M}$. \\
\hline 2. Prämolar & $6 \mathrm{~J} .2 \mathrm{M}$. & $5 \mathrm{~J} .6 \mathrm{M} . / 5 \mathrm{~J} .8 \mathrm{M}$. \\
\hline 1. Molar & $3 \mathrm{~J} .4 \mathrm{M}$. & $3 \mathrm{~J} .9 \mathrm{M}$. \\
\hline 2. Molar & $7 \mathrm{~J} .1 \mathrm{M}$. & $7 \mathrm{~J} .5 \mathrm{M}$. \\
\hline
\end{tabular}

Im Alter von 4 Jahren 10 Monaten wurden die Zähne 51 und 61 sowie 2 überzählige Zahnanlagen im Oberkieferfrontzahnbereich entfernt. Im Alter von 7 Jahren 1 Monat erfolgte die Entfernung des retinierten und verlagerten Zahnes 43. Die kieferorthopädische Behandlung ist zurzeit noch nicht abgeschlossen. Der partiell hypomineralisierte Zahnschmelz der 6-Jahrmolaren, die verkürzten Wurzeln der Unterkieferschneidezähne sowie der verlagerte Zahn 43 stellen für die zahnärztliche Behandlung eine Herausforderung dar.

Schlussfolgerungen: Da eine Dentitio praecox ein Symptom einer systemischen Erkrankung sein kann, muss diese als zugrundeliegende Ursache durch den Kinderarzt ausgeschlossen werden. In enger Zusammenarbeit mit einem (Kinder-)Zahnarzt und einem Kieferorthopäden müssen die oralen Auswirkungen eines generalisierten verfrühten Zahnwechsels behandelt und die Entwicklung des Gebisses überwacht werden.

\section{DGKJ-PV-012}

Inanspruchnahme zahnärztlicher Früherkennungsuntersuchungen in Niedersachsen

R. Schilke', A. Mitschke ${ }^{2}$

${ }^{1}$ Medizinische Hochschule Hannover, ${ }^{2}$ Kassenzahnärztliche Vereinigung Niedersachsen

Fragestellung: An den pädiatrischen Früherkennungsuntersuchungen nehmen bis zur $\mathrm{U}_{7}$ (21.-24. Lebensmonat) $>90 \%$, an U8 und $\mathrm{U}_{9}$ (bis zum 64. Lebensmonat) noch etwa 80\% der Anspruchsberechtigten teil. Seit dem 01. 07. 1999 sind auch zahnärztliche Früherkennungsuntersuchungen (FU) im Rahmen der vertragszahnärztlichen Abrechnung möglich. Dabei sind 3 zahnärztliche Früherkennungsuntersuchungen vorgesehen. Die erste Untersuchung sollte grundsätzlich im dritten Lebensjahr stattfinden. Die beiden weiteren Untersuchungen sollten bis zur Vollendung des 6. Lebensjahres erfolgen, wobei der Abstand zwischen den Untersuchungen mindestens 12 Monate betragen muss. Es sollte ermittelt werden, wie hoch die Inanspruchnahme der zahnärztlichen Früherkennungsuntersuchungen sowie der Anteil der diese Leistungen abrechnenden Praxen in Niedersachsen sind.

Methode: Von der Leistungserfassungsstelle der Kassenzahnärztlichen Vereinigung Niedersachsen wurden sämtliche gegenüber den gesetzlichen Krankenkassen abgerechneten zahnärztlichen Leistungen der Jahre 2003 sowie 2006 bis 2008 nach dem Alter der Patienten sowie dem prozentualen Anteil der Praxen, die diese Leistungen abgerechnet haben, stratifiziert. Die Daten zur Anzahl der Leistungspositionen wurden mit den bevölkerungsstatistischen Angaben des Landesbetriebs für Statistik und Kommunikationstechnologie Niedersachsen korreliert. 
Ergebnisse:

Tab.

\begin{tabular}{|llllll|}
\hline \multicolumn{5}{|c|}{$\begin{array}{l}\text { Anteil der Kinder, bei denen FU-Leistungen } \\
\text { abgerechnet wurden }\end{array}$} & $\begin{array}{l}\text { Anteil der Praxen, } \\
\text { die FU-Leistun- } \\
\text { gen abgerechnet } \\
\text { haben }\end{array}$ \\
\hline & $\begin{array}{l}\text { 3. } \\
\text { Lebens- } \\
\text { jahr }\end{array}$ & $\begin{array}{l}\text { 4. Le- } \\
\text { bensjahr }\end{array}$ & $\begin{array}{l}\text { 5. Le- } \\
\text { bensjahr }\end{array}$ & $\begin{array}{l}\text { 6. Le- } \\
\text { bensjahr }\end{array}$ & \\
\hline 2003 & $17,5 \%$ & $12,6 \%$ & $28,7 \%$ & $21,5 \%$ & - \\
\hline 2006 & $19,8 \%$ & $26,3 \%$ & $28,2 \%$ & $24,0 \%$ & $63,4 \%$ \\
\hline 2007 & $20,3 \%$ & $25,5 \%$ & $27,8 \%$ & $23,9 \%$ & $64,3 \%$ \\
\hline 2008 & $19,9 \%$ & $25,2 \%$ & $26,4 \%$ & $22,3 \%$ & $65,8 \%$ \\
\hline $\begin{array}{l}\text { Mit- } \\
\text { tel- } \\
\text { wert }\end{array}$ & $19,4 \%$ & $22,4 \%$ & $27,8 \%$ & $22,9 \%$ & $64,5 \%$ \\
\hline
\end{tabular}

Schlussfolgerung: Zahlreiche Publikationen über Prophylaxeprogramme belegen, dass eine frühzeitige zahnärztliche Vorstellung des Kindes das Auftreten von Karies deutlich reduziert. Um einen weiteren Rückgang der Kariesinzidenz im Gebiss der 1. Dentition zu erreichen, werden nachdrücklich Maßnahmen gefordert, die zu einer wesentlichen Steigerung der Inanspruchnahme sowie einer Erhöhung des Anteils der diese Leistungen erbringenden Praxen beitragen.

\section{Hämatologie und Onkologie I}

\section{DGKJ-PV-013}

Gastrointestinale Blutungen bei einem Säugling als Manifestation des Blue Rubber Bleb Nevus Syndroms - sind beta-Blocker wirksam? S. Bélard', A. Gerecke', P. Greiner', U. Saueressig'2 A. Superti-Furga', J. Rössler'

${ }^{1}$ Universitäts - Kinderklinik, ${ }^{2}$ Universitätsklinikum Freiburg

Hintergrund: Das Blue Rubber Bleb Nevus Syndrom (BRBNS; oder Bean-Syndrom, deutsch: blaues Gummibläschen Naevus-Syndrom) geht mit multiplen vaskulären Malformationen vor allem der Haut und des Gastrointestinaltraktes aber auch anderer Organe einher. Diese Malformationen sind oft schon bei Geburt vorhanden und zeigen sich im Verlauf progredient. Der Erbgang ist autosomal dominant, das Syndrom tritt jedoch zumeist de novo auf und manifestiert sich in der Regel klinisch durch akute oder chronische intestinale Hämorrhagien mit konsekutiver Anämie. Bisher sind an die 250 Fälle weltweit beschrieben. Ein standardisiertes Vorgehen für Diagnosestellung sowie Therapie ist bisher nicht etabliert

Fallbericht: Ein reifgeborener männlicher Säugling stellte sich im Alter von 1 Monat mit einer hospitalisationsbedürftigen RSV-Infektion vor. Neben der Atemnot fanden sich in der klinischen Untersuchung keine Pathologien und ein regelrecht entwickeltes Kind. Auffällig waren jedoch multiple kutane vaskuläre Fehlbildungen von 1-10 mm Durchmesser an Stamm, Extremitäten und perianal, deren Vorhandensein bereits in der $\mathrm{U}_{2}$ dokumentiert worden war. Das Hämoglobin (HB) lag bei Aufnahme bei 11,1 g/dl und das MCV bei $97 \mathrm{fl}$ (normwertig). Im Verlauf kam es mehrfach zu frischblutigem Erbrechen, Teerstuhl sowie akutem HB-Abfall auf minimal 7,2 g/dl, so dass wiederholt Erythrozytentransfusionen notwendig wurden. Zweimalig wurden Ösophagogastroduodenoskopien (ÖGD) durchgeführt, es zeigten sich jeweils multiple plane vaskuläre Fehlbildungen in der Magenschleimhaut. Die gastralen Befunde wurden mittels Argonlaser koaguliert. In einer Koloskopie fand sich lediglich eine solitäre vaskuläre Fehlbildung im Kolon. Ein Ganzkörper-MRT zum orientierenden Screening auf weitere Läsionen zeigte disseminierte, kleinfleckige Läsionen in der Lunge und im Thymus, eine flächige Läsion zwischen den Muskelschichten im Nacken und eine solitäre Läsion innerhalb des Spinalkanals. Eine oph- thalmologische Untersuchung erbrachte einen Normalbefund. Im Verlauf zeigte sich eine Progredienz der kutanen Läsionen in Größe und Anzahl innerhalb weniger Wochen.

Im Hinblick auf die mögliche Lebensbedrohlichkeit der Erkrankung, die aufgetretenen gastrointestinalen Blutungsrezidive trotz vorausgegangener Koagulationen, die Progredienz der kutanen Läsionen, die bisher in der Literatur beschriebenen insuffizienten medikamentösen Therapieversuche (mit u. a. Kortikosteroiden, Interferon alfa, Vincristin oder Octreotid) und die vielversprechenden Therapieerfolge proliferierender Hämangiome mit Betablockern, entschieden wir uns für einen Therapieversuch mit Propanolol (2 mg/kg KG/d). Unter Propanololtherapie zeigte sich der Hautbefund zunächst progredient und HBwirksame gastrointestinale Blutungen traten erneut auf. Abzuwarten bleibt nun die Langzeitbehandlung.

Schlussfolgerung: Bei limitierten Therapieoptionen des BRBNS soll die Wirksamkeit von Propanolol analog zur Therapie bei proliferierenden Hämangiomen geprüft werden.

\section{DGKJ-PV-014}

Die hereditäre Methämoglobinämie - eine seltene Ursache der Zyanose

J. Behnes ${ }^{1}$, K. Wiermann' ${ }^{1}$ E. Kohne ${ }^{2}$, R. Mallmann ${ }^{1}$

${ }^{1}$ Elisabeth-Krankenhaus, ${ }^{2}$ Universitätsklinik für Kinder- und Jugendmedizin

Ein 14-jähriger irakischer Junge wird zur Abklärung einer anamnestisch seit dem zweiten Lebensjahr bestehenden Akro- und Lippenzyanose sowie Belastungsdyspnoe mit dem Verdacht auf das Vorliegen eines Vitium cordis stationär eingewiesen. Ein Onkel väterlicherseits habe ähnliche Probleme. Voruntersuchungen im Heimatland hätten bislang keine Diagnose ergeben.

Blutbild und Entzündungslabor sind unauffällig. Echokardiographie, Röntgen des Thorax und Spirometrie ergeben keinen hinweisenden pathologischen Befund. In der Blutgasanalyse zeigt sich eine Methämoglobin-Konzentration von 14\%. Ein klinischer Anhalt für eine Vergiftung findet sich nicht.

Biochemisch wird eine weitgehend fehlende Methämoglobin-Reduktase-Aktivität als Ursache der Methämoglobinämie nachgewiesen. Die molekulargenetische Untersuchung identifiziert eine homozygote Transition $\mathrm{C} \rightarrow \mathrm{T}$ (CCC $\rightarrow$ CTC) im Codon 145 des NADH-Cytochrom-b5-Reduktase Gens, eine bislang nicht beschriebene Mutation. Die Untersuchung des Vaters - bei auffälliger Familienanamnese - zeigt mit einer Met-Hb-Konzentration von 3,0\% im Vergleich zu maximal $1 \%$ bei Gesunden und einer MetHb-Reduktase-Aktivität von 12,5 IU/ gHb (Normwert Gesunde: 19,2 +/- 3,9 IU/gHb) einen heterozygoten MetHb-Reduktase-Mangel.

Die Behandlung des Patienten mit Ascorbinsäure über einen Zeitraum von bislang zwei Monaten zeigt bis dato lediglich eine leichte Verbesserung der Methämoglobin-Konzentration auf $11 \%$ ohne merkliche Besserung des Allgemeinbefindens.

Die Methämoglobinämie stellt eine seltene Differentialdiagnose bei Patienten mit Zyanose ohne kardiopulmonale Ursache dar. Die Methämoglobinämie aufgrund eines Cytochrom-b5-Reduktase-Mangels ist eine autosomal-rezessive Erkrankung, die durch eine lebenslange Zyanose gekennzeichnet ist. Mehrere Gendefekte sind für diese Erkrankung beschrieben worden. Man unterscheidet zwei verschiedene Typen des Cytochrom-b5-Reduktase-Mangels. Symptom des Typ I ist vornehmlich die Zyanose, während der Typ II zusätzlich eine geistige Retardierung, Krampfanfälle, Gedeihstörung und Entwicklungsverzögerung beinhaltet. 
DGKJ-PV-015

Behandlung von Kindern und Jugendlichen mit Nebennierenrindentumoren in Deutschland - Ergebnisse und Ausblick der GPOH-METStudie

N. Boxberger ${ }^{1}$, A. Redlich'1, F. Piepe', D. von Schweinitz² ${ }^{2}$ P. Vorwerk ${ }^{1}$

${ }^{1}$ Universitätskinderklinik, ${ }^{2}$ Dr. von Haunersches Kinderspital

Im Rahmen der interdisziplinären multizentrischen Therapieoptimierungsstudie GPOH-MET 97 der Gesellschaft für Pädiatrische Onkologie und Hämatologie $(\mathrm{GPOH})$ werden Kinder und Jugendliche mit Nebennierenrindentumoren (ACT) prospektiv erfasst und betreut.

Fragestellung: Analyse von initialen Symptomen, Stadienverteilung, Histologie, Therapie und Überleben von Kindern und Jugendlichen mit ACT in Deutschland.

Ergebnisse: Von April 1997 bis Juni 2009 wurden 73 Patienten (49 Mädchen und 24 Jungen) im Alter von 0,2 bis 18,4 Jahren (Median 6,8 Jahre) in die Studie eingebracht. Bei 53 Patienten wurde ein Nebennierenrindenkarzinom (ACC), bei 15 Patienten ein Nebennierenrindenadenom (ACA) und bei 4 Patienten ein Tumor unklarer Dignität diagnostiziert. Ein Patient wurde erst im Rezidiv eines ACC erfasst.

Klinisch sichtbare Tumoraktivität führte in $86,6 \%$ der Fälle zur Diagnose. Laborchemisch zeigten $88,9 \%$ der Patienten pathologische Hormonwerte, hauptsächlich Androgenexzess. Abdominale Beschwerden waren nur bei 14,3\% der Kinder Erstsymptom. Die durchschnittliche Anamnesedauer betrug 8,6 Monate (o-72 Monate). Eine initiale Metastasierung trat bei ca. 28,3 \% der Patienten mit ACC vorzugsweise in der Lunge und in den regionalen Lymphknoten auf. Das mittlere Tumorvolumen unterschied sich signifikant zwischen den ACC (471,6 ml) und den ACA (94,9 ml). Tumoren unklarer Dignität wiesen ein mittleres Volumen von $267,7 \mathrm{ml}$ auf.

Informationen über das operative Vorgehen lagen von 67 Patienten vor: 64 Patienten wurden primär operiert, drei Patienten waren inoperabel und verstarben relativ schnell nach Diagnosestellung. Primär Ro-resezierte Patienten $(\mathrm{N}=49$, mittleres Tumorvolumen 262,4 ml) zeigten ein Gesamtüberleben (OS) nach 5 Jahren von $85,8 \%$ wogegen Patienten mit unvollständiger Resektion ( $\mathrm{R} 1 / 2, \mathrm{~N}=16$, mittleres Tumorvolumen $739,3 \mathrm{ml}$ ) nach 5 Jahren nur ein OS von 20,3\% aufwiesen. Bei vier Patienten war ein komplexer Zwei-Höhlen-Eingriff mit Entfernung von Tumorzapfen aus der V. cava notwendig. Präoperative Tumorbiopsien und die intraoperative Tumorruptur verschlechterten das Gesamtüberleben signifikant.

Patienten in fortgeschrittenen Tumorstadien erhielten eine systemische Chemotherapie mit Mitotane, Vincristin, Ifosfamid, Adriamycin, Carboplatin und VP-16. Zum downstaging als neoadjuvante Chemotherapie erhielten 13,7 \% der Kinder diese antineoplastische Therapie.

Fazit und Ausblick: Das Ergebnis der GPOH-MET 97 Studie zur Behandlung von Kindern und Jugendlichen mit ACT in Deutschland stellt im Vergleich zu anderen internationalen Studien ein hervorragendes Ergebnis dar. Einflussgrößen auf das Gesamtüberleben sind: Tumorgröße, Diagnosealter, primäre chirurgische Versorgung, Polychemotherapie und der Einsatz von Mitotane bei fortgeschrittenen ACC. Bei großen Tumoren, die eine primäre Ro-Resektion schwierig machen und chirurgische Komplikationen (Blutung, Tumoreröffnung) vermuten lassen, sollte eine neoadjuvante Chemotherapie inklusive Mitotane auch ohne histologische Sicherung des Tumors erwogen werden. Voraussetzung dafür ist eine enge interdisziplinäre Zusammenarbeit von Kinderendokrinologen, Kinderchirurgen und Kinderonkologen bereits bei der initialen Diagnostik und dem präoperativen Management.
DGKJ-PV-016

Lebereisenbestimmung mittels MRT bei Patienten mit sekundärer Eisenüberladung: verschiedene Techniken,verschiedene Ergebnisse, verschiedene therapeutische Konsequenzen?

H. Cario' ${ }^{1}$ A. Schulz', M. Juchems' ${ }^{2}$, A. Wunderlich ${ }^{2}$

'Universitätsklinik für Kinder- und Jugendmedizin, ${ }^{2}$ Universitätsklinik für Diagnostische und Interventionelle Radiologie

Hintergrund: Die Lebereisenbestimmung spielt eine zentrale Rolle in der Behandlung von Patienten mit transfusionsbedingter sekundärer Eisenüberladung. Die Entwicklung nicht-invasiver Techniken zur Lebereisenbestimmung erfordert die Kalibrierung und Validierung der Ergebnisse durch eine parallele Bestimmung des Eisengehaltes in Leberbiopsieproben. In Kliniken mit einer kleinen Patientenzahl ist dies nicht umsetzbar. Daher stellt die Verwendung von anderenorts etablierten Algorithmen zur Berechnung des Lebereisengehaltes aus vor Ort generierten MRT-Daten eine attraktive diagnostische Alternative dar.

Ziel: Vergleich zweier MRT-Methoden, basierend auf publizierten, validierten Protokollen zur Berechnung des Lebereisengehaltes unter Verwendung standardisierter Sequenzen.

Methoden: Zweiundachtzig Patienten mit sekundärer Hämochromatose (Alter 1,9-43,2 J., Median 16) wurden untersucht. MRT mit „spin echo"-Sequenzen (SE) erfolgten entsprechend des von St. Pierre et al. 1 entwickelten Protokolls. "Gradient echo"-Sequenzen (GRE) wurden nach dem von Gandon et al. ${ }^{2}$ publizierten Protokoll erfasst. Bei 27 Patienten mit hoher Eisenüberladung wurden zusätzliche GRE-Sequenzen ausgewertet, entsprechend der Protokollmodifikation durch Rose et al. ${ }^{3}$.

Ergebnisse: Trotz einer hochsignifikanten Korrelation unterschieden sich die Absolutwerte des mit beiden Methoden bestimmten Lebereisengehaltes deutlich. Die GRE-Werte lagen generell höher als die der SE-Untersuchungen (s. Abb.). Auch bei Berücksichtigung der Tatsache, daß die Kalibrierung beider MRT-Methoden auf der direkten Eisenbestimmung in unterschiedlich aufgearbeitetem Lebergewebe beruht (Paraffin-Einbettung vs. Frischgewebe), war die überwiegende Zahl der GRE-Werte höher als die SE-Werte. Betrachtet man publizierte Grenzwerte, die den bei Patienten mit sekundärer Hämochromatose akzep-

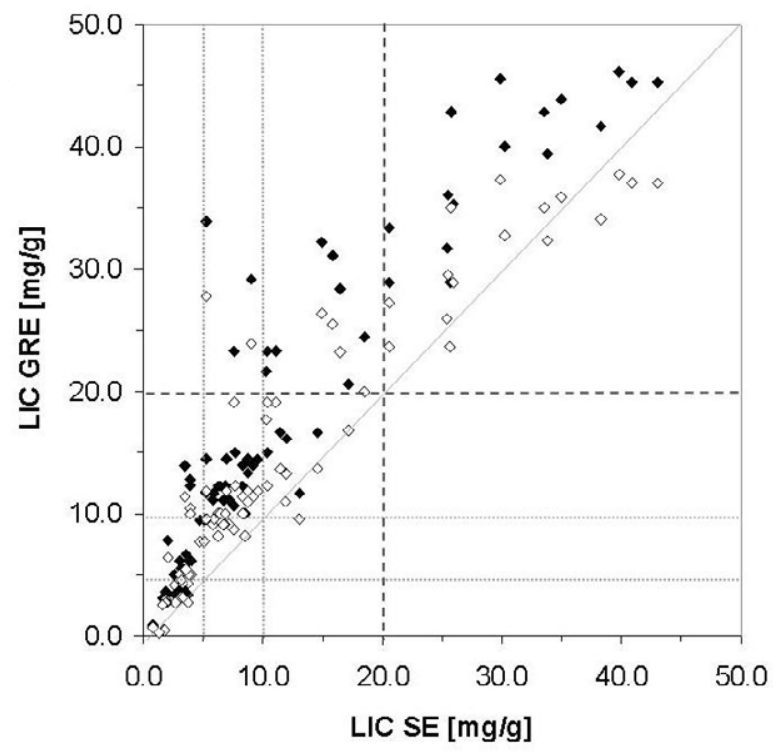

Abbildung: Lebereisengehalt nach SE- oder GRE-MRT. Volle Symbole repräsentieren GRE-Werte vor, leere nach Konversion zum Ausgleich der unterschiedlichen Kalibrierung $(\mathrm{F}=0,818)$.

Literatur: 1. St. Pierre TG et al. Blood 2005;105: 855-61.

2. Gandon Y, et al. Lancet 2004;363: 357-62.

3. Rose C, et al. Eur J Haematol 2006;77: 145-9 
DGKJ-PV-017

Effektive Therapie einer fulminanten GvHD der Lunge und der Haut durch third-party Transplantation humaner mesenchymaler Stammzellen

C. Wernicke, T. Grünewald, H. Juenger, S. Burdach, I. Teichert von Luettichau Kinderklinik der TU Krankenhaus München - Schwabing

Hintergrund und Fragestellung: Die schwere Spender-gegen-Empfänger-Erkrankung (GvHD) ist eine lebens-bedrohliche Komplikation nach allogener Transplantation hämatopoetischer Stammzellen (STX). Ein viel versprechender Ansatz zur Behandlung steroidrefraktärer GvHDs sind humane mesenchymale Stammzellen (hMSCs). hMSCs besitzen eine hohe Plastizität und die Fähigkeit zur Selbstregeneration. Sie scheinen deshalb eine wichtige Rolle bei der endogenen Geweberegeneration zu spielen. Zudem wirken hMSCs auch immunmodulatorisch, weshalb sie besonders attraktiv für den Einsatz bei schwerer GvHD erscheinen. Derzeit ist es allerdings unklar, ob hMSCs generell bei GvHD und insbesondere bei Kindern praktikabel sind.

Propositus und Methode: Kasuistik eines 10-jährigen männlichen Patienten mit fulminanter GvHD der Lunge und der Haut nach allogener STX bei sekundärer Spender-AML und Zustand nach rezidivierender primärer cALL. Therapie der GvHD durch Transplantation von third-party hMSCs.

Verlauf und Ergebnisse: Im Alter von 3 Jahren erkrankte unser Patient an einer Prä-B-ALL. Die Therapie erfolgte gemäß ALL-BFM $2000 \mathrm{im}$ Hochrisikozweig. Acht Monate nach Diagnosestellung erhielt er eine unverwandte STX, in Folge derer er eine akute, dann chronische GvHD der Haut und Gelenke mit Thrombozytopenie entwickelte. Diese wurde mit Ciclosporin, Glukokortikoiden, Mycophenolat, PUVA und extrakorporaler Photopherese behandelt. Trotzdem bildeten sich flächige Vernarbungen und Kontrakturen der Haut. Vier Jahre nach allogener STX erkrankte er an einer Donor-AML (Chimärismus 100\%; Blasten-Karyotyp 46,XX). Die daraufhin begonnene Chemotherapie führte nur zu einer transienten Remission, sodass eine haploidentische STX (Spender: Mutter) durchgeführt wurde.

Zwölf Tage nach STX entwickelte sich eine GvHD der Lunge mit ARDS, am Tag +18 eine fulminante GvHD der Haut (Grad 4). Aufgrund der nicht beherrschbaren GvHD entschlossen wir uns unseren Patienten am Tag +26 third-party hMSCs zu transplantieren. Die GvHD der Lunge verbesserte sich daraufhin erheblich und im Verlauf bildete sich ein völlig narbenfreies und intaktes Integument. Auch das Ansprechen auf Immunsuppressiva, die aktuell sukzessive reduziert werden, war nun besser. Kontrollen zeigen keinen Hinweis auf ein Rezidiv oder eine aktive GvHD.

Diskussion: Angesichts des herausragenden Therapieerfolgs bei unserem Patienten stellt sich die Frage, ob die Applikation von hMSCs bei fulminanter GvHD generell als Therapieoption in Erwägung gezogen werden sollte. Die aktuelle Datenlage weist auf eine mögliche Wirksamkeit von hMSCs mit Ansprechraten von bis zu 50\% bei steroidrefraktärer GvHD hin.

Schlussfolgerung: hMSCs sind unserer Erfahrung nach auch bei Kindern eine viel versprechende Option bei fulminanter refraktärer GvHD. Systematische Studien sind dingend erforderlich um die Praktikabilität und den Stellenwert von hMSCs in der Behandlung der GvHD im Kindesalter zu evaluieren.

\section{DGKJ-PV-018}

Klinischer Verlauf eines isolierten extramedullären Rezidivs einer dendritischen Zellleukämie im rechten Auge nach hämatopoetischer Stammzelltransplantation

J. Kästner', U. Voigt ${ }^{2}$, J. Füller ${ }^{3}$, K. Kentouche', J. Beck'1, B. Gruhn'

${ }^{1}$ Friedrich Schiller Universität Klinik f. Kinder-u.Jugendmed., ${ }^{2}$ Klinik für

Augenheilkunde, ${ }^{3}$ Klinik für Strahlentherapie und Radioonkologie

Einleitung: Rezidive nach hämatopoetischer Stammzelltransplantation gehen mit einer äußerst schlechten Prognose einher. Es wird der klinische Verlauf eines Patienten mit isoliertem extramedullären Rezidiv einer dendritischen Zellleukämie vorgestellt, das durch Operation und Bestrahlung behandelt wurde.

Fallbericht: Bereits bei Erstdiagnose der dendritischen Zellleukämie im Alter von 14 Jahren sowie beim ersten Rezidiv zwei Jahre später waren sklerokonjunktivale Einblutungen im rechten Auge des Patienten auffällig. Nach Chemotherapie gemäß den Protokollen ALL-BFM 2000 und ALL-REZ-BFM 2002 sowie Ganzkörperbestrahlung, Thiotepa und Etoposid wurde eine allogene Fremdspender-Stammzelltransplantation vorgenommen. Fünf Monate nach der Transplantation entwickelte der Patient erneut Einblutungen im rechten Auge mit deutlichem Sehverlust, sodass bei unauffälligem Knochenmarkbefund der dringende Verdacht auf ein isoliertes extramedulläres Rezidiv bestand. Aufgrund der sehr schlechten Prognose wurde die Enukleation des rechten Auges durchgeführt, wobei in der vorderen Augenkammer dendritische Leukämiezellen nachgewiesen wurden. Anschließend erfolgte die Bestrahlung der rechten Orbita mit einer Gesamtdosis von 30 Gy. Sechs Monate später entwickelte der Patient eine erneute schmerzhafte Schwellung des rechten Auges mit einer massiven Pansinusitis, welche trotz antibiotischer Therapie nur geringgradig rückläufig war. Es wurde daher die endonasale Pansinusoperation mit Gewebeentnahme durchgeführt.

Ergebnisse: Mit dem Nachweis von Blasten in der Schleimhaut beider Siebbeinzellen musste ein halbes Jahr nach Therapieende ein erneutes Lokalrezidiv der Leukämie festgestellt werden.

Schlussfolgerung: Trotz des aggressiven Therapieansatzes mit Enukleation des rechten Auges und Bestrahlung war eine komplette Eradikation der leukämischen Zellen nicht möglich.

\section{DGKJ-PV-019}

Erhöhte Inzidenz des atypischen Teratoid/ Rhabdoid Tumors - Vorstellung von vier Fällen innerhalb von 18 Monaten

A. Jansen, K. Kentouche, J. Kästner, B. Gruhn, J. Beck

Friedrich Schiller Universität Klinik f. Kinder-u.Jugendmed.

Kontext: Als atypischer Teratoid/Rhabdoid Tumor (AT/RT) wird ein frühkindlicher Rhabdoidtumor des zentralen Nervensystems bezeichnet. Dieser seltene embryonale Tumor zeichnet sich durch eine morphologische und histologische Vielfalt und eine sehr schlechte Prognose aus. Radiologisch kann der AT/RT als Medulloblastom imponieren, histologisch ähnelt er neuroektodermalen Tumoren wie sPNET, Medulloblastom oder choroidem Plexuskarzinom. Diagnostisch wegweisend ist der INI1-Verlust, der immunhistochemisch nachweisbar ist. Die genetische Grundlage ist eine Mutation im SMARCB1/SNF5/INI1Gen, die zu einer Störung im Chromatin-Remodeling-Komplex führt. Die Therapie besteht aus einem multimodalen Ansatz mit möglichst kompletter chirurgischer Entfernung, Chemotherapie und Radiotherapie, ggf. mit anschließender Hochdosistherapie (HDCT) und autologer Stammzelltransplantation (SZT). Aktuell werden alle Kinder mit AT/RT europaweit in die Therapieoptimierungsstudie EU-RHAB aufgenommen, wobei sich aus der Analyse vergangener Fälle die Bestrahlung als ein wichtiger prognostischer Faktor in der Therapie erwies.

Fall 1: 8 Monate altes Mädchen mit rezidivierendem Erbrechen und intermittierender Kopfschiefhaltung. Es zeigte sich eine Raumforderung infratentoriell im IV. Ventrikel. Therapie nach EU-RHAB mit anschließender Erhaltungstherapie, Ablehnung einer Bestrahlung. In der Verlaufskontrolle nach 17 Monaten Therapie zeigte sich ein Progress.

Fall 2: 3-jähriges Mädchen, das durch progrediente Kopfschmerzen und sekundäre Enuresis, später ausgeprägte Schmerzsymptomatik und Stimmungsschwankungen auffiel. Es wurde eine ausgedehnte Raumforderung rechts frontobasal mit cerebralen und cerebellären Metastasen nachgewiesen. Wir übernahmen die Patientin zur Fortführung der Chemotherapie. Die Patientin verstarb kurz nach Gabe des ersten Blockes nach EU-RHAB.

Fall 3: Ein 3 1/2 Jahre altes Mädchen fiel mit rezidivierendem Erbrechen und Kopfschmerzen auf. Es zeigte sich ein Primärtumor rechts temporal, eine ausgeprägte Meningeosis carcinomatosa mit Abtropfmetastase 
in Höhe LWK 3. Beginn der Chemotherapie nach EU-RHAB, nach 6 Blöcken Regredienz der Meningeosis. Planung einer HDCT mit autologer SZT und Bestrahlung.

Fall 4: Knapp 3-jähriger Junge, seit einigen Wochen nächtliches Erbrechen, gelegentlich Kopfschmerzen, zuletzt Anisokorie. Es zeigte sich ein großer Tumor rechtsfrontal mit Ausdehnung nach temporal. Nach 4 Blöcken Chemotherapie und 12 Bestrahlungssitzungen nach EURHAB nur geringe Regredienz. Planung der HDCT mit autologer SZT. Diskussion: Bei allen vier Patienten gelang der Nachweis einer Mutation im SMARCB1/SNF5/INI1-Gen im Tumormaterial. Eine Keimbahnmutation, die mit dem familiären Rhabdoid-Prädispositions-Syndrom und einer erheblich schlechteren Prognose einhergeht, wurde bei keinem unserer Patienten nachgewiesen.

Der histopathologische Nachweis des INI1 Verlustes, gefolgt von dem molekulargenetischen Nachweis führte zu einer scheinbaren Zunahme der Inzidenz des AT/RT. Möglicherweise sind vor Einführung dieser Nachweismethoden AT/RT anderen Tumorentitäten zugeordnet worden.

\section{DGKJ-PV-020}

Evaluierung des Blutungsrisikos bei neu aufgetretener immunmediierter Thrombozytopenie im Kindesalter innerhalb der ersten Woche nach Diagnosestellung

J. Pansy', M. Minkov'2, R. Dengg ', F. Quehenberger ${ }^{3}$, H. Lackner', P. Sovinz', W. Schwinger ${ }^{1}$, C. Urban', M. Benesch ${ }^{1}$

'Univ.-Klinik für Kinder- und Jugendheilkunde, Medizinische Universität Graz, ${ }^{2}$ St. Anna Kinderspital, ${ }^{3}$ Medizinische Universität Graz

Hintergrund: Die akute immunmediierte Thrombozytopenie im Kindesalter ist durch isoliert erniedrigte Thrombozyten gekennzeichnet. Obwohl sich schwere Blutungen (z. B. tamponadebedürftige Epistaxis) vorwiegend bei Patienten mit extrem erniedrigten Thrombozyten finden, zeigt die Mehrzahl der Kinder nur milde, meist kutane Blutungszeichen. Die Beurteilung des individuellen Blutungsrisikos zu Beginn und im Verlauf könnte Entscheidungen hinsichtlich Therapieeinleitung und Therapiedurchführung erleichtern. Patienten und Methode: Wir evaluierten Thrombozytenzahl und Blutungszeichen bei 30 Patienten mit neu aufgetretener immunmediierter Thrombozytopenie zu drei verschiedenen Zeitpunkten (bei Diagnose [ZP1], am Tag 2-3 [ZP2], und am Tag 5-8 $\left.\left[\mathrm{TP}_{3}\right]\right)$ innerhalb der ersten Woche nach Diagnosestellung. Die Blutungszeichen wurden anhand eines etablierten Blutungsscores („Buchanan-Score“) quantifiziert. Für die statistische Auswertung wurde ein Kumulativwert errechnet. Fünfzehn Patienten erhielten eine immunmodulatorische Behandlung. Ergebnisse: Die Thrombozyten an den drei Untersuchungszeitpunkten lagen im Median bei 13, 19, 32 x 109/L (unbehandelte Patienten) und 2, 7, 37 x 109/L (behandelte Patienten), die korrespondierenden medianen kumulativen Blutungsscores bei 5, 2, o (unbehandelte Patienten) bzw. 7, 6, 2 (behandelte Patienten). Behandelte Patienten hatten zum ZP1 signifikant niedrigere Thrombozyten und signifikant höhere Blutungsscores als unbehandelte Patienten. In beiden Gruppen zeigten die kumulativen medianen Blutungsscores und Thrombozytenzahlen eine inverse Korrelation, wobei dies für behandelte Patienten zum ZP1 und für unbehandelte Patienten zum $\mathrm{ZP}_{3}$ statistisch signifikant war. Die kumulativen medianen Blutungsscores sanken bei behandelten und unbehandelten Patienten innerhalb der ersten Woche statistisch signifikant ab. Schlussfolgerung: Die Blutungszeichen bessern sich innerhalb einer Woche nach Diagnosestellung bei dieser Erkrankung mit und ohne Therapie. Die wiederholte Beurteilung der Blutungsneigung mittels etablierter Blutungsscores kann helfen, das individuelle Blutungsrisiko im Verlauf der Erkrankung besser einzuschätzen.

\section{DGKJ-PV-021}

Alltägliche Probleme bei der Versorgung von Patienten mit einer Sichelzellkrankheit am Beispiel der Inkompatibilitäten erythrozytärer Antigene von Schwarzafrikanern und Kaukasiern

S. Lobitz' , B. Mayer', A. Salama', R. Dickerhoff' ${ }^{2}$ K. Seeger', G. Henze ${ }^{1}$

${ }^{1}$ Charité - Universitätsmedizin Berlin, ${ }^{2}$ Universitätsklinikum Düsseldorf

Die Sichelzellkrankheit ist weltweit die häufigste Erbkrankheit. In Deutschland gibt es jedoch nur 1000-1500 Patienten, die ausnahmslos einen Migrationshintergrund haben. Ihre Betreuung und Behandlung ist aufwändig und komplex und bedarf der Berücksichtigung vieler krankheitsspezifischer und ethnischer Besonderheiten. An der Kinderklinik der Charité werden 140 Kinder, Jugendliche und junge Erwachsene mit einer Sichelzellkrankheit betreut. Etwa die Hälfte dieser Patienten ist schwarzafrikanischer Herkunft.

In den zahlreichen humanen Blutgruppensystemen gibt es verschiedene Antigene, deren Expression sich zwischen Kaukasiern und Schwarzafrikanern teilweise erheblich unterscheidet. Von besonderer Relevanz sind hier die Duffy-Rezeptoren und die Glykoproteine des MNS-Systems. Darüber hinaus werden viele andere Antigene auf den Erythrozyten von Kaukasiern exprimiert, die auf den Zellen schwarzafrikanischer Patienten nicht oder mit einem anderen Expressionsmuster vorhanden sind. Derartige Konstellationen sind immer mit einem mehr oder weniger hohen Risiko einer Immunisierung verbunden. Dies gilt in besonderem Maße für die Sichelzell-Patienten, bei denen häufig Transfusionen erforderlich sind.

Der Duffy-Rezeptor ist ein Protein, das u. a. auf der Oberfläche von Erythrozyten exprimiert wird. Er lässt sich durch einen Polymorphismus an Position 42 der Aminosäurensequenz in zwei Antigen-Subtypen $\mathrm{Fy}(\mathrm{a})$ und $\mathrm{Fy}(\mathrm{b})$ unterteilen. Eine Mutation im Promotor-Bereich führt zu einem Null-Phänotypen Fy(a-b-), d. h. auf den Erythrozyten fehlen beide Duffy-Antigene. Während die physiologische Funktion des Duffy-Rezeptors weitgehend unklar ist, ist bekannt, dass die Malaria-Erreger Plasmodium vivax und Plasmodium knowlesi das Protein zum Andocken an Erythrozyten nutzen. Der Null-Phänotyp vermittelt daher eine Immunität gegen die entsprechenden Formen der Malaria. Dieser evolutionsbiologische Vorteil hat dazu geführt, dass heute 70 \% aller Schwarzafrikaner Duffy-negativ sind, während die kaukasischen Bevölkerungsgruppen zu nahezu $100 \%$ mindestens eins der beiden Duffy-Antigene auf ihren Erythrozyten tragen. Erhält ein Schwarzafrikaner Blut von einem kaukasischen Spender, so besteht das Risiko einer Immunisierung. Gegen ein Duffy-Antigen immunisierte Patienten können in der Folge nur noch Duffy-kompatibles Blut erhalten. Duffy-negative Erythrozytenkonzentrate sind aber derzeit europaweit nur schwer verfügbar. Der Import kryokonservierter Präparate ist mit enormen Kosten verbunden.

Nicht immer führt eine Immunisierung zur Bildung transfusionsrelevanter Antikörper. Dennoch wird am Beispiel des Duffy-Systems ein gravierendes Problem deutlich, das bei der Versorgung schwarzafrikanischer Empfänger mit dem Blut kaukasischer Spender auftritt. Sichelzell-Patienten sollten daher so selten wie möglich Transfusionen erhalten. Ist eine Transfusion unvermeidbar, so müssen Blutspender und Patient in den relevanten Blutgruppensystemen maximal kompatibel sein. Um dies zu erreichen müssen in Deutschland mehr Schwarzafrikaner zur Blutspende motiviert werden.

\section{DGKJ-PV-022}

Erfolgreiche Behandlung eines Säuglings mit metastasiertem Medulloblastom-Rezidiv durch Polychemotherapie ohne Strahlentherapie M. Knorr, A. Eggert

Universitätskinderklinik Essen

Einleitung: Die effiziente postoperative konservative Behandlung von Medulloblastomen im Säuglings- und Kleinkindalter ist schwierig, da das kindliche Gehirn auf Chemo- und insbesondere Radiotherapie sehr empfindlich reagiert. Eine erhebliche Störung der neurokognitiven Entwicklung ist daher eine häufige Folge der Behandlung. 
Fallbericht: Wir berichten über einen bei Erstvorstellung fünf Monate alten Säugling mit vergrößertem Kopfumfang und Sonnenuntergangsphänomen. Im initialen MRT des Schädels zeigte sich ein massiver Hydrozephalus, ausgelöst durch einen Tumor der hinteren Schädelgrube. Eine externe Drainage wurde angelegt. Nachfolgend konnte der Tumor subtotal reseziert und ein ventrikuloperitonealer Shunt implantiert werden. Histologisch zeigte sich ein desmoplastisches Medulloblastom. Das Mädchen erhielt dann eine Polychemotherapie mit den Substanzen Cyclophosphamid, Vincristin und Methotrexat (systemisch und intraventrikulär) entsprechend dem HIT 2000 Protokoll. Nach drei Chemotherapieblöcken zeigten sich ein erneutes Tumorwachstum und eine Meningeose. Die Behandlung wurde auf Etoposid und Carboplatin umgestellt. Danach konnte eine Tumorregression beobachtet werden. Eine Hochdosischemotherapie mit autologer Stammzellreinfusion wurde durchgeführt. Die Meningeose verschwand und der Resttumor blieb größenkonstant. Das Mädchen wurde anschließend für insgesamt zwei Jahre mit oralem Temozolomid behandelt. Das Kind befindet sich seit nunmehr zwei Jahren rezidivfrei in der Nachsorge. Bis auf eine weiterhin bestehende Bradydiadochokinese, eine leichte Ataxie und einen Strabismus entwickelte sich das Kind sehr gut.

Schlussfolgerung: Dieser Fallbericht zeigt einen erfreulichen Verlauf eines metastasierten desmoplastischen Medulloblastoms im Säuglingsalter mit alleiniger postoperativer Chemotherapie ohne Bestrahlung. Wie bereits zuvor veröffentlichte Studien berichteten, ist die Polychemotherapie als einzige konservative Behandlung insbesondere bei desmoplastischen Medulloblastomen in der Altersgruppe unter drei Jahren eine nebenwirkungsärmere Therapie mit guten Heilungsraten auch bei initial ausgedehnter Erkrankung. Die Kombination einer zytostatischen Chemotherapie inklusive einer Hochdosischemotherapie mit autologer Stammzellreinfusion und einer oralen Dauertherapie mit Temozolamid führte in dem hier berichteten Fall jedoch zu einem bislang rezidivfreien Verlauf.

\section{DGKJ-PV-023}

Mangel an Intrinsic Faktor als Ursache eines Vitamin B12-Mangels M. Laaß', F. Hauck', M. Suttorp', R. Knöfler', S. Tanner ${ }^{2}$

'Universitätsklinikum Carl Gustav Carus Kinderklinik, ${ }^{2}$ The Ohio State University, Department of Molecular Virology, Immunology and Medical Genetics

Einleitung: Ein Vitamin-B12-Mangel kann durch eine unzureichende Zufuhr, eine Resorptions- oder Transportstörung oder durch intrazelluläre Stoffwechseldefekte verursacht werden. Mutationen in folgenden Genen können einen Vitamin-B12 Mangel verursachen: Gastric Intrinsic Faktor (GIF), Cubilin (CUBN), Amnionless (AMN) und Transcobalamin (TCN). Der im Magen produzierte Intrinsic Faktor bildet mit dem Vitamin B12 einen Komplex, der im terminalen Ileum mit Hilfe eines aus CUBN und AMN gebildeten Rezeptors aufgenommen wird. Wir berichten über einen Jungen mit einem Vitamin B12-Mangel aufgrund eines genetischen Defektes im GIF (MIM*609342).

Fallbericht: Der $2^{1 / 2}$ Jahre alte Junge konsanguiner Eltern wurde uns mit einer ausgeprägten makrozytären Anämie vorgestellt: $\mathrm{Hb}$ 4,2 mmol/l (NB 6,7-7,9); Hk 0,21 (NB o,35-0,43), Erythrozyten 1. 92 TPt/l (NB 3,70-5,30), MCV $109 \mathrm{fl}$ (NB 73-101), Thrombozyten $111 \mathrm{Gpt} / \mathrm{l}$ (NB 150-400), neutrophile Granulozyten o,61 Gpt/l (NB 1,56-8,5). Die peripheren $\mathrm{CD}_{34}+$ Zellen waren erhöht auf 12/ $\mu$ (NB: 1-2). Im Urin wurde Methylmalonsäure vermehrt ausgeschieden und es bestand eine geringe Proteinurie. Der Serumwert für Vitamin B12 lag unterhalb der Nachweisgrenze von 45 pg/ml (NB: 211-911) und Homocystein i. S. war deutlich erhöht (126,8 $\mu \mathrm{mol} / \mathrm{l}, \mathrm{NB}$ 5,9-12,0). Klinisch waren lediglich eine seit 3 Monaten langsam zunehmende Müdigkeit und eine ausgeprägte Blässe aufgefallen.

Ein maligner Prozeß konnte durch eine Knochenmarkpunktion und eine atrophische Gastritis mittels Gastroskopie ausgeschlossen werden. Antikörper gegen den Intrinsic Faktor ließen sich nicht nachweisen. Der Schilling-Test mit radioaktiv markiertem Vitamin B12 ergab eine deutlich verminderte Resorption. Statt eines zweiten Schilling-Testes mit Intrinsic Faktor leiteten wir eine genetische Untersuchung ein und begannen eine parenterale Behandlung mit Vitamin B12.

Bei dem Jungen wurden compound-heterozytgote Mutationen im GIF nachgewiesen: c. $79+1 \mathrm{G}>\mathrm{A}$ (loss-of-function-Mutation) und c. ${ }_{137} \mathrm{C}>\mathrm{T}$; S46L (missense-Mutation). Beide Eltern sind heterozygot für je eine der Mutationen. Beide Mutationen wurden zuvor bei Patienten aus Westeuropa (c. $79+1 \mathrm{G}>\mathrm{A}$ ) und der Türkei (c. ${ }^{3} 7 \mathrm{C}>\mathrm{T}$; S46L) beschrieben. Unter intramuskulärer Vitamin B12-Gabe, die lebenslang notwendig sein wird, normalisierten sich die hämatologischen Parameter als auch alle anderen pathologischen Laborbefunde, ausgenommen jedoch die Proteinurie.

Diskussion: Der Intrinsic Faktor-Mangel (MIM \#26100o) ist von anderen genetischen Ursachen des Vitamin B12-Mangels wie dem Imerslund-Gräsbeck Syndrom (IGS), das durch Mutationen im CUBN oder AMN Gen verursacht wird, abzugrenzen. Die genetische Diagnostik könnte die klassischen nuklearmedizinischen Untersuchungsverfahren wie den Schilling-Test, die nicht überall verfügbar und auch mit einer Strahlenbelastung verbunden sind, bei der Diagnostik des Vitamin B12Mangels ablösen.

\section{DGKJ-PV-024}

Pharyngeale Atemwegsobstruktion als Erstsymptom eines eingebluteten Lymphangioms - erfolgreiche Sklerosierung mit attenuierten A-Streptokokken (Picibanil, OK-432)

R. Elling ${ }^{1}$, J. Rössler' ${ }^{1}$, J. Pfeiffer ${ }^{2}$, M. Schumacher ${ }^{3}$, M. Krüger ${ }^{1}$

${ }^{1}$ Universitäts - Kinderklinik, ${ }^{2}$ Universitätsklinik für Hals-, Nasen- und Ohrenheilkunde, ${ }^{3}$ Klinik für Neuroradiologie, Universitätsklinik

Einleitung: Lymphangiome sind kongenitale Fehlbildungen des Lymphgefäß-Systems, die keine Tendenz zur Involution zeigen. Die Mehrzahl der Läsionen liegt im Kopf-Hals-Bereich, im Rahmen banaler Infektionen oder spontaner Einblutungen kann es zu einer akuten Größenzunahme kommen.

Fallbeschreibung: Wir präsentieren den Fall eines 3 Jahre alten, bislang gesunden Jungen, der mit Fieber, Schluckstörung, einseitiger Pharynxschwellung und im Verlauf auch zunehmender Dyspnoe in eine auswärtige Klinik aufgenommen wurde. Bei der unter dem Verdacht eines Peritonsillarabszesses durchgeführten Tonsillektomie zeigte sich aber eine unklare bläulich schimmernde Raumforderung im Bereich des rechten Tonsillenbetts, weshalb der Patient beatmet in das Universitätsklinikum Freiburg verlegt wurde. Die Magnetresonanztomographie ergab ein großes rechts-cervikales und parapharyngeales, multizystisches Lymphangiom mit Einblutung, das zu einer kritischen Stenosierung des Oropharynx führte. Eine primäre operative Resektion war nicht möglich. Es wurde daher eine radiologisch-interventionell kontrollierte Sklerosierungsbehandlung mit transoraler Injektion von insgesamt 2 KE (0,2 mg) Picibanil (OK-432) in zehn Kompartimente des Lymphangioms in einer Sitzung durchgeführt. Lokale oder systemische Nebenwirkungen traten nicht auf. Die Kontroll-Bildgebung ergab einen deutlichen Größenregress der Raumforderung insbesondere im Bereich der oberen Luftwege, sodass der Patient extubiert werden konnte. Nach dieser einmaligen Behandlung mit OK-432 blieb der Patient im Verlauf symptomfrei.

Diskussion: Das Fehlen eindeutiger Begrenzungen und eine enge anatomische Lagebeziehung zu lebenswichtigen Strukturen macht die radikale chirurgische Resektion bei Lymphangiomen im Halsbereich oft unmöglich. Die Injektion sklerosierender Substanzen stellt ein alternatives Therapieregime dar. Bei OK-432 (Picibanil) handelt es sich um ein Lyophilisat attenuierter A-Streptokokken, welches eine Inflammationsreaktion und narbenfreie Regression von Lymghgefäß-Fehlbildungen hervorrufen kann. Auf Grund einer zunehmenden Anzahl positiver Studienergebnisse ist die Sklerosierung mit OK-432 inzwischen ein gut etabliertes Therapieverfahren nicht resektabler Lymphangiome.

Dieser Fall illustriert den sicheren und effektiven Einsatz von OK-432 bei einem nicht operablen Lymphangiom mit kritischer Stenosierung des Oropharynx. 
DGKJ-PV-025

Hohe Stabiltät von Phänotyp undGenexpressionsprofilen im seriellen NOD/SCID huALL Modell

M. Queudeville', E. Vendramini², M. Giordan², S. Eckhoff', G. Basso², T. te Kronnie$^{2}$, K. Debatin', L. Meyer ${ }^{1}$

${ }^{1}$ Universitätsklinik für Kinder- und Jugendmedizin, ${ }^{2}$ Universität Padua

Fragestellung: Primäre Zellen von pädiatrischen akuten lymphoblastischen Leukämien sind sehr schwer in vitro kultivierbar und verfügbare ALL- Zelllinien spiegeln nur unzureichend die Heterogenität verschiedener Patientenproben wider. Aus diesem Grunde werden zunehmend Maus- Xenotranslantationsmodelle verwendet. Es ist allerdings noch weitestgehend unklar, inwiefern xenotransplantierte ALL- Zellen nach mehreren Passagen in der Maus noch den ursprünglichen Leukämiezellen des jeweiligen Patienten entsprechen.

Material und Methoden: Primäre Leukämiezellproben $(\mathrm{N}=7)$, die zum Diagnosezeitpunkt von pädiatrischen Patienten mit de novo ALL isoliert wurden, wurden mittels intravenöser Injektion auf unkonditionierte NOD/SCID-Mäuse transplantiert. Die Mäuse wurden bei klinisch manifester Leukämie getötet und die aus Knochenmark und Milz isolierten Leukämiezellen auf sekundäre und später tertiäre Rezipienten weitertransplantiert. Genexpressionsprofile (Affymetrix U133 2. o) wurden von allen Leukämiezellproben der verschiedenen Passagen analysiert. Außerdem wurden die ALL- Proben durchflusszytometrisch bezüglich ihrer Oberflächenmarker und mittels PCR auf das Vorliegen von Fusionsgenen und MRD-Markern untersucht.

Ergebnisse: Alle transplantierten Proben führten zu klinisch manifester Leukämie in den Mäusen. Biologische Charakteristika der Leukämien blieben von der Diagnose über die Mauspassagen konstant. So führten primäre Leukämieproben von Patienten mit hoher Gesamtblastenzahl bei Diagnose auch im Mausmodell zu hoher Leukämielast im peripheren Blut. Weiterhin blieb der initiale Immunphänotyp über alle Mauspassagen konstant, zum Diagnosezeitpunkt nachweisbare Fusionsgene waren ebenfalls über die Mauspassagen detektierbar. Die Zeit von Transplantation einer Probe bis zur klinisch manifesten Leukämie in der Maus war von Patient zu Patient sehr unterschiedlich, blieb aber innerhalb der seriellen Passagen eines Patienten immer konstant. In den Genexpressionsprofilen zeigte sich eine hohe Stabilität zwischen den primären, sekundären und tertiären Xenotransplantatproben einer Patientenprobe.

Diskussion

Murine Xenotransplanataionsmodelle werden zur Amplifizierung von Leukämiezellen und späteren in vitro - Experimenten, sowie direkt für in vivo - Versuche eingesetzt. Bisher wurde aber noch nie konsequent untersucht, ob es in der Maus zur Selektion eines spezifischen Subklons oder zur klonalen Evolution über weitere Xenograft- Passagen kommt. Schlussfolgerung: Das NOD/SCID-Xenotransplantationsmodell für pädiatrische ALL rekapituliert biologische und phänotypische Charakteristika der primären Patientenprobe, zeigt ein nahezu unverändertes Genexpressionsprofil zur primären Patientenprobe und spiegelt somit die intrinsische Variabilität verschiedener Patientenproben wider.

\section{Endokrinologie, Pharmakologie und Rehabilitationsmedizin}

\section{DGKJ-PV-026}

\section{Tempo and amplitude in human growth}

M. Hermanussen

Kinderarztpraxis

Human growth is a dynamic process that needs careful documentation. Individual growth should be referred to a reference population by transforming the individual measurements into percentiles or standard deviation score (SDS) scales. A certain amount of percentile or SDS crossing is a physiological phenomenon that occurs at all ages and usually relates to the individual changes in developmental tempo. Between early childhood and adulthood, two thirds of all children and adolescents cross more than one standard deviation in height. Particularly during pubertal age, SDS crossings can lead to several characteristic patterns such as sharp downward or upward SDS peaks. Upward SDS peaks indicate faster than average tempo, downward SDS peaks indicate slower than average tempo. Almost half of the pubertal height variation consists of variation in tempo. Tempo - being fast or slow maturing - has to be carefully separated from amplitude - being tall or short. Several characteristic phenomena such as catch-up growth after periods of illness and starvation are largely tempo phenomena, and do usually not affect the amplitude component of growth. Applying Functional Data Analysis and Principal Component Analysis, the two main sources of height variance: tempo and amplitude can statistically be separate and quantified.

\section{DGKJ-PV-027}

\section{Zapfenepiphysen und einseitige Verkürzung des Femurs bei einem} dreijährigenMädchen

G. Schwabe', R. Placzek ${ }^{2}$, H. Mellerowicz ${ }^{3}$ D. Horn ${ }^{2}$

${ }^{1}$ Charite Kliniken f. Kinderheilkunde und Kinderchirugie, ${ }^{2}$ Charité, ${ }^{3} \mathrm{HELIOS}$ Klinikum Emil von Behring

Zapfenepiphysen sind definiert als Epiphysen mit einer zentralen knöchernen Projektion in die Metaphyse. Meist besteht eine korrespondierende Einbuchtung in der Metaphyse. Nach Giedion werden 38 Typen von Zapfenepiphysen verschiedener Formen und Größen unterschieden. Zapfenepiphysen treten bei bestimmten Syndromen wie bei der Cleidokranialen Dysplasie, beim Ellis-van-Creveld-Syndrom oder beim Tricho-Rhino-Phalangealen-Syndrom auf. Minimale Zapfenepiphysen werden gelegentlich auch bei Gesunden beobachtet. Wir beschreiben eine 2 10/12 Jahre alte Patientin, die uns mit einem humpelnden Gang des linken Beines vorgestellt wurde. Die Patientin ist ein Drillings-Frühgeborenes der $31+4$. SSW und erlitt in der Neonatalzeit eine durch Klebsiella oxytoca verursachte Meningitis. Die radiologische Diagnostik zeigte das Vorliegen von Zapfenepiphysen im Bereich beider distaler Femora. Die im weiteren Verlauf durchgeführte Röntgendiagnostik ergab außerdem ein um $3 \mathrm{~cm}$ verkürztes Femur links. Mittlerweile trägt die Patientin eine Schuherhöhung. Derartige Veränderungen der Epiphysen der großen Röhrenknochen werden selten nach einer Meninkokokkenmeningitis und bei Patienten mit multiplen Infarkten bei Sichelzellanämien beobachtet. Eine weitere Differentialdiagnose stellt eine metaphysäre Chondrodysplasie mit Zapfenepiphysen dar, eine Skelettdysplasie, für die Einzelfälle in der Literatur beschrieben sind. Geplant ist, die Wachstumsdifferenz weiter zu beobachten und ggf. im Schulkindalter durch einen intramedullären Verlängerungsnagel (ISKD oder Baumgart-Nagel) oder eine Kallusdistraktion mit einem monolateralen Fixateur externe (Orthofix) zu behandeln.

\section{DGKJ-PV-028}

Wachstumshormonexzess bei Neurofibromatose Typ I und opticohypothalamischem Gliom

M. Bornkamm', I. Teichert v. Lüttichau', M. Bidlingmaier², S. Burdach', W. Rabl'

${ }^{1}$ Kinderklinik der TU Krankenhaus München - Schwabing, ${ }^{2}$ Medizinische Klinik Innenstadt - Klinikum der Universität

Fragestellung: Gigantismus in der frühen Kindheit ist ein sehr seltenes Krankheitsbild. Fast immer ist er die Folge eines Wachstumshormon (GH)-sezernierenden Hypophysenadenoms. Ein ursächliches Opticusgliom im Rahmen einer Neurofibromatose Typ I ( $\left.\mathrm{NF}_{1}\right)$ mit hieraus resultierender hypothalamo-hypophysärer Dysregulation ist bisher in nur 7 Fällen beschrieben worden. Wir berichten über eine 4,8-jährige Patientin mit GH-Exzess bei bekannter NF1 und linksseitigem opticohypothalamischen Gliom, bei der zur Normalisierung der GH-Sekretion eine Therapie mit dem GH-Rezeptor-Antagonisten Pegvisomant und wegen Beeinträchtiguung des Visus eine Chemotherapie durchgeführt wurde bzw. wird. 
Material und Methode: Die Patientin wurde uns erstmals im Alter von 3,7 Jahren zur Abklärung eines generalisierten Krampfanfalls vorgestellt. Eine NF1 war klinisch frühzeitig diagnostiziert und molekulargenetisch gesichert worden. Ein kraniales MRT zeigte ein opticohypothalamisches Gliom links. Klinisch fielen neben multiplen Café-au-laitFlecken ein Hochwuchs und eine Makrozephalie bei präpubertärem Reifestatus auf. Retrospektiv fand sich bereits seit Beginn des zweiten Lebensjahres eine deutliche Beschleunigung des Wachstums mit einem Anstieg der Körperhöhe von der 3. auf die 97. Perzentile. Die endokri-

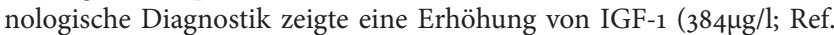
62-316) und von IGF-BP 3 (10,1mg/l; Ref. 1,71-6,30) sowie nicht supprimierte GH-Spiegel im oGTT $(3,39-14,4 \mathrm{ng} / \mathrm{ml})$. GHRH war unterhalb der Nachweisgrenze und Ghrelin mit 492 pg/ml unauffällig. Die Werte für LH, FSH, Östradiol, Prolaktin, Cortisol, ACTH, DHEAS, 17-OHProgesteron, $\mathrm{TSH}, \mathrm{fT}_{3}$ und $\mathrm{fT}_{4}$ sowie die Skelettreifung waren altersnormal. Ergebnisse Seit dem Alter von 3,9 Jahren erhielt die Patientin vorübergehend eine Therapie mit Pegvisomant (1omg s. c. alle $2 \mathrm{~d}$ ). Bei zunächst normalisiertem IGF-1-Wert $(180 \mu \mathrm{g} / \mathrm{l})$ wurde das Therapie-Intervall nach einem Monat auf $2 \mathrm{x} / \mathrm{w}$ verlängert. Hierunter kam es erneut zu einem IGF-1-Anstieg (354-413 $\mu \mathrm{g} / \mathrm{l})$. Wegen passagerer Transaminasenerhöhung wurde die Pegvisomantgabe vorerst unterbrochen. Aufgrund einer neu diagnostizierten Beeinträchtigung des Visus bei radiologisch nachgewiesenem Tumorprogress wurde im Alter von 4,3 Jahren die Indikation zum Beginn einer Chemotherapie im Rahmen der aktuellen Therapiestudie SIOP-LGG 2004 gestellt. Nach 24 Wochen zeigte sich der Tumor bereits deutlich größenregredient. Gleichzeitig scheint sich die Wachstumsgeschwindigkeit zu normalisieren. Diskussion Der Erfolg einer Chemotherapie bei Opticusgliom im Rahmen einer $\mathrm{NF}_{1}$ wird in der Literatur sehr unterschiedlich beurteilt. $\mathrm{Ob}$ sich bei unserer Patientin der beginnende Rückgang der Wachstumsgeschwindigkeit unter alleiniger Chemotherapie fortsetzen wird, bleibt abzuwarten.

Schlussfolgerung: Bei GH-Exzess im Rahmen einer NF1 mit Opticusgliom muss über eine Behandlung mit Pegvisomant bzw. Octreotid und/oder Chemotherapie jeweils an Hand individueller bzw. aktueller Parameter entschieden werden.

\section{DGKJ-PV-029}

Eine Pseudoachondroplasie-ähnliche Erkrankung ohne COMP-Mutation

U. Grieben' ', D. Horn², L. Graul-Neumann², A. Gencik³ , J. Funk², R. Placzek², D. Schnabel', G. Schwabe ${ }^{1}$

${ }^{1}$ Charite Kliniken f. Kinderheilkunde und Kinderchirugie, ${ }^{2}$ Charité, ${ }^{3}$ Zentrum für Medizinische Genetik

Die Pseudoachondroplasie (PSACH) ist eine dominant vererbte Skelettdysplasie, die durch dysproportionierten Kleinwuchs, Gelenkhypermobilität, eine irreguläre meta- und epiphysäre Verknöcherung sowie abgeflachte Wirbelkörper gekennzeichnet ist. PSACH wird durch Mutationen des COMP-Gens verursacht, das für das Cartilage Oligomere Matrixprotein kodiert. Dabei treten die Mutationen in den Calmodulin-ähnlichen, Kalzium-bindenden Repeats (Exons 8-14) oder in der C-terminalen Domäne (Exons 15-19) auf. Wir beschreiben einen 10-jährigen Jungen mit dysproportioniertem Kleinwuchs, Genua vara mit watschelndem Gang und den typischen meta- und epiphysären radiologischen Veränderungen einer PSACH. Bei dem Patienten liegt außerdem eine Innenohrschwerhörigkeit vor. Wir konnten keine Mutation in den oben genannten Exons des COMP-Gens nachweisen. Unsere Untersuchungen zeigen, dass die vorliegende Erkrankung nicht allelisch mit der PSACH ist. Es handelt sich vermutlich um eine neue Krankheitsentität, die durch ein bei der Knorpel- und Knochenentwicklung bedeutsames Gen hervorgerufen wird. Therapeutisch wurde eine passagere Epiphyseodese des distalen lateralen Femurs zur Wachstumslenkung mit je einer 8-Plate durchgeführt, die zu einer Verbesserung der Achsenfehlstellung von Grad $\mathrm{III}^{\oplus}$ auf derzeit $\mathrm{II}^{\circledR}$ nach Oest innerhalb der letzten 9 Monaten führte.

\section{DGKJ-PV-030}

Behandlung eines Hirntumors mit L-Thyroxin

Ö. Anvari, K. Ergezinger, C. Speer

Universitäts-Kinderklinik im Luitpold-Krankenhaus

Einleitung: Bei sekundärem Kleinwuchs liegen der Störung des Skelettwachstums extraossäre Faktoren wie z. B. endokrine Störungen zu Grunde. Wir berichten über einen kleinwüchsigen Jungen, bei dem eine primäre Hypothyreose mit massiver thyreotroper Hypophysenhyperplasie diag-nostiziert wurde.

Kasuistik: Vorstellung im Alter von 9 3/12 Jahren beim Hausarzt'wegen perzentilenflüchtiger Längen- und Gewichtsentwicklung seit dem 4. Lebensjahr und ausbleibendem Zahnwechsel. Schwangerschaft und Geburt unauffällig, keine wesentlichen Vorerkrankungen. In der Diagnostik massive TSH-Erhöhung, im cMRT Nachweis eines Hypophysentumors. Zunächst Überweisung in die Neurochirurgie zur Operation; über die neurochirurgischen Kollegen Vorstellung in der Kinderklinik zur endokrinologischen Diagnostik. Hier TSH 750 mU/l, erniedrigte periphere Schilddrüsenparameter und erhöhte TPO- und Thyreoglobulin-AK, typische sonographische Schilddrüsenveränderungen einer Autoimmunthyreopathie sowie milde Transaminasenerhöhung, PTT-Verlängerung und IGF-1-Erniedrigung. Bei hypothyreoter Stoffwechsellage Beginn einer Substitutionstherapie mit L-Thyroxin. Im Verlauf Normalisierung der Schilddrüsenwerte sowie aller auffälligen Laborparameter und vollständige Rückbildung des Hypophysentumors. Unter Substitution gutes Aufholwachstum und beginnender Zahnwechsel. In den weiteren cMRT-Verlaufskontrollen Nachweis einer Empty-Sella. Laborchemisch und klinisch kein Hinweis auf weitere endokrinologische Ausfälle.

Schlussfolgerung: Bei unserem Patienten ist von einer reaktiven, raumfordernden Vergrößerung der Hypophyse bei primärer Hypothyreose auszugehen. Diese Veränderung ist nur vereinzelt beschrieben, möglicherweise aber unterdiagnostiziert, da i. d. R. bei Autoimmunthyreopathie keine kranielle Bildgebung erfolgt. Unter Substitutionstherapie Normalisierung der Werte, gutes Aufholwachstum, klinisches Wohlbefinden und fehlender Hinweis auf weitere endokrinologische Ausfälle. Daher retrospektiv Ausschluss eines im Kindesalter sehr seltenen TSHoms. Bei jeder Kleinwuchsabklärung muss eine Hypothyreose als Ursache ausgeschlossen werden. Die Indikation zur kraniellen Bildgebung sollte mit einer spezifischen Fragestellung erfolgen, die Befunde müssen in Zusammenschau mit der endokrinologischen Diagnostik interpretiert werden.

\section{DGKJ-PV-031}

140 Kinder mit Autoimmunthyreoiditis aus einem Zentrum: Schilddrüsenfunktion und Sonografie zum Zeitpunkt der Diagnosestellung N. Hedtstück' ', R. Böttger' ${ }^{1}$ L. von Rohden², K. Mohnike ${ }^{1}$

${ }^{1}$ Universitäts-Kinderklinik Magdeburg, ${ }^{2}$ Klinik für Diagnostische Radiologie

Die Autoimmunthyreoiditis (AIT) ist die häufigste Ursache einer erworbenen Hypothyreose im Kindesalter. Die Erkrankungshäufigkeit nimmt mit dem Alter zu und liegt im Erwachsenenalter bei ca. $5 \%$. Bekannt ist eine Assoziation mit anderen Autoimmunphänomenen. Die AIT ist durch einen chronisch entzündlichen Prozess gekennzeichnet mit Nachweis von Autoantikörpern gegen Thyreoperoxidase (TPO) und Thyreoglobulin (TAK). Ein symptomarmer Verlauf ist typisch mit wechselnd hyper- und hypothyreoten Phasen. In der vorliegenden Analyse werden Schilddrüsenfunktion, Sonografie und auxiologische Daten im Kindesalter untersucht. Im Zeitraum von 19852007 sahen wir 140 Kinder und Jugendliche (Alter 4,6-18J.)mit AIT in unserer endokrinologischen Fachambulanz der Universitätskinderklinik Magdeburg. Folgende Daten bei Diagnosestellung wurden erfasst: Länge, Gewicht, Pubertätsstadium, spezifische Symptome, Schilddrüsenfunktion, Schilddrüsensonografie. Bei Diagnosestellung wiesen 59 der 140 Patienten eine hypothyreote Stoffwechsellage auf (42,86\%). Der TSH-Mittelwert lag bei $115 \mathrm{mU} / \mathrm{l}(7,15-1228)$. Die TPO-AK waren bei $80 \%$ unserer Patienten erhöht $(<34-16908 \mathrm{U} / \mathrm{ml})$. Das mittlere Alter der 
Patienten mit Hypothyreose lag mit 10,7 +/- 2,9 Jahren durchschnittlich 2,4 Jahre niedriger als bei Patienten mit Euthyreose (13,1+/- 2,4 Jahre). Klinische Symptome zeigten $42,4 \%$ der Patienten mit Hypothyreose, aber nur 21,3\% der Patienten mit initialer Euthyreose. Leitsymptom war die Strumain Kombination mit Schluckbeschwerden, Engegefühl, Luftnot sowie Müdigkeit/Adynamie. Ein Kleinwuchs (<-2,o SDS) bestand bei 3/59 hypothyreoten Kindern. Der BMI-SDS war bei 6/59 (10,1\%) Kindern erhöht(-2,o bis 3,0; MW o). Das Auftreten von Übergewicht bei hypothyreoten Patienten entspricht somit ungefähr der Häufigkeit eines Übergewichts bei allen unserer 140 Patienten (9,3\%). Die Schilddrüsensonografie zeigte bei vergrößertem Schilddrüsenvolumen eine inhomogene Textur, z. T. mit Knoten, Zysten und Septen durchsetzt. Im Verlauf war bei 3 Patienten ein Karzinom zu sichern. Nur bei Hypothyreose erfolgte eine Behandlung mit L-Thyroxin. Schlussfolgerungen: 1.) 43\% unserer Patienten wiesen bei Diagnosestellung eine hypothyreote Stoffwechsellage auf. 2.) Eine Wachstumsverzögerung (5,1\%) ist ebenso wie ein Übergewicht $(10,1 \%)$ nur selten Symptom einer Hypothyreose im Kindesalter. 3.) Die Sonografie hat einen hohen Stellenwert sowohl bei der Diagnosestellung, als auch für die Verlaufsbeurteilung. Es gibt Patienten mit unauffälligen oder nur moderat erhöhten Antikörpertitern bei denen die sonografische Beurteilung richtungweisend ist. Auch die Differenzierung zwischen M. Basedow und AIT bei nicht eindeutigen Antikörperbefunden kann sonografisch erfolgen. Die sonografische Verlaufkontrolle ist zu empfehlen, um ein Schilddrüsenkarzinom wie bei 3 unserer Patienten zu erfassen.

\section{DGKJ-PV-032}

\section{Identifizierung und molekulare Charakterisierung von drei neuen} Mutationen im PAX8 Gen bei Kindern mit angeborener Hypothyreose. P. Hermanns' ${ }^{1}$, H. Grasberger ${ }^{2}$, C. Freiberg ${ }^{3}$, H. Dörr', M. Morlot ${ }^{5}$, S. Refetoff ${ }^{6}$, J. Pohlenz'

${ }^{1}$ Klinikum der Johannes-Gutenberg Universität, ${ }^{2}$ Medical School University of Michigan, ${ }^{3}$ Universitäts- Kinderklinik, ${ }^{4}$ Universitäts-Kinderklinik, ${ }^{5}$ Endokrinologikum Hannover, ${ }^{6}$ University of Chicago

Ungefähr $80 \%$ der Patienten mit angeborener Hypothyreose weisen eine Anlagestörung der Schilddrüse auf. Bis jetzt wurden vier Transkriptionsfaktoren ( $P A X 8, T T F 1, T T F_{2}$ und $N K X 2$. 5) identifiziert, bei denen eine Mutation zur Anlagestörung der Schilddrüse führen kann. Bei drei nicht miteinander verwandten Kindern mit Schilddrüsenanlagedefekt identifizierten wir jeweils eine neue, bisher nicht beschriebene Mutation im PAX8 Gen (S54R, R133X, E234K).

Fragestellung: Sind die von uns identifizierten Mutationen für die Schilddrüsenanlagestörung verantwortlich?

Material und Methoden: Der Effekt der identifizierten Mutationen auf die Bindeeigenschaften an die Targetpromotoren wie z. B. den Schilddrüsenperoxidase (TPO)- und den Thyreoglobulin (TG)-promotor und die entsprechende Transaktivierungsaktivität der mutierten PAX8 Proteine wurde im Zellsystem getestet.

Ergebnisse: Alle drei mutierten PAX8-Proteine weisen eine normale zelluläre Lokalisation auf. Eine Mutation $\left(\mathrm{S}_{54} \mathrm{R}\right)$ konnte nicht mehr an die Targetpromotoren (TPO und TG) binden und somit auch die Transkription dieser Gene nicht mehr anschalten. Die zweite Mutation (R133Q) bindet zwar normal an die beiden Promotoren, aktiviert sie aber nicht, was durch einen dominant-negativen Mechanismus erklärt werden kann. Die dritte Mutation (E234K) bindet an und aktiviert die Targetpromotoren regelrecht. Auf DNA-Ebene führt diese Mutation aber zu einem zusätzlichen exonic splice enhancer (ESE), durch den es zu einem alternativen Spleißen der PAX8 mRNA kommt.

Diskussion: Die von uns identifizierten Mechanismen führen zur Hypothyreose, wie dies auch schon bei anderen Patienten mit bekannten PAX8 Mutationen beschrieben wurde. Unklar bleibt, warum auch innerhalb von Familien bei Individuen mit identischer Mutation unterschiedliche Phänotypen beobachtet werden.

Schlussfolgerung: Mutationen im PAX8 Gen können durch unterschiedliche Mechanismen zu einer Anlagestörung der Schilddrüse führen.
DGKJ-PV-033

Blutdruck-Perzentile nach Alter und Größe für nicht übergewichtige Jungen und Mädchen in Deutschland

H. Neuhauser', M. Thamm', U. Ellert' ${ }^{1}$, H. Hense'2, A. Schaffrath Rosario'

${ }^{1}$ Robert Koch-Institut, ${ }^{2}$ Institut für Epidemiologie und Sozialmedizin

Einleitung: Zur Zeit stehen in Deutschland zwei Referenzwertsysteme für die Beurteilung des Blutdrucks von Kindern und Jugendlichen zur Verfügung: Zum einen 1991 publizierte europäische Referenzwerte entweder nach Größe oder nach Alter, zum anderen US-Referenzwerte von 2004 nach Alter und Größe gleichzeitig. Die älteren europäischen Referenzwerte wurden insbesondere aufgrund von Datenheterogenität und der Berücksichtigung nur von Alter oder Größe in der Leitlinie der European Society of Hypertension 2009 nicht wieder empfohlen, sondern stattdessen wurde auf die US-Referenzwerte verwiesen. Ziel der vorliegenden Studie ist es, oszillometrische Blutdruckperzentile nach Alter und Größe gleichzeitig für nichtübergewichtige Kinder in Deutschland vorzustellen und die Unterschiede zu den US-Perzentilen aufzuzeigen.

Methoden: Im bundesweit repräsentativen Kinder- und Jugendgesundheitssurvey 2003-2006 (KiGGS) wurde bei 3- bis 17-jährigen Kindern und Jugendlichen eine zweimalige oszillometrische Blutdruckmessung mit einem bei Kindern validierten Gerät (Datascope Accutorr Plus) standardisiert durchgeführt. Es werden Blutdruckperzentile für nichtübergewichtige Kinder ( $n=12.199)$ nach Alter und Größe vorgestellt, die mittels eines modernen statistischen Verfahrens (GAMLSS, einer Verallgemeinerung der für anthropometrische Messzahlen weit verbreiteten LMS-Methode) modelliert wurden, das flexibler ist als das für die US-Referenzwerte verwendete. Der Einfluss des Ausschlusses übergewichtiger Kinder (definiert als BMI $>$ P9o nach Kromeyer-Hauschild) wurde untersucht durch einen Vergleich der Perzentile nach Alter für die gesamte Stichprobe vs. für die nicht-übergewichtigen Kinder.

Ergebnisse: Der Ausschluss übergewichtiger Kinder führte bei den Blutdruckperzentilen nach Alter zu bis zu $3 \mathrm{mmHg}$ niedrigeren systolischen P95 (diastolisch bis zu 2 mmHg niedriger). KiGGS BlutdruckReferenzwerte nach Alter und Größe gleichzeitig wurden für nichtübergewichtige Jungen und Mädchen modelliert, damit die Grenzwerte für Hypertonie im Kindesalter nicht von der Übergewichtsprävalenz der Referenzpopulation beeinflusst werden. Die KiGGS-Grenzwerte für hypertonen Blutdruck nach Alter und Größe für nicht-übergewichtige Kinder sind allgemein niedriger als die US-Referenzwerte, außer für Jungen über 14 Jahre. Der Unterschied KiGGS minus US beträgt bei gleicher cm-Größe (US-Größe P50) systolisch nach Alter zwischen -4 und $+4 \mathrm{mmHg}$ bei Jungen, bei Mädchen -2 bis +1 , diastolisch -6 bis +2 mmHg bei Jungen, -5 bis +2 bei Mädchen.

Diskussion: Die oszillometrischen KiGGS-Blutdruckreferenzwerte für nicht-übergewichtige Kinder basieren auf aktuellen repräsentativen Daten, Messungen mit einem bei Kindern validierten Messgerät, sind nicht beeinflusst von der Übergewichtsprävalenz in der Referenzpopulation und wurden mit neuesten statistischen Methoden berechnet, die die Verteilung des Blutdrucks im Kindesalter besser abbilden als bisher.

\section{DGKJ-PV-034}

Einseitige blutige Brustdrüsensekretion bei einem 10 Monate alten Mädchen

J. Noss, J. Peters

Kinderklinik Dritter Orden

Anamnese: Wir berichten über den Fall eines 10 Monate alten Mädchens mit seit 4 Monaten bestehender intermittierender blutiger Sekretion aus der linken Mamille. Anamnestisch und klinisch bestanden keine weiteren Auffälligkeiten bei altersentsprechender Entwicklung ohne Zeichen einer vorzeitigen Pubertätsentwicklung. Bei der Palpation der linken Mamille fiel eine kleine ovaläre Schwellung des Brustdrüsenkörpers auf. Durch seitlichen Druck ließ sich schmerzlos ein Tropfen blutiges Sekret exprimieren. 
Diagnostik: In der Sonographie der Brustdrüse kam die rechte Brust unauffällig zur Darstellung, linksseitig zeigte sich im Brustdrüsengewebe retromamillär hypoechogenes zystisches Gewebe mit einem Durchmesser von $4 \mathrm{~mm}$ ohne gesteigerte Durchblutung.

In der zytologischen Untersuchung des Sekretes ließ sich eine Erythrophagozytose mit Hämosiderinmakrophagen ohne Hinweis auf eine bakterielle Infektion nachweisen. Malignitätsverdächtige Zellen fanden sich nicht.

Zum Ausschluss einer endokrinologischen Ursache erfolgte eine Hormondiagnostik (Prolactin, Östradiol, Testosteron, B-HCG, LH, FSH, TSH)

Diskussion: Während eine milchige Brustdrüsensekretion mit einer tastbaren Brustvergrößerung bei Neugeborenen häufig gesehen wird, ist eine blutige Brustdrüsensekretion im Säuglings- und Kindesalter sehr selten. In der Literatur wurden bisher 23 Fälle beschrieben.

1983 wurden erstmalig 2 Fälle von Berkowitz und Inkelis mit einseitiger blutiger Brustdrüsensekretion beschrieben, die sich im Verlauf spontan zurückbildete. In den folgenden Jahren wurde bei 12 Kindern mit blutiger Brustdrüsensekretion eine subkutane Mastektomie durchgeführt. In der Histologie zeigte sich der einheitliche Befund einer benignen Milchgangsektasie mit eosinophilen Infiltraten, einer periduktalen Fibrose und zahlreichen Entzündungszellen. Sonographisch konnte neben normalem Brustdrüsengewebe in den Fällen mit tastbarer Schwellung retromamillär hypoechogenes zystische Gewebe mit erweiterten Milchgängen dargestellt werden.

Die benigne Milchgangsektasie wurde erstmalig 1951 von Haagensen als gutartige Brustveränderung mit Erweiterung der Milchgänge, ungebender entzündlicher Reaktion und Fibrose des periduktalen Stromas beschrieben. Auch wenn die benigne Milchgangsektasie im Säuglingsund Kindesalter sehr selten ist, so ist sie vermutlich die häufigste Ursache einer blutigen Brustdrüsensekretion. Differentialdiagnostisch muss in dieser Altersgruppe auch an eine Mastitis, ein Trauma, ein intraduktales Papillom, eine Gynäkomastie und bei Kindern über 3 Jahren an Brustkrebs gedacht werden.

Schlussfolgerung: Liegt der blutigen Brustdrüsensekretion zunächst keine infektiöse, traumatische oder hormonelle Ursache zugrunde und zeigt sich in der Sonographie der Befund einer Milchgangsektasie (hypoechogenes zystisches Gewebe) kann zugewartet werden. Kommt es binnen 6 bis 9 Monaten nicht zu einer Spontanremission, sollte ein Kinderchirurg hinzugezogen werden.

\section{DGKJ-PV-035}

Drei Jahre nach Inkrafttreten der EU-Verordnung „Better Medicines for Children" - Trifft die Verordnung den Kern des Problems?

M. Hermes

Institut für Pharmazeutische Technologie und Biopharmazie, Heinrich-Heine-Universität

Hintergrund: Die Behandlung von Kindern und Jugendlichen erfolgt weltweit mit zum Teil nicht für sie

zugelassenen Arzneimitteln. Die EU-Kommission erließ 2006 die Verordnung „Better Medicines for Children“, um die Situation in Europa zu verbessern. In unserer Studie wurde das Ausmaß des „unlicenseduse" auf pädiatrischen Krankenhausstationen in Deutschland kurz vor Inkrafttreten der Verordnung im Januar 2007 ermittelt und erste Entwicklungen drei Jahre danach abgeschätzt.

Material und Methoden: In 40 deutschen Krankenhausapotheken wurden über einen Zeitraum von sechs Monaten alle

Rezepturverordnungen für pädiatrische Patienten gesammelt und ausgewertet. Für häufig

verordnete Wirkstoffe wurde der aktuelle Zulassungsstatus ermittelt. Die Auswertung bislang

veröffentlichter Entscheidungen der EMA über pädiatrische Prüfkonzepte soll einen Ausblick auf die zukünftige Entwicklung ermöglichen. Ergebnisse: Es wurden über 4. 8 oo Verordnungen ausgewertet. Für 38 $\%$ (5 von 13) der am häufigsten verordneten Wirkstoffe ist keine altersgerechte Darreichungsform verfügbar. Werden Wirkstoffe mit kardiovaskulärer Indikation betrachtet, trifft dies auf 80 \% (16 von 20) der Stoffe zu. Der größte aktuelle Bedarf besteht in der Entwicklung kindgerechter Zubereitungen altbekannter Arzneistoffe. Deren Anteil an allen Anträgen auf Genehmigung eines PIP beträgt nur $3 \%$ (23 von 751). In den Dokumenten „Priority-list of off-patent medicinal products for paediatric studies“ und „Assessment of the paediatric needs" führt die EMA insgesamt 317 Wirkstoffe auf, von denen sie bislang für $10 \%$ Entscheidungen über PIPs veröffentlicht hat. Drei Jahre nach Inkrafttreten der EU-Richtlinie befinden sich somit erst wenige Wirkstoffe auf dem Weg zu einer Zulassung, die die Anwendung bei Kindern jeden Alters einschließt.

Schlussfolgerung: In der EU sind für neue Arzneistoffe die Entwicklung kindgerechter Zubereitungen und klinische

Untersuchungen bei Kindern Zulassungsvoraussetzungen. Die Entwicklung neuer, altersgerechter Arzneimittel mit nicht mehr patentgeschützten Wirkstoffen benötigt jedoch weitere Anreize, um die gegenwärtige Versorgungslücke zu schließen.

\section{DGKJ-PV-036}

Medikamentenentwöhnung auf der Intensivstation - Entzug verhindern oder lindern durch vorausschauende Therapie

S. Wendt, A. Nebgen, R. Huth, S. Gehring

Klinikum der Johannes-Gutenberg Universität

Einleitung: Bei pädiatrischen Patienten jeden Alters kommt es im Rahmen komplexer intensivmedizinischer Therapien, die mit einer Analgosedierung einhergehen, zur Entwicklung von Medikamententoleranz, Entzugssymptomen und physischer Abhängigkeit, was die Morbidität und Mortalität erheblich steigern kann und fast immer zu einer Verlängerung der Intensivbehandlungsdauer führt. Schon während der notwendigen Analgosedierung muss es daher Ziel sein, einen späteren Entzug zu verhindern. Dazu ist neben der Kenntnis der Risikofaktoren (Behandlungsdauer/Medikamentendosis) und einem standardisierten Monitoring (Scoring) auch ein planvolles Vorgehen hinsichtlich Auswahl der Medikamente und Therapiesteuerung notwendig.

Methoden / Patienten: Auf der Mainzer Kinderintensivstation werden jährlich ca. 400 Patienten nach kinder-, neuro- und kardiochirurgischen Eingriffen, Traumata, Infektionen und anderen Erkrankungen betreut, von denen ca. 70\% eine Analgosedierung benötigen. Standardisiert werden alle beatmeten Patienten nach geplanter Sedierungsdauer und Alter mit einer Opioid-Benzodiazepin-Kombination (Piritramid vs. Sufentanil mit Midazolam) oder bei einer voraussichtlichen Beatmungsdauer $<12 \mathrm{~h}$ und Schulalter mit Propofol therapiert. Bei beginnender Toleranzentwicklung oder Erreichen vorher festgelegter Dosisbereiche sowie bei voraussichtlich verlängerter Therapiedauer erfolgt die Hinzunahme von Clonidin. Zusätzlich können Phenobarbital oder Chloralhydrat zur zentralen Dämpfung verwendet werden. Bei absehbarer Beatmungsentwöhnung erfolgt die langsame Reduktion von Opioid und Benzodiazepin und bei Verwendung des Sufentanil nach Erreichen einer Dosis von ca. 0,1-0,15 $\mu \mathrm{g} / \mathrm{kg} / \mathrm{h}$ der Wechsel auf Piritramid. Überlappend erfolgt danach bei Patienten mit Entzugsrisiko die Oralisierung des Opioids auf Methadon entsprechend der Äquivalenzdosis. Clonidin wird erst im Anschluß reduziert und ggf. oralisiert. Die Entwöhnung vom Methadon erfolgt nach 72 h und dann standardisiert alle 2-3 Tage. Reizabschirmung und Einbindung der gut informierten Bezugspersonen sind neben der medikamentösen Therapie ebenfalls wichtige Komponenten.

Schlussfolgerungen: Ziele und Erfolgsparameter unseres Entwöhnungskonzeptes sind die Verhinderung oder Reduktion der Entzugssymptome, die Etablierung eines Schlaf-Wach-Rhythmus und Reduktion der Agitation sowie die Einsparung von Intensivtherapie- und ZVK-Tagen. Der wesentliche Schlüssel zum Erfolg liegt dabei in einem adäquaten weaning-Konzept, der Nutzung standardisierter Scores sowohl zur Evaluation des Sedierungsbedarfs als auch Einordnung der möglichen Entzugssymptomatik sowie die Nutzung alternativer Medikamente und Applikationswege zur Opiateinsparung. 
DGKJ-PV-037

Intervallrehabilitation und seitenalternierende Ganzkörpervibration bei Kindern mit Spina bifida

O. Semler', V. Anneken², C. Stark'1, W. Christiane ${ }^{3}$, E. Schönau'

'Univ.-Kinderklinik, ${ }^{2}$ Forschungsinstitut für Behinderung und Sport e.V,

${ }^{3}$ Deutsche Sporthochschule Köln

Einleitung: Kinder und Jugendliche mit Spina bifida haben Einschränkungen ihrer motorischen Funktionen. Neben den Auswirkungen der Grunderkrankung sind viele von den sekundären Folgen einer Immobilität betroffen (Kontrakturen, Sarkopenie, Osteopenie). Um diese Folgen zu behandeln, wurde ein multimodales Therapiekonzept unter Einbeziehung der seitenalternierenden Ganzkörpervibration entwickelt. Ziel ist es die Muskelfunktion zu steigern, Muskel- und Knochenmasse aufzubauen und die motorischen Fähigkeiten zu verbessern.

Intervention: Während eines 2-wöchigen stationären Aufenthaltes erhalten die Kinder und Jugendlichen nicht nur intensive Physiotherapie (Bobath), sondern führen auch eine Laufband- oder Lokomaten-Therapie, Medizinisches Gerätetraining und Trainingseinheiten im Bewegungsbad durch. Zusätzlich erlernen Patienten und Eltern das seitenalternierende Ganzkörpervibrationstraining mit dem Galileo-System ${ }^{\circ}$. Im Anschluß nutzen die Patienten das Vibrationssystem 6 Monate zu Hause und kommen zwischendurch nochmals für 1 Woche zur Therapie-intensivierung in die Rehabilitationseinrichtung.

Meßmethodik: Zur Beurteilung der Therapieeffekte werden zu Beginn und nach 6 Monaten Ganzkörper-DEXA-Messungen durchgeführt, aus denen sich auch Veränderungen in einzelnen Körperregionen (z. B. Beine) berechnen lassen. So werden Muskel- und Knochenmasse und Knochenflächendichte bestimmt. Die Muskelfunktion wird mit einer Bodenreaktionsmeßplatte (Leonardo ${ }^{\circ}$ ) erfasst. Hierbei beugen und Strecken die Patienten ihre Knie, während sie in einer Vertikalisierung von $45 \mathrm{Grad}$ auf einem Kipptisch liegen. Die motorischen Fähigkeiten werden mit einem modifizierten „Gross motor function measurement Test" evaluiert.

Ergebnisse: 24 Patienten (14 weiblich, medianes Alter bei Therapiebeginn 9,5 Jahre) mit einem lumbalen oder lumbosacralen Lähmungsniveau, haben die 6-monatige Trainingsphase durchlaufen. Die Ergebnisse sind in Tabelle 1 dargestellt.

\section{Tab.}

\begin{tabular}{|llll|}
\hline Parameter & $\begin{array}{l}\text { Verände- } \\
\text { rung }\end{array}$ & p & N \\
\hline $\begin{array}{l}\text { BMD/Länge Ganzkörper } \\
\text { DEXA Messung (ohne Kopf [g/ } \\
\mathrm{cm} 2 / \mathrm{m}] \text { ) }\end{array}$ & $1,14 \%$ & 0,02 & 24 \\
\hline $\begin{array}{l}\text { BMC/Länge (ohne Kopf [g/ } \\
\mathrm{cm}] \text { ) }\end{array}$ & $8,11 \%$ & $<0,0001$ & 24 \\
\hline $\begin{array}{l}\text { Knochenfläche / Länge [cm] } \\
\text { BMC Beine/ Beinlänge [g/cm] }\end{array}$ & $5,26 \%$ & $<0,0001$ & 22 \\
\hline $\begin{array}{l}\text { Muskelmasse Ganzkörper/ } \\
\text { Länge [kg/cm] }\end{array}$ & $2,27 \%$ & 0,02 & 24 \\
\hline $\begin{array}{l}\text { Muskelmasse Bein /Beinlänge } \\
\text { Muskelkraft (Beugen und }\end{array}$ & $2,67 \%$ & 0,12 & 20 \\
\hline $\begin{array}{l}\text { Strecken der Knie } \\
\text { bei 45 Grad Kipptischwinkel } \\
\text { [kN] }\end{array}$ & 0,01 & 18 \\
\hline \begin{tabular}{l} 
Modifizierter GMFM \\
\hline
\end{tabular} & $3,45 \%$ & 0,02 & 18 \\
\hline
\end{tabular}

Zusammenfassung: Das Kölner Rehabilitationskonzept „Auf die Beine" führt bei Kindern und Jugendlichen mit Spina bifida zu einer Steigerung der motorischen Funktionen, zu einer Zunahme von Knochen- und Muskelmasse und zu einer Verbesserung der Muskelkraft, ohne dass es zu therapiebedingten Nebenwirkungen gekommen ist.
DGKJ-PV-038

Malcompliance: Verbesserung des Outcomes durch stationäre Rehabilitation

K. Stirner, A. Jung, I. Heinrichs, C. Geidel, M. Möhrenschlager, R. Lauener Hochgebirgsklinik Davos

Einleitung: Unbefriedigende Symptomkontrolle durch Malcompliance aufgrund von unzureichendem Krankheitsverständnis und fehlender Therapieeinsicht stellen eine Herausforderung an die ambulante Betreuung von jugendlichen Patienten mit mittel- und schwergradigen chronischen Lungen- und Hauterkrankungen dar.

Kasuistik: 15-jähriges, adipöses Mädchen mit allergischem Asthma bronchiale und atopischer Dermatits. Seit dem 18. Lebensmonat rezidivierende obstruktive Bronchitiden, im Verlauf ausgeprägte allergische Komponente mit polyvalenter Sensibilisierung auf Inhalationsallergene; zudem Auftreten von anstrengungsinduzierten obstruktiven Atemwegssymtpomen. Mit Beginn der Adoleszenz Verschlechterung des Asthmakontrollgrades mit teilweise beatmungspflichtigen Dyspnoeanfällen bei genereller Verschlechterung der Compliance („Vergessen" der Medikamente, unzureichende Krankheitseinsicht). Parallel dazu vermehrte Exazerbationen der atopischen Dermatitis bei unregelmässig durchgeführter Basispflege und Therapie. Bei Aufnahme zur Rehabilitation deutlich eingeschränkte Lungenfunktion (FEV1 70,3\% v. Soll, MEF50 34,5\%, SRtot 515. 8\%, FeNo 45,1 ppb) mit unter hochdosierter Therapie mit ICS/LABA und Singulair; stamm- und extremitätenbetont entzündliche Makulae mit Exkorationen und SCORAD 62/103 Punkte trotz Verordnung von Cyclosporin und Kortikosteroiden systemisch. Interventionen: intensive Asthma- und Neurodermitischulung, Training der korrekten und konsequenten Medikamenten-Applikation, psychologische Unterstützung, sozialpädagogisch geleitete Aktivierung, sportliche Konditionierung. Outcome: Besserung der Lungenfunktionsbefunde (FEV1 98,4\%, MEF50 74,1\%, SRtot 142. 5\%, FeNO 4,4 $\mathrm{ppb})$, signifikante Reduktion der anstrengungsinduzierten Symptome, weitgehende Normalisierung des Hautzustandes (SCORAD 26/103 Punkte). Im Anschluss Reduktion der antiinflammatorischen und antiobstruktiven Therapie sowie Sistieren der Cyclosporingaben ohne Befundverschlechterung. Pulmonaler und dermatologischer Verlauf nach Entlassung stabil bei konsequent durchgeführter Therapie (Lungenfunktion 4 Wochen nach Entlassung: FEV1 109\%, MEF 50 65\%).

Schlussfolgerung: Durch eine multidisziplinäre Intervention im Rahmen einer stationären, mehrwöchigen Rehabilitationsbehandlung können mit dem betroffenen Patienten gemeinsam gezielt Ressourcen genutzt werden, um eine Verbesserung von Krankheitsverständnis, Selbstmanagement und Compliance zu erreichen und damit eine nachhaltige Verbesserung des Krankheitsverlaufes zu erzielen.

\section{Gastroenterologie I}

\section{DGKJ-PV-039}

Pouchfistel mit Retroperitonealabszess - eine seltene Spätkomplikation nach Kolektomie und Pouchanlage bei einem 14 jährigen Mädchen mit Colitis ulcerosa

E. Roeling', J. Stern², A. Ballauff'

${ }^{1}$ Klinikum Krefeld, ${ }^{2}$ St.-Josefs-Hospital Dortmund

Bei Patienten mit schwerer therapieresistenter oder steroidabhängiger Colitis ulcerosa ist die Proktokolektomie mit Pouchanlage eine wichtige Therapieoption. Leider entwickeln bis zu 50\% der Patienten im Verlauf eine Entzündung im Pouch, die aber meist unkompliziert medikamentös behandelbar ist. Eine chronische oder therapieresistente Pouchitis kann auch sekundär auf Grund anderer Ursachen, wie dem Vorliegen eines M. Crohn, einer Infektion oder auch chirurgischer Probleme, entstehen. Wir berichten über ein 14 jähriges Mädchen mit einer seltenen Komplikation als Ursache für eine chronische Pouchitis. 
Kasuistik: Erstdiagnose einer schweren Pancolitis ulcerosa im Alter von 10 Jahren bei blutigen Durchfällen und Fieber. Nach sehr verzögertem Ansprechen auf Steroide spontane Sigmaperforation mit eitriger Peritonitis in der Reduktionsphase. Notfallmäßig Sigmaresektion, Anlage eines endständigen Sigmastomas und Blindverschluss des Rektums. Steroidbedingt entwickelte das Mädchen ein Glaukom sowie eine Osteopenie mit Wirbelkörperfrakturen. Trotz Immunsuppression mit Azathioprin anhaltende Entzündung im linken Kolon. Als Konsequenz nach 11 Monaten zweizeitige Kolektomie und Pouchanlage, Verschluss des protektiven Stomas nach 3 Monaten. Weder endoskopische Voruntersuchungen noch das Kolektomiepräparat zeigten beweisende Aspekte für einen M. Crohn. Bereits nach 3 Monaten war eine erneute stationäre Aufnahme bei Durchfall, Erbrechen, Leukozytose und CRPErhöhung notwendig. Endoskopisch fanden sich eine Rötung im Ileum und einzelne Aphthen im Pouch. Histologie: aktive Entzündung, kein Hinweis für M. Crohn. Besserung erst nach Umsetzen von Metronidazol auf Ciprofloxazin, nach Absetzen jedoch rasche erneute Verschlechterung. Im Verlauf der nächsten 2 Jahre entwickelte sich eine häufig rekurrierende, antibiotikaabhängige Pouchitis mit Besserungstendenz unter Immunsuppression mit Azathioprin und lokaler Behandlung mit Budesonid. Im Sommerurlaub 2009 traten schließlich wieder Durchfälle und Fieber auf. Die Einnahme von $20 \mathrm{mg}$ Prednison/Tag blieb ohne Effekt, die Patientin wurde nach Rückkehr sofort stationär aufgenommen. Bei anhaltendem Fieber, CRP-Erhöhung und fehlendem Ansprechen auf Ciprofloxazin führten wir erneut eine Pouchoskopie durch. Es zeigte sich eine Entzündung des Pouches sowie eine kleine Fistelöffnung, aus der sich reichlich eitriges Sekret entleerte. Im MRT und in der anschließenden Operation wurde eine ca. $1 \mathrm{~cm}$ breite Fistel im Bereich der ehemaligen Naht mit präsakralem Retroperitonealabszess gefunden. Nach Fistelverschluss und Abszesssanierung erholte sich das Mädchen rasch. Seither besteht klinisch wie laborchemisch eine vollständige Remission ohne jegliche Medikation.

Fazit: Auch wenn viele Aspekte an einen M. Crohn denken lassen, fanden wir im Verlauf nie einen beweisenden Befund. Bei chronischer oder therapierefraktärer Pouchitis sollte immer auch an chirurgische Ursachen gedacht werden. Endoskopie und bildgebende Diagnostik sollten großzügig und ggf. wiederholt eingesetzt werden.

\section{DGKJ-PV-040}

Duodenalstenose mit Lochblendenmembran: Späte klinische Manifestation im 2. Lebensjahr

A. Bartels' ${ }^{1}$, A. Trebst' ${ }^{1}$, R. Wunsch'1, R. Tröbs ${ }^{2}$, T. Berger

'Vestische Kinderklinik, ${ }^{2}$ Kinderchirurgische Klinik im Marienhospital

Fallbericht: Wir berichten über eine Patientin mit membranöser Duodenalstenose, die erstmalig im Alter von einem Jahr und sechs Monaten mit relativ milder Symptomatik vorgestellt wurde: Alle 2-4 Wochen war es zu rezidivierendem Erbrechen teils unverdauter Nahrung mit einer Frequenz von $3-5 \mathrm{x} / \mathrm{d}$ gekommen, teilweise seien unverdaute Nahrungsmittel noch nach mehreren Wochen ausgespuckt worden. Die Ernährung erfolgte fast ausschließlich mit kleinen Portionen Formulanahrung und Muttermilch, selten mit festen Speisen. Der Schluckakt habe kein Problem dargestellt. Größe und Gewicht bei Aufnahme entsprachen der 10. Perzentile. In der Magen-Darm-Passage stellte sich eine Aufweitung des Duodenums im Übergang von der Pars descendens zur Pars horizontalis dar, ohne eindeutige Behinderung der Kontrastmittelpassage. In der Ösophago-Gastro-Duodenoskopie fand sich an gleicher Stelle eine membranartige Stenose mit einem Restlumen von ca. 5-10 $\mathrm{mm}$. Therapeutisch erfolgte eine Duodenotomie mit Membranresektion, nachdem zuvor eine endoskopische Laserdestruktion ohne ausreichenden Erfolg versucht worden war.

Diskussion: In den in der Literatur beschriebenen Fällen einer Duodenalstenose war die Diagnosestellung üblicherweise prä- bzw. einige Tage postnatal möglich. Eine pränatale Diagnose gelingt häufiger bei zusätzlich bestehenden Malformationen oder assoziierten Syndromen (M. Down). Es gibt Einzelfallbeschreibungen von erst im Erwachsenenalter erkannten membranösen Stenosen, welche sich durch Übel- keit, Erbrechen, abdominelle Schmerzen und Gewichtsverlust manifestierten. Eine japanische Studie beschreibt zwei Fälle von Kindern mit M. Down, bei welchen im Alter von zehn, bzw. zwölf Monaten die Erstdiagnose einer Duodenalstenose gestellt worden war. In beiden Fällen handelte es sich um eine wandartige Obstruktion mit einer verbleibenden Öffnung von 3-4 mm. In einer Arbeit von Mikaelson et al. konnte die Diagnose bei acht von sechszehn untersuchten Kinder in den ersten sechszehn Lebenstagen gestellt werden. Nur drei Kinder waren zum Zeitpunkt der Diagnose, wie unsere Patientin, über ein Jahr alt. Diese hatten verglichen mit dem geringen Restlumen des Duodenums nur milde Symptome. Sie waren durch rezidivierendes Erbrechen, eine Gedeihstörung und ein aufgetreibenes Epigastrium aufgefallen. Die Symptomatik war in einigen Fällen jedoch transient und lediglich postprandial aufgetreten. Das mittlere duodenale Restlumen lag in dieser Studie bei 5-6 mm, also in einem ähnlichen Bereich wie bei unserer Patientin.

Schlussfolgerung: Verglichen mit Patienten mit einer Duodenalatresie erfolgt die Diagnosestellung bei membranöser Duodenalstenose häufig deutlich später, sodass diese Anomalie als eigene Entität betrachtet werden sollte, um die Besonderheiten der klinischen Präsentation zu berücksichtigen.

\section{DGKJ-PV-041}

Das pflanzliche Therapeutikum STW 5 zur Behandlung gastrointestinaler Funktionsstörungen bei Kindern von 3-14 Jahren - eine prospektive nicht interventionelle Studie

\section{B. Vinson', W. Otto², G. Kühn², E. Lehmann², M. Radke ${ }^{3}$}

${ }^{1}$ Steigerwald Arzneimittelwerk, ${ }^{2}$ niedergelassene Praxis, ${ }^{3} \mathrm{Klinikum}$ Ernst v. Bergmann

Fragestellung: Bis $\mathrm{zu} 21 \%$ aller Kinder leiden heute an gastrointestinalen Funktionsstörungen wie funktionelle Dyspepsie (FD) oder Reizdarmsyndrom (irritable bowel syndrome, IBS). Diese Störungen präsentieren sich bei Kindern oft als heterogene und schwer behandelbare Symptommuster. Die Lebensqualität der betroffenen Kinder ist meist stark eingeschränkt. Wie auch bei den erwachsenen Patienten existiert bisher keine Standardtherapie. Eine umfassende Therapie, in welcher möglichst alle Symptome erreicht werden, wäre optimal. STW 5 ist ein pflanzliches Therapeutikum aus 9 Extrakten, von welchen jeder einen spezifischen Einfluss auf den Gastrointestinaltrakt hat. STW 5 ist in Deutschland zur Behandlung von FD und IBS zugelassen. In der vorliegenden nicht-interventionellen Studie wurde die Anwendung von STW 5 bei Kindern mit gastrointestinalen Funktionsstörungen im Alter von 3-14 Jahren in niedergelassenen Praxen untersucht.

Material und Methoden: 980 Kinder mit gastrointestinalen Funktionsstörungen wurden in 43 kinderärztlichen Praxen mit STW 5 optional und entsprechend der Einschätzung des Arztes für eine Woche behandelt. STW 5 wurde in einer altersentsprechenden Dosierung von 10-20 Tropfen $3 \mathrm{X}$ täglich angewendet. Unter- und Oberbauchbeschwerden sowie deren Verlauf während der Therapie wurden mit Hilfe eines gastrointestinalen Symptomenscores durch die behandelnden Ärzte ermittelt. Der Score bestand aus 14 FD- und IBS- spezifischen Symptomen, die vor und nach der Behandlung mit STW 5 ermittelt wurden. Die globale Wirksamkeit und Verträglichkeit wurde von den Kindern bzw. Eltern und den Ärzten beurteilt. Es wurden unerwünschte Ereignisse, Wechselwirkungen und Verträglichkeit dokumentiert.

Ergebnisse: Der mittlere Summenscore der Ober- und Unterbauchbeschwerden verringerte sich von 16.1 \pm 8.93 Score-Punkten ( \pm StandardAbweichung) zu Beginn der Therapie auf 3. $8 \pm 4.24$ Score-Punkte am Ende der Therapie. Die mittlere Veränderung des Scores lag bei 12. $3 \pm$ 8. 11 Punkten. Die Verringerung des Scores war bei den verschiedenen Indikationen und Altersgruppen übereinstimmend. 38. 6\% der Kinder bzw. Eltern beurteilten die Symptome als vollständig gebessert. 35. 6\% beendeten die Behandlung nach einer Woche aufgrund von Symptomfreiheit. Die Verträglichkeit wurde von 94. 8\% der Kindern bzw. Eltern als sehr gut und gut bewertet. Es wurden 7 unerwünschte Ereignisse 
berichtet. Davon wurden 4 unerwünschte Ereignisse in einem wahrscheinlichen bzw. möglichen Zusammenhang mit STW 5 beurteilt.

Diskussion und Schlussfolgerung: In dieser offenen Studie konnten durch STW 5 Ober- und Unterbauchbeschwerden bei Kindern von 3-14 Jahren innerhalb einer Woche deutlich gebessert werden. Der therapeutische Effekt war bei beiden Störungen (IBS und FD) sowie in den verschiedenen Altersgruppen gleich stark. Damit erwies sich STW 5 in dieser Studie als eine effektive und sichere Therapie-Option für Kinder mit gastrointestinalen Funktionsstörungen.

\section{DGKJ-PV-042}

Präsymptomatische Diagnosestellung eines Morbus Wilson durch Messung erhöhter Transaminasen bei einem 6-jährigen Jungen mit schwerer Hämophilie A

I. Hainmann, T. Woltering, P. Greiner, A. Superti-Furga, B. Zieger

Universitätsklinikum Freiburg

Bei einem 6-jährigen Jungen mit schwerer Hämophilie A (Intron 22 Inversion des FVIII Gens) wurden wiederholt leicht erhöhte Werte für die Leberenzyme GPT und GOT im Routinelabor gefunden. Es fanden sich keine Hinweise auf eine Virushepatitis (Hepatitis A, B oder C, CMV, EBV) oder eine Autoimmunhepatitis. Die weiterführende Diagnostik ergab deutlich erniedrigte Serumwerte für Coeruloplasmin und Kupfer, die 24 h Kupferausscheidung im Urin war signifikant erhöht. Die Diagnose Morbus Wilson konnte schließlich durch den Nachweis einer Compound Heterozygotie für Mutationen im ATP7B Gen (R1041W und N1270S) gesichert werden; die Eltern waren heterozygot. Bei Diagnose war die Leberfunktion uneingeschränkt, der Junge war neurologisch unauffällig, und es bestand kein Kayser-Fleischer Cornealring. Die Sonographie zeigte zwar eine Vergrößerung der Leber, diese wies jedoch eine normale Parenchymstruktur auf. Eine entkupfernde Therapie mit D-Penicillamin (Chelatbildner) wurde begonnen und das Therapieansprechen mittels Messung von Kupfer im $24 \mathrm{~h}$ Sammelurin sowie der Transaminasen überprüft. Unter der Therapie wies das Monitoring im Verlauf auf eine Incompliance des Patienten hin. Im Alter von 13 Jahren trat erstmalig eine neurologische Symptomatik mit Dystonie und konsekutiver Achillessehnenkontraktur auf. D-Penicillamin wurde abgesetzt und eine Behandlung mit Zinkacetat begonnen. Aktuell hat sich bei guter Toleranz und verbesserter Compliance eine deutliche neurologische Verbesserung erzielen lassen; die Transaminasen liegen fast im Normbereich. Differentialdiagnostisch ist eine primäre neurologische Manifestation des M. Wilson wahrscheinlich, eine sehr seltene Nebenwirkung unter D-Penicillamin nicht mit letzter Sicherheit auszuschließen.

Der Morbus Wilson ist eine autosomal-rezessive Erkrankung im Kupfermetabolismus, die durch Akkumulation von Kupfer in Leber, Gehirn, Nieren und Cornea zu hepatischer und neuropsychiatrischer Dysfunktion führen kann. Selbst eine leichte kontinuierliche Erhöhung der Transaminasen kann auf einen Morbus Wilson hinweisen. Unser Fall zeigt eindringlich, dass bei engmaschigem Monitoring eine kontinuierliche Erhöhung der Transaminasen einer weiterführenden Diagnostik bedarf, da sie auf eine komplexe Erkrankung wie den M. Wilson hinweisen kann. Die präsymptomatische Diagnosestellung ermöglicht die frühzeitige Einleitung einer Therapie. Insbesondere bei initial präsymptomatischen Patienten sind Compliance und Monitoring entscheidend für das langfristige Outcome.

\section{DGKJ-PV-043}

KRANKHEITSLAST DER ROTAVIRUS-GASTROENTERITIS IN DEUTSCHLAND - EINE AKTUALISIERUNG EPIDEMIOLOGISCHER UND ÖKONOMISCHER DATEN MITTELS EINER DELPHI-BEFRAGUNG -

N. Ezzat ${ }^{1}$, J. Schiffner-Rohe ${ }^{2}$, S. Schmitter ${ }^{2}$, B. Brüggenjürgen ${ }^{1}$

${ }^{1}$ Alpha Care GmbH, ${ }^{2}$ Sanofi Pasteur MSD GmbH

Fragestellung: Im Rahmen der europaweiten REVEAL-Studie (Rotavirus Gastroenteritis Epidemiology and Viral Types in Europe Accounting for Losses in Public Health and Society) wurden in den Jahren
2004 und 2005 zahlreiche Faktoren der klinischen und ökonomischen Krankheitslast durch Rotavirus-Gastroenteritiden (RVGE) bei Kindern bis 5 Jahren erhoben. Die deutschen Daten wurden ausschließlich in klinischen Zentren in Mecklenburg-Vorpommern erhoben. Weitere Angaben zur Krankheitslast sind aus der Literatur bekannt. Ziel dieser Arbeit war, abzuschätzen, ob die lokal erhobenen und in der Literatur genannten Daten aktuell und auf Gesamt-Deutschland übertragbar sind.

Material und Methode: Acht repräsentativ ausgewählte Pädiater nahmen an einer 2-stufigen Delphi-Befragung teil. Im Zeitraum von November bis Dezember 2009 wurde ein Fragebogen verschickt zur Epidemiologie der RVGE, zum Ressourcenverbrauch durch die ambulante und stationäre RVGE-Behandlung sowie zur notwendigen Betreuung bei an RVGE erkrankten Kindern Die Grundlage für den Fragebogen bildeten die REVEAL-Ergebnisse und die Literaturdaten.

Die Angaben zum Ressourcenverbrauch sowie nationale Vergütungssysteme und Statistiken wurden genutzt, um die Behandlungs- und Arbeitsausfallkosten durch RVGE zu berechnen.

Ergebnisse: Der Rücklauf betrug in der 1. Stufe 100\% und in der 2 . Stufe haben $75 \%$ der Experten geantwortet. Die Inzidenzen schätzten die Experten für ambulante RVGE-Fälle auf 48 pro 10oo, für stationäre RVGE-Fälle auf 6,69 pro 1000 und für nosokomiale Fälle auf 2,4 pro 1000. Die Experten haben damit weitestgehend die Angaben aus REVEAL und der internationalen Literatur bestätigt.

Den Krankenkassen entstehen laut der Befragung Kosten in Höhe von $207 €$ durch einen ambulanten RVGE-Fall, $1709 €$ durch einen stationären RVGE-Fall. Für nosokomiale RVGE-Fälle wurden $101 €$ mittels DRG-Systematik ermittelt. Die Kosten für die Gesellschaft betragen $353 €$ für einen ambulanten RVGE-Fall, $1896 €$ für einen stationären Fall und $726 €$ aufgrund eines nosokomialen Falls. Aus gesellschaftlicher Perspektive verursachen die RVGE-Fälle ohne medizinische Versorgung Kosten in Höhe von 267€, die größtenteils auf den Arbeitsausfall der betreuenden Eltern zurückzuführen sind.

Die in REVEAL erhobenen Kosten betragen aus Krankenkassenperspektive $110 €$ für ambulante RVGE-Fälle und $1545 €$ für stationäre Fälle sowie $432 €$ für ambulante RVGE-Fälle und $2085 €$ für stationäre Fälle aus gesellschaftlicher Perspektive. Die Kosten für RVGE-Fälle ohne medizinische Versorgung sowie nosokomiale RVGE-Fälle waren weder aus REVEAL noch aus der Literatur bekannt.

Diskussion: Entsprechend der Delphi-Befragung sind die in REVEAL erhobenen und aus der Literatur bekannten Angaben zur Inzidenz aktuell und für ganz Deutschland gültig. Dagegen gibt es bei den Kosten Abweichungen infolge von Änderungen in den Abrechnungssystemen und des nun berücksichtigten Kinderkrankenpflegegeldes. Dies ist bei aktuellen ökonomischen Analysen zu berücksichtigen.

\section{DGKJ-PV-044}

Verstärkte Schleimhautexpression von DMBT1 bei akuter Appendizitis

E. Kämmerer', U. Schneider', C. Klaus' ${ }^{1}$, A. Moßdorf', M. Renner'², N. Wagner', B. Kramer ${ }^{3}$, J. Mollenhauer, ${ }^{4}$ N. Gaßler ${ }^{1}$

${ }^{1}$ RWTH Aachen University, ${ }^{2}$ Universität Heidelberg, ${ }^{3}$ Maastricht University Medical Center, ${ }^{4}$ University of Southern Denmark

Fragestellung: Deleted in Malignant Brain Tumors 1 (DMBT1) kodiert ein sezerniertes Glykoprotein (gp340), das auch vom Deckepithel des Dünn- und Dickdarms gebildet wird. Experimentelle Befunde weisen darauf hin, dass DMBT1 Funktionen sowohl in der Epitheldifferenzierung als auch in der Pathogenabwehr hat. So können beispielsweise durch DMBT1 und kurze synthetische DMBT1-Peptidmotive Bakterien aggregiert werden. Gegenstand der aktuellen Arbeit war, ob eine akute, lokal begrenzte Entzündung des Darms mit einer Änderung der enterozytären DMBT1 Expression verbunden ist.

Material und Methoden: 26 Appendektomiepräparate (floride Entzündung: $n=13$; keine floride Entzündung: $n=13$ ) wurden bezüglich Expression und Synthese von DMBT1 mit verschiedenen Verfahren unter- 
sucht. Ein immunreaktiver Score zur Beurteilung der anti-DMBT1 Färbungen wurde erstellt.

Ergebnisse: DMBT1 zeigte eine konstitutive Expression (RT-PCR) und Synthese (Immunhistologie, Immunoblot) in der Schleimhaut der nicht floride entzündeten Appendix. Im Vergleich mit diesen Gewebeproben war bei florider Appendizitis die DMBT1 mRNA etwa dreimal stärker im Deckepithel exprimiert. Dieser Befund korrelierte mit einer etwa doppelt so starken Anfärbbarkeit der Zellen für DMBT1 Protein $(\mathrm{p}<0,005)$. Immunhistochemisch war sezerniertes DMBT1 an der Oberfläche der Deckepithelien bei florider Entzündung etwa um den Faktor 2,8 vermehrt nachweisbar $(\mathrm{p}<\mathrm{0}, \mathrm{0o01})$. Die lokoregionäre DMBT1 Expression war besonders stark im Deckepithel neben erosivulzerösen Läsionen.

Diskussion: Das DMBT1 Protein verfügt über SRCR-Domänen, deren Anzahl interindividuell variiert und Bedeutung für die Bindung von kommensalen und pathogenen Bakterien hat. Verschiedene Experimente ergaben bereits Hinweise auf eine anti-inflammatorische DMBT1 Funktion im Darm. Am Beispiel der floriden Appendizitis konnte jetzt eine Koinzidenz von lokal begrenzter akuter Entzündung und verstärkter $D M B T_{1}$ Expression gezeigt werden. Eine Aggregation von Bakterien ist möglicherweise bei lokal begrenzten Entzündungen protektiv, da bakterielle Dissemination und Invasion vermindert und lokale antiinflammatorische Effekte ausgeübt werden könnten. Zur weiterführenden Einordnung der $D M B T_{1}$ Expression bei Appendizitis wäre eine molekulare Analyse der SRCR-Domänen denkbar.

Schlussfolgerung: Die floride Appendizitis, bei der es sich um eine lokal begrenzte intestinale Entzündung handelt, ist mit einer verstärkten Expression, Synthese und Sekretion von DMBT1 an der Epitheloberfläche assoziiert. Funktionell hat dieser Befund möglicherweise dahingehend Bedeutung, dass DMBT1 eine lokale Modulation der Pathogenabwehr und/oder Entzündungsreaktion bewirkt.

\section{DGKJ-PV-045}

VENÖSE THROMBEMBOLISCHE ERKRANKUNGEN IM LEBERSTROMGEBIET - INDIKATION ZUR THROMBOPHILIEDIAGNOSTIK UND ANTIKOAGULATION MIT NIEDERMOLEKULAREM HEPARIN - 3 FALLBERICHTE S. Schmidt' ${ }^{1}$, A. Nordwig ${ }^{1}$, W. Luck ${ }^{2}$, R. Knöfler ${ }^{3}$, N. Lorenz ${ }^{1}$, M. Kabus ${ }^{1}$ ${ }^{1}$ Städtisches Krankenhaus, ${ }^{2}$ Charite Kliniken f. Kinderheilkunde und Kinderchirugie, ${ }^{3}$ Universitätsklinikum Carl Gustav Carus Kinderklinik

Einleitung: Hyperkoagulabilität durch Thrombophilien und rheologische Störungen durch myelodysplastische Syndrome führen im Splanchnikusgebiet zur Thrombose.

Fallberichte: Fall 1: FG 35. SSW, sonographischer Zufallsbefund: Kalkschatten im Milzhilus, Pfortaderthrombose (PT) bei vermehrter arterieller Perfusion der Leber. Intravenöse Gabe von Enoxaparin (prophylaktische Dosierung, Anti-Xa-Spiegelkontrolle). Normalisierung der Leberdopplersonographie in 5 Tagen. Später kein Nachweis einer Thrombophilie.

Fall 2: 4 10/12-jähriges Mädchen mit ätiologisch unklarem primärem Budd-Chiari-Syndrom (BCS). Regredienz klinischer und sonografischer Befunde unter Enoxaparin (prophylaktische Dosierung). Bisher kein Nachweis einer Thrombophilie. Bei Persistenz der Erhöhung von LDH und Harnsäure ist ein myeloproliferatives Syndrom auszuschließen.

Fall 3: Zur Diagnose 1 7/12 Jahre altes Mädchen mit Hyperspleniesyndrom und Ösophagusvarizen III $^{\star}$ durch PT bei heterozygoter FaktorV-Leiden-Mutation. Eigenanamnese (Schwangerschaft, Geburt) unauffällig, Dauertherapie mit Enoxaparin (prophylaktische Dosis), Anlage mesentericoportaler Rex-Shunt. Bei progredienter Hypersplenie mit 4 Jahren Coilembolisation der A. lienalis. Aktuell Hypersplenie, keine Ösophagusvarizen.

Diskussion: PT und BCS sind dopplersonographischer Diagnostik in der Pädiatrie gut zugänglich. Eine Therapie mit niedermolekularem Heparin kann bei frischen Thrombosen zu einer Rekanalisierung sowohl bei PT als als auch bei BCS führen.

\section{DGKJ-PV-046}

Das Hyperferritinämie-Katarakt-Syndrom: ein nur scheinbar seltenes Krankheitsbild?

H. Cario', C. Meneksedag', J. Berken², H. Gabriel', E. Kohne ${ }^{1}$

'Universitätsklinik für Kinder- und Jugendmedizin, ${ }^{2}$ Kinder- und Jugend-

ärztliche Gemeinschaftspraxis, ${ }^{3}$ diagenos, Humangenetische Praxis

Hintergrund: Das Hyperferritinämie-Katarakt-Syndrom (HKS) ist eine seltene autosomal-dominante Erkrankung, die durch eine erhöhte Serumferritinkonzentration und das Auftreten von Katarakten meist zwischen dem 6. und 40. Lebensjahr gekennzeichnet ist, die nicht auf eine Eisenüberladung zurückzuführen ist. Ursächlich für das HKS sind Mutationen im „iron-response-element (IRE)“ des Ferritin-Leichtketten-Gens FTL. Die Diagnose ist leicht zu stellen, wenn an sie gedacht wird. Die Diagnosestellung ermöglicht die frühe Identifizierung anderer betroffener Familienmitglieder und deren rechtzeitige medizinische Betreuung.

Ziel: Erhöhung der Aufmerksamkeit für dieses Krankheitsbild durch die Darstellung typischer Fälle und betroffener Familien.

Falldarstellung: In den Jahren 2005-2010 wurde in der Klinik bei drei Indexpatienten die Diagnose gestellt, darunter zwei Patienten deutscher sowie eine Patientin ukrainischer Herkunft. Die Anamnesen und die nachfolgenden Untersuchungen ergaben in den Familien insgesamt 18 weitere betroffene Familienangehörige (Familie 1: 4 Patienten in 3 Generationen, Familie 2: 5 Patienten in 3 Generationen, Familie 3: 12 Patienten in 5 Generationen). Bei vier Patienten wurde in Kenntnis der Diagnose der Indexpatienten durch Familienuntersuchungen eine beginnende Katarakt frühzeitig diagnostiziert. Die klinische Ausprägung der Katarakt war in Bezug auf das Manifestationsalter und die Schwere der Katarakt innerhalb der jeweiligen Familien variabel. Bei allen Patienten erfolgte die Bestimmung des Serumferritin im Rahmen der Abklärung einer Bauchschmerzsymptomatik. In allen Fällen gab es bekannte Kataraktpatienten in der Familie, bei denen zuvor jedoch keine Untersuchung des Serumferritin erfolgt war. Bei einer Indexpatientin war sechs Monate vor Diagnosestellung des HKS eine beginnende Katarakt, die als ,Cataracta congenita' eingestuft wurde, festgestellt worden. Bei einer anderen Indexpatientin gab es in der initialen Untersuchung zusätzlich zur Hyperferritinämie eine erhöhte Transferrinsättigung, so dass differenzialdiagnostisch zunächst auch an eine juvenile Hämochromatose gedacht werden musste. Die Transferrinsättigung normalisierte sich im Verlauf. Bei den Indexpatienten der Familien 1 und 2 wurde eine bekannte Mutation in der hoch konservierten „loop“-Region des IRE-Elements des FTL-Gens diagnostiziert $(\mathrm{IRE}+4 \mathrm{O} A>\mathrm{G})$, beim dritten Indexpatienten stehen die Ergebnisse der molekulargenetischen Untersuchung aus.

Schlussfolgerung: Das Hyperferritinämie-Katarakt-Syndrom ist eine seltene, möglicherweise in ihrer Häufigkeit aber unterschätzte Erkrankung. Die Familienanamnesen der hier vorgestellten Patienten belegen, dass in mehreren Fällen eine isolierte Diagnose einer Katarakt ohne weitergehende Überlegungen und diagnostische Maßnahmen gestellt wurde. Umgekehrt können bei ungeklärter, nicht reaktiv bedingter Ferritinerhöhung im Kindes- und Jugendalter aufwändige und eventuell gar invasive Untersuchungen zum Ausschluss anderer seltener Ursachen vermieden werden, wenn früh an die Diagnose gedacht wird. Anschließende Familienuntersuchungen ermöglichen die frühzeitige Identifizierung anderer erkrankter Angehöriger und deren adäquate Betreuung.

\section{DGKJ-PV-047}

Weniger Antibiotika, mehr Bifidobakterien im Stuhl und seltener Durchfälle unter oraler Prebiotikagabe bei langzeitig parenteral ernährten Kindern und Jugendlichen

J. Heller, M. Krawinkel

Zentrum für Kinderheilkunde der Justus-v.-Liebig-Universität

Kinder und Jugendliche unter langzeitiger parenteraler Ernährung weisen häufig eine bakterielle Fehlbesiedlung des Darms auf. Ziel der Studie 
war es, die Darmflora zu modulieren, die Barrierefunktion der Mukosa zu stärken und so mögliche enterogene Infektionen zu verhindern. Studie: 19 parenteral ernährte Kinder und Jugendliche (9 männl.,10 weibl.) im Alter von 1,1 bis 13,1 Jahren (Mittel 5,3 Jahre) aus ganz Deutschland nahmen teil. Einschlusskriterien waren Kurzdarmsyndrom und enterale Transportstörungen. Unterschiedlich waren die verbliebene Darmlänge und die Infusionen. Die Studie wurde als cross-over-study, placebokontrolliert und doppelblind durchgeführt. Als Prebiotika wurde ein Gemisch aus spezifischen kurzkettigen Galakto-, langkettigen Fruktound sauren Pektin-Oligosacchariden (Danone Research - Centre for Specialised Nutrition, Friedrichsdorf) eingesetzt. Als Placebo wurde in gleicher Menge und Verpackung Maltodextrin gegeben. Nach einer Randomisierungsliste nahmen die Teilnehmer jeweils 6 Monate täglich das Prebiotikagemisch und 6 Monate Maltodextrin zu sich. Dazwischen lag eine mindestens 6-wöchige Auswaschphase. Nach jeweils 3 Monaten wurden Blut- und Stuhlproben genommen und ein Fragebogen von den Eltern ausgefüllt. Methoden: Die Datenerhebung erfolgte per Fragebogen. Blutproben entnahm der betreuende Arzt. Stuhlproben wurden von den Eltern auf Trockeneis eingesandt und mittels PCR und FISH auf die Zusammensetzung der Bakterienflora sowie mit GCMS auf Laktat und kurzkettige Fettsäuren untersucht. Fragebögen und Ergebnisse aus Blut- und Stuhluntersuchungen wurden mit SPSS ausgewertet. Die Entblindung der Untersucher erfolgte erst nach Abschluss der gesamten Datenerhebung. Ergebnisse: 13 Patienten beendeten die Studie. Die Analysen zeigen, dass unter Einnahme der Prebiotika signifikant seltener Antibiotika gegeben wurden $(p<0,05)$. Weiterhin fand sich eine Tendenz zu weniger Fieberepisoden sowie seltenerem Auftreten von Übelkeit und Erbrechen, und es wurden häufiger Diarrhoe-freie Zeiträume berichtet. Der mittlere Stuhl-pH war unter Oligosaccharid-Gabe niedriger als unter Maltodextrin und im Stuhl fanden sich mehr Bifidobakterien $(\mathrm{p}<0,05)$, sowie weniger Bakterien der Gruppe Bacteroides, E. coli, Shigellen, Salmonellen, Klebsiellen und Clostridien. D-Laktat im Stuhl war unter Prebiotikagabe erhöht $(\mathrm{p}<0,05)$, ohne daß von D-Laktatazidosen berichtet wurde. Bei anderen Fettsäuren im Stuhl gab es keine signifikanten Unterschiede. Im Trend wurde mehr Acetat und L-Laktat, sowie weniger Propionat, Iso-Butyrat, Butyrat, Iso-Valerianat und Valerianat unter Prebiotikagabe gefunden. In der Studie wurde erstmals unter doppelblind-Vorgehen ein signifikanter Effekt von Prebiotika bei Kindern und Jugendlichen unter langzeitiger parenteraler Ernährung nachgewiesen.

\section{DGKJ-PV-048}

Antikörper gegen deamidierte Gliadinpeptide und Transglutaminase: Vergleich von 4 kommerziell erhältlichen Testkits für Diagnostik und Verlauf der Zöliakie von Kindern und Jugendlichen

P. Bufler, G. Heilig, G. Ossiander, F. Freudenberg, V. Grote, S. Koletzko

Klinikum der Universität München

Hintergrund: IgA- und IgG-Antikörper gegen deamidierte, synthetische Gliadinpeptide wurden kürzlich als valide Parameter in der Diagnostik der Zöliakie beschrieben. Antikörper gegen deamidierte Gliadinpeptide sind möglichweise besser für das Monitoring einer glutenfreien Diät geeignet, da sie direkt gegen das auslösende Antigen gerichtet sind. Wir untersuchten deshalb retrospektiv die Antikörper gegen deamidierte Gliadinpeptide in Seren von Kindern mit Zöliakie zum Zeitpunkt der Diagnosestellung und im Verlauf unter glutenfreier Diät. Es wurden 4 kommerziell erhältliche Testkits gegen TransglutaminaseIgA, deamidierte Gliadinpeptid-IgA und -IgG getestet.

Methoden: Es wurden insgesamt 392 Seren von Kindern mit Zöliakie ( $\mathrm{n}=90, \mathrm{w}: \mathrm{m}$ 1,3: 1) zum Zeitpunkt der Diagnosestellung $(\mathrm{n}=57)$ und im Verlauf unter Gluten-freier Diät untersucht. Das mediane Alter bei Diagnosestellung war 5,9 Jahre (25.-75. Perz. 3,4 - 9,0). Als Kontrollen wurden Seren von Kindern untersucht, die bei V. a. GÖRK oder CED endoskopiert wurden und eine unauffällige Dünndarmhistologie aufwiesen ( $\mathrm{n}=97, \mathrm{w}: \mathrm{m}$ 1: 1,1). Die Diagnose wurde bei allen Patienten durch Histologie der Dünndarmschleimhaut gesichert (MARSH IIIa, b). Ausgeschlossen wurden Patienten mit IgA-Mangel. Die Seren wur- den bei $-20^{\circ} \mathrm{C}$ gelagert und geblinded analysiert. Es wurden Testkits der Firmen TheBindingSite, Euroimmun, Phadia und Inova eingesetzt.

Ergebnisse: Die beste Sensitivität und Spezifität bei Erstdiagnose zeigten in unserer Kohorte die Transglutaminase-IgA (Sensitivität 100\% (alle Testkits), Spezifität 98-99\%). Die Titerhöhe der Testkits der verschiedenen Firmen korreliert hochsignifikant (o,96-0,98). Die Sensitivität und Spezifität der deamidierten Gliadinpeptid-IgG liegt bei 91-100\% bzw. 96-100\%, die Gliadinpeptid-IgA liegen mit 69-95\% bzw. $95-100 \%$ vor allem in der Sensitivität deutlich schlechter. Im Verlauf unter glutenfreier Diät normalisierten sich zuerst die GliadinpeptidIgA vor Gliadinpeptid-IgG und Transglutaminase-IgA. Bei Kindern mit Diätfehlern zeigten bei allen Testkits zunächst die Transglutaminase-IgA einen positiven Titeranstieg, wobei hier signifikante Unterschiede zwischen den einzelnen Herstellern bestehen.

Diskussion: Bei der serologischen Zöliakiediagnostik sind die Transglutaminase-IgA den Antikörpern gegen deamidierte Gliadinpeptide überlegen, wobei die Gliadinpeptid-IgG nur gering unterlegen sind. Anders als postuliert zeigen die Transglutaminase-IgA auch bei Diätfehlern ein rascheres Ansprechen, wobei die Gliadinpeptid-IgA unter glutenfreier Diät am schnellsten unter den Grenzwert abfallen.

\section{DGKJ-PV-049}

\section{Eosinophile Gastroenteritis oder doch M. Crohn?}

A. Thürigen ', A. Nordwig' ', S. Schmidt' ', B. Zuber ${ }^{2}$, T. Hellmich', M. Kabus ${ }^{1}$ 'Städtisches Krankenhaus Dresden-Neustadt, ${ }^{2}$ Gemeinschaftspraxis für Pathologie

Hintergrund: Die eosinophile Gastroenteritis ist eine seltene und heterogene Erkrankung, die durch eine eosinophile Entzündung des Darmes gekennzeichnet ist. Eine enge Assoziation besteht sowohl zu IgEals auch zu nicht-IgE-vermittelten Nahrungsmittelallergien und begleitenden anderen allergischen Erkrankungen. Die Abgrenzung zu einer beginnenden chronisch entzündlichen Darmerkrankung gestaltet sich z. T. schwierig.

Kasuistik: 13 3/12 Jahre altes Mädchen, Gewicht: $39 \mathrm{~kg}$ (P 7), Länge $162,5 \mathrm{~cm}$ (P 57); seit wenigen Tagen vor Aufnahme krampfartige Bauchschmerzen, rezidivierendes Erbrechen, Nahrungsverweigerung. Eigenanamnese: leichte atopische Dermatitis.

Befunde: Leukozyten 27,3 Gpt/l, CrP 114,5 mg/l, BSG 35/h, ALAT 1,04 $\mu \mathrm{kat} / \mathrm{s}^{\star} \mathrm{l}$, GGT 5,02 $\mu \mathrm{kat} / \mathrm{s}^{\star}$ l; Calprotectin $1045 \mu \mathrm{g} / \mathrm{g}$ Stuhl; keine IgEvermittelte Sensibilisierung gegen Nahrungsmittelallergene.

Gastroskopie: Corpus und Antrum mit z. T. flächenhaften fibrinbelegten Ulzera, Bulbus und Duodenum descendens entzündlich verschwollen, gerötet, vulnerabel; Histologie: im Schleimhautstroma des Magens und Duodenums ausgeprägte Infiltration mit eosinophilen Granulozyten, Helicobacter pylori negativ. Koloskopie: verdickte Bauhin-Klappe, sonst regelrecht; Histologie: dichte Infiltrate eosinophiler Granulozyten im Bereich der Bauhin-Klappe, keine Hinweise für CED.

Verlauf: Prednisolontherapie in absteigender Dosierung über 10 Wochen, Esomeprazol und kuhmilchfreie Ernährung. Darunter bis auf einmalige kurze (zwei Tage) Bauchschmerzepisode vier Monate nach Diagnosestellung klinische Beschwerdefreiheit sowie Normalisierung der Entzündungsparamter. Eine Kontrolle der Gastroskopie und Koloskopie sechs Monate nach Diagnosestellung zeigte makroskopisch eine geringgradige akute Gastritis, histologisch unauffällige Befunde.

Diskussion: Trotz histologisch eindeutigen Hinweisen für eine eosinophile Gastroenteritis entschieden wir uns bei Magenulcera und möglicher Leberbeteiligung unter dem Vd. auf M. Crohn zunächst zu einer Prednisolonmonotherapie. Der bisherige Verlauf mit (weitgehender) Beschwerdefreiheit und unauffälliger Kontrollendoskopie unter kuhmilchfreier Ernährung spricht für eine eosinophile Gastroenteritis. Nur der langfristige Verlauf wird die Differentialdiagnose M. Crohn oder eosinophile Gastroenteritis klären. Ein Auslassversuch der kuhmilchfreien Diät war bisher nicht erfolgt. 
DGKJ-PV-050

Exsudative Enteropathie bei kongenitalem Lymphödem-/Lymphangiektasiesyndrom (Hennekam-Syndrom)

J. Johne, J. Scharf, H. Kosmehl, A. Sauerbrey

HELIOS Klinikum Erfurt GmbH

Einleitung: Vorstellung einer 10-jährigen Patientin mit angeborener intestinaler Lymphangiektasie, sowie einseitigem Lymphödem. Klinisch imponierten ein Schwellung der rechten Gesichtshälfte, ein ausladendes Abdomen, eine Schwellung des rechten Beines, sowie ein weiter Augenabstand und leichter Epikanthus. Im Kleinkindalter insbesondere im Rahmen von Infekten wiederholt Ausbildung von Chylaskos mit wiederholter Punktionspflichtigkeit. Akute stationäre Aufnahme mit schwer beherrschbarer tetanischer Krise bei Hypokalzämie. Methoden: Nach Anamnese und klinischer Untersuchung folgten Laboruntersuchung, Sonographie, EKG, Echokardiographie, EEG, endoskopische Untersuchungen und Osteodensitometrie.

Ergebnisse: In der Laboruntersuchung ausgeprägte Hypokalzämie, Hypoalbuminämie, Hypomagnesämie und Hypothyreose. Unter Sedierung und Infusionstherapie mit i. v.-Substitution vom Kalzium rasche Besserung der Symptome. Nach Umstellung auf orale Gabe von Kalzium und Magnesium, langsame Stabilisierung der Kalzium- und Magnesiumwerte.

Bei bekannter kongenitaler Lymphangiektasie mit intestinalen Lymphödemen und mehrmals täglichen voluminös-breiigen Stühlen Erweiterung der Diagnostik. Es zeigte passend zu einer exsudativen Enteropathie mit Resorptionsstörung zusätzlich ein Mangel an fettlöslichen Vitaminen (A, D, E und K), eine Erniedrigung der Immunglobuline, sowie eine Verminderung der T-Helfer-Zellen. Aufgrund des Vitamin-D-Mangels und der Hypokalzämie sekundärer Hyperparathyreoidismus, Knochendichte im unteren Normbereich. In den endoskopischen Untersuchungen imponierte eine massive auf den Dünndarm beschränkte Schleimhautschwellung mit weißlichen Auflagerungen. Histologisch zeigte sich eine deutliche Lymphgefäßerweiterung.

Schlussfolgerung: Die Befunde weisen auf ein Hennekam-Syndrom (kongenitales Lymphödem-Lymphangiektasie- Syndrom) mit exsudativer Enteropathie hin. Dieses wurde erstmals 1989 beschrieben, wird autosomal-rezessiv vererbt und ist eine seltene Ursache einer exsudativen Enteropathie. Kennzeichnend sind Lymphödeme, eine intestinale Lymphangiektasie, faziale Dysmorphien, sowie geistige Retardierung unterschiedlichen Schweregrades. Die Ätiologie ist bislang noch ungeklärt, die Prognose je nach Ausprägung variabel. Die Diagnosesicherung erfolgt histologisch. Therapeutisch stehen eine symptomatische Therapie mit proteinreicher Kost, Nahrungsanreichung mit mittelkettigen Triglyceriden, Substitution der fehlenden Elektrolyte und Vitamine, sowie gegebenenfalls chirurgische Interventionen im Vordergrund.

\section{DGKJ-PV-051}

Kongenitaler Laktase-Mangel - erste genetische Diagnose in Mitteleuropa

W. Fazeli', S. Kaczmarek2 ${ }^{2}$ M. Kirschstein ${ }^{2}$, R. Santer ${ }^{1}$

'Univ.-Kinderklinik Eppendorf, ${ }^{2}$ Allgem. Krankenhaus Kinderkrankenhaus

Wir beschreiben einen Säugling konsanguiner türkisch-stämmiger Eltern, der im Alter von 17 Lebenstagen mit hypertoner Dehydratation und metabolischer Azidose stationär aufgenommen wurde. Er hatte unter Muttermilch und Pre-Nahrung seit Geburt bis zu 15 wässrige Stühle pro Tag gehabt. Zum Aufnahmezeitpunkt lag das Körpergewicht $14 \%$ unter dem Geburtsgewicht. Unter Nahrungskarenz normalisierte sich das Stuhlverhalten, und unter intravenöser Rehydrierung besserte sich der Allgemeinzustand. Sonographisch fiel eine Nephrokalzinose bei nachgewiesener Hyperkalzämie und -urie auf.

Bei deutlichem Ansprechen auf eine glukose-, galaktose- und laktosefreie Ernährung bestand zunächst der Verdacht auf eine Glukose-Galaktose-Malabsorbtion, der molekulargenetisch jedoch nicht bestätigt werden konnte; auch klinisch zeigte sich, dass die Zufuhr von Maltod- extrin gut vertragen wurde. Die Zufuhr von Laktose hingegen provozierte wässrige Durchfälle, sodass der Verdacht auf einen kongenitalen Laktase-Mangel bestand. Im Laktase-Phlorizin-Hydrolase (LCT) -Gen zeigte sich die bisher nicht beschriebene, in homozygoter Form vorliegende 1-bp-Deletion c. 3448delT in exon 8, aus der sich eine Verschiebung des Leserahmens und eine vorzeitige Beendigung der Translation ableitet (p. S115oPfsX19).

Bis dato sind lediglich neun verschiedene Mutationen im LCT-Gen als Ursache für einen kongenitalen Laktasemangel identifiziert. Neben den in Finnland relativ häufig beschriebenen Fällen sind erst vor kurzem die ersten beiden Fälle eines kongenitalen Laktasemangels ausserhalb Finnlands molekulargenetisch diagnostiziert worden. Unser Patient ist somit erst der dritte Fall eines genetisch nachgewiesenen kongenitalen Laktase-mangels außerhalb Finnlands. Die in der Vergangenheit erforderliche intestinale Biopsieentnahme zur Bestimmung der Laktase-Aktivität nach Dahlquist war somit überflüssig. Der Patient zeigte unter laktose-freier Ernährung unauffällige Stühle, gutes Gedeihen und eine altersentsprechende psychomotorische Entwicklung.

Unser Fall zeigt, (1) dass, trotz der Seltenheit der Krankheit, bei Neugeborenen mit osmotischer Diarrhoe unter Laktose-Zufuhr an einen kongenitalen Laktasemangel gedacht werden muss, dass (2) eine zuverlässige Diagnose des kongenitalen Laktasemangels mit molekulargenetischen Methoden möglich ist und dass daher (3) invasive Massnahmen zur Diagnosestellung der Vergangenheit angehören sollten.

\section{Hämatologie und Onkologie II}

\section{DGKJ-PV-052}

\section{Arteria cerebri media Infarkt bei Hereditärer Sphärozytose}

M. Olivieri, A. Kraxner, M. Kappler, U. Graubner, C. Bidlingmaier, K. Kurnik Dr. von Haunersches Kinderspital, Ludwig Maximilians Universität München

Einleitung: Hereditäre Sphärozytose (HS) ist die häufigste Ursache angeborener hämolytischer Anämien in Mitteleuropa. Bedingt durch erythrozytäre Membrandefekte mit Verminderung der Spektrin-, Ankyrin- oder Bande 3 Proteinkonzentration kommt es zu einem Elastizitätsverlust und verminderter mechanischer Resistenz mit vermehrtem Abbau von Erythrozyten in der Milz. Zerebrale Infarkte oder Thrombosen bei HS im Kindesalter sind nur in wenigen Einzelfallberichten (3 Patienten) beschrieben.

Fallbericht: Wir berichten über ein 3-jähriges Mädchen mit bekannter Sphärozytose, das im Rahmen einer pulmonalen Infektion eine hämolytische Krise entwickelte. Bei Hb Abfall auf 5,7g/dl trat eine inkomplette Hemiparese links auf. CCT und MRT Untersuchung zeigten rechtshemisphärische hypodense Areale vereinbar mit multiplen Infarktarealen sowie eine leichte Hirnatrophie rechts. Die konventionelle Angiographie (DSA) zeigte eine 60\% Stenose der A. carotis interna rechts, die Dopplersonographie deutlich verminderte Flußgeschwindigkeiten in der A. carotis interna und A. cerebri media rechts. Kein Nachweis einer Emboliequelle. Thrombozytenzahl in der Norm, CRP und D-Dimere minimal erhöht, kein Nachweis einer hereditären Thrombophilie. Es erfolgte eine primäre Antikoagulation mit unfraktioniertem Heparin i. v. (Ziel PTT 40-50s), sowie anschließend Umstellung auf niedermolekulares Heparin (NMH) s. c. (Clexane $1,4 \mathrm{mg} / \mathrm{kgKG} / \mathrm{d}$, Ziel Anti-Xa Spiegel o,6-o,8IU/ml). Bei stabilen Anti-Xa Spiegeln im oberen Zielbereich zeigte sich eine deutliche Besserung der Symptomatik, allerdings trat im Verlauf, bei stabilen $\mathrm{Hb}$-Werten, eine erneute Verschlechterung der Hemiparese auf, die sich innerhalb weniger Stunden, im Sinne einer transitorisch ischämischen Attacke (TIA), wieder verbesserte. Es erfolgte eine zusätzliche Antikoagulation mit Acetylsalicylsäure $(3,3 \mathrm{mg} / \mathrm{kgKG} / \mathrm{d})$ und leichte Reduktion der NMH Dosis (Ziel Anti-Xa Spiegel o,4-0,6IU/ml). Bereits bei Aufnahme erfolgten die Gabe eines Erythrozytenkonzentrats, sowie eine antibiotische Behandlung mit Cefotaxim und Azithromycin. 
Schlussfolgerung: In der Literatur sind Infarkte und Thrombosen im Kindesalter bei HS nur in Einzelfällen beschrieben. Infarkte treten vor allem im Erwachsenenalter nach Splenektomie aufgrund der Thrombozytose und Hyperlipidämie mit Arteriosklerose auf. Ein assoziiertes Moyamoya Syndrom ist in der Literatur bei 2 Kindern beschrieben. Eine einseitige Frühform eines solchen Moyamoya Syndroms kann zurzeit nicht mit Sicherheit ausgeschlossen werden. Aufgrund der zusätzlichen leichten Hirnatrophie gehen wir aber von einer angeborenen Carotisstenose aus. Ob die massive Hämolyse (mit möglicher Freisetzung von thrombogenen Substanzen) mit $\mathrm{Hb}$ - Abfall bei Infekt oder der Infekt alleine, auf dem Boden der vorliegenden Stenose ausreichend für den Infarkt war, bleibt ungeklärt.

\section{DGKJ-PV-053}

Fallvorstellung: Periphere Facialisparese als einziges Leitsymptom einer Akuten Leukämie

B. Krutz', M. Herr', J. Barleben'1, K. Seeger², A. von Moers ${ }^{1}$

'DRK Kliniken Westend, ${ }^{2}$ Charité Campus Virchow-Klinikum

Anamnese: Ein 6-jähriger Patient wurde zur Abklärung einer akut aufgetretenen Facialisparese stationär eingewiesen. Anamnestisch hatte er 2 Tage zuvor erhöhte Temperatur und Schmerzen hinter dem rechten Ohr und in der rechten Schulter gehabt. 2 Wochen zuvor hatte eine Zahnbehandlung bei rezidivierenden Schmerzen im rechten Unterkiefer stattgefunden. Die weitere Eigen- und die Familienanamnese waren unauffällig.

Befund: Wir sahen einen 6 Jahre alten Jungen in gutem Allgemeinzustand. Es fiel eine verwaschene Sprache auf sowie eine Gesichtsasymmetrie mit inkomplettem Lidschluss im Sinne einer Facialisparese rechts. Die Muskeleingereflexe waren an allen Extremitäten auffallend schwach auslösbar. Der übrige pädiatrisch-internistische und neurologische Status waren unauffällig.

Diagnostik: Nach der stationären Aufnahme erfolgten zur Abklärung einer Borrelieninfektion eine Blutentnahme und Lumbalpunktion. Liquordiagnostik und Borrelienserologie waren ohne pathologischen Befund.

Im Differenzialblutbild fanden sich jedoch bei insgesamt 15,8 Leukozyten/nl 23\% Lymphozyten und 10\% blastenähnliche Zellen. Die daraufhin bestimmte LDH (1424 U/l) und Harnsäure (9,7 mg/dl) waren deutlich erhöht. Ein Kontrollblutbild, das an das pädiatrisch-onkologische Labor der Charité geschickt wurde, bestätigte den Befund. Wir führten noch am selben Tag ein cMRT durch, das eine am ehesten mit einem Lymphknoten vereinbare Raumforderung von ca. 1X1x3 cm im Bereich des Proc. stylomastoideus rechts mit Verlagerung der A. carotis interna nach dorsal zeigte. Der Patient wurde zur weiteren Diagnostik und Therapie zügig in die Klinik für Pädiatrie mit Schwerpunkt Onkologie/Hämatologie der Charité verlegt. Dort wurde die Diagnose einer akuten B-Zell-Leukämie bestätigt.

Diskussion: Die erworbene periphere Facialisparese ist ein häufiges Krankheitsbild im Kindes- und Jugendalter und zu 50-60\% idiopathisch. Bei den symptomatischen Facialisparesen stehen an erster Stelle infektiöse Ursachen, am häufigsten die Neuroborreliose. Sie kann auch als Begleitsymptom neoplastischer Erkrankungen auftreten, wie z. B. bei Akustikusneurinomen, Parotismalignomen und Meningeomen. Als Symptom einer Leukämie sind in der Literatur nur Einzelfälle berichtet. Im Fall unseres Patienten war die periphere Facialisparese bis auf leichte Schmerzen der Schulter und hinter dem Ohr das einzige Symptom einer akuten Leukämie. Als Ursache kommen eine Kompression des Nerven durch Lymphknotenschwellung, bzw. durch Infiltration des umliegenden Gewebes, eine Meningeosis carcinomatosa oder eine Infiltration des Nerven mit Leukämiezellen in Frage. Für die genauere Abklärung bedarf es unter anderem eines MRT der Halsweichteile und einer Kontrastmitteluntersuchung der Meningen. Eine Meningeosis carcinomatosa konnte bei dem genannten Patienten nicht nachgewiesen werden.

\section{DGKJ-PV-054}

Immature Platelet Fraction: ein einfacher neuer Parameter in der Differentialdiagnose von Thrombozytopenien

G. Strauß, C. Vollert, G. Gaedicke, H. Schulze

Charite Kliniken $\mathrm{f}$. Kinderheilkunde und Kinderchirugie

Einleitung: Bisher werden bei der Erstellung eines Blutbildes in einem automatisierten Blutbildgerät für die Thrombozyten in der Regel nur nominelle Werte ermittelt. Gerade bei Thrombozytopenien unter 100. ooo $\mu \mathrm{l}$ ist es häufig nicht möglich zusätzliche Informationen über Thrombozytengröße und/oder Subpopulationen zu bekommen. Neue Blutbildgeräte sind inzwischen in der Lage weitere Informationen zu Thrombozyten zur Verfügung zu stellen. In dieser Studie evaluierten wir, ob die neuen Marker hilfreich in der Diagnostik von Thrombozytopenien sind.

Methode: Wir ermittelten Normwerte für Kinder für mean platelet volume (MPV), platelet distribution width (PDW), plateletcrit (PCT), platelet large cell ratio (P-LCR), relative immature platelet fraction (IPF), und absolute sIPF (IPF\#) und untersuchten 100 Kinder mit Thrombozytopenien.

Ergebnisse: Bei Patienten mit Thrombozytenproduktionsdefekten ermittelten wir niedrige Werte für IPF. Kinder mit Immunthrombocytopenie hatten ein deutlich erhöhtes IPF als Zeichen für einen vermehrten Plättchenturnover. Patienten mit chronischer ITP zeigten erhöhte IPF Werte, die über einen längeren Beobachtungszeitraum wenig schwankten. Überraschenderweise hatten Kinder mit einer akuten lymphoblastischen Leukämie ebenso erhöhte IPF Werte. Dies lässt vermuten, das die Thrombopoese auch in Abwesenheit von Progenitorzellen im Knochenmark

stimuliert is

t. Dabei ließen sich deutlich erhöhte Werte für IPF\# ermitteln.

Zusammenfassung: Unbestritten repräsentiert das IPF und das IPF\# die jungen Plättchen. Die beiden neuen Plättchenparameter sowohl der Prozentwert IPF als auch der Absolutwert IPF sind aus unserer Sicht ausgesprochen hilfreich in der Differentialdiagnose unterschiedlicher Thrombozytopenien.

\section{DGKJ-PV-056}

Über die Eignung der Schwartz-Formel zur Bestimmung der Kreatininclearance in der pädiatrischen Onkologie

I. Havermann, P. Eggert, A. Schrauder

Universitätskinderklinik

Hintergrund: Um den Aufwand einer Urinsammlung über 24 Stunden zur Bestimmung der Kreatininclearance zu umgehen, ist es in der Pädiatrie oft üblich, die glomeruläre Filtrationsrate (GFR) nach der Schwartz-Formel [GFR = k x Körpergröße / Plasmakreatininkonzenztration] abzuschätzen. Die Konstante k hängt vom Alter, Geschlecht und der Muskelmasse der Kinder ab. Eine Grundvoraussetzung ist hierbei, dass der Muskelstoffwechsel während den Untersuchungen konstant ist. Ob die Schwartz-Formel in der pädiatrischen Onkologie geeignet ist, wurde bisher nicht untersucht. Kritisch könnte dabei der Einsatz zytotoxischer Medikamente sein. Der vermehrte Muskelzelluntergang könnte zu erhöhten Plasmakreatininkonzentrationen führen, die GFR damit falsch niedrig bestimmt und die tatsächliche Nierenschädigung überschätzt werden. Die Chemotherapie würde daraufhin fälschlicherweise zu Lasten der Heilungschancen reduziert werden. Patienten und Methoden: Im Rahmen einer prospektiven klinischen Studie, erfolgte die Untersuchung eines pädiatrisch-onkologischen Patientenkollektivs im Gesamtverlauf einer Chemotherapie: $\mathrm{Zu}$ Beginn eines jeden Therapieblockes wurde mit Hilfe eines 24-StundenSammelurins die Kreatininclearance $(\mathrm{CCr} 24 \mathrm{~h})$ ermittelt und zugleich die GFR anhand der Schwartz-Formel (CCrschw) berechnet. Zudem wurde jeweils mit einer bioelektrischen Impedanzanalyse die Muskelmasse des Kindes, und somit ein eventueller Muskelzellverlust, ermittelt. Die Einteilung der Patienten in Gruppen erfolgte in Anlehnung an die Untersuchung von Schwartz et al[1] . 
Ergebnisse: Ein signifikanter Anstieg der Plasmakreatininkonzentration nach Chemotherapie zeigte sich nicht. Auch die Auswertung der Körperimpedanzanalyse ergab keinen Hinweis auf einen signifikanten Muskelzellzerfall. Vielmehr fand sich im Verlauf der Therapie eine Zunahme der Magermasse (gleichbedeutend mit der Muskelmasse). Im direkten Vergleich von CCrschw und CCr24h überschätzte die CCschw die tatsächliche CC24h in 90,5\%; bei zwei Patienten wurde eine pathologisch verminderte Kreatininclearance nicht durch die Schwartz-Formel demaskiert.

Diskussion: Die vorliegenden Ergebnisse widerlegen die These, dass die Schwartz-Formel durch einen zytotoxisch bedingten Zellzerfall die Nierenfunktion regelhaft unterschätzt und die Anwendbarkeit in der onkologischen Pädiatrie dadurch eingeschränkt ist. Jedoch spricht die Ungenauigkeit der mithilfe der Schwartz-Formel im Vergleich zu der durch Urinsammlung gemessenen Clearance (CC24h) gegen eine regelmäßige Verwendung dieser Methode zur Abschätzung der Nierenfunktion. Weiterhin ist daher an einer Kontrolle der Nierenleistung mittels 24-Stunden-Sammelurin zur Steuerung der cytotoxischen Therapie festzuhalten.

Schwartz et al., Pediatr. Clin. North. Am 1987. Jun; 34(3): 571-90

\section{DGKJ-PV-057}

Informationsvermittlung an pädiatrische Patienten und deren Angehörige: Einsatz von neuen Internettechnologien (Web2.0) für die ArztPatientenkommunikation

K. Sostmann', A. Schachinger ${ }^{2}$

'Charité - Universitätsmedizin Berlin, ${ }^{2} \mathrm{Humboldt}$ Universität

Einleitung: Das Internet entwickelt sich zunehmend zur Hauptinformationsquelle für chronisch kranke Patienten und deren Angehörige ${ }^{1}$. Neue Internet-Informationstechnologien, die unter dem Schlagwort Web 2. o und Social Software zusammen gefasst werden, ermöglichen einen leichteren Zugang der Patienten zu den Informationen ${ }^{2}$. Neu ist, dass mit der Einführung dieser Technologien die Kommunikation der Patienten untereinander verbessert wird und der Austausch über medizinisch relevante Daten zwischen Arzt und Patient und dessen Angehörigen kann erleichtert werden ${ }^{3}$.

Ziele: Im Rahmen einer Pilotstudie sollte überprüft werden, wie an ALL erkrankte Patienten verschiedener Altersgruppen und deren Angehörige in verschiedenen Stadien der Erkrankung für sie relevante medizinische Informationen zu ihrem Krankheitsbild suchen und verarbeiten. Aufgrund der erhobenen Daten soll ein Seminarkonzept für die Schulung von Patienten im Umgang mit medizinischen Informationen im Internet entwickelt werden.

Methodik: Im Rahmen der Präevaluation wurden 10 Familien bei Suche nach medizinischen Informationen im Internet beaufttragt. Ferner wurden Ihnen Aufgaben zur gezielten Suche in Bezug auf die akute lymphatischen Leukämie gestellt. Anschließend wurden Fokusgruppeninterviews durchgeführt und aufgrund der Ergebnisse ein Studieninstrument in Form eines Fragebogens entwickelt.

Ergebnisse: Es werden die Ergebnisse der Fokusgruppeninterviews vorgestellt, die zum Zeitpunkt der Einreichung des Abstrakts noch nicht abschließend vorlagen. Anhand dessen werden die Möglichkeiten für die Erstellung eines Fragebogens aufgezeigt und die daraus abgeleiteten Konsequenzen für die gezielte indikationsbezogenen Schulung von Patienten für die Nutzung des Internets zur Information über ihre Erkrankung dargestellt.

Diskussion: Die Nutzung des Internet durch Patienten, vor allem durch jüngere Patienten kann die therapeutischen Outcomes mit beeinflussen. Durch gezielte Vorbereitung der Patienten und deren Angehöriger auf die Nutzung des Internets können Fehlinformationen vermieden werden ${ }^{4}$. Das Vertrauen in der Arzt-Patienten-Beziehung kann gestärkt werden. Wichtig ist die Herstellung eines Informationsgleichgewichts zwischen Arzt und Patient ${ }^{5 .}$

1 Neverla, Irene: Wer krank ist geht ins Netz. Eine empirische Untersuchung zur Medien- und Internetnutzung im Krankheitsverlauf. Baden Baden: Nomos Verlag 2007
2 Schiffman, J. D., Csongradi, E., \& Suzuki, L. K. (2008). Internet use among adolescents and young adults (AYA) with cancer. Pediatric Blood \& Cancer, 51(3), 410-415.

3 Beale, I. L.,Kato, P. M., Marín-Bowling, V. M., Guthrie, N., Cole, S. W. (2007). Improvement in cancer-related knowledge following use of a psychoeducational video game for adolescents and young adults with cancer. Journal of Adolescent Health, 41, 263-270.

4 Bradlyn, A. S., Kato, P. M., Beale, I. L., \& Cole, S. W. (2004). Pediatric oncology professionals' perceptions of information needs of adolescent patients with cancer. Journal of Pediatric Oncology Nursing, 21(6), 335-342.

5 Salovey P, Williams-Piehota P, Mowad L, Moret ME, Edlund D, Andersen J. Bridging the digital divide by increasing computer and cancer literacy: community technology centers for head-start parents and families. J Health Commun. 2009 Apr-May;14(3): 228-45.

\section{DGKJ-PV-058}

Voll-automatische Quantifizierung der retikulierten Thrombozyten (immature platelet fraction) zur Differentialdiagnose und Verlaufskontrolle bei Thrombozytopenie

M. Cremer, H. Hammer, A. Weimann, C. Bührer, C. Dame

Universitätsklinikum Charité Med.Fakultät d.Humboldt-Univ.

Fragestellung: Die retikulierten Thrombozyten sind RNS-haltig und bilden das Analogon zur den Retikulozyten. Sie können als sogenannte immature platelet fraction (IPF) mittels Durchflusszytometrie in Blutanalyse-Automaten routinemäßig bestimmt werden. Die IPF ist geeignet, zwischen Thrombozytenverbrauch und -bildungsstörung zu unterscheiden. In der Pädiatrie sind vor allem Patienten mit hämatoonkologischen Krankheitsbildern sowie intensivpflichtige Patienten, insbesondere Neugeborene (NG), von einer Thrombozytopenie betroffen. Die IPF wurde daher in drei verschiedenen klinischen Situationen untersucht: 1) IPF zur Verlaufskontrolle bei thrombozytopenischen NG 2) IPF zur Differentialdiagnose bei neonataler early-onset Thrombozytopenie 3) IPF bei NG mit Sepsis und nekrotisierender Enterokolitis (NEC). Material und Methode: Blutbild und IPF wurden mit dem Blutanalyseautomaten XE-2100 (Fa. Sysmex, Japan) in jeweils $300 \mu \mathrm{l}$ EDTA-Blut bestimmt. Patienten: ad 1) unselektioniertes Kollektiv von NG, die auf der Intensivstation behandelt wurden. Ad 2) NG mit einer early-onset Thrombozytopenie auf Grund von intrauteriner Wachstumsretardierung oder bakterieller Infektion. Ad 3) NG mit mikrobiologisch bestätigter Sepsis oder NEC. Ergebnisse: Ad 1) Bei 612 NG wurden 1045 IPF/Thrombozyten-Werte gemessen. Ein Anstieg der IPF ging dem Anstieg der Thrombozyten voraus. Thrombozytopenische NG mit einer IPF $<8 \%$ zeigten ein 4,7 fach (Konfidenzintervall=1,9-11,8) erhöhtes Risiko für einen schweren Abfall der Thrombozytenzahl am folgenden Tag. Ad 2) 857 NG wurden untersucht. Unabhängig von der Ursache der Thrombozytopenie (Wachstumsretardierung oder Infektion), war IPF niedriger $(8,5 \pm 2,7 / \mathrm{nl})$ bei thrombozytopenischen $\mathrm{NG}(\mathrm{n}=682)$ als bei nicht-thrombozytopenischen NG $(9,5 \pm 3,6 / \mathrm{nl} ; \mathrm{p}<0,05)$. Ad 3$) 38$ NG (28 mit Sepsis, 10 mit NEC) wurden vor Beginn und im Verlauf der Erkrankung untersucht. Parallel zum Abfall der Thrombozyten im Verlauf der Erkrankung fiel die IPF in beiden Gruppen signifikant. Diskussion: Anhand von großen Patientenkollektiven konnte gezeigt werden, das IPF geeignet ist, den Verlauf bei thrombozytopenischen Patienten vorauszusagen und die Megakaryopoiese im peripheren Blut zu quantifizieren. Bei den unterschiedlichen Formen der neonatalen Thrombozytopenie liegt meist ein reduziertes IPF als Ausdruck einer verminderten Megakaryopoiese vor. Schlussfolgerung: Die Bestimmung der IPF sollte in die Routine integriert werden, um die Verlaufsbeobachtung und die Differentialdiagnose bei thrombozytopenischer Patienten zu optimieren. 
DGKJ-PV-059

Pneumocystis jirovecii Pneumonie nach Abschluss der chemotherapeutischen Behandlung eines Neuroblastoms bei einem 6 Monate alten Patienten

J. Opper, R. Huth, P. Gutjahr, S. Gehring

Universitätsmedizin Mainz

Hintergrund: Pneumocystis jirovecii - früher Pneumocystis carinii genannt - ist der Erreger einer interstitiellen Lungenentzündung. Bei Kindern und Jugendlichen mit bösartigen Erkrankungen ist diese eine der wichtigsten opportunistischen Infektionen. Ein hohes Erkrankungsrisiko und Morbidität hat zur Einführung einer Chemoprophylaxe bei Patienten, die eine Polychemotherapie erhalten, geführt. Seit mehr als zwei Jahrzehnten steht mit der Gabe von Trimethoprim/Sulfamethoxazol (TMP/SMX) eine bei krebskranken Kindern und Jugendlichen evaluierte, insgesamt gut verträgliche und effektive Chemoprophylaxe der PCP zur Verfügung. Empfohlen wird eine orale Gabe an drei aufeinander folgenden Tagen während der gesamten Behandlungsdauer.

Fallvorstellung: Wir berichten über einen Patienten, der im Alter von 2 Monaten mit Tachydyspnoe in unserer Klinik vorgestellt wurde. Sowohl die klinische Untersuchung als auch die Laborparameter ergaben keinen Hinweis für eine Infektion. Radiologisch zeigte sich eine Raumforderung thorakal. Die weitere Diagnostik erbrachte den Nachweis eines Neuroblastom ohne Hinweise auf eine Metastasierung. Wegen der ausgeprägten respiratorischen Symptomatik wurde nach Diagnosestellung und Staging mit einer sofortigen Polychemotherapie nach Protokoll NBo4 begonnen. Er erhielt 4 N4-Blöcke, die unter supportiven Maßnahmen gut vertragen wurde. 6 Wochen nach dem letzten Block stellte die Mutter den Patienten mit einer erneut aufgetretenen respiratorischen Symptomatik vor. In der klinischen Untersuchung war die Lunge seitengleich belüftet, keine Rasselgeräusche auskultierbar, jedoch intercostale Einziehungen sowie Nasenflügeln. Laborchemisch fanden sich bis auf einen erhöhten Wert für das C-reaktive Protein keine Hinweise auf eine Infektion. Das manuelle Blutbild zeigte eine gute Regeneration. Die Röntgen-Thorax-Aufnahme zeigte Veränderungen im Sinne einer interstitiellen Pneumonie. Im weiteren Verlauf verschlechterte sich der Zustand so, dass er auf unsere interdisziplinäre Intensivstation verlegt und im weiteren Verlauf intubiert und beatmet werden musste. In der Bronchiallavage ließen sich Pneumocystis jirovecii nachweisen. Unter der sofort begonnenen Therapie mit TMP/SMX kam es zu einer schnellen Besserung der respiratorischen Situation. Nach insgesamt 4-wöchigem stationärem Aufenthalt konnte der Patient mit einer für weitere 21 Tage gegebenen oralen Therapie mit TMP/SMX in sehr gutem AZ entlassen werden.

Schlussfolgerungen: Während die Chemoprophylaxe unter Therapie eine weit verbreitete Praxis ist, macht diese Kasuistik deutlich, dass es auch nach Abschluss der chemotherapeutischen Behandlung zu Infektionen mit Pneumocystis jirovecii kommen kann. Auf Grundlage dieser Fallvorstellung kann diskutiert werden, inwieweit und für wie lange eine Prophylaxe auch nach Beenden der Therapie bei gut regenerierender Hämatopoese gegeben werden sollte.

\section{DGKJ-PV-060}

c-CBLKeimbahnmutation mit Prädisposition zu juveniler myelomonozytärer Leukämie und Vaskulopathie

C. Niemeyer, I. Furlan, T. Gorr, C. Flotho

Universitäts - Kinderklinik

Die juvenile myelomonozytäre Leukämie (JMML) ist eine myeloproliferative Erkrankung des frühen Kindesalters, in deren Pathogenese eine Aktivierung des RAS-Signaltransduktionsweg durch erworbene und angeborene Mutationen eine wesentliche Rolle spielt: Bei ca. $60 \%$ aller Patienten können Mutationen in PTPN11, NRAS oder KRAS nachgewiesen werden, bei $11 \%$ der Kinder ist klinisch eine Neurofibromatose Typ 1 bekannt. Wir konnten kürzlich zeigen, dass weitere 10-15\% der Patienten in hämatopoetischen Zellen homozygote Missense Mutatio- nen in $c$ - $C B L$, einer $\mathrm{E}_{3}$ Ubiquitin-Ligase mit Adapterfunktion, aufweisen. Interessanterweise hatten alle Patienten eine heterozygote $c$-CBL Keimbahnmutation. Zum Phänotyp der autosomal dominant vererbten Entwicklungsstörung gehören (neben der JMML) Entwicklungsverzögerung, Kleinwuchs, Dysmorphien und Kryptorchismus. Einige der JMML Patienten mit $c$ - $C B L$ Mutation, die keine hämatopoetische Stammzelltransplantation erhielten, zeigten eine spontane Verbesserung der Myeloproliferation, entwickelten aber Symptome einer Vaskulitis größerer Gefäße mit Hochdruck, kardialen Veränderungen und Optikusatrophie. $C$-CBL verhält sich zumindest teilweise wie ein ist ein Tumorsuppressorgen, so entwickelte einer der Patienten auch einen Hirntumor. Zusammenfassend haben wir eine neue genetische Erkrankung bedingt durch $c$ - $C B L$ Keimbahnmutationen beschrieben, bei der eine Prädisposition für JMML und vermutlich andere Malignome vorliegt. In wie weit die sich einstellenden Gefäßveränderungen und andere Autoimmunerscheinungen auf einen zu postulierender Immundefekt zurück zu führen sind, muss der Gegenstand weiterer Untersuchungen sein.

\section{DGKJ-PV-061}

\section{Häufigkeit von Arzneimittelinteraktionen auf einer kinderonkologi-} schen Station

D. Schrey' ', A. Niemann'1, M. Trame², A. Henschel', N. Kontny'², J. Hövener², J. Boos'

'Westf. Wilhelms-Univ.- Kinderklinik, ${ }^{2}$ Institut für Pharmazeutische und Medizinische Chemie

Fragestellung: Polymedikation im Rahmen onkologischer Therapien ist die Regel. Ein bekanntes daraus resultierendes, aber schwer zu quantifizierendes Risiko sind Arzneimittelinteraktionen (IA) und deren klinische Bedeutung. Im Rahmen klinisch pharmakologischer Visiten wurden komplexe Arzneimittelkombinationen auf bekannte, zumindest theoretisch bedrohliche Interaktionen (IA) geprüft. Material und Methoden: Im Zeitraum von 11/2007 bis 04/2010 wurde einmal pro Woche eine klinisch pharmakologische Visite auf der kinderonkologischen Station angeboten. Individuell wurden bei insgesamt 97 Patienten Arzneimittelinteraktionenschecks durchgeführt und dokumentiert (Alter im Mittel 13 Jahre [12 Monate- 25 J], 58 m, 37 w, 2 nicht dokumentiert; stationäre Aufnahme auf Grund pädiatrisch onkologischer Erkrankungen). Dies geschah mit Hilfe der Interaktionsdatenbank Micromedex ${ }^{\bullet}$. Die potentiellen IA wurden nach ihrem Schweregrad in leicht, mittel und schwerwiegend eingeteilt und mit der Station diskutiert. Ergebnisse: $33 \%$ der Patienten erhielten $>4$ Medikamente zum Zeitpunkt der IA Checks. Es wurden insgesamt 175 einzelne IA Checks durchgeführt [Range: 1 IA/ Pat. - 9 IA/ Pat]. 93\% (163/175 IA) der überprüften Arzneimittelkombinationen hatten ein bekanntes, potentielles IA Risiko. Dies wurde in 51\% (84/163) als schwerwiegend, in $43 \%(70 / 163)$ als mittelschwer und in 6\% (9/163) als leicht eingestuft. Im Rahmen der potentiell als schwerwiegend eingestuften IA-Risiken waren am häufigsten P450-inhibierende Azolantimykotika (u. a. Voriconazol) beteiligt. Weiterhin waren IA-Konstellationen mit Aminoglykosiden (Gentamicin) und Schleifendiuretika (Furosemid) verbunden. Der häufigste Mechanismus der IA lag in veränderten Plasmakonzentrationen von Arzneistoffen mit erhöhtem Risiko. Diskussion: 48\% (84/175) aller durchgeführten IA Checks wurden von der benutzten Datenbank als zumindest theoretisch schwerwiegende Interaktion eingestuft. Auch wenn sich die dokumentierten, risikobelasteten Arzneimittelkombinationen nicht immer vermeiden lassen und die beschriebene IA auch im beobachteten Kollektiv kaum klinische Konsequenz hatten, so zeigt diese retrospektive Auswertung, dass bei zunehmender Anzahl der Medikamente erwartungsgemäß das Risikopotential durch unerwünschte IA steigt. Schlussfolgerung: Polymedikation ist auch in der Pädiatrie häufig. Risiken in diesem Zusammenhang wie Arzneimittelinteraktionen sind in ihrer Inzidenz nicht zu unterschätzen und sollten durch IA-Abfragen zumindest bewußt, möglichst jedoch vermieden werden. 
DGKJ-PV-062

Kasuistik: Zwei Monate altes Mädchen mit paroxysmal und strumpfförmig geröteten Füßen

M. Herr, A. von Moers

DRK Kliniken Westend

Anamnese: Ein 2 Monate altes Mädchen wurde in unserer Rettungsstelle vorgestellt, da es am gleichen Tag viermal plötzliche Unruhezustände mit Schreien und vorübergehend eine strumpfförmige Rötung und Überwärmung beider Füße gehabt habe. Die Beine hätten dabei schwach gewirkt. Seit der U2 Spreizhose bei Hüftdysplasie, ansonsten bisher keine Auffälligkeiten. Unkomplizierte Schwangerschaft und Geburt nach 38 SSW.

Befund: Wir sahen ein unruhiges Kind mit hochroten Füßen. Wenig später waren die Füße nicht mehr gerötet, der Muskeltonus aber in beiden Beinen vermindert, der PSR re. kaum auslösbar, li. lebhaft. Übriger pädiatrischer und neurologischer Status unauffällig. Nach weiteren $12 \mathrm{~h}$ keine neurologischen Auffälligkeiten mehr und normaler Muskeltonus. Kein Fieber, Blutdruck und Herzfrequenz normal, gutes Trinkverhalten.

Unter stationärer Beobachtung trat bald erneut eine strumpfförmig scharf begrenzte Rötung der Füße auf. Das Kind war während dieser Episode sehr unruhig und wirkte schmerzgeplagt. Währenddessen deutlich verminderte Motorik der Beine. Hyperreflexie und deutlich erhöhter Blutdruck an beiden Beinen. Der Zustand sistierte nach ca. $30 \mathrm{~min}$. Im weiteren Verlauf wieder unauffällige neurologische Untersuchung.

Differentialdiagnostisches Vorgehen: 1. Infektion: Klinisch und laborchemisch kein Anhalt

2. Einwirkung von Katecholaminen: Bestimmung VMA, HVA im Urin Sonographie: Abdomen (insb. Nebennieren) und spinal/paraspinal unauffällig

3. Andere onkologische Ursache: Diff.-BB, LDH, Harnsäure, AP unauffällig.

Abnahme Tumormarker: AFP, ß-HCG

4 Neurologisch: Unauffälliges EEG und Schädelsonogramm

NLG: sensibel bei Unruhe nicht möglich, keine axonale oder

demyelinisierende motorische Polyneuropathie

SSEP: N. tibialis: reproduzierbare spinale Reizantworten, zentral keine Reizantwort: Bei intermittierender Parese der Beine und auffälligen SSEP Durchführung eines spinalen MRT. Hier zeigte sich ein sanduhrförmiger, paravertebral und intraspinal gelegener Tumor mit kritischer Kompression des Rückenmarks. VMA und HVA im Urin waren deutlich erhöht. Daraufhin Notfallverlegung in die Abteilung für päd. Neurochirurgie der Charité zur Dekompression bei hochgradigem V. a. Neuroblastom. Histologisch bestätigte sich die Diagnose. Die neurologischen Ausfälle waren postoperativ rasch rückläufig und das Kind wurde einer Chemotherapie unterzogen.

Schlussfolgerung: Eine Flushsymptomatik in Verbindung mit fluktuierenden neurologischen Symptomen sollte an einen katecholaminproduzierenden Tumor denken lassen. Bemerkenswert ist im berichteten Fall, dass trotz eines zwischenzeitlich unauffälligen neurologischen Untersuchungsbefundes bereits eine kritische Kompression des Rückenmarks durch ein Neuroblastom vorlag.

\section{DGKJ-PV-063}

Frühe Diagnose einer bilateralen Nephroblastomatose (NBM) bei einem Säugling mit familiärer Wilmstumor-Belastung

C. Gudegast ${ }^{1}$, R. Stenger' ${ }^{1}$ S. Thiele' ${ }^{1}$ S. Otto ${ }^{2}$, C. Müller ${ }^{3}$, H. Lode ${ }^{1}$

${ }^{1}$ Ernst-Moritz-Arndt Universität, ${ }^{2} \mathrm{Klinik}$ für diagnostische Radiologie, ${ }^{3} \mathrm{Klinik}$ und Poliklinik für Kinderchirurgie

Einleitung: Diefamiliäre Belastung mit Wilmstumoren erfordert regelmäßige sonographische Kontrollen, um so eine frühzeitige Tumorerkennung und effektive Behandlung zu gewährleisten. Eine kugelige Raumforderung entspricht zumeist einem Wilmstumor. Die NBM bezeichnet das diffuse oder multifokale Auftreten nephrogener Reste und zeichnet sich eher durch elliptoide Läsionen aus, die sich in der Sonographie hypo-, iso oder hyperechogen und in allen bildgebenden Verfahren homogen darstellen. Heterogenität in der Bildgebung zeichnet den Wilmstumor aus. In der von uns beobachteten Familie waren der Vater und ein Geschwisterkind wegen eines Wilmstumor erfolgreich behandelt worden. Im Verlauf der postnatalen sonographischen Kontrollen eines weiteren Kindes zeigten sich Hinweise für eine bilaterale NBM.

Kasuistik: Der 8 Mo. alte Knabe wurde mit 4080 g KG und $55 \mathrm{~cm} \mathrm{KL}$ spontan geboren. Wegen der Tumoranamnese erfolgten unmittelbar postnatal und im 4. LM Ultraschalluntersuchungen ohne pathologische Hinweise. Bei einer weiteren planmäßigen Kontrolle des Säuglings im Alter von 8 LM zeigten sich jedoch an beiden oberen Nierenpolen 2 gut abgrenzbare elliptoide, hyperechogen-homogene Tumoren mit einer Ausdehnung von 4,0 x 4,4 X 4,3 cm re. und breitem Kontakt sowie 2,3 X 2,6 x 3,7 cm li. ohne sicheren Kontakt zum Nierenbeckenkelchsystem. Das MRT bestätigte als Referenz die Sonographiebefunde. Familienanamnese, Tumorform und Textur gaben Hinweise auf eine bilaterale NBM. Unter der begonnenen präoperativen Chemotherapie trat eine deutliche Tumorregression ein. Nach insgesamt 12-wöchiger Chemotherapie bestätigte sich nach linksseitiger oberer Polresektion (12. LM) eine intralobäre NBM, 6 Wo. danach erfolgte die Nephrektomie re. mit gleichem histopathologischen Ergebnis.

Schlussfolgerungen: Durch das erhöhte Risiko einer familiären Nephroblastom-Belastung sind engmaschige Ultraschalluntersuchungen der Folgegenerationen notwendig. Eine frühzeitige Tumorerkennung schon im Säuglingsalter mit nachfolgender Chemo- und operativer Therapie erlaubt die lebenswichtige Organerhaltung.

\section{Neonatologie I}

\section{DGKJ-PV-064}

Was wissen wir über Phytotherapie in der Neonatologie: Eine Literaturübersicht

M. Thiel', A. Längler', T. Ostermann²

${ }^{1} G$ emeinschaftskrankenhaus, Abteilung für Kinder- und Jugendmedizin, 2Universität Witten/Herdecke

Hintergrund und Ziel: Es existieren zahlreiche Daten über Phytotherapeutika hinsichtlich verschiedener Aspekte u. a. Umsatz, Nutzen und Nebenwirkungen in verschiedenen Altersgruppen auch des Kindesalters einerseits und während der Schwangerschaft andererseits. Wir überprüften den Einsatz während der Neugeborenenzeit mittels einer systematischen Literaturübersicht.

Methodik: Entsprechend der PRISM-Guidelines 2009 führten wir eine systematische Recherche in folgenden Datenbanken durch: Cochrane, EMBASE, NCCAM, NLM, CAMbase, Medline sowie den Archiven von Karger, Kluwer, Thieme, Springer und Merkurstab. Schlüsselwörter waren Neonatologie, Neugeborene, Frühgeborene einerseits und Phytotherapie, Pflanzenheilkunde und Phytomedizin andererseits, auf deutsch und auf englisch bezüglich klinscher Studien über Phytotherapie.

Ergebnisse: Wir fanden 11 Studien, die die Einschlusskriterein erfüllten. Dabei waren die Themen 1)Aromatherapie (5 Fall-Kontrollstudien, z. T. randomisiert), 2)der topische Einsatz von pflanzlichen Ölen (4 Fall-Kontroll-Studien. 1 davon randomisiert) und 3)der interne Einsatz von pflanzlichen Tees (2 Studien, 1 prospektiv, placebo-kontrolliert, doppelblind, eine Studie mittels Fragebogen)

Diskussion: Indikationen, Studiendesign und Aussagekraft sind sehr heterogen. Daten über Aromatherapie erscheinen für praktische Belange vielversprechend.

Schlussfolgerung: Eine seriöse Einschätzung über den Einsatz von Phytotherapeutika in der Neonatologie ist aufgrund der derzeitigen Datenlage nicht möglich. 


\section{DGKJ-PV-065}

\section{Ist Kangarooing analgetisch?}

M. Thiel ${ }^{1}$, T. Ostermann

${ }^{1}$ Gemeinschaftskrankenhaus, Abteilung für Kinder- und Jugendmedizin, ${ }^{2}$ Universität Witten/Herdecke

Hintergrund: Seit der Einführung von Kangaroo-Care durch Rey und Martinez 1983 hat sich die Methode weiter verbreitet und entwickelt. Von der WHO im Jahr 2003 empfohlen, im gleichen Jahr durch eine Cochrane-Review relativiert, gibt es zahlreiche Publikationen, die ihre Effekte beschreiben.

Wir konzentrieren uns auf den möglichen schmerzreduzierenden Effekt, für den wir mittels systematischer Literaturrecherche die Datenbasis beschreiben.

Methode: Systematische Literaturrecherche anhand der PRISM 2009-Guidelines in Medline, BIOSIS Previews, DAHTA, Deutsches Ärzteblatt, EMBASE, EMBASE Alert, gms, gms Meetings, Karger, Kluwer, Krause\&Pachernegg, SciSearch, Springer, Springer PrePrint und Thieme.

Schlüsselwörter Kangarooing, Kangaroo-Care, Kangaroo-MotherCare, Skin-to-skin-Care sowie Neonatologie, Neugeborene, Frühgeborene in klinische Studien, auf deutsch und auf englisch.

Ergebnisse und Diskussion: Wir fanden insgesamt 11 randomisierte, 2-3armige Studien mit Patientenzahlen von 10-10o. Obwohl die Studiendesigns sehr ähnlich waren bestanden fundamentelle Unterschiede in einigen wichtigen Details. Die Defintion von „Standard-“ oder „Routine-Versorgung, die Länge der Kangaroo-Care-Phase vor der schmerzhaften Intervention, das korrigierte Alter zu dieser Zeit und andere Faktoren waren nicht vollständig zu vergleichen. Andererseits zeigte sich, dass Kangarooing nicht nur einen Methode für Frühgeborene ist und dass die Methode in verschiedenen geographischen Regionen mit unterschiedlichen medizinschen Ansätzen, Systemen und Resourcen verwendet wird. Die verwendeten Schmerzscores waren ähnlich oder identisch. Auch ist keine Studie älter als 7 Jahre, was die Aktualität des Themas unterstreicht. Obwohl nicht spezifisch untersucht ist bemerkenswert, dass keine Nebenwirkungen beobachtet wurden. (Zusammenfassung hierzu 1 Abbildung und 1 Tabelle)

Schlussfolgerung: Die Literaturrecherche liefert gute Argumente für einen Einsatz von Kangaroo-Care als ein einfaches und kostengünstiges Mittel mindestens leichte Schmerzen bei Früh- und Neugeborenen zu reduzieren, möglicherweise als Teil eines multimodalen Konzeptes. Die sich daraus ergebenden Fragen könnten Teil weiterer Studien sein.

\section{DGKJ-PV-066}

Effekte von Bluttransfusionen auf die Gewebeoxygenierung von Gehirn und Niere / Splanchnikusgebiet bei Frühgeborenen \&lt; $1500 \mathrm{~g}$ Geburtsgewicht: Eine Pilotstudie

D. Spengler, W. Nikischin

Universitätskinderklinik

Fragestellung: Frühgeborene mit einem Geburtsgewicht unter $1500 \mathrm{~g}$ benötigen häufig Bluttransfusionen. Gründe der Frühgeborenenanämie sind die Unreife des Knochenmarks sowie häufige Blutentnahmen. Derzeit fehlen Daten über die Effekte von Bluttransfusionen auf die Gewebeoxygenierung, gerade bei den für Hypoxie besonders vulnerablen Organen wie Gehirn und Niere bzw. Splanchnikusgebiet.

Ziel dieser Pilotstudie war es, durch kontinuierliches Monitoring mittels Near-Infrared-Spectroscopy (NIRS) erste Daten über die Gewebeoxygenierung von Gehirn und Niere / Splanchnikusgebiet vor und nach Bluttransfusion zu erfassen.

Material und Methoden: Eingeschlossen wurden bisher 1o Frühgeborene mit einem Geburtsgewicht $<1500 \mathrm{~g}$ und einem Lebensalter $>8$ Tage, die auf der neonatologischen Intensivstation des Universitätsklinikums Schleswig-Holstein, Campus Kiel im Jahr 2009 behandelt wurden. Die Kinder wurden nach den in der Klinik praktizierten Richtlinen transfundiert. Transfusionen erfolgten altersabhängig bei einem
Hkt von $<35 \%$ (8-14. Lebenstag), bei einem Hkt $<30 \%$ (15-28. LT) und bei einem Hkt von $<25 \%$ ( $>28 \mathrm{LT}$ ).

Vier Stunden vor Beginn bis 72 Stunden nach Ende der Transfusion wurde die Gewebeoxygenierung mittels NIRS gemessen. Zusätzlich erfolgte das Standardmonitoring (Puls, Atemfrequenz, pulsoxymetrische Sättigung mit Erfassung von Apnoen, Bradykardien und Desaturationen).

Untersucht wurden die Effekte auf die Gewebeoxygenierung vor und nach Transfusion. Dazu wurde die Zeitperiode vor Transfusion jeweils mit den Zeitintervallen 0-24 h, 24-48 h und 48-72 h nach Transfusion verglichen (ANOVA mit Meßwiederholung, post-Hoc-Test nach Holm-Sidak).

Ergebnisse: Nach Transfusion verbesserten sich sowohl die cerebrale $(64,8 \%$ vs. $68,2 \%, \mathrm{p}<0,001)$, und insbesondere auch die somatische (renale / mesenteriale) Gewebeoxygenierung (50,2\% vs 62,8\%, p < $0,001)$, jeweils bezogen auf die Zeitspanne vor und o-24 h nach Transfusion. Dieser Effekt hielt mindestens 48 Stunden an.

Diskussion: Die kleine Gruppengröße lässt noch keine eindeutige Interpretation zu. Auch fehlen noch Normwerte für die somatische Oxygenierung. Interessant ist jedoch, dass die cerebrale Oxygenierung vor Transfusion den zuvor publizerten Normwerten für Säuglinge (62\% \pm 4 ) entspricht und der Anstieg der somatischen Oxygenierung deutlich stärker ist. Dies könnte ein Hinweis darauf sein, dass unter der Bedingung einer Anämie die cerebrale Oxygenierung zu Ungunsten anderer Organsysteme konstant gehalten wird.

Schlussfolgerung: Bluttransfusionen bei Frühgeborenenanämie können die cerebrale und somatische Oxygenierung signifikant verbessern. Unabhängig davon bleibt die cerebrale Oxygenierung auch bei Anämie im Vergleich zu anderen Organsystemen konstant.

Weitere Daten sind notwendig, um sinnvolle Schwellenwerte für eine Bluttransfusion bei Frühgeborenen zu finden, auch im Hinblick auf eine mögliche renale / mesenteriale Hypoxie bei schwerer Anämie.

\section{DGKJ-PV-067}

\section{Konnataler Stridor bei Valleculazyste, Falldarstellung}

E. Tackmann, S. Niemeier, U. Lienicke, C. Fehlandt, M. Jungehülsing, C. ErleBischof

Klinikum Ernst-v.-Bergmann

Einleitung: Bei einer großen Anzahl von Neugeborenen fällt unmittelbar nach der Geburt ein inspiratorischer Stridor auf. Häufigste Ursache hierfür ist ein infantiler Larynx (Minimalform der Laryngotracheomalazie), der üblicherweise bei unproblematischer postnataler Adaptation und gutem Gedeihen keiner therapeutischen Maßnahmen bedarf.

Anamnese: Hypertrophes Reifgeborenes (Geburtsgewicht $4130 \mathrm{~g}$ ). Postnatale respiratorische Adaptationsstörung, Maskenbeatmung (APGAR: 2 / 6 / 8, NApH 7,24). Unauffälliger Verlauf bis auf leichten inspiratorischen Stridor bei Aufregung bei stets unauffälligen Vitalparametern mit guter Trinkleistung und unauffälligen Blutglukosewerten.

Im Alter von 1 Monat Infekt der oberen Atemwege, Trinkschwäche, Gewichtsverlust (Aufnahmegewicht 3900 g), Dyspnoe, Verfall des Allgemeinzustandes. Einweisung durch den Kinderarzt.

Aufnahmestatus: 1 Monat alter männlicher Säugling in massiv beeinträchtigtem Allgemeinzustand mit deutlichen inspiratorischen Einziehungen, Stridor, Tachydyspnoe. Pulmo seitengleich belüftet bei insgesamt eher abgeschwächtem Atemgeräusch, vereinzeltes Giemen. Rachenring gerötet und verschleimt. Der übrige körperliche und orientierend neurologische Untersuchungsbefund waren unauffällig.

Temperatur: $36,8^{\circ} \mathrm{C}, \mathrm{SaO}_{2} 100 \%$ bei $1 \mathrm{l} / \mathrm{min} \mathrm{O}_{2}$ über Nasenbrille.

Verlauf: Symptomatische Therapie bei Verdacht auf Bronchiolitis und Atemhilfe mittels CPAP mit Sauerstoffsubstitution. RöntgenthoraxAufnahme vereinbar mit der Arbeitsdiagnose.

Im Verlauf massive Verschlechterung der pulmonalen Situation, daher Entscheidung zur endotrachealen Intubation und maschinellen Beatmung. 
Laryngoskopisch von rechts kommende Raumforderung, mit erschwerter Intubation. Im Rahmen der Intubation Asystolie, Herzdruckmassage.

Hypothermiebehandlung unter Analgosedierung (Morphin) und Relaxierung (Rocuronium) über $48 \mathrm{~h}$. Keine klinisch-neurologisch oder laborchemisch Hypoxiefolgen.

Unter Beatmung erneute Verschlechterung der respiratorischen Situation. Radiologisch Nachweis einer Totalatelektase links und einer Oberlappenatelektase rechts. Durchführung einer Bronchoskopie und Lavage, bei der reichlich zähes, möglicherweise fibrinhaltiges Sekret entfernt wurde

Nach klinischer Stabilisation operative Marsupialisation (Ausschälung) der Raumforderung. Intraoperativ Darstellung einer Valleculazyste (2 $\mathrm{cm}$ Durchmesser), Zustand nach spontaner Entleerung hatte.

Problemlose Extubation am 2. postoperativen Tag, Entlassung am 7. postoperativen Tag.

Zusammenfassende Bewertung: Dekompensation der durch og. Raumforderung von vornherein leicht behinderten respiratorischen Funktion durch Infekt der oberen Atemwege.

Diskussion: In seltenen Fällen können neben der häufigen Laryngomalazie / dem infantilem Larynx andere anatomische Ursachen für einen konnatalen inspiratorischen Stridor vorliegen, die ausgeschlossen werden sollten.

Fazit: Eine laryngoskopische Untersuchung aller Kinder mit einem konnatalen inspiratorischen Stridor ist anzustreben.

\section{DGKJ-PV-068}

Intraabdominelle Hypertonie und Abdominelles Kompartmensyndrom im Kindesalter - Vorab-Ergebnisse einerdeutschlandweiten Fragebogenerhebung

T. Kaussen ', F. Staudt ${ }^{1}$, M. Sasse ${ }^{2}$, G. Steinau ${ }^{3}$, A. Schachtrupp ${ }^{3}$

${ }^{1}$ Kinderklinik Dritter Orden, ${ }^{2}$ Kinderklinik der Med. Hochschule, ${ }^{3}$ Med. Einrichtungen der RWTH Aachen

Hintergr.: IAH und AKS sind in der Pädiatrie seltene (Inzidenz 1-15\%), aber fatale Entitäten mit einer Mortalität von 60\%. Im Erw.-Alter haben sie sich als unabh. Prädiktoren für das Entstehen von MOV und Sepsis erwiesen. Altersabh. herrscht im Neugeb.- und Säugl.-Alter das prim. AKS vor (Urs.: Gastroschisis, Omphalozele, NEC, Darmperforation/ -ileus, Tumor, Transplantation), im Kindesalter findet sich dagegen eher das sek. AKS (Urs.: Trauma, Verbrennung, Sepsis, Schock). Diagnostik- und Therapieempfehlungen sind von der WSACS bislang nur für das Erwachsenenalter definiert worden (www. WSACS. org). Es bestehen Hinweise darauf, dass in Abh. von Größe und Spektrum der behandelnden Einrichtung IAH und AKS zwar zunehmend bekannte, im klin. Alltag aber noch wenig beachtete Entitäten sind. Eine regelhafte abdominelle Druckmessung bei Patienten mit intensivmedizin. Behandlungsbedarf scheint vor dem Hintergrund unklarer intraabdomineller Druckgrenzen sowie für das Kindesalter fehlender Therapieempfehlungen derzeit die Ausnahme zu sein. Im klin. Alltag beruht eine Diagnosestellung eher auf der klin. Einschätzung als auf der Anwendung von Leitlinien. Mit abnehmendem Alter und zunehmender Unreife scheint die Bereitschaft zu sinken, relativ invasive Druckmessmethoden wie die Blasendruckmessung durchzuführen. Das im Erwachsenenalter zunehmend akzeptierte aktive Senken des IAD bei manifestem AKS mittels dekompressiver Laparotomie mit temporärem Bauchdeckenverschluss ist in der neonatologisch-pädiatrischen Intensivmedizin die Ausnahme. Stattdessen scheinen nicht-operative Therapieoptionen durch Drainagen von intra- und extrakavitären Flüssigkeiten vorzuherrschen.

Methodik: In 5/2010 wurde ein 2-seitiger Fragebogen (15 Fragen) an alle deutschen Neonatologien und päd. Intensivstationen mit der Bitte um Antwort bis 7/2010 versandt.

Ziel: Erhebung von Wahrnehmung, Inzidenz, Outcome von IAH und AKS sowie von diesbezüglichem Vorgehen (Messverhalten/-verfahren, verwendete Grenzwerten Therapieindikationen usw.). Die Daten sol- len eine Einschätzung der aktuellen Situation bei päd. IAH und ACS in Deutschland ermöglichen.

Ergebn.: Bei Drucklegung ausstehend

\section{DGKJ-PV-069}

Neugeborenenscreening auf metabole und endokrine Störungen: Wie wahrscheinlich ist eine Erkrankung bei auffälligem Befund? Grundlage für die Aufklärung nach dem Gendiagnostikgesetz

U. Nennstiel-Ratzel' ', A. Lüders' ${ }^{1}$, O. Blankenstein ${ }^{2}$, R. Ensenauer ${ }^{3}$, M. Lindner ${ }^{4}$, A. Schulze

${ }^{1}$ Bayerisches Landesamt für Gesundheit und Lebensmittelsicherheit, ${ }^{2}$ Charite Kliniken f. Kinderheilkunde und Kinderchirugie, ${ }^{3}$ Klinikum der Universität München, ${ }^{4}$ Klinikum d.Ruprecht-Karl- Universität, ${ }^{5}$ The Hospital for Sick Children, University of Toronto

Hintergrund: Das Neugeborenenscreening (NGS) unterliegt den Regelungen der „Kinderrichtlinie“ und seit 01. 02. 2010 zusätzlich dem Gendiagnostikgesetz (GenDG). Dieses fordert eine Aufklärung zu Zweck, Art, Umfang und Aussagekraft der Untersuchung. Hierzu gehören die im Elterninformationsblatt beschriebenen Informationen $\mathrm{zu}$ Screeningprozess und Zielkrankheiten sowie das Wissen um die Wahrscheinlichkeit, mit der die Zielkrankheiten generell und insbesondere bei Vorliegen eines auffälligen Screeningbefundes auftreten. Eine valide Schätzung dieser Wahrscheinlichkeit ist auf Basis von 3,5 Mio. Screeningdaten, die aus ganz Deutschland seit 2004 vorliegen, für diese seltenen Erkrankungen möglich.

Methode: Die Deutsche Gesellschaft für Neugeborenenscreening erfasst jährlich Prozessdaten und Ergebnisse aller deutschen Screeninglaboratorien und wertet diese aus. Aus der Anzahl der gescreenten Kinder, der auffälligen Befunde sowie der Erkrankten lassen sich die Spezifität (Gesunde mit unauffälligem Befund) und die Prävalenz (Häufigkeit) der Zielkrankheiten ermitteln. Die Wahrscheinlichkeit für ein auffälliges Screeningergebnis lässt sich aus der Recallrate (auffällige Befunde) ableiten. Ebenfalls aus diesen Daten ablesbar ist der positive prädiktive Wert (PPV), die Wahrscheinlichkeit für ein Kind mit auffälligem Befund tatsächlich erkrankt zu sein. Der PPV ist abhängig von der Spezifität und Sensitivität (Kranke mit auffälligem Befund) des Tests und der Prävalenz der Erkrankung. Für die verwendeten Tests kann eine Sensitivität $>99,9 \%$ angenommen werden.

Ergebnisse: In den Jahren 2004-2008 wurden in Deutschland knapp 3,5 Mio. Kinder gescreent. Bei 2. 509 Kindern konnte eine der Zielkrankheiten bestätigt werden, d. h. eines von 1. 370 gescreenten Neugeborenen ist von einer der Zielkrankheiten betroffen. Die durchschnittliche Recallrate lag bei o,8\%, d. h. bei 16.570 Kindern musste das Screening wegen eines auffälligen Befundes kontrolliert werden. Für die häufigsten Krankheiten sind Recallrate, PPV und Prävalenz tabellarisch dargestellt:

\begin{tabular}{|lllll|}
\hline Tab. & Recallrate & PPV $\%$ & Erkrankte & Prävalenz \\
\hline Krankheit & $\%$ & & & \\
\hline Hypothyreose & 0,09 & 30 & 918 & $1: 3.740$ \\
\hline $\begin{array}{l}\text { Adrenogenitales } \\
\text { Syndrom (AGS) }\end{array}$ & 0,50 & 2 & 279 & $1: 12.307$ \\
\hline $\begin{array}{l}\text { Phenylketonurie } \\
\text { (PKU/HPA) }\end{array}$ & 0,03 & 59 & 643 & $1: 5.340$ \\
\hline MCAD-Mangel & 0,03 & 38 & 324 & $1: 10.598$ \\
\hline $\begin{array}{l}\text { alle übrigen } \\
\text { Krankheiten }\end{array}$ & 0,16 & 6 & 345 & $1: 10.100$ \\
\hline \begin{tabular}{l} 
gesamt \\
\hline
\end{tabular} & 0,81 & 9 & 2.509 & $1: 1.370$ \\
\hline
\end{tabular}

Für die Praxis lassen sich damit folgende Aussagen machen:

Unter 1 . ooo gescreenten Kindern ist bei 8 Kindern ein auffälliger Befund zu erwarten (Recallrate). 
Unter 100 Kindern mit auffälligem Befund sind 9 erkrankte Kinder zu erwarten (PPV). Dies variiert allerdings für die einzelnen Krankheiten erheblich (s. Tabelle).

Fazit: Die vorliegenden Daten liefern die Grundlage für eine qualifizierte Aufklärung nach dem Gendiagnostikgesetz. Der Anteil der falsch positiven Befunde ist beim NGS im Vergleich zu anderen Screeningverfahren extrem niedrig, der PPV in Anbetracht der Seltenheit der Erkrankungen sehr hoch.

\section{DGKJ-PV-070}

Volvulus ohne Malrotation bei sehr kleinen Frühgeborenen

S. Mark' ', S. Böckelmann' ${ }^{1}$ A. Weltzien², M. Bartsch'1, E. Mildenberger ${ }^{1}$

'Zentrum für Kinder- und Jugendmedizin, Universitätsmedizin der Johannes-Gutenberg Universität Mainz, ${ }^{2}$ Kinderchirurgie, Universitätsmedizin der Johannes-Gutenberg Universität Mainz

Hintergrund: Ein Frühgeborenes von $24+3$ SSW war in der 6. Lebenswoche in einer stabilen Phase unter CPAP-Atemunterstützung bei Raumluft. Der enterale Nahrungsaufbau war verzögert mit wiederholter subakuter Obstruktion verlaufen. Am 39. Lebenstag trat ein Volvulus mit Befall des gesamten Dünndarms und anschließendem Kurzdarm-Syndrom auf. Eine Malrotation wurde nicht gefunden - was uns veranlasste, in der Literatur nach ähnlichen Fällen zu suchen.

Ergebnisse: Beim Volvulus des Neugeborenen ohne Malrotation wird in der Literatur zwischen einer frühen und einer späten Verlaufsform unterschieden. Der frühe Volvulus ohne Malrotation liegt entweder bereits konnatal vor oder tritt in den ersten Lebenstagen auf und betrifft Früh- und Reifgeborene. Der späte Volvulus ohne Malrotation tritt im Alter jenseits von 3 Lebenswochen auf. Alle 6 in einer Fallserie publizierten Patienten mit später Verlaufsform waren Frühgeborene zwischen 24 und 33 SSW. Alle bis auf das Frühgeborene von 33 SSW hatten - wie unser Patient - eine CPAP-Atemunterstützung. Bei allen war der enterale Kostaufbau verzögert mit wiederholter subakuter Obstruktion verlaufen. Auch dies traf auf unseren Patienten zu.

Schlussfolgerung: Ein spät auftretender Volvulus stellt eine prognostisch relevante Differentialdiagnose der akuten Verschlechterung des Allgemeinzustandes mit abdomineller Symptomatik des sehr kleinen Frühgeborenen dar, der ohne zugrunde liegende Malrotation vorkommen kann. Als Gemeinsamkeiten und mögliche Risikofaktoren lassen sich CPAP-Atemunterstützung und verzögerter enteraler Nahrungsaufbau identifizieren.

\section{DGKJ-PV-071}

Ist das konventionelle Management pränatal diagnostizierter Myelomeningozelen noch zeitgemäß?

S. Mayer, M. Weisser, H. Till, G. Gräfe, C. Geyer

Universitätsklinikum Leipzig

\section{Fragestellung}

Die Myelomeningozele (MMC) ist eine der wenigen kongenitalen Anomalien, für die die Möglichkeit einer intrauterinen Therapie (intrauterine MMC repair; IUMR) besteht. Deren Benefit gegenüber einem konventionellen Vorgehen wird aktuell in einer randomisiert-kontrollierten Studie (MOMS) in den USA untersucht. Ziel unserer retrospektiven Querschnittsstudie war der Vergleich konventionell geführter Patienten mit publizierten Daten nach pränatalem Verschluss.

Material und Methode: Daten von Kindern mit MMC, deren Defekt innerhalb der ersten 2 Lebenstage korrigiert wurde und die zwischen 2008 und 2009 in unserer MMC-Sprechstunde vorstellig wurden, wurden hinsichtlich Geburtsalter und -gewicht, der Anlage einer ventrikulären Ableitung innerhalb des 1. Lebensjahrs und Alter bei Shuntanlage sowie Blasenfunktion, Mobilität und Bildungsgrad untersucht. Die statistische Analyse erfolgte mittels t-Test und Fisher-Test für $\mathrm{p}<0,05 \mathrm{im}$ Vergleich zu publizierten Daten [Tulipan N. Pediatr Neurosurg (2003); Johnson MP. Am J Obstet Gynecol (2006); Bruner JP Am J Obstet Gynecol (2004)].
Ergebnisse: Daten von 43 zwischen 1979 und 2009 geborenen Patienten mit zumeist lumbosakraler MMC wurden analysiert. Durchschnittliches Geburtsalter (37,8 $\pm 2,3$ vs. 36,4 Wochen) und Geburtsgewicht $(2921,3 \pm 760,3$ g vs. 2512 g) der postnatal versorgten Patienten waren signifikant höher als nach IUMR $(\mathrm{p}<0,01)$. Der Bedarf an einer zentraler Ableitung war in unserer Kohorte und nach IUMR gleich $(69,8 \%$ vs. $54,3 \% ; \mathrm{p}=0,1)$, wobei die Shuntanlage nach IUMR signifikant später erfolgte (21,2 vs. $16,4 \pm 10,7$ Tage; $\mathrm{p}=0,03) \cdot 56,4 \%$ unserer Patienten im Alter von 13,3 $\pm 8,9$ Jahren und 92. 6\% nach IUMR im Alter von 5,6 $\pm 1,5$ Jahren sind mit Hilfsmitteln mobil ( $\mathrm{p}<\mathrm{0}, 01) .64,1 \%$ unserer Patienten besuchen eine Regelschule. 69,7\% werden regelmäßig katheterisiert.

Diskussion: Das im Vergleich zu unserer Kohorte signifikant verminderte Geburtsalter und -gewicht nach IUMR spiegelt das bekannte Problem der Frühgeburtlichkeit bei pränatalen Interventionen wieder. Im Gegensatz zu historischen Kontrollen mit einer Shuntrate von $85 \%$ zeigte sich kein signifikanter Unterschied in der Shuntrate unserer konventionell geführte Kohorte und IUMR, wenngleich die Shuntanlage nach IUMR im Durchschnitt 10 Tage später erfolgte. Der deutlich höhere Anteil mobiler Patienten nach IUMR relativiert sich in Anbetracht des signifikant erniedrigdem Durchschnittsalters bei bekanntem Mobilitätsverlust von MMC-Patienten bis zur Adoleszenz.

Schlussfolgerung: Für eine sichere Beurteilung von Vor- und Nachteilen der IUMR in der Behandlung von Kindern mit pränatal diagnostizierter Myelodysplasie sollten die Ergebnisse der randomisierten MOMS Studie abgewartet werden.

\section{DGKJ-PV-072}

Intrahepatische Cholestase in der Schwangerschaft: Bedrohung für das Kind!

A. Puls', G. Emons'², T. Paul', S. Seeliger'

${ }^{1}$ Universitäts- Kinderklinik, ${ }^{2}$ Universitätsmedizin Göttingen

Einleitung: Die intrahepatische Cholestase in der Schwangerschaft (ICP) ist eine schwangerschafts-assoziierte Erkrankung der Leber, die mit einem generalisierten Juckreiz sowie einer Erhöhung der Gallensäuren im maternalen Serum einhergeht. Der Erkrankungsgipfel liegt im dritten Trimenon. Obgleich die ICP für die Mutter eine harmlose Erkrankung darstellt, so bedeutet sie doch für den Feten eine akute Bedrohung. Das Risiko der Frühgeburtlichkeit ist auf 19-60\%, das des intrauterinen Fruchttodes auf 1-2\% erhöht. Bei erhöhten maternalen Gallensäuren kommt es in Folge zu einem gesteigerten plazentaren Transfer. Durch die fetale Akkumulation von Gallensäuren kann es zu einer akuten fetalen Stresssituation kommen.

Fallbericht: In der hiesigen Universitätsfrauenklinik stellte sich eine Viertgravida, Drittpara in der 31. SSW mit generalisiertem Juckreiz und stark erhöhten Gallensäuren $(370 \mu \mathrm{mol} / \mathrm{l})$ vor. Anamnestisch wurde bereits eine ICP in den vorausgegangenen Schwangerschaften beschrieben. Umgehend wurde nun die Lungenreife mit Dexamethason eingeleitet und ein medikamentöse Therapieversuch mit Desoxycholsäure begonnen. Die fetale Überwachung erfolgte mittels kontinuierlichem Cardiotokogramm. Im Verlauf wurde in der 32 SSW aufgrund von fetalen Herzrhythmusstörungen mit akuter prolongierter Deszeleration die Indikation zur Notsektio gestellt. Postpartal zeigte sich in der StandartEKG-Ableitung ein neonataler ventrikulärer Bigeminus. Die Gesamtgallensäuren im kindlichen Serum waren post partum auf maximal 160 $\mu \mathrm{mol} / \mathrm{l}$ erhöht.

Schlussfolgerung: Die ICP ist assoziiert mit einem erhöhten Risiko der Frühgeburtlichkeit und des intrauterinen Fruchttodes. Der Pathomechanismus der fetalen Schädigung ist nicht vollständig geklärt. Aufgrund der kindlichen Gefährdung sollte eine engmaschige Überwachung prä- wie auch postpartal erfolgen, um Anzeichen einer fetalen Gefährdung nicht zu übersehen. 
DGKJ-PV-073

Neue Aufgabe für Neonatologen

V. von Loewenich , R. Schloesser

Univ.-Klinikum

Seit dem 1. Januar 2010 ist die Neufassung des Schwangerschaftskonfliktgesetzes in Kraft.

Es enthält genaue Anweisungen, wie im Rahmen der Pränataldiagnostik beraten werden muß.

Neu ist $\S 2 \mathrm{a}$ : Absatz 1 lautet u. a.: „Sprechen nach den Ergebnissen von pränataldiagnostischen Massnahmen dringende Gründe für die Annahme, dass die körperliche oder geistige Gesundheit des Kindes geschädigt ist, so hat der Arzt, der der Schwangeren die Diagnose mitteilt, ..... unter Hinzuiehung von Ärzten, die mit dieser Gesundheitsstörung bei geborenen Kindern Erfahrung haben, zu beraten." Gesprächstpartner der pränataldiagnostisch tätigen Frauenärzte sind in erster Wahl Neonatologen. Mit ihnen ist der Frauenarzt vertraut, er wird daher in der Regel den mit ihm kooperierenden Neonatologen zuziehen. Damit ergibt sich für diesen die Pflicht, für die Beratung der betroffenen Schwangeren bzw. Paare zur Verfügung zu stehen. Selbstverständlich muß man als Neonatologe nicht über alle infrage kommenden Störungen Bescheid wissen, insbesondere nicht über LangzeitVerläufe. Aber als Neonatologe ist man es ohnehin gewohnt, Kollegen anderer pädiatrischer Disziplinen zu konsultieren. Die Pflicht hierzu ergibt sich aus dem Gesetzestext. Andererseits hat man als Neonatologe die Übersicht, wessen Expertise zur Verfügung steht.

Die Beratung hat ergebnis-offen zu geschehen. Vor einer zu optimistischen Darstellung der auf die Betroffenen zukommenden Probleme ist zu warnen, auch wenn man als Pädiater einem Spätabort kritisch gegenüber stehen mag. Vorwürfe oder auch Schadenersatz-Forderungen sind nicht ohne weiteres auszuschliessen. Daher ist es ratsam, diese Beratertätigkeit der eigenen Haftpflichtversicherung zu melden. Angestellte Ärzte sollten sich diese Beratertätigkeit von ihrem Krankenhausträger zur Dienstaufgabe erklären lassen, da dann die Haftungspflicht beim Krankenhausträger lieg, solange dem Berater grobe Fahrlässigkeit nicht vorgeworfen werden kann.

Der Hinweis auf Selbsthilfegruppen ist nicht problemfrei. Wie zu erfahren ist können Eltern mit von der jeweiligen Gesundheitsstörung betroffenen Kindern eine Beratung von Paaren, die noch vor der Entscheidung für oder gegen das Kind stehen, selbst schlecht verkraften, wird doch ihre eigene Entscheidung damit wieder aufgerollt und ggf. in Frage gestellt.

\section{DGKJ-PV-075}

Einflüsse von Phenobarbital auf die Hirnentwicklung bei Neugeborenen

i. enders

Städtisches Klinikum St. Georg Kinderklinik

Abstract: Hintergrund: Zur Ikterusbehandlung in der Neugeborenenperiode wird Phenobarbital zwar heute nicht mehr verwendet, es wird aber in der Perinatalmedizin unter anderen Indikationen vielfach eingesetzt, so dass an der Analyse langfristiger Nebenwirkungen ein großes Interesse besteht. Tierexperimentelle Studien haben Hinweise auf eine apoptotisch bedingte Degeneration des Gehirns durch therapeutische Phenobarbitaldosen ergeben.

Fragestellung: An einem Kollektiv neurologisch gesunder Neugeborener, die zum Teil Phenobarbital vor 1990 zur Ikterusprophylaxe erhalten hatten, wurden mögliche neurokognitive Entwicklungsverzögerungen durch die Substanz anhand eines Vergleichs der Entwicklung zwischen behandelten und unbehandelten Kindern untersucht.

Material und Methodik: Katamnestische Untersuchung von 124 Neugeborenen, von denen 53 während der ersten 3 Lebenstage mindestens $30 \mathrm{mg} / \mathrm{kg}$ Phenobarbital erhalten hatten, im Alter zwischen 14 und 17 Jahren. Aus den Krankenunterlagen wurden Patientendaten wie Gestationsalter, Geburtsgewicht, mütterliche Erkrankungen während der Schwangerschaft und Parameter der postnatalen Adaptation sowie ggf. die verabreichte Phenobarbitaldosis erhoben. Die Entwicklung der Kinder wurde anhand eines Elternfragebogens eruiert, der neben Angaben zum sozialen Status die Daten des ersten freien Laufens, des Sprechens und der Stuhlkontrolle, Fragen nach motorischen und kognitiven Funktionen sowie dem Sozialverhalten und die schulischen Leistungen enthielt.

Ergebnisse: Die Kinder, die Phenobarbital erhalten hatten, hatten im Durchschnitt ein niedrigeres Gestationsalter $(37,2 \pm 2,2$ vs. $39,7 \pm 1,3$ Wochen in der Kontrollgruppe, $p<0,001)$; sehr kleine Frühgeborene wurden allerdings in der Studie nicht berücksichtigt. Die multivariate statistische Prüfung ergab auch nach Berücksichtigung des Gestationsalters einen deutlichen und statistisch signifikant unabhängigen Einfluss der Phenobarbitalgabe auf die Entwicklung im Hinblick auf das Sprechen (30,2 vs. 9,9\%>18 Monate), das Laufen (23,1 vs. $2,8 \%$ $>18$ Monate) und die Harn- und Stuhlkontinenz ( 75,5 vs. $50,7 \%>18$ Monate). Kinder der Studiengruppe wiesen ferner schlechtere Schulnoten im Fach Kunst auf, und dieser Effekt nahm ebenso wie die Entwicklungsverzögerung beim Sprechen mit steigender Dosis des Pharmakons zu.

Schlussfolgerung: Der Einsatz von Phenobarbital zur Behandlung bzw. Verhütung von Krampfanfällen ist heute durchaus noch üblich, wenn auch eher als Mittel der ferneren Wahl. Diese Anwendungsmodalität ist aus entwicklungsphysiologischer Sicht nach den Ergebnissen unserer Untersuchung nicht unbedenklich, und nach Alternativen sollte gesucht werden. Eine weitergehende Klärung der Kausalverhältnisse könnte durch prospektive Langzeitstudien erreicht werden. Eine neurologisch-psychologische Nachuntersuchung der Kinder mit und ohne Phenobarbitaltherapie könnte eine Objektivierung der Interviewergebnisse ermöglichen und gleichzeitig Störungen bei Kindern mit Phenobarbital evaluiert werden.

\section{DGKJ-PV-076}

Sensitivität und Spezifität des deutschen Risikoscreenings zur Früherkennung der Hüftdysplasie

T. Seidl', J. Lohmaier ${ }^{2}$, H. Trouillier ${ }^{2}$

${ }^{1}$ Charité - Universitätsmedizin Berlin, ${ }^{2}$ Franziskus Hospital

Einleitung: Seit 1996 ist in Deutschland im Rahmen der U3 die sonographische Untersuchung der Säuglingshüfte nach Graf gesetzlich vorgeschrieben. Ausschließlich Hüften von Neugeborenen mit Vorliegen von Risikofaktoren müssen unmittelbar postnatal sonographisch untersucht werden (sog. Risikoscreening).

Fragestellung: Wie spezifisch und sensitiv kann mit Hilfe des Risikoscreenings eine Hüftdysplasie oder Luxation beim Neugeborenen erkannt werden?

Material und Methodik: Retrospektive Untersuchung der zwischen 01/06 und 12/o8 erhobenen Hüftsonographiebefunde aller im Franziskus Hospital geborener Säuglinge.

Ausgeschlossen wurden Befunde von Neugeborenen, deren Mütter z. B. sprachbedingt keine anamnestischen Angaben bezüglich dem Vorliegen von Risikofaktoren machen konnten.

Ergebnis: Über einen Zeitraum von 36 Monaten wurden 4302 Neugeborenenhüften untersucht. Der Typ I nach Graf kam bei 3586 Neugeborenenhüften (in 742 Fällen trotz Vorliegen von Risikofaktoren) vor, die Prävalenz beträgt damit 83,4\%. Der Typ IIa nach Graf kam bei 653 Neugeborenenhüften (in 200 Fällen trotz Vorliegen von Risikofaktoren) vor, dies entspricht einer Prävalenz von 15,2\%. Der Typ IIc stabil/ instabil nach Graf wurde bei 14 Hüften diagnostiziert, wobei 11 anamnestisch und klinisch ohne pathologischen Befund waren, die Prävalenz beträgt 0,3\%. 30 Hüften mussten dem Typ D nach Graf zugeordnet werden, wobei 16 klinisch und anamnestisch stumm waren (Prävalenz 0,7\%). Der Typ III nach Graf kam bei 18 Hüften, 8 davon klinisch und anamnestisch unauffällig, vor. Die Prävalenz betrug damit $0,4 \%$. Eine klinisch und anamnestisch unauffällige Hüfte musste dem Typ IV nach Graf zugeordnet werden, Prävalenz 0,02\%.

Diskussion: Aufgrund des gesetzlich vorgeschriebenen Risikoscreenings wären in unserem Kollektiv 942 Hüften Typ I/IIa nach Graf 
„Zuviel“ untersucht worden. 36 dysplastische oder luxierte Hüftgelenke wären erst im Rahmen der $\mathrm{U}_{3}$ untersucht worden.

Die Sensitivität des Risikoscreenings zur Früherkennung der Hüftdysplasie liegt damit bei $42,9 \%$, die Spezifität bei $77,8 \%$.

Fazit: In unserem Kollektiv wären $77,8 \%$ der gesunden Hüften als solche erkannt worden, jedoch nur $42,9 \%$ der pathologischen Hüften. Damit hätten bei Durchführung des in der Bundesrepublik vorgeschriebenen Risikoscreenings zur Früherkennung der Hüftdysplasie in unserem Haus nicht einmal die Hälfte der dysplastischen oder luxierten Gelenke einer frühzeitigen Therapie zugeführt werden können.

\section{Gastroenterologie II}

\section{DGKJ-PV-077}

Hereditäres Angioödem: Sonographische Befunde bei intestinaler Symptomatik

M. Scheffler', G. Schweintzger', G. Hammersen ${ }^{1}$

${ }^{1}$ Cnopfsche Kinderklinik, ${ }^{2}$ Landeskrankenhaus Leoben-Eisenerz

Akute Bauchschmerzen mit Koliken und Erbrechen können bei Kindern viele Ursachen haben. Die Sonographie hat bei der differenzialdiagnostischen Klärung einen hohen Stellenwert. Anhand von 2 Kasuistiken soll dargestellt werden, dass eine seltene Ursache solcher Bauchschmerzen - intestinale Manifestation eines hereditären Angioödems (HAE) - auf Grund des charakteristischen Ultraschallbefundes sonographisch relativ sicher diagnostiziert werden kann.

Beim HAE führt das Fehlen des C1-Esterase-Inhibitors anfallsweise zur Vasodilatation und Ödembildung, was bei intestinaler Manifestation eine Darmwandverdickung / -ödem und Aszites bedingt. Da das intestinale Ödem streng auf die Submucosa begrenzt ist, finden sich perlschnurartig aufgereihte echoarme Areale in der verdickten Darmschleimhaut. Diese echoarmen Herde entsprechen einem interstitiellen Ödem im Bereich der KERCKRINGschen Falten, plicae circulares. Diese Veränderungen sind bei gleichzeitiger intraperitonealer Flüssigkeitsvermehrung geradezu pathognomonisch für eine intestinale Manifestation eines hereditären Angioödems und erlauben sonographisch eine eindeutige Abgrenzung gegenüber anderen Erkrankungen mit ähnlicher Symptomatik und verdickter Darmwand, z. B. M. CROHN, infektiöse Colitis, Einblutungen bei einer Purpura SCHÖNLEIN-HENOCH oder Darminfiltration bei malignen Systemerkrankungen.

\section{DGKJ-PV-078}

Stellenwert der Gamma-GT bei chronischer Cholestase. Diagnose des Byler-Syndrom bei einem 2 Monate alten Mädchen - ein Fallbericht. L. Kurzidim

Klinikum Ernst v. Bergmann

Anamnese: Term-Eutrophes Neugeborenes mit postnatal guter Adaptation. Für 2 Wochen voll gestillt. Laut Eltern seit Geburt hellgelbe Stühle sowie zunehmender Sklerenikterus. In der 9. Lebenswoche Blutabnahme über den Kinderarzt: ASAT 10,2 $\mu \mathrm{mol} / \mathrm{l} / \mathrm{s}$, ALAT $10 \mu \mathrm{mol} / \mathrm{l} / \mathrm{s}$, Gesamtbilirubin $145 \mu \mathrm{mol} / \mathrm{l}$ (direkt 76), Gamma-GT normal. Die Großmutter des Kindes mütterlicherseits leidet seit dem 50. Lebensjahr an einer Leberzirrhose sowie einem Diabetes mellitus. Die weitere Kranken-, Familien- und Sozialanamnese ist unauffällig. Die Eltern sind deutscher Herkunft und nicht verwandt.

Aufnahmestatus: 9 Wochen alter weiblicher Säugling in stabilem Allgemeinzustand, eutropher Ernährungszustand, deutlicher Sklerenund Hautikterus, Leber ca. $2 \mathrm{~cm}$ unter dem Rippenbogen palpabel, Milz unauffällig, übriger internistischer und neurologischer Status unauffällig.

\section{Tab.}

\section{Laborwerte:}

ASAT $10,9 \mu \mathrm{mol} / \mathrm{s}^{*}$ ( (20fach erhöht)

ALAT $9,1 \mu \mathrm{mol} / \mathrm{s}^{*} \mathrm{I}$ (20fach erhöht)

Gesamtbilirubin $136 \mu \mathrm{mol} / \mathrm{l}$ (direkt

$112 \mu \mathrm{mol} / \mathrm{l})$

Cholinesterase $76 \mu \mathrm{mol} / \mathrm{s}^{*}$ ( ver-

mindert).

Gamma-GT: im Normbereich

3. Labortechnisch Ausschluss von:

Virushepatitis

Alpha-1-Antitrypsinmangel

Morbus Wilson

Mukoviszidose

Stoffwechselstörung

Alagille-Syndrom

Harnwegsinfekt

\section{Sonographie:}

Schädel: unauffällig

Abdomen: unauffällig,

keine Hinweise auf eine Gallengangsatresie

4. Leberbiopsie:
Bild einer neonatalen Riesenzell-
hepatitis mit gering vermehrter
portaler Fibrose ohne angedeutete
zirrhotische Transformation. Die Gal-
lensalz-ausscheidung scheint massiv
gestört zu sein.
Hinweise auf eine progressive fa-
miliäre intrahepatische Cholestase
(Byler-Syndrom).

Verlauf und Therapie: Auffällig war die Konstellation der massiv erhöhten Transaminasen (2ofach) gegenüber der normalen Gamma-GT. Differentialdiagnostisch musste daher an eine progressive familiäre intrahepatische Cholestase (Byler-Syndrom) gedacht werden. Die Leberbiopsie bestätigte diesen Verdacht. Die Gen-Sequenzierung wird derzeit im Zusammenhang mit der genetischen Beratung der Eltern durchgeführt.

Zur Verbesserung der Galleausscheidung wurde Ursodesoxycholsäure mit initial $30 \mathrm{mg} / \mathrm{kg} \mathrm{KM}$ eingesetzt. Die Transaminasen und das Bilirubin waren damit stark rückläufig, die Cholinesterase stieg wieder auf Normalwerte an. Auch die Stuhlfärbung normalisierte sich. Die fettlöslichen Vitamine A, E, D sind stark reduziert und werden (zusammen mit Vitamin K) substituiert.

Morbus Byler/Byler-Syndrom: Die Progressive Familiäre Intrahepatische Cholestase (PFIC) ist eine seltene autosomal rezessiv vererbte Lebererkrankung, die erstmalig 1965 durch Clayton et $a . l$ bei einer Amish-Familie (Stammvater Jacob Byler) beschrieben wurde. Es sind derzeit 3 Subtypen identifiziert, die per Mutationsanalyse nachgewiesen werden können (ATP8B1-Gen, ABCB11-Gen, ABCB4-Gen). Zentraler Punkt ist die gestörte Gallesekretion bei Gallensäuren- und Gallelipidtransportdefekten. PFIC-1 und PFIC-2 weisen massiv erhöhte Transaminasen bei charakteristischerweise normalen Gamma-GT-Werten auf. Diese beiden Formen manifestieren sich bereits im frühen Säuglingsalter und sind rasch progressiv. Die Therapie setzt medikamentös auf die Gabe von Ursodesoxycholsäure und später auf eine partielle biliäre Diversion (die aber im Grunde schon eine Palliativmassnahme darstellt). Bei Versagen dieser Behandlung und bei bereits manifester Zirrhose ist eine Lebertransplantation erforderlich.

\section{DGKJ-PV-079}

Schwere Dysphagie durch langstreckige Ösophagusstenose bei eosinophiler Ösophagitis im Alter von 16 Monaten - Therapie?

I. Böhm', M. Hemminghaus², D. Pilic', J. Glock', E. Hamelmann'1, R. Tröbs², A. Schmidt-Choudhury ${ }^{1}$

${ }^{1}$ Klinik für Kinder- und Jugendmedizin St. Josef-Hospital, Klinikum der RuhrUniversität Bochum, ${ }^{2}$ Kinderchirurgische Klinik im Marienhospital

Fallvorstellung: Ein 15 Monate altes Mädchen wird wegen progredienter Dysphagie nach Einführung fester Nahrung in der gastroenterologischen Ambulanz der Kinderklinik vorgestellt. Flüssige und pürierte Nahrung werde toleriert. Vor der daraufhin geplanten Endoskopie und $\mathrm{pH}$-Metrie mit Impedanzmessug kommt es zur notfallmäßigen Aufnahme wegen akuter Bolusimpaktation. Endoskopisch findet sich bei $17 \mathrm{~cm}$ ab Zahnreihe eine mit dem Endoskop (Olympus GIF N 180, 4,5 $\mathrm{mm}$ Außendurchmesser) eben passierbare Stenose mit narbiger Ver- 
ziehung, zirkulären weißlichen Belägen und histologischem Nachweis einer eosinophilen Ösophagitis. Die Barium-Kontrastdarstellung bestätigt eine langstreckige Stenose mit Lumeneinengung um 50\%. Therapeutisch erfolgt eine einmalige Ballondilatation bis maximal 15 $\mathrm{mm}$. Postinterventionell kommt es zu einem Haut- und Mediastinalemphysem bei kleiner Ösophagusperforation, so dass das Kind intensivmedizinisch weiter betreut wird. Die Ösophagusperforation heilt unter konservativer Therapie aus. Kontrollendoskopien im Abstand von 14 Tagen und drei Monaten zeigen unauffällige makroskopische Befunde, bei persistierender Eosinophilie in der Ösophagusschleimhaut. Die aktuelle Medikation besteht aus $10 \mathrm{mg}$ Omeprazol 1x/Tag. In der Allergiediagnostik finden sich spezfische IgE - Antikörper die RAST-Klasse 1 gegen Kuhmilch und Hühnerei. Die daraufhin empfohlene Eliminationsdiät wird von den Eltern bislang nicht umgesetzt. Diskussion: Wenige retrospektive pädiatrische Untersuchungen zur Therapie einer eosinophilen Ösophagitis mit Striktur wurden bisher publiziert. Beschrieben werden konservative Therapien mittels lokaler oder systemischer Immunmodulation (Fluticason geschluckt, Montelukast, Prednison systemisch, Azathioprin). Eine aktuelle Untersuchung (Robles-Mendranda et al, JPGN, 2010) erbrachte unter konventioneller Therapie auch bei höhergradigen Stenosen gute Erfolge. Hier wurden nur nicht passierbare Stenosen mit begleitender topischer Steroidtherapie in mehreren Sitzungen dilatiert (pro Sitzung 1-2mm bis maximal 10 mm bei Kleinkindern). In der Zusammenschau der aktuellen Studienlage sollte bei Patienten mit symptomatischer eosinophiler Ösophagitis eine lokale Immunsuppression mit geschlucktem Fluticason diskutiert werden, höhergradige Stenosen, die nicht mit dem Endoskop passierbar sind, sollten zusätzlich einer endoskopischen Intervention zugeführt werden.

\section{DGKJ-PV-080}

\section{Congenitale Pylorusagenesie als Falldarstellung}

J. Hoyer-Schuschke', S. Pötzsch², H. Haß3 ${ }^{3}$, H. Krause' ${ }^{3}$, A. Rißmann'

${ }^{1}$ Med. Fakultät der Otto-von-Guericke Universität, ${ }^{2}$ Vogtland-Klinikum Plauen $\mathrm{GmbH},{ }^{3}$ Universitätsklnik für Allgemein-, Viszeral- und Gefäßchirurgie

Einleitung: Die kongenitale Pylorusagenesie ist eine extrem seltene Fehlbildung und tritt mit einer Prävalenz von 1 pro 10o. ooo Neugeborene auf. Sie stellt etwa $1 \%$ der angeborenen gastrointestinalen Malformationen dar. Die genaue Ätiologie der congenitalen Pylorusagenesie ist unklar. Der Zeitpunkt der embryologischen Entwicklung des Pylorus liegt zwischen der 5. und 12. Schwangerschaftswoche.

Methoden: Es erfolgt an Hand einer Kasuistik die Darstellung der Klinik und Diagnostik bei congenitaler Pylorusagenesie. Bei Klassifikation der Pylorusagenesie (Typ A: Pylorusobstruktion durch Membran oder Gewebe, häufigster Typ; Typ B longitudinale Segmentatresie, d. h. das Pyloruslumen ist ein einzelner Strang; Typ C Pylorusagenesie, d. h. es besteht eine Lücke zwischen Magen und Duodenum) zeigt sich auch die Operationsmethode der Wahl.

Ergebnisse: Die Pylorusatresie kann als isolierte Fehlbildung auftreten, häufiger ist die Kombination mit anderen genetisch bedingten Erkrankungen. So kann die congenitale Pylorusagenesie dem hereditären multiplen intestinalen Atresie Syndrom zugeordnet sein oder in Kombination mit hereditären Fehlbildungen der Haut auftreten. Teilweise zeigen Untersuchungen einzelner Kasuistiken eine familiäre Häufung, so dass man von einem autosomal-rezessiven Erbgang ausgehen muss. Wir berichten über einen weiblichen Säugling mit congenitaler Pylorusagenesie. In der pränatalen Diagnostik zeigte sich ein Double-BubblePhänomen. Mit Verdacht auf Duodenalatresie/-stenose erfolgte in der 37. Schwangerschaftswoche die Sectio caesarea. Postnatal fiel ein leicht geblähtes Abdomen und ein vermehrter Speichelfluss auf. In der röntgenologischen Abdomenübersichtsaufnahme war eine große Magenblase ohne Luft-Füllung der distalen Anteile des Magen-Darmtraktes sichtbar. Unter Verdacht auf Pylorusobstruktion erfolgte die Operation. Im intraoperativen Situs zeigte sich dann die Lücke zwischen Magen und Duodenum. eine Gastroduodenostomie wurde komplikationslos durchgeführt. Assoziierte Fehlbildungen beim Neugeborenen: Nierenagenesie rechts und präaxiale Polydaktylie.

Schlussfolgerung: Die congenitale Pylorusagenesie ist eine seltene angeborene Fehlbildung die oft mit anderen hereditären Erkrankungen assoziiert ist. Die frühe Diagnose ist für den Operationserfolg und das Outcome der Kinder von größter Bedeutung. Weitere assoziierte Fehlbildungen sollten bei Nachweis einer Pylorusatresie ausgeschlossen werden.

\section{DGKJ-PV-081}

Fokale noduläre Hyperplasien (FNH) als Folge einer Abernethy- Malformation

P. Lauenstein', R. Stenger', M. Wegner', A. Follak', W. Luck², A. Findeisen' 'Ernst-Moritz-Arndt Universität, ${ }^{2}$ Charite Kliniken f. Kinderheilkunde und Kinderchirugie

Einleitung: Benigne und maligne Lebertumoren treten im Kindesalter selten auf. Dies gilt auch für die FNH. Nach der Diagnostik durch Bildgebung müssen sie laborchemisch und durch eine PE histologisch gesichert werden. Bei fehlender Therapieindikation werden die Leberveränderungen im Verlauf zunächst durch die Bildgebung und paraklinisch weiter verfolgt. Pathophysiologisch können FNH auch in Folge einer kongenitalen Abernethy-Malformation auftreten. Diese wurde erstmalig von dem englischen Chirurgen und Pathologen John Abernethy (1764-1838) beschrieben. Der zu Grunde liegende portosystemische Shunt des mesenterialen Kreislaufs direkt in die V. cava inferior kann vollständig (Typ 1) oder partiell (Typ 2) sein. Entsprechend der Ausprägung des Shunts kann diese Fehlbildung bis zum Leberversagen führen. Fehlbildungen weiterer abdomineller Organe und des Herzens sind oft mit dem Typ 1 assoziiert.

Kasuistik: Wir betreuen eine Patientin, bei der im frühen Kleinkindesalter ein operativer Verschluss eines ASD erfolgte. Ein Jahr später wurde im Rahmen eines anstehenden HNO-ärztlichen Eingriffs ein erniedrigter Quickwert festgestellt. Durch die weitere Diagnostik wurden FNH festgestellt und durch eine PE gesichert. Neben der weiteren Progredienz der FNH bis zu $6 \mathrm{~cm}$ im Diameter zeigten sich in der Bildgebung mit Farbdopplersonographie und MR-Angiographie ein portosystemischer Shunt und eine aneurysmatische Aufweitung der extrahepatischen Portalvene im Leberhilus. Ein intrahepatischer portaler Verlauf war nicht zu verfolgen. Die morphologischen Leberveränderungen, die Pathologie der Gefäße und der Hämodynamik sowie das bereits operativ versorgte Vitium cordis führten zur Diagnose einer Abernethy-Malformation vom Typ 1 B (70\% des Typ 1) mit der gemeinsamen Einmündung von Mesenterial- und Milzvene über einen Konfluenz in die untere Hohlvene. Infolge dieses Shuntings zirkulieren vermehrt hepatotrophische Substanzen (Insulin, Glukagon u. a.) wodurch die benignen oder malignen Leberneoplasien verursacht werden. Die resultierenden Leberstrukturveränderungen führen zum langsamen hepatischen Funktionsversagen mit Hyperammonämien. Eine engmaschige Kontrolle ist deshalb erforderlich. Eine im 10. LJ. aufgetretene Unterschenkelvarikosis bei der Patientin wurde mit dem veränderten kavalen Abstrom erklärt.

Schlussfolgerungen: Die Abernethy-Malformation ist wenig bekannt und wird zumeist erst im Jugendalter diagnostiziert. Weltweit wurden beim Typ 1 erst etwa 10o Fälle publiziert. Bei allen Leberneoplasien muss auch eine Abernethy-Malformation als mögliche Ursache unbedingt ausgeschlossen werden. Patienten mit dem Typ 1 haben wegen der progredienten Leberschädigung eine schlechte Prognose. Eine Lebertransplantation ist im Verlauf die einzige Behandlungsmöglichkeit, um auch eine Enzephalopathie zu vermeiden. 
DGKJ-PV-082

Intrazelluläre Transportprozesse von Gliadin in Enterozyten und deren Modulation durch Zöliakieserum

N. Lübbing', S. Rudloff', I. Panzer', M. Barone², R. Troncone², S. Auricchio², K. Zimmer ${ }^{1}$

'Zentrum für Kinderheilkunde der Justus-v.-Liebig-Universität, ${ }^{2}$ University Federico II

Der Zöliakie liegt ein Versagen der physiologischen oralen Toleranz gegenüber den Speicherproteinen von Weizen (Gliadin), Roggen, Gerste und Hafer zugrunde. Das Stillen während des ersten Zufütterns von Gluten in der Säuglingszeit scheint gegenüber der Zöliakie protektiv zu wirken. Dieser Effekt ist möglicherweise ausgelöst durch Gliadin und gliadinspezifische Antikörper, die in der Muttermilch enthalten sind. Die Hypothese dieser Arbeit besagt, dass polyvalente GliadinAK-Komplexe bis in späte Endosomen von Enterozyten transportiert werden. Späte Endosomen von Enterozyten sind HLA-DR positiv, d. h. die dorthin endozytierten Nahrungsmittelantigene können zur Toleranzinduktion an der basolateralen Membran gegenüber supprimierenden T-Lymphozyten präsentiert werden. Das toxische Gliadinpeptid 31-49 erreicht späte Endosomen von Enterozyten nicht.

Dünndarmbiopsien von Zöliakie- und Kontrollpatienten wurden mit Gliadin und mit Serum von Zöliakiepatienten als Antikörper-Quelle für $1 \mathrm{~h}$ bei $37^{\circ} \mathrm{C}$ inkubiert. Die Proben wurden gemäß der Technik von Tokuyasu verarbeitet und eine Immunogoldfärbung an ultradünnen Gefrierschnitten durchgeführt. Außerdem wurden intestinale Caco-2Zellen mit lissaminmarkierten Gliadinpeptiden (toxisches Peptid 31-43 und Kontroll-Peptid 56-68) und Serum von Zöliakie- und Kontrollpatienten inkubiert und immunfluoreszenmikroskopisch untersucht. Mit Hilfe von Antikörpern gegen Gliadin und späte Endosomen (Cathepsin D) wurde jeweils deren Co-Lokalisierung in Enterozyten bestimmt. Der für eine orale Toleranzinduktion bedeutende Anteil von Gliadin in späten Endosomen in Biopsien ließ sich durch eine Inkubation mit Zöliakieseren in Zöliakiebiopsien um Faktor Vier steigern. Durch Inkubation der Caco-2-Zellen mit Zöliakieserum gelangte das Peptid 31-43 verstärkt in späte Endosomen. Der Kolokalisationsfaktor ließ sich mit Zöliakieseren auf o,8 steigern, während Kontrollseren und Zellkulturmedium Faktoren von unter 0,5 erzielten.

Die Inkubation mit Zöliakie-Seren fördert ex vivo und in vitro die Aufnahme des toxischen Gliadinpeptids in späte Endosomen von Enterozyten. Dieser Prozess ist für die Antigenpräsentierung eines toxischen Antigens erforderlich und möglicherweise für die Toleranzentwicklung gegenüber Gliadin in genetisch disponierten Säuglingen verantwortlich. Der protektive Effekt des Stillens gegenüber der Zöliakie könnte über Gliadin-Antikörper der Muttermilch vermittelt werden.

\section{DGKJ-PV-083}

\section{Trichuris Suis Ova (TSO) in der Behandlung des pädiatrischen $M$.} Crohn - Ergebnisse von drei Heilversuchen

D. Scholz', K. Heesch², S. Disse', M. Jacobsen², K. Zimmer ${ }^{1}$

'Zentrum für Kinderheilkunde der Justus-v.-Liebig-Universität, ${ }^{2}$ BernardNocht-Institut für Tropenmedizin

Einleitung: Chronisch-entzündliche Darmerkrankungen sind bisher nicht heilbar. Ziel der Therapie sind Induktion und Erhaltung der Remission durch immunsuppressive und immunmodulatorische Medikamente. Wir berichten über die Ergebnisse eines Heilversuchs mit Trichuris suis ova (TSO) an drei Patienten mit steroidabhängigem M. Crohn.

Methoden: Ein Mädchen und zwei Jungen im Alter von 9-16 Jahren und deren Eltern wurden über mögliche Risiken des in der Pädiatrie noch nicht zugelassenen Medikaments TSO aufgeklärt. Die Erkrankungsdauer lag zwischen 1,1 und 2,5 Jahren. Trotz Behandlung mit systemischen Kortikosteroiden, Azathioprin und Mesalazin sowie Ernährungstherapie mit Modulen IBD war es nicht zur anhaltenden Remission gekommen. Nach endoskopischer Bestimmung von Ausmaß und Lokalisation der entzündlichen Veränderungen erfolgte körperge- wichtsadaptiert in ansteigender Dosierung alle 14 Tage eine orale Gabe von 500-2. 500 lebenden TSO der Firma Ovamed GmbH. Die übrigen Medikamente wurden

wie zuvor

weiter eingenommen. Der pediatric Crohn's disease activity index nach Hyams, der sonografische Befund, das Calprotectin und die Ausscheidung von Wurmeiern und Parasiten im Stuhl wurden monatlich kontrolliert. Nach Abschluss der 20-wöchigen Behandlung erfolgte eine erneute endoskopische Untersuchung. T-Lymphozyten wurden vor und unter der Behandlung isoliert und ex vivo kultiviert.

Ergebnisse: Subjektiv kam es bei allen drei Patienten initial zu einer Besserung der Symptomatik unter der Gabe von TSO, Probleme mit der Therapieadhärenz wurden bislang nicht berichtet. Die Bewertung der im Verlauf erhobenen objektiven Daten steht noch aus, Hinweise auf eine anhaltende Infektion mit Trichuris suis fanden sich soweit nicht.

An ex vivo kultivierten T Zellklonen der Patienten konnte das Zytokinprofil der T-Zell-Repertoires (CMV-spezifisch und generell), sowie deren Phänotyp und Differenzierungsstadium bestimmt werden.

Diskussion: Die Entzündung beim M. Crohn wird durch Zytokine wie TNF- $\alpha$, IFN- $\gamma$ und IL-12 vermittelt, die im Rahmen einer T-Helfer-1(TH1)-Zell-Antwort produziert werden. Eine Infektion mit Helminthen löst eine $\mathrm{TH}_{2}$-dominierte Reaktion und die Aktivierung regulatorischer T-Lymphozyten aus. Die Ingestion von Eiern des Schweinepeitschenwurms Trichuris suis induziert eine Immunreaktion im Gastrointestinaltrakt des Menschen, bevor die Larven im Fehlwirt zugrunde gehen. Pilotstudien an Erwachsenen demonstrierten eine höhere Remissionsrate bei M. Crohn und Colitis ulcerosa unter zusätzlicher Gabe von TSO als unter ausschließlich immunsuppressiver Therapie. In unserem Heilversuch bestätigte sich bis dato die gute Verträglichkeit von TSO. Der Nachweis der Wirksamkeit bei der Remissionsinduktion steht noch aus. Die TH1/TH2-Polarisation der Lymphozyten soll Hinweise auf die immunmodulatorische Wirkung im Sinne einer Konversion der T-Helfer-Zell-Antwort geben. Kontrollierte Langzeit-Studien an einem größeren Patientenkollektiv sind dringend notwendig, um Nutzen und Risikoprofil der Behandlung mit TSO zur Induktion und Erhaltung der Remission beim M. Crohn im Kindes- und Jugendalter zu überprüfen.

\section{DGKJ-PV-084}

\section{Transiente Elastographie - Normwerte bei gesunden Kindern}

U. Teufel, C. Gebhardt, G. Engelmann, E. Wühl, G. Hoffmann, J. Schenk Klinikum d.Ruprecht-Karl- Universität

Einleitung: Leberfibrose und Leberzirrhose sind auch bei Kindern und Jugendlichen die gemeinsame Endstrecke zahlreicher Lebererkrankungen. Die frühe Feststellung einer Leberfibrose ist wichtig, um ein Voranschreiten zur Zirrhose und den damit verbundenen Komplikationen zu vermeiden. Bisher ist die Leberbiopsie der Goldstandard zur Feststellung und Einschätzung der Fibrose. Seit ein paar Jahren kommt eine neue nicht-invasive Methode (transiente Elastographie) vor allem bei Erwachsenen, aber vereinzelt auch bereits bei Kindern, zum Einsatz. Hierbei wird eine Impulswelle in die Leber abgegeben. Durch die Bestimmung der Ausbreitungsgeschwindigkeit, die direkt proportional zur Steifigkeit ist, kann direkt auf den Grad der Leberfibrose geschlossen werden. Bei Kindern gibt es bisher keine Normwerte für diese Untersuchung. Wir haben daher die Durchführbarkeit im Kindes- und Jugendalter untersucht und altersspezifische Normwerte für ein großes gesundes Kollektiv erstellt.

Methode: Bisher wurde bei 530 lebergesunde Kinder zwischen o und 18 Jahren die transiente Elastopgraphie durchgeführt. Das Vorliegen einer Lebererkrankung wurde mittels ausführlicher Anamnese, klinischer Untersuchung, Labordiagnostik und Sonographie vorher ausgeschlossen.

Ergebnisse: Die gemessenen Werte der Steifigkeit lagen zwischen 2,4 $\mathrm{kPa}$ (Minimum) und 10,5 kPa (Maximum). Der Median beträgt 4,6 $\mathrm{kPa}$. $95 \%$ der Werte lagen zwischen $2,4 \mathrm{kPa}$ und 7,4 $\mathrm{kPa}$. Erstellt man 
anhand der Daten mittels der LMS-Methode nach Cole Perzentilenkurven der Steifigkeitsmesswerte bezogen auf das Alter, zeigt sich ein leichter Anstieg der Werte mit zunehmendem Alter. So liegt z. B. im Alter von 0-1 Jahre die 50. Perzentile bei 4,18 kPa und steigt bis 5,04 kPa im Alter von 18 Jahren an.

Zusammenfassung: Die transiente Elastographie ist eine einfach durchführbare neue Methode. Sie ersetzt nicht die Leberbiopsie bei der Diagnosestellung sondern wird ihren Wert v. a. in der Verlaufsbeobachtung haben. Die von uns erhobenen Normwerte ermöglichen eine Einordnung der bei Patienten mit Lebererkrankungen erhobenen Befunde.

\section{DGKJ-PV-085}

Hypertrophe eosinophile Gastritis als Manifestation eines systemischen Lupus erythematodes

S. Arens' ${ }^{1}$, R. Melchior ${ }^{2}$, F. Tegtmeyer ${ }^{1}$

${ }^{1}$ Kinder-Klinik Park Schönfeld, ${ }^{2}$ Praxis für Kindergastroenterologie

Gastrointestinale Symptome treten bei circa $40 \%$ der Patienten mit einem systemischen Lupus erythematodes (SLE) auf, bereits bei Manifestation und nicht selten in Assoziation mit einer Pankreatitis. Eine hypertrophe Gastropathie oder eine eosinophile Erkrankung des Magen-Darm-Traktes ist jedoch kaum bekannt. Wir beschreiben eine Patientin, bei der eine hypertrophe eosinophile Gastritis zur Diagnose eines SLE führte.

Bei der bisher gesunden 17-jährigen, eutrophen Patientin wurde nach mehrwöchigen Oberbauchbeschwerden eine endoskopisch diagnostizierte Gastritis mit Omeprazol behandelt. Auf Grund anhaltender Beschwerden erfolgte eine Reevaluation in unserer Klinik, dabei zeigte sich eine deutliche Blut-Eosinophilie (>30\%), eine mikrozytäre Anämie sowie endoskopisch ein auffälliges Relief der Magenwand im Antrum. Sonographisch fand sich eine scharf begrenzte Struktur mit Aufhebung der normalen Wandschichtung, die ebenso in der MRT nachgewiesen wurde, weitergehende strukturelle Auffälligkeiten bestanden nicht. Histologisch wurde eine ausgeprägte eosinophile entzündliche Infiltration nachgewiesen. Parasitäre Erkrankungen wurden ausgeschlossen. Im Stuhl wurde ein deutlicher enteraler Proteinverlust gefunden, korrespondierend zu einem leicht erniedrigten Serum-Eiweiß. Die Diagnose des SLE wurde dann durch hochpositive Doppelstrang-DNA-Antikörper $(397,5 \mathrm{IE} / \mathrm{ml})$ und einen ANA-Titer von 1: 3200 sowie die Blutbildveränderungen und begleitende Arthralgien gestellt. Unter Prednisontherapie besserten sich die abdominellen Beschwerden innerhalb von Tagen, der Serum-Eiweißwert normalisierte sich und endoskopisch sowie sonographisch zeigte sich eine deutliche Besserung des Lokalbefundes im Antrum.

Die primären eosinophilen Erkrankungen des Magen-Darm-Traktes sind seltene Erkrankungen, die jeden Abschnitt vom Ösophagus bis zum Kolon betreffen können und typischerweise durch eine periphere Eosinophilie, segmentale eosinophile Infiltration und funktionelle Störungen gekennzeichnet sind. Die Schleimhautbeteiligung äußert sich in einem enteralen Eiweißverlust, Wandverdickungen führen zu Motilitätsstörungen. Speziell die Abgrenzung zu allergischen Erkrankungen kann schwierig sein. Die Assoziation mit autoimmunen Erkrankungen ist beschrieben, bisher nur in Einzelfällen auch mit einem systemischen Lupus erythematodes. Das Procedere entspricht hier den Prinzipen der SLE-Therapie, in welcher systemische Corticosteroide eine führende Rolle einnehmen.

\section{DGKJ-PV-086}

\section{Säuglingstoxikose (hypertone Dehydratation) nach Gastroenteritis} durch Adenoviren

U. Neitzke, S. Niemeier, C. Fehlandt, M. Radke

Klinikum Ernst v. Bergmann

Die akute Gastroenteritis ist mit 0,9 - 1,9 Episoden pro Jahr in den ersten 3 Lebensjahren eine häufige Erkrankung. Durch Wasser- und Elektrolytverlust kommt es zur Dehydration.
Der Typ der Dehydratation, isoton, hypoton oder hyperton, ist unabhängig vom Erreger.

Fallbeispiel: Anamnese: 1 1/12 Jahre alter Junge mit anhaltendem Durchfall (7 Tage), Erbrechen (2 Tage), seit dem Vortag Fieber bis $40^{\circ} \mathrm{C}$, bisherige Behandlung mit oraler Elektrolytlösung, Fiebersaft, Dimenhydrinat. Bei Aufnahme in einem auswärtigen Krankenhaus Hypernatriämie (175 mmol/l), Hyperglykämie $(22,8 \mathrm{mmol} / \mathrm{l})$, Hyperkaliämie (6,2 mmol/l), metabolische Azidose ( $\mathrm{pH} 7,12, \mathrm{BE}-16,2 \mathrm{mmol} / \mathrm{l})$, Zeichen einer Niereninsuffizienz (Kreatinin 152,5 $\mu \mathrm{mol} / \mathrm{l}$, Harnstoff 20,65 $\mathrm{mmol} / \mathrm{l})$. Bei Verdacht auf diabetische Ketoazidose Beginn der Rehydratationstherapie mit halbisotoner Elektrolytlösung + Glukose 5\%, Gabe von Insulin i. v., Pufferung mit Natriumbicarbonat, Verlegung in unsere Klinik mit dem Hubschrauber.

Aufnahmestatus: Deutlich reduzierter Allgemeinzustand, Temp. $40^{\circ} \mathrm{C}$, reagiert auf Ansprache, Hautturgor stark vermindert, stehende Hautfalten, Akren kühl, Augen haloniert, Fontanelle eingesunken, Schleimhäute trocken und borkig, Herzfrequenz tachykard (200/min), RR $114 / 60 \mathrm{mmHg}$, Herzaktion rhythmisch, Tachypnoe (6o/min), keine Infektzeichen, keine meningitischen Zeichen, intermittierend somnolent mit Augenverdrehen. KG: ca. 9 kg, Gewichtsabnahme ca. 1,5 kg (15$20 \%$ des Körpergewichts).

Labor: Na $186 \mathrm{mmol} / \mathrm{l}$, Kalium 3,6 mmol/l, Osmolalität $384 \mathrm{mOsmol} /$ $\mathrm{kg}$, Kreatinin $150 \mu \mathrm{mol} / \mathrm{l}$, Harnstoff $24 \mathrm{mmol} / \mathrm{l}$, SB-Status: metabolische Azidose ( $\mathrm{pH}$ 7,28, BE -10,5 mmol/l), BZ 4 mmol/l.

Verlauf: Rehydratation mit physiologischer Kochsalzlösung und Glucose $10 \%$. Intermittierend auch Infusion von 1 molarer Natriumchloridlösung notwendig, um das Serumnatrium um maximal $0,5 \mathrm{mmol} / \mathrm{l} / \mathrm{h}$ zu senken. Innerhalb der ersten 8 Stunden hatte der Patient zwei cerebrale Krampfanfälle von jeweils wenigen Minuten Dauer. Das NotfallSchädel-CT war unauffällig, kein Anhalt für ein Hirnödem/Einklemmung. Ab dem 2. Tag orale Aufnahme geringer Mengen Rehydratationslösung, ab dem 3. Tag Beendigung der Infusionstherapie möglich, am 4. Behandlungstag waren die Elektrolyte ausgeglichen, die Retentionsparameter und der Blutzucker normalisiert.

Fazit: Bei der hypertonen Dehydratation ist der Natriumverlust $>$ Wasserverlust, durch Hyperosmolalität des Extrazellularraums kommt es zur Flüssigkeitsverschiebung von intra- nach extrazellular. Die Hämodynamik bleibt relativ lange gut erhalten, deshalb wird das Ausmaß der Dehydratation häufig unterschätzt. Bei übermäßiger Zufuhr von hypoosmolaren Lösungen, freiem Wasser besteht Gefahr des Hirnödems. Bei hypertoner Dehydratation mit $\mathrm{Na}>160 \mathrm{mmol} / \mathrm{l}$ ist die langsame Senkung des Natriums (max. $10 \mathrm{mmol} / \mathrm{l} / 24 \mathrm{~h}$ ) zur Verminderung der Gefahr eines Dysäquilibriums wichtig. Ausgleich des Flüssigkeitsdefizits über mindestens $48 \mathrm{~h}$.

Bei dem beschriebenen Fall wurde durch langsame Rehydratation und Absenkung des Serumnatriums ein Hirnödem vermieden. Es lagen keine Veränderungen der Retentionsparameter und des Blutzuckers mehr vor. Allerdings zeigten sich nach 5 Tagen ataktische Bewegungsstörungen/Gleichgewichtsstörungen sowie eine Sprachentwicklungsverzögerung bisher unklarer Genese.

\section{DGKJ-PV-087}

Überleben und Komplikationen nach pädiatrischer Lebertransplantation - Analyse in einem „,neuen“ Zentrum

S. Schulz-Jürgensen, M. Kohl, M. Krause, B. Dresske, M. Schulze, D. Bröring, M. Burdelski

Universitätsklinikum Schleswig-Holstein, Campus Kiel, Kliniken für Allgemeine Pädiatrie und Chirurgie

Fragestellung: Die Ergebnisse der pädiatrischen Lebertransplantation (LTX) konnten seit den Anfängen 1978 kontinuierlich verbessert werden. Die internationalen Transplantationszentren konnten dabei an Überleben und Komplikationen eine Lernkurve demonstrieren, die für die letzten Jahre 1- und 5-Überlebensraten im Bereich von 90-95\% zeigten, mit Patientenverlusten v. a. im ersten Jahr nach Transplantation. Da sich neue Zentren mit diesen sehr guten Ergebnissen messen müssen, sollte untersucht werden, ob ein „neues“ Zentrum mit lebertrans- 
plantations-erfahrener pädiatrischer und chirurgischer Leitung, an die Ergebnisse dieser Lernkurve anknüpfen kann.

Material und Methode: Die 59 Transplantationen bei 55 Patienten im seit 2007 bestehenden Kinderlebertransplantationszentrum in Kiel wurden retrospektiv untersucht. Es handelte sich um 38 Lebend- und 21 Fremdspenden, das Empfängeralter betrug im Median 11,3 Monate (Range 2,2-121,5), die Beobachtungszeit nach LTX 18,o Monate (Range $0,5-43,8)$. Indikationen waren Gallengangsatresie $(53 \%)$, cholestatische Lebererkrankungen (14\%), Stoffwechselstörungen (13\%), vaskuläre Probleme (5\%), und sonstige (14,5\%). Es wurden chirurgische (Gefäß- und Gallengangsprobleme, Narbenprobleme) und pädiatrische (Abstossung, Transplantatverlust, -dysfunktion, Komplikationen der Immunsupression) Komplikationen unterschieden.

Ergebnisse: Es zeigte sich ein bisheriges Gesamtüberleben von $98 \%$, der eine verstorbene Patient war bereits in intensivmedizinisch sehr kritischem Zustand und als Notfallindikation in die LTX gegangen. Das Transplantatüberleben betrug 93,2\%, Gründe für Organverlust waren primäre Nichtfunktion, Thrombose der A. hepatica und chron. Dysfunktion. An chirurgischen Komplikationen wurden 12\% Gallengangs-, 14\% Pfortader-, 5\% Arterienprobleme, 8\% Wundheilungsstörungen und 7\% Darmprobleme beobachtet. Pädiatrische Komplikationen waren: 30\% Hypertonus, 23\% Infektionen, 21\% Abstossung, 7\% Small-for-size-Syndrom, $5 \%$ Nephrotoxizität, $2 \%$ prim. Transplantatversagen, $2 \%$ Lebertoxizität, $2 \%$ Milzinfarkt, $2 \%$ Hodgkin-Lymphom). Die unterschiedlichen Nachbeobachtungszeiten $(<1,1-2$ oder $>2$ Jahre) zeigten keinen signifikanten Unterschied.

Diskussion: Die Ergebnisse liegen durchweg im oberen Bereich der international berichteten Lernkurve der letzten Jahre. Es ist somit davon auszugehen, dass Vorerfahrungen der pädiatrischen und chirurgischen Leitungen in einem neuen Team nutzbar sind und zu mit langjährigen Zentren vergleichbaren Ergebnissen führen.

Schlussfolgerung. Bei entsprechender pädiatrischer und chirurgischer Kompetenz und Erfahrung der Leitung ist ein „neues“ Zentrum in seinen Ergebnissen mit langjährigen Zentren konkurrenzfähig.

\section{DGKJ-PV-088}

Schwerer Verlauf einer Rotavirusinfektion mit Hyponatriämie und cerebralem Krampfstatus bei einem 10 Wochen alten ehemaligen Frühgeborenen der 34 . SSW

A. Kirchner, D. Kober, W. John, T. Uhlig

Klinik für Kinder und Jugendliche, RoMed Klinikum Rosenheim, Lehrkrankenhaus der LMU München

Hintergrund: Die Rotavirusenteritis im Kindesalter, eine der häufigsten Todesursachen in Entwicklungsländern, gilt in entwickelten Ländern als relativ problemlos zu behandelnde Erkrankung, die in der Regel komplikationslos verläuft. Wir berichten hier über einen ausgesprochen schweren und komplizierten Verlauf einer Rotavirusinfektion bei einem ehemaligen Frühgeborenen.

Case Report: Das ehemalige Zwillingsfrühgeborene der 34. SSW (GG $1630 \mathrm{~g})$ konnte nach zunächst problemlosem postpartalem Verlauf und guter Gewichtszunahme bereits im Alter von 6 Wochen nach Hause entlassen werden. Drei Tage vor der erneuten stationären Aufnahme kam es zu Erbrechen und dünnen Stühlen mit zunehmender Verschlechterung des AZ. Die stationäre Einweisung erfolgte durch den Notarzt nachdem ein ausgeprägter Zyanoseanfall beobachtet wurde. Bei Aufnahme entwickelte das Kind einen tonischen über 12 Minuten andauernden Krampfanfall. Begleitend wurde eine Hyponatriämie von $117 \mathrm{mmol} / \mathrm{l}$ festgestellt. Unter antikonvulsiver Therapie sistierte der Krampfanfall, allerdings machten fortbestehende rezidivierende Apnoen und Bradykardien eine Intubation und maschinelle Beatmung notwendig. Zur Kreislaustabilisierung waren mehrerer Volumengaben und zusätzlich Katecholamine notwendig. Entzündungsparameter, Blut- und Liquorkulturen sowie Liquorstatus waren unauffällig, ebenso EEG-Befund, Ultraschall und MR des ZNS. Als Ursache des Krankheitsbildes war lediglich eine Rotavirusinfektion nachweisbar. Nach knapp 3 Wochen stationärer Behandlung konnte der Säugling entlassen werden.

Diskussion: Obgleich die Rotavirusenteritis bei entsprechender Therapie meist komplikationslos verläuft, werden in der Literatur immer wieder auch Einzelfälle mit sehr schweren Verläufen berichtet. Gerade neurologische Komplikationen, wie auch bei unserem Patienten, scheinen hier regelmäßig beobachtet zu werden, weshalb hierfür auch jüngst eine ESPED-Erhebung etabliert wurde. Ob ehemalige Frühgeboren hierfür ein erhöhtes Risiko haben ist bisher nicht systematisch untersucht, gilt allerdings als wahrscheinlich. Zur Prophylaxe der Rotavirusinfektion stehen zwei wirksame und gut verträgliche Impfstoffe zur Verfügung. Unser Patient hätte von aufgrund seines Alters bereits geimpft sein können, was den schweren Verlauf mit großer Wahrscheinlichkeit verhindert hätte.

Schlussfolgerungen: Rotavirusinfektionen können bei Säuglingen und möglicherweise gerade bei ehemaligen Frühgeborenen sehr schwere Verläufe mit neurologischer Manifestation verursachen. Dies sollte bei der Risiko/Nutzen Abwägung der Rotavirusschutzimpfung berücksichtigt werden.

\section{DGKJ-PV-089}

\section{Enteric-Coated Cysteamine Bitartrate for the Treatment of NAFLD in} Children

S. Schmeltzer', T. Wang ${ }^{2}$, B. Cabrera2, J. Durelle'2, P. Shragg ${ }^{2}$, J. Schwimmer ${ }^{2}$, J. Lavine², R. Dohil²

'Departments of Pediatrics, University of California, San Diego, CA and Department of Pediatrics, Carl-Thiem-Klinikum Cottbus, ${ }^{2}$ Departments of Pediatrics, University of California, San Diego, CA

Background. Nonalcoholic fatty liver disease (NAFLD) is common in children. Hepatic fat accumulation and oxidative stress contribute to its pathogenesis. The thiol agent cysteamine bitartrate $\left(\right.$ Cystagon $\left.{ }^{R}\right)$ readily crosses cellular membranes and is FDA approved for the treatment of the lysosomal storage disorder cystinosis. Cysteamine is a scavenger of reactive oxygen species and a potent antioxidant through increased intra-cellular glutathione production.

Aim. Evaluate the safety and potential efficacy of enteric-coated (EC) cysteamine therapy for NAFLD in children.

Method. Children $>10$ y with biopsy proven NAFLD and elevated ALT were treated with twice-daily EC-Cysteamine for 6 months. Drug dosage was increased as tolerated over $9 \mathrm{~d}$ to maximum (100omg). Monthly physical examination, AST/ALT, weight/body mass index (BMI). Subjects with $>50 \%$ sustained reduction in ALT reached end-point for the study. GI symptom scores (maximum score 14) were measured.

Results. 11 of 13 children (11-17y, mean 14. oy) were enrolled and completed EC-Cysteamine therapy (final dose range 200-100omg, mean $695 \mathrm{mg}$ or $7.6 \mathrm{mg} / \mathrm{kg}$ body weight /dose). For these 11 patients the mean ALT levels at baseline and after 6 months EC-Cysteamine were 120. 2 and $54.5 \mathrm{iu} / \mathrm{l}$, respectively (p<0.004), and for AST levels were 60. 3 and $35.7 \mathrm{iu} / \mathrm{l}$, respectively $(\mathrm{p}=\mathrm{0} . \mathrm{02})$. Of the 11 subjects, primary end-point was reached in 7 and normalization of ALT/AST levels in 6. The mean BMI was 34.5 at baseline and $34.2 \mathrm{~kg} / \mathrm{m}^{2}$ after treatment $(\mathrm{p}=0.37)$. Although the mean symptom scores at baseline (1.1) and after 6 months EC-Cysteamine (o. 7) were similar, some patients did initially report mild GI symptoms which either resolved spontaneously or with dose reduction. No major adverse events were reported.

Conclusions. EC-Cysteamine reduces ALT and AST levels in children with NAFLD without reduction in BMI. Transient GI symptoms may be due to rapid initial drug dosing. Further studies are required to evaluate optimal cysteamine dose and effect on liver histology in NAFLD patients. 


\section{Stoffwechselstörungen und Neuropädiatrie}

\section{DGKJ-PV-090}

Neuraminidase-Defekt und verwandte Stoffwechselkrankheiten

E. Strehle

Faculty of Medical Sciences

Der Neuraminidase-Defekt, auch Sialidose genannt, ist eine seltene lysosomale Speicherkrankheit, die durch eine Fehlfunktion des Enzymes Neuraminidase (Sialidase) verursacht wird. Dieser Enzymdefekt führt zu einer intrazellulären Speicherung von zuckerähnlichen Substanzen, den Sialinsäuren. Das korrespondierende Gen NEU1, das beim Neuramindase-Defekt mutiert ist, befindet sich auf dem kurzen Arm von Chromosom 6. Beim Menschen gibt es zwei Formen der Sialidose: den leichteren Typ I, der in der Pubertät oder dem frühen Erwachsenenstadium beginnt, und den schwereren Typ II, der bei der Geburt oder in der frühen Kindheit auftritt. Gegenwärtig existiert keine Therapie für diese progrediente Erkrankung. Der vorliegende Beitrag gibt einen Überblick des Enzymes Sialidase und seines Substrates Sialinsäure, des relevanten genetischen Hintergrundes und der verschiedenen Untergruppen der Sialidose einschliesslich des klinischen Managements. Darüberhinaus werden weitere Krankheiten diskutiert, die den Sialinsäure-Metabolismus betreffen: Galaktosialidose, Sialurie und Sialinsäurespeicherkrankheit.

\section{DGKJ-PV-091}

\section{SELTENE PÄDIATRISCHE STOFFWECHSELERKRANKUNGEN - DÜNN-} SCHICHTCHROMATOGRAPHIE ALS RATIONALE SCREENINGMETHODE G. Kalkum, E. Mengel, M. Beck

Klinikum der Johannes-Gutenberg Universität

Fragestellung: Wenn bei Patienten mit Symptomen lysosomaler Speichererkrankungen die Routinediagnostik nicht wegweisend ist, kann mit Hilfe der Dünnschichtchromatographie der Oligosaccharide (thin layer chromatography/TLC) ein Diagnoseweg aufgezeigt werden.

Material und Methoden: Wir stellen Ihnen Fälle von sehr seltenen Stoffwechselerkrankungen sowie deren Diagnostik vor. In unbehandelten Urinproben (Sammelurin) der Patienten wurden mit TLC die Oligosaccharide aufgetrennt. Pathologische Oligosaccharidmuster führten zur Diagnose dieser seltenen Stoffwechselerkrankungen.

Ergebnisse: Alle Patienten haben MPS (Mukopolisaccharidosen) ähnliche Symptome und eine normale MPS-Ausscheidung. Die TLC zeigte bei diesen Patienten auffällige Muster, die richtungsweisend für die Diagnose waren. Darunter sind Sialin-Transporterdefekt (= Salla disease), Sialidose (= Neuraminidasedefekt = Mukolipidose I), Aspartylglukosaminurie, Mannosidose und Fukosidose.

Diskussion: Leitbefunde für lysosomale Speichererkrankungen können Hydrops fetalis, neurodegenerative Symptome, muskuläre Hypotonie, Dysostosis multiplex und Hepato-/Splenomegalie sein.

Bei diesen Patienten kann die TLC über das MPS-Screening hinaus wertvolle Hinweise auf die richtige Diagnose geben. Obwohl die Differenzierung der einzelnen Erkrankungen nur mit Hilfe der TLC gelang, gibt es für jede Erkrankung wegweisende Symptome: Beim SialinTransporterdefekt die muskuläre Hypotonie; im Fall der Mannosidose eine Schwerhörigkeit; Angiokeratome bei der Fukosidose und kirschroter Fleck sowie Hydrops fetalis bei der Sialidose.

Schlussfolgerung: Bei Kindern mit Symptomen die auf lysosomale Speichererkrankungen hinweisen, kann die weitergehende Diagnostik in einem Stoffwechselzentrum mit Dünnschichtchromatographie wegweisend sein.
DGKJ-PV-092

Hyperinsulinismus-Hyperammonämie-Syndrom (HHS) mit hoher Ammoniak-Konzentration

A. Makowski', U. Schnackenberg' ${ }^{1}$ R. Santer², J. Dembinski'

${ }^{1}$ Kinderklinik Klinikum Itzehoe, ${ }^{2}$ Kinderklinik UKE

Einleitung: Das Hyperinsulinismus-Hyperammonämie-Syndrom (HHS) wird durch aktivierende Mutationen im Gen der Glutamatdehydrogenase (GLUD1) verursacht. Es wird vermutet, dass die dabei beobachtete Hyperammonämie $u$. a. durch verminderte Bildung von N-Acetylglutamat verursacht wird, das die Carbamyl-Phosphat-Synthetase (CPS), ein wichtiges Harnstoffzyklusenzym, aktiviert. Typisch ist die Manifestationsalter im Säuglings- oder Kleinkindalter mit Hypoglykämien und in der Regel milder Hyperammonämie. Kasuistik: 10 Monate alter männlicher Säugling ohne Vorerkrankungen mit generalisierten zerebralen Krampfanfällen und Erbrechen nach Genuss von Milchprodukten. Glucose i. S. 1,9 mmol/l (32 mg/dl). Übrige Laborwerte o. p. B.. Normale somatische und statomotorische Entwicklung, keine Dysmorphie, keine Hepatomegalie, unauffällige perinatale Anamnese, gesunde nicht-konsanguine Eltern und Geschwister. Die weitere Diagnostik zeigte $\mathrm{NH}_{3}$-Konzentrationen im Blut bis $268 \mathrm{mmol} / \mathrm{l}$ als Hinweis auf ein HHS. Ursächlich war eine in heterozygotem Zustand vorliegende Mutation, c. 956A $>\mathrm{G}$ (p. Tyr266Cys), im Exon 7 des GLUD1-Gens. Die Hyperammonämie konnte durch Carbamylglutamat-Behandlung nicht beeinflusst werden. Der Hyperinsulinismus sprach gut auf Diazoxid (+Hydrochlorothiazid) und eiweißreduzierte Diät an. Schlussfolgerung: Im Rahmen eines HHS können ungewöhnlich hohe $\mathrm{NH}_{3}$ Konzentrationen (auch $>200 \mathrm{umol} / \mathrm{l}$ ) auftreten. Diese waren in unserem Fall nicht mit akuten Intoxikationszeichen verbunden; es sind aber HHS-Fälle mit mentaler Retardierung und Anfallsleiden beschrieben. Die genaue Ursache hoher $\mathrm{NH}_{3}$-Konzentrationen bei HHS ist noch nicht bekannt. $\mathrm{Ob}$ und $\mathrm{ab}$ welcher $\mathrm{NH}_{3}$-Konzentrationen bei HHS mit zerebraler Schädigung zu rechnen ist und wie diese von den Effekten des Hyperinsulinismus abzugrenzen sind, ist aktuell unklar.

\section{DGKJ-PV-093}

Ist der klassischeBH4-Test nach Blasovic geeignet um eine $\mathrm{BH}_{4}$-Sensitivität bei Patienten mit PKU festzustellen? Eine retrospektive Studie. H. Pfeiffer, I. Franke, M. Lentze

Universitätsklinik Zentrum f. Kinderheilkunde

Einleitung: In den letzten Jahren wurde in vielen Studien gezeigt, dass durch die Gabe von hochdosiertem $\mathrm{BH}_{4}$, die phenylalaninarme Diät von Patienten mit PKU gelockert, teilweise sogar beendet werden kann. Kann der klassische $\mathrm{BH}_{4}$-Belastungstest nach Blasovic die Patienten, die sensibel auf $\mathrm{BH}_{4}$ reagieren, herausfiltern?

Methode: Wir führten eine retrospektive Studie anhand der Akten von 112 Patienten mit PKU, die wir regelmässig in unserer Ambulanz betreuen, durch. Bei 24 Patienten fand sich ein verwertbarer $\mathrm{BH}_{4}$-Test (durchgeführt in den Jahren 1977-1999). Bei 20 dieser 24 Patienten lag eine Genotypisierung vor. Bei 5 von 24 Patienten wurde vor dem $\mathrm{BH}_{4}$ Test ein Phenylalaninbelastungstest mit $180 \mathrm{mg} / \mathrm{kg} / \mathrm{KG}$ durchgeführt. Es wurde der $\mathrm{BH}_{4}$-Test nach Blasovic mit $20 \mathrm{mg} / \mathrm{kg} / \mathrm{KG}$ durchgeführt. Der Phenylalaninspiegel und Tyrosinspiegel wurden zum Zeitpunkt o $\mathrm{h}, 4 \mathrm{~h}$ und $8 \mathrm{~h}$ nach $\mathrm{BH}_{4}$-Gabe bestimmt. Der mittlere Phenylalaninspiegel vor Beginn des Testes lag bei 16 . o mg/dl (3,1 bis $42,8 \mathrm{mg} / \mathrm{dl}$ ), nach 4 Stunden $16,7 \mathrm{mg} / \mathrm{dl}$ (4,5 $\mathrm{mg}$ bis $48,0 \mathrm{mg} / \mathrm{dl})$ und nach 8 Stunden 16,8 $\mathrm{mg} / \mathrm{dl}(2,75-33,9 \mathrm{mg} / \mathrm{dl})$.

Ergebnisse: Obwohl unter den Patienten mehrere waren, die aufgrund ihres Genotypes sensibel auf $\mathrm{BH}_{4}$ reagieren müssten, kam es keinem der Patienten zu einer statistisch signifikante Reduktion des Phenylalanins nach $\mathrm{BH}_{4}$-Gabe.

Wir kommen daher zu dem Ergebnis, dass der klassische $\mathrm{BH}_{4}$-Test nach Blasovic nicht geeignet ist um eine $\mathrm{BH}_{4}$-Sensitivität bei Patienten mit PKU festzustellen. Viele Authoren beschreiben, dass es nach hochdosierter $\mathrm{BH}_{4}$ Gabe oft erst nach 12-24 Stunden zu einer Reduktion des Phenylalaninspiegels kommt. Bei Patienten, deren Genotyp für 
das Vorliegen einer $\mathrm{BH}_{4}$ Sensitivität spricht, sollte daher ein $\mathrm{BH}_{4}$-Test mit Bestimmung des Phenylalaninspiegels nach oh, $4 \mathrm{~h}, 8 \mathrm{~h}, 12 \mathrm{~h}$ und $24 \mathrm{~h}$ durchgeführt werden.

\section{DGKJ-PV-094}

Konfirmationsdiagnostik bei M. Niemann-Pick Typ C, eine retrospektive Analyse

R. Hartung, H. Runz, M. Beck, E. Mengel

Klinikum der Johannes-Gutenberg Universität

Hintergrund: Daten aus anderen europäischen Ländern, insbesondere England und Frankreich, lassen weiterhin vermuten, dass der M. Niemann-Pick Typ C unterdiagnostiziert ist. Eine entscheidende Ursache dafür könnte das Fehlen eines Testes sein, der einen M. Niemann-Pick $\mathrm{C}$ eindeutig beweist oder ausschließt.

Zur Beurteilung der diagnostischen Wertigkeit der häufigsten Untersuchungen haben wir retrospektiv die Daten von 46 in unserer Ambulanz mit M. Niemann-Pick Typ C diagnostizierten Patienten ausgewertet.

Methodik: Wir haben retrospektiv die Daten von 46 Patienten (40 Patienten und 6 betroffene Geschwister) bzgl. Chitotriosidase, FilipinTest, Molekulargenetik des NPC1- und NPC2-Genes, Knochenmarkausstrich, vertikaler Blickparese und Splenomegalie ausgewertet. Das Alter der Patienten bei Diagnose lag zwischen o und 42 Jahren.

Als pathologisch wurde gewertet:

Chitotriosidase: $>200 \mathrm{mU} / \mathrm{ml}$ (bzw. $>100 \mathrm{mU} / \mathrm{ml}$ bei heterozygoter Mutation im Chito1-Gen)

Filipin-Test (Cholesterolspeicherung in Fibroblasten): klassisch oder variant

Molekulargenetik: 2 Mutationen (1 Mutation unklar, nur in Zusammenhang mit der Klinik beurteilbar)

Knochenmarksausstrich: Nachweis von Schaumzellen

Vertikale Blickparese: Sakkadenstörung oder Blickparese

Splenomegalie: >2 Standardabweichungen der Altersnorm.

Resultat: Bei 40 nichtverwandten Patienten zeigten sich folgende Ergebnisse:

Chitotriosidase (38 Pat.): 30 ( $79 \%)$ erhöht, 5 (13\%) nicht signifikant erhöht, 3 (8 \%) nicht auswertbar (Homozygote Mutation im Chito1Gen)

Filipin-Test (25 Pat.): 25 (100 \%) pathologisch

Molekulargenetik (29 Pat.): 21 (72\%) pathologisch mit 2 Mutationen, 4 (14\%) unklar bei 1 Mutation, 4 (14\%) ohne Mutation

Knochenmarksausstrich (15 Pat.): 14 (93\%) pathologisch, 1 (7 \%) unauffällig

Vertikale Blickparese (28 Pat.): 22 (79\%) pathologisch, 6 (21 \%) unauffällig

Splenomegalie (35 Pat.): 34 (97 \%) pathologisch, 1 (3\%) unauffällig.

Diskussion: Von den zur Diagnostik des M. Niemann-Pick Typ C durchgeführten Tests zeigte sich der Filipin-Test stets pathologisch. Dabei ist jedoch zu berücksichtigen, dass bei der hiesigen Analyse keine Spezifität und Sensitivität berechnet werden kann und es bei anderen lysosomalen Speicherkrankheiten oder nach wiederholten Passagen der Fibroblastenkultur zu pathologischen Filipin-Testen kommen kann. Ein negativer Test schließt einen M. Niemann-Pick Typ $\mathrm{C}$ weitestgehend aus. Gleichsinnig ist die Splenomegalie zu bewerten. Auch die Knochenmarksbiopsie zeigte mit hoher Wahrscheinlichkeit Schaumzellen. Hier ist jedoch neben anderen Erkrankungen zusätzlich eine Selektion des Patientengutes zu berücksichtigen, da die invasive Untersuchung nur bei ausgewählten meist unklaren Fällen durchgeführt wurde. Die Molekulargenetik des NPC1- und NPC2-Gens wird häufig propagiert, konnte aber nur in $72 \%$ ein eindeutiges Ergebnis liefern.

Aufgrund des Fehlens eines einzigen spezifischen Tests bei sehr guten weiteren Diagnostikmöglichkeiten, bietet sich die mit einem spezialisierten Zentrum abgestimmte Durchführung der o. g. Tests an, um eine möglichst rationale Diagnostik zu erzielen.

\section{DGKJ-PV-095}

Perioperatives und intensivmedizinisches Management von Patienten mit Mukopolysaccharidosen - wie viel ist nötig, wie viel ist möglich?

S. Wendt, K. Linz, E. Miebach, E. Mengel, M. Beck, R. Huth, S. Gehring

Klinikum der Johannes-Gutenberg Universität

Einleitung: Patienten mit Mukopolysaccharidosen, einer Gruppe angeborener lysosomaler Stoffwechseldefekte, leiden unter einer progredient verlaufenden Multisystemerkrankung. Limitierend ist neben der nicht bei jedem Subtyp auftretenden zentralnervösen Beeinträchtigung die Atemwegs- und muskuloskeletale Beteiligung. Beide führen altersabhängig häufig zu operationswürdigen Befunden. Dabei kommt es gehäuft zu Beatmungs- und intensivmedizinischen Komplikationen, wie z. B. der Notwendigkeit einer Tracheotomie, so dass sich die Frage nach der Möglichkeit einer gezielten Vorbereitung und angepassten Patientenführung stellt.

Patienten/Methoden: Wir untersuchten retrospektiv über einen Zeitraum von 3,5 Jahren alle MPS-Patienten, die postoperativ auf der pädiatrischen Intensivstation behandelt wurden, auf präoperative Risikofaktoren wie vorangegangene OPs, Schwere der Grunderkrankung, spezifische präoperativ vorbereitende Untersuchungen, OP- und Narkoseverlauf sowie postoperativen Verlauf einschließlich Beatmungsdauer, Komplikationen und respiratorisches Outcome.

Ergebnisse: 33 stationäre Aufenthalte von 26 Patienten mit MPS I, II, IV und VI im Alter zwischen 4 und 34 Jahren wurden untersucht. Die häufigste Operation war die kraniospinale Dekompression $(\mathrm{n}=21)$, hinzu kamen verschiedene orthopädische und HNO-Eingriffe, ein Herzklappenersatz, drei VP-Shuntanlagen und eine Appendektomie. Präoperativ wurden neben den eingriffspezifischen Untersuchungen wie MRT und SEP bei kraniospinaler Dekompression eine routinemäßige Evaluation des Schweregrades der Grunderkrankung mit Echokardiographie, 6-Minuten-Gehtest, Gelenkbeweglichkeitstestung und Lungenfunktionstest durchgeführt. Bei 19 Patienten erfolgte eine Bronchoskopie, die bei allen Patienten eine Trachealstenose zeigte. Postoperativ mussten 8/33 Patienten nachbeatmet werden. Von diesen benötigten nach Extubation zwei eine non-invasive Beatmung und fünf erhielten ein Tracheostoma. Ein Patient verstarb im unmittelbaren postoperativen Verlauf, jedoch nicht an einer Beatmungskomplikation. Ein Zusammenhang zwischen Trachealstenose und postoperativer Nachbeatmung konnte nicht hergestellt werden, es bestand jedoch ein deutlicher Zusammenhang zwischen klinischer und anästhesiologischer Einschätzung (Mallampati/McCormack) und Beatmungspflichtigkeit. Diskussion: Ein chirurgischer Eingriff ist, besonders bei fortgeschrittener Grunderkrankung, als anästhesiologische und intensivmedizinische Herausforderung zu sehen. Diese umfasst die präoperative Vorbereitung, Atemwegssicherung, Beatmungsführung und postoperativer Nachbehandlung bis zur erfolgreichen Beatmungsentwöhnung. Dabei scheinen invasive präoperative Untersuchungen weniger aussagekräftig als die klinische Untersuchung der Atemwege und die frühe Extubation wesentlich nicht nur für den Verlauf, sondern das endgültige respiratorische Outcome.

\section{DGKJ-PV-096}

Ungewöhnliches Bild bei multipler Sklerose im Jugendalter

K. Jülich, B. Lala, B. Spors, A. Kaindl

Charite Kliniken f. Kinderheilkunde und Kinderchirugie

Etwa 2-5\% aller an Multipler Sklerose (MS) Erkrankten zeigen bereits im Kindes- bzw Jugendalter erste Symptome. Gerade in diesem Alter kann die Diagnosestellung einer Multiplen Sklerose Schwierigkeiten bereiten, da häufiger als bei Erwachsenen atypische klinische Verläufe auftreten. Differentialdiagnostisch müssen infektiöse, entzündliche, metabolische, neoplastische und demyelinisierende Erkrankungen wie eine akute disseminierte Enzephalomyelitis (ADEM) sowie Mitochondriopathien, Leukodystrophien und Vaskulopathien in Betracht gezogen werden. Wir präsentieren eine zwölfjährige Patientin, die zum 
Zeitpunkt der Vorstellung über in das Bein ausstrahlende Schmerzen der rechten Hüfte und des Rücken klagte, die seit etwa zwei Wochen bestünden und sie beim Laufen erheblich einschränkten. Die Behandlung mit NSAR durch einen Orthopäden, bei dem sie sich zunächst vorgestellt hatte, brachte keine Besserung. In der Aufnahmeuntersuchung fielen zusätzlich eine Fußheberparese und ein positiver Babinskireflex rechts, eine Hypästhesie im Bereich des Thorax und der Streckseite des linken Oberschenkels sowie eine Abduktionsschwäche des linken Auges auf. Im Verlauf trat eine passagere Schluckstörung auf. In der kraniellen MRT zeigten sich multiple hypo- und hyperintense Läsionen im Marklager, subkortikal, im Mesenzephalon und über das gesamte Spinalmark verteilt, die nach Kontrastmittelgabe teilweise ein geschlossenes ringförmiges Kontrastmittelenhancement aufwiesen. Im Liquor bestand eine milde Pleozytose ohne Hinweis auf maligne Zellen und mit oligoklonalen Banden ohne Serumkorrelat. ZNS-Infektionen wie Toxoplasmose, Histoplasmose und Kryptokokkose, Tbc, HIV, Lues, Neuroborreliose und andere wurden ausgeschlossen. Wir interpretierten die Befunde als Hinweis auf das Vorliegen einer MS. Unter der Stoßtherapie mit Methylprednisolon über fünf Tage kam es zu einer Besserung der Beschwerden, freies Laufen war wieder möglich. Bei einer MS im Kindesalter treten im Vergleich zu Erwachsenen weniger typische und mehr atypische Veränderungen auf. Im Gegensatz zu tumefaktiven Läsionen mit offenem Ringenhancement sind die bei unserer Patientin in der MRT sichtbaren Läsionen mit geschlossenem ringförmigem Kontrastmittelenhancement auch für junge Patienten ungewöhnlich. Ebenso sind Schmerzen als subjektives Leitsymptom kaum beschrieben. Wie dieses Beispiel zeigt, kann das Bild einer Multiplen Sklerose im Kindesalter sehr variabel sein. Die Kenntnis der verschiedenen Phänotypen und Differentialdiagnosen ist wichtig, um die Diagnose zu stellen und die Patienten korrekt zu behandeln.

\section{DGKJ-PV-097}

ErsteErfahrungen mit einer neuen Methode der Low-Dose-Ganzkörper-Computertomographiezur Darstellung des ventrikuloperitonealen Shuntverlaufes im Kindesalter

M. Thiel' ', T. Kral ${ }^{2}$, H. Hamou ${ }^{2}$, C. Tödt'², F. Schellhammer ${ }^{2}$

${ }^{1} G$ emeinschaftskrankenhaus, Abteilung für Kinder- und Jugendmedizin, ${ }^{2}$ Gemeinschaftskrankenhaus

Hintergrund: Die radiologische Darstellung eines ventrikulo-peritonelaen Shuntverlaufes kann zeitaufwendig und strahlenrelevant sein ohne dass immer ein verlässliches Ergebnis erzielt wird.

Wir berichten über erste Erfahrungen mit einer modifizierten Low-Dose-Ganzkörper-Computertomographie zur Darstellung des zur Darstellung des ventrikuloperitonealen Shuntverlaufes im Kindesalter.

Methodik: Nach Lagerung des Patienten wir die CT durchgeführt und im Anschluss eine 3-D-Rekonstruktion angefertigt. Wir untersuchten die Parameter Untersuchungszeit, Strahlenexposition und diagnostischer Wert.

Ergebnisse: Die Untersuchungszeit war kürzer, der diagnostische Wert besser und die Strahlenexposition geringer.

Diskussion: Während die Untersuchungszeit kürzer zu sein scheint und der diagnostische Wert möglicherweise höher als bei projektionsradiographischen Aufnahmen, ist die Situation bezüglich der Strahlenexposition unklar, da ein optimales Modell zur Dosiskalkulation fehlt. Schlussfolgerung: Die Methode scheint die Kombination von guter diagnostischer Qualität in kurzer Untersuchungszeit zu erlauben. Solange die Strahlenexposition unklar ist setzen wir sie nicht routinemäßig ein. Wir stellen unsere Analyse der Methode sowie deren Vergleich mit theoretischen Daten und Literaturangaben vor und zur Diskussion.
DGKJ-PV-098

Über die Eignung der Startle-Reflex-Inhibition in der Diagnostik der Aufmerksamkeitsdefizit-Hyperaktivitäts-Störung

K. Rösicke, H. Polchau, P. Eggert

Universitätskinderklinik

Fragestellung: Es gibt Hinweise, dass die zentrale Reflexkontrolle, gemessen als Inhibition eines Schreckreflexes, bei Kindern mit Hyperaktivität eine wichtige Rolle bei der Pathogenese dieser Störung spielt. Die Hypothese liegt daher nahe, dass dieser Parameter zur Diagnose einer ADHS/ADS geeignet ist.

Material und Methode: Es wurde eine prospektive klinische Studie an Kindern $(n=26)$ durchgeführt, die sich zur primären Diagnostik mit Verdacht auf ADS/ADHS in einer Kinderarztpraxis vorstellten. Die Probanden durchliefen die übliche, umfassende Diagnostik auf ADS/ ADHS (Fragebögen, Intelligenztests, Konzentrationstests, Gedächtnistests, körperliche Untersuchung, Verhaltensbeobachtung). Zusätzlich wurde die Startle-Reflex-Inhibition gemessen. Dabei wurden den Probanden die akustischen Stimuli über einen Kopfhörer präsentiert und der Startle-Reflex (Lidschluss) als Elektromyogramm abgeleitet. Die Inhibition des Reflexes wurde durch einen leiseren Vorton induziert. Unterschieden wurde zwischen den Präpuls-60-Stimuli (Vorton 6oms vor Startle-Stimulus) und den Präpuls-120-Stimuli (Vorton 120ms vor Startle-Stimulus). Die Messergebnisse der Präpulsinhibition (PPI) wurden mit altersabhängigen Normwerten der Startle-Reflex-Inhibition von Kindern verglichen. PPI-Werte unter der 25. Perzentile der Norm wurden als auffällig gewertet. Die so ermittelten PPI-Daten wurden mit den Ergebnissen der konventionellen ADHS-Diagnostik verglichen.

Ergebnisse: Bei 11 Kindern wurde konventionell die Diagnose ADHS gestellt, bei vier die Diagnose ADS. Nach Messung der Präpuls-6o-Stimuli wurden 14 Kinder als auffällig eingestuft, nach Messung der Präpuls-120-Stimuli zeigten sich 11 auffällige Kinder. Es konnte jedoch keine signifikante Korrelation zwischen konventioneller Diagnostik und Messung der Startle-Reflex-Inhibition festgestellt werden.

Diskussion: Die Hypothese, dass Kinder mit ADS/ADHS sich grundsätzlich durch eine gestörte sensomotorische Hemmung (sensorimotor gating) auszeichnen und sich leicht durch eine schlechte PPI diagnostizieren lassen, ließ sich nicht bestätigen. Allerdings werden aufgrund der breit gefächerten konventionellen Diagnostik unter der Diagnose ADS/ADHS unterschiedlichste Störungen zusammengefasst von denen die vorgestellte Methode nur ein schmales Spektrum erfassen kann. Ein Hinweis darauf ist der, wenn auch schwache, Zusammenhang von PPI und Konzentrationsvermögen.

Schlussfolgerung: Die bekannten Methoden zur Diagnostik des ADS/ ADHS erfassen ein sehr uneinheitliches Störungsbild. Die vorgestellten Befunde geben dennoch Anlass zur Hoffnung, dass sich die Startle-Reflex-Inhibition für ein spezielles Segment dieser Patienten sowohl zur Diagnostik als auch zur Therapiekontrolle eignet.

\section{DGKJ-PV-099}

Bobble-Head-Doll Syndrom

B. Kasper' ${ }^{1}$, R. Brucker' ${ }^{2}$, S. Agsari' ${ }^{2}$ I. Henrichs' ${ }^{1}$, L. Haftel ${ }^{1}$

${ }^{1}$ Kliniken St. Elisabeth Klinik f. Kinder.- u. Jugendmedizin, ${ }^{2}$ Klinikum Ingolstadt

Einleitung: Das Bobble Head Doll Syndrom (= Wackelpuppenkopfsyndrom) ist eine seltene Bewegungsstörung mit neuropathologischer Ursache. Es lässt sich durch Konzentrationsaufgaben oder Schlaf unterbrechen und ist bisher, mit nur 34 Fällen weltweit seit Erstbeschreibung 1966, bei Kindern und Jugendlichen beschrieben worden (2).

Falldarstellung: Wir berichten über einen $13 / 12$ Jahre alten Jungen, der uns mit Rückschritten der motorischen Entwicklung, zunehmendem Makrozephalus und Strabismus divergens vorgestellt wurde. Daneben fielen ein langsamer Tremor des Kopfes und der Arme, sowie das Vorhandensein der Babinski-Reflexe beidseits auf. In der ZNS-Sonographie zeigte sich ein Hydrozephalus internus. In der kraniellen MRT bestätigte sich dieser (Abb. 2-4), als Ursache konnte eine zystische 
Raumforderung im Bereich des dritten Ventrikels identifiziert werden. Damit stellten wir die Diagnose eines Bobble-Head-Doll Syndromes. Es wurde darauf eine endoskopische Ventrikulozystostomie in Allgemeinnarkose durchgeführt. Dabei stellte sich die Raumforderung als supraselläre Subarachnoidalzyste des dritten Ventrikels dar. Bei der im Rahmen der Operation entnommenen Proben gelang histologisch der Nachweis einer Kolloidzyste.

Im Verlauf zeigte sich ein deutlicher Rückgang der neurologischen Auffälligkeiten, nickende Kopfbewegungen bestanden nicht mehr, zuckende Armbewegungen nur noch sehr selten. Weiterhin war jedoch phasenweises Schielen erkennbar. In der Kontroll-MRT konnten lediglich rudimentäre und denaturierte Reste der abgetragenen Zyste, sowie ein deutlicher Rückgang der Seitenventrikelerweiterung gesehen werden.

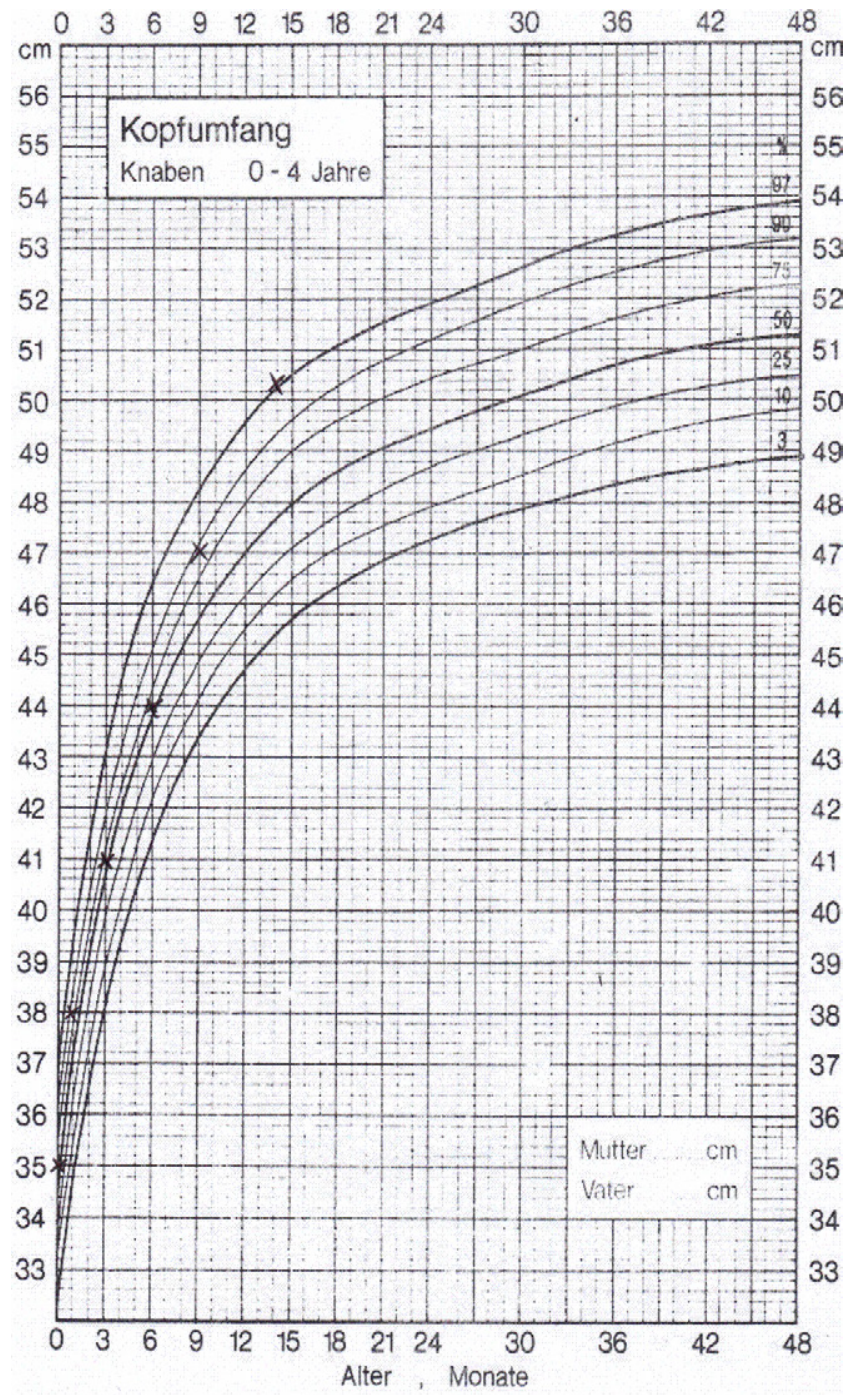

Kopfumfang Knaben 0 - 4 Jahre

Literatur: A. Prader et al. Helv. Paediat. Acta Suppl.52 pl - 1251989

Abb. 1: perzentilenkeuzendes Kopfwachstum

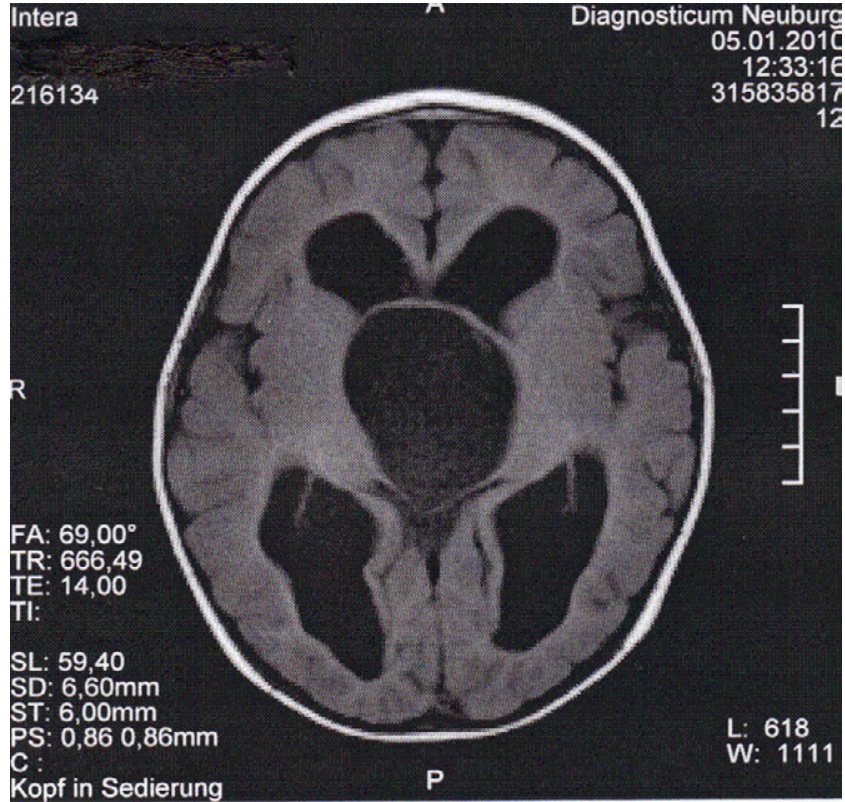

Abb. 4: Transversalschnitt mit Darstellung der Zyste und deutlich erweiterter Seitenventrikel

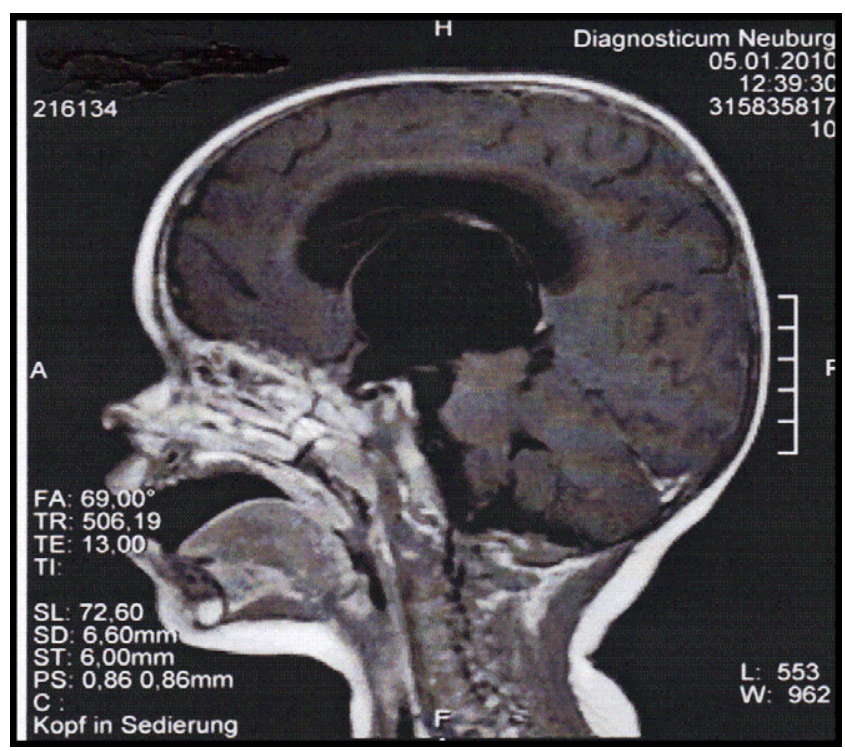

Abb. 3: Darstellung im Sagitalschnitt 


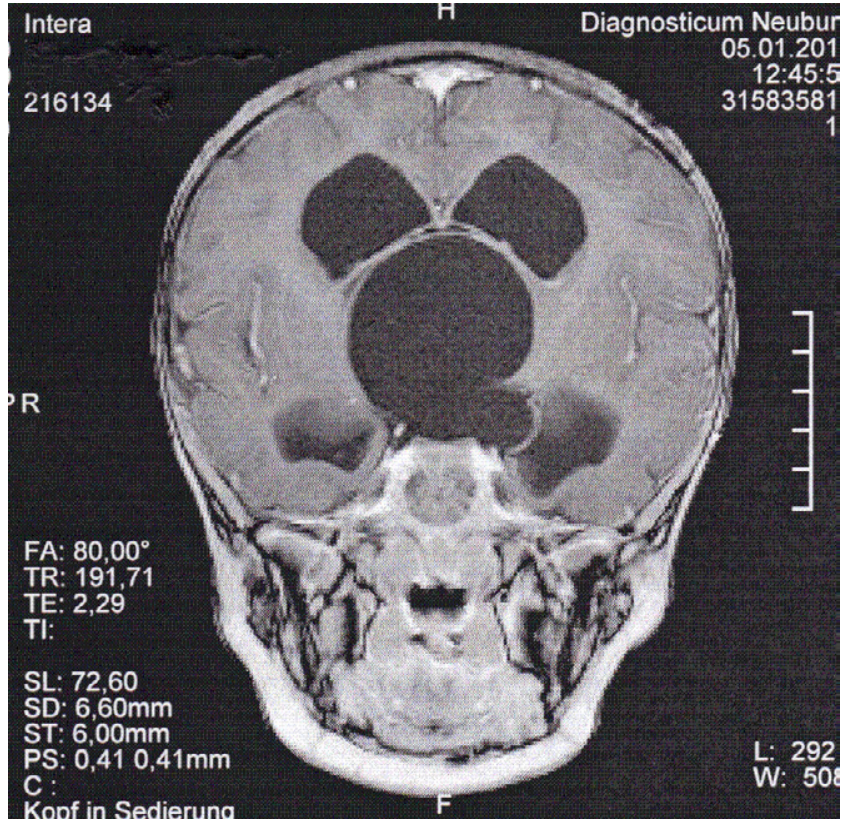

Abb. 2: MRT ( Koronarschnitt) mit zystischer Raumforderung im Bereich des dritten Ventrikels

Diskussion: Symptome des Wackelpuppenkopfsyndromes sind ein langsamer Tremor des Kopfes und eventuell des Rumpfes mit 1-3/sec und ein zunehmender Makrozephalus. Manifestationsalter ist vor allem $\mathrm{ab}$ der 7. Lebenswoche bis zum 5. Lebensmonat. Da dem Syndrom eine Fehlbildung mit sich langsam entwickelndem Hirndruck, meist eine Zyste im Bereich des dritten Ventrikels mit Einengung der Foramina Monroe zugrunde liegt, sollte zeitnah eine chirurgische Intervention erfolgen. Bei länger bestehender Symptomatik liegt die Erfolgsrate für das Verschwinden der Bewegungsstörung nach chirurgischer Intervention bei lediglich $50 \%$ (3).

Schlussfolgerung: Ein Kopftremor im Säuglings- und Kleinkindalter, Entwicklungsrückschritte, okkulomotorische Symptome und Makrozephalus sollten auch ohne klassische Symptome wie Nüchternerbrechen und Kopfschmerzen an einen sich langsam entwickelnden Hirndruck mit der Möglichkeit einer neurochirurgischen Therapie denken lassen.

Literatur: (1) Michaelis, Niemann (2004): Entwicklungs-neurologie und Neuropädiatrie. Thieme, 3. Aufl., S 257

(2) Nellhaus, G. (1967): Bobble-Head Doll Syndrome-A tic with a neuropathological basis. Pediatrics, 40 (2), 250-253.

(3) Goikhman, I., Zelnik, N., \& Peled, N. (1998). Bobble-head doll syndrome: A surgically treatable condition manifested as a rare movement disorder. Movement Disorders, 13(1), 192-194

Email: birgit. kasper@kliniken-st. elisabeth. de

\section{DGKJ-PV-100}

Veränderungen der Prä-Puls-Inhibition des akustischen Startle-Reflexes durch Methylphendiat bei Kindern mit $A D(H) S$ ?

A. Thiemann, S. Schulz-Jürgensen, P. Eggert

Universitätsklinikum Schleswig-Holstein, Campus Kiel

Fragestellung: Die Aufmerksamkeitsdefizit-/Hyperaktivitätsstörung (ADHS) ist die häufigste emotionale, kognitive und motorische Verhaltensstörung im Kindes- und Jugendalter. Sie ist relativ häufig mit einer nächtlichen Enuresis assoziiert. Studien an Kindern mit Enuresis konnten eine reduzierte Reflexhemmung (Prä-Puls-Inhibition (PPI)) in Startle-versuchen nachweisen, die durch ein gleichzeitig vorliegendes $\mathrm{AD}(\mathrm{H}) \mathrm{S}$ noch stärker ausgeprägt war, jedoch bei $\mathrm{AD}(\mathrm{H}) \mathrm{S}$ ohne
Enuresis nicht nachweisbar war ${ }^{1}$. Erwachsene mit $\mathrm{AD}(\mathrm{H}) \mathrm{S}$ haben nach Studienlage eine normale $\mathrm{PPI}^{2}$.

Die PPI ist Teil eines Reifungsprozesses, der bei verschiedenen Erkrankungen verzögert verläuft. Da bei Kindern mit Enuresis durch die dDAVP-Therapie eine Verbesserung der PPI erreicht werden $\mathrm{kann}^{3}$, und auch einzelne Patienten mit beiden Problemen von einer Besserung beider Symptomatiken durch eine Medikation berichteten, sollte hier die Hypothese untersucht werden, ob die Methylphenidat-Therapie bei $\mathrm{AD}(\mathrm{H}) \mathrm{S}$ Einfluss auf die PPI hat.

Material und Methoden: Im Rahmen einer doppelblinden, randomisierten, placebokontrollierten Cross-over-Studie wurden 28 Kinder mit $\mathrm{AD}(\mathrm{H}) \mathrm{S}$ untersucht, von denen 19 (Altersmedian 12, Range 7-16 Jahre, 4 Mädchen) auswertbar waren. Nach akustischer Stimulation (105 dB white noise burst, $50 \mathrm{~ms}$ ) wurde die Startle-Antwort als Ausschlag im Orbicularis oculi EMG gemessen, die PPI als prozentuale Reduktion durch einen Präpuls (7o dB $1000 \mathrm{~Hz}, 25$ ms Dauer, 120 ms vor Stimulus) errechnet.

Ergebnisse: Die mediane PPI von 51,7\% unter Placebo im Gesamtkollektiv lag unter dem erwarteten Altersnormwert von $73 \%$, es kam durch die Methylphenidattherapie zu keinem Anstieg (PPI 52,4\%, p=0,49). Die Subgruppenanalyse zeigte weder für ADHS vs. ADS-H oder geschlechtsspezifisch Unterschiede.

Diskussion: Die reduzierte PPI bei $\mathrm{AD}(\mathrm{H}) \mathrm{S}$ ohne Komorbidität ist bislang weder für Kinder noch für Erwachsene beschrieben. Unsere Hypothese, dass es zu einer verbesserten PPI unter Methylphenidat kommt, konnte jedoch nicht bestätigt werden. Da gleichzeitig ein Therapieansprechen des Methylphenidats dokumentiert war, scheint die Wirkung des Methylphenidats unabhängig von einer PPI-Veränderung zu sein. Schlussfolgerung: Wir konnten nicht zeigen, dass Methylphenidat zu einer Verbesserung der reduzierten PPI bei $\mathrm{AD}(\mathrm{H}) \mathrm{S}$ führt und somit einen positiven Einfluss auf das sensomotorische Gating hat. Die in unserer Gruppe reduzierte PPI scheint daher am ehesten ein Epiphänomen zu sein, das eher das gemeinsame Auftreten mit Störungen wie Enuresis als die Pathopysiologie des $\mathrm{AD}(\mathrm{H}) \mathrm{S}$ erklärt.

Zusätzlich wäre bei einer heterogenen Störung wie dem $\mathrm{AD}(\mathrm{H}) \mathrm{S}$ die Wiederholung der Untersuchung an genauer definierten Subgruppen mit Korrelation zum Therapieansprechen interessant.

Literatur: 1 Ornitz EM et al. (1999) Biol Psychiatry 45: 1455-66

2 Hanlon MC et al. (2009) Int J Neuropsychopharmacol. 12: 701-7

3 Schulz-Juergensen S et al. (2007) J Pediatr 151: 571-4

\section{DGKJ-PV-101}

Lebensqualität und Zufriedenheit mit der Medikation von Kindern und Jugendlichen bei Einnahme von Equasym ${ }^{\circledR}$ Retard (Methylphenidat) unter Routinebedingungen - eine Anwendungsbeobachtung in Deutschland

M. Döpfner', O. Dangel ${ }^{2}$, A. Rothenberger ${ }^{3}$

${ }^{1}$ Uniklinik Köln, ${ }^{2}$ Shire Deutschland $\mathrm{GmbH},{ }^{3}$ Universitätsmedizin Göttingen

Fragestellung: Methylphenidat (MPH) ist der Wirkstoff der Wahl zur symptomatischen Behandlung der Aufmerksamkeits-Hyperaktivitätsstörung (ADHS). MPH-Präparate der zweiten Generation, die bei einmal täglicher Einnahme MPH über den Tag verzögert freisetzen, haben in klinischen Studien eine genauso gute Wirksamkeit gezeigt, wie die mehrmalige Gabe eines schnell freisetzenden MPH-Präparates. Die Wirksamkeit von MPH bei der Behandlung von ADHS wurde in zahlreichen Studien dokumentiert. Jedoch wurde bisher der MPH-Effekt auf die Lebensqualität (LQ) und die Zufriedenheit mit Medikation kaum untersucht.

Material und Methode: Um die Wirksamkeit und Verträglichkeit von Equasym $^{\bullet}$ Retard (Methylphenidat) über den Tag unter Routinebedingungen untersuchen zu können, wurde eine offene Studie konzipiert. Ausgehend von den Diagnosekriterien nach ICD-10 und DSM IV-TR wurden 852 Schulkinder im Alter von 6-17 Jahren von 169 ADHS-Spezialisten in Deutschland eingeschlossen, bei denen eine Therapie mit dem verzögert $\mathrm{MPH}$-freisetzenden Equasym ${ }^{\bullet}$ Retard indiziert war. Im Zeitraum von maximal 3 Monaten bewerteten Ärzte, Eltern, Kin- 
der und Lehrer anhand von Fragebögen die ADHS-Symptome, Verträglichkeit, LQ und die Zufriedenheit mit Medikation zu Beginn ( $\mathrm{t} 1$ ), nach 1-3 Wochen (t2), und nach 6-12 Wochen ( $\left.t_{3}\right)$ nach der ersten Gabe der Medikation. Außerdem sollten Eltern und Kinder bei t 1 und $t_{3}$ die LQ mit Hilfe verschiedener Versionen von KINDL ${ }^{\bullet}$ 6-17 Jahren und die Zufriedenheit mit Medikation durch einen neuen Fragebogen (SAMS) bewerten. Die Subgruppen wurden nach der zuvor verordneten Medikation analysiert.

Ergebnisse: Die klinische Bewertung, wie auch die von Eltern, Lehrern und Kindern zeigte eine signifikante Reduktion der Symptome unter der Behandlung mit Equasym ${ }^{\circledR}$ Retard im Vergleich zur Situation zuvor. Sowohl die LQ als auch die Zufriedenheit mit Medikation nahm von t1 bis t3 zu. Analysen zeigten eine moderate Korrelation zwischen Zufriedenheit, LQ und Symptomreduktion. Subguppenanalysen zeigten den stärksten Medikationseffekt bei vorher unbehandelten Kindern, aber auch bei Kindern mit alternativer ADHS-Medikation war ein Effekt nachweisbar. Die Art und Häufigkeit von Nebenwirkungen deckt sich mit Beobachtungen aus früheren Studien.

Diskussion: Für eine umfassende Beurteilung der MPH-Wirkung über den Tag sind Information von Lehrern, Eltern und den betroffenen Kindern nötig. In der täglichen Praxis fehlen umfangreiche Informationen oft. Hierfür wurde diese offene Studie initiiert, um die Wirksamkeit und Verträglichkeit von Equasym ${ }^{\circledR}$ Retard über den Tag aus Sicht aller Beteiligten unter Routinebedingungen zu bewerten. Der neu entwickelte SAMS-Fragebogen zeigte eine gute innere Konsistenz.

Schlussfolgerung: Equasym ${ }^{\circ}$ Retard reduzierte die ADHS-Symptome, verbesserte die LQ und zeigte eine gute Zufriedenheit mit Medikation sowohl bei therapienaiven als auch bei bereits vorbehandelten Patienten.

(Diese Präsentation wurde unterstützt durch Shire Development, Inc.)

\section{Neonatologie II}

\section{DGKJ-PV-102}

NT-Pro-BNP Werte sind bei dystrophen Säuglingen ohne Herzinsuffizienz erhöht

L. Mänhardt', C. Willaschek', C. Müller', K. Norozi², R. Buchhorn'

${ }^{1}$ Caritas Krankenhaus Bad Mergentheim, ${ }^{2}$ University of Western Ontario

Dystrophe Säuglinge haben im späteren Leben ein erhöhtes kardiovaskuläres Risiko (Barker Hypothese). Das natriuretische Peptid NTPro-BNP (BNP) wird einerseits zur Risikostratifizierung bei Herzinsuffizienz eingesetzt, andererseits handelt es sich um ein kreislaufaktives Hormon, welches u. a. vom Ernährungszustand beeinflusst wird.

Wir haben bei 15 Säuglingen im Alter von 4 Wochen bis einem Jahr mit einem Gewicht unter der 10\% Perzentile BNP bestimmt und mit den Werten von 11 schwer herzinsuffizienten und 23 gesunden, eutrophen Säuglingen verglichen. Ursache der Dystrohie war eine kalorische Unterversorgung, Säuglinge mit organisch bedingter Dystrophie wurden ausgeschlossen. Alle Kinder erhielten eine Echokardiografie.

Die BNP Werte der dystrophen Säuglinge $(530,119-3150 \mathrm{pg} / \mathrm{ml})$ waren gegenüber der gesunden Kontrolle (115, 15-1121 pg/ml) hoch signifikant erhöht und unterschieden sich nicht signifikant von den schwer herzinsuffizienten Säuglingen $(673,408-11310 p g / \mathrm{ml})$. Es bestand kein signifikanter Unterschied hinsichtlich Geburtsgewicht, Lebensalter und Gestationsalter.

Mit dieser Pilotstudie wird erstmals ein Zusammenhang zwischen dem Ernährungszustand und dem kreislaufaktiven Hormon BNP im Säuglingsalter aufgezeigt. Dieser Zusammenhang erscheint uns wichtig für die Pathophysiologie von Herz-Kreislauf-Erkrankungen im späteren Lebensalter und erklärt möglicherweise die große Streuung der BNP Normalwerte für das Säuglingsalter in der Literatur.
DGKJ-PV-103

Neonataler Lupus erythematodes durch Anti-U1-RNP-Antikörper bei einem Frühgeborenen

H. v. Osten ${ }^{1}$, N. Bachmaier' , K. Kohl' ${ }^{2}$, K. Linnemann' ${ }^{1}$, H. Küster' ${ }^{1}$, R. Stenger ${ }^{1}$ ${ }^{1}$ Ernst-Moritz-Arndt Universität, ${ }^{2}$ Klinik und Poliklinik für Hautkrankheiten

Einleitung: Der neonatale Lupus erythematodes (NLE) ist ein seltenes Alloimmunphänomen, das bei Neugeborenen auftritt, bei deren Müttern Lupus-Antikörper nachzuweisen sind. Etwa die Hälfte der Mütter ist zum Zeitpunkt der Diagnose beim Kind asymptomatisch. Zu den Symptomen des NLE gehören Hautläsionen, Herzrhythmusstörungen (v. a. AV-Blockierungen), Thrombozytopenie und eine Leberbeteiligung.

Fall: Wir berichten über ein männliches Frühgeborenes von $29+5$ SSW (APGAR 5/9/9, NapH 7,35), Geburtsgewicht 1050g, bei dem am 2. Lebenstag erythematöse Plaques innerhalb weniger Stunden an Beinen, Stamm und im Anogenitalbereich auftraten. Diese Läsionen zeigten über eine Woche Entzündungsaktivität, um dann im Verlauf der nächsten Wochen narbenlos abzuheilen. Eine vorübergehende Thrombozytopenie (Thrombozyten min. $125 \mathrm{Gpt} / \mathrm{l}$ ) war ohne Transfusion rückläufig. Nach zwei Lebenswochen fiel eine Cholestase (Bilirubin direkt max. $14 \mu \mathrm{mol} / \mathrm{l})$ ohne Transaminasen-Erhöhung auf, welche über die nächsten 2 Monate unter Therapie mit Ursodeoxycholsäure langsam rückläufig war. Herzrhythmusstörungen wurden bei unserem Patienten zu keinem Zeitpunkt beobachtet. Im Rahmen der Diagnostik der Hautläsionen stellte sich bei näherer Betrachtung der Familien-Anamnese bei der Schwester der Mutter des Patienten ein Lupus erythematodes mit Vorliegen von Antiphospholipid-Antikörpern heraus. Bei der Mutter unseres Patienten war anamnestisch ein Abort bekannt, auf näheres Nachfragen gab sie an, einmal eine tiefe Beinvenenthrombose durchgemacht zu haben. In der durchgeführten Antikörper-Diagnostik fand sich bei Mutter und Kind ein hoher ANA-Titer (Mutter 1: 160o, Patient 1: 80o), in der Differenzierung Nachweis von hochtitrigen Anti-U1RNP-Antikörpern. Weder Anti-SSA(Ro)-, Anti-SSB(La)- noch Anti-dsDNA-Antikörper waren nachweisbar. Bei der Mutter konnten wir außerdem einen Antiphospholipid -Antikörper vom Typ IgM nachweisen.

Schlussfolgerungen: Aufgrund der Kinetik der diaplazentaren Antikörper-Übertragung, die in der Mitte des zweiten Trimesters beginnt und ihren Höhepunkt erst in den letzten Schwangerschaftswochen erreicht, ist die Ausbildung eines NLE bei Frühgeborenen unter 30 SSW sehr ungewöhnlich. Zusätzlich konnten wir in unserem Fall einen isolierten Anti-U1RNP-Antikörper nachweisen ohne gleichzeitigen Nachweis von Anti-dsDNA- oder vor allem SSA(Ro)- oder SSB(La)-Antikörpern. Letztere sind in über $95 \%$ aller Fälle von NLE nachweisbar. In der Literatur sind bislang nur wenige Fälle eines NLE mit Nachweis nur dieses Antikörpers beschrieben. Dieser Fall demonstriert auch deutlich die Wichtigkeit der sorgfältigen Familien-Anamnese in der Diagnostik neonataler Immunphänomene.

\section{DGKJ-PV-104}

Elektive einseitige Bronchusintubation bei einseitigem bullösem Emphysem - Bericht über 9 Neugeborene.

A. Jakob', C. Bender ${ }^{2}$, M. Henschen ${ }^{2}$, H. Schützle', P. Franck', R. Hentschel ${ }^{1}$ ${ }^{1}$ Universitäts - Kinderklinik, ${ }^{2}$ Städt. Kinderkrankenhaus

Einleitung: Ein lobäres Lungenemphysem kann bei Frühgeborenen z. B. im Rahmen einer BPD entstehen. Ein einheitliches Therapiekonzept für diese Patienten existiert nicht. Über die selektive Bronchusintubation zur vorübergehenden Ausschaltung des betroffenen Lungenflügels existieren nur wenige Berichte.

Methodik: Retrospektive Analyse der Daten von 9 Frühgeborenen mit erworbenem einseitigem Lungenemphysem. Die selektive Bronchusintubation wurde als erfolgreich gewertet, wenn das BPD-Stadium nach Weinstein anschließend radiologisch mit $<$ Grad III beurteilt wurde.

Ergebnisse: Insgesamt wurden 9 Frühgeborene mit einem Gestationsalter von 24-35 SSW und einem Geburtsgewicht von 500-3170 g einseitig intubiert. Beginn der einseitigen Beatmung zwischen dem 12. und 
35. Lebenstag. Dauer der einseitigen Beatmung: 24 Stunden - 7 Tage. Bei drei Patienten erfolgte eine linksseitige Intubation. 3 Patienten erhielten 2 Zyklen einer einseitigen Beatmung, 1 Patient erhielt sogar 3 Zyklen. Bei 7 Patienten wurde der Eingriff als erfolgreich gewertet, es trat kein weiteres Emphysem mehr auf.

Diskussion: Die Methode ist insbesondere bei der linksseitigen Intubation technisch aufwändig, aber erfolgversprechend und mit entsprechender bronchoskopischer Erfahrung risikoarm anzuwenden. Wenn es gelingt für mindestens 48 Stunden eine Totalatelektase der betroffenen Lunge zu erzielen scheinen die Erfolgsaussichten gut zu sein.

\section{DGKJ-PV-105}

\section{Neonatale Enterobacter-Meningitis mit zerebralem Infarkt}

C. Chao', D. Faas', A. Hahn', G. Alzen², U. Nestler'3 , M. Heckmann'

'Zentrum für Kinderheilkunde der Justus-v.-Liebig-Universität, ${ }^{2}$ Institut für Radiologie, ${ }^{3}$ Klinik für Neurochirurgie

Hintergrund: Die bakterielle Meningitis beim Frühgeborenen geht mit einer hohen Letalität (10\%) und einer hohen Rate an dauerhaften neurologischen Folgeschäden (bis 50\%) einher. Dies ist auf Schädigung des Gehirns durch Ventrikulitis, Hirnabszess und zerebrale Insulte mit/ ohne zystische Degeneration zurückzuführen. Fallbericht: Ein weibliches Frühgeborenes wurde bei pathologischem CTG und Doppler, fehlenden Infektzeichen der Mutter in der $29+5$ SSW entbunden (APGAR 5/8/9, Na-pH 7,14, CRIB-Score 2). Bei ANS ${ }^{\circ}$ I und Apnoe-BradykardieSyndrom erfolgte eine CPAP-Therapie für 3 Tage. Am 23. LT trat eine akute klinische Verschlechterung mit Apnoen, Bradykardien, gräulichem Hautkolorit, Temperaturregulationsstörung und Berührungsempfindlichkeit auf. Bei negativen Entzündungswerten (CRP 3,1mg/l, IL-6<5opg/ml, IT-Quotient 0,04) wurde eine Therapie mit Ceftazidim und Vancomycin begonnen. Die Laborwerte am Folgetag betrugen: CRP 118mg/l, Liquor: Zellen 22. ooo/ul, Glukose 2mg/dl, Eiweiß $3223 \mathrm{mg} / \mathrm{l})$. Die Sonografie des Gehirns zeigte eine paraventrikuläre Echogenitätserhöhung links. Die Therapie wurde zunächst mit Cefotaxim, Vancomycin, Aciclovir und Voriconazol fortgeführt. Im Liquor wurde Enterobacter cloacae nachgewiesen. Sieben Tage nach Therapiebeginn war der Liquor steril. Zwei Tage später bestand sonografisch der V. a. beginnende Abszedierung links paraventrikulär, MR-tomografisch zeigte sich eine Kolliquationsnekrose nahezu des gesamten Occipitallappens (Versorgungsgebiet der A. c. posterior sinistra) links mit zystischer Degeneration und Kommunikation zum Hinterhorn des linken Seitenventrikels. Es fand sich ein Rand-Enhancement, das sich nicht auf den Ventrikel fortsetzt und einer Abszessmembran entsprechen könnte. Daher erfolgte eine Punktion der zystischen Formation mit Anlage einer externen Liquordrainage im linken Seitenventrikel. Das Punktat ergab xanthochromen Liquor (530/ul Zellen, Glukose 9mg/dl, Eiweiß 6220mg/l) ohne Keimnachweis. Zwei Wochen nach Anlage Entfernung der externen Liquordrainage, Enterobacter c. wurde noch in der PCR, aber nicht wachsend in Kultur nachgewiesen. Die antibiotische Therapie wurde nach 5 Wochen beendet. Drei Wochen später entwickelte sich ein zunehmender Hydrozephalus. Eine endoskopische Ventrikulostomie des 3. Ventrikels war erfolgreich. Schlussfolgerung: Erstens: Eine bakterielle Meningitis mit Enterobacter c. beim Frühgeborenen kann sich initial rein klinisch ohne positive Frühmarker einer Infektion (IT-Quotient, IL-6) manifestieren. Zweitens: Als Folge der Enterobacter-Meningitis kann sich eine Kolliquationsnekrose mit zystischer Degeneration i. S. eines ischämischen Infarktes entwickeln, die sich MR-tomografisch wie ein Abszess präsentiert.

\section{DGKJ-PV-106}

Entwicklung eines Score zur Frühdiagnose der Late-onset Sepsis bei VLBW-Frühgeborenen

H. Küster ${ }^{1}$, A. Höpfl' ${ }^{2}$ A. Willeitner ${ }^{3}$, T. Arenz $z^{4}$, I. Jeremias ${ }^{5}$, R. Geiger ${ }^{6}$

${ }^{1}$ Ernst-Moritz-Arndt Universität, ${ }^{2}$ Krankenhaus St. Marien, ${ }^{3}$ Children's

Hospital Oklahoma, ${ }^{4}$ Universitätsspital Bern, ${ }^{5} \mathrm{Helmholtz}$ Zentrum München, ${ }^{6}$ Medizinische Universität Innsbruck

Fragestellung: Entwicklung eines Scores zur Vorhersage der Late-Onset Sepsis bei VLBW-Frühgeborenen

Material und Methodik: Zwei prospektive multizentrische Beobachtungsstudien bei VLBW-Frühgeborenen: Die Daten der Frühgeborenen der ersten Studie wurden zur Berechnung des Scores verwendet, die der zweiten zu seiner Validierung.

Die Frühgeborenen wurden prospektiv anhand definierter Kriterien in drei Gruppen unterteilt: Sepsis Gruppe, Nicht-Sepsis Gruppe und Nicht-bestimmbare Gruppe. Täglich wurden 39 definierte Parameter standardisiert erfasst. Verglichen wurde Tag -3 bis Tag o der Sepsis zwischen den Frühgeborenen der Sepis- und der Nicht-Sepsis Gruppe. Der Score wurde entwickelt durch Kombination der Parameter, die die größte Fläche unter der ROC Kurve hatten.

Ergebnisse: Die Studien für die Berechnung bzw. Validierung des Scores erfolgten in 6 Perinatalzentren über 19 bzw. 30 Monate. Eingeschlossen wurden 158 bzw. 268 Kinder, von denen 57 bzw. 75 wegen früher Verlegung oder unvollständiger Daten nicht in die Auswertung einbezogen werden konnten. Von den untersuchten Parametern hatten in der ROC-Analyse folgende an einem der untersuchten Tage eine Area under the curve (AUC) > o,8: minimaler Basenexzess, minimale Thrombozytenzahl, orale Nahrungsmenge, $\mathrm{FiO}_{2}$, Nahrungsintoleranz, Hautfarbe, IT-Ratio.

Nach stufenweiser Elimination nicht-relevanter Parameter und deren Gruppierung entstand ein Score aus den fünf Kategorien:

\section{Tab.}

\begin{tabular}{|c|c|c|}
\hline \# & Kategorie & Parameter \\
\hline 1 & $\begin{array}{l}\text { Periphere Durchblu- } \\
\text { tung }\end{array}$ & Rekapillarisierungszeit $>3 \mathrm{~s}$ \\
\hline \multirow[t]{2}{*}{2} & \multirow[t]{2}{*}{ Atmung } & $\begin{array}{l}\text { Anstieg* des FiO2 um } 20 \% \text { absolut oder } \\
\text { Anstieg* des mittleren Beatmungsdrucks } \\
\text { um } 3 \mathrm{~cm} \mathrm{H} 2 \mathrm{O}\end{array}$ \\
\hline & & $\begin{array}{l}\text { Verdopplung }{ }^{*} \text { von Apnoen }>20^{\prime \prime} \text { oder Brady- } \\
\text { kardien }<80 \text { /min oder Entsättigungen }<80 \%\end{array}$ \\
\hline 3 & Ernährung & $\begin{array}{l}\text { Reduktion* der enteralen Nahrungsmenge } \\
\text { um } 20 \%\end{array}$ \\
\hline \multirow[t]{3}{*}{4} & \multirow[t]{3}{*}{ Allgemeine Laborwerte } & Thrombozytenzahl $<150.000 / \mu \mathrm{l}$ \\
\hline & & Basenexzess $<-7 \mathrm{mmol} / \mathrm{l}$ \\
\hline & & Anstieg oder Abfall des Blutzuckers um 50\% \\
\hline \multirow[t]{2}{*}{5} & \multirow{2}{*}{$\begin{array}{l}\text { Infektionsspezifische } \\
\text { Laborwerte }\end{array}$} & $\mathrm{CRP}>10 \mathrm{mg} / \mathrm{l}$ \\
\hline & & IT-Ratio $>0,15$ \\
\hline
\end{tabular}

Der Score gilt als positiv, wenn mindestens zwei der fünf Kategorien positiv sind. In der Validierungsgruppe zeigte der Score an Tag o eine Sensitivität von 84,0 \% und eine Spezifität von $97,1 \%$ in der Vorhersage der Late-Onset Sepsis, sein positiver prädiktiver Wert betrug 87,5 $\%$, sein negativer prädiktiver Wert $89,2 \%$, die AUC in der ROC Analyse $0,950 \pm 0,032$

Schlussfolgerung: Der entwickelte Score hat eine hohe Prädikativität zur Diagnose der Late-Onset Sepsis bei VLBW-Frühgeborenen. Er hat eine ähnliche Vorhersagekraft wie Zytokine, ist aber schneller verfügbar und deutlich billiger. Zusätzlich könnte er beim Vergleich von Kindern mit Sepsis in multizentrischen Studien von Wert sein. 
DGKJ-PV-107

Autonome Inbalance im Kleinkindalter bei ehemaligen SGA Neugeborenen - Verminderte Vagotonie als mögliche Ursache eines erhöhten cardiovaskulären Risikos

C. Willaschek, C. Müller, L. Mänhardt, R. Buchhorn

Caritas Krankenhaus

Einleitung: Ehemalige Small for Gestational Age (SGA) Neugeborene zeigen im Langzeitverlauf ein erhöhtes Risiko für metabolische Erkrankungen, arterielle Hypertension, sowie ein erhöhtes Risiko für Tod durch Herz- und Gefäßerkrankungen (Barkerhypothese). Als Ursache wird eine unterschiedliche Programmierung der cardiovasculären Kontrollmechanismen diskutiert.

Methoden: Wir untersuchten 25 gesunde SGA Neugeborene mit einem Geburtsgewicht unter der dritten Perzentile in den ersten Lebenstagen sowie im Kleinkindalter (Mittel 1,99 Jahre) mittels 24h-HRV Analyse und verglichen diese mit einem gesunden gleichaltrigen Kontrollkollektiv.

Ergebnisse: In den ersten Lebenstagen konnte kein signifikanter Unterschied der HRV in beiden Gruppen gezeigt werden. Im Kleinkindalter wurde in der Gruppe ehemaliger SGA eine signifikante Reduktion der rMSSD (Mittelwert [SD]) gemessen, eines Parameters, der eng verknüpft ist mit der parasympathischen Aktivität $(26,68[8,3]$ vs 41,14 [21,5]; p . 004).

Diskussion: Diese Untersuchung zeigt bei ehemaligen SGA Neugeborenen bereits im Kleinkindalter Zeichen einer autonomen Inballance. Möglicherweise liegt in der hier beschriebenen Reduktion der sich vom Kindes- bis ins Jugendalter zunehmend entwickelnden Vagotonie eine Ursache der erhöhten Langzeitmorbidität und Mortalität ehemaliger SGA Neugeborener.

\section{DGKJ-PV-108}

Besteht ein Zusammenhang zwischen Strukturqualität und Behandlungsergebnis in Perinatalzentren in Baden-Württemberg?

T. Böhler, B. Schaeff, B. Waibel, M. Mohrmann

MDK Baden-Württemberg

Hintergrund: Neonatologische Einrichtungen in Deutschland werden auf Grundlage einer Vereinbarung des Gemeinsamen Bundesausschusses (G-BA) über Maßnahmen zur Qualitätssicherung der Versorgung von Früh- und Neugeborenen einer von 3 Versorgungsstufen zugeordnet: Perinatalzentren (PNZ) Level 1 repräsentieren die höchste Versorgungsstufe, PNZ Level 2 eine intermediäre Versorgungsstufe und Perinatale Schwerpunkte stellen die perinatologische Basisversorgung sicher. PNZ sind seit dem Jahr 2009 verpflichtet, im Internet Angaben zur Ergebnisqualität ihrer Behandlungen zu veröffentlichen und die Einhaltung einer Mindestbehandlungszahl nachzuweisen. Die Größe dieser Mindestmenge ist wissenschaftlich wie gesundheitspolitisch umstritten.

Methoden: Die Gesamtbewertung der Struktur- und Prozessqualität von 28 neonatologischen Einrichtungen durch den MDK im Jahr 2008 in Form einer "Gesamtbewertungszahl“ wurde in Beziehung gesetzt zu den von diesen Kliniken im Internet veröffentlichten Daten zur Mortalität und Kurzzeitmorbidität der im gleichen Jahr behandelten Frühgeborenen mit einem Geburtsgewicht (GG) $<1.500$ g. Des weiteren wurde eine Modellrechnung zu den Auswirkungen der derzeit festgelegten bzw. diskutierten Vorgaben für Mindestmengen auf die Anzahl der Perinatalzentren im Land und die möglichen Einflüsse einer stärkeren Zentralisierung der Versorgung auf die Behandlungsergebnisse kleiner Frühgeborener durchgeführt.

Ergebnisse: In den 28 neonatologischen Einrichtungen des Landes wurden im Jahr 2008700 Kinder mit einem GG <1. 250 g und 441 mit einem GG zwischen 1. 250 und 1. 499 g behandelt. Zwischen der Gesamtbewertungszahl und dem Prozentsatz der überlebenden bzw. der im Wesentlichen schadensfrei verlegten oder nach Hause entlassenen kleinen Frühgeborenen (GG $<1.500$ g) bestand keine signifikante Korrelation. Je mehr extrem kleine Frühgeborene ( $G G<750$ g) in einer Einrichtung versorgt wurden, desto weniger kleine Frühgeborene ( $G G<1.500$ g) konnten ohne höhergradige Hirnblutung oder chronische Lungenerkrankung des Frühgeborenen bzw. ohne Operation einer nekrotisierenden Enterokolitis oder Frühgeborenen-Retinopathie verlegt oder nach Hause entlassen werden. Höhere Mindestmengen als die derzeit vereinbarten 14 Behandlungsfälle pro Jahr würden zu einer Konzentrierung der Versorgung führen: bei einer Mindestmenge von 36 Behandlungen sehr kleiner Frühgeborener (GG $<1$. 250 g) pro Jahr müssten 7 PNZ Level 1, bei einer Mindestmenge von 50 Behandlungen kleiner Frühgeborener $(\mathrm{GG}<1.500 \mathrm{~g})$ pro Jahr müssten 8 PNZ Level 1 die Versorgung für alle kleinen Frühgeborenen übernehmen. Effekte einer solchen Zentralisierung auf die Behandlungsergebnisse sind anhand der verfügbaren Daten nicht sicher vorherzusagen. Schlussfolgerungen: Eine zentralisierte Behandlung kleiner Frühgeborener mit einem GG $<1.500 \mathrm{~g}$ in den gemäß G-BA-Kriterien am besten ausgestatteten bzw. organisierten Kliniken in Baden-Württemberg würde ähnlich wie eine höhere Mindestmengenregelung nahezu zur Verdoppelung der jährlichen Fallahlen in 7 bis 8 PNZ führen. Eine Begründung für eine solche Zentralisierung ergibt sich am ehesten aufgrund gesundheitsökonomischer Erwartungen. Bei einer wissenschaftlichen Evaluation der Auswirkungen einer verstärkten Zentralisierung der perinatologischen Versorgung könnte auf Routinedaten der Erfassung von Struktur- und Prozessqualität durch den MDK zurückgegriffen werden.

\section{DGKJ-PV-109}

Erstbeschreibung einer Pontine Tegmental Cap Dysplasia bei einem Extrem-Frühgeborenen - seltene und/oder unterdiagnostizierte Erkrankung?

S. Hartenstein' ', H. Proquitté', K. Kalache', E. Boltshauser², A. Kaindl' ${ }^{1}$ Charité - Universitätsmedizin Berlin, ${ }^{2}$ Universitäts-Kinderklinik Medizinische Klinik

Einleitung: Die Pontine Tegmental Cap Dysplasia (PTCD) ist eine sehr seltene, 2007 erstmals definierte Gehirnfehlbildung, die durch eine Hypoplasie der ventralen Pons und einem Hervorspringen des dorsalen Tegmentums in den IV. Ventrikel gekennzeichnet ist. Gemein ist den Betroffenen neben einer globalen Retardierung u. a. eine Hirnnervenbeteiligung, Schluckstörungen, bilaterale Taubheit und Ataxie. Vermutete Ursache ist eine angeborene Störung der axonalen Aussprossung; eine genetische Ursache konnte noch nicht identifiziert werden. Kasuistik: Bei dem hypotrophen weiblichen Frühgeborenen $(25+2$ SSW, 580 g, II. Zwilling, 46,XX, Schwangerschaft nach IVF) fiel sonographisch prä- und postnatal eine Kleinhirnhypoplasie auf. Klinisch imponierte in den ersten Lebenswochen neben den klassischen Problemen eines sehr unreifen Frühgeborenen eine progrediente generalisierte muskuläre Hypotonie, eine Hypomimie mit asymmetrischer Ptosis, intermittierendem Pendelnystagmus und horizontaler Blickparese, ein hoher Gaumen sowie eine zentrale Temperaturregulationsstörung. Als Dysmorphien bestanden Schädelasymmetrie, schmales Lippenrot, Hypertelorismus, nach lateral abfallende Lidachsen und Mundwinkel sowie ein präaurikuläres Ohranhängsel. Noch vor Erreichen des errechneten Geburtstermins (75. Lebenstag) traten fraglich generalisierte Krampfanfälle auf, welche mit Phenobarbital behandelt wurden. Im weiteren Verlauf imponierten zunehmend Unruhezustände mit Trigeminusneuralgie (DD Blepharospasmus des rechten Auges), welche mit Carbamazepin probatorisch behandelt werden. Die Muskulatur ist jetzt, mit korrigiert 3 Monaten, nur noch diskret hypoton, der Saugreflex ist weiterhin sehr schwach, Nahrung kann z. T. geschluckt werden, und die Patientin zeigt zunehmende Spontanmotorik. Klinik und Befunde der elektrophysiologischen Diagnostik (VEP, AEP) sprechen für eine schwere zentrale Hör- und Sehstörung. Der Zwillingsbruder ist nicht von einer PTCD betroffen.

Diskussion: Dies ist die erste Kasuistik eines extrem unreifen Frühgeborenen mit einer PTCD, welche mittels cMRT diagnostiziert werden konnte. Bislang nicht beschriebene Krankheitsmerkmale sind neben der Besserung des Muskeltonus in den ersten Lebensmonaten 
eine Trigeminusneuralgie (DD Blepharospasmus). Aufgrund der Neuheit, Seltenheit und nicht bekannten Pathogenese dieser Erkrankung ist eine prognostische Einschätzung nicht möglich. Ob das Fortschreiten degenerativer Prozesse an einer progredienten Involution von Kleinhirn und Pons (prä- und postnatale Schädelsonographien) im Verlauf erkennbar ist, muss der weitere Verlauf zeigen.

Schlussfolgerung: Die sehr seltene PTCD ist eine, aufgrund von Unkenntnis evtl. noch unterdiagnostizierte Gehirnfehlbildung. Das noch bestehende Informationssdefizit gilt es zu schließen, um in Zukunft betroffenen Familien nicht nur eine genetische Diagnosestellung ermöglichen, sondern eine prognostische Einschätzung des klinischen Verlaufes ihrer Kinder anbieten zu können.

\section{DGKJ-PV-110}

Seltene Diagnose einer diffusen neonatalen Hämangioendotheliomatose

E. Eilers' , C. Uhrig', M. Emeis' , C. Philipp², L. Ketteler' ${ }^{1}$, R. Rossi'

'Vivantes Klinikum Neukölln, ${ }^{2}$ Ev. Elisabeth Klinik

Eine neonatale Hämangioendotheliomatose ist eine sehr seltene Erkrankung des Neugeborenen, bei der es sowohl zu kutanen als auch viszeralen Manifestationen kommen kann. Die klinische Präsentation ist sehr variabel, die Hämangiome können in den ersten Wochen postnatal an Zahl und Größe deutlich zunehmen.

Wir berichten über ein Frühgeborenes der $35+5$ SSW.

Die Mutter ist eine 29 Jährige I Gravida I Para mit unauffälliger Familienanamnese. Während der Schwangerschaft war ein Oligohydramnion festgestellt worden, bei Aufnahme in der Geburtshilfe fiel ein Anhydramnion auf. Eine intrauterine Wachstumsretardierung war bereits bekannt, Organschalle waren stets unauffällig.

Bei pathologischen CTG wurde eine Sectio durchgeführt und ein Mädchen geboren, APGAR 3/7/7, NapH 7,27, Geburtsgewicht (2050 g, 5. Perz.), Körperlänge ( $46 \mathrm{~cm}, 17$. Perz.) und Kopfumfang (30 cm, 17. Perz.). Das Kind war respiratorisch insuffizient und muskulär hypoton. Wir sahen multiple rötliche knötchenförmige Erhebungen der Haut, zum Teil subkutan liegend, sowie deutliche Ödeme der Augen und der unteren Extremität. Es zeigte sich eine Anämie ( $\mathrm{Hb}$ 9,1 mg/dl), eine Thrombozytopenie (65/nl) und eine generalisierte Gerinnungsstörung im Sinne eines Kasabach-Meritt-Syndroms.

Im MRT fanden sich in der gesamten Muskulatur diffus nodulär glatt begrenzte Raumforderungen. Biopsien ergaben den Befund eines Glut 1 negativen Hämangioendothelioms.

Es wurde eine Therapie mit Steroiden $(5 \mathrm{mg} / \mathrm{kg} / \mathrm{die})$ begonnen. Eine Therapie mit Beta-Blockern $(2 \mathrm{mg} / \mathrm{kg} / \mathrm{die})$, die allerdings nicht bei Hämangioendotheliomen evaluiert ist, wurde aufgrund eines Hypertonus notwendig.

Im Verlauf kam es bei nicht zu stabilisierender Kreislaufsituation sowie anhaltender Gerinnungsstörung zu einem Multiorganversagen, das Kind verstarb am 9. Lebenstag.

Bei generalisierten Hämangioendotheliomen kann frühzeitig der Versuch einer Chemotherapie begonnen werden, in unserem Fall allerdings wurde der Verlauf kompliziert durch die massive Gerinnungsstörung.

Es gibt zum derzeitigen Zeitpunkt nur einzelne Fallberichte einer erfolgreichen Behandlung einer generalisierten Hämangioendotheliomatose, wobei ein generalisierter Muskelbefall wie bei unserer Patientin bisher in der Literatur nicht beschrieben wurde.

\section{DGKJ-PV-111}

\section{Exposure to high altitudes induces inflammatory processes}

E. Tutdibi, D. Monz, S. Dietrich, J. Landerer, L. Gortner

Universitäskinderkliniken des Saarlandes

Objective: To identify changes in the pattern of cytokines and growth factors associated with hypoxia during sojourn in high altitude. Background: Sojourn in high altitudes leads to decreased mean partial pressures of arterial oxygen. These changes may be associated with inflam- matory processes comparable to the situation in preterms with reduced oxygen partial pressures in case of placental insufficiency. Methods: Blood samples were obtained from 27 participants of a Himalaya expedition to Damphus Peak. Samples were taken at sea level, $5100 \mathrm{~m}$ and $6000 \mathrm{~m}$ ( 8 of the participants). After immediate centrifugation, the samples were kept at $-20^{\circ} \mathrm{C}$ until further analysis. The following cytokines and growth factors were analysed using multiplex bead technology (Luminex): IL-1ra, IL-1 $\beta$, IL-4, IL-6, IL-8, IL-10, IL-12(p40), IP-10, TNF $\alpha$, MCP-1, IFN- $\gamma$, MIP-1 $\alpha$, MIP-1 $\beta$, EGF, FGF-2, G-CSF, GM-CSF. Results: Comparing the pattern of cytokines and growth factors at sea level and at high $5100 \mathrm{~m}$, we found an increase in IL-12(p40), IL-8, MCP-1, MIP- $1 \beta$, TNF $\alpha$, IL-4, IL-1ra, G-CSF, GM-CSF, EGF and VEGF. IFN- $\gamma$ and MIP-1 $\alpha$ were down regulated in high altitudes. IL-10, IL-1 $\beta$, Il-2, IL-6, IP-10 and FGF-2 did not show any changes. In the group that climbed up to an altitude of $6000 \mathrm{~m}$, no further changes were observed. Conclusion: Exposure to high altitudes induces an inflammatory response that leads to proliferation and differentiation of different immune cells, like neutrophil granulocytes and monocytes. The upregulation of EGF and VEGF may further indicate processes to counteract hypoxia.

\section{DGKJ-PV-112}

Der NO-Donor FK-409 verbessert die Verformbarkeit von aktivierten neutrophilen Granulozyten reifer Neugeborener und Erwachsener im Cell-Transit-Analyzer

P. Ruef, E. Craciun, L. Koch, D. Frommhold, J. Pöschl

Klinikum d.Ruprecht-Karl- Universität

Hintergrund: Aktivierte neutrophile Granulozyten haben einen wesentlichen Einfluss auf die Mikrozirkulation. NO führt im Tiermodell zu verringerter Sequestration neutrophiler Granulozyten in der Lunge und kann experimentell zu geringeren Organschädigungen bei Infektionen und Lebertransplantaten beitragen. Fragestellung: Da die neutrophilen Granulozyten Neugeborener im Vergleich zu Erwachsenen wesentliche Unterschiede in ihren funktionellen Eigenschaften zeigen (verringerte intrazelluläre Abtötung, verringerte Chemotaxis, verringerte Adhäsionsfähigkeit), wurde der Einfluss von FK-409 (4-Ethyl2-hydroxyimino-5-nitro-3-hexenamide) auf die Verformbarkeit und die Elastasekonzentrationen dieser Zellen untersucht.

Material und Methode: Mit einem Cell Transit Analyzer $(8 \mu \mathrm{m}$ Filterporen) wurden die Passagezeiten durch $8 \mu \mathrm{m}$ Filterporen von neutrophilen Granulozyten gesunder reifer Neugeborener $(n=18)$ und gesunder Erwachsener $(\mathrm{n}=18)$, die durch IL-8 (10ong/ml) aktiviert wurden, gemessen.

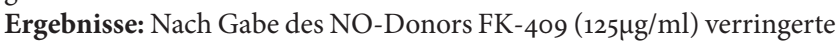
sich die Passagezeit bei zuvor aktivierten neutrophilen Granulozyten Erwachsener von 9,3 $\mathrm{s} \pm 2,9 \mathrm{~s}$ auf $5,4 \mathrm{~s} \pm 1,6 \mathrm{~s}$ und bei aktivierten neutrophilen Granulozyten Neugeborener von 10,7 \pm 3,27 s auf 5,6 $\pm 1,1$ s. Die Elastasekonzentrationen von aktivierten Granulozyten (Neugeborene $1621 \pm 839 \mathrm{ng} / \mathrm{ml}$; Erwachsene $1569 \pm 467 \mathrm{ng} / \mathrm{ml})$ verringerte sich unter der Wirkung von FK-409 (Neugeborene $920 \pm 514 \mathrm{ng} / \mathrm{ml}$; Erwachsene $827 \pm 236 \mathrm{ng} / \mathrm{ml}$ ) bis auf die Werte von passiven neutrophilen Granulozyten (Neugeborene $1034 \pm 452$ ng/ml; Erwachsene $1172 \pm$ $457 \mathrm{ng} / \mathrm{ml}$ ). Trotz der funktionellen Unterschiede neutrophiler Granulozyten Neugeborener war der Einfluss von FK-409 auf die Passagezeiten nicht unterschiedlich zu neutrophilen Granulozyten Erwachsener. Die Passagezeiten von passiven, nicht aktivierten neutrophilen Granulozyten konnten durch die Gabe von FK-409 nicht ganz erreicht werden (Erwachsene 3,7 $\pm 0,8 \mathrm{~s}$, Neugeborene 4,2 $\pm 0,7 \mathrm{~s}$ ).

Schlussfolgerung: NO-Donor können bei Infektionen und Mikrozirkulationsstörungen durch Hypoxie-Ischämie, die zu einer Aktivierung zirkulierender neutrophiler Granulozyten führen, neben dem Einfluss auf die Makrozirkulation einen günstigen Effekt auf die Mikrozirkulation durch die Verbesserung der Verformbarkeit aktivierter neutrophiler Granulozyten haben. 
DGKJ-PV-113

Frühzeitiger Beginn der Enzymersatztherapie (ERT) bei infantilem Morbus Pompe

S. Gökce', R. Hartung' ', V. Ocker², C. Kampmann'1, M. Beck', E. Mengel'

${ }^{1}$ Klinikum der Johannes-Gutenberg Universität, ${ }^{2}$ Olgahospital Päd. Zentrum

Einleitung: Seit 2006 ist eine kausale Enzymersatztherapie für infantile Morbus Pompe Patienten zugelassen. Die Standard-Dosierung für infantile Patienten beträgt $20 \mathrm{mg} / \mathrm{kgKG} / 2$ Wochen. Die Herzbeteiligung bei infantilem M. Pompe wird durch Enzymersatztherapie zumeist positiv beeinflusst, problematischer ist das Therapieansprechen bezogen auf die motorische Funktion. Das frühzeitige Ansprechen nach Beginn der Enzymersatztherapie verbessert das Erreichen der motorischen Meilensteine. Wir behandelten drei infantile M. Pompe Patienten mit verschiedenen Diagnose-/Therapistartzeitpunkten. Das Erreichen der motorischen Meilensteine wurde mit Alberta Infant Motor Scale (AIMS) ermittelt.

Patienten: Patient 1: ${ }^{\star} 09 / 2003: 1$. Kind nicht konsanguiner Eltern, 1. Infusion ab 21. LW (im Rahmen der Phase III-Studie), 9. LM: 9 P., 11. LM: 13 P., 14. LM: 18 P., 16. LM: 21 P., 20. LM: 28 P., 22. LM: 29 P., 2. LJ, 2 $1 / 3$ J: 30 P., seit 4. LJ: Stagnation bei 39 P.

Patient 2: ${ }^{\star} 05 / 2007: 2$. Kind konsanguiner Eltern, 1. Kind: Versterben mit 10. LM an infantiler M. Pompe. 1. Infusion am 5. LT: AIMS altersgerecht.

Patient 3: ${ }^{\star}$ 07/2008: 1. Kind konsanguiner Eltern, im 2. LM aufgefallen mit Kardiomegalie, Hypotonie, Dyspnoe und Trinkschwäche. 1. Infusion ab 10. LW., wobei bis zur 24. LW. wöchentliche Enzymersatztherapien erfolgten, danach Umstellung auf zweiwöchentliche Gaben.

2. LM: 1 P., 7. LM: 19 P., 11. LM: 42 P., 13. LM: 51 P., 16. LM: 58 P., 20. LM: $58 \mathrm{P}$.

Ergebnisse: Patient 1 ist rollstuhlpflichtig und hat die motorischen Meilensteine nicht vollständig erreicht. Patient 2 erlangte die motorischen Meilensteine wie seine Altersgenossen. Patient 3 hingegen holte nach Beginn der Enzymersatztherapie die motorischen Defizite innerhalb von einem Jahr vollständig nach.

Diskussion: Die obigen Fälle zeigen eindrucksvoll den unterschiedlichen Verlauf der Erkrankung in Abhängigkeit vom Therapiebeginn. Entscheidend für den optimalen Therapieerfolg erweist sich die frühzeitige Diagnosestellung, bevor irreversible Muskelzellstörung nachweisbar ist. Welchen Einfluss dabei Antikörperbildung und ausbleibende Toleranzentwicklung spielen, muss in größeren Patientenkollektiven untersucht werden.

\section{DGKJ-PV-114}

Zytokinkonzentration im Nabelschnurblut reifer Neugeborener nach primärer Sektio im Vergleich zur Spontangeburt

E. Tutdibi, A. Hunecke, D. Monz, U. Lindner, L. Gortner

Universitätskinderkliniken des Saarlandes

Einleitung: Zytokine nehmen bei der Induktion des Geburtsmechanismus sowohl bei der Frühgeburt als auch beim spontanen Termingeburt eine wichtige Rolle ein. In beiden Fällen werden ähnliche, immunologisch gesteuerte Prozessabläufe zur Wehentätigkeit unterstellt. Fragestellung: Ziel unserer prospektiven Studie war es, die Konzentration von pro- und antiinflammatorischen Zytokinen im Nabelschurblut reifer Neugeborener nach Geburt aus wehenfreiem Uterus (primäre Sektio) und Spontangeburt zu untersuchen. Es sollte geklärt werden, ob die unkomplizierte Spontangeburt mit einer inflammatorischen Aktivierung einhergeht. Methodik: Eingeschlossen wurden gesunde reife Neugeborene (NG) mit einem Gestationsalter von $37+0$ bis $41+6$ SSW nach unkomplizierter Schwangerschaft sowie ohne mütterliche und neonatale Infektionszeichen. Arterielles Nabelschnurblut wurde unmittelbar postnatal abgenommen und das abzentrifugierte Serum bei $-80^{\circ} \mathrm{C}$ gelagert. Interleukin-1a, IL-1b, IL-2, IL-4, IL-5, IL-6, IL-8, IL-10, IL-12, IL-17, IL-1ra, -, G-CSF, GM-CSF, IFN-a2, IFN-g, IP-10, MCP-1, TNF-a, TNFb, TGF-b1 und sCD4oL wurden mittels eines Multiplex-Luminex-Systems bestimmt und mit den maternalen und neonatalen Daten ausge- wertet. Ergebnisse: Es wurden 6o NG untersucht (mittleres Gestations-

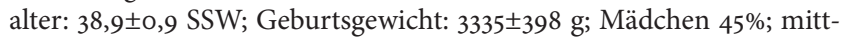
leres Alter der Mutter: 29,3 $\pm 5,5$ J; Erstpara: 41,7\%; primäre Sectiorate: $58,3 \%)$. Die mediane TGFb1-Konzentration im Nabelschnurblut war bei Spnatangeborenen siginifkant erhöht im Vergleich nach primärer Sektio [7137 vs. 2519 pg/ml; p<0. 013]. Die Serumkonzentrationen der übrigen untersuchten Zytokine ergaben keine Unterschiede zwischen beiden Gruppen. Schlussfolgerung: Unsere Daten zeigen eine Assoziation von spontaner Wehentätigkeit und der Aktivierung von TGF-b1. Die unkomplizierte Spontangeburt führt nicht zu einer inflammatorischen Aktivierung im Nabelschnurblut.

\section{Ernährung zur Prävention von Krankheiten}

\section{DGKJ-SY-002}

Opitimix ${ }^{\circledast}$ als Marke - Marketing von Ernährung als Prävention

M. Kersting

Forschungsinstitut für Kinderernährung (FKE)

Trotz zahlreicher Aufklärungsmaßnahmen werden seit Jahren dieselben Probleme bei der Kinderernährung beklagt, z. B. ein zu geringer Verzehr von Gemüse und Vollkornprodukten, zu viel Limonade, Verzicht auf das Frühstück. Deshalb sind neue Strategien erforderlich, um eine gesunde Ernährung für Kinder attraktiv zu vermitteln.

Wie die Lebensmitteldatenbank LEBTAB des FKE und die Verzehrsdaten der DONALD Studie dokumentieren, wird die Ernährungspraxis von Kindern zunehmend durch Fertigprodukte geprägt, angefangen vom Babygläschen bis hin zur Tiefkühlpizza. Die Identifizierung von geeigneten Produkten ist in der Vielfalt des heutigen Lebensmittelmarktes selbst für aufgeklärte Verbraucher allerdings nicht leicht.

Das FKE setzt hier auf die Marke optimiX ${ }^{\oplus}$. Mit optimiX werden Produkte ausgezeichnet, die die Kriterien der Optimierten Mischkost, dem vom FKE entwickelten Präventionskonzept für die Ernährung von Kindern und Jugendlichen, erfüllen. Mit optimiX wird eine positiv besetzte Botschaft vermittelt ohne dass der Konsument die Inhalte der Optimierten Mischkost im einzelnen kennen muss.

Die Marke optimiX richtet sich auch an die Ernährungswirtschaft, vom Einzelhandel bis hin zu Essensanbietern in Kindertagesstätten und Schulen. Im Sinne des Wissenstransfers von der Forschung in die Wirtschaft möchte das FKE Unternehmen bei der Entwicklung optimierter Produkte unterstützen. Dazu zählt auch die Vergabe des optimiX Gütesiegels, das als Marketinginstrument im Wettbewerb eingesetzt werden kann. Ein solch erleichterter Zugang zu gesunden Nahrungsprodukten entspricht dem Konzept der Verhältnisprävention, die sich an Bevölkerungsgruppen wendet, die mit den klassischen Aufklärungsmaßnahmen nicht erreicht werden.

Ob die Marke optimiX die Entwicklung und den Konsum gesunder Nahrungsprodukte bei Kindern effektiv unterstützen kann, wird in dem Forschungsprojekt ,Previkids NRW' 2009-2012 der FKE GmbH Dortmund (Förderung: Land NRW und Europäische Union) untersucht.

\section{Impfen bei Frühgeborenen}

\section{DGKJ-SY-008}

Immunsystem Frühgeborener: Reif für die Impfung?

M. Zemlin

Zentrum für Kinder- und Jugendmedizin

Infektionen verursachen bei Frühgeborenen aufgrund der „physiologischen Immundefizienz" eine erhebliche Morbidität und Mortalität. Eine besondere Gefährdung geht u. a. auch von impfpräventablen 
Erkrankungen wie z. B. Pertussis, Haemophilus influenzae Typ B und Pneumokokken aus.

Bei der Immunantwort auf eine Impfung wird ebenso wie bei einer Wildtyp-Infektion ein komplexes Gedächtnis-Netzwerk etabliert, an dem zahlreiche Komponenten des Immunsystems beteiligt sind. Das (Impf-) Antigen wird durch Zellen des angeborenen Immunsystems aufgenommen und prozessiert. Dendritischen Zellen und T-Zellen präsentieren die Antigene den B-Zellen, die zu spezifischen Gedächtnis- und Plasmazellen reifen. Physiologische Weise überwiegt bei der protektiven Immunantwort ein Th1-wendiges Zytokinmilieu. Beim Feten, der noch auf das Erlernen der Immuntoleranz gegenüber eigenen und mütterlichen Antigenen eingestellt ist, überwiegt eine Th2wendige Immunlage. Im Vergleich zum Erwachsenen haben Feten eine veränderte Granulozytenfunktion, einen höheren Anteil plasmozytoider dendritischer Zellen und ein „leeres“ Gedächtnis der adaptiven Immunabwehr. Die Frühgeburt verursacht eine vorzeitige Aktivierung des adaptiven Immunsystems. Wir konnten zeigen, dass Frühgeborene an ihrem errechneten Geburtstermin bereits eine wesentlich größere Vielfalt an IgG- und IgA-Antikörpern als gesunde Reifgeborene. Passend hierzu belegten mehreren Studien anderer Arbeitsgruppen, dass Frühgeborene nach einer Impfung im postnatalen Alter von 8 Wochen eine protektive Antikörperantwort etablieren können. Allerdings ist die Konzentration und Affinität der Antikörper geringer als beim Reifgeborenen. Die theoretisch hergeleitete Befürchtung einer Toleranzinduktion bei „zu früher“ Impfung des Frühgeborenen hat sich nicht bestätigt. Aufgrund des verminderten Nestschutzes ist beim Frühgeborenen bei einer Impfung die Interferenz mit mütterlichen Impfantikörpern geringer. In aktuellen und zukünftigen Studien muss geklärt werden, ob die Impfantwort bei Frühgeborenen durch einen angepassten Impfkalender und/oder durch die Verwendung von Adjuvantien noch verbessert werden kann.

Schlussfolgerung: Das Immunsystem des Frühgeborenen ist nach heutigem Kenntnisstand nicht nur reif genug für eine protektive Impfantwort, sondern es ist gleichzeitig so unreif dass es keinesfalls länger als nötig dem erhöhten Risiko impfpräventabler Infektionen ausgesetzt werden darf. Die Impfungen sollten daher wie von der STIKO empfohlen entsprechend dem postnatalen und nicht entsprechend dem postkonzeptionellen Alter erfolgen.

\section{DGKJ-SY-009}

Impfungen bei Frühgeborenen - was, wann, wo?

E. Herting

Klinik für Kinder- und Jugendmedizin, Universität zu Lübeck

Frühgeborene weisen ein erhöhtes Risiko für impfpräventable Erkrankungen wie etwa die systemischen Pneumokokkeninfektionen auf. Die ständige Impfkommission (STIKO) erwähnt daher die Frühgeburtlichkeit ausdrücklich unter dem Begriff der „falschen Kontraindikation“. Die Empfehlung im epidemiologischen Bulletin des Robert-Koch-Institutes lautet folglich: „Frühgeborene sollten unabhängig von ihrem Reifealter und dem aktuellen Gewicht entsprechend dem empfohlenen Impfalter geimpft werden. "Bei kleinen Frühgeborenen sollte deshalb die erste 6-fach- und die Pneumokokkenimpfung regelhaft noch während des stationären Aufenthaltes erfolgen. Nachdem im Jahr 2008 die Fachinformationen von Impfstoffen für Säuglinge geändert wurden, empfiehlt die Deutsche Akademie für Kinder- und Jugendmedizin, eine 48- bis 72 -stündige stationäre Überwachung von Frühgeborenen $<28$ Schwangerschaftswochen um das Risiko/die Folgen von Apnoen nach Durchführung der Impfung zu minimieren. Kommt es bei der (Erst)Impfung zum (erneuten) Auftreten von Apnoen, so ist auch die jeweilige Folgeimpfung unter stationärer Überwachung durchzuführen. Bezüglich der Hepatitis-B-Impfung gelten die für reife Neugeborenen entwickelten Empfehlungen der STIKO auch für Frühgeborene. Ehemalige Frühgeborene mit einer bronchopulmonalen Dysplasie sollten jenseits des 6. Lebensmonats gegen Influenza geimpft werden. Bezüglich der Immunprophylaxe gegen RS-Viren sei auf die gemeinsamen Empfehlungen der Fachgesellschaften verwiesen. Neben einem adäqua- ten Impfschutz für das Frühgeborene sollte während des stationären Aufenthaltes auch der Impfstatus der Eltern, der Geschwister und der übrigen Kontaktpersonen kritisch hinterfragt und ggf. eine Komplettierung veranlasst werden. Gerade was Pertussis, Influenza und Pneumokokken angeht gilt es, auch im Interesse der Frühgeborenen, die Impflücken im Erwachsenenalter zu schließen.

\section{DGKJ-SY-010}

(Neue) Influenza und Frühgeborene - Schwein gehabt?

C. Härtel, E. Herting

Klinik für Kinder- und Jugendmedizin Lübeck

Frühgeborene haben aufgrund ihrer immunologischen Unreife und pulmonalen Morbidität ein erhöhtes Risiko, bei einer Influenza-Infektion schwer zu erkranken. Das gilt für die saisonale Influenza und auch für die sogenannte Neue Grippe, hervorgerufen durch das Influenzavirus A/H1N1, die im März 2009 ausbrach. Da Frühgeborene überwiegend auf Intensivstationen betreut werden, hat die Kontaktübertragung von Influenzaviren durch medizinisches Personal und Besucher eine zentrale Bedeutung. Wir stellen die epidemiologische Datenlage dar und halten Rückschau auf die $\mathrm{H}_{1} \mathrm{~N}_{1}$-Pandemie bzw. deren medizinische und gesellschaftspolitische Konsequenzen. Dabei werden die Besonderheiten von Frühgeborenen im Hinblick auf $\mathrm{H}_{1} \mathrm{~N}_{1}$-Infektionen dargestellt, insbesondere die klinische Symptomatik sowie Therapieindikation mit Oseltamivir, jedoch auch die Bedeutung von Nestschutz, Basishygienemaßnahmen und Präventionsmöglichkeiten.

\section{Adipositas - Gastroösophagealer Reflux und Obstruktives Schlafapnoe-Syndrom}

\section{DGKJ-SY-011 \\ „Schlaf dich dünn!“ - ein Therapiekonzept für adipöse Kinder? \\ F. Kirchhoff \\ Klinikum Südstadt, Kinderklinik}

In epidemiologischen Studien konnte deutlich gezeigt werden, dass es einen Zusammenhang zwischen kurzer Schlafdauer und hohem BMI gibt. Es konnte gezeigt werden, dass die kurze Schlafdauer ein unabhängiger Prediktor für eine spätere Adipositas ist. Neuere Studien zeigen auch die pathophysiologischen Zusammenhänge auf, die zur Adipositas führen. So beeinflusst eine kurze Schlafdauer deutlich den Glukosestoffwechsel und die Sekretion von Leptin und Ghrelin. Eine ausreichende Schlafdauer ist somit für die Prophylaxe und die Therapie der Adipositas sehr wichtig.

\section{DGKJ-SY-013}

Gastroösophagealer Reflux und Schlaf bei Säuglingen und Kindern T. Wenzl

Klinik für Kinder- und Jugendmedizin, Universitätsklinikum der RWTH Aachen

Gastroösophagealer Reflux (GÖR) und gestörter Schlaf sind häufige, unspezifische Symptome bei Säuglingen und Kindern und assoziiert mit zahlreichen physiologischen und pathologischen Umständen. Umweltfaktoren, wie Exposition gegenüber Tabakrauch, spielen hierbei eine Rolle und die individuelle Reaktion und Altersabhängigkeit ist ebenso erheblich wie die Variabilität der elterlichen Erwartungshaltung.

Das Konzept, daß Schlafstörungen bei Säuglingen eine nachgewiesene Manifestation von GÖR darstellen, ist überwiegend aus an Erwachsenen erhobenen Daten übernommen, wobei die Zusammenhänge komplex sind und Ursache und Wirkung bidirektional sein können. Die Horizontalisierung während des Schlafes kann ebenso wie im Schlaf physiologischerweise herabgesetze Clearance-Mechanismen (vermindertes Schlucken, verminderte Salivation und primäre ösophageale 
Motilität) zur erhöhten GÖR-Inzidenz beitragen. Ob der vermehrte GÖR zu beeinträchtigem Schlaf als Effekt einer verbesserten RefluxClearance oder der tiefe Schlaf zu vermehrtem GÖR führt, bleibt gelegentlich unklar. Beide Situationen können sich jedoch gegenseitig verstärken. In Studien an Säuglingen konnte gezeigt werden, daß Säuglinge mit GÖR verzögertes Einschlafen, vermehrtes nächtliches Erwachen, vermehrte Schlafphasen-Wechsel und vermehrte Tagesschläfrigkeit aufwiesen.

Von der zur Verfügung stehenden Evidenz kann eine empirische GÖRTherapie bei Kindern mit ätiologisch unklaren Schlafstörungen nicht abgeleitet werden. Ein Symptom-Tagebuch oder eine Phase der stationären Beobachtung können hier hilfreich sein um Differentialdiagnosen wie u. a. Allergien, Infektionen, Atemwegs- oder neurologische Erkrankungen abzugrenzen. Die Schlafstörung möglicherweise begleitende GÖR-Symptome, die den Eltern nicht unmittelbar als Problem erkennbar sind, wie respiratorische Symptome oder Apnoen, bedürfen einer diagnostischen Klärung, idealerweise mittels synchroner Registrierung von Schlaf-, Atmungs- und GÖR-Symptomen in einem entsprechend ausgestatteten Schlaflabor.

\section{DGKJ-SY-015}

Wirtschaftliches Management der klinischen Schlafmedizin B. Hoch

Kinderkrankenhaus Josefinum. Pädiatrische Schlafmedizin

Einleitung: Die Situation auf dem Gesundheitsmarkt hat sich in den letzten Jahren zunehmend verschärft. Auch in Zukunft ist damit zu rechnen. Die Gründe sind einerseits in steigendem Konkurrenz- und Kostendruck und andererseits in der Reduktion der Bettenzahl und der Belegungstage zu sehen. Um dem adäquat begegnen zu können, sollte der heterogene Gesamtmarkt "Gesundheit" in homogene Teilmärkte segmentiert und Nischen besetzt werden. Dies gelingt aber nur mithilfe einer stetigen Überprüfung und Optimierung der Wirtschaftlichkeit. Methode und Ergebnis: Anhand des Schlaflabores am Josefinums in Augsburg soll aufgezeigt werden, wie eine solche Überprüfung und Anpassung erfolgen kann. Zunächst stellt sich die Frage, wie die Umwelt des Schlaflabores zu bewerten ist (Umweltanalyse). Hier zeigt sich, dass die strategische Geschäftseinheit ein regionaler Angebotsmonopolist ist, das Einzugsgebiet trotzdem jedoch mehr Potential bietet. Die Unternehmensanalyse deutet an, dass die Anzahl der zuweisenden Ärzte in Relation zur Gesamtzahl sehr gering ist. Weiter zeigt die Altersanalyse der Patienten, dass die Patientenzahlen im Alter fallen. Das DRG-Spektrum der im Schlaflabor gestellten Diagnosen weist darauf hin, dass die meisten Diagnosen in die E63Z eingruppiert werden können. Diese DRG ist jedoch nur mit einem relativen Kostengewicht von 0,261 bewertet. Betrachtet man nun die Gewinnsituation des Schlaflabores am Josefinum, so zeigt sich, dass diese strategische Geschäftseinheit ein Defizit erwirtschaftet. Da jedoch zahlreiche Patienten des Schlaflabores als „Wiederkehrer“ mit anderen Erkrankungen ins Josefinum kommen, müssen diese in die Unternehmens-/Wirtschaftlichkeitsanalyse integriert werden. So ergibt sich ein positives Ergebnis der strategischen Geschäftseinheit "Schlaflabor“. Abschließend ist im Rahmen der Unternehmensanalyse noch die Einbettung des Schlaflabores in den Gesamtkontext des Josefinums mittels Portfolio zu betrachten. Nur so kann sich für alle strategischen Geschäftseinheiten des Josefinums eine Strategie ableiten.

Konklusion und Procedere: Betrachtet man die Unternehmens- und Umweltanalyse zusammenfassend, so zeigt sich, dass die Fallzahlen wie aber auch die höher bewerteten Diagnosen nur gesteigert werden können, wenn Marketing betrieben wird. Hierzu werden zunächst die beiden Zielgruppen „Ärzte“ und „Patienteneltern“ betrachtet, so dass in Abhängigkeit davon der Marketing-Mix im Rahmen der Marketingplanung aufgestellt werden kann. Hier werden gezielte Maßnahmen des Schlaflabores am Josefinums zu den vier P's (product, price, place, promotion) wie aber auch zum personal relationship aufgestellt, so dass die Wirtschaftlichkeit des Schlaflabores verbessert werden kann. Abschließend sollte jedoch noch eine Überprüfung des Marketingprozesses erfolgen, so dass das Marketing ein integrativer Bestandteil der Unternehmensführung ist und damit strategischen Charakter hat.

\section{Jungenmedizin}

\section{DGKJ-SY-016}

„Warum nur bin ich ein Mann geworden?" - das benachteiligte

Geschlecht, verkannt und verdammt

N. Weissenrieder

Praxiszentrum Saarstrasse

In den letzten Jahren wurde vor allem in den Medien daraufhingewiesen, dass Jungen (und Männer) als das benachteiligte Geschlecht erkannt wurden. Dies bezieht sich nicht nur auf den Bildungsbereich, in dem Jungen zunehmend schlechtere Bildungschancen als Mädchen eingeräumt werden.

Geschlechtsspezifische Unterschiede bestehen bereits pränatal und lassen sich über die gesamte Entwicklung (Fet, Säugling, Kleinkind, Schulkind, Jugendlicher) auch in ihren Auswirkungen auf Gesundheit und Gesundheitsverhalten im medizinischen Bereich nachweisen. Die unterschiedlichen Morbiditäten und Mortalitäten von Jungen und Mädchen werden dargestellt. Es gibt aber nur wenig genderspezifische Ansätze in Therapie oder Prävention. Die Unterschiede im Bildungsbereich von Jungen und Mädchen stellen die Benachteiligung von Jungen programmatisch dar.

\section{DGKJ-SY-018}

\section{Wie geht's den Jungs - was müssen (Jugend)Ärzte wissen}

Jungen und Männer leben risikoreicher, gehen weniger zum Arzt und nehmen Beratungseinrichtungen seltener in Anspruch. Dabei wird völlig übersehen, dass es dringend an der Zeit ist jungenmedizinische Kompetenzen zu fördern, mehr geschlechterbewusste Beratungs- und Erziehungsarbeit zu leisten und mehr gesundheitsfördernde Betreuungstrukturen für Jungen zu schaffen.

Gesundheitserziehung muss bei der Vermittlung von Geschlechterleitbildern bereits vor der Pubertät ansetzen und konkret den Jungen beibringen, dass z. B. auch Schwäche, Traurigkeit und Hilfsbedürftigkeit normal, jedenfalls keineswegs „nmännlich“ sind. Jungen brauchen Ärzte, die Kompetenz in Jungengesundheit (auch medizinische) besitzen und sich zuständig zeigen für deren gesundheitlichen Belange. Männergesundheit fängt mit Jungengesundheit an. Medizinisches Schrifttum zum Thema Jungenmedizin ist bislang rar gesät und sich zuständig fühlende Ärzte ebenfalls. Das Wissen über jungenmedizinische Probleme ist nach wie vor nicht ausreichend vorhanden. Solange es aber kaum Angebote einer Jungenmedizin gibt und gesundheitsfördernde Beratungsangebote nur sporadisch vorhanden sind, kann auch keine Inanspruchnahme erfolgen, selbst wenn eigentlich Bedarf besteht. Dass Jungen und Männer die Mortalitäts- und in vielen Bereichen auch die Morbiditätsstatistiken anführen, lässt sich nur durch eine gendergerechte und kompetent vertretene Jungenmedizin zum Positiven verändern. „Naturgegeben“ ist es sicherlich nicht.

\section{Innovative Therapiekonzepte in der Neuropädiatrie}

\section{DGKJ-SY-021}

Molekulargenetische Therapiekonzepte bei der Muskeldystrophie Duchenne

V. Straub

Insitut of Human Genetics, University of Newcastle

Vor nahezu 25 Jahren wurde der der Muskeldystrophie Duchenne (DMD) zugrundeliegende Gendefekt identifiziert; ein Meilenstein in 
der Geschichte der Humangenetik. Bis heute ist das Dystrophin-Gen das größte in der Natur bekannte Gen, was Ansätze für eine Genersatztherapie deutlich erschwert. Die Natur hat die Kliniker jedoch gelehrt, dass, solange das Leseraster erhalten bleibt, auch große Deletionen im Dystrophin-Gen mit geringen klinischen Symptomen einhergehen können. Diese klinisch milden Mutationen führen zu einer Dystrophinexpression und zum Krankheitsbild der Becker Muskeldystrophie (BMD), wohingegen es bei der schweren allelischen DMD aufgrund von Mutationen, die das Leseraster im Dystrophin-Gen verschieben, zu keinerlei Dystrophinexpression in der Skelettmuskelfaser kommt, was letztlich zu Muskeldegeneration und Muskelschwund führt. Therapeutisch lassen sich die Erkenntnisse zum Pathomechanismus der DMD und BMD auf verschiedene Weise nutzen. Mit Hilfe viraler Vektoren kann auch ein verkleinertes, sogenanntes Minidystrophin-Gen, in Skelettmuskelzellen von DMD Patienten eingeschleust werden und zu einer funktionell verbesserten Dystrophinexpression führen. Bei der Therapie mit Antisensoligonukleotiden basiert das Prinzip darauf, eine Mutation welche das Leseraster verschiebt durch entsprechendes Exon-Skipping in eine Deletion mit erhaltenem Leseraster zu überführen. Erste Studien zur Genersatztherapie und zur systemischen Applikation von Antisensoligonukleotiden sind bereits in klinischer Erprobung. Ein weiterer therapeutischer Ansatz, der in die posttranskriptionale Modifikation von mRNA eingreift, wurde kürzlich in einer internationalen multizentrischen Studie untersucht, in der DMD Patienten mit einer Stop-Mutation mit Ataluren ${ }^{\infty}$ behandelt wurden. Die Studie konnte jedoch keine signifikante Verbesserung der Gehfähigkeit von DMD Patienten zeigen.

Ein vollkommen anderer Ansatz zur möglichen Behandlung der DMD wird derzeit in einer Studie mit einem rekombinanten Protein aus dem Activin Rezeptor IIB und einem humanen Antikörper untersucht. Das Protein bindet Faktoren, die das Muskelwachstum hemmen, was zu Muskelwachstum und verbesserter Muskelkraft führen soll.

Es ist ermutigend zu sehen, dass verschieden therapeutische Ansätze zur Behandlung von DMD Patienten derzeit in klinischen Studien getestet werden. Es ist anzunehmen, dass die neuen Therapiemöglichkeiten, wichtige Ergänzungen zu den derzeitig gültigen Behandlungsrichtlinien bieten, sie jedoch nicht ersetzen werden.

\section{Update Jugendgynäkologie}

\section{DGKJ-SY-027 \\ HPV-Impfung - Was sollten Kinder- und Jugendärzte wissen}

M. Heinz

Sprechstundenzentrum Sana Klinikum, Fachärztin für Gynäkologie und Geburtshilfe

Erreger: Humane Papillomaviren (HPV) sind kleine unbehüllte Viren mit weltweiter Verbreitung.

Von den mehr als 100 identifizierten Typen können 40 von ihnen benigne oder maligne Erkrankungen der Anogenitalregion und im HalsRachenbereich verursachen. $15-20$ sind onkogenetisch. $\mathrm{Zu}$ unterscheiden sind Hochrisikotypen (high risk), wie z. B. HPV 16 und 18, die häufig Tumorvorstufen bzw. Tumorerkrankungen an Zervix, Vulva, Penis oder After verursachen und Niedrigrisikotypen (low risk) wie z. B. HPV 6 und 11, die Genitalwarzen (Condylomata acuminata) oder eine respiratorische Papillomatose verursachen können.

Die Übertragung erfolgt überwiegend beim Geschlechtsverkehr (oral, vaginal, anal), seltener auch nichtsexuell z. B. perinatal, durch Kontakt zu infizierter Haut, Schleimhaut, op. Handschuhe oder Unterwäsche. Die Übertragung ist nicht an den Austausch von Körperflüssigkeiten gebunden.

Infektionshäufigkeit und Erkrankungen: Etwa 70\% der sexuell aktiven Frauen und Männer infizieren sich mit HPV der Typen 16 und 18. Der Häufigkeitsgipfel liegt zwischen 18 und 24 Jahren. 1 - 2 Jahre nach der Infektion ist bei den meisten keine HPV-DNA mehr nachweisbar.
Etwa 10 \% werden chronisch und können dann bei weiterhin HPV-positiven Frauen nach Monaten oder Jahren bevorzugt zu Präkanzerosen der Zervix führen mit der Notwendigkeit einer operativen Intervention (Hochrechnung für Deutschland. 140. ooo Konisationen/Jahr) mit allen damit verbundenen Ängsten. Bei jungen Frauen mit Kinderwunsch können nach Konisation nachweislich Komplikationen während der Schwangerschaft, wie erhöhte perinatale Mortalität, Frühgeburt vor der 37. Schwangerschaftswoche u. a. auftreten.

Ca. 1\% aller Frauen mit persistierender HPV-Infektion erkranken an einem Zervixkarzinom:

In Deutschland 6. 500 Neuerkrankungen mit 1. 700 Todesfällen (2005), in Europa 26. ooo Sterbefälle (2005) und weltweit 500. ooo Neuerkrankungen bei 275. ooo Todesfällen (2002).

Condylomata acuminata haben eine Inzidenz von ca. $1 \%$ bezogen auf alle sexuell aktiven Frauen. Auch Kinder können erkranken. Eine nichtsexuelle Übertragung ist möglich. Das lebenslange Risiko an anogenitalen Warzen zu erkranken wird auf ca. 10\% geschätzt. In Deutschland konsultieren deshalb jährlich 40. ooo bis 50. ooo Frauen einen Arzt. Condylomata acuminata sind fast immer benigne, werden aber als sehr peinvoll und beängstigend von den Betroffenen empfunden. Die Spontanremissionsrate beträgt $>40 \%$. Bei Persistenz ist trotz Behandlung (topisch oder chirurgisch) mit einer Rezidivrate bis zu 65\% zu rechnen. Respiratorische Papillomatosen haben einen Altersgipfel bei Kindern zwischen 2 und 4 Jahren und bei Erwachsenen zwischen 20 und 40 Jahren. Sie sind benigne und wesentlich verursacht durch HPV 6 und 11. Infolge ihrer hohen Rezidivrate können sie eine wiederholte chirurgische Therapie erfordern um die Luftwege von ihrer Obstruktion zu befreien. Möglicherweise spielt insbesondere HPV 16 eine wesentliche Rolle bei der Entstehung von Karzinomen im oralen, oropharyngealen und laryngealen Bereich. Die Risikofaktoren für diese Karzinome sind die gleichen wie für die Entstehung eines Zervixkarzinoms.

Es gibt keine kausale Therapie gegen eine persistierende Infektion mit HPV.

Wenn eine persistierende HPV-Infektion besteht mit den am häufigsten vorkommenden Präkanzerosen im Genitalbereich (Dysplasie, Neoplasie) sind invasive chirurgische Maßnahmen, Strahlen- oder Chemotherapie erforderlich.

Die primäre (kausale) Prävention ist die HPV-Impfung: Sie verhindert, dass eine Infektion mit HPV überhaupt entstehen kann. Sie ersetzt aber nicht die Teilnahme am Früherkennungsprogramm, da sie nicht vor allen HPV-Typen schützt.

Sekundäre Prävention: Früherkennungsuntersuchungen wie Zervixabstrich mit zytologischer Untersuchung (PAP-Abstrich) oder der z. Zt. noch nicht obligate HPV-DNA-Nachweis sind eine sekundäre Prävention, da hier bereits Dysplasien bestehen.

Kondome verhindern eine HPV-Infektion nicht sicher, da die Viren im Unterschied zu anderen sexuell übertragbaren Errregern nicht durch Samenflüssigkeit übertragen werden sondern durch Kontakt mit infizierten Hautpartien, die nicht durch das Kondom geschützt sind, z. B. Introitus vaginae, Vulvabereich. Kondome sollten aber immer empfohlen werden zum Schutz vor anderen sexuell übertragbaren Erkrankungen,z. B. Chlamydien, HIV u. a.

Impfung: In Deutschland stehen 2 gentechnologisch hergestellte Totimpfstoffe zur Verfügung:

Das tetravalente Gardasil ${ }^{\mathrm{R}}$ wirksam gegen HPV 6, 11,16 und 18, zugelassen September 2006 und das bivalente Cervarix ${ }^{\mathrm{R}}$ wirksam gegen HPV 16 und 18, zugelassen September 2007.

Die STIKO hat im März 2007 die Impfung für alle 12 - 17jährigen Mädchen empfohlen. Die Impfung mit 3 Dosen muss innerhalb eines Zeitraumes von 6 - 12 Monaten erfolgen und sollte vor dem ersten Geschlechtsverkehr abgeschlossen sein.

Wirksamkeit: Bei HPV-naiven Mädchen beträgt die Wirksamkeit $>95 \%$ in der Verhinderung von Infektionen mit HPV 16 und 18. Der Impfschutz hält nach Studienbeginn für mindestens 7 Jahre an. Bei bereits HPV-infizierten Frauen ist die Wirksamkeit deutlich reduziert. Die Impfung hat keinen therapeutischen Effekt bei bereits bestehenden Infektionen oder bereits vorhandene Zellveränderungen an der Zervix. 
Nebenwirkungen: Sie betreffen wesentlich die auch nach anderen Impfungen auftretenden Beschwerden an der Impfstelle wie Schmerzen, Rötung und Juckreiz und auch Fieber. Für einen ursächlichen Zusammenhang von ernsthaften Erkrankungen wie Guillain-Barré- Syndrom oder Synkopen mit dem Impfstoff gibt es keine Nachweise. Auch bei den Todesfällen weltweit, die in einem zeitlichen Zusammenhang mit der HPV-Impfung standen, konnte bisher eine ursächliche Rolle der Impfung nicht belegt werden. Aktuelle Informationen zu Nebenwirkungen auf der homepage des Paul-Ehrlich-Institutes www. pei. de Kosten der Impfung: Sie betragen für die abgeschlossene Grundimmunisierung mit drei Injektionen ca. 480 Euro in Deutschland. Die gesetzlichen Krankenkassen übernehmen die Kosten für 12 - 17-jährige Mädchen. Einige Kassen zahlen auch voll oder teilweise bis zum 26. Lebensjahr

Fazit: Die Impfung gegen HPV ist auf die besonders sensible Zielgruppe der Jugendlichen im Prozess ihres körperlichen und sexuellen Entwicklungsprozesses gerichtet. Nach der derzeitigen Studienlage ist die HPV-Impfung ein wirksames Mittel zur Verringerung von Infektionen durch die häufigsten HPV-Typen und damit von anogenitalen und oral-pharygealen Präkanzerosen und Karzinomen mit ihrer Krankheitslast.

Kinder- und Jugendärzte müssen sich einen eigenen kompetenten Standpunkt zu dieser präventiven Impfung erarbeiten und verständlich an die Jugendlichen, ihre Väter und Mütter vermitteln. Ein aktives Ansprechen der HPV- Impfung seitens der Pädiater ist unabdingbar, insbesondere weil Jugendliche andere Probleme haben als an eine Vorsorge jeglicher Art zu denken und viele Eltern sich emotional weigern mit ihrem Kind über dieses zwangsläufig mit Sexualität verbundene Thema zu sprechen. Jeder Arzt sollte darüber nachdenken ob eine indifferente Haltung oder gar Verweigerung dieser Primärprävention gegenüber den später Betroffenen vermittelbar oder vertretbar wäre.

\section{Adipositas im Vorschulalter}

\section{DGKJ-SY-029}

Ernährung bei Vorschulkindern: Empfehlungen und Realität

M. Kersting

Forschungsinstitut für Kinderernährung Dortmund (FKE)

Das Vorschulalter bietet sich aufgrund entwicklungs- und ernährungsphysiologischer Besonderheiten, aber auch aus lerntheoretischen Gründen dazu an, Kinder an eine gesunde Ernährung zu gewöhnen. Die Optimierte Mischkost, kurz optimiX, ist ein lebensmittelund mahlzeitenbezogenes Konzept für eine präventiv ausgerichtete Ernährung von Kindern in Familien ebenso wie in Kindertagesstätten und Kindergärten. Mit einfachen Botschaften werden die wesentlichen Regeln für die Lebensmittelauswahl an Eltern, Erzieher und Kinder vermittelt: reichlich Getränke und pflanzliche Lebensmittel, mäßig tierische Lebensmittel, sparsam fett- und zuckerreiche Lebensmittel. Vorbildhaftes Ernährungsverhalten der Erwachsenen und eine flexible Ernährungserziehung fördern eine gesunde Ernährung und Gewichtsentwicklung der Kinder.

Wie die DONALD Studie (Dortmund Nutritional and Anthropometric Longitudinally Designed Study) zeigt, weicht die reale Ernährung von Vorschulkindern mit zunehmendem Alter mehr und mehr von wesentlichen Präventionsempfehlungen $\mathrm{ab}$, insbesondere durch einen $\mathrm{zu}$ niedrigen Verzehr von pflanzlichen Lebensmitteln mit niedriger Energiedichte (Gemüse, Obst, Kartoffeln) und durch einen zu hohen Verzehr von energiedichten, fett- und/oder zuckerreichen Lebensmitteln (Süßigkeiten, Limonade). Während junge Säuglinge dank ihrer natürlichen Hunger-Sättigungsregulation ihre Nahrungsmenge noch an die Energiedichte der Milchnahrung anpassen, erhöht sich im Kindesalter das Risiko für eine Überernährung durch zunehmende äußere Einflüsse auf das Essverhalten, wie eine rigide Ernährungserziehung, energiedichte und große Mahlzeiten.
Die große Mehrheit der Kinder besucht heute einen Kindergarten oder eine Kindertagesstätte und wird dort mit einer oder mehreren Mahlzeiten verköstigt. Mit einem gesunden Nahrungsangebot in diesen Einrichtungen können Kinder aller sozialen Schichten niederschwellig erreicht und damit wesentliche Schritte zur präventiven Verbesserung der heutigen Ernährung von Vorschulkindern getan werden.

\section{DGKJ-SY-031}

Adipositas im Vorschulalter: Prävention und Intervention

T. Reinehr

Department of Paediatric Endocrinology, Diabetes and Nutrition Medicine, Vestische Youth Hospital, University of Witten/Herdecke

The prevalence of overweight and obesity is increasing dramatically in Europe children and effective prevention and treatment is necessary. However, randomized controlled trials have demonstrated that lifestyle interventions based on nutrition education, physical activity and behaviour therapy have a limited effect and the generalisibility is questionable since long-term success was reported only in specialised treatment centres. Furthermore, primarily families of the upper and middle class lay claim to these lifestyle interventions, while families of lower social status are underrepresented in contrast to the increased risk of obesity in their social class. Therefore, interventions in the school or kindergarten setting with day-care seem meaningful to reach children of all social classes. However, randomized control trials based on education and/or behaviour therapy concerning nutrition and physical activity have shown that health behaviour can be improved in the school and pre-school setting, while the effectiveness on weight status is only moderate: Only a moderate decrease of incidence and no effect on prevalence of overweight were reported. Important disadvantages are the difficulties to reach the parents and the questionable motivation to change health behaviour which is mandatory for any behavioural approach. Arrangement of an anti-obesity environment in the day care setting such as installing of drink water fountains and the prohibition of sweated drinks have the same effects as compared to the behavioural approach but are much cheaper. Further prospective randomized studies are urgently necessary to optimize the interventions.

\section{DGKJ-SY-032}

"gesunde kitas - starke kinder" - Ein Pilotprojekt der Plattform Ernährung und Bewegung zur Prävention von Übergewicht im Kleinkind-

alter

A. Lambeck' ${ }^{1}$ A. Berg' ${ }^{1}$, W. Tietze ${ }^{2}$

'Plattform Ernährung und Bewegung e.V. (pep), ${ }^{2}$ Freie Universität Berlin Fachbereich Erziehungswissenschaft und Psychologie Kleinkindpädagogik / PädQuis gGmbH

Fragestellung: Ziel war, ganzheitliche Gesundheitsförderung nachhaltig in Kitas, auf Träger- und kommunaler Ebene zu implementieren um Übergewicht bei Kindern vorzubeugen. Mit der Evaluation des Pilotprojektes "gesunde kitas -starke kinder" sollten drei übergreifende Fragestellungen beantwortet werden:

1. Wodurch zeichnet sich das Projekt gegenüber vergleichbaren Vorhaben im Kita-Bereich aus?

2. Wie gut konnte das Konzept umgesetzt werden?

3. Wie werden die Unterstützungsstrategien (Workshops, Coaching, Materialien) beurteilt?

Methodik: In die Evaluation einbezogen wurden 46 KiTas aus den Pilotstandorten Mülheim, Bielefeld, Augsburg, München. Als Vergleichsgruppe dienten 23 Einrichtungen an denselben Standorten mit vergleichbaren projektrelevanten Bedingungen, jedoch ohne Teilnahme am Programm. Alle Leitungskräfte (69) sowie 353 zufällig ausgewählte pädagogische Fachkräfte aus den 69 Einrichtungen wurden mit einem Selbstevaluationsfragebogen zur Realisierung der Qualitätskomponenten befragt. Ebenso wurde 1. ooo Eltern aus den Piloteinrichtungen befragt. Zusätzlich wurde die Umsetzung dieser Komponenten durch unabhängige externe Evaluatoren beurteilt. 
Ergebnisse: 1. Im Vergleich zu anderen Kindergartenprojekten integriert das Projekt "gesunde kitas -starke kinder" seine Komponenten Ernährung, Bewegung, Entspannung, Elterndialog in den Kita-Ablauf und bezieht das gesamte Kita-Team ein. Es grenzt sich von „Paket-Ansätzen“ ab, die vorwiegend von außen an die Einrichtungen herangetragen werden. Das Projekt verfügt über einen umfassenden Implementierungsansatz, der nachhaltig das gesamte Team einbezieht.

2. Die Umsetzung der Ziele des peb-Konzepts ist aus der Perspektive der unterschiedlichen Adressatengruppen weitgehend erfüllt. So sind die Unterschiede der Selbsteinschätzungen der pädagogischen Fachkräfte im Vergleich zu Einrichtungen ohne peb-Programm statistisch signifikant und substanziell. Auf einem Qualitätsbarometer sehen die LeiterInnen und pädagogischen Fachkräfte eine projektinduzierte Qualitätssteigerung gegeben. Die externen Evaluatoren sehen das Ausmaß der Zielerreichung zwar kritischer, machen aber ebenfalls deutliche, statistisch signifikante Unterschiede zu den Vergleichseinrichtungen aus. Die Eltern der Piloteinrichtungen beurteilen das Programm als wichtig für den Familienalltag der Kinder und sehen dessen Umsetzung im Erziehungsalltag erfüllt. Die Kriterien eines gelingenden Gesundheitsdialogs sehen die Eltern ebenso gegeben wie die LeiterInnen der Piloteinrichtungen.

3. Die LeiterInnen wie auch die Fachkräfte der Piloteinrichtungen würden das Projekt zu 90\% anderen Einrichtungen empfehlen. LeiterInnen und Fachkräfte stimmen darin überein, dass von dem Projekt in erster Linie die Kinder profitieren.

Ausblick: Die Ergebnisse weisen auf einen guten Erfolg des peb-Projekts in der Pilotphase hin. Im Rahmen eines Roll-outs soll der Coaching-Ansatz mit verschiedenen zusätzlichen Instrumenten (Trainthe-Trainer, e-Learning) verbreitet werden.

\section{Die Zukunft der Allergieprävention}

\section{DGKJ-SY-033 \\ Epidemiologie der Allergieprävention: E. von Mutius}

Dr. von Haunersches Kinderspital der Ludwig-Maximilians-Universität München

Es gibt zahlreiche Daten, die belegen, dass Kinder, die auf einem Bauernhof aufwachsen, vor der Entwicklung eines Asthma bronchiale, eines Heuschnupfens und der Entwicklung eines positiven Allergietests geschützt sind. Diese Daten sind nicht nur in Bayern erhoben worden, sondern über ganz Europa bestätigt worden, wie auch in Kanada, Neuseeland und zum Teil in den USA. Dieser Schutz hält mindestens bis in's frühe Erwachsenenalter an, bei andauernder Exposition auch länger. Es zeigt sich hierbei, dass der Schutz vor Asthma und allergischen Erkrankungen über Expositionen im bäuerlichen Umfeld und hier vor allem über die Exposition zu Nutztieren, insbesondere Kühen, Schweinen und Geflügel sowie deren Futtermittel (Heu, Stroh, Silage) vermittelt wird. Zudem ist der Konsum der unbehandelten Kuhmilch ein starker protektiver Faktor, insbesondere für das Asthma bronchiale. Dieser Schutz ist besonders ausgeprägt, wenn bereits die Mutter in der Schwangerschaft exponiert ist und der Säugling bzw. das Kleinkind in den ersten Lebensjahren weiterhin exponiert ist. Es ist anzunehmen, dass Bioaerosole, die im Nutztierstall generiert werden und dort in großer Menge vorkommen, über die Atemwege in den oberen und unteren Atemwegstrakt gelangen und dort ihren Schutzeffekt bewirken. Es ist weiterhin anzunehmen, dass ein Teil dieses Schutzeffektes durch eine mikrobiologische Exposition zu nicht-pathogenen Keimen erklärt werden kann. Hierzu gibt es einerseits epidemiologische Daten, die aufgezeigt haben, dass die Menge an gram-positiven wie gram-negativen Bakterien sowie auch bestimmter Schimmelpilze, einen Schutz vor Asthma und Allergien darstellt. Andererseits sind bestimmte Bakterien aus dem Stall isoliert worden und in experimentellen Studien an Mäusen intranasal verabreicht worden. Diese intranasale Verabreichung hatte zur Folge, dass ein allergisches Asthma bronchiale bei diesen Tie- ren nicht mehr ausgelöst werden konnte. Neueste Ergebnisse zu mikrobiologischen Untersuchungen bäuerlichen Umfeldes zeigen, dass möglicherweise nicht die Diversität der mikrobiellen Exposition sondern spezifische einzelne Keime für diesen Schutz verantwortlich sein könnten. Zudem haben neueste Studien ergeben, dass auch Substanzen aus dem Pflanzenreich, wie sie in Heu oder Stroh zu finden sind, zumindest im Mausmodell eine gute Allergieprotektion bewirken können.

\section{DGKJ-SY-034}

Neue Substanzen zur Allergieprotektion und ihre immunologischen Wirkmechanismen

A. Bufe

Experimentelle Pneumologie -RUB, Bermannsheil

Epidemiologische Untersuchungen auf Bauernhöfen in den Alpenregionen Deutschlands, Österreichs und der Schweiz haben hinlänglich belegt, dass Kinder, die entweder pränatal oder im ersten Lebensjahr postnatal einer Stallumgebung gegenüber exponiert sind, langfristig zu hohen Anteilen vor der Entwicklung von allergischen Sensibilisierungen und daraus resultierender Erkrankungen geschützt sind. In der Luft der Tierställe auf diesen Bauernhöfen finden sich multiple respirierbare Substanzen, die an der inhalativ vermittelten Allergieprotektion beteiligt sein können. Wir konnten zeigen, dass ein Extrakt aus Stallstaub, der in dieser Umgebung gesammelt wurde, im Tiermodel (Ovalbumin-Asthma-Model der Maus) zur vollständigen Inhibition von Sensibilisierung, allergischer Inflammation und Atemwegshyperreagibilität führt, wenn der Extrakt während der Sensibilisierung inhaliert wird (Peters M. et al 2006 Thorax 61: 134-9). Nach Inhalation können die Substanzen des Extraktes eine Aktivierung der mukosalen dendritischen Zellen (DCs) bewirken, die in Folge das anti-inflammatorische Zytokin IL-10 freisetzen und so die DCs selber gegenüber weiterer Aufnahme von Antigenen und der Vermittlung von Sensibilisierung tolerant machen (Gorelik L. et al 2008 Innate Immunity 14: 345-55). Im Weiteren konnten wir verantwortliche Substanzen identifizieren, welche die Allergieprotektion bewirken. Es zeigte sich, dass unter den zahlreichen Umweltbakterien zwei Spezies besonders wirksam sind (Debarry J. et al. 2007 JACI 119: 1514-21). Beide induzieren im Tiermodel und in vitro eine Immunantwort der T-Zellen im Sinne einer Th1-Antwort. Zusätzlich vermitteln Mütter, die eben diese Bakterien inhalieren über die Aktivierung von Antigen präsentierenden Zellen (APCs) Zytokine, die umgekehrt in der Plazenta und im Feten zu einer Herunterregulation von Rezeptoren des angeborenen Immunsystems (Toll-like Rezeptoren; TLRs) führen. Dies geht mit einer geringeren Wahrscheinlichkeit für Sensibilisierung in den Kindern dieser Mütter einher (Conrad ML. et al. 2009 J Exp Med 206: 2869-77). Den weitaus größeren Anteil an Substanzmasse im Stallstaubextrakt (immerhin 13\%) bilden Zuckermoleküle, hier hauptsächlich Arabinogalaktane (AG), die über Gräser und Heu in den Stall gelangen. Wir demonstrieren im Tiermodel, dass AG einen starken Allergie protektiven Effekt hat und anders als die Bakterien wie der Stallstaubextrakt über die Freisetzung von IL-10 zur Tolerierung von DCs führen (Peters M et al 2010 JACI in press). Zusätzlich finden wir synergistische Allergie protektive Effekte zwischen den oben genannten Bakterien (Lactococcus lactis) und dem AG im inhaltiven Mausmodel. Beide Substanzen zeigen also bei geringerer Konzentration im Gemisch höhere Aktivität. Interessanterweise finden wir im Stallstaubextrakt eine Serinprotease mit hoher proteolytischer Aktivität. Sie stammt dem Gelben Mehlwurm, einem natürlichen Bewohner von Heu in Tierställen (Stiehm M. et al 2010 in preperation). Diese Protease spaltet explizit Komplementfaktor 5 in C5a und C5b und führt zur Erhöhung der C5a Konzentration in der Mukosa, wenn Stallstaubextrakt oder die reine Protease inhaliert wird. C5a wirkt seinerseits als Chemokin und lockt plasmocytoide DCs an. Letztere sorgen, wenn sie im Vergleich zu myeloiden DCs vermehrt in der Mukosa zu finden sind, für die Inhibition der Allergie assoziierten Th2 Antwort der T-Zellen. Zusammengefasst haben wir nicht nur neue Substanzen zur Allergieprotektion identifiziert sondern wir verstehen die Wirkweise dieser Moleküle auch besser. Man muss davon ausgehen, 
dass Allergieprotektion im traditionellen Alpenbauernhof durch eine Mischung verschiedener Substanzen bedingt ist und im Wesentlichen von einer Toleranzreaktion des Immunsystems begleitet wird.

\section{Influenza}

\section{DGKJ-SY-039}

Impfung gegen die neue Influenza $\mathrm{A} / \mathrm{H}_{1} \mathrm{~N}_{1}$

M. Knuf

Klinik für Kinder und Jugendliche HSK, Dr. Horst Schmidt Kliniken GmbH

Seit den ersten Fällen mit akuter respiratorischer Erkrankungen in Mexiko im Februar/März 2009, bei denen ein dahin unbekanntes Influenza-A-virus mit einer genomischen triple - Reassortante aus Anteilen von Schweine-, Vogel- und menschlichen Influenzaviren nachgewiesen wurde, kam es binnen zwei Monaten zu einer rasanten weltweiten Verbreitung des Virus.

Auch wenn die mit der Neuen Grippe einher gehende klinische Symptomatik überwiegend mild waren, so trat die Erkrankung vor allem bei Kindern, Jugendlichen, jungen Erwachsenen und Schwangeren auf. Kinder bis zum 4. Lebensjahr erkrankten besonders häufig derart schwer, dass sie stationär behandelt werden mussten. Letal endende Verlaufsformen wurden vor allem bei jungen Erwachsenen, aber auch bei Kindern beobachtet; zwei Drittel von ihnen hatten allerdings eine chronische Grunderkrankung.

Nachdem im Juni 2006 die WHO die Pandemie- Alarmstufe 6 ausgerufen hatte, wurde - basierend auf Erfahrung mit zugelassenen „mockup"-Impfstoffen - unter Hochdruck ein pandemischer A/H1N1 - Impfstoff entwickelt, welcher den Anforderungen genügen musste,, bei bisher für $\mathrm{A} / \mathrm{H}_{1} \mathrm{~N}_{1}$ naive Personen effektiv das Immunsystem zu stimulieren, schnellstens ausreichend vorhanden sein und eine möglichst hohen und lang anhaltende Protektion bei allen Altersgruppen $\mathrm{zu}$ induzieren bei guter Verträglichkeit und Sicherheit.

Die virologischen Grundlagen des H1N1-Virus, die Pathogenese und Klinik der $\mathrm{H}_{1} \mathrm{~N}_{1}$-Infektion unter Berücksichtigung der unterschiedlichen Altersgruppen, aktuelle epidemiologische Befunde sowie der bisherige Pandemieverlauf werden dargestellt. Pathogenese und Klinik der H1N1-Infektion unter Berücksichtigung der unterschiedlichen Altersgruppen werden erläutert.

Die Anforderungen an Influenzaimpfstoffe und insbesondere an pandemische Impfstoffe 1 werden erläutert, die Studienergebnisse der pandemischen Musterimpfstoffe sowie das Prinzip der Adjuvanssysteme. werden dargestellt. Die zugelassenen pandemischen Impfstoffe werden vorglichen hinsichtlich Zusammensetzung sowie der bisherigen Ergebnisse zu Immunogenität, Verträglichkeit und Sicherheit. Eigene Erfahrungen im Rahmen einer großen Pandemieimpfaktion sowie der Einfluss der Medien auf die Akzeptanz der Bevölkerung werden berichtet, Es werden die Rationalen für die Empfehlungen der „STIKO“ zu der H1N1-Impfung 2009, künftige Impfstrategien, mögliche Influenzaverläufe und Verbesserungsstrategien aus der Pandemie sowie - Impfaktionen diskutiert.

\section{Neues aus der Kinderernährung: Aktuelle Themen der Primärprävention}

DGKJ-SY-044

Frühkindliche Faktoren der Übergewichtsprävention

A. Buyken

Forschungsinstitut für Kinderernährung

Zahlreiche Studien zeigen, dass die Funktionsweise von Organen und Organsystemen bereits in der frühen Kindheit nachhaltig beeinflusst werden kann. Auch für die Entstehung von Übergewicht wird eine solche frühkindliche „Prägung“ diskutiert. So fand sich in vielen epidemiologischen Studien ein enger Zusammenhang zwischen einem niedrigen Geburtsgewicht und einer späteren stammbetonten Adipositas. Andererseits kann auch ein hohes Geburtsgewicht das Risiko für späteres Übergewicht erhöhen, sofern es mit einem hohen Anteil an abdominellem Körperfett einhergeht. Darüber hinaus wird ein hoher Körperfettanteil des Säuglings bei der Geburt auch durch mütterliches Übergewicht, starke Gewichtszunahme während der Schwangerschaft, sowie die Entwicklung eines Gestationsdiabetes begünstigt. Nach der Geburt erhöht eine rasche Gewichtszunahme in den ersten beiden Lebensjahren das Risiko für späteres Übergewicht deutlich - auch bei Kindern, die bei Geburt normal schwer bzw. groß waren. Eine langfristig schützende Funktion von Stillen wird in letzter Zeit zwar vermehrt in Frage gestellt, allerdings zeigte eine Analyse von Daten der DONALD Studie am Forschungsinstitut für Kinderernährung in Dortmund einen ausgeprägten protektiven Effekt des Stillens für die Söhne übergewichtiger Mütter. Während des Übergangs zur Familienkost könnte sich zudem eine hohe Proteinzufuhr (v. a. aus Milch und Milchprodukten) längerfristig kritisch auswirken. Schließlich legen neuere Daten der DONALD Studie nahe, dass auch eine kurze Schlafdauer in der frühen Kindheit mit einer ungünstigeren Entwicklung der Körperfettmasse in der Kindheit einhergeht. Insgesamt bieten Schwangerschaft und frühe Kindheit wie kaum eine andere Lebensphase die Möglichkeit, die Gesundheit des Kindes nachhaltig zu beeinflussen. Vor allem Frauen-, Kinder- und Jugendärzte nehmen daher eine Schlüsselrolle in der frühkindlichen Übergewichtsprävention ein.

\section{DGKJ-SY-045}

Ernährung in der Kindheit und spätere Krankheiten: Erkenntnisse aus der Knochenentwicklung

L. Libuda

Forschungsinstitut für Kinderernährung

Eine ausgewogene gemischte Kost von Kindheit an ist ein maßgeblicher Bestandteil der Gesundheitsförderung und Primärprävention. Dies gilt auch für Erkrankungen wie Osteoporose, die in der Regel in fortgeschrittenem Alter auftreten. In der DONALD Studie wurden mittels peripherer quantitativer Computertomographie (pQCT) Daten zum diaphysealen Knochenstatus bei Kindern und Jugendlichen erhoben, um die Zusammenhänge zwischen Ernährungsfaktoren und frühen Risikomarkern für die Entstehung einer Osteoporose zu untersuchen. Bei prepuberalen Kindern wurden für die lokale Muskelmasse und das Steroid Androstenediol die stärksten Zusammenhänge mit dem radialen Knochenmineralgehalt (KMG) beobachtet. Die Zufuhr von Protein hatte bei prepuberalen Kindern allerdings einen ähnlichen knochenanabolen Effekt wie Androstenediol. Auch bei Kindern und Jugendlichen insgesamt wurden positive Zusammenhänge zwischen Proteinzufuhr und KMG beobachtet. Eine geringere Zufuhr von Protein ist auch die Hauptursache für negative Auswirkungen eines hohen Softdrink-Verzehrs auf den Knochenstatus von Kindern und Jugendlichen. Entgegen früheren Annahmen zeigte sich, dass dieser Zusammenhang nicht allein auf einer Verdrängung der Milch aus der Ernährung beruht. Möglicherweise könnte das Koffein in Colagetränken auch direkt einen negativen Einfluss auf den Knochen haben. Insgesamt scheint bei Kindern ohne ersichtlichen Nährstoffmangel die Proteinzufuhr der bedeutendste knochenanabole Einflussfaktor in der Ernährung zu sein. Aller- 
dings sollte der mit einer hohen Proteinzufuhr einhergehende Anstieg der ernährungsbedingten Säurelast durch eine basenreiche Ernährung mit ausreichend Obst und Gemüse ausgeglichen werden, da eine hohe Säurelast knochenkatabol wirkt. Somit bestätigen die Ergebnisse der DONALD Studie den Stellenwert einer ausgewogenen Ernährung in der Kindheit hinsichtlich der Prävention von Osteoporose.

\section{DGKJ-SY-046}

Von der Gläschenkost zur Tiefkühlpizza: Können Convenienve-Produkte optimiert werden?

U. Alexy

Forschungsinstitut für Kinderernährung (FKE)

Convenience Food (CF) bedeutet „Bequemlichkeits-Essen“. Aber nicht nur Bequemlichkeit ist die Ursache für die weite Verbreitung von CF, sondern breit gefächerte gesellschaftliche Veränderungen. Es ist $\mathrm{zu}$ erwarten, dass sich auch in Zukunft der Trend hin zu CF fortsetzen wird.

Schon Babys bekommen CF: In Deutschland sind zur Zeit knapp 1000 Beikost- und Kleinkindprodukte auf dem Markt. Nach dem Ende der ausschließlichen Milchernährung wird der Gemüse-Kartoffel-FleischBrei besonders häufig als Fertigprodukt (Menü) gegeben. Zwar ist die Fleischmenge und damit der Eisengehalt in kommerziellen Menüs in den letzten Jahren gesunken und liegt nun bei der gesetzlich vorgeschriebenen Mindestmenge. Allerdings beeinträchtigte in der DINOStudie dieses die Eisenversorgung von Säuglingen im Allgemeinen nicht.

Neben Eisen ist Jod im 1. Lebensjahr ein kritischer Nährstoff. Allerdings ist eine Jodanreicherung von Beikost nicht gesetzlich vorgeschrieben. Zur Zeit ist nur etwa die Hälfte der Beikostprodukte mit Jod angereichert, überwiegend Milchfertigbreie. Damit auch bei Selbstzubereitung von Beikost eine bedarfsgerechte Jodzufuhr erreicht werden kann, wären reine Instant-Getreideflocken mit Jodzusatz wünschenswert.

Nach dem Übergang zur Familienernährung nimmt der Verzehr von CF wie Tütensuppen, Konserven und Tiefkühlgerichten vom Kleinkindalter (3\% des Gesamtverzehrs) bis zum Jugendlichenalter (5-7\%) zu. Dabei tragen CF im Vergleich zur Energie- und Kohlenhydratzufuhr überproportional zu Fettzufuhr bei. Die mittlere Energiedichte der CF lag über derjenigen in der Mittagsmahlzeit der Optimierten Mischkost, allerdings mit deutlichen Unterschieden zwischen den Produktgruppen. Der Verzehr von CF hatte in einer longitudinalen Auswertung keinen Einfluss auf die Entwicklung des Körpergewichts bei Kindern und Jugendlichen der DONALD Studie. Aus Gründen der Übergewichtsprävention wäre dennoch die Entwicklung von Produkten mit einem größeren Anteil an Gemüse wünschenswert.

\section{DGKJ-SY-047}

Außerhausverpflegung in Kita und Schule: ein niederschwelliger Zugang zu gesundem Essen und Trinken

K. Clausen

Forschungsinstitut für Kinderernährung (FKE)

Die Außerhausbetreuung von Kindern wird zukünftig in Deutschland auch mit Hilfe staatlicher Investitionsprogramme systematisch weiter voran getrieben. Bis zum Jahr 2013 sollen für $35 \%$ aller unter dreijährigen Betreuungsplätze zur Verfügung stehen; bei den 4-5jährigen werden bereits mehr als $90 \%$ in Tageseinrichtungen betreut und die Anzahl an Ganztagsschulen ist in den letzten Jahren auf heute mehr als 10. ooo Schulen mit etwa 10 Mio. betreuten Schülern angewachsen. Kinder benötigen regelmäßige Mahlzeiten zur Sicherung der Versorgung mit Energie und Nährstoffen und zur Prävention von Übergewicht. Bei Außerhausbetreuung geht ein Teil der Mahlzeiten, z. B. Mittagessen und Zwischenmahlzeitenaus aus der Verantwortung der Familie in institutionelle Verantwortung über. Dies erfordert eine Abstimmung der verbleibenden Mahlzeiten in der Familie, z. B. Frühstück und Abendessen. Wie die bundesweite EsKiMo-Studie und die DONALD-
Studie in Dortmund zeigen, essen Kinder weniger Gemüse und weniger Kartoffeln/Nudeln/Reis, aber mehr Fleisch als in dem vom FKE entwickelten Präventionskonzept der Optimierten Mischkost empfohlen wird. Mit ausgewogenen Mittagsmahlzeiten in Kindertagesstätten und Schulen bieten sich hervorragende Möglichkeiten, die Kinderernährung präventiv zu verbessern. Verbindliche Richtlinien zur Gestaltung der Mahlzeiten in der institutionellen Betreuung von Kindern gibt es in Deutschland bisher nicht. Die Optimierte Mischkost bietet mahlzeitenbezogene Empfehlungen und konkrete evaluierte und von Schülern getestete Rezepte für die Mittagsmahlzeit. Essensanbieter können ihre Rezepte beim FKE prüfen und mit der Marke optimiX ${ }^{\star}$ auszeichnen lassen und damit werben. Das optimiX ${ }^{\oplus}$-Gütesiegel bietet somit ein Sicherheitsnetz für eine gesunde Ernährung in Kindertagesstätten und Schulen. Eine solche Maßnahme der Verhältnisprävention durch erleichterten Zugang zu gesunden Nahrungsmitteln gilt in der Public Health Forschung als vielversprechender Weg, auch Bevölkerungsgruppen zu erreichen, die mit der klassischen Verhaltensprävention durch Informationsvermittlung nicht erreicht werden.

\section{Pubertätsentwicklung: Was ist (noch) normal?}

\section{DGKJ-SY-048}

Physiologie der Pubertätsentwicklung: S. Heger

Kinderkrankenhaus auf der Bult

Die Pubertät ist ein wichtiger Schritt in der Entwicklung des Kindes zum Erwachsenen. Sie ist gekennzeichnet durch einschneidende physiologische Prozesse, die tiefgreifenden Veränderungen in der körperlichen, seelischen und psychosozialen Entwicklung des Menschen nach sich ziehen. Physiologische Veränderungen sind der Anstieg der Hormonproduktion, die Ausbildung

reproduktionsfähiger Gameten und die Entwicklung sekundärer Geschlechtsmerkmale. In Gang gesetzt wird die Pubertät durch eine Aktivitätszunahme der hypothalamischen GonadotropinreleasingHormon Neurone (GnRH), die pulsatil das gleichnamige Hormonprodukt in das portale Gefäßsystem ausschütten, über das es zur Hypophyse gelangt. Dort werden im Hypophysenvorderlappen die Gonadotropine Luteinisierendes Hormon (LH) und Follikelstimulierendes Hormon (FSH) ausgeschüttet, die über die Blutbahn zu den Gonaden gelangen. Die gonadalen Steroide Östrogen und Testosteron, wie auch adrenale Steroide, üben einen Einfluss auf die physische Erscheinung des Körpers aus. Sie wirken sich aber auch auf das zentrale Nervensystem und das Verhalten aus. Hormonelle Effekte auf das Gehirn sind beim Menschen noch wenig untersucht, man nimmt jedoch aufgrund von tierexperimentellen Studien an, dass dieser Effekt über zwei Mechanismen funktioniert: Organisation und Aktivierung. Organisatorische Prozesse erfolgen während der Embryonal- und Perinatalphase, das Ergebnis ist ein männlicher bzw weiblicher „Gehirnphänotyp“. Aktivierende Effekte treten bei Pubertätsbeginn auf. Hier wirken die gonadalen Hormone auf ruhende neuronale Schaltkreise ein und rufen adultes Reproduktionsverhalten hervor.

In den vergangenen 200 Jahren hat sich das Alter bei Menarche, ein später Pubertätsmarker, der circa 2 Jahre nach Pubertätsbeginn auftritt, von 17 auf circa 13 Jahre verschoben. Für diesen Rückgang werden verbesserte Lebens- und Ernährungsbedingungen, sowie bessere Hygienemaßnahmen angeführt. Das Alter bei Pubertätsbeginn und Menarche war im Folgenden für einige Dekaden unverändert bis Studien aus den USA, durchgeführt in den goer Jahren, von einem dramatisch früheren Auftreten von Brustentwicklung und Menarche berichteten. Obwohl einige dieser Studien methodische Schwächen aufweisen, so werden die Ergebnisse jedoch weitestgehend durch heutige europäische Studien bestätigt, die ebenfalls einen Trend zum früheren Pubertätsbeginn aufzeigen. Das Bruststadium 2 (Pubertätsbeginn) zeigt dabei einen gröBeren Shift nach vorn als das Menarchealter. Betroffen sind insbesondere adipöse Kinder. Neben dem Gewicht scheinen aber auch Umwelt- 
faktoren, hormonell aktive Substanzen Einfluss auf den Pubertätsbeginn und -verlauf zu nehmen. Verschiedene Forschergruppen haben sich derzeit dieser Thematik angenommen, die eine nicht unerhebliche Bedeutung für die mit einem früheren Pubertätsbeginn assoziierten Erkrankungen hat.

\section{DGKJ-SY-049}

\section{Diabetes in Pubertät und Entwicklung}

T. Rohrer

Universitätskinderklinik Homburg/Saar, pädiatrische Endokrinologie und Diabetologie

Fragestellung: Chronische Erkrankungen wie Mukoviszidose oder chronisch entzündliche Darmerkrankungen führen zu einem verspäteten Wachstumsschub und Pubertätseintrittsalter. Vor diesem Hintergrund untersuchten wir die Pubertätsentwicklung bei Kindern mit Typ 1-Diabetes (T1DM) und den Einfluss der Güte der Therapie-Einstellung, der relativen Diabetes-Dauer, der Insulin-Dosis und des Körpermassenindex auf den Pubertätsbeginn.

Methodik: Die Deutsche pädiatrische Diabetes-Qualititäts-Initiative DPV (Diabetes-Patienten-Verlaufsdaten) erfasst die Daten von 205 deutschen und österreichischen Zentren für Diabetes. Für die einzelnen Pubertätsstadien wurden uns die Daten von 1879 bis 2588 Mädchen und von 1761 bis 2251 Jungen (Alter 7-16,9 Jahre) mit T1DM zur Verfügung gestellt. Das Alter bei Auftreten der Pubertätsstadien nach Tanner wurde mit deutschen Normwerten (Greil et al. 2005; Anthrop. Anz.) verglichen. Als Einflussgrößen wurden die Güte der Diabetes-Einstellung (anhand des HbAic), die relative Diabetesdauer (Alter bei Diagnose/Alter bei Pubertätsbeginn), die Insulin-Dosis (IU/kg KG/Tag) und der BMI-SDS (nach Kromeyer-Hauschild) analysiert. Als Pubertätsbeginn wurde das Auftreten des Stadiums 2 nach Tanner für Brustentwicklung/Schambehaarung bei Mädchen und für Genitalentwicklung/Schambehaarung bei Jungen definiert.

Ergebnisse: Die Thelarche (B2) tritt bei Mädchen mit T1DM durchschnittlich im Alter von 11,4 Jahren und damit 1,4 Jahren später als bei gesunden Kindern auf $(\mathrm{p}<0,001)$. Das Alter bei Pubarche $\left(\mathrm{PH}_{2}\right)$ liegt bei 11,5 Jahren (o,1 Jahre später $\mathrm{p}<0,01)$. Beim Auftreten des maturen Status zeigt sich kein Unterschied zwischen den Populationen. Das Menarchealter liegt mit 13,2 Jahren 0,5 Jahre später $(\mathrm{p}<0,001)$. Bei Jungen beginnt die Pubertät mit der Genitalentwicklung ( $\left.\mathrm{G}_{2}\right)$ im Alter von 12 Jahren (o,9 Jahre später, $\mathrm{p}<0,001)$. Die Pubarche beginnt mit 12,2 Jahren (o,4 Jahre später, $\mathrm{p}<0,001)$. Beim Auftreten des maturen Status zeigt sich auch bei Jungen kein Unterschied zum Normkollektiv. Ein erhöhter HbA1c Wert verzögert den Pubertätsbeginn bei Mädchen und Jungen signifikant (jeweils $\mathrm{p}<\mathrm{o}, \mathrm{OO} 1$ ). Die Pubertät tritt bei Kindern mit niedrigen BMI-SDS signifikant später auf. Relative Diabetesdauer und Insulin-Dosis zeigen keinen Einfluss.

Schlussfolgerungen: Der Pubertätsbeginn bei Mädchen und Jungen mit $\mathrm{T}_{1} \mathrm{DM}$ ist verzögert im Vergleich zu gesunden Kindern. Das Alter bei Auftreten des maturen Status zeigt keinen Unterschied. Je schlechter die Therapieeinstellung und je niedriger der Körpermassenindex, desto später treten die ersten Pubertätszeichen auf.

DGKJ-SY-051

Psychosoziale Veränderungen in der Pubertät

K. Lange

Medizinische Psychologie MHH

Mit der Adoleszenz ist nicht nur ein eindrucksvoller Wandel der körperlichen Erscheinung verbunden, auch die kognitive Leistungsfähigkeit und die Verarbeitung emotionaler Belastungen erreichten ein höheres Niveau. Typische Entwicklungsaufgaben, z. B. der Aufbau einer stabilen Identität und die Autonomie von den Eltern, stellen hohe Ansprüche, vor allem an Jugendliche, die bereits durch eine chronische Krankheit gefordert sind. Strukturelle und funktionelle Veränderungen diverser neuronaler Strukturen im Gehirn, vor allem im Bereich des präfrontalen Kortex und des limbischen Systems, sind für die Fortentwicklung kognitiver Denkprozesse und eine gesteigerte Effektivität neuronaler Prozesse relevant. Chronisch kranke Jugendliche können ihre Therapien besser verstehen und dafür Verantwortung übernehmen, sie realisieren jedoch auch die „Lebenslänglichkeit“ der Krankheit und deren langfristig einschränkenden Folgen. Emotionale Belastungen und Akzeptanzprobleme wirken sich wiederum negativ auf das Verhalten und die Behandlungsergebnisse aus. Veränderungen in den Amygdalae und im limbischen System korrelieren mit variablen - überschießenden - Gefühlszuständen und Reaktionen auf Stressoren. Sie werden in Beziehung zur erhöhten Prävalenz affektiver Störungen (Mädchen) und externalisierenden Verhaltensweisen (Jungen) in diesem Lebensabschnitt allgemein gesehen. Bei chronisch kranken Jugendlichen ist die Rate depressiver Störungen, Angststörungen, negativem Selbstbilds und subklinischer Essstörungen nochmals erhöht. Diese psychischen Belastungen sind gleichzeitig zentrale Prädiktoren für eine langfristig unzureichende Selbsttherapie bei somatischen Krankheiten. Zunehmende Selbstständigkeit, lange Zeiten außerhalb elterlicher Betreuung mit der Peergruppe als zentraler Sozialisationsinstanz und die Umstrukturierung der Eltern-Kind-Beziehung kennzeichnen den Prozess der Individuation aller Jugendlichen. Chronische kranke Jugendliche, die seit früher Kindheit von ihren Eltern mit Hilfe anspruchsvoller Therapiekonzepte behandelt wurden, stehen hier vor besonderen Aufgaben. Einerseits sind sie noch von den Erfordernissen der Therapie überfordert und benötigen Hilfen, andererseits streben sie altersgemäß eine Lösung aus der intensiven Eltern-Kind-Bindung an. Zusätzlich erschweren der flexible Lebensstil, das alterstypische Risikoverhalten und der Konformitätsdruck der Peergruppe eine sachgerechte Therapie. Akute somatische und psychische Risiken bestehen hier vor allem für Jugendliche, die zu früh von ihren Eltern mit der Therapie allein gelassen werden. Dies gilt gehäuft für Jugendliche aus prekären sozioökonomischen Verhältnissen, mit psychisch kranken Eltern, aus konfliktbelasteten oder allein erziehenden Elternhäusern. Behandlungskonzepte sollten in dieser Altersgruppe die typischen Konfliktfelder berücksichtigen, psychische Risiken frühzeitig identifizieren und geschlechtsspezifische Beratungen zur Förderung eines positiven Selbstbildes anbieten.

\section{Diabetes bei Kindern und Jugendlichen - Ergebnisse des Kompetenznetzes Diabetes des Bundesministeriums für Bildung und Forschung}

\section{DGKJ-SY-052}

Typ 1 Diabetes bei Kindern und Jugendlichen - sind soziale Ungleichheit und Kosten ein Thema?

C. Bächle', J. Rosenbauer', R. Holl², O. Razum³ , T. Kapellen', G. Giani', A. Icks ${ }^{5}$ 'Deutsches Diabetes-Zentrum, Institut für Biometrie und Epidemiologie, ${ }^{2}$ Universität Ulm, Institut für Epidemiologie, ${ }^{3}$ Universität Bielefeld, Fakultät für Gesundheitswissenschaften, ${ }^{4}$ Universitätskinderklinik Leipzig, ${ }^{5}$ Heinrich-Heine-Universität Düsseldorf, Funktionsbereich Public Health und Deutsches Diabetes-Zentrum, Institut für Biometrie und Epidemiologie

Die zunehmende Belastung des Sozialsystems und - daraus resultierend - Möglichkeiten der Kostenreduktion werden in wachsendem Maße zum Gegenstand politischer und gesellschaftlicher Diskussionen. Diabetes mellitus Typ 1 ist eine häufige chronische Erkrankung im Kindesalter. Deshalb sind die Ermittlung von sozialen und sozioökonomischen Bestimmungsfaktoren für den Krankheitsverlauf sowie der resultierenden Kosten von Bedeutung. Bisherige Studien zeigten ein vermehrtes Auftreten von Hyperglykämien und Ketoazidosen unter Kindern aus sozial benachteiligten Familien und Familien mit Migrationshintergrund [1]. Die diabetesbezogenen direkten Kosten nach Manifestation beliefen sich 2000 auf 2. 000-2. $500 €$ pro Patient, bei Kindern aus sozial benachteiligten Familien waren sie ca. 1,8fach erhöht [2]. In der hier vorgestellten bundesweiten Studie werden der Zusammenhang zwischen Migrationshintergrund und sozioökonomischen Bedin- 
gungen und zentralen Prozessen und Outcomes der gesundheitlichen Versorgung analysiert und direkte Kosten von pädiatrischem Diabetes mellitus Typ 1 sowie deren Zusammenhang zur sozialen Lage des Kindes und Veränderungen seit 2000 geschätzt.

Material und Methoden: Diese Studie ist Teilprojekt des Verbundes Future Pediatric Diabetes, einem von 7 Verbünden desKompetenznetzes Diabetes mellitus des BMBF.

Klinische Outcomes (mittl. HbA1c, Inzidenzen von Krankheitsereignissen) und Daten zur Leistungsinanspruchnahme für die Schätzung direkter Krankheitskosten stammen aus dem bundesweiten computergestützten Dokumentationssystem DPV, aggregierte Daten zur sozioökonomischen Lage wurden aus amtlichen Statistiken (Mikrozensus, statistische Bundes- und Landesämter) ergänzt. Zur Identifikation einer türkischen Herkunft wurde ein rechnergestützter namens-basierter Algorithmus in DPV implementiert [3]. Der Zusammenhang zwischen Outcomes und Einflussfaktoren wird mittels multipler Regressionsverfahren analysiert. Zur Kostenschätzung werden die in DPV enthaltenen Leistungen mit Vergütungspauschalen und Handelspreisen bewertet.

Ergebnisse und Diskussion

Erste regionale SES-Variablen und der Namensalgorithmus sind in DPV implementiert. Es wird angenommen, dass sich die Kostenstruktur durch die Umgestaltung der Vergütungsstrukturen des deutschen Gesundheitssystems und Veränderungen im Therapieregime seit 2000 geändert hat. Unklar ist bislang, inwieweit sich in diesem Zeitraum auch der Zusammenhang zwischen der sozialen Lage und dem Krankheitsverlauf geändert hat.

Schlussfolgerung: Die Ergebnisse sollen zur Weiterentwicklung zielgruppenspezifischer Interventionsprogramme beitragen - und damit zur Reduktion der individuellen und gesellschaftlichen Krankheitslast. Referenzen: 1. Icks A, Rosenbauer J, Straßburger K, Grabert M, Giani G, Holl RW, for the DPV Wiss Initiative (2007): Persistent significant social disparities in hospitalization risk for pediatric diabetes patients in Germany - prospective data from 1,277 diabetic children and adolescents. Diabetic Medicine 24, 440-442

2. Icks A, Rosenbauer J, Haastert B, Rathmann W, Grabert M, Gandjour A, Giani G, Holl RW (2004): Direct costs of pediatric diabetes care in Germany and their predictors. Exp Clin Endocrinol Diab 112, 302-309 3. Razum O, Zeeb H, Akgün S (2001): How useful is a name-based algorithm in health research among Turkish migrants in Germany? Tropical Medicine and International 6, 654-661

\section{DGKJ-SY-053}

\section{Besonderheiten des Diabetes bei Kleinkindern}

J. Rosenbauer', A. Stahl' ', C. Bächle' ${ }^{1}$, A. Icks' ${ }^{1}$, K. Lange² ${ }^{2}$ T. Meissner ${ }^{3}$, C. Graf4, T. Kapellen ${ }^{5}$, R. Holl ${ }^{6}$, G. Giani'

'Deutsches Diabetes-Zentrum (DDZ), Institut für Biometrie und Epidemiologie, ${ }^{2}$ Medizinische Hochschule Hannover, Medizinische Psychologie, ${ }^{3}$ Universitätsklinikum Düsseldorf, Klinik für Allgemeine Pädiatrie, ${ }^{4}$ Deutsche Sporthochschule Köln, Institut für Bewegungs- und Neurowissenschaft, ${ }^{5}$ Universitätsklinik und Poliklinik für Kinder und Jugendliche , ${ }^{6}$ Universität Ulm, Institut für Epidemiologie

Die Inzidenz des Typ 1-Diabetes mellitus ( $\mathrm{T} 1 \mathrm{DM})$ steigt bei Kindern unter 5 Jahren besonders stark an. Für Europa wird bis 2020 eine Verdopplung der Neuerkrankungen in dieser Altersgruppe erwartet. Der frühkindliche Diabetes bedeutet für Betroffene ein besonders hohes Risiko für diabetische Komplikationen und vielfältige somatische und psychosoziale Probleme. Welche Besonderheiten bestehen bei frühem Erkrankungsbeginn hinsichtlich Manifestation, Therapie und Verlauf der Erkrankung? Wichtige Erkenntnisse zu Einflussfaktoren der somatischen und psychosozialen Entwicklung dieser betroffenen Heranwachsenden ermöglicht der Vergleich mit Gleichaltrigen ohne Diabetes.

Material und Methoden: Anhand vorliegender Untersuchungen auf der Basis der prospektiven DPV-Verlaufsdokumentation von Diabetespatienten werden Unterschiede zwischen Patienten mit frühem oder späterem Erkrankungsbeginn hinsichtlich Manifestation, Therapie und Verlauf der Erkrankung aufgezeigt. Im Rahmen des BMBF-Kompetenznetzes Diabetes wird 2009-2011 eine deutschlandweite Studie zum Verlauf des T1DM bei Patienten mit Manifestation im Alter von o-4 Jahren im Zeitraum 1993-1999 (aktuelles Alter 11-21 Jahre, Diabetesdauer $>10$ Jahre) durchgeführt. Untersucht werden Stoffwechseleinstellung, diabetische Komplikationen, die Lebenssituation und Einflussfaktoren dieser Zielgrößen. Die Studie nutzt als komplementäre Datenquellen ESPED, die DVP-Datenbank, einen an die KiGGS-Erhebung angelehnten Fragebogensurvey für Patienten/Eltern und den KiGGSPublic-Use-File.

Ergebnisse

Kinder unter 5 Jahren $(26,3 \%)$ weisen bei Manifestation häufiger eine diabetische Ketoazidose $(\mathrm{pH}<7,3)$ auf als ältere Kinder $(=21,7 \%)$. In den letzten Jahren hat sich die Diabetestherapie insbesondere bei Kleinkindern zu einer intensivierten Therapie mit $=4$ Injektionen $(36 \%)$ oder Pumpentherapie (48\%), häufigeren Blutzuckerselbstkontrollen (>5/d) und häufigeren Verwendung von Analoginsulinen hin verändert. Tendenziell wurde eine Verbesserung der Stoffwechselkontrolle erreicht. Im Vergleich zu älteren Kindern weisen Kleinkinder eine gute Stoffwechseleinstellung auf, Hypoglykämien und Ketoazidosen treten bei Kleinkindern im Verlauf nicht häufiger auf.

Eine Zwischenauswertung des Fragebogensurveys der Patienten mit früher Manifestation und 10-jähriger Diabetesdauer $(\mathrm{N}=565$, davon: 11-17 Jahre: $\mathrm{N}=440$ ) zeigt: Die derzeitige Diabetesbehandlung/-beratung bewerteten $78 \%$ der 11 - bis 17 -Jährigen und $88 \%$ ihrer Eltern als sehr gut oder gut. Unter den 18- bis 21-Jährigen kamen $81 \%$ zu dieser positiven Beurteilung. Der subjektiv empfundene Gesundheitszustand wurde von $83 \%$ der 11 - bis 17 -Jährigen und $75 \%$ der 18 - bis 21 -Jährigen als sehr gut oder gut bewertet. Die gesundheitsbezogene Lebensqualität (KINDL-R) wurden von den Eltern der 11- bis 17-Jährigen mit T1DM (Median: 71,9 vs. 75,0 ) sowie von den Patient(inn)en selbst (Median: 71,9 vs. 73,9 ) nur geringfügig schlechter eingeschätzt als in der KiGGSVergleichsgruppe. Psychische Auffälligkeiten (SDQ-Fragebogen) sowie Verdachtsfälle von Essstörungen (SCOFF-Fragebogen) wurden bei Kindern und Jugendlichen nicht häufiger aufgedeckt als im KiGGS.

Schlussfolgerungen: Der frühkindliche Diabetes stellt eine besondere Herausforderung für die Diabetesbetreuung dar. Die Möglichkeiten der modernen Diabetestherapie (z. B. Pumpe) gestatten bei Kleinkindern das Erreichen einer guten Stoffwechseleinstellung und damit einen komplikationsarmen Verlauf der Erkrankung. Die Kenntnis von Gemeinsamkeiten und Unterschiede zwischen Patienten mit frühem T1DM und Gleichaltrigen ohne Diabetes kann zu einem besseren Verständnis des Erkrankungsverlaufes und somit zu einer Verbesserung des Diabetes-Managements beitragen

Die Arbeit wurde unterstützt durch das „Kompetenznetz Diabetes mellitus", gefördert vom deutschen Bundesministerium für Bildung und Forschung (Förderkennzeichen o1GIo802, 01GI0859).

\section{DGKJ-SY-055}

Häufige und seltene Diabetesformen bei Kindern: Daten der Diabetes-Patienten-Verlaufsdokumentation (DPV-Register)

R. Holl' ${ }^{1}$, T. Kapellen², A. Icks ${ }^{3}$, U. Hoffmeister ${ }^{4}$, M. Grabert ${ }^{5}$, M. Borkenstein ${ }^{6}$, J. Rosenbauer ${ }^{7}$

'Universität Ulm, Zentralinstitut für Biomedizinische Technik, ${ }^{2}$ Universitätsklinik und Poliklinik für Kinder- und Jugendliche, ${ }^{3}$ Deutsches Diabetes Zentrum, ${ }^{4}$ Universität Ulm, Institut für Epidemiologie, ${ }^{5}$ Universität Ulm, ${ }^{6}$ Universitätsklinik für Kinder- und Jugendheilkunde, ${ }^{7}$ Deutsches Diabetes Zentrum, Institut für Biometrie und Epidemiologie

Fragestellung: Die pädiatrische Diabetologie unterscheidet sich in vielen Aspekten von der Behandlung Erwachsener mit Diabetes. Bis vor wenigen Jahren wurde Diabetes im Kindesalter mit Typ-1-Diabetes gleichgesetzt. Entwicklungen wie die Entdeckung monogener Ursachen des neonatalen Diabetes, der breiten Verfügbarkeit genetischer Diagnostik auf MODY-Diabetes, gesteigerter Lebenserwartung bei Mukoviszidose und Ausweitung der Transplantationsmedizin in der 
Pädiatrie haben das Diagnosenspektrum des Diabetes in der Pädiatrie deutlich verändert.

Patienten und Methoden: Die DPV-Software ermöglicht eine standardisierte, prospektive Dokumentation pädiatrischer und internistischer Patienten mit Diabetes. Anonymisierte Verlaufsdaten werden zweimal jährlich von den teilnehmenden Behandlungseinrichtungen - Kliniken, Praxen, Reha-Einrichtungen - exportiert und zur gemeinsamen Auswertung an die Studienzentrale übermittelt. Inkonsistente Daten werden in einem Korrekturlauf überprüft. Basierend auf den DPV-Daten werden Benchmarking-Berichte zur Struktur-, Prozeß- und Ergebnisqualität pädiatrischer Diabetestherapie erstellt, die Darstellung erfolgt sowohl longitudinal als auch im Querschnitt (QS-DPV). Darüber hinaus dient die kumulative DPV-Datenbank als Basis für multizentrische Studien und für klinische und versorgungsepidemiologische Auswertungen (DPV-Wiss). Bis März 2010 wurden 1005256 Verlaufsuntersuchungen von insgesamt 55566 pädiatrischen Diabetespatienten (Alter bei Diagnose $<20$ Jahre) aus 326 Behandlungseinrichtungen erfasst.

Ergebnisse: Von den kumulativ erfassten Patienten wurden 94. $3 \%$ als Typ-1 klassifiziert (mittleres Manifestationsalter: 8.8 Jahre, mittl. BMISDS -0. 50). 1120 pädiatrische Typ-2-DM-Patienten waren signifikant älter bei Manifestation (13. 7 Jahre) und deutlich übergewichtig (BMISDS +2. 32). Über die letzten 15 Jahre nahm der Anteil der Typ-2-Patienten zu (1995: 0. 9 \%, 2009: 2. 3 \%). Bei den ,anderen spezifischen Diabetestypen“" (Typ-3-DM), findet sich am häufigsten ein MODY ( $\mathrm{n}=$ 492), gefolgt von 385 Patienten mit CF-Diabetes, 219 Patienten mit Pankreasdiabetes und 181 Patienten mit DM bei Trisomie 21. Es folgen seltenere genetische Ursachen wie DIDMOAD $(n=38)$, UTS $(n=26)$, PWS $(n=28)$, mitochondrialer Diabetes $(n=39)$ oder Insulinrezeptormutationen $(n=14)$. Bei 129 Patienten besteht der Verdacht auf eine medikamenteninduzierte Form, bei 66 ein connataler Diabetes. Alle diese Patientengruppen unterscheiden sich untereinander, sowie vom Typ1- und Typ-2-Diabetes bezüglich Manifestationsalter, Geschlechtsverhältnis, Anthropometrie, gewählter Therapieform und Stoffwechselergebnis.

Diskussion: Die DPV-Wiss-Datenbank stellt ein nahezu komplettes Register pädiatrischer Diabetespatienten in Deutschland und Österreich dar. Auch wenn die überwiegende Mehrheit pädiatrischer Patienten entsprechend den Leitlinien als Typ-1-Diabetes klassifiziert wird, gibt es doch ein breites Spektrum ätiologisch anderer Ursachen des Diabetes in der Pädiatrie. Einige dieser Erkrankungen wurden in den letzten Jahren neu beschrieben (Kir6. 2, SUR1-Mutationen beim neonatalen Diabetes), andere werden aufgrund moderner molekularbiologischer Möglichkeiten deutlich häufiger diagnostiziert (MODY), oder sie sind durch veränderte Lifestyle-Faktoren (Typ-2-DM) bzw. iatrogen durch neue Therapieformen (Immunsuppression, Steroide, Antidepressiva) bedingt.

\section{DGKJ-SY-056 \\ Neues zur Immunologie und Prävention des Typ 1 Diabetes bei Kin- dern und Jugendlichen \\ K. Warncke, A. Ziegler \\ Klinik und Poliklinik für Kinder- und Jugendmedizin, Kinderklinik München \\ Schwabing und Forschergruppe Diabetes der Technischen Universität München}

Typ-1-Diabetes mellitus (T1DM) ist die häufigste chronische Autoimmunerkrankung bei Kindern und Jugendlichen mit zunehmender Inzidenz. Früherkennung und Prävention gewinnen zunehmend an Bedeutung.

Immunologie/ Prädiktion

Mit Hilfe von genetischen Untersuchungen und Antikörper-Diagnostik können Individuen mit einem besonders hohen Diabetesrisiko identifiziert werden. Im peripheren Blut sind bereits Monate bis Jahre vor Ausbruch der Erkrankung Autoantikörper nachweisbar. Neben den seit Jahren etablierten Antikörpern ICA, GADA, IA-2A und IAA gewinnt der Zink-Transporter-8-Antikörper (ZnT8Ak) in der Diagnostik/ Prädiktion des TiDM zunehmend an Bedeutung.
Prävention: Immunmodulatorische Therapieansätze zielen auf die Entstehung von Inselautoimmunität (Primär-), sowie auf deren Progression (Sekundär-) beziehungsweise den Erhalt der verbleibenden ß-Zell-Restfunktion (Tertiär-Prävention) bei bereits bestehendem Diabetes.

Primärprävention: Primärprävention soll die Entstehung von Inselautoimmunität bei Personen mit hohem genetisch bedingtem Erkrankungsrisiko verhindern. In bisherigen Studien wurden meist diätetische Modifikationen eingesetzt.

Seit Anfang dieses Jahres prüft die Pre-Point-Studie eine Immunintervention bei Antikörper-negativen Patienten mit oralem Insulin im Sinne einer Schutzimpfung.

Sekundärprävention: Sekundärprävention hat das Ziel, den Ausbruch von Diabetes bei Antikörper-positiven Personen zu verhindern. Bisherige Programme konnten dieses Ziel leider nicht erreichen.

Seit kurzer Zeit ist nun in Deutschland die Teilnahme an „INIT 2“ möglich. Es handelt sich dabei um eine randomisierte, doppel-blinde, Placebo-kontrollierte Phase 2 Studie mit intranasal applizierbarem Insulin/ Placebo. In der Vorläuferstudie konnten die Sicherheit und der Effekt auf das Immunsystem bereits demonstriert werden.

Tertiärprävention: Ziel der Tertiärprävention ist ein längerer Erhalt der verbleibenden Beta-Zellreserve und eine verlängerte eigene Insulinsekretion.

Aktuell werden bei Erwachsenen monoklonale Antikörper wie Anti CD 3 und Rituximab erfolgreich und mit tolerablen Nebenwirkungen eingesetzt.

Im Jahr 2009 konnten Kinder und Jugendliche mit neu manifestiertem Diabetes mellitus in Europa an der „Diamyd ${ }^{\circ}$-Studie“ teilnehmen. Dia$\mathrm{myd}^{\oplus}$ ist ein Impfstoff und besteht aus rekombinant hergestellter Glutamatdecarboxylase (rhGAD65) und Allhydrogel, einem Adjuvans aus Aluminiumhydroxid (Alum). 2008 wurden die Ergebnisse einer Phase 2 Vorläufer Studie publiziert, an der 70 Kinder mit neu manifestiertem T1DM teilnahmen. Bei den behandelten Kindern zeigte sich nach 30 Monaten ein signifikant geringerer Abfall des C-Peptids als in der Placebo-Gruppe. Dies könnte ein Hinweis auf einen protektiven Effekt von Diamyd $^{\star}$ auf die B-Zell-Restfunktion sein. Ob sich der Effekt auch an der größeren Kohorte zeigen lässt, und ob es sich dabei um einen langfristigen Benefit handelt, soll die aktuelle Studie zeigen. Neben der Diamyd $^{-}$-Studie, deren Rekrutierung abgeschlossen ist, besteht derzeit in Deutschland nur für Kinder, bei deren Geburt Nabelschnurblut eingelagert wurde, die Möglichkeit einer immunmodulatorischen Therapie. Ob immunmodulatorische Therapien, die bei Erwachsenen erfolgreich eingesetzt werden, auch Kindern zugänglich gemacht werden sollten, wird weiterhin Gegenstand der Diskussion bleiben.

\section{Erwünschte und unerwünschte Wirkungen von Biologika auf das Immunsystem}

\author{
DGKJ-SY-059 \\ Juvenile Idiopathische Arthritis in Remission - besteht das Risiko \\ einer Zell Anergie? (CTLA-4, CD 28 und Abatacept) \\ K. Tenbrock \\ Klinik für Kinder und Jugendmedizin, Klinikum der RWTH Aachen
}

Aktivierte T-Zellen scheinen bei der Rheumatoiden Arthritis und der Juvenilen Idiopathischen Arthritis (JIA) eine Rolle zu spielen, indem sie die Aktivierung von Entzündungszellen und die Zytokinproduktion fördern. Für eine effiziente T-Zell Aktivierung braucht man 2 Signale, zum einen die Antigenpräsentation über MHCII, welche direkt den T-Zellrezeptor aktiviert und ein kostimulatorisches Molekül, z. B. CD8o auf der Oberfläche der antigenpräsentierenden Zelle, welches an CD28 auf der T-Zelle bindet und so die vollständige Aktivierung der T-Zelle einleitet. CTLA-4 ist ein Oberflächenmolekül auf T-Zellen, das kompetetiv neben $\mathrm{CD} 28$ an CD8o binden und dadurch die T-Zell Akti- 
vierung vermindern kann. Dies führt zu einer sog. T-Zell Anergie, d. h. die T-Zelle reagiert nicht mehr auf das ihr präsentierte Antigen.

Die CTLA-4 Blockade mittels Abatacept nutzt dieses Prinzip und führt zu einer verminderten T-Zell Aktivierung durch das lösliche CTLA-4/ IgFc Fusionsprotein. Seit kurzem ist Abatacept in der polyartikulären JIA nach Therapieversagen mit einem TNFa Blocker zugelassen. Aus dem oben genannten Wirkmechanismus ergibt sich theoretisch das Risiko einer T-Zell Anergie auch gegenüber potentiell gefährlichen wie beispielsweise bakteriellen Antigenen oder Tumorantigenen. Dieses Risiko wird im Rahmen des Vortrages diskutiert werden.

\section{Historisches Symposium}

\section{DGKJ-SY-064}

Werner Catel, Leipzig und die Kindereuthanasie

U. Rottleb

Archiv für Leipziger Psychiatriegeschichte, Klinik und Poliklinik für Psychiatrie und Psychotherapie

Werner Catel war eine zentrale Person im Gefüge der nationalsozialistischen Kinder-Euthanasieverbrechen. An seiner Klinik fand Ende 1938/ Anfang 1939 der Präzedenzfall „Kind K“ als überhaupt erste Euthanasie im Dritten Reich statt. Zugleich gehörte er dem Gutachterausschuss des RA an. An seiner Kinderklinik bestand mindestens seit Oktober 1940 eine KFA. Die Gründung der KFA in der Landesanstalt Dösen ist durch ihn angeregt und befördert worden. Forschungsschwerpunkte waren Trisomie 21, Spaltbildungen sowie Schwachsinnsformen. Begleitet wurden die Forschungen vom Histopathologischen Labor der Anstalt Dösen (Dr. Friedrich, Präp. Kranzler). Die Unterlagen der KFA der Kinderklinik sind 1945 vernichtet worden, allerdings sind die Akten der KFA Dösen (z. T. vernichtet) und später der KFA Großschweidnitz (wenig vernichtet) erhalten geblieben, so dass aus den dortigen Schriftwechseln Rückschlüsse möglich sind. Von Interesse sind auch korrespondierende Einrichtungen wie die Staatlichen Gesundheitsämter (Überlieferung unterschiedlich) sowie die Kinderbeobachtungsstation der Universitäts-Nervenklinik. Opferzahlen lassen sich bis jetzt nur für Dösen verifizieren. Statistische Untersuchungen zu Mortalitäten der Kinderklinik befinden sich in Vorbereitung.

\section{DGKJ-SY-065}

Heimkinder und NS-"Kindereuthanasie"

L. Pelz

Univ.-Kinder- und -Jugendklinik Rostock

Die NS-"Kindereuthanasie" (1939-1945) funktionierte unter der zentralen Verantwortlichkeit der Kanzlei des Führers (KdF) auf drei Ebenen, - der „Aktion T 4 “

- der Begutachtung und Entscheidung durch den „Reichsausschuß zur wissenschaftlichen Erfassung von

erb-und anlagebedingten schweren Leiden" sowie

- der „wilden Euthanasie“, d. h. Einweisung und Tötung von Patienten lagen im Ermessensspielraum der

einzelnen Ärzte.

Darüber findet sich eine umfangreiche Literatur. Auch das Wissen um die Beteiligung „ganz normaler, angestellter und niedergelassener Kinderärzte “ und ihre Verstrickung in das Netz der „Kindereuthanasie“ ist angewachsen (Pelz 2003, 2005, 2009). Beispiele finden sich in der die Jahrestagung begleitenden Ausstellung.

Bei der Analyse der Patientenunterlagen der Kinderfachabteilungen Görden bei Brandenburg und Sach-senberg bei Schwerin fiel auf, dass ein großer Anteil von kindlichen und jugendlichen Opfern aus Kinder- heimen unterschiedlicher Träger (u. a. sowohl staatlich als auch kirchlich geführten Heimen) stammten. Dieser speziellen Gruppe von NS- „Euthanasie“-Opfern wurde bisher nur wenig Aufmerksamkeit gewidmet; es soll daher an Hand der genannten Materialien sowie wei- terer Quellen auf ausgewählte Probleme von Heimkindern in der NS„Kindereuthanasie“ eingegangen werden.

\section{DGKJ-SY-066}

Die „Euthanasie“ an Kindern in den beiden Hamburger Kinderfachabteilungen

M. Burlon

Klinik für Psychiatrie und Psychotherapie, Zentrum für psychosoziale Medizin, Universitätsklinikum Hamburg-Eppendorf

Dargestellt wird die „Euthanasie“ an Kindern im „Dritten Reich“ in Hamburg. In der Hansestadt wurden während des Zweiten Weltkriegs zwei Kinderfachabteilungen unabhängig voneinander gegründet, die für die Untersuchung und Tötung von Kindern zuständig waren. Die Geschichte der beiden Kinderfachabteilungen wird nachgezeichnet und die mit der Organisation der Kinderfachabteilungen verwickelten Personen dargestellt.

Die Kinderfachabteilung im Kinderkrankenhaus Rothenburgort wurde von dem Kinderarzt Wilhelm Bayer geleitet, der auch die Leitung des gesamten Krankenhauses inne hatte. Die Staatsanwaltschaft Hamburg ging anhand noch vorhandener Akten davon aus, dass diese Fachabteilung Mitte/Ende 1940 ihre Arbeit aufnahm und erst bei Kriegsende geschlossen wurde.

Die historische Aufarbeitung der Hamburger „Euthanasie“ an Kindern ist eng mit der juristischen Aufarbeitung der Taten in der Nachkriegszeit verbunden, da sie die Hauptquelle an Informationen darstellt.

\section{DGKJ-SY-067}

Pädiatrie und NS-Euthanasie. Erinnerungskultur und berufsethische Implikationen

S. Topp

Institut für Geschichte der Medizin

Die deutsche Pädiatrie ist seit 1945 neben der Verfolgungsgeschichte jüdischer Pädiater mit einem zweiten schweren Erbe konfrontiert: die Beteiligung einer noch ungeklärten Zahl von Kinderärzten an dem 1939-1945 geheim durchgeführten Euthanasie-Programm, dem weit über 5. ooo Kinder und Jugendliche mit spezifischen Erkrankungen zum Opfer fielen. Während die Forschung zur Realgeschichte der NSKindereuthanasie in den letzten zehn Jahren neue Impulse erfahren hat, ist auch die Auseinandersetzung der deutschen Nachkriegspädiatrie mit diesem Erbe in das Blickfeld des Quellenstudiums gerückt. Wie haben sich Kinderärzte und deren Fachgesellschaften (DGK/GP der DDR/DGKJ) dieser geschichtlichen Bürde gestellt? Der Blick in die Quellen offenbart eine Reihe von besonderen Entwicklungen: 1.) Anstoß einer "neuen“ Euthanasie-Debatte im Zuge des Streits um/mit Werner Catel (5oer/6oer Jahre), 2.) die stark verzögert einsetzende, breite Auseinandersetzung mit ethischen Problemkreisen in der Pädiatrie (8oer Jahre), 3.) der erinnerungspolitische Paradigmawechsel etwa zehn Jahre nach Gründung der Historischen Kommission und die seit dem beobachtbare, schrittweise Annahme der historischen Verantwortung: bezüglich der in der NS-Zeit verfolgten jüdischen Kollegen (Dresden 1998) sowie der Beteiligung von Kinderärzten an der NS-Euthanasie (Potsdam 2010). 70 Jahre danach fordert die Beschäftigung mit der NS-Euthanasie und ihren Opfern vielleicht mehr denn je zu Fragen nach dem historischen und berufsethischen Selbstverständnis der deutschen Pädiatrie - auch nach Potsdam - heraus. 


\section{Samstag, 18. September 2010}

\author{
Agenda 2020: Zukunft der Kinder- und \\ Jugendmedizin in Deutschland \\ DGKJ-GEM-40 \\ Gesundheitsversorgung im ländlichen Raum am Beispiel Mecklen- \\ burg-Vorpommern \\ W. Hoffmann
}

Insitut für Community Medicine, Ernst-Moritz-Arndt-Universität Greifswald

Die demografische Entwicklung Mecklenburg-Vorpommerns ist im Vergleich zu anderen Regionen Deutschlands und Europas durch eine besonders schnell voranschreitende Alterung der Bevölkerung bei gleichzeitigem Bevölkerungsrückgang gekennzeichnet. Ursachen des Bevölkerungsrückgangs sind die steigende Lebenserwartung, die starke Verringerung der Geburtenzahlen seit der Wiedervereinigung Deutschlands und ein negativer Wanderungssaldo mit Abwanderung vor allem der jüngeren Altersgruppen. Die demografischen Entwicklungen führen nicht nur zu einer starken Zunahme der älteren Bevölkerung, sondern auch zu einer Abnahme der Bevölkerung in den jüngeren Altersgruppen. Der Anteil der über 65-jährigen wird von 21\% im Referenzjahr 2006 auf $36 \%$ in 2030 steigen, der Anteil der unter 20-jährigen dagegen von $17 \%$ in 2006 auf $14 \%$ in 2030 sinken [1].

Die demografischen Änderungen haben einen großen Einfluss auf die Patientenzahlen und damit auf die Bedarfe und Randbedingungen der medizinischen Versorgung. Der Anstieg der Bevölkerungszahlen in den höheren Altersgruppen in Mecklenburg-Vorpommern bewirkt einen Anstieg der Fallzahlen altersassoziierter Erkrankungen, der durch die Abnahme der Bevölkerungs- und Fallzahlen in den jüngeren Altersgruppen nicht ausgeglichen wird [2,3].

In der Konsequenz bedeutet dies einen Anstieg chronischer Erkrankungen und Multimorbidität sowie eine Abnahme der Mobilität (und damit einen erhöhten Bedarf an Hausbesuchen).

Dem erhöhten Versorgungsbedarf steht in Mecklenburg-Vorpommern ein hoher Wiederbesetzungsbedarf frei werdender Arztsitze im hausärztlichen und zukünftig auch im fachärztlichen Versorgungsbereich gegenüber. Insgesamt besteht bis 2020 im hausärztlichen Bereich einen Wiederbesetzungsbedarf von etwa 40\% (Referenzjahr: 2006).

Im kinderärztlichen Bereich ist dieser Zahl mit $42 \%$ ähnlich hoch. Insbesondere in ländlichen Regionen kann die kinderärztliche Versorgung problematisch werden, da Praxen durch die geringe Kinderzahl in vielen Fällen nicht mehr rentabel sein werden.

Eine gute medizinische Versorgung ist eine wichtige infrastrukturelle Voraussetzung für gleichwertige Chancen für alle Einwohner des Landes. Für die zukünftige Sicherstellung einer qualitativ hochwertigen medizinischen Versorgung, sowohl für Kinder- und Jugendlichen als für die höheren Altersgruppen ist daher ein besonders effektiver Einsatz bestehender Ressourcen und die Etablierung neuer flexibler, bedarfsorientierter Versorgungskonzepte notwendig. Die Inhalte und Struktur der Modelle sowie die Rolle der beteiligten Akteure sollten dabei abhängig vom Bedarf der jeweiligen Region in Kooperation entwickelt werden.

Beispiele für flexible und regionalisierte Konzeptoptionen sind:

- Flexible Lösungen für die Erreichbarkeit der medizinischen Leistungen, z. B. im öffentlichen Personennahverkehr;

- Eine vernünftige Arbeitsteilung zwischen den Gesundheitsberufen, z. B. (Sektorübergreifende) Delegationsleistungen (AGnES-Leistungen) im haus- und fachärztlichen Bereich sowie im Krankenhaus [4, 5, 6];

- Telemedizinisches Monitoring von dafür geeigneten Patienten. Telemedizinische Funktionalitäten können bei Bedarf mit Delegationsleistungen kombiniert werden $[7,8,9]$;

- Telemedizinische Konzepte für die Kommunikation zwischen den Leistungsanbietern, z. B. zwischen Klinik und niedergelassenem Arzt;
- Integration der Möglichkeiten des Vertragsarztrechtsänderungsgesetzes (z. B. Zweigpraxen eines Facharztes, Möglichkeiten der Anstellung im Krankenhaus, ggfs. kombiniert mit einer Teilniederlassung, ...); - Integration von regionalen Case Management-Leistungen [3]; Wichtig ist die nachhaltige Integration der Konzepte in das flächenbezogene Versorgungssystem der gesamten Region.

Literatur: 1. Statistisches Amt Mecklenburg-Vorpommern (2009) Bevölkerungsentwicklung der kreisfreien Städte und Landkreise in Mecklenburg-Vorpommern bis 2030 (Basisjahr 2006). Statistische Berichte. Eigenverlag, Schwerin

2. Siewert U, Fendrich K, Doblhammer-Reiter G, Scholz RD, SchuffWerner P, Hoffmann W. Health care consequences of demographic changes in Mecklenburg-West Pomerania: projected case numbers for age-related diseases up to the year 2020, based on the Study of Health in Pomerania (SHIP). Dtsch Arztebl Int. 2010;107(18): 328-34.

3. Fendrich K, van den Berg N, Siewert U, Hoffmann W. Demographischer Wandel - Anforderungen an das Versorgungssystem und Lösungsansätze am Beispiel Mecklenburg-Vorpommern. Bundesgesundheitsblatt 2010;53: 479-485.

4. van den Berg N, Fiß T, Meinke C, Heymann R, Scriba S, Hoffmann W. GP-support by means of AGnES-practice assistants andthe use of telecare devices in a sparsely populated regionin Northern Germany proof of concept. BMC Family Practice 2009, 10: 44.

5. van den Berg N, Meinke C, Heymann R, Fiß T, Suckert E, Pöller C, Dreier A, Rogalski H, Karopka T, Oppermann R, Hoffmann W. AGnES: Supporting General Practitioners With Qualified Medical Practice Personnel - Model Project Evaluation Regarding Quality and Acceptance. Dtsch Arztebl Int 2009; 106(1-2): 3-9.

6. van den Berg N, Meinke C, Matzke M, Heymann R, Fleßa S, Hoffmann W. Delegation of GP-home visits to qualified practice assistants: assessment of economic effects in an ambulatory healthcare centre. BMC Health Services Research 2010, 10: 155.

7. Terschüren C, Fendrich K, van den Berg N, Hoffmann W. Implementing new technology in the daily routine of a GP practice in a rural setting in northern Germany. J Telemed Telecare 2007;13 (4) : 197-201.

8. van den Berg N, Meinke C, Hoffmann W. Möglichkeiten und Grenzen der Telemedizin in der Flächenversorgung. Der Ophthalmologe 2009; 106(9): 788-794.

9. Bobrowski C, Kroos K, van den Berg N, Fleßa S, Hoffmann W. Gesundheitsökonomische Evaluation telemedizinischer Projekte in Vorpommern. In: Duesberg F (Hrsg.). e-Health 2010. Informationstechnologien und Telematik im Gesundheitswesen. 1. Aufl., Solingen: medical future verlag 2009, 42-46.

\section{DGKJ-GEM-44}

Quo vadis Kindermedizin - Transition am Beispiel Kinderkardiologie

N. Haas

Herz und Diabeteszentrum Nordrhein-Westfalen

In wenigen Gebieten der Kinderheilkunde hat im Verlauf der vergangenen Jahre eine derart rasche und praktisch bedeutsame Entwicklung auf diagnostischem als auch therapeutischem Gebiet stattgefunden wie der Kinderkardiologie.

Die Behandlung angeborener Herzfehler (AHF) galt noch vor hundert Jahren als obsolet, da wohl kaum ein Kind das Erwachsenenalter erreichen würde. Operationen am Herzen waren ebenfalls verpönt, diese anerkannte Lehrmeinung wurde erst 1896 durch Rehn unterlaufen, der eine Naht am Herzen setzte. 1931 gelang Sauerbruch dann eine geplante Operation am Herzen, 1944 erfolgte die erste Operation einer Isthmusstenose durch C. Crawford. Es folgten die ersten Operationen am offenen Herzen, unterstützt und vereinfacht durch die Einführung der Herz-Lungen-Maschine. Moderne Herzkatheterechniken begleiteten diese Entwicklung, beginnend mit dem Selbstversuch des Herzkatheters durch Forssmann 1929, 1966 erfolgte der erste PDA-Verschluss durch Portsmann sowie die Ballonatrisoeptosptomie durch William Rashkind, 1974 dilatierte Grünzig erstmals eine Koronararterie. 
Begünstigt durch diese Entwicklungen sowie vor allem eine moderne postoperative Intensivtherapie erreichen fast alle Kinder mit AHF das Erwachsennealter, die Zahl der Erwachsenen steigt, in Deutschland leben derzeit mehr Erwachsene mit AHF als Kinder und Jugendliche zusammen. Neben dem „einfachen“ Überleben erhält seit einigen jahren auch auch das Outcome der Patienten zusätzliche Bedeutung, die neurologische Entwicklung, die schulischen und beruflichen Leistungen sowie die Eingliederung in die Gesellschaft.

Häufig bestehen bei Jugendlichen und Erwachsenen mit angeborenen Herzfehlern (JEMAH bzw. EMAH) besondere Bedürfnisse hinsichtlich der medizinischen Betreuung und Versorgung, damit auch Erwachsene mit AHF trotz komplexer Herzfehler adäquat medizinisch betreut sind und ein zufriedenstellendes Leben führen können. Aufgrund der Besonderheiten der Krankheitsbilder entstand - unterstützt von den Fachgesellschaften der Kinderkardiologie, Kardiochirurgie und Kardiologie eine spezielle Fachweiterbildung als EMAH-Arzt, die durch ein besonderes Ausbildungskurrikulum definiert ist. Derzeit besitzen in Deutschland ca. 200 Spezialisten diese Zusatzbezeichnung, der überwiegende Anteil davon sind Kinderärzte bzw. Kinderkardiologen. Diese exemplarische Entwicklung - vom nicht behandelbaren pädiatrischen Patienten über das klassische pädiatrische Spezialgebiet mit wenig therapeutischen Optionen, zum hochspezialisierten Gebiet mit erheblichem Aufwand an Technik, Intensivtherapie, moderne OP-Verfahren, HK-Verfahren, etc. und schließlich zum Begleiten der Patienten aus der Kindheit und Jugend hinaus ins Erwachsenenalter - mag ein Beispiel auch für andere Krankheitsbilder darstellen, um eine adäquate Betreuung spezieller Patientengruppen zu gewährleisten - federführend in der Hand der Kinderärzte.

\section{DGKJ-GEM-45 \\ Familienprobleme und psychisch kranke Kinder? Auf dem Weg zu einer interdisziplinären Versorgung \\ S. Wiegand-Grefe \\ Universitätsklinikum Hamburg-Eppendorf, Klinik für Kinder- und Jugend- psychiatrie und -psychotherapie}

Familiäre Bedingungen und Faktoren spielen bei einer gesunden Entwicklung der Kinder eine wesentliche Rolle. Eine psychische Erkrankung eines Elternteils wird seit langem als Risikofaktor für eine Reihe von Familienproblemen (Trennung, Scheidung, niedriger sozioökonomischer Status, Armut, Arbeitslosigkeit) gesehen. In jüngster Zeit ist sie auch als wesentlicher Risikofaktor für die psychische Gesundheit der Kinder verstärkt in das Interesse der Fachöffentlichkeit getreten (Lenz, 2010). In Deutschland leben nach Schätzungen ca. 2-3 Millionen Kinder psychisch kranker Eltern (Mattejat, 2008), die als Hochrisikogruppe für die Entwicklung eigener Auffälligkeiten bekannt sind. Neben genetischen Faktoren spielen psychosoziale Umweltbedingungen, Belastungs- und Risikofaktoren eine wesentliche Rolle bei der Frage, ob die Kinder später selbst erkranken (Wiegand-Grefe et al. 2009). Präventionen sind notwendig, um betroffene Kinder frühzeitig zu unterstützen.

Im Vortrag werden die Zusammenhänge von Familienproblemen, psychischer elterlicher Erkrankung und psychischer Gesundheit der Kinder eingehender beleuchtet. Es wird ein Forschungs- und Präventionsprojekt für Kinder aus Familien mit psychisch kranken Eltern vorgestellt, das in der Klinik für Psychiatrie und Psychotherapie des Kindesund Jugendalters am Universitätsklinikum Hamburg Eppendorf durchgeführt und evaluiert wird (Wiegand-Grefe et al. 2010).

Literatur: Lenz, A. (2010). Ressourcen fördern. Materialien für die Arbeit mit Kindern psychisch kranker Eltern. Göttingen: Hogrefe. Mattejat (2008). Kinder mit psychisch kranken Eltern. In: Mattejat F \& Lisofsky B (Hrsg.) (2008) Nicht von schlechten Eltern. Kinder psychisch Kranker. Erweiterte Neuauflage, Bonn: Psychiatrie Verlag.

Wiegand-Grefe, S., Geers, P., Plaß, A., Petermann, F. \& Riedesser, P. (2009). Kinder psychisch kranker Eltern. Zusammenhänge zwischen subjektiver elterlicher Beeinträchtigung und psychischer Auffälligkeit der Kinder aus Elternsicht. Kindheit und Entwicklung,18, 111-121.
Wiegand-Grefe, S., Halverscheid, S. \& Plaß, A. (2010). Kinder und ihre psychisch kranken Eltern. Familienorientierte Prävention - der CHIMPs Beratungsansatz. Göttingen: Hogrefe, im Druck.

DGKJ-GEM-46

Was erwarten die Eltern von Kinder- und Jugendärzten? Ergebnisse einer bundesweiten Umfrage

R. Schmid

Kindernetzwerk e.V.

Die Erwartungen, die insbesondere Eltern-Selbsthilfegruppen an die Kinder- und Jugendärzte stellen, sind hoch. Das wissen die Kinderund Jugendmediziner und sie wissen auch, dass sie diese Erwartungshaltung nicht immer erfüllen können. Nach den Ergebnissen einer Umfrage von Kindernetzwerk e. V. unter 53 bundesweiten Mitgliedsorganisationen und weiteren Erkenntnissen von Kindernetzwerk e. V., die aufder 106. Jahrestagung der Deutschen Gesellschaft für Kinder- und Jugendmedizin in Potsdam vorgestellt werden, haben fast zwei Drittel aller Befragten angegeben, nicht ausreichend über die Krankheit, Entwicklungsstörung oder Behinderung ihrer Kinder informiert worden zu sein.

Dass es im Praxis- und Klinikalltag schwierig ist, alle Fragen der Eltern zu beantworten, weiß auch die Eltern-Selbsthilfe. Dass zudem gerade bei Erstgespräch direkt nach Diagnosestellung nicht alles Gesagte bei den Eltern hängen bleibt, da diese in der Situation sicher nur bedingt aufnahmefähig sind, ist auch klar. Ob die 21,8 Minuten ausreichen, die sich die Ärzte nach den Ergebnissen der Umfrage Zeit nehmen, um die Eltern in einem Erstgespräch über die Diagnose und mögliche Auswirkungen auf das künftige Leben der betroffenen Familien aufzuklären, ist deshalb auch schwierig zu beurteilen. Eindeutig ernüchternd ist es aber, wenn drei Viertel aller Eltern bei ihren Kinder- und Jugendärzten Hinweise auf die Eltern-Selbsthilfe vermissen. Trotz aller Fortschritte bei der Kooperation zwischen Kinder und Jugendärzten und Eltern-Selbsthilfegruppen scheinen hier also weiterhin massive Defizite zu bestehen. Hier wird von Seiten der Pädiatrie enormes Potential liegen gelassen, da gerade über die Eltern-Selbsthilfegruppen vieles an erlebter Kompetenz weiter gegeben werden, kann, die auch die Pädiater in Praxis und Klinik merklich entlasten kann. Je seltener eine Erkrankung ist, desto mehr verfügen betroffene Eltern auch über medizinisches Wissen, da sie sich im Gegendsatz zum Kinder- und Jugendarzt gerade im Internet-Zeitalter sehr intensiv mit dem Krankheitsbild befassen können und dies in der Regel auch tun.

Über diese und viele weitere Erwartungen und Wünsche der Eltern und der Eltern-Selbsthilfe an die Kinder- und Jugendärzte, die in den vergangenen Jahren im Kindernetzwerk gesammelt worden sind, wird Kindernetzwerk-Geschäftsführer Raimund Schmid im Rahmen der gemeinsamen Veranstaltung aller am Kongress beteiligter Verbände "Agenda 2020: Zukunft der Kindermedizin in Deutschland“ referieren. Dabei wird es unter anderem auch um die Themen „Vernetzung in der Pädiatrie“, der „Empathie von Kinder- und Jugendärzten“ sowie um „Krankheitsbewältigung/Psychosoziale Versorgung“ gehen. Abgerundet wird die Präsentation mit konkreten Vorschlägen, wie sich die Kinder- und Jugendmedizin im Jahr 2020 aus Sicht der Eltern-Selbsthilfe in Deutschland positionieren sollte, um sich den hohen qualitativen Anforderungen des eigenen Faches und dem finanziellen Druck sowie der „Konkurrenz" anderer Arztgruppen auch in Zukunft erfolgreich stellen zu können. 


\section{Infektiologie I}

\section{DGKJ-PV-115}

Pharmakoökonomische Bewertung von Probiotika zur Prophylaxe der Clostridium difficile-Infektion

A. Furmaniak, H. Brunner

Universitätskliniken Köln

Hintergrund: Die Inzidenz von Clostridium difficile-Infektionen (CDI) ist in den vergangenen Jahren bei Kindern und Erwachsenen stark angestiegen. CDI beeinträchtigen die Lebensqualität der Patienten und verursachen erhebliche Kosten im Gesundheitswesen, insbesondere durch eine Verlängerung der Liegezeit. Neben einem Krankenhausaufenthalt ist Hauptrisikofaktor für die Entwicklung einer CDI eine Therapie mit Antibiotika, die das bakterielle Gleichgewicht der Darmflora schwächt. Probiotika sollen die Kolonisationsresistenz des Darmes wiederherstellen und spezifisch gegen $C$. difficile und seine Toxine wirken. Bei der Prävention von Antibiotika-assoziierten Diarrhöen haben Probiotika bei Kindern gute Ergebnisse gezeigt.

Fragestellung: Ist die Gabe von Probiotika zur Prophylaxe einer CDI bei Kindern, die im Krankenhaus antibiotisch behandelt werden, kosteneffektiv?

Material und Methoden: Es wurde ein Entscheidungsbaum mit einem pädiatrischen Modellpatienten konzipiert, der Antibiotika erhält. Einbezogen wurden die Inzidenz von CDI bei antibiotisch behandelten Kindern und die Effektivität von Probiotika, die randomisierten kontrollierten klinischen Studien (RCT) entnommen wurde. Zur Berechnung des Kosteneffektivitätsquotienten „Kosten pro erfolgreicher Prophylaxe" flossen die Kosten von Probiotika und die Kosten einer Infektionsbehandlung im Krankenhaus anhand des deutschen DRG-Systems in das Modell ein. Mit univariaten Sensitivitätsanalysen wurde der Einfluss der Veränderung der Parameter auf das Ergebnis untersucht.

Ergebnisse: Es wurden drei RCT zur Prophylaxe mit Probiotika bei Kindern eingeschlossen, die als Outcome das Auftreten einer CDI betrachten. Für Erwachsene lagen sieben publizierte Studien vor. Die Entscheidungsbaumsimulation ergab unter den modellbildenden Annahmen eine Kostenersparnis bei gleichzeitigem Nutzengewinn. Die Sensitivitätsanalysen zeigten, dass dies nicht eindeutig gesichert ist, da die Ergebnisse der Studien zur Effektivität von Probiotika statistisch nicht oder nur grenzwertig signifikant waren.

Diskussion: Nicht in die Berechnung des Modells einbezogen wurde die mögliche Ansteckung weiterer Patienten im Krankenhaus beim Auftreten einer CDI. Die Einbeziehung würde sowohl die Kostenersparnis als auch den Nutzengewinn noch verstärken. Überschätzt werden die Kosten der Infektionsbehandlung tendenziell durch die Annahme, dass jede CDI stationär behandelt wird. CDI können auch ambulant erworben werden, so dass eine prophylaktische Gabe von Probiotika im ambulanten Bereich ebenfalls in Erwägung zu ziehen ist. Schlussfolgerung: Probiotika zur Prävention von CDI bei antibiotisch behandelten Kindern könnten zu einem Gewinn an Lebensqualität und zu Kostenersparnissen im Gesundheitswesen führen. Erst beim Vorliegen größerer randomisierter Studien mit statistisch signifikanten Ergebnissen zur klinischen Effektivität kann aber eine eindeutige Aussage zur Kosteneffektivität getroffen werden.

\section{DGKJ-PV-116}

Mucoid impaction: Fallbericht einer 7 jährigen Patientin mit Unterlappenatelektase bei Mykoplasmenpneumonie.

H. Robl', S. Flasch ${ }^{2}$, M. Griese ${ }^{3}$, U. Wintergerst ${ }^{1}$

${ }^{1}$ Krankenhaus St. Josef, ${ }^{2}$ Krankenhaus St.Josef, ${ }^{3}$ Klinikum der Universität München

Hintergrund: Die „mucoid impaction“ und der fakultativ resultierende Verschluss eines proximalen Bronchus ist eine seltene Komplikation, die im Rahmen von Asthma bronchiale, obstruktiver Bronchitis, zystischer Fibrose oder allergisch bronchopulmonaler Mykosen beobachtet werden kann.
Fallpräsentation: Wir berichten über ein $7^{1 / 2}$ Jahre altes Mädchen, bei dem perkutatorisch eine Dämpfung und radiologisch eine linksseitige Unterlappenatelektase diagnostiziert wurde. Klinisch hatte das Mädchen seit 5 Tagen Husten mit gelbgrünlichem Expektorat. Sie war bei Aufnahme in unsere Abteilung fieberfrei bei nur mäßig erhöhten Entzündungswerten. Eine allergische Diathese mit Asthma bronchiale und atopischer Dermatitis war vorbekannt.

Bei protrahiertem Verlauf unter konservativer Therapie (mit kalkulierter Antibiotikatherapie mit Cefuroxim und Gentamicin, Inhalationenen mit hypertoner NaCl-Lösung, Antiobstruktiva und Physiotherapie) kam es zu keiner Besserung. Die nun daraufhin durchgeführte Bronchoskopie zeigte makroskopisch eine chronische Bronchitis mit diskreter Eosinophilie. Hauptbefund war eine „mucoid impaction“ der linksseitigen Bronchusostien des Unterlappens. Diese konnte durch die Intervention zunächst frei gespült werden. Weiters trat ein pneumonisches Infiltrat nach erfolgreicher Intervention im wieder belüfteten Lobus inferior auf. Leider kam es wenige Tage darauf zu einem Rezidiv der Atelektase. In der erneut durchgeführten Bronchoskopie konnte in der Spülflüssigkeit mittels PCR jetzt Mycoplasma hominis nachgewiesen werden. Nach Erhalt des mikrobiologischen Ergebnisses führten wir eine zusätzliche Therapie mit zunächst Azithromycin und nach nochmaliger klinischer Verschlechterung mit Levofloxacin durch. Erst jetzt ließen sich sowohl Atelektase als auch die, das Asthma exacerbierende Mykoplasmenpneumie, erfolgreich therapieren.

Schlussfolgerung: Wir interpretierten den Verlauf der Patientin dahingehend, dass bei zugrunde liegendem Asthma bronchiale eine Infektion mit Mykoplasmen zu einer „mucoid impaction“ führte. Erst die intensivierte erregerspezifische Therapie führte zu einer Restitutio ad integrum.

\section{DGKJ-PV-117}

Symptomatik und Verlauf der Influenza A/H1 N1 bei 100 stationär behandlungsbedürftigen Kindern und Jugendlichen

S. Boxhammer, R. Lepler, H. Lenhartz, B. Püst, P. Höger

Kinderkrankenhaus Wilhelmstift

FRAGESTELLUNG: Die Altersgruppe der Kinder und Jugendlichen war von der Influenza A/H1N1-Pandemie besonders betroffen. Über die klinische Symptomatik, Verlauf und Komplikationen bei stationär behandlungsbedürftigen Kindern in Deutschland liegen bisher keine Veröffentlichungen vor.

MATERIAL und METHODIK: Wir analysierten retrospektiv ein Kollektiv von 100 Kindern und Jugendlichen, die in der Zeit zwischen dem 1. August 2009 und 1. März 2010 aufgrund einer mittels PCR im Nasopharynxabstrich gesicherten Influenza $\mathrm{A} / \mathrm{H}_{1} \mathrm{~N}_{1}-$ Infektion in einem großen Hamburger Kinderkrankenhaus stationär behandelt wurden. Erfasst wurden Symptomatik, Verlauf, mögliche Vorerkrankungen, Laborbefunde und Ansprechen auf die Therapie.

ERGEBNISSE: $28 \%$ der behandelten Kinder waren Säuglinge, 33\% Kleinkinder, 29 \% Schulkinder (6-12 Jahre) und 10 \% Jugendliche (>12 Jahre). Bei $79 \%$ der Patienten bestanden bei Aufnahme Luftwegssymptome und bei $76 \%$ Fieber $>39{ }^{\circ} \mathrm{C}$. Unter den Luftwegssymptomen waren Husten und pulmonale Obstruktion führend. Interessanterweise bestanden bei $64 \%$ der Patienten entweder ausschließlich oder zusätzlich zu respiratorischen Symptomen (54 \%) gastrointestinale Beschwerden in Form von Diarrhoe, Erbrechen oder Bauchschmerzen.

Bei 23\% traten neurologische Symptome auf, darunter am häufigsten Krampfanfälle (11\%), Meningismus ( $8 \%$ ) und bei $3 \%$ eine Enzephalopathie.

Die Entzündungsparameter waren bei den meisten Patienten nur geringfügig erhöht (CRP 10,3 mg/l, Median; Range <1-406 mg/l). Bei Aufnahme bestand eine leichte Neutrophilie (69\%; Range 11-95\%) und relative Lymphozytopenie (21\%; Range 3-72\%). Die durchschnittliche Erkrankungsdauer von Symptombeginn bis Entlassung betrug im Mittel 7 Tage. Kinder unter 12 Monaten waren im Mittel länger krank als ältere Kinder, während Patienten mit pulmonaler Vorerkrankung 
$(n=14)$ nicht länger erkrankten als Patienten ohne chronische Grunderkrankung.

Bei den innerhalb der ersten 48 Stunden nach Krankheitsbeginn mit Oseltamivir behandelten Patienten $(n=20)$ betrug die mittlere Erkrankungsdauer 4,8 Tage und war damit um $24 \%$ kürzer als bei nicht antiviral behandelten Patienten (6,4 Tage). Im Rahmen der stationären Behandlung kam es zu keinem Therapieabbruch.

Todesfälle traten nicht auf.

Diskussion und Schlussfolgerung: Das Spektrum der Symptomatik der an Influenza A/HiN1 erkrankten Kinder und Jugendlichen unterscheidet sich von dem saisonaler Influenzaerkrankungen. Viele Kinder weisen extrapulmonale Symptome auf. Säuglinge erkrankten länger als ältere Kinder. Anders als bei den saisonalen Influenza-Erkrankungen stellten pulmonale Vorerkrankungen in unserem Patientenkollektiv keinen Risikofaktor hinsichtlich der Erkrankungsdauer dar. Die antivirale Therapie mit Oseltamivir kann den Krankheitsverlauf günstig beeinflussen.

\section{DGKJ-PV-118}

Chronische Osteomyelitis der Mandibula-Einordnung und Therapieoptionen des Krankheitsbildes anhand eines Fallberichtes

K. Linden, O. Moser, A. Simon, G. Fleischhack, D. Dilloo

Universitätsklinik Zentrum f. Kinderheilkunde

Hintergrund: Die Einordnung der chronischen Osteomyelitis der Mandibula scheint schwierig, da in der Literatur häufig verschiedene Begriffe wie chronic recurrend multifocal osteomyelitis oder diffus sklerosierende Osteomyelitis zur Einordnung der Erkrankung gebraucht werden. Anhand des Fallberichtes möchten wir versuchen die chronische Osteomyelitis der Mandibula des pädiatrischen Patienten einzuordnen und mögliche Therapieoptionen aufzeigen.

Fallbericht: Wir möchten über ein 1ojähriges Mädchen berichten, welches sich seit zwei Jahren in unserer Behandlung befindet. Das Mädchen präsentierte sich initial mit einer immer wieder auftretenden schmerzhaften Schwellung der linken Wange. Während sich in der Sonographie ein aufgetriebener M. masseter links darstellte zeigte die Magnetresonanztomographie zusätzlich eine pathologische Signalanhebung des Ramus mandibulae links. Bei zunächst geäußertem Verdacht auf eine tumoröse Genese wurde eine Probeexzision durchgeführt, die den Befund einer chronisch fibrosierenden Osteomyelitis erbrachte. Ein Erregernachweis konnte nicht erbracht werden. Ebenso waren die Laborparameter bis auf eine deutlich erhöhte Blutsenkungsgeschwindigkeit unauffällig. Zusätzlich wurde eine Skelettszintigraphie durchgeführt, die eine Anreicherung im Bereich der gesamten linken Mandibula zeigte, sonst jedoch keine weiteren Anreicherungen aufwies. Die Patientin wurde intravenös antibiotische sowie mit Antiphlogistika oral behandelt. Eine orale antibiotische Therapie schloss sich an. Zusätzlich erfolgte eine hyperbare Sauerstofftherapie.

Nach fünf Monaten stellte sich die Patientin erneut mit massiver Schwellung der linken Wange vor. Die Magnetresonanztomographie zeigte erneut das Bild einer aufgetriebenen Mandibula.

Schlussfolgerung: Die hier beschriebene nicht-pustulierende chronisch-inflammative Erkrankung lässt sich unter dem Begriff der primär chronischen Osteomyelitis einordnen. Teilweise wird hierfür auch der Begriff der diffus sklerosierenden Osteomyelitis verwendet. Speziell in den letzten Jahren wurden jedoch verschiedene Arbeiten veröffentlicht, die insbesondere die primär chronische Osteomyelitis der Mandibula des pädiatrischen Patienten als eigene Entität ansehen.

Zur Diagnosestellung der primär chronischen Osteomyelitis der Mandibula im Kindesalter sollten Röntgenaufnahmen sowie eine Magnetresonanztomographie oder Computertomographie erfolgen. Zum Auffinden möglicher weiterer Läsionen sollte eine Skelettszintigraphie erfolgen. Ebenso ist eine Biopsie zum Ausschluss einer tumorösen Genese, möglichem kulturellen Erregernachweis und histologischer Sicherung der Diagnose notwendig. Zur Therapie gehören nicht-steroidale Antiphlogistika sowie der Versuch einer Therapie mit Corticosteroiden. Ebenso findet man die Empfehlung zur Decortication und schlussend- lich die Möglichketi der Therapie durch Resektion und Rekonstruktion. Mit hyperbarer Sauerstofftherapie konnte teilweise eine Besserung der Beschwerden erreicht werden.

\section{DGKJ-PV-119}

H1N1-Pandemie: Infektion, Impfverhalten und Nebenwirkungen bei lebertransplantierten Kindern

I. Goldschmidt' ${ }^{1}$, M. Plonka-Sobota' ', E. Pfister' ${ }^{1}$, M. Becker², S. Häckl², O. Bott²,

U. Baumann' ${ }^{1}$ U. Baumann

'Kinderklinik der Med. Hochschule, ${ }^{2}$ Fachhochschule Hannover

Einleitung: Im Zuge der $\mathrm{H}_{1} \mathrm{~N}_{1}-\mathrm{Pandemie}$ rieten wir ab Oktober 2009 allen lebertransplantierten Kindern bei mehr als ein Jahr zurückliegender Transplantation zur H1N1-Schutzimpfung. Die vorliegende Arbeit untersucht Impfverhalten und Nebenwirkungen der H1N1-Impfung sowie H1N1-Infektionen bei diesen Patienten.

Methodik: Retrospektive Fragebogen-basierte Datenerhebung bei allen von uns betreuten lebertransplantierten Kindern, deren Transplantation am 1. 10. 2009 länger als 1 Jahr zurücklag. Erhebung von Daten zu Impfverhalten, Impfmotivation, Impfnebenwirkungen, Infektionsrate sowie von klinischen Daten. Kontrollgruppen für Vergleich der Impfnebenwirkungen: 1 . Gesunde Geschwisterkinder $(\mathrm{n}=27,17 \mathrm{~m} / 12 \mathrm{~W}$, Alter 2-21 (Median 9) Jahre) 2. Probanden der Zulassungsstudie FLU D-PAN H1N1-023 ( $\mathrm{n}=244,128 \mathrm{~m} / 116 \mathrm{w}$, Alter 3-17 Jahre)

Ergebnisse: Von 137 Patienten standen 127 (62m/65W, Alter 1-19 (Median 11) Jahre) für die Befragung zur Verfügung. 72 Patienten (56\%) wurden gegen $\mathrm{H}_{1} \mathrm{~N}_{1}$ geimpft. In $22 \%$ erhielten auch alle weiteren Familienmitglieder die Impfung. Die Entscheidung für die Impfung war überwiegend durch unsere Empfehlung (64\%) und den Kinderarzt (22\%), weniger durch die öffentliche Diskussion (Medien/Internet $7 \%$ ) beeinflusst worden. 53 Kinder ( $74 \%$ der Geimpften) berichteten über Nebenwirkungen. Im Vergleich zur GSK-Zulassungsstudie traten bei den immunsupprimierten Patienten Lokalreaktionen (61\%), Fieber (25\%), Arthralgien (1\%) und Schwitzen (3\%) gleich häufig auf, Kopfschmerzen (12\%), Durchfall (6\%), Müdigkeit (10\%) und Myalgien (3\%) waren signifikant seltener. Im Vergleich zu gesunden Geschwisterkindern fanden sich keine signifikanten Unterschiede in den Nebenwirkungsraten. Bei den geimpften Kindern waren die Transaminasen vor der Impfung bei 58\% normal, bei $28 \%<1,5$ fach erhöht und bei $14 \%$ $>1,5$ fach erhöht. 4 Wochen nach der Impfung waren die Transaminasen bei $85 \%$ unverändert, bei 10\% zeigte sich ein Anstieg, bei 5\% ein Absinken. Bei einem Patienten wurde eine Leberbiopsie durchgeführt, welche minimale unspezifische Veränderungen zeigte. 3 geimpfte Kinder (4\% der Geimpften) machten 4-14 Tage nach Impfung eine gesicherte H1N1-Infektion durch.

56 Patienten (44\%) wurden nicht gegen $\mathrm{H}_{1} \mathrm{~N}_{1}$ geimpft. In 7 Fällen wurden jedoch andere Haushaltsangehörige geimpft. 14 Kinder $(25 \%$ der Ungeimpften) erlitten eine gesicherte $\mathrm{H}_{1} \mathrm{~N} 1$-Infektion. Insgesamt 13 Patienten (10\%, davon 2 geimpfte) wurden mit Oseltamivir behandelt. Zusammenfassung: $56 \%$ unserer Patienten wurden gegen $\mathrm{H}_{1} \mathrm{~N}_{1}$ geimpft. Nebenwirkungen waren teilweise seltener als im nicht-immunsupprimierten Kontrollkollektiv, schwerwiegende Nebenwirkungen traten nicht auf. $4 \%$ der geimpften und $25 \%$ der ungeimpften Kinder erkrankten an $\mathrm{H}_{1} \mathrm{~N} 1$.

Schlussfolgerung: Die H1N1-Impfung wird von immunsupprimierten Patienten gut vertragen und bietet weitgehenden Schutz vor einer Infektion. Angesichts der hohen Infektionsrate ungeimpfter immunsupprimierter Patienten müssen die Anstrengungen für eine Durchimpfung verstärkt werden. 
DGKJ-PV-120

Hohe Rate unerwünschter Ereignisse nach Impfung mit Pandemrix ${ }^{\circledast}$ gegen Neue Influenza $A / H_{1} N_{1}$ bei medizinischem Personal an einer Universitätskinderklinik

M. Hufnagel, K. Blessing, F. Lander, A. Gerecke, P. Henneke, R. Berner

Universitäts - Kinderklinik

Hintergrund: Im Juni 2009 wurde von der WHO aufgrund der weltweiten Ausbreitung der Neuen Influenza A/H1N1 die Pandemiestufe 6 ausgerufen, das erste Mal seit rund 40 Jahren. Ab Oktober 2009 stand in Deutschland ein adjuvantierter Spaltimpfstoff (Pandemrix ${ }^{\oplus}$ ) als Impfstoff zur Verfügung, der nach einem beschleunigten Zulassungsverfahren (sog. „Mock-up“-Verfahren) von der EMEA für Europa zugelassen wurde. Aufgrund des beschleunigten Zulassungsverfahrens beruhen Daten zu unerwünschten Ereignissen (UAE; unwanted adverse events) zu Beginn der Pandemie nur auf relativ kleinen Fallzahlen. Methodik: Prospektive Erfassung von unerwünschten Ereignissen nach einmaliger freiwilliger Impfung von Klinikpersonal am Zentrum für Kinderund Jugendmedizin (ZKJ) Freiburg mittels eines standardisierten Fragebogens. Ergebnisse: An 4 angebotenen Impfterminen am Arbeitsplatz ließen sich 233 Mitarbeiter des ZKJ (Ärzte, Pflege- und Verwaltungspersonal mit Patientenkontakt) einmalig mit dem Impfstoff Pandemrix impfen. 72 Impfdosen wurden ärztlichem Personal verabreicht, das entspricht einer Impfquote von $72 \%$. Knapp die Hälfte der geimpften Mitarbeiter füllte den freiwilligen Fragebogen aus $(\mathrm{n}=115)$. Mindestens 1 UAE wurde von 89,6\% (103/115) der geimpften Personen angegeben. Lokale Impfreaktionen wurden in 85,2\% (98/115), Allgemeinsymptome wie Gelenk-, Muskel-, Kopfschmerzen, Müdigkeit, Unwohlsein und Fieber in $66,9 \%$ (77/115) berichtet. Die UAE waren meist milder Natur (in 78,6-84,2\% Grad 1-2) und hielten selten länger als 4 Tage (in 16,6-29,8\%) an. In 3 Fällen wurden Muskelschmerzen mit einer Dauer >21 Tage berichtet, ein Impfling erlitt eine schwere reaktive Arthritis, die zu einer Hospitalisation und lang anhaltender Immobilisation führte. Andere schwere Nebenwirkungen insbesondere ein GuillainBarré-Syndrom traten nicht auf. Zusammenfassung: Das freiwillige Impfangebot gegen die Neue Influenza $\mathrm{A} / \mathrm{H}_{1} \mathrm{~N}_{1}$ wurde am ZKJ Freiburg vom gesamten medizinischen Personal nur mäßig angenommen, das ärztliche Personal ließ sich hingegen in der Mehrzahl impfen. Die Rate an unerwünschten Ereignissen lag wesentlich höher als in publizierten Vergleichstudien, was möglicherweise mit der gezielten Nachfrage durch den strukturierten Fragebogen zusammenhängen könnte. Die meisten UAE waren mild ausgeprägt und von kurzer Dauer. Eine schwere UAE mit reaktiver Arthritis ist aufgetreten. Schlussfolgerung: Trotz einer hohen Rate an überwiegend milde verlaufenden unerwünschten Ereignissen sollte die Impfung gegen die Neue Influenza $\mathrm{A} / \mathrm{H}_{1} \mathrm{~N}_{1}$ bei medizinischem Personal aufgrund des Morbiditätsund Mortalitätsrisikos wie auch des Übertragungsrisikos auf Patienten im Falle einer weiteren epidemiologischen Welle erneut propagiert und mit Impfaktionen vor Ort aktiv unterstützt werden.

\section{DGKJ-PV-121}

Rezidivierende Hautinfektionen bei Kindergartenkindern durch Panton-Valentine-Leukozidin-bildenden Staphylococcus aureus - Kasuistik -

E. Behl', R. Möritz' , A. Kola² , K. Hübschmann'1, P. Gastmeier' ${ }^{2}$, M. Radke'

${ }^{1}$ Klinikum Ernst v. Bergmann, ${ }^{2}$ Charité Universitätsmedizin Berlin

Einleitung: Haut- und Weichteilinfektionen werden häufig durch Staphylococcus aureus hervorgerufen. Handelt es sich um chronische oder rezidivierend auftretende Infektionen bei immunkompetenten Patienten muss an einen Panton-Valentine-Leukozidin (PVL)-produzierenden Staphylococcus aureus-Stamm gedacht werden. Dieses Zytotoxin, das Leukozyten und Makrophagen lysiert, ist ein zusätzlicher Virulenzfaktor. Neben dem Auftreten multipler bzw. rezidivierender Abszesse sind selten auch schwere Krankheitsverläufe mit nekrotisierender Pneumonie, Fasciitis und Osteomyelitis möglich.
Kasuistik: Wir berichten über 2 sonst gesunde Kleinkinder, die in unserer Klinik in kurzem Zeitabstand wegen rezidivierender Hautbzw. Weichteilabszesse behandelt wurden und deren Väter zeitgleich mit o. g. Symptomatik erkrankten. Es stellte sich heraus, dass beide Kinder denselben Kindergarten besuchen.

In den mikrobiologischen Untersuchungen des Abszesseiters wurden jeweils Staphylococcus aureus nachgewiesen. In den Isolaten erfolgten mittels gesondert angeforderter molekularbiologischer Untersuchungen (PVL-Gen-PCR) und Genotypisierungen (Sequenzierung des Protein A-Gens, spa-Typisierung) der Nachweis des gleichen spa-Typs t435.

Wir berichten über den Verlauf, die Umgebungsuntersuchungen, die Therapie und die Schwierigkeiten bei der Durchführung der umfangreichen Sanierungsmaßnahmen.

Zusammenfassung: PVL-produzierende Staphylococcus aureusStämme verursachen $u$. a. chronische und rezidivierende Infektionen der Haut und Weichteile gehäuft bei Kindern und jungen Erwachsenen ohne besondere Hinweise auf Infektionen in der Anamnese. Die Infektionen sind ambulant erworben. Die Erreger kolonisieren bevorzugt die Nasenvorhöfe und werden über direkten Kontakt übertragen. In der Literatur wird über eine schnelle Ausbreitung und lokale Ausbrüche berichtet. Dieses kann nur durch strikte Einhaltung von Hygienemaßnahmen vermieden werden. Die Therapie erfolgt durch eine weitreichende chirurgische Intervention und bei floriden Infektionen durch Antibiotika (z. B. Kombination von Rifampicin und Cotrimoxazol).

\section{DGKJ-PV-122}

Rezidivierende Fieberschübe als Monosymptom einer chronischen Yersinien-Infektion

Z. Demir, R. Beetz, V. Umlauf, W. Mannhardt-Laakmann

Universitätsmedizin der Johannes Gutenberg-Universität Mainz

Hintergrund: Etwa 1\% der infektiösen Durchfallerkrankungen werden durch Yersinien verursacht. Eine Chronifizierung ist - erst recht im Kindesalter - selten und findet sich dann oft im Zusammenhang mit chronischer Lymphadenopathie, einem Erythema nodosum oder findet den Übergang in eine reaktive Arthritis.

Kasuistik: Über einen Zeitraum von 6 Monaten durchlief unser 12-jähriger Patient in Abständen von 6-9 Wochen insgesamt 4 Fieberschübe über eine Zeitdauer von jeweils 7-10 Tagen mit Temperaturen bis $39^{\circ} \mathrm{C}$. Bis auf vermehrte Müdigkeit während des Fiebers fanden sich keine weiteren klinischen Auffälligkeiten. In einer abermaligen Anamneseerhebung wurde schließlich von einem 6 Monate vor dem ersten Fieberschub zurückliegenden Spanien-Aufenthalt berichtet, im Anschluss sei eine Gastroenteritis aufgetreten, welche nach wenigen Tagen wieder abgeklungen sei.

Diagnostik: Während der Fieberschübe fielen unspezifische Entzündungszeichen auf (CRP maximal 61 g/dl, BSG 45/79 mm nW., CH50 93 U/l). Die Differentialblutbilder zeigten niedrig-normale Leukozytenzahlen und eine milde Monozytose, jedoch keine (zyklische) Neutropenie. Sonografisch ließ sich eine leichte Hepatosplenomegalie, jedoch keine intestinale Lymphadenopathie darstellen; der Röntgen-Thorax war ebenso wie die kardiologische Diagnostik unauffällig. Die Knochenmarkspunktion zeigte ein unauffälliges Myelogramm. Infektionen der Harnwege, Zähne und Knochen wurden ebenso ausgeschlossen wie Fiebersyndrome sowie Infektionserkrankungen durch Borrelien, Mykobaterien, Toxoplasmen, EBV, Parvo B19, CMV und Pilze. Die Serologie auf Yersinia species war für IgM und IgG positiv, für IgA negativ (ELISA). Die Stuhlkultur war negativ.

Therapie: Während der ersten drei Fieberschübe erfolgte eine symptomatische Therapie mit Ibuprofen und Paracetamol ohne wesentlichen Einfluss auf das Fieber. Während der vierten und letzten Fieberepisode begannen wir zunächst eine antiinflammatorische Therapie mit Naproxen, worunter die Temperaturen dauerhaft in den subfebrilen Bereich gesenkt werden konnten. Zudem führten wir nach Erhalt der positiven Yersinien-Serologie eine antibakterielle Therapie mit zunächst Ceftazidim intravenös und schließlich mit Cefpodoxim oral über insgesamt 
14 Tage durch. Hierunter entfieberte der Patient dauerhaft, die Entzündungsparameter normalisierten sich. In den ersten 6 Monaten Nachbeobachtungszeit ist der Patient anhaltend beschwerde- und fieberfrei. Diskussion: Rezidivierende Fieberschübe ohne weitere klinische Symptomatik stellen eine diagnostische Herausforderung dar. Neben den seltenen Fiebersyndromen sollten auch seltene infektiologische Ursachen wie die chronische Yersiniose bedacht werden. Yersinien-spezifisches IgM persistiert bei chronischen Verläufen in seltenen Fällen länger als 3 Monate und IgG in der Regel über Jahre, wohingegen IgA bei der chronischen Yersiniose oft nur im Zusammenhang mit einer gleichzeitig bestehenden reaktiven Arthritis länger als 2-4 Monate nachweisbar bleibt.

\section{DGKJ-PV-123}

Falldarstellung: Eitrige Pyomyositis als seltene Differentialdiagnose einer akuten Gehverweigerung

M. Nestler, M. Herr, A. von Moers

DRK Kliniken Berlin | Westend

Anamnese: Ein 1 Jahre und 9 Monate alter Junge wurde mit einer plötzlichen Gehverweigerung und Schmerzen bei Beugung im Hüftgelenk in unsere Klinik eingewiesen. Sechs Tage vor Aufnahme habe ein feinfleckiges Exanthem bestanden. Fieber bis $38^{\circ} \mathrm{C}$ war erstmals am Aufnahmetag aufgetreten. Ein Trauma war nicht erinnerlich, es gab keinen Anhalt für eine knöcherne Verletzung. Das Kind war vorher immer aktiv und konnte frei laufen.

Befund: Wir sahen einen altersentsprechend entwickelten Jungen in stabilem Allgemeinzustand mit einer Schonhaltung des linken Beines und Gehverweigerung. Im Sitzen weinte der Junge. Links paravertebral auf Höhe BWK 10 - LWK 3 fielen eine druckdolente Schwellung und Verhärtung der Rückenmuskulatur ohne Rötung und ein deutlicher Wirbelsäulenklopfschmerz auf Höhe LWK 1 auf. Die Innenrotation der linken Hüfte war schmerzhaft. Ein feinfleckiges Exanthem betraf den gesamten Stamm des Kindes. Im Übrigen bestand ein unauffälliger pädiatrischer und neurologischer Untersuchungsbefund. Temperatur $38,4^{\circ} \mathrm{C}$.

Differentialdiagnostisches Vorgehen: Eine Coxitis fugax ließ sich sonographisch ausschließen. Mäßig erhöhte laborchemische Entzündungsparameter (BSG $34 / 56 \mathrm{~mm} / \mathrm{h}$ und $\mathrm{CrP} 4,4 \mathrm{mg} / \mathrm{dl}$ ) und anhaltend hohes Fieber bis max. $39,2^{\circ} \mathrm{C}$ legten einen entzündlichen oder infektiösen Prozess nahe. Blutbild und manuelles Diff.-BB waren unauffällig. Bei weiter ansteigenden Entzündungswerten (BSG 5o/86 mm/h und $\mathrm{CrP} 7,3 \mathrm{mg} / \mathrm{dl}$ ) führten wir zur Abklärung einer Osteomyelitis, Spondylodiszitis oder Myositis ein MRT des Beckens und der unteren Wirbelsäule durch. Hier fanden sich keine Hinweise für eine Diszitis oder Osteomyelitis, aber eine entzündliche Infiltration der autochthonen Rückenmuskulatur links vom Os sacrum bis in Höhe LWK 2 ohne Nachweis von Abszedierungen. Sonographisch zeigte sich eine Auflockerung der Muskulatur. Die CK war normwertig. Mehrere Blutkulturen erbrachten keinen Erregernachweis. Auf eine Muskelbiopsie verzichteten wir. Die bei einem feinfleckigen Exanthem zusätzlich bestimmten Autoimmun-Marker (ANA, ANCA, Cardiolipin-AK, Rheumafaktor) waren negativ.

Therapie und Verlauf: Aufgrund der erhobenen Befunde stellten wir die Diagnose einer Pyomyositis der paravertebralen Muskulatur links. Wir behandelten insgesamt 12 Tage mit Cefuroxim intravenös. Der Junge entfieberte rasch und es kam zu einer deutlichen klinischen Besserung des Lokalbefundes. Bei Entlassung war das Kind aktiv, schmerzfrei und hatte unauffällige laborchemische Entzündungsparameter. Schlussfolgerung: Neben einer Coxitis, Osteomyelitis oder einer Diszitis kommt differentialdiagnostisch auch eine Pyomyositis als seltene Ursache für eine Schonhaltung oder Bewegungseinschränkung im Hüftgelenk in Frage. Diese tritt in nahezu allen Altersgruppen auf. Der häufigste Erreger ist Staphylococcus aureus.

\section{DGKJ-PV-124}

INFLUENZA A (H1N1) 2009 ASSOZIIERTE PÄDIATRISCHE HOSPITALISATIONEN IN NORDBAYERN

A. Wieching', J. Al-Tahan', A. Streng', S. Hanke', B. Weißbrich², C. Kohlhauser-Vollmuth ${ }^{3}$, J. Liese ${ }^{1}$

'Universitätskinderklinik Würzburg, ${ }^{2}$ Institut für Virologie und Immunbiologie, Universität Würzburg, ${ }^{3}$ Kinderklinik am Mönchberg

Hintergrund und Ziele: Aufgrund der begrenzten Datenlage für Kinder besteht bezüglich des Schweregrades und der Komplikationen von Infektionen mit pandemischer Influenza A ( $\left.\mathrm{H}_{1} \mathrm{~N}_{1}\right) 2009$ (PIA) eine erhebliche Unsicherheit. Ziel der Studie war die Erfassung von laborbestätigten Hospitalisationen und die Schätzung der HospitalisationsInzidenz für die erste Saison (2009/2010) der pandemischen Influenza A ( $\left.\mathrm{H}_{1} \mathrm{~N}_{1}\right) 2009$ Epidemie in einer geographisch definierten Region in Nordbayern.

Methoden: Von Juli 2009 bis März 2010 wurden klinische Daten aller Patienten $\leq 18$ Jahren mit Polymerase-Kettenreaktion (PCR) - bestätigter pandemischer Influenza A ( $\left.\mathrm{H}_{1} \mathrm{~N}_{1}\right) 2009$ erfasst, die in zwei Kinderkliniken in Würzburg stationär aufgenommen wurden. Die Inzidenz der Hospitalisationen wurde für das Haupteinzugsgebiet der beiden Kliniken berechnet.

Ergebnisse: Insgesamt wurden 95 Kinder (60\% Jungen) mit PCR-bestätigter pandemischer Influenza A ( $\left.\mathrm{H}_{1} \mathrm{~N}_{1}\right) 2009$ stationär aufgenommen. Ihr Alter betrug im Median 6,5 Jahre (IQR 1,6-10,8) und die Aufenthaltsdauer 4 Tage (IQR 3-6). Die häufigsten Diagnosen waren Infektion der oberen Luftwege (55\%), Pneumonie (16\%) und Bronchitis (11\%). Intensivstationär wurden vier (4\%) Kinder mit einem medianen Alter von 5,1 Jahren (IQR 0,1-10,6) mit einer medianen Aufenhaltsdauer von 5 Tagen (IQR 2-41) behandelt. Ein elfjähriges Mädchen mit schwerer neurologischer Grunderkrankung verstarb an einer Pneumonie und respiratorischer Insuffizienz. Eine chronische Grunderkrankung wurde bei $42 \%$ aller hospitalisierten Kinder dokumentiert, wobei Asthma am häufigsten vorkam (10,5\%). Die Inzidenz für Hospitalisationen bei Kindern $\leq 18$ Jahren beträgt 103/100. ooo/Saison. Für die Altersgruppe der 0-5 bzw. 6-18-jährigen Kinder ergibt sich eine Inzidenz von 166 bzw. 79/100. 0oo/Saison.

Diskussion: Die Inzidenz der pädiatrischen Hospitalisationen bei pandemischer Influenza A ( $\left.\mathrm{H}_{1} \mathrm{~N}_{1}\right) 2009$ war für die Altersgruppe der o-16-jährigen doppelt so hoch (99,5/10o. ooo) verglichen mit früheren Inzidenzschätzungen der Hospitalisationen aufgrund von saisonaler Influenza A in Deutschland (53/100. ooo; Weigl et al. 2002). Für die Altersgruppe der 6-16-jährigen (22/100. 000) war die Inzidenz sogar fünfmal höher (91/10o. ooo). Im Vergleich zu publizierten Daten zu hospitalisierten Kindern mit pandemischer Influenza A (H1N1) 2009 Infektion aus Argentinien (Libster et al. 2010) waren Komplikationen bei hospitalisierten Kindern in Deutschland deutlich seltener (intensivstationäre Behandlung $19 \%$ vs. $4 \%$, Todesfälle $5 \%$ vs. $1 \%$ in Deutschland). Dieses könnte eher auf Unterschiede in diagnostischen Verfahren, Hospitalisationsraten, Krankenversicherungsschutz und primärem Zugang zum Gesundheitssytem zurückzuführen sein, als auf Unterschiede in der Pathogenität des zirkulierenden Influenza A/H1N1 Virus.

DGKJ-PV-125

Enterovirus-Surveillancebei ZNS-Infektionen in Deutschland - auch ein Instrument der Polioüberwachung

S. Böttcher ${ }^{1}$, K. Neubauer', K. Beyrer ${ }^{2}$, S. Diedrich ${ }^{1}$

${ }^{1}$ Robert Koch-Institut, ${ }^{2}$ Niedersächsisches Landesgesundheitsamt

Ziel: Die globale Polioeradikation unter Führung der WHO wird seit 1988 angestrebt. Seither konnte die Zahl der weltweit registrierten Fälle um 99,5\% gesenkt werden und nur noch vier Länder gelten als Endemiegebiete: Nigeria, Indien, Pakistan und Afghanistan. Obwohl im Jahr 2002 die WHO-Region Europa als poliofrei deklariert wurde, müssen weiterhin die Strategien der Polioeradikation mit Impfung und Überwachung in allen Mitgliedsstaaten aufrecht erhalten werden, da insbesondere die Gefahr durch importierte Fälle nach wie vor real vor- 
handen ist (Beispiel: Polioausbruch in Tadschikistan 2010). Das Programm zur Polioüberwachung in Deutschland wurde seit 1997 vom Niedersächsischen Landesgesundheitsamt in Kooperation mit dem Nationalen Referenzzentrum für Poliomyelitis am Robert Koch Institut (RKI) durchgeführt und ist seit 2010 komplett in den Aufgabenbereich des RKI integriert worden. Material/Methoden: In einem bundesweiten qualitätsgeprüften Labornetzwerk (LaNED) werden Stuhlund Liquorproben auf Enteroviren mittels PCR, Anzucht und Typisierung untersucht. Im Rahmen der Enterovirus-Surveillance wird allen pädiatrischen und neurologischen Kliniken die kostenlose Untersuchung einer Probe pro Patient zur Abklärung aseptischer Meninigitiden bzw. akuter schlaffer Paresen angeboten. Ergebnisse: Bisher nutzen 212 Kliniken (175 Kinderkliniken und 37 neurologische Abteilungen) die Enterovirus-Surveillance (Stand 17. 5. 2010). Seit Oktober 2005 wurden 10632 Proben eingesandt, bei 3015 Proben konnte ein positives PCR Ergebnis erzielt werden $(28,4 \%)$ und in 2164 Fällen der Erreger bestimmt werden $(20,3 \%)$. Die Altersverteilung mit einer deutlichen Verschiebung hin zu Patienten in den jüngeren Altersbereich (o - 15 Jahre) spiegelt auch das verstärkte Interesse der Kinderkliniken an der Enterovirus-Diagnostik wider. Die saisonale Verteilung der Einsendungen zeigt die klassische Dominanz der Enteroviren in den Sommermonaten teils auch mit einer regionalen Erkrankungshäufung. Die Nachweisrate von Enteroviren aus Stuhlproben ist der aus Liquorproben deutlich überlegen. Die Ergebnisse der Enterovirus-Surveillance sind auf der Homepage des RKI abrufbar. Schlussfolgerung/Diskussion: Durch die qualitativ hochwertige Enterovirus-Surveillance wird eine differentialdiagnostische Abklärung der aseptischen Meningitiden/Enzephalitiden unterstützt Zudem ist es möglich, Ausbrüche frühzeitig zu erkennen und somit zum Infektionsschutz beizutragen. Neben diesen individual- und bevölkerungsmedizinischen Aspekten stellt sie ein verlässliches Überwachungssystem zum Nachweis der Poliofreiheit in Deutschland dar.

\section{DGKJ-PV-126}

\section{Procalcitonin - unterschätzter Marker zur Differentialdiagnose Kawa-} saki-Syndrom?

S. Holz' ${ }^{1}$ V. Jansen², R. Keitzer ${ }^{3}$, M. Botsch ${ }^{1}$

${ }^{1}$ Ev. Freikirchl. Krankenhaus Bernau, ${ }^{2}$ Laborverbund Bernau, ${ }^{3}$ Charite Kliniken $\mathrm{f}$. Kinderheilkunde und Kinderchirugie

Einleitung: Procalcitonin findet zunehmend Einsatz als Entzündungsmarker bei der Diagnose einer bakteriellen Sepsis. Ein starker Anstieg des Wertes beim Kawasaki-Syndrom ist bislang nur ungenügend untersucht und seine Bedeutung im Rahmen der differentialdiagnostischen Abklärung unklaren Fiebers noch unbekannt. Wir berichten von einer Patientin mit atypischem Kawasaki-Syndrom und erheblicher Erhöhung der Procalcitonin-Serum-Spiegel.

Fallbericht: Weibliche, 3 1/12-jährige Patientin, seit 3 Tagen bis $40^{\circ} \mathrm{C}$ fiebernd in reduziertem Allgemeinzustand. Exanthem, teilweise konfluierend an unteren Extremitäten, Stamm, Wangen und Gesäß, Palmarerythem ohne Schuppung, gerötete Lippen, geschwollene und gerötete Zunge, hyperplastische Tonsillen. Da Kawasakikriterien nicht erfüllt, bei hohem CrP und deutlicher Linksverschiebung des weißen Blutbildes ohne erkennbaren Fokus weitere Diagnostik inklusive Blutkulturen, Lumbalpunktion, Echokardiographie und Röntgen-Thorax. Beginn einer i. v.-antibiotischen Therapie. Bei ausbleibender Besserung zur Abklärung einer Sepsis rückwirkende Bestimmung der deutlich erhöhten Procalcitonin-Serum-Spiegel (21,8 ng/ml). Diagnose bakterielle Sepsis und Erweiterung der i. v.-antibiotischen Therapie.

Bei weiterhin bestehendem hohen Fieber und schlechtem Zustand Erweiterung der Therapie um i. v.-Immunglobulin und hochdosiert ASS.

Im weiteren Verlauf sukzessive Entfieberung und rasche Besserung des Status. Weiterhin Schuppung der Fingerbeeren. Stellung der Diagnose atypisches Kawasaki-Syndrom. Abfall der Entzündungsparameter CrP, Procalcitonin und der Leukozytenzahl auf Normwerte. Regelmä- ßige echokardiographische Kontrollen bislang mit unauffälligen Koronarien.

Diskussion: Die Bestimmung der Procalcitonin-Werte findet derzeit Anwendung zur Diagnose einer bakteriellen Sepsis. In mehreren Arbeiten wurde eine Erhöhung der Procalcitonin-Werte im Rahmen des Kawasaki-Syndroms beschrieben, wobei Hinweise bestehen, daß eine Korrelation zwischen Höhe des Procalcitonin-Wertes und einer Koronarbeteiligung vorliegen.

Gerade bei Beginn des Kawasaki-Syndroms mit lediglich hohem Fieber und $\mathrm{CrP}$ und noch ohne klassische Symptome fällt die Abgrenzung zu bakteriellen Infektionen häufig schwer. Bei dem dargestellten Fall fiel bei der nachträglichen Bestimmung der Procalcitonin-Serum-Spiegel eine deutliche Erhöhung auf, die zunächst als deutlicher Hinweis auf eine Sepsis gedeutet wurde. Retrospektiv muß jedoch von einer Erhöhung des Procalcitonins im Rahmen des Kawasaki-Syndroms ausgegangen werden.

Schlussfolgerungen: Neben der bekannten Erhöhung der CrP-Werte kommt es im Rahmen des Kawasaki-Syndroms zu einem starken Anstieg von Procalcitonin. In weiteren Studien muss geklärt werden, ob der Verlauf der Procalcitonin-Erhöhung sich zur Sicherung der Diagnose Kawasaki-Syndrom eignet und ob eine prospektive Aussage zum Verlauf, insbesondere zur Koronarschädigung, möglich ist.

\section{DGKJ-PV-127}

Rezidivierdene neonatale E.coli-Sepsis/Meningitis: Ein Immundefekt? A. Gerecke' ${ }^{1}$, M. Hufnagel', O. Moske-Eick' ${ }^{2}$ S. Ehl' ${ }^{3}$, R. Berner ${ }^{1}$

'Zentrum für Kinder- und Jugendmedizin, ${ }^{2}$ Abteilung Neuroradiologie, ${ }^{3}$ Centrum für Chronische Immundefizienz

Hintergrund: Rezidivierende invasive bakterielle Infektionen müssen an einen Immundefekt denken lassen. Zur sorgfältigen Abklärung gehören neben der immunologischen Diagnostik auch die Suche nach funktionellen oder strukturellen anatomischen Auffälligkeiten sowie die Berücksichtigung einer adäquaten spezifischen antiinfektiösen Therapie.

Fallbericht: Bei einem hypotrophen Neugeborenen mit Mikrozephalie wurde am 5. Lebenstag bei Fieber, reduziertem Trinkverhalten, Unruhe, Blässe und Tachydyspnoe eine E. coli-Sepsis diagnostiziert und der Patient 7 Tage mit Ampicillin und Cefotaxim i. v. behandelt. Eine Lumbalpunktion wurde nicht durchgeführt. Die zweite Sepsisepisode trat im Alter von 18 Tagen auf, in Blut- und Liquorkulturen wurden erneut E. coli nachgewiesen und der Patient 14 Tage mit Ampicillin und Cefotaxim behandelt. Eine 3. Episode mit Nachweis von E. coli in der Blutkultur trat im Alter von 6 Wochen auf, die wiederum 7 Tage i. v.-antibiotisch behandelt wurde.

Eine Woche nach Beendigung der letzten Antibiotikatherapie wurde der Patient zum Ausschluss eines Immundefekts erstmalig ambulant in unserem Zentrum vorgestellt. Aufgrund jeweils eher kurzer antibiotischer Therapiezyklen wurde zur Fokussuche und Abklärung struktureller Anomalien eine neuroradiologische Bildgebung des Schädels und der Wirbelsäule durchgeführt. In MRT- und CT-Schädel zeigte sich eine Signalanhebung mit Flüssigkeitsverhalt und Lufteinschluss im rechten Mastoid mit Kontrastmittelaufnahme und reaktiver Duraverdickung. Intraoperativ fand sich das gesamte Mastoid unter der Kortikalis mit entzündlichen Granulationen ausgefüllt. Histologisch bestätigte sich die schwere floride und chronisch granulierende Mastoiditis. Nach operativer Ausräumung und dreiwöchiger Therapie mit Cefotaxim erholte sich der Patient vollständig. Eine ergänzend durchgeführte ausführliche immunologische Diagnostik ergab Normalbefunde in allen Kompartimenten. Es traten über einen Beobachtungszeitraum von 1 Jahr keine erneuten Infektionsepisoden auf.

Schlussfolgerung: Trotz suggestiver Anamnese und typischem Krankheitsbild für einen möglichen Immundefekt muss neben immunologischer Diagnostik auch eine Suche nach Streuherden durchgeführt werden. Bei einer unzureichenden antibiotischen Vortherapie kann es zu infektiösen Absiedelungen kommen, die zu Ausgangspunkten für erneute septische Komplikationen werden. 


\section{Varia I}

\section{DGKJ-PV-128}

Peer teaching im Blockpraktikum Pädiatrie - Evaluation des Einsatzes studentischer Tutoren an der Universitäts-Kinderklinik Essen

R. Büscher, D. Weber, A. Büscher, M. Hölscher, M. Hegenbarth, P. Hoyer

Klinik für Kinder und Jugendmedizin der Universität

Hintergrund: An der Universitäts-Kinderklinik Essen werden seit 1986 studentische Tutoren in einem vierzehntägigen Intensivkurs ausgebildet, um im Blockpraktikum Pädiatrie Studierende des 3. und 4. Klinischen Semesters am Krankenbett in basalen pädiatrischen Untersuchungstechniken zu unterrichten („peer-to-peer-teaching“). Die Tutoren werden für ein Jahr als studentische Hilfskräfte in der Klinik eingestellt. Der Schwerpunkt der Tutorenausbildung liegt auf der Vermittlung affektiver und sensomotorischer Fertigkeiten, wie zum Beispiel Kontaktaufnahme zu Eltern und Kindern, sowie auditive und manuelle Fertigkeiten. Zielsetzung: In dieser prospektiven Studie sollte untersucht werden, ob die Tutoren spezifische pädiatrische Untersuchungstechniken ähnlich gut vermitteln können, wie ein erfahrener pädiatrischer Dozent. Methodik: Einhundertdreiundzwanzig Studierende wurden auf zwei Gruppen verteilt, die entweder einem pädiatrischen Dozenten oder einem studentischen Tutor zugeteilt wurden. Nach einer einstündigen Unterrichtseinheit mussten die erlernten manuellen und verbalen Fähigkeiten im Rahmen einer 1ominütigen OSCE-Prüfung demonstriert werden. Ergebnisse: Gegenüber einer Vortest-Gruppe von 23 Studierenden, die bisher an keinem Unterricht teilgenommen hatte, erzielten beide Untersuchungsgruppen ein signifikant besseres Prüfungsergebnis. Die Studierenden, die von einem Tutor unterrichtet wurden, erreichten dabei im direkten Vergleich eine ähnliche Gesamtpunktzahl, wie die Gruppen, die von einem pädiatrischen Dozenten ausgebildet wurden $(21,7 \pm 4,1$ vs. $22,6 \pm 3,6$ von 36 Punkten, $p=0$,203). Insbesondere in der Teilaufgabe, in der ausschließlich praktische Fertigkeiten überprüft wurden, zeigte die Gruppe der von einem Dozenten unterrichteten Studierenden keinen punktwerten Vorteil (7,44 $\pm 2,15$ vs. $7,97 \pm 1,87$ von maximal 16 Punkten, $p=0,154$ ). Die Mehrzahl der Studierenden (77\%) gab an, dass sie den Unterricht mit den Tutoren als lernfördernd angesehen haben. Schlussfolgerung: Die Ergebnisse der quantitativen Lernstudie können belegen, dass der Einsatz von studentischen Tutoren im klinischen Unterricht sinnvoll und lernfördernd ist, wenn diese selektive Aufgaben übernehmen. Die studentischen Tutoren ersetzen nicht die Lehraufgaben der Dozenten, erleichtern durch ihre Zwischenstellung in der Krankenhaushierarchie aber die Aufgabe der Lehrenden.

\section{DGKJ-PV-129}

Interprofessionelles Blended Learning mit Virtuellen Patienten und praktischem Skills Lab Training zur Verbesserung der pädiatrischen Notfallversorgung: Bedarfsanalyse und Konzeption

R. Lehmann, A. Simon, E. Karmrodt, B. Tönshoff, G. Hoffmann, S. Huwendiek Zentrum für Kinder- und Jugendmedizin

Fragestellung: Es bestehen Hinweise darauf, dass in der Notfallversorgung von Kindern erhebliche Defizite auch bei professionellen Helfern bestehen (Hunt et al. 2008 et 2009). Daher wird am Zentrum für Kinder- und Jugendmedizin Heidelberg ein interprofessioneller Blended Learning Kurs für Ärzte und Pflegende bestehend aus Virtuellen Patienten, Online-Diskussion und praktischem Skills Lab Training etabliert. Bisher existieren nur wenige Daten zum Einsatz von Blended Learning in der medizinischen Weiterbildung, insbesondere für den interprofessionellen Einsatz. Beim Einsatz von Virtuellen Patienten als Vorbereitung für ein studentisches Skills Lab Training wurden bereits positive Erfahrungen vor Ort gesammelt (Lehmann et al. 2010).

Methodik: Die Projektentwicklung erfolgt angelehnt an den 6-schrittigen Ansatz von Kern et al. zur medizinischen Curriculumsentwicklung (Kern et al. 1998). Die vorliegende Arbeit beschäftigt sich mit Schritt eins und zwei der Curriculumsentwicklung, nämlich der Erhebung der allgemeinen Bedarfsanalyse und der spezifischen Bedürfnisse der beteiligten Zielgruppen. Hierzu werden im Sommer 2010 Pflegende und Ärzte per Fragebogen und Fokusgruppen befragt, wie deren bisherige Weiterbildung in der Versorgung pädiatrischer Notfälle aussah, wie diese empfunden wurde und wie diese idealerweise aussehen sollte. Ergebnisse: Die Ergebnisse der Bedarfsanalyse unter Ärzten und Pflegenden und die Gesamtkonzeption des Trainings werden vorgestellt. Schlussfolgerung: Ein Blended Learning Kurs zum pädiatrischen Notfalltraining, basierend auf einer Vorbereitung mit Virtuellen Patienten und einem praktischen Training an Simulatoren ist ein innovativer Ansatz in der Weiterbildung von Ärzten und Pflegenden. Kernelemente des Projekts, hervorgehend aus der Bedarfsanalyse werden vorgestellt werden.

Literatur: Hunt EA, Walker AR, Shaffner DH, Miller MR, Pronovost PJ (2008): Simulation of in-hospital pediatric medical emergencies and cardiopulmonary arrests: highlighting the importance of the first 5 minutes. Pediatrics 121(1): e34-43

Hunt EA, Vera K, Diener-West M, Haggerty JA, Nelson KL, Shaffner $\mathrm{DH}$, Pronovost PJ (2009): Delays and errors in cardiopulmonary resuscitation and defibrillation by pediatric residents during simulated cardiopulmonary arrests. Resuscitation $80(7)$ : 819-25

Kern DE, Thomas PA, Howard DM, Bass EB (1998): Curriculum Development for Medical Education: A Six-Step Approach. John Hopkins University Press, Baltimore

Lehmann R, Bosse HM, Huwendiek S (2010): Blended learning using virtual patients and skills laboratory training. Med Educ, Publikation im Druck

\section{DGKJ-PV-130}

Reanimation im Kindesalter - Ausbildungsdefizit und Schulungsansatz

D. Vlajnic, R. Knies, S. Dannemann, J. Breuer

Universitätsklinik Zentrum f. Kinderheilkunde

Fragestellung: Die Reanimation im Kindesalter stellt eine besondere Herausforderung an Ärzte und Pflegekräfte dar. Die Leitlinien des European Resuscitation Council von 2005 bieten allgemeingültige und gut verständliche Algorithmen zur Wiederbelebung im Kindesalter an. Leider mangelt es weiterhin an einem flächendeckenden diktaktisch guten Schulungsangebot.

Material und Methode: Aus diesem Grunde haben wir 2008 das „Kindernotfallteam NRW“ ins Leben gerufen. Dieses Team hat als Hauptziel, für eine kontinuierliche und nachhaltige Lehre und Ausbildung in der Reanimation im Kindesalter für medizinisches Personal und Laien zu sorgen. In Zusammenarbeit mit der Hochschule BonnRhein-Sieg haben wir ein innovatives Simulationsmodul entwickelt, welches realitätsnahe Szenarien an jedem Geräte- und Monitortyp durchführbar macht. Dadurch ist es möglich, möglichst kostengünstig und flächeneckend Kurse anzubieten.

Ergebnisse: Zurzeit erhalten alle Mitarbeiter und Studenten des Klinikums der Universität Bonn kostenlos sowohl Kurse in Basismaßnahmen (4 Stunden) als auch erweiterten lebensrettenden Maßnahmen (12 Stunden). Bisher konnten 145 Personen im Zeitraum von 12 Monaten geschult werden. In einem Fragebogen zu Beginn des Kurses zeigten sich deutliche Lücken vor allem bei jungen Ärzten, insgesamt wurden von über $40 \%$ aller weniger als $60 \%$ der Fragen richtig beantwortet. Nach Absolvieren der Kurse zeigten sich die Teilnehmer deutlich sicherer im Umgang mit lebensbedrohlichen Zuständen im Kindesalter (security score 3,1 vor Beginn der Kurse vs. 2,1 unmittelbar nach den Kursen). Nach 6 Monaten sind allerdings kaum noch Kenntnisse nachweisbar und es zeigen sich in praktischen Übungen deutliche Unsicherheiten. Durch das Simulationsmodul erscheinen die Szenarien realitätsnaher und die Akzeptanz dieser steigt (score 2,3 vs. 1,8)

Schlussfolgerung: Ein regelmäßiges Training mit realitätsnahen Szenarien ist Voraussetzung für erfolgreiches Management von kindlichen Notfällen. Durch unser speziell entwickeltes Simulationsmodul ist es möglich, vielen Studenten, Ärzten und Pflegekräften kostengüns- 
tig eine realitätsnahe Übungsmöglichkeit zu bieten und den sicheren Umgang mit Kindernotfällen zu fördern.

\section{DGKJ-PV-131}

Die Körperliche Untersuchung im Kindesalter (KUK) - ein videobasiertes Lehrprojekt für Studierende und Ärzte

A. Simon, R. Lehmann, H. Bosse, M. Petersen, G. Hoffmann, S. Huwendiek Klinikum d.Ruprecht-Karl- Universität

Fragestellung: Die körperliche Untersuchung des Kindes unterscheidet sich in vielfältiger Weise von der eines Erwachsenen. Wenn Studierende am 4-wöchigen Pädiatrie-Block des Heidelberger Curriculum Medicinale (HeiCuMed) teilnehmen, ist dies oft der erste und einzige Kontakt zu pädiatrischen Patienten während der gesamten medizinischen Ausbildung. Die körperliche Untersuchung von Kindern wird hauptsächlich während des Unterrichts am Krankenbett demonstriert und selbst geübt ( 6 Lehreinheiten à $45 \mathrm{~min}$ pro Woche). Um diese kurze Zeit intensiver nutzen zu können, wurde ein videobasiertes Lehrprojekt zur besseren Vorbereitung der Studierenden auf das praktische Üben entwickelt und dessen Einsatz in einer Pilotevaluation durch Studierende bewertet.

Material \& Methoden:

20 Lehrvideos, die eine korrekte körperliche Untersuchung im Kindesalter sowie klinische Prozeduren wie Lumbalpunktion oder Neugeborenenreanimation vermitteln, wurden unter Supervision von Oberärzten unserer Klinik erstellt. Alle Videos mit dazugehörigen Checklisten sind über die Heidelberger Lernplattform online zugänglich. Den Studierenden werden diese zu Beginn des Moduls vorgestellt und zur gezielten Vorbereitung auf den Unterricht am Krankenbett empfohlen. Mittels eines papierbasierten Fragebogens werden Akzeptanz und Nutzen der Lehrvideos im Sommersemester 2010 in einer Pilotphase evaluiert.

Ergebnisse: Bisher liegt die Auswertung des ersten Moduls im Sommersemester 2010 vor $(n=35)$; die endgültige Präsentation wird die Ergebnisse der gesamten Pilotphase beinhalten ( $\mathrm{n}$ 130).

$87 \%$ der Studierenden halten die angebotenen Lehrvideos für eine hilfreiche Vorbereitung für die Durchführung der körperlichen Untersuchung am Kind, $71 \%$ fühlten sich dadurch sicherer in deren Ausübung (Prozentangaben jeweils als Summe der Zustimmung auf Likert-Skala 4 \& 5). 84\% halten die Lehrvideos für praxisnahe Beispiele zum Ablauf der kindlichen Untersuchung. 93 \% nutzten sie zur Vorbereitung auf die praktische Prüfung und halten das Angebot für eine lohnende Lernerfahrung. Die durchschnittlich vergebene Schulnote war 1,8 (in $87 \%$ Note 1 oder 2). In Freitextkommentaren wurden die Lehrvideos als sehr positives Lehrangebot begrüßt.

Diskussion: Das Angebot der Lehrvideos wurde von den Studierenden insgesamt positiv und als hilfreiche Vorbereitung auf die Durchführung der körperlichen Untersuchung im Kindesalter bewertet. Ob die Studierenden dadurch tatsächlich besser vorbereitet in den klinischen Unterricht gehen und die Zeit effektiver genutzt werden kann, werden weitere Studien klären, die sich aktuell in Vorbereitung befinden.

Eine weitere Anwendung der Videos besteht darin, diese als Instrument zur Standardisierung der Lehre der körperlichen Untersuchung zu nutzen und Dozenten zu schulen.

Schlussfolgerung: Lehrvideos zur körperlichen Untersuchung im Kindesalter wurden von den Studierenden als positiv und hilfreich bewertet. Weitere Studien befinden sich in Vorbereitung, um zu klären, inwiefern deren Einsatz tatsächlich zur verbesserten Vorbereitung der Studierenden und Standardisierung des Unterrichts führt.
DGKJ-PV-132

Veränderung von Gesundheits- und Krankheitswissen bei Vorschulkindern durch die „Teddybärklinik“

L. Badners, C. Leonhardt, J. Margraf-Stiksrud, A. Szerencsi, R. Maier

Philipps-Universität

Fragestellung: National wie auch international wird an vielen medizinischen Fakultäten von Medizinstudierenden eine sogenannte „Teddybärklinik" angeboten, um Kinder über Abläufe bei einem Arztbesuch bzw. Krankenhausaufenthalt anhand ihrer Kuscheltiere aufzuklären und Ängste vor diesen Situationen zu reduzieren (Bloch \& Tokor, 2008). Wir wollten untersuchen, ob sich das Gesundheits- und Krankheitswissen von Vorschulkindern durch den Besuch der „Teddybärklinik" verbessert.

Material und Methode: Durch einen Prä-Post-Vergleich (N=139 Kinder) wurde geprüft, ob sich durch den Besuch der „Teddybärklinik“ eine Zunahme des gesundheitsbezogenen Wissens im Vergleich zu einer Kontrollgruppe zeigte. Die Untersuchungen fanden im Abstand von drei Wochen als Gruppenbefragungen in Kindergärten statt. Als Erhebungsinstrument wurde ein selbstentwickelter Fragebogen in Bildformat in Anlehnung an Schmidt et al. (1994) sowie Ball (2004) verwendet. Das Messinstrument ist hinsichtlich seiner Reliabilität ausreichend (Cronbachs $\alpha=0,60$, Retestreliabilität $=0,83$ ). Eltern und Erzieher wurden zur Erfassung möglicher Einflussvariablen befragt. Die statistische Überprüfung der Hypothese erfolgte durch eine Kovarianzanalyse (Ausgangswerte als Kovariate).

Ergebnisse: Kinder, die die „Teddybärklinik“ besuchten, zeigten zum zweiten Messzeitpunkt ein signifikant und bedeutsam besseres Wissen zu Gesundheit und Krankheit $\left(\mathrm{p}<0,01 ; \eta^{2}=0,55\right)$ als Kinder, die nicht in der „Teddybärklinik“ waren. Insbesondere die Kenntnisse der Interventionsgruppe über das Organlagewissen im Körper waren im Vergleich zur Kontrollgruppe signifikant größer $(\mathrm{p}<0,01)$.

Diskussion: Die Ergebnisse der vorliegenden Studie beweisen eine deutliche Wirksamkeit der „Teddybärklinik Marburg" hinsichtlich einer positiven Veränderung des gesundheits- und krankheitsbezogenen Wissens. Einschränkend müssen die fehlende Randomisierung sowie die Beschränkung auf die Kurzzeitwirkung berücksichtigt werden.

Schlussfolgerung: Mit dem Konzept „Teddybärklinik“ steht ein kindgerechtes Vehikel für die Vermittlung von gesundheitsförderndem Wissen zur Verfügung. Von weiterem Interesse wäre die Langzeitwirkung der „Teddybärklinik“ hinsichtlich der Veränderung und den Auswirkungen des neu erworbenen Wissens über Krankheit und Gesundheit. Literatur: Ball J (2004) Untersuchung und Erfassung von kindlichen Krankheitskonzepten im Grundschulalter. Dissertation. Marburg: Fachbereich Psychologie.

Bloch YH \& Tokor A (2008) Doctor, is my teddy bear okay? The „Teddy Bear Hospital" as a method to reduce children's fear of hospitalization. IMAJ 10: 597-9.

Schmidt LR et al. (1994) Krankheitskonzepte von Kindern. Zeitschrift für Gesundheitspsychologie, (2) 4: 292-308.

\section{DGKJ-PV-133}

Gibt es eine Verhärtung der Herzen im Medizinstudium? Stellvertretende Empathie als Meßgröße für persönliches Engagement Studierender im heidelberger Pädiatrieblock

F. Fehr

Klinikum d.Ruprecht-Karl- Universität

Newton et. al zeigten 2008, das die stellvertretende oder nachempfundene Empathie Medizinstudierender in Abhängigkeit von Geschlecht und Facharztpräferenz im Verlauf des Studiums sinkt. Können diese Befunde für das heidelberger Medizinstudium bestätigt werden? Ist ein longitudinales studierendenzentriertes Programm wie das pädiatrische Patenschaftsprogramm PäPP dazu geeignet, diesen Trend abzuschwächen oder gar umzukehren? Wir untersuchten heidelberger Medizinstudierende unseres Programmes* und einer Kontrollgruppe 
mit der Balanced Emotional Empathie Scale (BEES) von Albert Mehrabian. PäPP ist ein freiwilliges pädiaterbegleitetes Programm, wo Studierende des 2. Studienjahres über 24 Monate ein gesundes Kind verfolgen, an Praxis- und Hausbesuchen teilnehmen und seine Entwicklung in der Familie beobachten. Über die Hälfte des Studiensemesters bewirbt sich derzeit um die Teilnahme. Im 3. Programmjahr werden je 16 Studierende zwei Interventions- bzw. Kontrollgruppen zugelost. Unsere Befunde legen nahe, daß auch in Heidelberg das Medizinstudium eine wesentliche Determinante der stellvertretenden Empathie ist, die durch Geschlecht und Facharztinteressen unterschiedlich wirksam wird. Ein Mentoren-Tutoren-Programm wie PäPP ist geeignet, Empathie zu fördern, die wiederum kritisch für gelingende ArztPatient-Beziehungen ist. ${ }^{\star}$ http: //www. egms. de/static/en/meetings/ rme20o9/ogrme19. shtml

\section{DGKJ-PV-134}

Nekrotisierende Panösophagitis bei Säureingestion mit 80 \%iger Essigessenz

P. Wöckinger, A. Harner, U. Wintergerst

KH St. Josef Braunau am Inn

Einleitung. Im deutschsprachigen Raum ist mit etwa 500 gefährlichen Ingestions-Intoxikationen und 20-40 Todesfällen bei Kindern / Jahr zu rechnen. Rund $90 \%$ aller Ingestionsunfälle betreffen Kleinkinder im Alter von 10 Monaten bis $4 \frac{1}{2}$ Jahren mit einem deutlichen Altersgipfel bei 1- $2 \frac{1}{2}$ Jahren.

Fallbericht: Wir berichten von einem 2 2/12 Jahre alten Buben, der 45 Minuten nach Ingestion einer 80\%igen handelsüblichen Essigsäureessenz in unserer Ambulanz vorgestellt wurde. Der Knabe hat die Flasche, die einen defekten Sicherheitsverschluss hatte, aus dem Küchenregal genommen und wenige Tropfen in den Mund geträufelt und geschluckt.

Bei Aufnahme war der Bub in gutem AZ. Keine Hypersalivation, keine Verätzungszeichen im Mund und Rachenbereich. Es wird nach Legen einer Venenverweilkanüle Prednisolon $2 \mathrm{mg} / \mathrm{kg} \mathrm{KG} \mathrm{Omeprazol} 2 \mathrm{mg} /$ $\mathrm{kg} \mathrm{KG}$ in je zwei ED verabreicht, sowie eine antibiotische Therapie mit Cefuroxim 10omg / kg KG, parenterale Ernährung und orale Nahrungskarenz.

In der Ösophagogastroduodenoskopie zeigten sich schon beginnend am oberen Ösophagussphinkter massive fibrinartige Nekrosen mit spontan abschilfernden Membranen (Gradeinteilung nach Miller et al. 1993 IIb). Auch die Magenschleimhaut zeigt eine diffuse hochgradige Rötung, aber ohne erosive oder ulcerative Veränderungen. Die parenterale Ernährung wurde weitergeführt und am 5 . Tag erfolgte eine Kontroll ÖGD mit Legen einer Duodenalsonde . Hier zeigte sich eine Befundbesserung, aber dennoch Nekrosen mit Fibrinbelägen über den gesamten Ösophagus. Der Bub wurde dann 9 Tage aussschliesslich über die Sonde ernährt und die Therapie mit Prednisolon, Omeprazol und Antibiotika fortgeführt. Bei Husten erfolgte ein Thoraxröntgen ohne Hinweis für Infitration oder Aspiration.

Bei der Kontroll-ÖGD am 10. Tag waren die Schleimhautläsionen im oberen und unteren Ösophagusdrittel weitgehend ohne Strikturen abgeheilt, im mittleren Ösophagusdrittel noch Fibrinbeläge ohne tiefe Ulcerationen. Am 25. Tag waren die Läsionen vollständig ohne narbige Strikturen abgeheilt und epitheliasiert,.

Prednisolon wurde reduziert und nach 1 Monat zusammen mit Omeprazol abgesetzt.

Diskussion und Schlussfolgerung: Die anamnestisch erhobene Menge der ingestierten Menge und der gute Allgemeinzustand standen im Gegensatz zum Ausprägungsgrad der Verätzung. d. h auch wenn die Indikation zur ÖGD den Literaturangaben nach bei scheinbar asymptomatischem Kind großzügig gestellt war, so legt der Fall doch nahe, welch ausgeprägte und therapierelevante Veränderungen bei Ingestion von $80 \%$ Essigessenz auftreten können.

Eltern mögen sich fragen, ob eine $80 \%$ ige Essigessenz im Haushalt wirklich nötig ist.
Literatur: 1. Von Schweinitz, Ure, Kinderchirurgie, Springer Medizin Verlag 2009

2. Muehlendahl, Vergiftungen im Kindesalter, 4. Auflage Thieme Ver$\operatorname{lag} 2003$

3. Gupta et al.. Is Esophagogastroduodenoscopy Necessary in all Caustic Ingestions?

JPGN 2001: 4. Marsha Kay and Robert Wyllie, Caustic ingestions in Children, Current Opinion in Pediatrics

\section{DGKJ-PV-135}

Arteria-spinalis-anterior-Syndrom eines Jugendlichen nach Verletzung im Taekwondo-Kampf: Ein Fallbericht

H. Meinicke' ${ }^{1}$, O. Moske-Eick², A. Letzgus' ${ }^{1}$ B. Zieger' ${ }^{1}$ J. Kirschner'

${ }^{1}$ Universitäts - Kinderklinik, ${ }^{2}$ Universitätsklink

Ein akuter Querschnitt durch ein Arteria-spinalis-anterior-Syndrom (ASAS) ist bei Kindern und Jugendlichen eine seltene aber schwerwiegende Diagnose, die durch eine akkurate klinisch-neurologische Untersuchung und typische MRT-Befunde gestellt werden kann. Das ASAS umfasst folgende Symptome: Plötzliches Einsetzen von Schmerz und schlaffer Para- oder Tetraparese, Verlust der Blasenkontrolle und eine dissoziierte Sensibilitätsstörung mit einer Beeinträchtigung des Schmerz- und Temperaturempfindens bei erhaltener Tiefensensibilität. Anamnese: Wir stellen den Fall eines 13-jährigen Jungen vor, der sich in unserer Ambulanz mit eingeschränkter Gehfähigkeit vorstellte. Anfangs hatte er ein Wärmegefühl im Rücken verspürt, welches in die Beine hinabwanderte. Gleichzeitig entwickelte sich eine progressive Schwäche der Beine. Eine Woche zuvor hatte sich der Leistungssportler bei einer Taekwondo-Meisterschaft eine schwere Zerrung bei einer Drehtrittbewegung zugezogen, erholte sich aber zunächst rasch. Die Eigen- und Familienanamnese zeigte keine Auffälligkeiten, insbesondere keine Thrombophilieneigung, Schlaganfälle, KHK oder Hämorrhagische Diathese.

Klinische Untersuchung: Es fieleneine schlaffe Paraparese mit reduzierten Muskeleigenreflexen und Analgesie und Thermanästhesie der unteren Extremitäten auf, wohingegen Berührung und Vibrationsempfinden intakt waren. Pädiatrisch-internistischer und übriger neurologischer Befund unauffällig.

Diagnostik: In der Laboruntersuchung waren das Blutbild, alle klinisch-chemischen, immunologischen und infektiologischen Marker sowie der Liquorbefund unauffällig. Dahingegen zeigte die Gerinnungsanalyse erhöhte Werte für von-Willebrand-Faktor, RistocetinCo-Faktor und D-Dimere.

Bildgebung: Das MRT der Wirbelsäule am Aufnahmetag war unauffällig, womit ein Tumor, eine Blutung oder ein Bandscheibenvorfall ausgeschlossen werden konnten. Im MRT zwei Tage später zeigten sich jedoch in den thorakalen Schnitten eine erhöhte Signalintensität im ventralen Bereich des Rückenmarks, vereinbar mit Ischämie nach ASAS.

Die Therapie umfasste die Anlage eines suprapubischen Blasenkatheters, eine Antikoagulation mit niedermolekularem Heparin sowie den raschen Transfer in eine Rehabilitationsklinik, wo der Patient mit multipler physikalischer Therapie beübt wurde.

Verlauf: Nach fünf Monaten konnte der Patient etwas unsicher ohne Gehhilfe gehen. Bei voller Blasenkontrolle wurde der suprapubische Blasenkatheter entfernt.

Diskussion: Nach Ausschluss bekannter Risikofaktoren sehen wir die Ätiologie für das ASAS des Jungen in der Verletzung beim Taekwondo-Kampf. Diese Zerrung könnte die Intima der Aorta am Abgang der Adamkiewicz-Arterie, einer der Hauptversorgungsäste der Spinalarterie, oder der Arteria spinalis anterior direkt verletzt haben. Wahrscheinlich hat ein wachsender Thrombus die Arterie innerhalb einer Woche verschlossen und die Blutzufuhr unterbrochen. Dieser Fall eines akuten Querschnitts unterstreicht die Wichtigkeit einer aufmerksamen körperlich-neurologischen Untersuchung und sorgfältigen Anamnese sowie der raschen bildgebenden und Gerinnungsdiagnostik mit konsekutivem Transfer in eine spezialisierte Rehabilitationseinrichtung. 
DGKJ-PV-136

Hypoglykämie nach Intoxikation mit retardiertem Metoprolol bei

\section{Kleinkind}

K. Schuster, U. Stedtler, M. Hermanns-Clausen

Vergiftungs-Informations-Zentrale

Einleitung: Medikamentenintoxikationen gehören zu den häufigen Pathologien im Kindes- und Jugendalter. Metoprolol ist ein kardiospezifischer Beta-1-selektiver Adrenozeptorantagonist, der besonders zur Therapie arterieller Hypertonie, KHK und chronischer Herzinsuffizienz angewendet wird. Leitsymptome einer Vergiftung mit Betablockern sind in der Regel Blutdruckabfall und Bradykardien. Vor allem bei Kleinkindern kann sich jedoch bereits bei einer niedrigen, eventuell sogar noch therapeutischen Dosis auch Stunden später noch eine symptomatische Hypoglykämie entwickeln.

Fallbericht: Der 20 Monate alte Junge habe mittags an einer Tablette Metohexal succ. $190 \mathrm{mg}$ der Großeltern gelutscht. Diese konnten nach eigenen Angaben einen kleinen Teil der Tablette wieder aus dem Mund entfernen. Etwa acht Stunden später fiel der Mutter erstmals Kaltschweißigkeit und Zittern der Extremitäten auf. Auf Anraten des befragten Giftnotrufs ließ sie den Jungen ein Stück Zucker lutschen und stellte ihn in einer Kinderklinik zur Überwachung vor. Der Blutzucker betrug kurz nach Zuckerzufuhr 107 mg/dl. Das Kind erhielt nochmals Kohlenhydrate; im Anschluss wurde wiederum ein unauffälliger Blutzucker gemessen. Mit dem Hinweis, dem Jungen weiterhin regelmäßig Kohlenhydrate zuzuführen, erfolgte die Entlassung nach Hause. In der Nacht wurde die Mutter insgesamt viermal durch erneutes Zittern des Kindes geweckt. Nach eigenen Angaben ließ sie ihren Sohn jeweils ein bis zwei Zuckerstücke lutschen bis das Zittern nachließ. Am nächsten Morgen erfolgte die Vorstellung beim Hausarzt, wo sich der kleine Patient zwar müde und leicht weinerlich, aber in insgesamt gutem AZ präsentierte. Tagsüber erhielt er Kohlenhydrate in kleinen Zwischenmahlzeiten. Die letzte Mahlzeit erfolgte in Form eines „Mitternachtsimbisses" am Folgeabend, da er fünf Stunden nach dem Abendessen erneut unruhig wurde. Im späteren Verlauf traten keine weiteren Ereignisse auf.

Diskussion: Eine zeitnahe Gabe von Aktivkohle hätte die klinische Symptomatik unter Umständen weitgehend verhindern können. Nach Ingestion von Betablockern in einer toxischen Dosis wird bei Kleinkindern eine Überwachung von acht Stunden post ingestionem oder aber bis zum Abklingen von Symptomen angeraten. Die Wirkdauer einer Retardtablette Metoprolol kann allerdings durch Nachresorption bis zu 24 Stunden betragen. Symptome einer Hypoglykämie können dabei analog zum Erwachsenen

teilweise durch Betablockade maskiert sein.

Typisch für Retardpräparate ist zudem ein symptomfreies Intervall, das die Diagnose einer solchen Vergiftung initial verkompliziert. Therapeutisch steht eine regelmäßige Kohlenhydratzufuhr im Vordergrund, welche sich jedoch nachts schwierig gestalten kann.

Schlussfolgerung: Dieser Fall illustriert, dass eine 24-stündige Überwachung von Kleinkindern nach Intoxikation mit einer relevanten Menge Betablockern in Retardform, vor allem bei Symptomentwicklung, dringend anzuraten ist.

\section{DGKJ-PV-137}

5 Jahre Erfahrung mit der Ponseti Methode bei der Behandlung kongenitaler Klumpfüße

J. Funk', S. Lebek'2 R. Placzek'

${ }^{1}$ Charité - Universitätsmedizin Berlin, ${ }^{2}$ Universitätsklinik und Poliklinik für Orthopädie

Obwohl die Behandlungsmethode nach Ponseti seit einem halben Jahrhundert etabliert ist, dauerte es bis zum Beginn dieses Jahrtausends bis zur Einführung in Deutschland. Heute ist diese Methode der Goldstandard für die initiale Behandlung aller Klumpfüße ungeachtet ihrer Ätiopathogenese. Die in den letzten 5 Jahren behandelten Fälle wurden hinsichtlich des Behandlungsergebnisses unter besonderer Berück- sichtigung zugrunde liegender Erkrankungen und der Compliance der Eltern untersucht.

Von 2004 bis 2009 wurden 67 Kinder mit 106 Klumpfüßen behandelt. 15 dieser 67 Kinder mit 26 betroffenen Füßen litten an Grunderkrankungen, die mit Klumpfußdeformitäten einhergehen, wie Spina bifida $(n=3)$, Arthrogrypose $(n=2)$, DiGeorge Syndrom $(n=2)$ und anderen syndromalen Komplexen ( $n=8)$. 4 Patienten mit 6 betroffenen Füßen zeigten komplexe Klumpfußdeformitäten und wurden entsprechend therapiert. Die Behandlung wurde bei allen außer 6 Patienten innerhalb der ersten 2 Wochen nach der Geburt begonnen. Gipswechsel wurden wöchentlich durchgeführt. Für alle Patienten wurde die gleiche Abduktionsschiene mindestens bis zum 3. Lebensjahr verwendet. Rezidive wurden ebenfalls nach Ponseti behandelt.

Das durchschnittliche Follow-up betrug 35 (8-61) Monate. Nach Beendigung der Gipsredression waren alle Füße abgesehen von der Dorsalextension vollständig korrigiert. Eine perkutane Achillotenotomie wurde bei allen Kindern außer einem (98\%), die an idiopathischen Klumpfüßen litten, durchgeführt. Bei den komplexen Klumpfüßen erfolgte die Achillotenotomie immer. Bei 2 Patienten (13\%) mit sekundären Klumpfüßen konnte aufgrund der Schwere der Erkrankung keine Achillotenotomie erfolgen.

Das Behandlungsergebnis ist hochgradig abhängig von der Compliance der Eltern bezüglich der Abduktionsschiene. 4 der Patienten (8\%) mit idiopathischen Klumpfüßen benötigten eine Revision während des Nachuntersuchungszeitraumes. Bei 3 dieser Patienten war die Compliance der Eltern schlecht. Laufbeginn war bei allen ansonsten gesunden Patienten innerhalb der normalen 8 bis 18 Monate. Einer der Patienten mit komplexem Klumpfuß (25\%) und 2 Patienten mit Grunderkrankungen (13\%) mußten im operativ revidiert werden. Bei einem Spina bifida Patienten traten rezidivierend Hautprobleme sowohl in der Schiene als auch im Gips auf. Ein Patient mit DiGeorge Syndrom weigerte sich, seine Schiene zu tragen.

Gemäß dem Ponseti-Konzept benötigten 2 der Patienten mit idiopathischen Klumpfüßen eine Achillessehnenverlängerung allein und 2 Patienten eine zusätzliche Tibialis-anterior-Sehnen-Verlagerung. Bei der Revision des komplexen Klumpfußes wurde neben der perkutanen Achillessehnenverlängerung zusätzlich ein Plantarfaszienrelease durchgeführt. Bei den Patienten mit sekundären Klumpfüßen waren dorsomediale Release Operationen mit offener Achillessehnenverlängerung und partiellem Kapselrelease notwendig.

Zusammenfassend ist zu sagen, dass initial alle Klumpfüße unabhängig ihrer Ätiopathogenese nach dem Ponseti-Konzept behandelt werden sollten, da sich damit gute funktionelle Ergebnisse erzielen lassen. Die wesentlichste Voraussetzung für den langfristigen Erhalt des guten Ergebnisses ist die Compliance bei der Abduktionsbehandlung. Bei Patienten mit sekundären Klumpfüßen als Folge von Grunderkrankungen läßt sich durch Ponseti-Behandlung das Ausmaß der notwendigen operativen Therapie reduzieren.

\section{DGKJ-PV-138}

Inzidenz und Follow up pathologischer Hüftbefunde im Rahmen der SNiP Studie.

A. Lange ${ }^{1}$, A. Hagenguth ${ }^{2}$, R. Thyrian ${ }^{3}$, H. Merk ${ }^{4}$, W. Hoffmann ${ }^{3}$, H. Lode', J. Haas $^{5}$

${ }^{1}$ Ernst-Moritz-Arndt Universität, ${ }^{2}$ Städtisches Krankenhaus, ${ }^{3}$ CommunityMedicine, ${ }^{4}$ Orthopädie und Wiederherstellungschirurgie der EMAU-Greifswald, ${ }^{5}$ Kinderklinik und Rheuma-Kinderklinik der Rummelsberger Anstalten

Fragestellung: Erhebung der Inzidenz von Hüftgelenksdysplasien im Rahmen der $\mathrm{U}_{2}$ Untersuchung in der SNiP Kohorte.

Material und Methoden: Im Rahmen der populationsbasierten Neugeborenenstudie "Surveillance of Neonates in Pommerania (SNiP)" sind 4039 Neugeborene eingeschlossen. Davon erhielten 2534 Kinder einen Hüftgelenksultraschall im Rahmen der U2 (61,9\%). Das mittlere Gestationsalter lag bei 38,9 SSW, bei Frühgeborenen 32,7 SSW $(n=376)$. Bei 69,9\% der Frühgeborenen erfolgte der Hüftgelenksultraschall im korrigierten Alter von 4-5 Tagen und die sonografische Einteilung wurde 
nach Graf vorgenommen. Die prädiktive Aussage der pathologischen Hüftgelenksbefunde, wurde durch Fragebögen bei den niedergelassenen Kinderärzten erhoben.

Ergebnisse: Initial fanden sich bei 1,66\% $(\mathrm{N}=24)$ ein therapiebedürftiger Befund ( $\geq$ IIc nach Graf). Davon war bei 18 Kindern ein beidseitiger Befund zu erheben. Die Analyse der Geschlechtsverteilung zeigte ein signifikant gehäuftes auftreten bei Mädchen (32 vs. $10 \mathrm{p}<0,023$; $\mathrm{X}^{2}$ Test). In der Gruppe der Frühgeborenen hatten nur 3 Kinder (o,8\%) eine Hüftgelenksdysplasie. Die Betrachtung der betroffenen Seite ergab keine signifikanten Unterschiede (rechts $1,14 \%$ vs. links $1,22 \%, P>0,1$ ). Erwartungsgemäß zeigten aus Beckenendlage entbundene Kinder mit 4,6\% eine signifikante Häufung gegenüber Neugeborenen aus Schädellagen $(1,4 \%)$. Insgesamt war bei 7,14\% der Kinder eine familiäre Prädisposition festzustellen.

Im follow up konnten insgesamt 918 von 1100 Fragebögen ausgewertet werden. Bei $48,3 \%$ der Kinder erfolgte ein Hüftsonografie im Rahmen der U2, $96 \%$ bei der $U_{3}$. Die Kinder ließen sich in zwei Gruppen einteilen: (1.) Kinder die sowohl einen Hüftgelenksultraschall im Rahmen der $\mathrm{U}_{2}$ und $\mathrm{U}_{3}$ erhalten hatten, und (2.) Kinder mit Erstuntersuchung bei $U_{3} .13$ Kinder hatten hier noch einen pathologischen Hüftgelenksbefund vom Typ IIC und höher. Von diesen 13 Kindern hatten 7 einen Hüftgelenksultraschall im Rahmen der U2 erhalten. Diese Kinder wurden mit einer Tübingerschiene versorgt. Von den 7 Kindern hatten noch 2 Kinder einen pathologischen Hüftgelenksbefund bei der $\mathrm{U}_{3} .5$ Kinder waren somit innerhalb von 4-6 Wochen erfolgreich therapiert worden.

Schlussfolgerung: Therapiebedürftige Hüftgelenksdysplasien weisen eine statistisch signifikante Häufung beim weiblichen Geschlecht auf. Der frühzeitige Nachweis ermöglicht einen früheren Therapiebeginn als eine Befundung erst bei der $\mathrm{U}_{3}$. Da zur Zeit jedoch nur knapp 60\% der Kinder im Rahmen der U2 untersucht werden, kann keine Aussage über die Inzidenz erfolgen. Eine Untersuchung zum Zeitpunkt $\mathrm{U}_{2}$ würde sicherlich die Untersuchungsrate steigern. Inwieweit sich eine substanzielle Verbesserung der Therapieerfolge ergibt müßte eine prospektive Untersuchung klären.

\section{DGKJ-PV-139}

Intraabdominelle Hypertonie und Abdominelles Kompartmensyndrom im Kindesalter - ein Literaturüberblick

T. Kaussen ${ }^{1}$, M. Sasse ${ }^{2}$, F. Staudt ${ }^{1}$, G. Steinau ${ }^{3}$, A. Schachtrupp ${ }^{3}$

${ }^{1}$ Kinderklinik Dritter Orden, ${ }^{2}$ Kinderkardiologie und Päd. Intensivmedizin, Universitätskinderklinik der MHH Hannover, ${ }^{3}$ Chirurgische Uni- und Poliklinik, Universitätsklinikum der RWTH Aachen

Hintergrund: Intraabdominelle Hypertonie (IAH) und Abdominelles Kompartmentsyndrom (AKS) sind in der Pädiatrie seltene (Inzidenz o,1-15\%), aber fatale Entitäten mit einer Mortalität von über $60 \%$. Im Erwachsenenalter haben sie sich als unabhängige Prädiktoren für das Entstehen von MOV und Sepsis erwiesen. Altersabhängig herrscht im Neugeborenen- und Säuglingsalter das primäre AKS vor (Urs.: Gastroschisis, Omphalozele, NEC, Darmperforation/ -ileus, Tumor, Transplantation), im Kindesalter findet sich dagegen eher das sekundäre AKS (Urs.: Verbrennung, Trauma, Sepsis, Schock). Bis heute ist unklar, ob die von der WSACS veröffentlichen Definitionen und Empfehlungen auch für das Kindesalter gelten (www. wsacs. org).

Fragestellung: Erhebung der in der gängigen Literatur verfügbaren Datenlage zu Inzidenz, Outcome, Messverfahren und -verhalten, pädiatrischen Grenzwerten für intraabdominellen Druck (IAD), Therapieindikationen und -möglichkeiten samt zugehörigen Evidenzgraden im Kindesalter

Material und Methode: Eine PubMed-Analyse der Suchbegriffe „Abdominal Compartment Syndrome + Children“ ergab 81 Treffer, von denen 67 Artikel auf das AKS bezogen waren (32 Case-Reports, 10 retrospektive Studien, 9 prospektive, nicht-randomisierte Arbeiten sowie Reviews). Anhand der zugehörigen Literaturverzeichnisse wurden zusätzlich 25 relevante Studien und Veröffentlichungen eingeschlossen.
Ergebnisse und Diskussion: Im klinischen Alltag scheint die Diagnosestellung eher auf Beobachtungen als auf der Anwendung spezifischer, IAD-bezogener Definitionen zu beruhen. Mit abnehmendem Alter und zunehmender Unreife sinkt die Bereitschaft, relativ invasive Druckmessmethoden wie die Blasendruckmessung durchzuführen. Peritonealdialysekatheter werden als Druckaufnehmer verwendet, sofern sie ohnehin vorhanden sind. Die intragastrale Messung erfolgt nur sehr selten. Die dekompressive Laparotomie mit temporärem Bauchdeckenverschluss gilt als Standard. Eine zusätzliche Behandlungsoption stellt die Punktion und Drainage von Flüssigkeit dar.

Die von der WSACS definierte druckabhängige Stadieneinteilung der IAH ist nicht auf das Kind übertragbar, denn der Übergang in ein AKS bei Kindern bereits bei einem IAD von 10-15 $\mathrm{mmHg}$ beobachtet wird. Schlussfolgerung: IAH und ACS werden bei Kindern zu wenig beachtet. Studien sind dringend notwendig, um eine altersadaptierte Einteilung intraabdomineller Druckverhältnisse und daraus ableitbarer Therapieschemata für das Kindesalter zu erhalten. V. a. in Risikogruppen sollte die IAH-Diagnostik durch IAD-Messungen objektiviert werden.

\section{DGKJ-PV-140}

Innerhalb von nur $6 \mathrm{~h}$ verursacht eine Intraabdominelle Hypertonie (IAH) histologisch nachweisbare Organschäden

T. Kaussen', J. Otto ${ }^{2}$, M. Afify ${ }^{3}$, R. Tolba ${ }^{3}$, A. Schachtrupp ${ }^{2}$

${ }^{1}$ Kinderklinik Dritter Orden, ${ }^{2}$ Chirurgische Uni- und Poliklinik, Universitätsklinikum Aachen, ${ }^{3}$ Insitut für Versuchstierkunde am Universitätsklinikum Aachen

Hintergrund: Bauchdeckenerweiterungsplastiken zur Revision bei Omphalozelen und Gastroschisis sind Paradebeispiele einer adäquaten Therapie bei Intraabdomineller Hypertonie (IAH) und Abdominellem Kompartmentsyndrom (AKS) und haben zu einer Mortalitätsreduktion von 80 auf $10 \%$ geführt. Andere in der pädiatrischen Intensivmedizin typische Krankheitsbilder wie NEC, Verbrennung, Trauma, Sepsis und Schock können gleichermaßen zu IAH führen, frühzeitige Dekompressionen sind in Bezug auf diese Entitäten aber weiterhin die Ausnahme. In Vorstudien konnte herausgefunden werden, dass in einem porcinen Modell des AKS eine Druckbelastung von über $18 \mathrm{~h} \mathrm{zu}$ mittelbis hochgradigen Organschäden führt, selbst wenn durch intensivierte Volumentherapie das Cardiac Output (CO) aufrecht erhalten wird und infolge dessen klinische "Kardinalsymptome“ eines AKS wie Oligurie bzw. Anurie vermieden werden.

Zielsetzung: Führt eine intraabdominelle Druckbelastung über 6 bzw. $12 \mathrm{~h}$ bei Aufrechterhaltung des $\mathrm{CO}$ zu histomorphologischen Schäden? Material und Methodik: 16 männliche Schweine (5okg, SD 3. 8) wurden mittels Ketamin und Pentobarbital analgosediert und volumenkontrolliert ventiliert. Mittels $\mathrm{CO}_{2}$-Pneumoperitoneum wurde der intraabdominelle Druck (IAD) über 6 bzw. 12h (je $\mathrm{n}=6$ ) auf $30 \mathrm{mmHg}$ erhöht. In der Kontrollgruppe $(n=4)$ blieb der IAD unverändert (3. $9 \mathrm{mmHg}$, SD 5. 4). Kontinuierlich wurden Herzfrequenz (HF), mittlerer arterieller Druck (MAD), Zentralvenendruck (ZVD), CO und Beatmungsspitzendruck (PIP) registriert. Zusätzlich zum Flüssigkeitserhalt $(2 \mathrm{ml} / \mathrm{kg} / \mathrm{h})$ wurde den Prüftieren bedarfsadaptiert Ringer-Lösung infundiert, so daß das $\mathrm{CO}$ auf dem Level der Kontrolltiere verblieb. Am Versuchsende wurden die Tiere durch eine Überdosis Pentobarbital euthanasiert und sektioniert. Gewebeschäden an Lunge, Herz, Nieren, Leber und Magen wurden quantifiziert als kein, gering-, mittel- oder hochgradig. Darm-Proben wurden nach der Park-Klassifikation beurteilt. Die statistische Auswertung erfolgte mittels ANOVA mit post-hoc-Analyse bzw. gepaarten t-Tests. Die Signifikanzgrenze wurde mit $\mathrm{p}<0.05$ festgelegt und im Falle multipler gepaarter Tests nach Bonferroni angehoben.

Ergebnis: ZVD und PIP stiegen signifikant an, während die übrigen hämodynamischen Parameter stabil blieben. Im Vergleich zur Kontrollgruppe fanden sich in beiden Prüfgruppen signifikante Schäden an Lunge, Nieren, Leber, Magen (nur 12h-Gruppe) und Darm. Lediglich das Myokard zeigte keine relevanten Läsionen. 
Schlussfolgerung: Eine nur kurzfristige IAD-Erhöhung über $6 \mathrm{~h}$ führt zu histologischen Organschäden, selbst wenn durch intensivierte Volumentherapie das CO aufrecht erhalten wird. Für den klinischen Alltag implementieren diese Ergebnisse die Notwendigkeit einer schnellstmöglichen Dekompression bei Vorliegen eines kritisch erhöhten IAD.

\section{Neonatologie III und Kardiologie}

\section{DGKJ-PV-141}

\section{Cutis marmorata teleangiektasia congenita}

N. Lazer, T. Paul, S. Seeliger

Universitäts- Kinderklinik

Einleitung: Cutis marmorata teleangiektasia congenita (CMTC) ist eine seltene, meist angeborene netzartig angeordnete, livide Hautverfärbung mit Teleangiektasien und Phlebektasien, die 1922 durch die niederländische Kinderärztin C. van Lohuizen erstbeschrieben wurde. Histopathologisch zeigen sich erweiterte dermale Kapillaren und subkutane Venen sowie eine erhöhte Gesamtzahl der Blutgefäße in den Hautschichten.

CMTC kann mit Anomalien vergesellschaftet sein, die die weitere Prognose bestimmen. In der Literatur wurden bis heute ungefähr 300 Fälle publiziert, wobei gerade die aktuellen Fallbeschreibungen häufig Assoziationen mit noch unbekannten Anomalien beschreiben. Patienten ohne weitere Assoziationen anderer Organsysteme werden eher selten veröffentlicht.

Fallbericht: Bei unserem Patienten handelt es sich um ein Reifgeborenes gesunder Eltern mit unauffälliger postnataler Anpassung, welches schon seit Geburt livide Marmorierungen v. a. der unteren Extremität und einzelner Areale am Rücken aufwies. Unsere durchgeführte Diagnostik mit körperlicher Untersuchung, Labor, EKG, ECHO, Schädelsonographie, Dopplersonographie der großen Gefäße, Augenarztkonsil, Neuropädiatrisches Konsil blieb unauffällig. Nebenbefundlich fand sich lediglich eine kleine Ohrfistel rechts. Die in der Literatur beschrieben Differentialdiagnosen, wie physiologische Cutis marmorata congenita, kongenitale Livedo, diffuse genuine Phlebektasie, Ataxia teleangiektasia Hereditäre, hämorrhagische Teleangieektasie, Phakomatosen sowie Lupus erythematodes konnten ausgeschlossen werden, so dass die Diagnose einer CMTC ohne assoziierte Anomalien gestellt wurde. Eine spezifische Therapie gibt es nicht. Empfehlungen sind engmaschige Kontrollen durch den Kinderarzt, Kälteschutz und ggf. erneute Untersuchungen.

Diskussion: Die CMTC stellt eine insgesamt seltene Erkrankung und ohne assoziierte Anomalien eine harmlose Erkrankung dar. Mögliche Differentialdiagnosen müssen aber ausgeschlossen werden, da hier ggf. eine kausale Therapie erforderlich ist. Über einen teilweisen Rückgang der Hautveränderungen bei CMTC in den ersten Lebensjahren wird bei über 50\% der Patienten berichtet, nur einigen Patienten leiden unter einem persistierenden Residualsymptom.

\section{DGKJ-PV-142}

Angeborene Herzfehler- aktuelle Prävalenzdaten 2000-2009 des Fehlbildungsmonitoring Sachsen-Anhalt und Management in einer ausgewählten Geburtsklinik

J. Hoyer-Schuschke', S. Pötzsch², D. Bretschneider', J. Karstedt³ , A. Rißmann ${ }^{4}$ ${ }^{1}$ Klinik St. Marienstift, ${ }^{2}$ Vogtland-Klinikum Plauen $\mathrm{GmbH},{ }^{3}$ Kinderkardiologische Praxis, ${ }^{4}$ Med. Fakultät der Otto-von-Guericke Universität

Einleitung: Angeborene Fehlbildungen des Herzens gehören zu den häufigsten Fehlbildungen im Neugeborenenalter. Im Fehlbildungsmonitoring Sachsen-Anhalt werden alle bei Neugeborenen beobachteten Fehlbildungen des Herzens zentral erfasst. Anhand der Prävalenzdaten kann das notwendige Management zur sicheren Detektierung für angeborene Fehlbildungen des Herzens an einer Geburtsklinik ohne angeschlossene Kinderklinik überprüft werden.
Methode: Zur Auswertung kamen die im Zeitraum 2000-2009 im Fehlbildungsmonitoring Sachsen-Anhalt eingegangenen Meldungen $\mathrm{zu}$ angeborenen Fehlbildungen des Herzens. Dabei wurde insbesondere auch nach kritischen Herzfehlern differenziert. Weiterhin erfolgte die Analyse der Daten bezogen auf die Geburtsklinik St. Marienstift und die von den Ärzten in dieser Klinik detektierten und registrierten Neugeborenen mit angeborenen Herzfehlern. In der Klinik erfolgte ab 2005 bei den Neugeborenen am ersten Lebenstag zusätzlich ein Pulsoximetriescreening. Retrospektiv wurden die Ergebnisseder Pulsoximetrie bei einem cutt off $<92 \%$ hinsichtlich ihrer Sensitivität und Spezifität für einen kritischen Herzfehler analysiert.

Ergebnisse: Die Auswertung aller Neugeborenen mit angeborenen Herzfehlern in Sachsen-Anhalt im angegeben Zeitraum ergab eine Prävalenz von 144 Pro 10. ooo Geborene. In der Magdeburger Geburtsklinik St. Marienstift wurden in den Jahren 2000-2009 im Mittel bei 1,5\% der Neugeborenen postnatal ein Herzfehler diagnostiziert. Ab 2005 konnten 95\% (2807) der Geborenen in dieser Klinik am ersten Lebenstag eine Pulsoximetrie erhalten. Dabei war die Pulsoximetrie bei allen Kindern, bei denen ein kritisches Vitium zu diagnostizieren war, positiv, die Sensitivität betrug $100 \%$. Allerdings lag die Spezifität nur bei 98\%. D. h. ein Pulsoximetriescreening allein kann nicht die klinische Beurteilung durch einenKinderarzt oder regelmäßige Beobachtung durch erfahrenes Pflegepersonal ersetzen. Es zeigt sich dass ein pränatal unauffälliger Ultraschallbefund nicht gleichbedeutend mit dem Ausschluss eines auch kritischen Herzfehlers ist. Dahingegen bietet die Routine Pulsoximetrie aber eine sichere ergänzende Methode zur Frühdiagnose eines kritischen Herzfehlers.

Schlussfolgerung: Besonders auf Wochenstationen mit 24-Stunden Rooming-In ist es wichtig, das Management zur Erkennung von angeborenen Herzfehlern, insbesondere kritischen Herzfehlern, beim Neugeborenen zu optimieren.

\section{DGKJ-PV-143}

Prävalenzanalyse chronischer Erkrankungen bei gebärfähigen Frauen, sowie deren Outcome während der Schwangerschaft anhand der SNiP-Studie

A. Lange ${ }^{1}$, I. Kersten ${ }^{1}$, R. Thyrian ${ }^{2}$, W. Hoffmann ${ }^{2}$, H. Lode ${ }^{1}$

${ }^{1}$ Ernst-Moritz-Arndt Universität, ${ }^{2}$ Community-Medicine

Einleitung und Methode: Neben akut auftretenden Krankheiten können chronische Erkrankungen den Verlauf einer Schwangerschaft beeinflussen und zeigen Effekte bis hin zur Geburt. Im Rahmen der populationsbasierten Neugeborenenstudie „Surveillance of Neonates in Pommerania (SNiP) untersuchten wir 5330 Frauen hinsichtlich Prävalenz chronischer Erkrankungen in Relation zum Geburtsoutcome.

Ergebnisse: Populationsbasiert wurden $n=1141$ Frauen als chronisch krank identifiziert $(21,4 \%)$ gegenüber $\mathrm{n}=4189$ nicht chronisch kranker Frauen (78,6\%). Am häufigsten traten Allergien (11,3\%), Asthma bronchiale $(2,7 \%)$ und Schilddrüsenerkrankungen $(2,3 \%)$ auf. Weiterhin zeigten Hauterkrankungen $(2,2 \%)$, Hypertonien $(1,1 \%)$ und Migräne $(1,5 \%)$ hohe Prävalenzen. Die Fertilität war in der chronisch kranken Gruppe nicht herabgesetzt, allerdings lagen diese Frauen im Verlauf ihrer Schwangerschaft im Durchschnitt zwei Tage länger stationär $(\mathrm{p}<\mathrm{o}, \mathrm{o1})$. Der Hauptgeburtsmodus war in beiden Gruppen die Spontangeburt. Chronisch kranke Frauen wurden jedoch signifikant häufiger per Sectio entbunden $(\mathrm{p}<0,01)$, erhielten signifikant häufiger eine Lungenreifeinduktion $(\mathrm{p}<\mathrm{0}, \mathrm{01})$ und jede 10. Frau brachte ein frühgeborenes Kind $(<37$. SSW) zur Welt im Gegensatz zu nicht chronisch kranken Frauen (jede 13.; p<0,05). Kinder chronisch kranker Frauen waren daher signifikant kleiner bezüglich Körperlänge und Kopfumfang und mussten häufiger stationär aufgenommen werden $(\mathrm{p}<0,01)$.

Dagegen traten Infektionen und vaginale Blutungen während der Schwangerschaft signifikant häufiger in der gesunden Gruppe auf $(\mathrm{p}<0,05)$.

Schlussfolgerung: Die vorliegende Analyse ist die erste populationsbasierte Studie, in der die Prävalenzen aller auftretenden chronischen Erkrankungen erfasst wurden und stellt somit eine wichtige epidemio- 
logische Grundlage an einer einzigartigen Kohorte im Studiengebiet Ostvorpommerns dar.

\section{DGKJ-PV-144}

Kardiale Manifestationen bei Lyme Borreliose

R. Eyermann

Dr. Richard Eyermann

Neben einer Vielzahl unterschiedlicher viraler Erreger sind bakterielle Infektionen für die Entwicklung einer Myokarditis von Bedeutung. Dies gilt vor allem für Borrelia burgdorferi, dem Erreger der Lyme-Karditis, der durch Zecken übertragen wird. Eine kardiale Beteiligung entwickelt sich bei ca. 10\% der Patienten während der ersten drei Monate nach Infektion mit oder ohne vorausgehendem Erythema chronicum migrans im Stadium 2. Eine Beteiligung des Reizleitungssystems, vor allem des AV-Knotens, kann im Vordergrund stehen.

Alsklinische Kriterienfür die Diagnose der Manifestation Lyme-Karditis unter Berücksichtigung der „EUCALB clinical case definitions for Lyme borreliosis" (2008) werden als notwendige Hauptkriterien angesehen: akut einsetzender AV-Block (II.-III. Grades), Rhythmusstörungen, manchmal Myokarditis oder Perikarditis (eine Zeckenexposition wird vorausgesetzt unabhängig davon ob ein Zeckenstich nachweislich vorausgegangen ist). Als unterstützende Kriterien gelten gleichzeitig bestehendes oder vorausgegangenes Erythema (chronicum) migrans. Alslabordiagnostische Kriterien für die Diagnose der Manifestation Lyme-Karditis unter Berücksichtigung der „EUCALB clinical case definitions for Lyme borreliosis" (2008) werden als notwendige Hauptkriterien angesehen: Nachweis von IgG- und IgM-Antikörper gegen B. burgdorferi im Serum oder signifikanter Anstieg des IgG-Antikörpertiters gegen B. burgdorferi oder kultureller oder Nukleinsäure-Nachweis von B. burgdorferi aus einer Herzbiopsie.

Das histologische Bild gleicht einer lymphozytären Virusmyokarditis und ist durch lymphozytäre Infiltrate mit interstitieller Fibrose charakterisiert (Abbildung 1).

\section{Morphologische Befunde bei infektiöser Myokarditis - Lyme-Karditis}

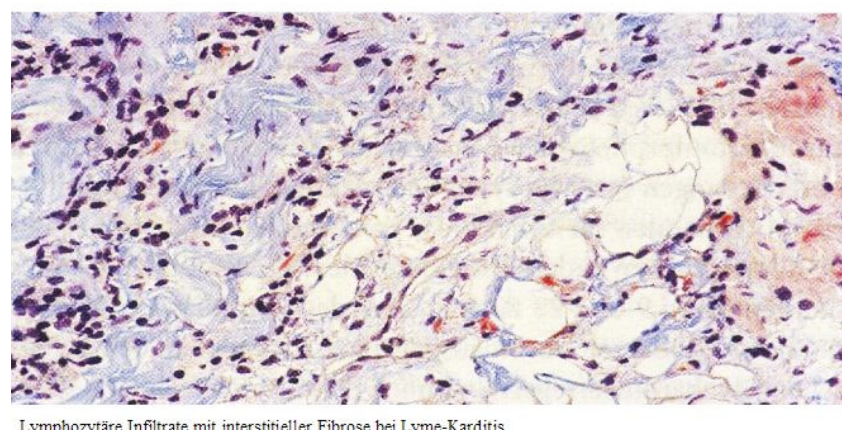

Lymphozytäre Infiltrate mit interstitieller Fibrose bei Lyme-Karditis.

Therapieempfehlungen: Frühe Manifestationen z. B. Erythema (chronicum migrans) undAV-Block Grad 1, P-R-Intervall > 0,3 s: wenn möglich Doxycyclin 2x 10omg p. o. für 14-21 Tage (Ausnahmen Kinder $<8$ Jahre und Schwangere), sonst Amoxicillin 3X 50omg p. o. für 14-21 Tage. Bei Vorligen einer Allergie gegen Doxycyclin und Amoxicillin ist Cefuroximacetil als Mittel der 3. Wahl und Erythromycin oder andere Makrolide als Mittel der 4. Wahl anzusehen. Bei Lyme-Karditis, höhergradigem AV-Block: Ceftriaxon 1x 2g/d i. v. für 28 Tage, sonst Cefotaxim 3X 2g/d i. v. für 28 Tage oder Penicillin G 4X 5 Mio. E i. v. für 28 Tage. Dauer der i. v. Therapie grundsätzlich i. v. und länger, über 28 Tage. Keine Therapie mit Doxycyclin.

Konklusion: Grundsätzlich sollte jede Manifestation der Lyme-Borreliose bei typischem klinischen Bild mit Erythema migrans antibiotisch therapiert werden, um die Entwicklung einer lymphozytären Meningo- radikulitis, der Lyme-Karditis oder auch einer Lyme-Arthritis zu verhindern. Auswahl und Dosierung des Antibiotikums sowie Art und Dauer der Applikation richten sich nach dem klinischen Bild. Der Erreger kann trotz antibiotischer Therapie im Herzen persistieren.

\section{DGKJ-PV-145}

\section{Kardiovaskuläre Risikofaktoren (CVRF) im Kindes- und Jugendalter} R. Eyermann

Dr. Richard Eyermann

Der atherosklerotische Prozess beginnt früh im Leben. Invasive Techniken (intravaskulärer Ultraschall) u. Autopsie-Studien belegen ein gesteigertes u. progressives Atheromwachstum in den Koronararterien bereits bei Teenagern v. a. mit CVRF.

Ergebnisse: Einschätzung u. Management von CVRF bereits in der Kindheit sind entscheidende Strategie zur Risikoreduktion schwerer atherosklerotischer Krankheiten, wie KHK, Schlaganfall, paVK, über die gesamte Lebenszeit. Das Verstehen von Evolution der frühen Atherosklerose u. Einwirkung von Interventionen im jungen Alter wird durch die Entwicklung nicht-invasiver Tests zur Detektion früher Veränderungen der arteriellen Funktion u. Struktur (Endothelfunktion, IMT) auf kausalem Weg der später klinisch manifesten Erkrankung erleichtert. Dadurch hat sich die Senkung einer Reihe von CVRF in der Kindheit zeigen lassen, die mit Reversibilität von frühen vaskulären u. kardialen Abnormalitäten (Endotheldysfunktion, Zunahme IMT, Zunahme linksventrikuläre Muskelmasse) assoziiert waren.

Neue CVRF sind im frühen Alter in Assoziation mit Verfall von Lebensstil u. Verhalten der Bevölkerung aufgedeckt worden. Falsche Ernährung $\mathrm{u}$. weniger physische Aktivität haben zur Epidemie von kindlicher Fettsucht geführt (26 Mio. übergewichtige Kinder u. Jugendliche in der EU, 2010). Die metabolischen atherogenen Konsequenzen zeigen sich bereits bei vielen Kindern u. Jugendlichen in familiären Komponenten des metabolischen Syndroms, incl. Dyslipidämie (hohes LDL-C, niedriges HDL-C), Hypertension u. Insulinresistenz (höhere Insulinspiegel), u. dies in Abhängigkeit vom Grad von Übergewicht bzw. Adipositas. Höhere LDL-C-Spiegel führen bereits bei Kindern zu reduzierter arterieller Dehnbarkeit.

Im zeitlichen Verlauf zunehmend schlechte Daten auch für Deutschlands Kinder u. Jugendliche: 1,9 Mio. übergewichtig (15\%), davon 800. ooo adipös $(6,3 \%)$, über 50 . ooo mit iGT, über 8 . ooo mit Typ-II-Diabetes, $4-5 \%$ essenzielle Hypertoniker, Raucher bis $43,3 \%$ Jungen u. $42 \%$ Mädchen, Erreichen sportmotorischer Leistungsfähigkeit vs. 1995 heute nur noch $80 \%$ Jungen u. $74 \%$ Mädchen.

„Early life programming“. Niedriges Geburtsgewicht assoziiert mit gesteigerter kardiovaskulärer Mortalität in prospektiver Kohorte bei Frauen u. Männern.. Geburtsgewicht korreliert sign. positiv mit flussbedingter Dilatation (FMD) bei Adoleszenten. Jedoch scheint postnatale Wachstumsakzeleration von ungünstigem Einfluß zu sein, mehr als antenatale Events („Catch up growth Hypothese“). Kritisches postnatales Fenster für Langzeitentwicklung scheint von einigen Wochen zu einigen Monaten zu variieren.

Konklusion: Evidenz, dass der atherosklerotischeProzess im frühen Leben beginnt, durch CVRF sign. beeinflusst wird u. daher frühe Intervention erfordert. Pädiater müssen involviert werden in Beurteilung u. Management von CVRF von Kindheit an , bei allgemeiner Population u. Hochrisikokindern. Medizinische Profession, in Addition, sollte aktiv assoziiert sein mit Familien, Lehrern, Vertretern im Gesundheitsdienst u. Politikern, um Verständnis für Bedeutung von lebenslangen Anstrengungen u. Investment in Reduktion von CVRF zu fördern. Sonst werden evidenzbasiert erreichbare Benefits, wie sign. Reduktion atherosklerotischer Last, durch das Gegenteil - eine Epidemie von dramatischen Verschlechterungen des CVRF- Profils (KHK, $\mathrm{Dm} 2$, MS etc.) in nächster Generation - verdrängt u. zum Kollaps der Gesundheitssysteme führen. 
26 Mio. übergewichtige Kinder u. Jugendliche 2010 in EU Übergewichtige Kinder - Arterien bereits früh geschädigt: bereits mit 12 Jahren signifikant pathologische Endothelfunktion (Reaktiver Hyperämie-Index, RHI) und IMT bei adipösen Kindern im Vergleich zum Kontrollkollektiv
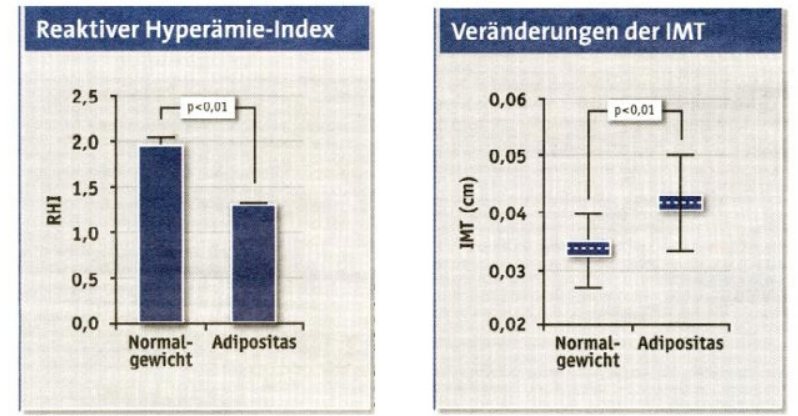

\section{DGKJ-PV-146}

Blasse Affektkrämpfe (Pallid Breath-Holding Spells) mit Asystolie: Schrittmachertherapie bei Kleinkindern und Säuglingen B. Kolterer', F. Riede' ', R. Gebauer', P. Kinzel', B. Hennig'², J. Janousek' , M. Kostelka' ${ }^{1}$ I. Dähnert

${ }^{1}$ Herzzentrum Leipzig, ${ }^{2}$ Friedrich Schiller Universität Klinik f. Kinder-u. Jugendmed.

Einleitung: Blasse Affektkrämpfe sind meist harmlose synkopale Zustände, die im Säuglings- und Kleinkindalter auftreten und in der Regel spontan sistieren. Es handelt sich dabei um vagale Synkopen, die durch äußere Einflüsse wie Aufregung, Schreck oder Schmerzen ausgelöst werden. In einzelnen Fällen können im Rahmen solcher Synkopen Bradykardie und kurzzeitige Asystolie auftreten.

Ergebnisse: Wir berichten über 6 Patienten, die in unserem Haus erfolgreich mittels Schrittmacherimplantation behandelt wurden. Das mediane Alter der Patienten zum Zeitpunkt der Implantation lag bei 22 Monaten ( 8 bis 47 Monate). Im Langzeit-EKG wurden bei diesen Patienten Asystolien von 12 bis 21 Sekunden Dauer nachgewiesen. In allen Fällen konnten durch die Schrittmacherimplantation (VVI mit repetitiver Hysterese) weitere Asystolien verhindert werden. In zwei Fällen traten weiter regelmäßig Affektkrämpfe mit kurzer Bewußtlosigkeit auf, in zwei Fällen zeigten sich nach Schrittmacherimplantation regelmäßig auftretende Präsynkopen ohne weitere Komplikationen, in zwei Fällen wurden keine weiteren synkopalen oder präsynkopalen Zustände mehr beobachtet.

Erweiterte Diskussion: Die Schrittmacherimplantation bei blassen Affektkrämpfen kann bei Nachweis von Asystolie die Symptome lindern und weitere Anfälle verhindern. In unserer Ambulanz werden aktuell 6 Patienten nach Schrittmacherimplantation betreut. In allen Fällen konnte die Symptomatik gebessert und die Anfallshäufigkeit deutlich gesenkt werden. In zwei Fällen traten die Anfälle mehrmals täglich auf, es bestand ein erheblicher Leidensdruck seitens der Patienten sowie der Angehörigen. In beiden Fällen konnte die Anfallshäufigkeit signifikant gesenkt werden ( $1 \mathrm{x} /$ Woche bzw. $1 \mathrm{x} /$ Monat), den Angehörigen ist es möglich, die Anfälle gezielt zu durchbrechen oder ganz zu unterbinden. Bei einem dieser beiden Patienten handelt es sich um ein ehem. hypotrophes Zwillings-Frühgeborenes der 36. SSW mit Z. n. ventrikuloperitonealer Shuntanlage. Die neurologische Abklärung inkl. EEG war bei allen 6 Patienten im Vorfeld erfolgt und blieb jeweils ohne pathologischen Befund. Ein weiterer Patient bot vor Schrittmacherimplantation nur vereinzelte, allerdings dramatische Episoden von gemischt blass-zyanotischen Anfällen, letztendlich verhinderte die Implantation des Schrittmachers weitere Bewußtlosigkeit, konnte die überschießende vagale Reaktion insbesondere auf Schmerzreize jedoch nicht unterbinden, so daß weiterhin über vereinzelte Episoden mit blass-zyanotischen Anfällen ohne Bewußtlosigkeit berichtet wird (2-3 x /Jahr). In den übrigen Fällen besteht nach Schrittmacherimplan- tation Anfallsfreiheit, eine Patientin klagt inzwischen nach über 5 Jahren der Verlaufskontrolle über gelegentliche thorakale Missempfindungen bei sportlicher Betätigung, so daß eine Explantation des Schrittmachers diskutiert wird. Zusammenfassend terminiert der Herzschrittmacher die nach initialer Tachykardie auftretende bradykarde Phase und verhindert so effektiv das Auftreten einer Asystolie, die letztendlich für die Bewußtlosigkeit bei schweren blassen Affektkrämpfen verantwortlich ist.

\section{DGKJ-PV-147}

Kardiale Gefährdung und Prävention des plötzlichen Herztodes (SCD) beim Sport

R. Eyermann

Dr. Richard Eyermann

SCDs treten bei Leistungs- u. Freizeitsportlern immer wieder auf. Weltweit beispielhaft hat italienisches Vorsorgeprogramm 90\%-igen Rückgang der SCDs bei jungen Wettkampfsportlern erreicht.

Ergebnis: Meist Herzvorschädigung. Unmittelbare Ursache elektrische Instabilität mit resultierenden schwerwiegenden Herzrhythmusstörungen.

\section{Ursachen des plötzlichen Herztodes beim Sport im jüngeren Alter $(\mathbf{n}=\mathbf{2 0 7})$}

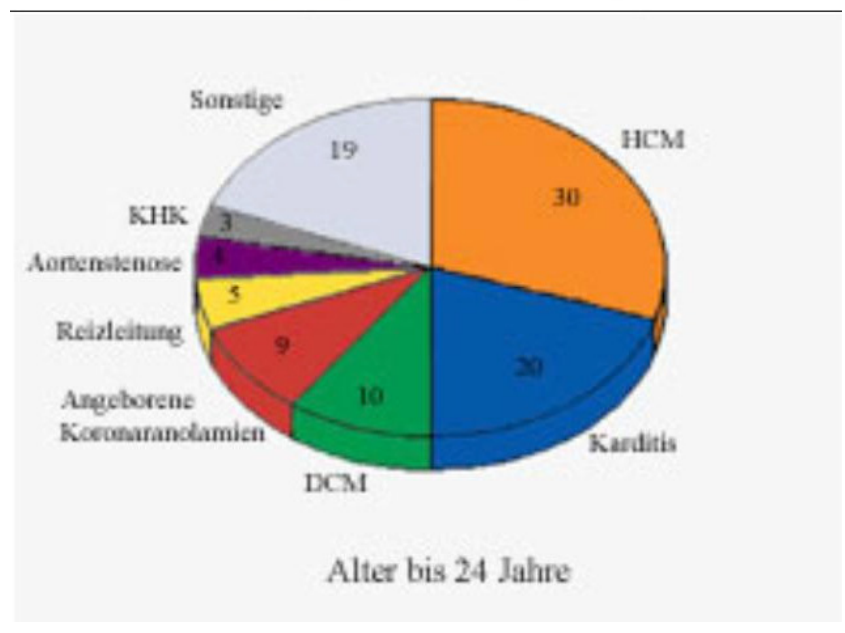

2 Hauptursachen für SCDs beim Sport: Bei Personen < 35-40 J. meist Kardiomyopathien (HCM, DCM), v. a. HCM, bei jüngeren Sporttreibenden meist akute u. chron. entzündliche Herzerkrankungen sowie Gefäßanomalien des Herzens.

Daten Ursachenhäufigkeiten für SCD beim Sport im jüngeren Alter bis 24 Jahre $(\mathrm{n}=207)$ : HCM $30 \%$, Karditis $20 \%$, DCM $10 \%$, angeborene Koronaranomalien (ektoper Ursprung, Winkelverlauf, beides (s. o.), Ostiumstenose) 9\%, Reizleitungsstörungen 5\%, Aortenstenose 4\%, KHK $3 \%$ Sonstige $19 \%$.

Jenseits des 35.- 40. J. sind bekannte kardiovaskuläre Risikofaktoren, ist KHK, häufigste Ursache.

Daten Ursachenhäufigkeiten für SCD beim Sport im zunehmenden Alter bis 40 Jahre $(n=703)$ : HCM 21\%, KHK 18\%, Karditis 14\%, angeborene Koronaranomalien 9\%, MKP 5\%, DCM 5\%, Reizleitungsstörungen $4 \%$, ARVC $4 \%$, Sonstige $20 \%$. 


\section{Ursachen des plötzlichen Herztodes beim Sport im weiter fortschreitenden Alter $(n=703)$}

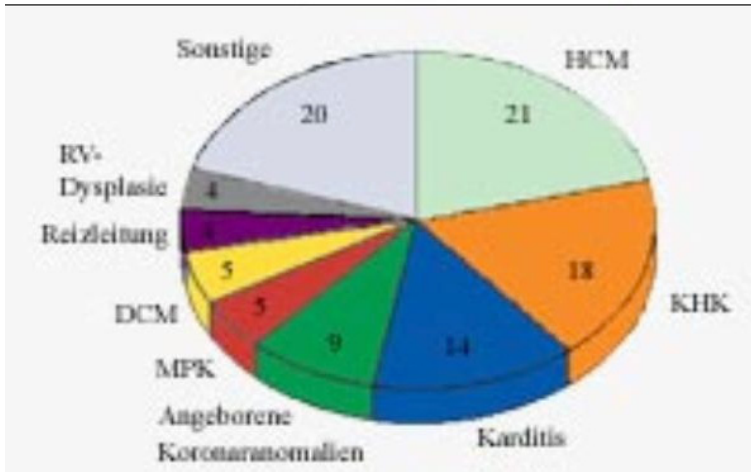

Alter bis 40 Jahren
Weitere Ursachen des plötzlichen Herztodes beim Sport Sog. „Brïckenbildungen des Myokards“ und anomale Koronargefäßverläufe mit Einengung der Koronarien v.a. unter Belastung
HINTEN

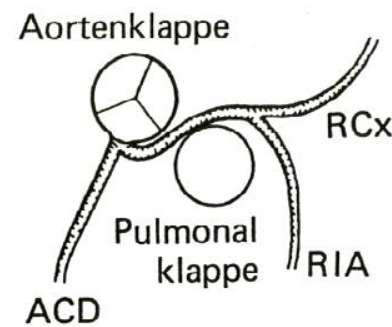

VORN

Weitere Ursachen des plötzlichen Herztodes beim Sport Traumata, starke stumpfe Schlageinwirkungen, wie $\boldsymbol{\iota}$.B. durch einen Zusammenprall mit Spielpartnern, Ball, Puck oder Sturz auf den Thorax können reflexbedingt Koronarspasmen auslösen

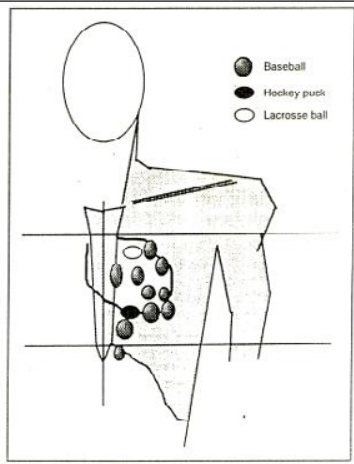

-Kontusionspunkte am Thorax mit dem Ergebnis einer Commotio cordis

Hohe Belastungsintensitäten bedingen größere Gefährdung. V. a. Alter u. mangelnder Trainingszustand von Bedeutung: Statistisch höchstes Risiko für SCD beim Sport bei >40j. männlichen Sport- oder Wiedereinsteigern mit $=/>2$ kardiovaskulären Risikofaktoren bei ungewohnt hoher Belastung mit z. T. statischer bzw. Haltearbeit.
Risiko SCD beim Sport weniger von der betriebenen Sportart als von der individuellenGefährdung abhängig: Sportarten an Spitze der Mortalitätsstatistiken, die von Männern im mittleren bis höheren Lebensalter am häufigsten durchgeführt werden, wie Jogging, Tennis u. Kegeln. Aufgrund HCM bereits junge Sportler untersuchen! Meist Ruhe-EKG bereits wegweisend, aber nur bei $75 \%$ Hypertrophiezeichen, bei $25 \%$ diskretere Veränderungen wie Abweichungen Herzachse o. erhöhte ST-Streckenabgänge in V1-V6. Echokardiographie anstreben. Sinnvoll Untersuchungen zum Pubertätsabschluss - bis dahin Kardiomyopathie meist ausgeprägt. Aus Familienanamnese Hinweise.

Bei $>35 j$. Sportlern Anamnese auf kardiovaskuläre Risikofaktoren u. Sportaktivitäten. Familiäre Hypercholesterinämie? In dieser Altersgruppe immer Belastungs-EKG. Weitere Untersuchungen nach individuellen Gegebenheiten.

Bei 50\% später Verstorbener Prodromi(!). Fehlende Prodromi schließen aber Herzerkrankung nicht aus.

Weitere Ursachen für SCD sog. „Brückenbildungen des Myokard“" mit Einengung der Koronarien v. a. unter Belastung u. Traumata, starke stumpfe Schlageinwirkungen, wie durch Zusammenprall mit Spielpartnern, Ball, Puck o. Sturz auf Thorax, mit reflexbedingten Koronarspasmen.

Konklusion: SCD-Risiko im Sport weniger von betriebener Sportart als von individueller Gefährdung abhängig.

Hauptursachen: HCM, Myokarditis, KHK, angeborene Koronaranomalien, ARVC, MKP, Erkrankungen der Aorta einschl. Aortenklappen, Störungen der Reizbildung u. Reizleitung.

Auf Prodromi achten!

Sportmedizinische Vorsorgeuntersuchungen für alle ambitionierten Sportler in jedem Lebensalter.

Beachtung von KI für Sport wie bei akuten Erkrankungen sowie von Trainingsempfehlungen v. a. nach längerer Inaktivität durch negativen Lebensstil o. nach Erkrankungen (sonst Übersterblichkeiten bis 1060x belegt).

Bei besonders Thoraxtrauma-gefährdenden Sportarten Protektoren, wie Brustpanzer, zu diskutieren.

DGKJ-PV-148

Hämophagozystische Lymphohistiozytoseim Rahmen eines Kawasaki Syndroms

C. Müller, C. Willaschek, L. Mänhardt, R. Buchhorn

Caritas Krankenhaus

Die hämophagozystische Lymphohistiozytose (HLH) stellt ein seltenes Sepsis-ähnliches Krankheitsbild dar. Man unterscheidet eine primäre Form von einer sekundären oder erworbenen Form. Die Erkrankung geht mit einer generalisierten Phagozytose einher und wird anhand verschiedener Diagnosekriterien gestellt. Das Kawasaki Syndrom (KS) ist eine akute Vaskulitis, der kleinen und mittleren Gefäße. Es geht mit einem erhöhten Risiko für Koronaraneurysmen einher.

Im vorliegenden Fall handelt es sich um einen 6 Monate alten Jungen, der mit unklarem Fieber, Lymphknotenschwellung, Konjunktivitis und makulopapulösem Exanthem vorgestellt wurde. Bei massiv erhöhten Entzündungszeichen wurde initial bei Verdacht auf bakterielle Genese eine anitbiotische Therapie, ohne Erfolg, durchgeführt. In der Folge wurde bei klinisch beweisenden Kriterien für ein Kawasaki Syndrom inklusive tubulären Koronaraneurysmen mit Immunglobulinen und Acetylsalicylsäure (ASS) behandelt. Bei Therapieresistenz wurde bei V. a. Immunaktivierung eine Steroidtherapie begonnen.

Die weiterführende Diagnostik erbrachte den Nachweis eines HLH. Unter der Steroidtherapie war eine kontinuierliche Besserung des Krankheitsbildes zu beobachten. Der kleine Patient entwickelt sich aktuell altersgerecht. Es ist lediglich die Einnahme von ASS auf Grund der Koronaraneurysmen notwendig.

In der Weltliteratur werden momentan weniger als 10 Fälle beschrieben, die einen Zusammenhang zwischen KS und HLH zeigen. Ob es sich dabei um eine Koinzidenz handelt oder ob ein eigenständi- 
ges Krankheitsbild vorliegt ist noch unklar. Bei den berichteten Fällen zeigt sich scheinbar ein erhöhtes Auftreten von Koronaraneurysmen im Gegensatz zu Patienten mit solitärem KS. Bei Diagnoseverzögerung der genannten Krankheitsbilder wurde sogar von einem Todesfall auf Grund der Koronaraneurysmen berichtet.

\section{DGKJ-PV-149}

Männlicher Säugling mit kardialer Dekompensation bei angeborenem intralobären Lungensequester

S. Szekely' ${ }^{1}$ T. Wanka', R. Gitter ${ }^{2}$, U. Wintergerst ${ }^{1}$

${ }^{1}$ Krankenhaus St. Josef, ${ }^{2} \mathrm{AKH}$ Linz

Hintergrund: Angeborene Sequestrationen der Lunge sind komplexe Fehlbildungen infolge frühembryonaler Entwicklungsstörungen. Man unterscheidet zwischen extra- und intralobären Sequestrationen. Beiden gemeinsam sind akzessorische Arterien, die eine zusätzliche Versorgung aus dem systemischen Kreislauf darstellen, der venöse Abfluss erfolgt in der Regel über die Vena pulmonalis. Klinisch relevante Symptome können sich durch die Größe dieses AV-Shuntvolumens ergeben. Häufigste Komplikationen sind Infektionen aufgrund der Kommunikation mit dem Bronchialsystem.

Fallpräsentation: Wir berichten über das 5. Kind gesunder Eltern. Nach unauffälligem Schwangerschaftsverlauf kam es in der 41. SSW zur Spontangeburt eines Knaben. Am 2. Lebenstag fiel ein 2/6-Systolikum auf, das p. m. war im 4. ICR rechts . Das Thorax-Röntgen zeigte einen ausgeprägten Pneumothorax links mit Dextropositio cordis .

Im weiteren Verlauf war das Neugeborene stabil ohne Dyspnoe. In der Echokardiographie zeigte sich ein ASD II bei sonst unauffälligem Herzen. Am 9. Lebenstag konnte der Knabe nach kompletter Rückbildung des Pneumothorax in häusliche Pflege entlassen werden.

Bei den echokardiologischen Kontrollen fiel eine zunehmende Volumenbelastung des linken Vorhofs und Ventrikels sowie eine erhöhte Flussgeschwindigkeit über der Mitralklappe auf. Die Ursache dieser Belastung war zunächst unklar.

Im Alter von 3 Monaten erfolgte die stationäre Aufnahme wegen einer ausgeprägten Dyspnoe aufgrund einer infektassoziierten obstruktiven Bronchitis. Bereits zwei Wochen später war eine neuerliche Aufnahme wegen zunehmender Dyspnoe erforderlich. Radiologisch wurde eine Pneumonie rechts mit Atelektase im rechten Oberlappen diagnostiziert. Weiters fanden sich eine Tachykardie, eine nochmalige Zunahme der linkskardialen Volumenbelastung sowie eine beginnende Volumenbelastung rechtskardial als Zeichen eines high-cardiac-output-failure. Aufgrund dieser Symptomatik wurde nun eine Herzkatheteruntersuchung durchgeführt. Es zeigte sich ein Sequester des rechten Lungenunterlappens, welcher von einer großen singulären Kollaterale aus dem Truncus coeliacus versorgt wurde. Es bestand ein großer links-linksShunt mit Druckerhöhung im linken Vorhof. Durch interventionellen Verschluss des zuführenden Gefäßes mit einem „Plug“ konnte der Shunt eliminiert und der linksatriale Druck sofort normalisiert werden. Bei den nachfolgenden Verlaufskontrollen hatten sich die Zeichen der kardialen Volumenbelastung bereits nach drei Monaten vollständig zurückgebildet. Auch traten keine Dyspnoe und bronchopulmonale Infektionen mehr auf. Bei unserem Patienten handelte es sich um einen intralobären Lungensequester Typ I nach Pryce, bei dem die akzessorische Arterie normales Lungengewebe versorgt. In diesem Fall kann nach transarteriellem Verschluß auf eine operative Entfernung des Sequesters verzichtet werden (1).

1. Waldschmidt J. et al. , Marseille Verlag, 2007, 105 -119

\section{DGKJ-PV-150}

Primäre Ziliäre Dyskinesie (PCD) als Differentialdiagnose bei Heterotaxie

J. Wallmeier', B. Stiller', H. Olbrich², A. Becker-Heck', N. Loges', H. Omran²

${ }^{1}$ Universitäts - Kinderklinik, ${ }^{2}$ Westf. Wilhelms-Univ.- Kinderklinik

Die Primäre Ziliäre Dyskinesie (PCD) ist eine seltene, meist autosomal rezessiv vererbte, genetisch heterogene Erkrankung mit einer Inzidenz von $\sim 1 / 20$. ooo. Charakteristischerweise führt eine chronisch-destruktive Entzündung der Atemwege zu Bronchieektasen.

Bei ca. 50\% der Patienten geht die PCD mit einem Situs inversus einher. Ursächlich hierfür ist der fehlende nodale Flüssigkeitsstrom während der früh-embryonalen Entwicklung, welcher von motilen Zilien des Knotens erzeugt wird und die rechts/links-Determinierung bewirkt. Weicht die Situs-Anatomie in Thorax oder Abdomen vom Situs solitus ab oder liegt ein Situs inversus vor, so spricht man von Heterotaxie. In einer Studie lag bei 6,3\% der Patienten mit PCD eine Heterotaxie vor. Dies ist klinisch bedeutsam, da Heterotaxie mit Organanomalien wie Polysplenie und Asplenie, aber auch mit komplexen kongenitalen Herzfehlern (CHD) assoziiert ist. Vor diesem Hintergrund ergab sich die Frage ob bei Patienten mit schwerem kongenitalem Herzfehler (ASD, VSD, TOF, DORV, AS, PS) und/oder Heterotaxie, bei denen zu Beginn der Studie keine weitere Abklärung pulmonaler Symptome erfolgt war, eine PCD genetisch nachgewiesen werden kann. Dazu wurde in einer Kohorte von 101 Individuen mit CHD +/- Heterotaxie das $\mathrm{DNAH}_{5}$ Gen, eines der bei PCD am häufigsten mutierten Gene, auf Mutationen untersucht. Nach schriftlicher Einwilligung wurde von den Patienten 2-5ml Vollblut gewonnen. Die DNA wurde entweder mittels Standardverfahren direkt aus Blutproben oder aus Lymphozyten Kulturen nach Eppstein-Barr Virus Transformation gewonnen. Mittels PCR wurden 80 Genabschnitte des DNAH5 Gens amplifiziert, die jeweils ein Exon und zusätzlich einige angrenzende intronische Basen beinhalteten. Die Amplifikate wurden bidirektional sequenziert und mit Hilfe der CodonCode-Software ausgewertet.

Bei einer Patientin konnte eine compound heterozygote Mutation (Stop- /Frameshift-Mutation) im $\mathrm{DNAH}_{5}$ Gen nachgewiesen werden [c. $\left.\mathrm{C}_{4237} \mathrm{~T}\right]+$ [c. 10083delC] [p. Gln1413X] + [p. Asn3361fs17X]. Bei der Patientin liegt ein Situs inversus mit Dextrocardie und ein schweres kongenitales Herzvitium vor. In der Herzanatomie zeigt sich ein schwerer AVSD mit einer Fallotschen Tetralogie, eine Pulmonalstenose, eine Pulmonalisstammhypoplasie, eine Insuffizienz der gemeinsamen Aortenklappe, ein rechter Aortenbogen sowie eine linksseitige Azygoskontinuität.

Bei ca. $1 \%$ unserer Patienten mit CHD und/oder Heterotaxie konnten wir eine Mutation im $D N A H_{5}$ Gen nachweisen. Da nur ein kleiner Teil von PCD-Patienten $\mathrm{DNAH}_{5}$-Mutationen aufweist, liegt die PCD-Prävalenz bei CHD-Patienten wahrscheinlich deutlich höher. Daraus lässt sich schließen, dass bei Patienten mit angeborenen Herzfehlern (CHD), insbesondere mit schweren pulmonalen Symptomen, die PCD eine wichtige Differentialdiagnose darstellt. Da Patienten mit PCD deutlich von einer frühen spezifischen Atemwegstherapie profitieren, sollte bei CHD eine PCD immer differentialdiagnostisch erwogen werden.

\section{DGKJ-PV-151}

Medizinische Komorbidität bei übergewichtigen und adipösen Kindern und Jugendlichen: gemeinsame Auswertung der KiGGS-Daten des RKI und der EvAKuJ-Beobachtungsstudie der BZGA an insgesamt 14301 Patienten / Probanden

U. Hoffmeister', M. Thamm², C. Goldapp 3 , R. Mann 3 , M. Flechtner-Mors', M. Bullinger ${ }^{4}$, A. van Egmond-Fröhlich ${ }^{5}$, T. Reinehr ${ }^{6}$, U. Ravens-Sieberer ${ }^{4}$, J. Westenhöfer ${ }^{7}$, R. Holl ${ }^{1}$

${ }^{1}$ Institut für Epidemiologie, ${ }^{2}$ Robert Koch Institut, ${ }^{3} \mathrm{BZgA},{ }^{4}$ Univ.-Kinderklinik Eppendorf, ${ }^{5}$ Universitätskinderklinik, ${ }^{6}$ Vestische Kinderklinik, ${ }^{7}$ Hochschule für angewandte Wissenschaften

Hintergrund: Übergewicht und Adipositas bei Jugendlichen stellen eine ernstzunehmende Herausforderung für das Gesundheitswesen und die Gesellschaft dar. Nach heutigem Stand wird mittel- und langfristig das Leben dieser Patientengruppe durch ein deutlich erhöhtes Gefäßrisiko geprägt sein, wobei behandelbare Risikofaktoren wie Dyslipidämie und Hypertension eine große Rolle spielen. Ziel dieser Untersuchung ist es, basierend auf den populationsbezogenen Daten der KiGGS-Studie des Robert-Koch-Instituts und der von der Bundeszentrale für gesundheitliche Aufklärung initiierten EvAKuJ-Studie bei adipösen Kindern und Jugendlichen in spezialisierten verhaltensthera- 
peutischen Adipositasprogrammen die Häufigkeiten und Odds-Ratios dieser Risiken in Abhängigkeit von der BMI-Kategorie zu beschreiben. Daten und Methoden: Basierend auf einer Angebotserhebung durch das UKE im Jahre 2005 über die in Deutschland verfügbaren Adipositas-Therapieangebote wurden - getrennt für 6 Angebotsvarianten insgesamt 48 Zentren nach dem Zufallsprinzip ausgewählt. An diesen Zentren wurden in den Behandlungsjahren 2005 und 2006 insgesamt 5976 Patienten betreut. Aus der populationsbezogenen KiGGS-Studie (o-17 Jahre) wurden 8326 Teilnehmer im Altersspektrum 8 bis 16,9 Jahre standardisiert untersucht, eine Blutentnahme war bei 7728 Probanden verfügbar. Patienten und Probanden wurden nach den Referenzwerten der AGA in normalgewichtig (48\%), übergewichtig (13\%), adipös (zwischen der 97. und der 99,5. Perc., $23 \%$ ) und extrem adipös (> 99,5. Perc, $16 \%$ ) eingeteilt. Basierend auf einer logistischen Regression wurden die Odds-Ratios für kardiovaskuläre Risikofaktoren mit SAS 9. 2 ermittelt (Referenzkategorie: Normalgewicht).

Ergebnisse: Das mittlere Alter betrug 12,5 Jahre (8 bis 17 Jahre), 49\% Jungen. In der Gesamtgruppe fand sich bei $13 \%$ eine Hypertension (syst. oder diast. RR > 95. Perc.), bei $4 \%$ ein erniedrigtes HDL-Cholesterin $(<35 \mathrm{mg} / \mathrm{dl})$, bei $8 \%$ ein LDL-Cholesterin über $130 \mathrm{mg} / \mathrm{dl}$. In der multiplen Regressionsanalyse für Hypertension, adjustiert für Alter und Geschlecht, ergaben sich Odds-Ratios von 2,43 [1,98 - 2,97, 95\%CI] für übergewichtige Patienten, 5,76 [4,97-6,68] für adipöse und 10,99 $[9,44-12,8]$ für extrem adipöse Patienten. Die entsprechenden OddsRatios für ein erniedrigtes HDL-Cholesterin betrugen 2,68 [1,93-3,74], $3,84[2,94-5,01]$ und 5,65 [4,33- 7,38], für ein erhöhtes LDL-Cholesterin $1,62[1,33-1,99], 1,79[1,50-2,13]$ und $1,77[1,45-2,16]$.

Schlussfolgerung: Bereits bei Kindern und Jugendlichen steigt das Risiko einer Dyslipidämie und einer Hypertension deutlich mit dem Grad von Übergewicht und Adipositas an. Eine ganzheitliche, am langfristigen Gesundheitsrisiko orientierte Betreuung dieser Patientengruppe muss dies berücksichtigen und - sollte eine Gewichtsabnahme nicht gelingen - eine pharmakologische Therapie in Erwägung ziehen.

\section{DGKJ-PV-152}

Veränderungen der Hautmikrozirkulation und Intima-Media-Dicke bei ehemaligen extrem kleinen Frühgeborenen

H. Lee, S. Eicher, R. Dalla Pozza, O. Genzel-Boroviczeny

Klinikum der Universität München

Ziel dieser Studie war es, den Blutdruck, die Intima-Media-Dicke (IMT) der A. carotis communis und die kapilläre Dichte in der Hautmikrozirkulation von Kindern mit extrem geringen Geburtsgewicht zu bestimmen.

54 Frühgeborene $(753 \pm 152 \mathrm{~g})$ und 16 Reifgeborene $(3395 \pm 558 \mathrm{~g})$ wurden im Alter von 11,8 Jahren nachuntersucht. Die IMT wurde mittels eines hochauflösenden Ultraschallgerätes im B-Mode ermittelt. Zur Aufnahme der funktionalen Gefäßdichte (FVD) und des Gefäßdurchmessers kam die sog. Sidestream Dark Field (SDF)-Intravitalmikroskopie zum Einsatz. Gemessen wurde vor, während und nach arteriellem Gefäßverschluss.

Die Gruppe der Frühgeborenen wies signifikant erhöhte Blutdruckwerte $(p=0,0003)$ und IMT-Messwerte auf $(0,45 \pm 0,03 \mathrm{~mm}$ vs. $0,38 \mathrm{~mm}, p<0,0001)$. Zudem zeigten sie sowohl eine signifikant erhöhte FVD im Ruhezustand (33,6 $\pm 14,5$ (SD) vs. $23,0 \pm 7,1 \mathrm{~cm} / \mathrm{cm}^{2}$, $p=0,002)$ als auch eine geringere Reaktivität während arteriellem Verschluss $\left(\mathrm{Chi}^{2}\right.$ 7,14, $\left.p=0,008\right)$. Es besteht keine Korrelation zwischen diesen beiden Parametern und dem erhöhten Blutdruck (FVD r $=-0,2$, $p=0,09$, IMT $\mathrm{r}=0,2, p=0,18$ ).

Als frühe Gefäßveränderung im Rahmen der Atheromentwicklung stellt eine erhöhte Intima-Media-Dicke dar, so wie sie unsere Frühgeborenen zeigen. Es ist jedoch weiterhin unklar, ob Frühgeburtlichkeit an sich als Ursache dieser Verdickung angesehen werden kann. Zudem weist unsere Studiengruppe eine erhöhte kapilläre Dichte in der Hautmikrozirkulation auf. Dies steht im Gegensatz zu bisherigen Studien, die Frühgeburtlichkeit mit einer erniedrigten Zahl an Kapillaren assoziierten bzw. keine Unterschiede aufzeigen konnten. Grund hierfür ist vermutlich die Messmethode. Wir nutzten die Eigenschaften der SDFBildgebung, die die Mikrozirkulation in einer höheren Hautschicht misst als andere Methoden, wie Intravitalmikroskopie oder LaserDoppler. Im Zusammenhang mit erhöhtem Blutdruck kann die erhöhte kapilläre Dichte kombiniert mit den Gefäßen geringerer Reaktivität zu einem vergrößerten Widerstand im weit dichteren Gefäßnetz führen und dadurch erhöhte Blutdruckwerte verursachen. Dieser vergrößerte Druck kann im Erwachsenenalter in einer Verminderung der kapillären Dichte und folglich zu Einschränkungen der Hautmikrozirkulation im Rahmen der Anpassungsreaktion führen.

Frühgeburtlichkeit ist assoziiert mit erhöhten IMT-Werten und Veränderungen der Hautmikrozirkulation bei gesunden Jugendlichen. Longitudinale Studien sind notwendig, um Auswirkungen der Frühgeburt auf Veränderungen der Mikrozirkulation und IMT vollständig ermitteln zu können.

\section{Infektiologie II und Dermatologie}

\section{DGKJ-PV-153}

Die Urachuszyste als Ursache akuter und chronischer Bauchschmerzen

P. Bayer, M. Herr, R. Bitterlich, K. Riebe, A. von Moers

DRK Kliniken Westend

Fragestellung: Anhand von drei Fallbeispielen soll der persistierende Urachus als Differenzialdiagnose akuter und chronischer Bauschmerzen dargestellt werden.

Material und Methoden: Vorstellung von klinischen Symptomen, Diagnostik und Therapie bei drei Patienten, die von Juni 2009 bis April 2010 in unserer Klinik behandelt wurden.

Ergebnisse: Drei Patienten im Alter zwischen zwei und zwölf Jahren wurden untersucht. Patient 1 (2 J. altes Mädchen) und Patient 2 (4 J. alter Junge) stellten sich mit akuten Bauschmerzen und Fieber in der Rettungsstelle vor, Patient 3 (12 J. altes Mädchen) litt seit dem Kleinkindalter an chronischen Bauchschmerzen. Bei den Patienten 1 und 2 mit akut aufgetretenen Bauchschmerzen fielen eine tastbare Raumforderung periumbilikal mit deutlicher Abwehrspannung, Fieber sowie laborchemisch erhöhten Entzündungsparametern auf. Patient 2 wurde bereits zwei Monate zuvor wegen eines eitrigen Nabels und bei V. a. einen persistierenden Ductus omphaloentericus in einer auswärtigen Klinik operiert. Patient 3 hatte einen Druckschmerz im Oberbauch ohne Hinweis auf eine akute Entzündung. Bei allen drei Patienten konnte sonographisch eine Urachuszyste mit einer Größe von $8,5 \mathrm{~cm}$ (Patient 1), $4 \mathrm{~cm}$ (Patient 2) und $4 \mathrm{~mm}$ (Patient 3) diagnostiziert werden, wobei sich bei Patient 3 der Urachus nur mit halbvoller, nicht aber mit voller Blase darstellen ließ. Patient 1 erhielt zusätzlich eine MRT, da eine Ovarialzyste nicht sicher ausgeschlossen werden konnte. Präoperativ erhielten alle Patienten ein MCU: bei keinem der drei Patienten konnte hier ein persistierender Urachusgang dargestellt werden. Die Verdachtsdiagnose der Urachuszyste konnte intraoperativ und histologisch gesichert werden. Bei Patient 1 und 2 konnte eine Infektion mit Staphylococcus aureus nachgewiesen werden. Ergänzend zur operativen Therapie wurde eine intravenöse Antibiotikatherapie durchgeführt. Die klinischen Beschwerden sistierten bei allen Patienten postoperativ, die Infektzeichen und laborchemischen Entzündungsparameter waren rückläufig.

Diskussion: Neben rezidivierenden Harnwegsinfektionen können auch Bauchschmerzen die Folge eines unvollständig obliterierten Urachusganges sein. In allen drei aufgeführten Fallbeispielen war, wie auch in der Literatur beschrieben, die Sonographie der wegweisende diagnostische Schritt. Eine MRT-Untersuchung ist zu empfehlen, falls sonographisch Unsicherheiten bestehen bleiben. Präoperativ ist ein MCU zum Ausschluss von Urachusfisteln unentbehrlich. Therapeutisch ist bei abszedierten Urachuszysten ein zweizeitiges operatives Vorgehen in 
Erwägung zu ziehen, besteht keine akute Entzündung, so ist direkt eine Laparoskopie mit Entfernung des Urachusreliktes indiziert.

Schlußfolgerung: Trotz ihrer geringen Prävalenz stellt die Urachuszyste bei akuten und chronischen Bauchschmerzen ein relevante Differenzialdiagnose dar. Diagnostik der ersten Wahl ist die Sonographie.

\section{DGKJ-PV-154}

\section{Welche klinischeRelevanz haben hMPV- Infektionen bei Kindern?}

A. Haaß, A. Eis-Hübinger, M. Born, M. Lentze, I. Franke

Universitätsklinikum Bonn

Hintergrund: Der respiratorische Infekt ist eine der häufigsten Erkrankungen im Kindesalter. Im Jahr 2001 wurde das humane Metapneumovirus (hMPV) als häufiger Erreger (laut Literatur ca. 8\%) dieser Erkrankungen identifiziert. Der klinische Verlauf reicht hierbei von Infekten der oberen Luftwege bis hin zu intensivpflichtigen Pneumonien. Der Nachweis des hMPV gelingt mittels PCR aus nasalem Sekret. An der Universitätsklinik Bonn gehört die hMPV-PCR zum respiratorischen Panel, das routinemäßig aus dem Rachenspülwasser bei Patienten durchgeführt wird, die wegen einer Atemwegserkrankung stationär behandelt werden.

Methoden: Wir führten eine retrospektive Studie durch, um den Krankheitsverlauf von hMPV-Infektionen der Patienten der Universitätskinderklinik Bonn zu untersuchen. In die Studie eingeschlossen wurden 17 Patienten zwischen o und 7 Jahren, die zwischen Januar 2009 und März 2010 stationär behandelt wurden und bei denen hMPV im Rachenspülwasser nachgewiesen werden konnte. Die Daten von 11 weiteren Patienten werden derzeit noch ausgewertet.

Ergebnisse: Die Haupterkrankungszeit lag zwischen November und März. Das mediane Erkrankungsalter lag bei 1,25 Jahren (o,25-7 Jahre). Bestimmt wurde das klinische Bild durch eine Atemwegsobstruktion. Die stationäre Aufnahme erfolgte in $70 \%$ in deutlich reduziertem Allgemeinzustand, eine respiratorische Insuffizienz mit Sauerstoffbedarf zeigte sich bei $47 \%$ der Patienten. In 52,9\% der Fälle ließ sich radiologisch eine Pneumonie nachweisen. Die Therapie erfolgte symptomatisch mit einer antiobstruktiven Inhalationstherapie aus Salbutamol und Ipratropiumbromid. Die mittlere Krankenhausverweildauer lag bei 5,4 Tagen.

Schlussfolgerung: Die klinische Präsentation und der Krankheitsverlauf einer hMPV-Infektion lassen sich nicht von einer RSV-Infektion unterscheiden, die Anzahl der radiologisch gesicherten Pneumonien ist signifikant höher. Schwere Verläufe, die eine intensivmedizinische Betreuung erforderlich machen, wurden von uns nicht beobachtet.

\section{DGKJ-PV-155}

Häufung von Hand-Fuß-Mund-Krankheit in Baden-Württemberg 2008: Vielfalt der Serotypen

S. Diedrich', S. Böttcher', G. Pfaff²

${ }^{1}$ Robert Koch-Institut, ${ }^{2}$ Regierungspräsidium Stuttgart

Die Hand-Fuß-Mund-Krankheit (HFMK) ist eine durch Enteroviren hervorgerufene, weit verbreitete Erkrankung, die hauptsächlich Kinder im Kindergarten- und Grundschulalter betrifft. Sie verläuft in den meisten Fällen harmlos oder asymptomatisch, kann jedoch in Einzelfällen zu schweren Verläufen führen. Die Übertragung erfolgt durch direkten Kontakt mit virushaltigen Körperflüssigkeiten (Bläschenflüssigkeit, Speichel, Nasen- und Rachensekreten,) oder durch Schmierinfektion (fäkal-oral) sowie über kontaminierte Oberflächen. Infektionen mit Enteroviren treten gehäuft in den Sommermonaten auf und können große Epidemien auslösen. Material/Methoden. Im Sommer 2008 wurden in Baden-Württemberg Hinweise auf ein gehäuftes Auftreten von Hand-Fuß-Mund-Erkrankungen bei Kindern in Tageseinrichtungen registriert. Für die virologische Diagnostik wurden Enterovirus-spezifische PCR-Systeme in verschiedenen Genombereichen (5'NCR und $\mathrm{VP}_{1}$ ) mit anschließender Sequenzierung sowie die serologische Typisierung nach Virusanzucht verwendet. Ergebnisse. Es wurden 41 Patientenproben untersucht. (90,2\% Stuhl, 7,4\% Bläschen- flüssigkeit, 2,4\% Rachenabstrich). In 75\% der Proben konnte mittels PCR eine Enterovirus-Infektion bestätigt werden. Es konnten acht verschiedene Enterovirus-Serotypen identifiziert werden: Coxsackievirus A16(CoxA16; 15/22), Echovirus Typ 3 (2/22), sowie Echovirus Typ 25, CoxA2, CoxA8, CoxA9, CoxA1o (jeweils 1/22). Der Hauptanteil der Einsendungen (32/41) erfolgte im Juli/August. 93,5\% der bestätigten Patienten waren unter 10 Jahre, wobei Mädchen etwas häufiger betroffen waren. Diskussion/Schlussfolgerung. Obwohl die berichtete Krankheitshäufung zeitlich und räumlich begrenzt war, handelte es sich nicht um ein einheitliches Infektionsgeschehen. Neben dem häufigsten Erreger der HFMK (CoxA16) konnten weitere Enterovirus-Serotypen identifiziert werden. Auch wenn diese Erkrankung in den meisten Fällen ohne Komplikationen und selbstheilend verläuft, kommt es zu einer starken Beeinträchtigung der Patienten aufgrund der klinischen Symptome. Daher sollte eine rasche Ausbreitung durch konsequente Hygienemaßnahmen verhindert werden. Die molekularepidemiologischen Untersuchungen tragen zu einem besseren Verständnis enteroviraler Infektionen bei. Stuhlproben stellen bei der Enterovirusdiagnostik das Material der Wahl dar.

\section{DGKJ-PV-156}

Anwendung von LightCycler ${ }^{\circledast}$ SeptiFast bei pädiatrischen Patienten C. Dohna-Schwake', E. Tschiedel', J. Steinmann², U. Felderhoff-Müser', J. Buer' ${ }^{2}$ P. Rath ${ }^{2}$

${ }^{1}$ Klinik für Kinder und Jugendmedizin der Universität, ${ }^{2}$ Institut für Medizinische Mikrobiologie, Universitäts-Klinikum Essen

Hintergrund: Goldstandard in der Diagnostik einer systemischen bakteriellen Infektion ist die Blutkultur.

Seit kurzem steht ein Multiplex PCR-System (LightCycler ${ }^{\star}$ SeptiFast, Roche) zur Verfügung, mit dem innerhalb von weniger als $6 \mathrm{~h}$ die DNA von 20 Bakterien und Pilzen im Blut nachgewiesen werden kann.

Für SeptiFast liegen bereits einzelne klinische Studien an Erwachsenen vor, die andeuten, dass ein Keimnachweis v. a. bei immunsupprimierten Patienten und bereits antibiotisch behandelten Patienten häufiger und schneller gelingt.

Material und Methoden: Wir haben zwischen Mai 2009 und Januar 201034 Proben von 26 pädiatrischen Patienten mittels Septifast untersucht. Zeitgleich wurden immer auch Blutkulturen und Kulturen aus anderen Patientenproben (Trachealsekret, Rachenspülwasser, Pleurasekret, Urin, Abstriche) angelegt.

Alle Patienten befanden sich mit klinischen Symptomen einer schweren Infektion in stationärer Behandlung, viele waren bereits antibiotisch vorbehandelt.

Ergebnis: Mittels SeptiFast gelang in 11/34 (32\%) Proben ein Keimnachweis, mittels Blutkultur in 4/34 (12\%). Übereinstimmende Ergebnisse in beiden Methoden ergaben sich bei 3/34 (9\%) Proben. Eine positive Blutkultur bei negativem SeptiFast fand sich einmal (3\%). Hier lag ein Keim vor, der mittels SeptFast nicht detektiert werden kann (Meningokokken).

Bei vier Proben mit positivem SeptiFast aber negativer Blutkultur konnte in anderen Kulturen der gleiche Keim wie im SeptiFast nachgewiesen werden.

In einem Fall wurden SeptiFast und Kultur nicht aus Blut, sondern aus Pleura-flüssigkeit angelegt. Auch hier gelang im SeptiFast ein Keimnachweis, in der Kultur nicht. 


\begin{tabular}{|llll|}
\hline Tab. & SeptiFast & SeptiFast - & gesamt \\
\hline & + & & \\
\hline Blutkultur + & $3 / 34$ & $1 / 34$ & 4 \\
\hline $\begin{array}{l}\text { Blutkultur - } \\
\text { [davon andere Kultur +] }\end{array}$ & $8 / 34$ & $22 / 34$ & 30 \\
\hline gesamt & $14 / 8]$ & & \\
\hline
\end{tabular}

Diskussion: SeptiFast kann auch bei Kindern von zusätzlichem diagnostischem Interesse sein. Ein DNA-Nachweis von Bakterien oder Pilzen war bei unseren zumeist schwer kranken und antibiotisch vorbehandelten Patienten häufiger als der kulturelle Nachweis. In prospektiven Studien ist der mögliche klinische und wirtschaftliche Nutzen von SeptiFast noch zu belegen.

\section{DGKJ-PV-157}

Cryptokokken-Enzephalitis bei einem immunkompetentem Kind S. Mangold, K. Nolte, H. Peltroche-Llacsahuanga, K. Tenbrock, M. Hütten, N. Wagner, M. Häusler

Med. Einrichtungen der RWTH Aachen

Einleitung: Erfahrungsberichte zu zerebralen Cryptokokken-Infektionen bei immunkompetenten Patienten sind selten.

Fallbericht: Ein 10-jähriger Junge entwickelte zunächst Kopfschmerzen, hohes Fieber und Erbrechen. Unter Meningitisverdacht (Liquorpleozytose) wurde eine Behandlung mit Ceftriaxon begonnen. Dennoch traten innerhalb einer Woche eine Bewusstseinsstörung und Beatmungspflichtigkeit auf. Die kraniale Kernspintomographie (MRT) zeigte eine Hirnstammenzephalitis. Trotz Umstellung der antibiotischen Therapie auf Meropenem und Vancomycin war der MRT Befund rasch progredient. Es fanden sich multiple bilaterale supratentorielle, teilweise Kontrastmittel aufnehmende Läsionen, Mark und Cortex betreffend. Die Liquorzellzahl war weiter erhöht (Granulozytose), die Liquor-Glucose erniedrigt. Daraufhin wurde die Therapie zwei Wochen nach Krankheitsbeginn um Amphotericin B und Flucytosin erweitert. Bei unauffälliger umfangreicher virologischer und mikrobiologischer Liquordiagnostik erfolgte zudem eine Hirnbiopsie. Im Biopsat gelang mittels PCR sowie mikroskopisch der Nachweis von Cryptokokken. Im Verlauf stabilisierte sich der Patient langsam, er wurde etwa 3 Wochen nach Krankheitsbeginn extubiert. Nach vierwöchiger Behandlung mit Amphothericin B und Flucytosin wurde diese auf Fluconazol umgestellt, dann jedoch aufgrund eines erneuten Fieberschubes für weitere 4 Wochen fortgesetzt und schließlich durch eine orale Fluconazol-Dauertherapie ersetzt. Im Verlauf auftretende Fieberschübe wurden als zentrales Fieber gewertet.

In den folgenden 1,5 Jahren, nach initialer Rehabilitation und unter oraler Fluconazol-Dauertherapie, besserte sich der Patient deutlich. Er läuft und spricht, zeigt aber eine erhebliche emotionale Labilität und kognitive Defizite. Im MRT fand sich bis 1 Jahr nach Manifestation eine zunehmende Besserung. Die Genese der zerebralen Infektion blieb unklar.

Diskussion: Zerebrale Cryptokokken-Infektionen sind auch bei immunkompetenten Patienten eine Differentialdiagnose. Die Diagnosestellung erfordert unter Umständen eine Biopsie. Die optimale Therapiedauer ist unklar. Bei langsamer Regredienz der Herde ist möglicherweise auch eine Langzeitbehandlung indiziert.

\section{DGKJ-PV-158}

Das PANDAS-Syndrom (Pediatric Autoimmune Neuropsychiatric Disorders Associated with Streptococcal infection)

A. Peters, M. Noeker, C. Poralla, M. Born, M. Lentze, I. Franke

Universitätsklinik Zentrum f. Kinderheilkunde

Einleitung: Das PANDAS-Syndrom beschreibt die Assoziation zwischen Neuauftreten bzw. Exazerbation einer Tic-Störung und/oder
Zwangserkrankungen und vorausgegangener Infektion mit ß-hämolysierenden Streptokokken der Gruppe A (GABHS) im Kindesalter. Für die Diagnose des PANDAS-Syndrom gibt es 5 Kriterien:

1. Manifestation nach dem 3. Lebensjahr, aber vor der Pubertät;

2. Vorhandensein von Zwangssymptomen und/oder Tics;

3. plötzlicher Beginn und/oder episodischer Verlauf;

4. zeitlicher Zusammenhang zwischen GABHS-Infektion und Symptomverschlechterung

5. choreiforme Bewegungen während der Symptomverschlechterung.

Patienten: Wir berichten über einen 11-jährigen Jungen, der sich akut mit choreiformen Bewegungen vorstellte. Im Alter von 9 Jahren litt er an rezidivierenden Infektionen mit GABHS, was zur Tonsillektomie führte. Zeitgleich begann bei ihm eine Tic-Störung mit fazialen und oralen Tics. Während des klinischen Aufenthaltes zeigte sich ein buntes Muster paroxysmaler Attacken mit Tics, choreiformen Bewegungen, plötzlichem Gefühl von Atemnot sowie astatischen Anfällen. In einer simultanen Doppelbild-Aufzeichnung (Video/EEG) wurden mehrere Anfälle bei unauffälligem EEG aufgezeichnet. Im Labor fanden sich erhöhte Antistreptolysin-, Antistreptodornase B- und Antistreptokinasetiter. Damit lagen alle diagnostischen Kriterien für ein PANDAS-Syndrom vor. Sicherlich waren auch psychogene Ursachen für die Symptome mitverantwortlich. Die Komorbidität mit anderen psychiatrischen Symptomen als Charakteristik des PANDAS-Syndroms wird beschrieben.

Gestufte Therapieversuche mit Erythromycin und Tiaprid schlugen fehl.

Diskussion: Die genaue Pathophysiologie des PANDAS-Syndroms ist unklar, vermutlich handelt es sich um eine antikörper-vermittelte Erkrankung. Es wurden kreuzreaktive Antikörper gefunden, zudem gibt es Nachweise struktureller Veränderungen im MRT, die den Entzündungsprozess widerspiegeln, sowie in vitro Modelle, die einen direkten pathogenetischen Effekt der antineuronalen Antikörper nahe legen. Diese AAK (anti-HU, anti-Ma) waren bei unserem Patienten negativ.

Therapeutisch gibt es Hinweise, dass Antibiotika die akuten Symptome bessern sowie die Anzahl der klinischen Exazerbationen senken. Immunglobuline iv oder Plasmaaustausch zeigten vielversprechende, aber auch widersprüchliche Ergebnisse, so dass Therapieversuche nur im Rahmen von klinischen Studien unternommen werden sollten.

Schlussfolgerung: Das akute Auftreten von Tic-Störungen bzw. Zwangserkrankungen mit choreiformen Bewegungsstörungen sollte im Zusammenhang mit einer nachgewiesenen GABS Infektion an ein PANDAS-Syndrom denken lassen. Die Prognose wird in Einzelfallberichten als äußerst gut beschrieben, meist enden die Symptome mit Einsetzen der Pubertät.

\section{DGKJ-PV-159}

Phototoxische Dermatitis durch Hautkontakt mit Dictamnus albus (L.) bei zwei Kindern

T. Rose', L. Rose ${ }^{2}$

${ }^{1}$ Praxis für Kinderheilkunde und Jugendmedizin, ${ }^{2}$ Albrecht-von-Haller-Institut für Pflanzenwissenschaften

Mitte Juni 2007 wurden uns ein 8-jähriges Mädchen und seine 6-jährige Schwester mit akut aufgetretener bullöser Dermatitis an den Oberschenkeln vorgestellt. Bis zu $4 \mathrm{~cm}$ Durchmesser große, teilweise konfluierende, mit seröser Flüssigkeit gefüllte, schmerzhafte und juckende Blasen wurden abgetragen. Die Wundflächen heilten ohne spezifische Behandlung innerhalb von 10 Tagen $a b$, hinterließen aber eine leichte Hyperpigmentierung, die erst ein Jahr später komplett verschwand.

Ursache der Dermatitis war Hautkontakt mit der phototoxischen Pflanze Dictamnus albus (L.). Diese war kurz zuvor im Spielbereich der Patientinnen gepflanzt worden und stand in Blüte. Sie gehört zur Familie der Rutaceen (Rautengewächse) und wird bis zu 1,20 m hoch. Sie hat gefiederte Blätter, rote oder weiße Blüten und verströmt einen zitronenartigen Duft. Die Hauptblütezeit ist im Frühsommer. Dictamnus albus kommt vor allem im Mittelmeerraum vor. In Deutschland ist die unter 
Naturschutz stehende Pflanze an trockenen, geschützten Standorten sowie als beliebte Zierpflanze in heimischen Gärten zu finden. Die Fruchtstände dunsten an heißen Sommertagen große Mengen ätherischer Öle aus, die sich entzünden lassen. Daher rührt die Bezeichnung „Feuerbusch“ oder „brennender Busch“. Bei Kontakt werden vor allem 5-Methoxypsoralen, 8-Methoxpsoralen und Dictamin freigesetzt. Die Toxizität beruht auf der Reaktion mit Pyrimidin-Basen der DNA unter UV-Licht und Feuchtigkeit (Schwitzen).

Die Toxizität von Dictamnus albus ist seit 1929 bekannt. Es liegen Berichte über Erwachsene (vor allem Gärtner oder Biologen) mit schweren Formen einer Dermatitis bullosa striata pratensis vor. Beim Auftreten einer bullösen Dermatitis in den Sommermonaten sollte die Exposition gegenüber Dictamnus albus unbedingt in die Differentialdiagnose einbezogen werden, um eine weitere Gefährdung zu verhindern. Die Familie unserer Patientinnen hat den Busch umgehend entfernt.

\section{DGKJ-PV-160}

\section{Erfrierung ersten Grades bei einer Jugendlichen nach unsachgemäs- ser Anwendung eines Deosprays: Fallbericht aus der Hochgebirgskli- nik Davos}

M. Möhrenschlager, K. Stirner, R. Lauener

Hochgebirgsklinik Davos

Fragestellung: Deosprays werden vielfach täglich von Jugendlichen und anderen Personen verwendet. Über gesundheitliche Gefährdungen bei unsachgemässer Anwendung ist wenig bekannt.

Material und Methode: Klinischer Fallbericht.

Ergebnisse: Eine 14-jährige Patientin mit bekanntem atopischem Ekzem sowie allergischem Asthma bronchiale stellte sich mit einer schmerzhaften Verfärbung am Handrücken vor. Vorausgegangen war eine Besprühung der Haut aus wenigen Zentimetern Entfernung mit einem Deospray für etwa 15 Sekunden im Rahmen einer „Mutprobe“. Als Hautbefund zeigte sich am rechten Handrücken eine scharf begrenzte erythematöse Macula (Durchmesser 3 x $4 \mathrm{~cm}$ ) ohne epidermale Beteiligung. Daneben bestand eine ausgeprägte Sebostase sowie ein Dermographismus albus.

Diskussion: Für die Kälte-induzierende Wirkung von Deosprays werden $u$. a. die niederen Siedepunkte der verwendeten Treibgase angeschuldigt (z. B. Propan $-42.2^{\circ} \mathrm{C}$, Isobutan $-11.7^{\circ} \mathrm{C}$, Butan -o. $6^{\circ} \mathrm{C}$ ).

Lacour und Mitarbeiter berichten über die Erfrierung bei einem 8-jährigen Jungen, welcher seine Haut aus grosser Nähe (exakte Distanz nicht eruierbar) für eine unbekannt lange Dauer mit einem Toilettenraum-Duft-Spray besprühte. Wie die Autoren durch eigene Messungen belegen konnten, vermochte das Duft-Spray Temperaturen bis $-40^{\circ} \mathrm{C}$ zu erzeugen.

Eliot beschreibt den Fall eines jungen Mannes, welcher zur Erlangung eines „euphorisierenden“ Effekts ein Aerosolspray in die Mundhöhle einsprühte. Nachfolgend entwickelte sich eine zweitgradige Erfrierung der Wangenschleimhaut, der Zunge, des Gaumens sowie der Unterlippe.

Aus „Neugierde“ besprühten zwei Schülerinnen die Haut ihrer Extremitäten für 20 bis 30 Sekunden aus etwa $1 \mathrm{~cm}$ Entfernung mit einem Deospray (Camp et al.). Nachfolgend entwickelten sich auf den besprayten Arealen Erfrierungen ersten bzw. zweiten Grades. Camp et al. konnten bei Verwendung eines baugleichen Deosprays - ausgehend von einer Temperatur von $+21^{\circ} \mathrm{C}-$ aus $1 \mathrm{~cm}$ Sprühdistanz nach 5 Sekunden Sprühdauer eine Temperatur von $0^{\circ} \mathrm{C}$ induzieren. Nach 10 Sekunden Sprühdauer erzielten sie $-8^{\circ} \mathrm{C}$, nach 15 Sekunden $-13^{\circ} \mathrm{C}$ und nach 20 Sekunden $-15^{\circ} \mathrm{C}$.

In dem hier berichteten Fall wurden in dem verwendeten Deospray die Treibgase Propan, Isobutan sowie Butan verwendet (s. o.). Der Hersteller weist auf seinen Warnhinweis auf dem Deospray auf einen einzuhaltenden Mindestabstand von $15 \mathrm{~cm}$ bei der Anwendung hin.

Schlussfolgerung: Der vorgestellte Fallbericht weist auf eine mögliche, wenngleich wenig bekannte Schädigungsmöglichkeit des Hautorgans durch unsachgemässen Gebrauch eines Deosprays hin.
Literaturverzeichnis: Lacour M, Le Coultre C (1991) Spray-induced frostbite in a child: a new hazard with novel aerosol propellants. Ped Dermatol 8: 207-9

Elliot DC (1991) Frostbite of the mouth: a case report. Mil Med 156: 18-19

Camp DF, Ateaque A, DicksonWA (2003) Cryogenic burns from aerosol sprays: a report of two cases and review of the literature. Br Assoc Plast Surg 56: 815-817

\section{DGKJ-PV-161}

Differentialdiagnostische Herausforderung unilaterales laterothorakales Exanthem: Fallbericht aus der Hochgebirgsklinik Davos

M. Möhrenschlager, R. Lauener

Hochgebirgsklinik

Fragestellung: Grossflächige erythematöse Maculae und Papeln in ungewöhnlicher Anordnung mit gelegentlich auftretendem Pruritus bereiten im Kindesalter bisweilen bei der diagnostischen Einordnung Probleme.

Material und Methode: Klinischer Fallbericht.

Ergebnisse: Ein 4-jähriger Junge mit bekanntem atopischem Ekzem wurde mit plötzlich aufgetretenen Hautveränderungen im Winter vorgestellt. Die Hautveränderungen begannen in der rechten Thorakalregion und dehnten sich nachfolgend auf Abdomen, obere und untere Extremitäten der rechten Körperhälfte aus. Es bestand milder Juckreiz. Vorausgegangen war eine fieberhafte Rachenentzündung, welche 14 Tage vor Erstkonsultation abgeklungen war.

Bei der makroskopischen Inspektion imponierten $z$. T. scharf begrenzte erythematöse Maculae und Papeln mit geringer epidermaler Beteiligung, welche streng rechtsseitig angeordnet waren und den ventralen Rumpf sowie die proximalen Extremitäten betrafen.

Im durchgeführten Labor fand sich ein unauffälliger CRP-Wert. Differentialblutbild, Virusserologien sowie läsionale Hautabstriche auf Bakterien, Dermatophyten sowie Hefepilze waren gleichfalls ohne pathologischen Befund.

Diskussion: Das unilaterale laterothorakale Exanthem (ULE) ist eine seltene Hauterkrankung ungeklärter Ätiologie. Es betrifft meist Kinder vom 1. bis 5. Lebensjahr. Mädchen scheinen häufiger als Buben zu erkranken. Eine Krankheitshäufung im Winter und Frühjahr wird berichtet. Aufgrund einer häufig beobachteten Assoziation mit Infektionen des Rachens, des Magen-Darm-Trakts, des Ohres sowie bei immunsuppremierten Kinden wird eine infektiöse oder parainfektiöse Ursache vermutet. Vielfach - wie auch bei unserem Patienten lassen entsprechende Laboranalysen keinen direkt oder indirekt kausalen Erreger detektieren.

Klinisch zeigen sich einseitig erythematöse Maculae und Papeln mit geringer epidermaler Beteiligung in morbilliformer, scarlatiniformer, anulärer oder retikulärer Anordnung. Pruritus besteht in etwa $50 \%$ der Fälle. Betroffen sind Brust- und/oder Bauchregion sowie die angrenzenden Extremitätenabschnitte. Gesicht, Hände und Füsse bleiben typischerweise ausgespart. Ein bilateraler Befall nach unilateralem Beginn der Erkrankung ist möglich.

Differentialdiagnostisch müssen u. a. virale Exantheme, seborrhoische Dermatitis, Kontaktdermatitis mit und ohne hämatogener Streuung, Pityriasis rosea, Roseola infantum, Scharlach, Milaria, Erythema infectiosum sowie Tinea corporis abgegrenzt werden.

Therapeutisch kommen aufgrund des selbstlimitierenden Charakters der Erkrankung topische und systemische Antipruriginosa bei stärkeren Juckreizsensationen in Betracht.

Schlussfolgerung: Bei einseitigen Hautveränderungen im Kindesalter darf die Differentialdiagnose eines unilateralen laterothorakalen Exanthems nicht ausser Betracht bleiben.

Literaturverzeichnis: Reinerth G, Bruch-Gerharz D, Gerber PA, et al (2006) Unilaterales laterothorakales Exanthem. Hautarzt 57: 903-912 
DGKJ-PV-162

Vasospasmen als Ursache dermaler Nekrosen und Akrozyanose der unteren Extremität bei einem 14Jährigen

M. Klein, T. Ankermann, R. Fölster-Holst, N. Charalambous, P. Eggert

Universitätsklinikum Schleswig-Holstein

Der Fall: 14 jähriger Patient mit kryptogen-fokaler Epilepsie mit Sultiam-Therapie. Zwei Monate vor Vorstellung fiel erstmals eine livide, nicht schmerzhafte, aber zunehmende Verfärbung der vierten Zehe links bei kühlen Füßen auf. Im Verlauf Ausbreitung auf die übrigen Zehen des linken und auch des rechten Fußes. Nach ASS-Therapieversuch Verschlechterung mit Hautnekrose an der Dorsalseite von Dig III links. A. tibialis posterior und A. dorsalis pedis bds. gut palpabel. Weiterer Untersuchungsbefund unauffällig.

Labor: Blutbild, Gerinnung, Eiweißelektrophorese und Sammelurin unauffällig. Harnstoff, Kreatinin, AST, ALT, LDH, CRP, Ferritin, TSH, Laktat, Ammoniak im Normbereich, ANA/dsDNA negativ, BSG: 2/5 n. W.. Aminosäuren im Plasma/Serum sowie Trockenblut und Acylcarnitine unauffällig. Kryoglobuline und -agglutinine nicht nachgewiesen.

Diagnostik: Augenbefund, Echokardiographie, Sono-Abdomen mit Gefäßdoppler, Nervenleitgeschwindigkeiten regelrecht.

Dopplersonographie: A. dorsalis pedis und Interdigitalarterie Dig II links regelrecht, kein Hinweis auf Abknicken eines Gefäßes.

MRT-Angio: Beidseits kein Nachweis von hämodynamisch signifikanten Stenosen oder Aneurysmata.

Histologie Digitus III, linker Fuß: Dermale Muzinablagerung ohne wesentliche entzündliche Veränderungen, vereinbar mit einem Myxödem.

Angiographie Beidseits deutliche Verzögerung des peripheren Abstroms mit inframalleolärem Verdämmern der A. tibialis posterior und der A. tibialis anterior. A. plantaris, A. dorsalis pedis, Aa. metatarsales stellen sich nicht dar. Nach Nitroglycerin-Gabe Verbesserung des Abstroms mit Kontrastierung aller Gefäße.

Diskussion: Vasospasmen letztlich unklarer Genese können auch im Jugendalter zu Perfusionsstörungen der Extremitäten und Hautnekrosen führen. Nach mehrwöchiger Therapie mit einem vasoaktiven Calciumantagonisten (Amlodipin) war der Patient beschwerdefrei. Bei fehlenden Zeichen einer Vaskulitis wurde eine gestörte vasomotorische Funktion nach Kälteexposition oder parainfektiös diskutiert. Eine Genese aufgrund der Sultiam-Therapie ist in der Literatur bislang nicht beschrieben.

\section{DGKJ-PV-163}

Propranolol für die Therapie von ulzerierten Hämangiomen

T. Schill' ${ }^{1}$, A. Bährr', F. Bross², J. Otten³ ${ }^{3}$ K. Rückauer ${ }^{4}$, J. Rößler ${ }^{1}$

'Zentrum für Kinder- und Jugendmedizin, ${ }^{2}$ Universitäts-Hautklinik, ${ }^{3}$ Klinik

für Kiefer-, Mund-, Gesichtschirurgie, ${ }^{4}$ Chirurgische Universitätsklinik

Einleitung: Ulzerationen treten bei ca. 15\% aller proliferierenden Hämangiome auf. In ca. $40 \%$ der Fälle werden Blutungen und in weiteren $15 \%$ Infektionen beobachtet. Für die Behandlung von Ulzerationen werden in der Regel eine Farbstofflasertherapie oder eine medikamentöse Behandlung mit Steroiden, Vincristin oder Interferon eingesetzt. Topisch wird meist mit verschiedenen Verbandsmaterialien und lokaler Antibiotikagabe behandelt. Im Sommer 2008 wurde erstmals über die effektive Wirkung von Proporanolol bei proliferierenden Hämangiomen berichtet. Im Rahmen individueller Heilversuche haben wir Propranolol für die Behandlung von ulzerierten Hämangiomen eingesetzt.

Methoden: Im Zeitraum von Januar 2009 bis April 2010 wurden 40 Patienten mit proliferierenden Hämangiomen mit Propranolol an der Interdisziplinären Sprechstunde für „Hämangiome und vaskuläre Malformationen" am Universitätsklinikum Freiburg behandelt; hiervon hatten 5 Patienten ein ulzeriertes Hämangiom. Nach Aufklärung und kardiologischer Diagnostik mittels Echokardiographie und EKG wurde Propranolol mit $1 \mathrm{mg} / \mathrm{kg} \mathrm{KG/Tag} \mathrm{in} 2$ Gaben während des 1 . Tages, danach mit $2 \mathrm{mg} / \mathrm{kg} \mathrm{KG}$ in 2 Gaben verabreicht. Die Patienten wur- den für 2 Tage stationär mit Puls, Blutdruck und Blutzucker überwacht. Eine Fotodokumentation erfolgte vor Therapiebeginn, nach 2 Wochen, 4 Wochen und 3 Monaten.

Ergebnisse: Zu Beginn der Propranolol Therapie waren die Patienten 41, 51, 52, 58 und 180 Tage alt. Die ulzerierten Hämangiome waren am Mundwinkel, Ohrmuschel, Unterlippe, Labium majus und am behaarten Kopf lokalisiert. Bei 2 Patienten war bereits zuvor eine Farbstofflasertherapie durchgeführt worden. Bei 4 Hämangiomen zeigten sich 2 Wochen nach Therapiebeginn eine deutliche Abheilung und Abblassung des Hämangioms. Nach 4 Wochen waren alle Ulzera abgeheilt und eine Volumenreduktion vorhanden. Die Behandlung wurde nach 3 und 9 Monaten beendet und wird bei den anderen Patienten seit 4, 5 und 7 Monaten weiter fortgesetzt. Als Nebenwirkung trat lediglich bei einem Patienten eine Aktivitätsminderung auf.

Zusammenfassung: Ulzerierte Hämangiome sprechen auf die Therapie mit Propranolol sehr gut an. Es bleibt weiterhin unklar, welche Dosis und welche Therapiedauer gewählt werden muss. Klinische Studien sind hier unbedingt erforderlich.

\section{DGKJ-PV-164}

\section{Congenitale selbstheilende Retikulohistiozytose (CSHR) (Hashimoto-} Pritzker)

K. Linnemann' ', C. Niesytto ${ }^{2}$, A. Arnold ${ }^{3}$, S. Vogelgesang ${ }^{4}$, H. Cremer ${ }^{5}$,

R. Stenger ${ }^{1}$

${ }^{1}$ Ernst-Moritz-Arndt Universität, ${ }^{2}$ Kreiskrankenhaus Wolgast, ${ }^{3}$ Klinik und Poliklinik für Hautkrankheiten, ${ }^{4}$ Inst. für Pathologie, ${ }^{5}$ Heilbronn

Hintergrund: Die congenitale selbstheilende Retikulohistiozytose ist eine seltene sich nur an der Haut manifestierende histiozytäre Erkrankung. Die Diagnose wird aufgrund des klinischen Aspektes, des Verlaufs und der Histologie mit Immunhistochemie gestellt. Bislang sind nur ca. 6o Fälle weltweit beschrieben, es wird eine hohe Dunkelziffer angenommen, da die Diagnose aufgrund des günstigen Verlaufs wahrscheinlich häufig nicht gestellt wird.

Kasuistik: Nach unauffälliger Schwangerschaft Spontangeburt eines männlichen Kindes in der $39+2$ Schwangerschaftswoche. Unkomplizierte Primäradaptation. Initial fallen ca. $1 \mathrm{~cm}$ große livide Hautveränderungen im Verlauf mit hellem Grund auf. Bei Verdacht auf eine Infektionskrankheit wurde eine antibiotische-Therapie begonnen. Bei negativem IL-6 und CrP, negativer Serologie (Hepatitis A, B, C, HSV, CMV, VZV, Enterovirus, Röteln, Parvovirus B19, Toxoplasmose, Lues) und steriler Blutkultur und ansonsten klinisch unauffälligem Kind wurde die antibiotische Therapie abgesetzt. Nach Hinzuziehen eines externen Spezialisten wurde anhand von Fotos der hochgradige Verdacht auf eine CSHR gestellt und anhand einer anschließend durchgeführten Hautbiopsie mit typischem Nachweis Cdia positiver Langerhanszellen die Diagnose gesichert. Im Verlauf kam es zur vollständigen Abheilung der Effloreszenzen. Das Kind ist in onkologischer Betreuung, da nur durch den weiteren Verlauf eine systemische Langerhanszellhistiozytose sicher ausgeschlossen werden kann.

Diskussion und Schlussfolgerungen: Wir zeigen den seltenen Fall einer CSHR um auf dieses zumeist gutartig verlaufende Krankheitsbild aufmerksam zu machen. Die Diagnose konnte erst nach Hinzuziehen eines ausgewiesenen Spezialisten gestellt werden. Es ist wichtig die Diagnose zu stellen, weil in seltenen Fällen dem Bild einer CSHR eine systemische Langerhanszellhistiozytose zugrunde liegen kann und deshalb CSHR Patienten kinderonkologisch kontrolliert werden sollten.

DGKJ-PV-165

Differentialdiagnostische Besonderheiten bei kongenitalen vaskulären Tumoren

B. Jennewein

Ev. Elisabeth-Klinik

Der Vortrag befaßt sich mit differentialdiagnostischen Besonderheiten bei kongenitalen vasculären Tumoren. Es wird das Hämangioendotheliom klinisch vom tufted angioma abgegrenzt. Die Klinik, FKDS-Be- 
funde sowie die Therapie der Erkrankungen werden anhand von klinischen Beispielen erläutert.

\section{Varia II}

\section{DGKJ-PV-166}

Sektorenübergreifende Behandlungspfade als fachliches und ökonomisches Steuerungsmittel in der Pädiatrie

T. Wygold' ${ }^{1}$ W. Hellmann ${ }^{2}$, M. Hilmer'

${ }^{1}$ Kinderkrankenhaus auf der Bult, ${ }^{2}$ Fachhochschule Hannover

Seit seiner Einführung hat das moderne Krankenversorgungssystem keinen solchen ökonomischen Druck erfahren wie aktuell. Die Gründe sind vielfältig. Dieser Kostendruck, verbunden mit Erwartungen der Eltern bezüglich einer raschen Entlassung, trägt maßgeblich zu einer stetigen Verkürzung der Liegezeiten in der Pädiatrie bei. Damit rückt der ambulante und teilstationäre Sektor ins gesundheitsökonomische Interesse, um die Verkürzung oder Vermeidung einer stationären Behandlung kompensieren zu können. Das Kinderkrankenhaus auf der Bult hat sektorenübergreifende Behandlungspfade für die Beschwerdekomplexe „Chronische Bauchschmerzen“ und „Dystrophie“ eingeführt. Dafür wurden im Vorfeld Krankenunterlagen von 82 Patienten aus dem Patientengut der Tagesklinik des Kinderkrankenhauses auf der Bult aus einem Zeitraum von sechs Monaten retrospektiv ausgewertet bezüglich der Dauer der Beschwerden bis zu ihrer Abklärung und des Umfangs der im Kinderkrankenhaus durchgeführten Diagnostik. Für die Patienten mit chronischen Bauchschmerzen erfolgte die Auswertung außerdem spezifisch getrennt nach einweisenden Kinderärzten und einweisenden Hausärzten. Ergebnisse: Die mittlere Beschwerdedauer bis zur Vorstellung in der Tagesklinik betrug bei den Patienten mit chronischen Bauchschmerzen, wenn sie vom Kinderarzt eingewiesen wurden, 57,75 Wochen, wenn vom Hausarzt eingewiesen 95,82 Wochen, bei der Abklärung einer Dystrophie 42,08 Wochen. Die Kinderärzte unterschieden sich von den Hausärzten signifikant durch umfangreichere Vordiagnostik. Die Personal,- Sach- und Fixkosten zur Abklärung der Krankheitsbilder waren für das Kinderkrankenhaus auf der Bult so erheblich, dass in der Gewinn-Verlust Bilanz ein Gewinn von nur noch ca. $€$ 50,- pro Fall bei Patienten mit chronischen Bauchschmerzen blieb, pro Fall zur Abklärung einer Dystrophie ein Gewinn von ca. $€ 6,50$. Durch Einführung sektorenübergreifender Behandlungspfade für beide Krankheitsbilder wurde das diagnostische Vorgehen gemäß den derzeit gültigen Empfehlungen der Fachgesellschaften neu festgelegt und in Zusammenarbeit mit den niedergelassenen Kinder- und Hausärzten den verschiedenen ambulanten und teilstationären Institutionen zugeordnet. Dadurch konnte eine Steigerung der diagnostischen Qualität und daraus folgend Verkürzung der Beschwerdedauer erzielt werden bei gleichzeitiger Gewinnoptimierung für das Kinderkrankenhaus. Fazit: Sektorenübergreifende Behandlungspfade verbessern das Zusammenspiel ambulanter, teilstationärer und stationärer Versorgungsinstitutionen und optimieren das diagnostische Vorgehen und den ökonomischen Ertrag. In der Zukunft wird eine institutionsübergreifende Behandlung v. a. chronisch kranker Patienten ohne Einsatz sektorenübergreifender Behandlungspfade undenkbar sein.

\section{DGKJ-PV-167}

\section{Haar-Tourniquet-Syndrome}

L. Haftel, N. Noll, S. Gaupp, F. Wild, I. Henrichs

Kliniken St. Elisabeth Klinik f. Kinder.- u. Jugendmedizin

Ein 6 Wochen alter Säuglin wurde in der Notfallambulanz unserer Klinik vorgestellt, nachdem der Mutter ein langes Kopfhaar, welches sich um die 2., 3. und 4. Zehe des Kindes geschnürt hatte, aufgefallen sei. Die Mutter habe bereits versucht, das Haar von den Fußzehen zu lösen, was ihr aber nur von der 2. und 3. Zehe gelang.
Die klinische Untersuchung zeigte einen 6 Wochen alten Säugling in leicht reduziertem Allgemeinzustand mit einer dunkel lividen Verfärbung und Schwellung des 4. Zehen-endgliedes und Blasenbildung durch proximale zirkuläre Einschnürung der Haut. An der 2. und 3. Fußzehe zeigten sich kleine Einschnürungen der Haut als Zeichen nach Entfernung des strangulierenden Haars. Eine chirurgische Intervention wurde eingeleitet. Es konnten einzelne, die Fußzehe umschnürende Haarsträhnen entfernt werden. In den folgenden Wochen kam es zu einer kompletten Ausheilung ohne Gewebeverlust.

Das Haar-Tourniquet-Syndrom ist ein seltener Notfall, bei dem es zu Strangulationen von Fingern, Zehen und Genitalien durch Fremdmaterialien wie Haare, Schnüre oder Fasern kommt, die bei nicht sofortiger Entfernung zu Weichteilischämie und Nekrose führen können.

Das Haar-Tourniquet-Syndrom wird gehäuft bei Säuglingen im 4. Lebensmonat beobachtet, da in dieser Zeit bis zu 90\% aller Mütter einen übermäßigen postpartalen Haarausfall erleben. In den meisten Fällen handelt es sich um eine akzidentelle (ungewollte) Erkrankung. Einzelne Fälle sind in der Literatur aber auch in Verbindung mit Kindesmisshandlung beschrieben. Diese medizinische Notfallsituation verlangt stets eine rasche und effektive medizinische Intervention.
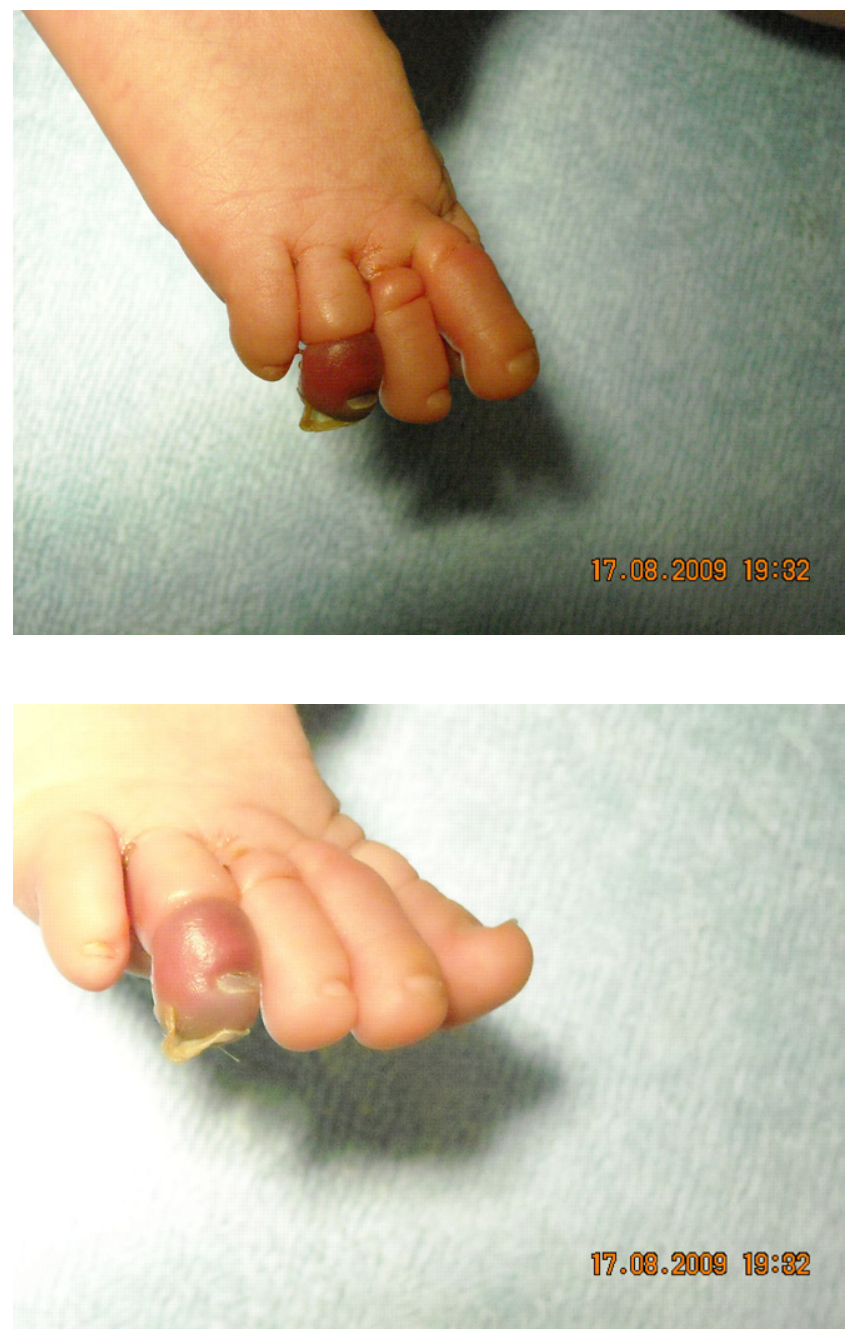

1: Alverson B. A genital hair tourniquet in a 9-year-old girl. Pediatr Emerg Care. 2007 Mar;23(3): 169-70.

2: Mat Saad AZ, Purcell EM, McCann JJ. Hair-thread tourniquet syndrome in an infant with bony erosion: a case report, literature review, and meta-analysis. Ann Plast Surg. 2006 Oct;57(4): 447-52. 
Kontakt: Dr. Lior Haftel, Klinik für Kinder- und Jugendmedizin $>$ St. Elisabeth<, Müller-Gnadenegg-Weg 4, D-86633 Neuburg. haftel20oo@ yahoo. de

\section{DGKJ-PV-168}

Nebenhodensarkoidose bei einem präpubertären Jungen V. Umlauf, W. Coerdt, R. Stein, R. Beetz

Universitätsmedizin der Johannes Gutenberg-Universität Mainz

Einleitung: Die Sarkoidose ist eine seltene multisystemische granulomatöse Entzündung unklarer - möglicherweise autoimmunologischer - Ätiologie, die sich klinisch im Kleinkindesalter durch die Trias Rash, Uveitis und Arthritis und im Jugendlichenalter als Lymphadenopathie mit pulmonaler Beteiligung präsentiert; weitere Organsysteme können betroffen sein.

Kasuistik: Der 12-jährige Junge befand sich bereits auf Grund rezidivierender Fieberschübe sowie Muskel- und Gelenkbeschwerden in unserer Betreuung. Akuter Vorstellungsgrund war eine schmerzhafte Schwellung des rechten Hodens, die zunächst auf ein sieben Tage zurückliegendes Trauma zurück geführt wurde. Die Ultraschalluntersuchung zeigte ein Hämatom des rechten Hodens, welches sich in der sonografischen Verlaufskontrolle 4 Wochen später nicht mehr nachweisen ließ. Klinisch zeigte sich nun jedoch eine indolente Verdickung des linken Hodens.

Diagnostik: Die Ultraschalldarstellung zeigte nun eine prominente Schwellung des linken und eine Verdickung des rechten Nebenhodens. Die Labordiagnostik ergab eine Beschleunigung der Blutsenkungsgeschwindigkeit, einen erhöhten löslichen Interleukin-2-Rezeptor sowie eine Erhöhung des Angiotensin-Converting-Enzymes (ACE). Der Tuberkulin-Hauttest war negativ. Die ophthalmologische Untersuchung ergab keinen Hinweis auf eine Uveitis; in der Röntgen-ThoraxDiagnostik konnte eine pulmonale Sarkoidose ausgeschlossen werden. Die Histologie des linken Nebenhodens ergab ein durch eine granulomatöse Entzündung destruiertes Nebenhodengewebe aus einem dichten Fibroblasten- und Kapillargefäß-Netz. In dieses eingebettet fanden sich zu Riesenzellen konfluierende CD68-positive Makrophagen, zwischen welche $\mathrm{CD}_{3}$-T-Lymphozyten eingestreut waren. Das histologische und immunhistochemische Bild ist vereinbar mit einer Sarkoidose.

Therapie: Wir begannen eine Steroidtherapie, in deren Verlauf es zu einer Normalisierung des ACE sowie einem Rückgang der Entzündungsparameter und der rechtsseitigen Nebenhodenschwellung kam. Die weiteren Kontrollen zeigten einen komplikationslosen Verlauf unter Langzeitsteroidtherapie, die nach 15 Monaten beendet werden konnte.

Diskussion: Der Urogenitaltrakt ist bei der Sakoidose selten beteiligt (o. $2 \%$ der erwachsenen Patienten). Weltweit sind in der Literatur etwa 6o Patienten mit urogenitaler Sarkoidose beschrieben, welche im Alter zwischen 20 und 40 Jahren oder selten älter waren. Wir beschreiben hier nach Erstbeschreibung 1982 die erste weitere Kasuistik eines Patienten mit Sarkoidose des Nebenhodens im Kindesalter. Zur Diagnosesicherung ist die Feinnadelbiopsie Methode der Wahl.

\section{DGKJ-PV-169}

Kinderklinik, Konsiliararzt und Patient Anspruch,Sicherheit, Wirtschaftlichkeit am Beispiel Kinderkardiologie.

M. Thiel' ${ }^{1}$ J. Hartmann², A. Längler ${ }^{1}$

'Gemeinschaftskrankenhaus, Abteilung für Kinder- und Jugendmedizin, ${ }^{2}$ Kinderkardiologische Schwerpunktpraxis

Aufgrund einer hohen Anzahl von entdeckten/bestätigten pathologischen Echokardiographiebefunden im Rahmen von durch Kinderärzte angeforderten kinderkardiologischen Konsiluntersuchungen führten wir eine retrospektive Analyse der untersuchten Patienten durch.

Es zeigte sich, dass bei der der Facharzt-gebundenen Indikationsstellung zur weitergehenden Untersuchung durch den kinderkardiologischen Konsilarzt die „Trefferquote“ sehr hoch war.
Durch ein durchdachtes Konzept für die Indikation zur Echokardiographie und zum kinderkardiologischen Konsil kann bei höchstmöglicher Sicherheit die Trefferquote optimiert werden und damit eine Ressourcen-schonende und damit auch kosteneffiziente Medizin gewährleistet werden.

\section{DGKJ-PV-171}

Erfahrungen von Kinder- und Jugendärzten in der Betreuung von Patienten mit Migrationshintergrund - Ergebnisse einer Querschnittsbefragung

T. Langer ${ }^{1}$, F. Aksu' ${ }^{2}$, O. Ipsiroglü ${ }^{3}$, E. Sievers ${ }^{4}$, M. Huemer ${ }^{5}$, M. Knipper ${ }^{6}$ ${ }^{1}$ Klinikum Wuppertal GmbH Zentrum f. Kinder- u. Jugendmedizin, ${ }^{2}$ Vestische Kinderklinik, ${ }^{3}$ University of British Columbia, ${ }^{4}$ Akademie für öffentliches Gesundheitswesen in Düsseldorf, ${ }^{5}$ Landeskrankenhaus Bregenz, ${ }^{6}$ Zentrum für Kinderheilkunde der Justus-v.-Liebig-Universität

Einleitung: Ungefähr 20\% aller Menschen in Deutschland haben einen Migrationshintergrund. Die medizinische Versorgung dieser heterogenen Bevölkerungsgruppe ist häufig durch sprachliche Verständigungsprobleme sowie kulturelle und sozio-ökonomische Unterschiede geprägt und teilweise erschwert. Einsichten in die Erfahrungen von Pädiatern in der Versorgung von Kindern in Familien mit Migrationshintergrund können helfen, gezielte Unterstützungsangebote für die Praxis zu entwickeln.

Methode: Bei der 106. Jahrestagung der DGKJ war Transkulturelle Paediatrie ein Hauptthema. Aus diesem Anlass wurde eine schriftliche Befragung der Kongressteilnehmer durchgeführt. Ein multidisziplinäres Team aus den Bereichen Pädiatrie, Ethnologie und Fragebogenentwicklung entwickelte den aus 39 Items und drei offenen Fragen bestehenden Fragebogen, der in kognitiven Pretests mit 5 Kinderärzten getestet wurde.

Im Anschluss an die schriftliche Befragung wurden vertiefende, halbstrukturierte Telefoninterviews mit Teilnehmern durchgeführt, die sich dazu bereit erklärten.

Die Auswertung der quantiativen Daten erfolgt mittels deskriptiver Statistik, die der offenen Fragen und Transkripte der Telefoninterviews mittels integrativ hermeneutischer Verfahren in einer Gruppe.

Ergebnisse

229 Teilnehmer füllten den Fragebogen aus (33\% niedergelassen, 67\% angestellt, $18 \%$ mit Migrationshintergrund). Sprachliche Verständigungsprobleme wurden häufig genannt $(75 \%)$. Übersetzung durch Familienangehörige (65\%) oder Mitarbeiter und Kollegen mit Fremdsprachenkenntnissen (35\%) sind die am häufigsten genannten Hilfsstrategien. Der Einfluss von kulturellen und Bildungsunterschieden auf Diagnoseverständnis und Therapieadhärenz wird sehr unterschiedlich bewertet. Unter den befragten Ärztinnen und Ärzten lassen sich idealtypisch 3 verschiedene Grundhaltungen gegenüber dieser Thematik identifizieren: 1) Kulturelle Vielfalt als Bereicherung, 2) Idealistisch, den Benachteiligten helfend, 3) Belastet durch mangelndes Verständnis der Patienten.

Diskussion: In der pädiatrischen Praxis bestehen erhebliche sprachliche und sozio-kulturelle Herausforderungen. Wie diese Probleme erlebt und bewertet werden, hängt zum einen von soziodemographischen Faktoren der Patienten im eigenen Berufsfeld, zum anderen auch von Faktoren der Ärzte selbst ab. Maßnahmen zur Verbesserung der Gesundheitsversorgung von Patienten mit Migrationshintergrund sollten neben der Bereitstellung von adäquaten Übersetzungshilfen auch Fortbildungen im Bereich transkultureller Kommunikation umfassen, die gezielt die Wahrnehmungen, Erfahrungen und in der Praxis als hilfreich erprobte Handlungsoptionen berücksichtigen. 
DGKJ-PV-172

Daidalos-ein Projekt zur Prävention und Gesundheitsvorsorge an einer Münchner Brennpunktschule

i. v. Blomberg', A. STREBER ${ }^{2}$

${ }^{1}$ Referat für Gesundheit und Umwelt ${ }^{2}$ Ernährungsinstitut Kinderleicht

Fragestellung: Die Gesundheitsrisiken für sozial benachteiligte Kinder und Jugendliche sind Bewegungsmangel, Fehlernährung und Übergewicht sowie psychosoziale Belastungen und können zu chronischen körperlichen und psychischen Störungen und eingeschränkter schulischer Leistungsfähigkeit führen. Dieses beeinträchtigt die Chancengleichheit für einen gesunden Eintritt ins Erwachsenenalter. Um diese Risikogruppe zu erreichen, sind niederschwellige, interdisziplinäre Angebote vor Ort, in der Lebenswelt der Kinder und Jugendlichen erforderlich. Diesen Voraussetzungen entspricht das präventive Projekt Daidalos, das an einer Hauptschule in einer Brennpunktregion im Münchner Norden durchgeführt wird. Material und Methoden: Über einen Zeitraum von 2 Jahren (März 2009-Februar 2011) nehmen 200 Schüler/innen der 5ten und 6ten Klasse an gesundheitsfördernden Maßnahmen teil. Dazu gehören Bewegungsförderung, Bio Frühstück und Mittagessen, Entspannungstraining, erlebnispädagogische Aktivitäten und Adipositasschulung. Zusätzlich finden Fortbildungen und Supervision für Lehrer und Schulsozialarbeit, Elternbildung, Multiplikatorenschulung zu Ess- und Kochverhalten Eltern-Kind-Aktivitäten statt. Die Kinder werden körperlich untersucht (To,T1 und T2) ebenso eine vergleichbare Kontrollgruppe (To / T1 ohne Intervention). Es werden Schüler, Eltern und Lehrerfragebögen zu Selbstwert, Lebensgefühl, subjektiven Gesundheitsfragen (To/T1) analysiert. Zwischenergebnisse: Teilnahme: 106 Schüler/innen und Eltern ( $53 \%$ von 200), davon 55,5 \% Mädchen 44,4\% Jungen, Migrationshintergrund 80,8 \%, davon größte Gruppe $29 \%$ türkisch-, gefolgt von $7,5 \%$ afghanischstämmigen Kindern. Übergewicht Jungen 30,7\%, Mädchen $28 \%$. Im Deutschen Motoriktest (DMT) zeigte sich eine geschlechtsunspezifische, signifikante Unterdurchschnittlichkeit. Von den 60 angesprochenen Kindern haben sich $24 \mathrm{zu}$ einem außerschulischen wöchentlichen Sportförderprogramm angemeldet. Von den 30 übergewichtigen Kindern nehmen 8 Jungen und 10 Mädchen an einer einjährigen spezifischen Adipositasschulung an der Schule teil. Ergebnisse zu Auswirkungen auf Lernverhalten und Konzentration stehen noch aus (Lehrerbeobachtungen und Selbsteinschätzung). Diskussion: In der ersten Hälfte der Projektlaufzeit (2009 - 2011) konnten verschiedene Module im Bereich Bewegung, Ernährung und Entspannung eingesetzt werden. Die gute Compliance bei der Adipositasschulung bestätigt, dass Präventionsangebote für sozial benachteiligte Kinder vor Ort in der Schule durchgeführt werden sollten. Große Schwierigkeiten zeigen sich hingegen in der Elternbeteiligung. Auch hier braucht es ein Angebot vor Ort (Gehstruktur). Schlussfolgerungen: Kinder aus sozial schwachen Familien müssen aktiv an einen gesunden Lebensstil herangeführt („, an die Hand genommen") werden. Dieses ist nur in ihrer üblichen Lebenswelt möglich. Da das häusliche Umfeld dieses oft nicht leistet, bietet sich die Schule/Kindergarten für diesen ganzheitlichen Settingansatz an. Nachhaltigkeit kann nur über die erfolgreiche und dauerhafte Implementierung als gesundheitsfördernde Schule erreicht werden. Auch die Einbindung der Kinder- und Jugendärzte/innen des ÖGD mit regelmäBiger Präsenz an der Schule ist erforderlich, um auf der individuellen Ebene Gesundheitsvorsorge anzubieten und die Kinder der regulären medizinischen Versorgung (geringe Akzeptanz der J1+2) zuzuführen.

\section{DGKJ-PV-173}

\section{Maligne Hyperthermie: ,,abortive“ Form - und doch gefährlich}

B. Klawitter, A. Heinzmann, A. Superti-Furga

Universitäts - Kinderklinik

Hintergrund: Die Maligne Hyperthermie (MH) ist eine potentiell dramatisch verlaufende Krankheit der Skelettmuskulatur, welche durch die Gabe von Triggersubstanzen (Suxamethonium, volatile Anästhetika) ausgelöst wird. Eine Vielzahl zugrunde liegender Mutationen im Rya-
nodin-Rezeptor-Gen (RYR1) sind bekannt. Neben dem „klassischen“ fulminanten Verlauf mit metabolischer Entgleisung (Hyperkapnie, Hypoxie, Azidose), massiver Rhabdomyolyse, Hyperthermie und Multiorganversagen ist ein weites klinisches Spektrum von sogenannten „abortiven“ Verläufen bis hin zur Minimalform des isolierten Masseterspasmus beschrieben. Kasuistik: Der 2-jährige Junge bedurfte nach einem häuslichen Unfall einer chirurgischen Wundversorgung. Nach Narkoseeinleitung und Relaxation mittels Suxamethonium fiel ein ca. 6o Sekunden anhaltender Masseterspasmus auf; der weitere Verlauf der Narkose war problemlos. Bei Übernahme zur postoperativen Überwachung sahen wir ein klinisch unauffälliges Kind in stabilem Zustand. Es zeigten sich jedoch stark erhöhte Werte für Kreatinkinase (CK) und Myoglobin im Serum, die CK stieg im Folgenden bis auf ein Maximum von $44000 \mathrm{U} / \mathrm{l}$ an. Die Verdachtsdiagnose einer $\mathrm{MH}$ wurde gestellt. Nach Rücksprache mit der MH-Hotline wurde bei klinisch stets unauffälligem Kind, ausgeglichenem Säure-Base-Haushalt, Normothermie und stabiler Kreislaufsituation keine Dantrolen-Therapie durchgeführt. Unter forcierter Hydrierung stets stabile Diurese, keine Myoglobinurie, keine Zeichen der Entwicklung einer Crush-Niere. Die Entlassung erfolgte am 3. postoperativen Tag, bis zum 10. Tag nach OP kam es zur kompletten Normalisierung aller Laborparameter bei anhaltend unauffälliger Klinik. Im folgenden Nachweis der MH-definierenden Mutation G730oA (Exon 45). Schlussfolgerung: Ein gesteigerter Muskeltonus im Zuge einer Vollnarkose unter Verwendung potentieller Triggersubstanzen der $\mathrm{MH}$ ist stets ernst $\mathrm{zu}$ nehmen und erfordert eine intensive perioperative Überwachung sowie gegebenenfalls die rasche Gabe von Dantrolen. Auch bei klinisch blandem Verlauf kann - wie bei unserem Patienten - eine progrediente Rhabdomyolyse auftreten, der Übergang in eine fulminante MH ist noch Stunden nach Ende der Narkose möglich. Negative Familienanamnese für MH und/oder frühere ereignislose Narkosen des Patienten selbst sind kein sicherer Indikator gegen das Vorliegen einer MH. Die Verwendung von Suxamethonium in der Kinderanästhesie sollte daher nach Möglichkeit vermieden werden. Bei Verdacht auf MH-typische Symptome bei früherer Narkose oder Nachweis einer MH- Mutation beim Patienten oder bei Familienangehörigen muss konsequent auf ein triggerfreies Narkoseverfahren geachtet werden. MH-Patienten bedürfen ausführlicher Aufklärung über die Erkrankung sowie der Ausstellung eines Notfallausweises, welcher stets am Körper getragen werden sollte.

\section{DGKJ-PV-174}

\section{Sexueller Missbrauch durch Minderjährige - eine Fallanalyse}

D. Vlajnic ${ }^{1}$, M. Krause ${ }^{2}$, M. Mensching ${ }^{2}$, M. Noeker ${ }^{1}$, M. Lentze' ${ }^{1}$, I. Franke ${ }^{1}$

${ }^{1}$ Universitätsklinik Zentrum f. Kinderheilkunde, ${ }^{2}$ St. Marien-Hospital

Fragestellung: Der sexuelle Missbrauch durch minderjährige Täter ist häufiger als angenommen. Die Daten der Kinderschutzgruppe Zürich weisen 199941 Prozent aller Täter unter 18 Jahren auf, 2007 waren es bereits 57\%. (Landolt, Kinderschutzgruppe Zürich). Ziel unserer Untersuchung war es, in unserem Patientenklientel das Täterprofil unter diesem Aspekt zu erfassen

Material und Methode: 2006 wurde die KinderSchutzGruppe der Universitätskinderklinik Bonn ins Leben gerufen, seit 2009 besteht eine gemeinsame Kinderschutzgruppe für Bonn bestehend aus allen Kliniken, die Kinder behandeln. Kinder mit Verdacht auf stattgehabten Missbrauch werden seit 2009 in zwei Zentren der Kinderschutzgruppe vorgestellt: St.-Marien-Hospital Bonn und Universitätskinderklinik Bonn. Erfasst wurden alle Kinder, die sich ab 2009 einer kindergynäkologischen Untersuchung in einem dieser Zentren unterzogen haben. Eine psychologische Betreuung wurde bei Opfern und Tätern durchgeführt.

Ergebnisse: In 17 Monaten wurden 31 Kinder im Alter zwischen 3 Jahren und 12 Monaten kindergynäkologisch untersucht. Eine stattgehabte Penetration konnte bei zwei Kindern nachgewiesen werden. Bei 12 Kindern (40 \%) wurden als mutmaßliche Täter Minderjährige angegeben. Der jüngste mutmaßliche Täter war 8 Jahre alt, der älteste 16 Jahre. Bei präpubertären Tätern wurde oft eine Penetration - ohne Erfolg - ver- 
sucht oder der Koitus nachgeahmt; bei pubertären Tätern wurden in den meisten Fällen sexuelle Handlungen „erprobt“. Sämtliche Täter waren männlich. Meistens waren es Verwandte (Geschwister, Cousin), die im Rahmen ihrer sexuellen Entwicklung ein sexuell fehlgeleitetes Verhalten aufwiesen und sich primär keiner Schuld bewusst waren. Ein geringerer Teil waren Freunde oder Bekannte. Sämtliche dieser 12 Fälle wurden in psychologischen Gesprächen mit den Tätern aufgearbeitet und haben sich somit bestätigt.

Diskussion: Laut BKA-Statistik stellen männliche Jugendliche - gemessen an ihrem Anteil an der Gesamtbevölkerung - den größten Anteil der Tatverdächtigen bei Delikten gegen die sexuelle Selbstbestimmung von Mädchen und Jungen (Waschlewski 1999).

In unserer Studie waren die psychologischen Auswirkungen bei den Opfern unverändert zu den Opfern, die von Erwachsenen missbraucht wurden. Bei den Tätern fiel auf, dass die meisten kein Schuldbewusstsein hatten und es als harmloses "Spiel“ betrachteten.

Schlussfolgerung: In 40\% der Fälle von sexuellem Missbrauch von Kindern und Jugendlichen waren Kinder und Jugendliche die Täter. Trotz des großen Ausmaßes der sexuellen Gewalt durch minderjährige Täter mangelt es bislang an Konzepten zur Täterprävention. Kinder und Jugendliche, die unter dem Verdacht auf sexuellen Missbrauch vorgestellt werden sollten ihre körperliche und psychologische Untersuchung unter dem Dach einer Kinderschutzgruppe erfahren.

Mehr Informationen zu Kinderschutzgruppen in Deutschland unter www. KinderSchutzGruppe. de

\section{DGKJ-PV-175}

Massiver primär vaginaler Chylus-Ausfluss bei einem 12-jährigen Mädchen mit ausgeprägter Lymphopenie.

K. Lang' ', S. Puig ${ }^{2}$, A. Handke-Vesely ${ }^{3}$, A. Schulz' ${ }^{1}$ C. Posovszky

${ }^{1}$ Klinik für Kinder- und Jugendmedizin, ${ }^{2}$ Radiologische Klinik Universitätsklinikum Ulm, ${ }^{3}$ Universitätsfrauenklinik Ulm

Das Chylus-Reflux-Syndrom ist eine Manifestationsform einer primären oder sekundären lymphatischen Obstruktion. Aufgrund eines unzureichenden lymphatischen Abflusses über die Lymphgefäße und deren Klappen kann es zum Ausfluss von Lymphe über die Blase, Rektum, Uterus oder Vagina kommen. Wir berichten über eine 12-jährige Patientin mit der sehr seltenen Manifestation eines primären vaginalen Chylus-Reflux-Syndroms.

Bei Vorstellung litt das Mädchen unter massivem vaginalem Ausfluss von über 11 und war genötigt, Windeln zu tragen. Außerdem bestand eine Staphylodermie. Zunächst wurde sie gynäkologisch untersucht und ein Fremdkörper sowie eine Infektion als Ursache ausgeschlossen. Im Labor fand sich jedoch eine ungewöhnlich ausgeprägte Lymphopenie mit 50o/ $\mu \mathrm{l}$ und eine Hypoproteinämie. Die anschliessende zytologische Untersuchung des Ausflusses zeigte hauptsächlich lymphomonozytäre Zellen. In der MR-Tomografie mit Kontrastmittel des Abdomens inklusive Beckens fanden sich deutlich dilatierte Lymphbahnen beidseits entlang der inneren Beckenwand bis auf Höhe der Nieren. Ein ursächlich obstruierender Tumor in diesem Bereich konnte ausgeschlossen werden. Es fanden sich auch keine weiteren lymphatischen Malformationen.

Lymphangiektasien werden primär chirurgisch entfernt oder auch radiologisch interventionell verödet. Wir haben aufgrund des nicht unerheblichen Risikos dieser Eingriffe zunächst einen konservativen diätetischen Versuch unternommen. Unter der Vorstellung einer Volumenreduktion der gesamten Lymphflüssigkeit durch Reduktion der zu transportierenden Fette erhielt die Patientin eine Diät mit mittelkettigen Triglyceriden (MCT). Hierunter ist sie beschwerdefrei, der Ausfluss ist sistiert und es ist keine Lymphopenie sowie keine Hypoproteinämie mehr nachweisbar.
DGKJ-PV-176

Erfolgreiche lokale Lysetherapie bei akutem arteriellem Gefäßverschluß des Unterschenkels bei einem Schulkind mit angeborenem Herzfehler

L. Celik', E. Fiehn², K. Papakostas', J. Reissmann², R. Hambrecht'², J. Nürnberg'

'Zentralkrankenhaus links der Weser Klinik für Kinder und Jugendlicher, ${ }^{2}$ Klinik für Kardiologie und Angiologie

Ein akuter thrombotischer arterieller Gefäßverschluß ist im Kindesalter sehr selten. Therapieoption ist die systemische Lyse oder chirugische Thrombektomie, die aufgrund der kleinen kindlichen Gefäße Limitationen hat. Alternativ kann eine lokale Lysetherapie (LT) erfolgreich eingesetzt werden.

9 jähriges Mädchen (136 cm, 26,4 kg), biventrikulär korrigierter komplexer Herzfehler, epikardialer Schrittmacher (SM) bei postop. AVBlock III ${ }^{\oplus}$, Synkope beim Fußballspiel durch kardiale Dekompensation bei SM-Batterie-Erschöpfung unbekannter Dauer. Intensivmed. Rekompensation und SM-Aggregatwechsel. Danach arterielle Thrombose linker Unterschenkel (US) ungeklärter Genese (HIT, DIC, Embolie?), schmerzfreie Gehstrecke $125 \mathrm{~m}$. Systemische LT (r-tPA) ohne erfolgreiche Revaskularisation (Abbruch 3. Tag, Hämatome, Hb-Abfall von 11,6 g/dl auf 8,2 g/dl). Angiographisch Verschuß der A. poplitea, Perfusion des US über Kollateralen, fehlende Perfusion im distalen US und Fuß. Nach Aspiration thrombotischen Materials (Art. femoralis links ${ }_{5} \mathrm{~F}$ ) lokale LT über 10/135 Lysekatheter (LK) (r-tPA, Bolus $2 \mathrm{mg}$, DTI $0,7 \mathrm{mg} / \mathrm{kg} / 24 \mathrm{~h}$ ). Nach 5 Stunden vital bedrohliche Ischämie des distalen US und Fuß bei Spastik der A. femoralis superficialis (AFS) um den LK, Verschluß der distalen AFS am Übergang zur A. poplitea, US-Gefäße nicht darstellbar. Entfernen des LK, Angioplastie der AFS (2,8 mm), Wechsel auf 4 F Schleuse, Fortführung der arteriellen LT ohne LK und additive Vasodilatation (Alprostadil, Bolus $10 \mu \mathrm{g}$, DTI $0,5 \mathrm{ng} / \mathrm{kg} / \mathrm{min}$ für $12 \mathrm{~h}$ ). Erfolgreiche Reperfusion, Lepirudin-DTI für 5 Tage. Sonographisch komplette Rekanalisation. Sekundärprophylaxe mit Warfarin und ASS für 3 bzw. 7 Monate. Rezidivfreiheit 15 Monate (Laufbandbelastung $1023 \mathrm{~m}$ ohne Beschwerden).

Eine lokale LT kann auch im Kindesalter bei arterieller Thrombose und ineffektiver systemischer LT, eine therapeutische Option darstellen. Kleine Schleusen und eine additive lokale medikamentöse Vasodilatation können notwendig sein.

\section{DGKJ-PV-178}

Multiple Hämangiome und Hämangiomatose - Risikofaktoren für Organmanifestation und Ergebnisse über einen Zeitraum von acht Jahren

C. Schupp 1 , S. Holland-Cunz' ${ }^{1}$ J. Schenk' ${ }^{1}$ H. Weisser ${ }^{1}$, D. Grimm², P. Günther ${ }^{1}$ ${ }^{1}$ Universitätsklinikum Heidelberg, ${ }^{2}$ Klinikum d.Ruprecht-Karl- Universität

Einleitung: Hämangiome sind die häufigsten Tumore des Säuglingsalters. Multiple Hämangiome können mit Hämangiomen von inneren Organen einhergehen. Zu den Risikofaktoren dieser Organmanifestationen, sowie zu den Langzeitergebnissen von Patienten mit multiplen Hämangiomen gibt es nur wenige Daten. Patienten und Methoden: Patienten mit drei oder mehr kutanen Hämangiomen wurden hinsichtlich patientenbezogener Daten, Verteilung der Hämangiome, Ergebnissen radiologischer Bildgebung, Therapieformen, klinischem Verlauf und klinischen Ergebnissen evaluiert. Wir analysierten Risikofaktoren für Organbeteiligung, sowie den klinischen Verlauf. Ergebnisse: Bei den 52 Patienten betrug das durchschnittliche Geburtsalter 32. 8 SSW. Die Bildgebung zeigte intraabdominelle Hämangiome in $13,5 \%$, aber keine intracerebralen Hämangiome. Frühgeborene $(\mathrm{p}=0.02)$ und Kinder mit einer hohen Anzahl an kutanen Hämangiomen ( $\mathrm{p}=0.02)$ hatten ein höheres Risiko für Organmanifestationen. Kryotherapie wurde zu zumindest einmal und in einer Lokalisation bei 73. 1\% der Patienten durchgeführt, eine farbstoffgepulste Laserung bei 11. $5 \%$, eine perkutane/ intraläsionale Laserung bei 28. 8\%, eine Exzision bei 32. $7 \%$ und eine systemische Medikamentengabe bei $15.4 \%$. Eine lebensbedrohli- 
che Komplikation ergab sich bei einem Kind (1. 9\%). Keiner der Patienten starb. Schlussfolgerung: Die Verläufe von Patienten mit multiplen Hämangiomen zeigen zumeist ein positives Ergebnis. Organmanifestationen sind relativ häufig, Komplikationen selten, aber potentiell lebensbedrohlich. Wir empfehlen ein Ultraschallscreening, ggf. auch ein MRT des Abdomens bei Patienten mit drei oder mehr kutanen Hämangiomen, besonders bei Frühgeborenen. Hinsichtlich der Therapieoptionen ist Propranolol eine Alternative für eine steigende Anzahl von Kindern.

\section{DGKJ-PV-203}

Parry-Romberg-Syndrom und zirkumskripte Sklerodermie „en Coup de Sabre" mit kontralateraler cerebraler Beteiligung bei einem 12 Jahre alten Jungen -Kasuistik-

M. Dreesmann', T. Grimm', B. Weschke², R. Keitzer², K. Terstegge ${ }^{3}$, M. Radke' ${ }^{1}$ Klinik für Kinder- und Jugendmedizin, Ernst-von-Bergmann-Klinikum, ${ }^{2} \mathrm{Kli}$ nik für Neuropädiatrie und Klinik für Pädiatrie, Charité Universitätsmedizin, ${ }^{3}$ Mediclin Plau am See

Einleitung: Die zirkumskripte Sklerodermie en Coup de Sabre und die progressive faziale Hemiatrophie (Parry-Romberg-Syndrom) sind seltene, bisher ätiologisch nicht geklärte Erkrankungen des Kindesalters und treten nicht selten zusammen auf. Bei der linearen zircumskripten Sklerodermie entwickelt sich an Orbita, Stirn und Schädel eine chronisch fibrosierende Bindegewebsreaktion bis hin zu einer narbigen Alopezie. Das Parry-Romberg-Syndrom geht mit einer atrophischen Umwandlung von subkutanem Fettgewebe, Muskel und Knochen einer Gesichtshälfte einher. Bei einer cerebralen Beteiligung können die Patienten beschwerdefrei sein, häufig finden sich als Symptome Krampfanfälle, Kopfschmerzen, Verhaltensstörungen und Lernschwächen.

Kasuistik: Wir berichten über einen 12 Jahre alten Jungen, der im Alter von 10 Jahren aus dem Laufen heraus gestürzt war und sich ein leichtes Schädelhirntrauma sowie eine Klavikulafraktur zugezogen hatte. Ursächlich für den Sturz wurde ein Krampfanfall diskutiert. Die Vorgeschichte des Patienten ist bis auf eine periphere Facizalisparese rechts ohne Borreliennachweis unauffällig. In der bildgebenden Diagnostik fanden sich in der rechten Hemisphäre fleckförmige, nicht scharf abgegrenzte und zum Teil konfluierende Hyperintensitäten. MRT-Verlaufsuntersuchungen ergaben zusätzlich neu auftauchende und wieder verschwindende zyklische Strukturen, die Kontrastmittel anreicherten. Klinisch zeigte sich neben einer Alopezie links parietal eine linksseitige, progrediente Gesichtsasymmetrie mit Beteiligung von Stirn- und Periorbitalregion. Der neurologische Befund ergab im Verlauf eine Hemiparese links sowie migräneartige Kopfschmerzen. Wir berichten über die durchgeführte Diagnostik und Therapie.

Zusammenfassung: Krampfanfälle, Paresen, Kopfschmerzen und andere unspezifische Symptome können auf eine zirkumskripte Sklerodermie en Coup de Sabre oder ein Parry-Romberg-Syndrom mit cerebraler Beteiligung hinweisen. Eine gründliche Inspektion von Haut und Haaren sowie die Begutachtung der Gesichtssymmetrie sind wegweisend für die Diagnosestellung. Die neurologische Untersuchung kann klinische Hinweise zu den betroffenen Hirnregionen liefern. Insbesondere bei unklaren cerebralen MRT-Veränderungen sollte eine rheumatologische Grunderkrankung immer in die Differentialdiagnostik aufgenommen werden.

\section{Jugendmedizin}

\section{DGKJ-PV-179}

Die Probandeninformation in der Forschung mit Kindern und Jugendlichen Eine Analyse und ein Vorschlag aus der Praxis der Ethikkommission

E. Fukala

Ethikkommission des Landes Sachsen-Anhalt

In 30 bei nicht-universitären Ethikkommissionen eingereichten Forschungsprojekten mit Kindern und Jugendlichen wurden die Probandeninformationen für Eltern und Kinder untersucht. Viele Patienteninformationen für Eltern waren unvollständig oder fehlerhaft. Die angemessenen Informationen für Kinder fehlten entweder in fast jeder zweiten Prüfunterlage und/oder hatten Mängel, wie ungenügende und abwiegelnde Auskünfte über mögliche unangenehme Begleiterscheinungen und Schutz vor Schwangerschaft. Das Recht der Kinder auf Information und Selbstbestimmung sowie das Arzneimittelgesetz erfordern bei der Forschung mit Kindern sorgfältig ausgearbeitete und redliche Patienteninformationen. Es wird ein Entwurfs-Vorschlag für 10-14 jährige Kinder angeboten.

\section{DGKJ-PV-180}

Was wird aus unseren Kindern und Jugendlichen? : Kardiovaskuläres Risikofaktorenprofil von Adoleszenten und jungen Erwachsenen in Deutschland

R. Eyermann

Dr. Richard Eyermann

Kardiovaskuläre Erkrankungen sind führende Ursache für Morbidität u. vorzeitige Mortalität in industrialisierten Staaten u. vielen Entwicklungsländern.

Kardiovaskuläre Risikofaktoren (CVRF) u. gesundheitlich ungünstige Lebensgewohnheiten werden zunehmend früher etabliert. Studien zum Bewegungs-, Ernährungs- u. Gesundheitsverhalten von Heranwachsenden dokumentieren besorgniserregende Entwicklungen. Ungünstige Lebensgewohnheiten, wie z. B. Bewegungsmangel, Fehl-/Überernährung u. Rauchen, werden häufig schon in der Schulzeit fixiert. Untersuchungen fokussieren insbesondere auf schulpflichtige Kinder $u$. Jugendliche bis zum Alter von $18 \mathrm{~J}$..

Fragestellung: Inwieweit verstärken sich negative Verhaltensmodifikationen bei jungen Erwachsenen?

Ergebnisse: Anthropometrische (BMI, Taillenumfang, Körperfettanteil) u. gesundheitsrelevante Daten (Bewegungsmangel, Rauchen) sowie Häufigkeit CVRF belegen im Querschnitt in der Altersgruppe 16-25 J. eine deutliche Zunahme gesundheitlich ungünstiger Merkmale v. a. bei 20- bis 25-Jährigen: Bei 25-jährigen Männern $50 \%$ übergewichtig, $60 \%$ rauchen u. ca. 1/3 sportabstinent. Bei 16-25 jährigen Frauen "nur" 1/4 übergewichtig, jedoch Frauen wesentlich seltener sportlich aktiv. Nur 1/4 aller 16-25 Jährigen weist keinen näher betrachteten CVRF auf.

Diskussion: „Fit-fürs-Leben“-Analysen belegen erhebliche Dynamik ungünstiger Lebensstilentwicklungen nach 18. Lj.. Beunruhigende Feststellung wird verstärkt bei Vorbetrachtung von Kindern u. Jugendlichen: Im zeitlichen Verlauf zunehmend schlechte Daten für Deutschland, Kinder u. Jugendliche: 1,9 Mio. übergewichtig (15\%), davon 800000 adipös $(6,3 \%)$, über 50000 mit iGT, über 8000 mit Dm2, $4-5 \%$ essenzielle Hypertoniker, Raucher bis 43,3\% Jungen u. 42\% Mädchen, sportmotorische Leistungsfähigkeit vs. 1995 heute nur noch 80\% Jungen u. $74 \%$ Mädchen.

V. a. übergewichtige Jugendliche mit geringem Bildungsniveau u. Bewegungsmangel erwerben bereits im jungen Erwachsenenalter signifikante CVRF. Bislang initiierte Präventionsmaßnahmen sind ineffizient. Auch ist die praktische Umsetzung effizienter Präventionskonzepte nach Verlassen der Schule schwieriger. Im Hinblick auf gravierenden Anstieg von übergewichtigen bzw. untrainierten 20-25 jährigen ist Aufwertung der Prävention u. Implementierung spezifischer Maß- 
nahmen erforderlich. Viele Menschen gilt es möglichst früh zu aktivem, gesunden Lebensstil zu motivieren. Ziel setzt als vordringliches gesamtgesellschaftlichen Anliegen - inzwischen weltweites Anliegen: „die Fettwelle rollt" u. damit auch das metabolische Syndrom, Dm2 u. Herz-Kreislauf-Erkrankungen - ebensolchen Ansatz voraus u. gelingt nur, wenn in institutionsübergreifenden Präventionskampagnen Kindergärten, Schulen, Vereine, Gesundheitskassen, Betriebe, Medien u. Politik zusammenarbeiten u. uns Ärzte unterstützen. Interessante Aspekte dabei Ganztagsschulen mit Vorteil positiver Lebenstilmodifikation (Ernährung, Bewegung u. Sport, Rauchen, PC- u. TV-Konsum) aber auch wesentlich mehr Präventionsanreize durch Krankenkassen u. Gesundheitspolitik, mit enormem potenzierenden präventivmedizinischen Benefit u. Gesundheitskosteneinsparung.

Konklusion: Gesundheitlich negative Entwicklungen nehmen nach dem 20. Lj. erheblich zu. Dringend erforderlich sind effiziente, institutionsübergreifende Präventionskampagnen, die gesundheitsbewussten Lebensstil fördern $\mathrm{u}$. begleiten.

26 Mio. übergewichtige Kinder u. Jugendliche 2010 in EU Übergewichtige Kinder - Arterien bereits früh geschädigt: bereits mit 12 Jahren signifikant pathologische Endothelfunktion (Reaktiver Hyperämie-Index, RHI) und IMT bei adipösen Kindern im Vergleich zum Kontrollkollektiv
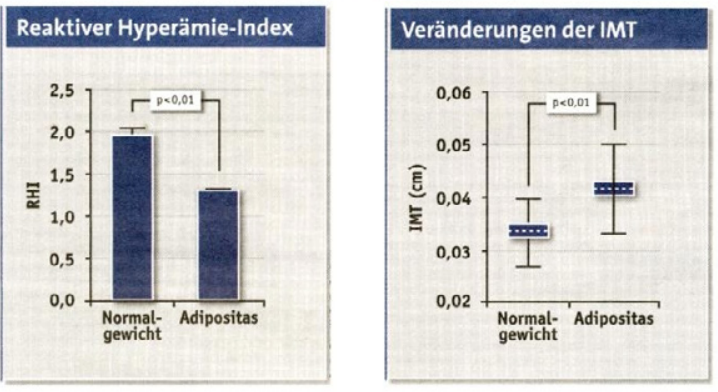

\section{DGKJ-PV-181}

Ist das Aufmerksamkeitsdefizitsyndrom eine Erkrankung des autonomen Nervensystems?

R. Buchhorn, C. Willaschek, V. Kinderärzte des Main Tauber Kr Caritas Krankenhaus Bad Mergentheim

Am 2. 9. 2006 wurde eine sog. „black-box Warnung“ der Food and Drug Administration FDA zum Risiko von Herzkreislauf-Erankungen beim Einsatz von Stimulantien bei Aufmerksamkeitsdefizitsyndrom (ADS) publiziert. Seither führen wir regelmäßig auf Zuweisung bei diesen Kindern Langzeit EKG Untersuchungen durch. Die systematische Auswertung dieser Untersuchungen hat wichtige Erkenntnisse zur Pathophysiologie des ADS ergeben.

Methode: Es erfolgte eine Rhythmus- und Herzfrequenzvariabilitätsanalyse (HRV) des 24h Langzeit EKG's mit dem Pathfinder System $\left(\right.$ Spacelabs $\left.^{\odot}\right)$ von 21 Patienten mit ADS unter Stimulatientherapie (ADS+; Alter 10,7 \pm 3,4 Jahre) und 10 Patienten ohne medikamentöse Therapie (ADS -; Alter Alter 10,8 \pm 2,7 Jahre). Die Diagnostik und Therapie erfogte durch den Kinderarzt oder Kinder- und Jugendpsychiater. Als Kontrolle dienen die Parameter von 19 gleichaltrigen gesunden Patienten (Kontrolle; Alter 10,7 \pm 2. 1 Jahre).

Ergebnisse: Bei vergleichbaren Herzfrequenzverhalten zeigen die unbehandelten Patienten mit ADS (ADS -) eine hochsignifikante Erniedrigung der nächtlichen Vagusaktivität, gemessen mit den HRV Parametern sNN50 und RMSSD. Diese Veränderungen sind unter der Stimulantientherapie bei den meisten Kindern komplett reversibel (ADS+). In fünf weiteren Fällen hatte die sympathovagale Imbalance zu einer Herzrhythmusstörung mit mehr als 2000 ventrikulären Extrasystolen pro Tag bishin zu ventrikulären Tachykardien geführt, die ebenfalls einer circadianen Rhythmik folgen. Diese Herzrhythmusstörungen waren unabhängig von der medikamentösen Therapie.

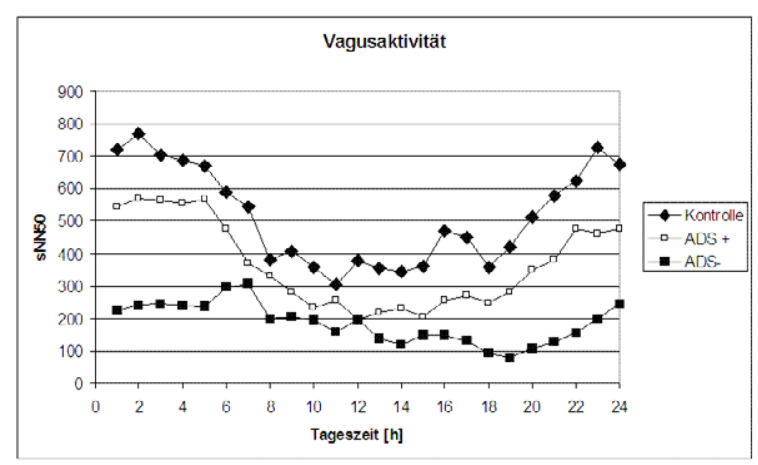

Diskussion: Kinder mit ADS zeigen eine ausgeprägte sympathovagale Imbalance mit Verlust der nächtlichen Vagusaktivität, die diagnostisch genutzt werden kann. Therapeutische Interventionen wie die Stimulantientherapie können mit Hilfe der HRV Analyse überwacht werden. Aufgrund der hohen Inzidenz ventrikulärer Herzrhythmusstörungen, welche durch die medikamentösen Therapie mit z. T. proarrhythmogenen Substanzen unkontrolliert beeinfluß werden, erscheint uns ein solches Monitoring unabdingbar.

DGKJ-PV-182

Das Fetale Alkoholsyndrom: Entwicklung unserer Patienten bis ins

Erwachsenenalter

R. Feldmann

Westf. Wilhelms-Univ.- Kinderklinik

Mütterlicher Alkoholmissbrauch in der Schwangerschaft führt beim Kind zu körperlichen und geistigen Beeinträchtigungen sowie zu sozialen und emotionalen Störungen, die irreversibel sind. Für Jugendliche und junge Erwachsene mit Fetalem Alkoholsyndrom (FAS) ergeben persistierende Folgen, die bislang unzureichend erfasst werden. Patienten und Methode: In einer kontrollierten Studie wurden 135 Kinder und Jugendliche mit FAS untersucht (IQ, Konzentrations- und Gedächtnisleistungen, Motorik, soziale und emotionale Probleme). Ergänzend erfasst wurden biographische Verlaufsdaten von 60 jungen Erwachsenen mit FAS. Ergebnisse: Kinder und Jugendliche mit einem FAS zeigen überdauernd starke kognitive Defizite sowie belastende soziale und emotionale Störungen. Erwachsene mit FAS erreichen überwiegend keine Verselbständigung. Der schulische und berufliche Werdegang der Patienten istdurch häufige Wechsel und Abbrüche gekennzeichnet. Soziale und emotionale Probleme blieben bis in das Erwachsenenalter bestehen. Drei von vier Erwachsenen mit FAS wurden bereits Opfer von (sexuellem) Missbrauch. Schlussfolgerung: Aufgrund ihrer ihrer kognitiven Einschränkungen, ihrer überdauernden Arglosigkeit und mangelnden Selbständigkeit, die sich auf alle Lebensbereiche auswirkt, sind auch Jugendliche und Erwachsene mit FAS noch dauerhaft auf Hilfe, Betreuung und Schutz angewiesen.

\section{DGKJ-PV-183}

Das Berliner Transitionsprogramm: Ein strukturiertes Konzept für den Übergang von chronisch kranken Jugendlichen in die Erwachsenenmedizin

S. Müther', A. von Moers' ${ }^{1}$, W. Burger', B. Müller' ${ }^{1}$, K. Müller-Schlüter², H. Nolting $^{3}$

'DRK Kliniken Berlin | Westend, ${ }^{2}$ Evang. Krankenhaus Herzberge, ${ }^{3}$ IGES Institut GmbH

Fragestellung: Der Übergang in die Erwachsenenmedizin (Transition) findet im Alter von 18-20 Jahren statt. Er ist besonders für chronisch kranke Jugendliche ein kritischer Einschnitt. Etwa 40\% dieser Patienten fallen dabei aus der notwendigen Spezialbetreuung heraus, z. T. 
mit dramatischen Gesundheitsfolgen. Strukturierte Transitionsprogramme mit prozessorientiertem Fallmanagement können die Rate auf 10\% reduzieren. In Deutschland ist die Transition bis auf einzelne lokal begrenzte Initiativen aber weder strukturell noch finanziell geregelt. Das Berliner Transitionsprogramm, gefördert durch die Robert Bosch Stiftung, soll eine strukturierte Transition chronisch Kranker im Rahmen der Regelversorgung erarbeiten. Konzeption und Projektleitung erfolgt durch die DRK Kliniken Berlin, wissenschaftliche Begleitung durch das IGES Institut.

Methodik: Anhand zweier exemplarischer Erkrankungen (Diabetes mell. Typ 1 und Epilepsie) wurde ein Transitionsprogramm entwickelt und in einer Pilotregion (Berlin/Brandenburg) implementiert. Nach Abschluss der Evaluation (2011) soll mit Fachgesellschaften und Kostenträgern die Ausweitung auf weitere Indikationen und Regionen vorbereitet werden. Das Projekt umfasst Konzeption, Implementierung, Evaluation und Aufbereitung als übertragbares Programm. Es beinhaltet ein abgestuftes Versorgungskonzept, ein Finanzierungskonzept (Integrierter Versorgungsvertrag (IVV)) und Umsetzungsmaterialien (Infomaterial, Checklisten, etc.). Als zentrales Element übernimmt ein Fallmanagement die Koordination der interdisziplinären Betreuung und Dokumentation von Struktur- und Ergebnisvariablen. Das Projekt ist eine Machbarkeitsstudie mit prospektiver Kohorte und überwiegend qualitativem Forschungsansatz.

Ergebnisse: Die Konzeptionsphase mit Ausarbeitung des Versorgungspfades, Vertragspartnerrekrutierung (Kostenträger, Leistungserbringer), die Entwicklung eines IVV, Materialerstellung sowie die Etablierung eines FM sind abgeschlossen und das Berliner Transitionsprogramm wird seit dem 1. Juli 2009 für Jugendliche mit Epilepsie oder Diabetes mellitus im Alter von 16 bis 20 Jahren angeboten. Es umfasst die Transitionsvorbereitung, den Übergang selbst und die Zeit bis zur gesicherten Etablierung des Patienten in der Erwachsenenmedizin. AOK Berlin, BKK VBU, TK, weitere Kassen mit Einzelfallentscheidungen und Leistungserbringer aus der Kinder/Jugend- und Erwachsenenmedizin sind dem Vertragskonzept beigetreten. Bis zum 30. 04. 2010 haben insgesamt 78 Patienten Interesse am Programm geäußert, 30 Patienten nehmen bereits aktiv teil. Konzeption, Ablauf und erste Ergebnisse werden vorgestellt.

Schlussfolgerungen: Strukturierte Transitionsprogramme mit Fallmanagement verbessern die Transition chronisch kranker Jugendlicher. Eine erfolgreiche Integration in das Gesundheitssystem erfordert die Finanzierung der zusätzlichen Leistungen und die Integration spezial- und hausärztlicher Betreuung. Das Berliner Transitionsprogramm soll die Basis für eine flächendeckende Regelung der Transition auch in Deutschland schaffen.

\section{DGKJ-PV-184}

Werden Alkoholintoxikationen bei Jugendlichen durch Verhalten und Fehleinschätzung der Eltern begünstigt?

A. Jakobs' ${ }^{1}$, M. Klein ${ }^{2}$, P. Eggert ${ }^{2}$

${ }^{1}$ Altonaer Kinderkrankenhaus, ${ }^{2}$ Universitätskinderklinik

Einleitung: Bundesweit steigt die Anzahl der Jugendlichen, die mit Alkoholintoxikation stationär aufgenommen werden. Die Gründe hierfür sind vielfältig. In der vorliegenden Studie wird untersucht, ob der Alkoholmissbrauch der Jugendlichen durch eine mögliche Fehleinschätzung der Eltern begünstigt sein könnte.

Materialien und Methoden: Die an der Universitätskinderklinik Kiel, am Städtischen Krankenhaus Kiel sowie am Krankenhaus RendsburgEckernförde durchgeführte prospektive Untersuchung, basiert auf der Befragung von 114 wegen Alkoholintoxikation stationär aufgenommenen Jugendlichen und deren Eltern zum Trinkverhalten und zur elterlichen Einschätzung mittels spiegelbildlicher Fragebögen. Die Angaben von Eltern und Jugendlichen zu entsprechenden Fragen wurden miteinander verglichen.

Ergebnisse: Die Jugendlichen zwischen 12 und 17 Jahren (Median: 16 J., $55 \%$ m., $45 \%$ w.) konsumierten zu 95\% hochprozentige Alkoholika. $72 \%$ waren schon wiederholt betrunken und 15\% wiederholt mit Alkoholintoxikation im Krankenhaus.

Weitgehende Übereinstimmung fand sich bei folgenden Fragen: Trinkmotiv der Jugendlichen: $74 \%$ „Spaß“ (Einschätzung der Eltern: 63\%), 20\% Probleme/Konflikte (Einschätzung der Eltern: 23\%). $85 \%$ der Jugendlichen und 93\% der Eltern geben an, miteinander über Alkohol zu sprechen. 90\% der Eltern geben Verhaltensregeln vor (laut Jugendlichen $74 \%$ ). Nach Angabe von 66\% der Jugendlichen und $75 \%$ der Eltern sind den Eltern die Freunde der Jugendlichen bekannt. Mögliche Ansprechpartner bei Problemen sind für Jugendliche: bei $76 \%$ Eltern (lt. Eltern 75\%), bei 85\% Freunde (lt. Eltern 44\%), bei 53\% Geschwister (lt. Eltern $40 \%$ ) und bei $35 \%$ die Klinik (lt. Eltern $42 \%$.).

Signifikante Unterschiede lagen bei folgenden Fragen vor: $53 \%$ der Jugendlichen trinken mindestens wöchentlich, die Eltern vermuten einen regelmäßigen Alkoholkonsum jedoch nur bei $28 \%$. 92\% der Jugendlichen geben an, schon Wodka konsumiert zu haben, $45 \%$ der Eltern glauben, ihr Kind habe noch nie Wodka probiert. Beeinflussung durch die Gruppe nehmen nur 23\% der Jugendlichen aber $73 \%$ der Eltern an.

Schlussfolgerungen: Der Konsum hochprozentiger Alkoholika und die Regelmäßigkeit des Alkoholkonsums ihrer Kinder werden von Eltern deutlich unterschätzt. Das Konsummuster, mit Spirituosen innerhalb kurzer Zeit einen nicht kalkulierbaren Rausch herbeizuführen, scheint den Eltern nicht bewusst. Obwohl die meisten Eltern mit den Jugendlichen über das Problem „Alkohol“ kommunizieren, den Freundeskreis kennen, Strukturen vorgeben und das vorrangige Trinkmotiv richtig einschätzen, ist es offensichtlich, dass aufgrund der unzureichenden Kenntnis der Eltern über das riskante Konsummuster der Jugendlichen eine adäquate Aufklärung behindert und das Entstehen von Alkoholintoxikationen indirekt begünstigt wird. Zukünftige Aufklärungskampagnen sollten diese Aspekte berücksichtigen.

\section{DGKJ-PV-185}

Ernährungs- und Lebensstilfaktoren bei Jugendlichen mit Kopfschmerzen - Ergebnisse einer Querschnittsstudie

A. Milde-Busch', A. Blaschek'2, F. Heinen'², A. Straube', R. von Kries'

${ }^{1}$ Ludwig-Maximilians-Universität München, ${ }^{2}$ Klinikum der Universität München

Hintergrund. Kopfschmerzen zählen zu den bedeutendsten gesundheitlichen Problemen von Kindern und Jugendlichen. In Studien an Erwachsenen wurde gezeigt, dass Ernährungs- und Lebensstilfaktoren, z. B. Rauchen oder der Konsum von Kaffee oder Alkohol, mit Kopfschmerzen assoziiert sind. Ziel unserer Studie war die systematische Untersuchung von Zusammenhängen zwischen Kopfschmerzen bzw. verschiedenen Kopfschmerztypen und Ernährungs- sowie Lebensstilfaktoren bei Jugendlichen.

Methoden. In einer Querschnittsstudie an 1. 26o jugendlichen Gymnasiasten der 10. und 11. Klassen wurde der Kopfschmerztyp (Migräne, Spannungskopfschmerz, andere Kopfschmerzen) bei denjenigen Teilnehmern erhoben, die angaben, in den vergangenen sechs Monaten mindestens eine Kopfschmerzepisode pro Monat erlebt zu haben. Folgende Ernährungsfaktoren wurden erhoben: Einnahme von Frühstück, Pausenmahlzeiten und einer warmen Mahlzeit, Verzehr von Obst und Gemüse sowie Aufnahme von alkoholfreien Getränken. Folgende Lebensstilfaktoren wurden erhoben: Konsum von Bier, Wein, Cocktails und Kaffee, Rauchen sowie körperliche Aktivität. Mittels multipler logistischer Regressionsmodelle wurde der Zusammenhang zwischen diesen Ernährungs- bzw. Lebensstilfaktoren und prävalenten Kopfschmerzen ermittelt; dabei wurde für soziodemografische Variablen adjustiert.

Ergebnisse. Migräne wurde von 129 (10,2\%), Spannungskopfschmerzen von 614 (48,7\%), Migräne und Spannungskopfschmerzen von 249 $(19,8 \%)$ sowie andere Kopfschmerzen von 55 (4,4\%) der Schüler berichtet (insgesamt: 1,047 [83,1\%] Schüler mit Kopfschmerzen). Nach Adjustierung für multiples Testen wurden folgende statistisch signifikante Assoziationen ermittelt: Ein hoher Konsum von Cocktails (Odds Ratio: 
3,4; 95\% Konfidenzintervall: 1,9-6,0) und Kaffee $(2,4 ; 1,3-4,7)$, Rauchen $(2,7 ; 1,4-5,1)$ und mangelnde körperliche Aktivität $(2,2 ; 1,3-3,7)$ gingen mit einer höheren Prävalenz von Migräne und Spannungskopfschmerzen einher. Ein hoher Konsum von Kaffee $(3,4 ; 1,6-7,0)$ und mangelnde körperliche Aktivität waren insbesondere mit prävalenter Migräne assoziiert (4,2; 2,2-7,9), mangelnde körperliche Aktivität zudem mit prävalenten Spannungskopfschmerzen $(1,7 ; 1,1-2,7)$. Das Auslassen von Mahlzeiten oder eine unzureichende Flüssigkeitszunahme waren mit keinem der Kopfschmerztypen assoziiert.

Schlussfolgerungen. Es wurde bestätigt, dass Kopfschmerzen bei Jugendlichen mit einigen Ernährungs- und Lebensstilfaktoren zusammenhängen. Jugendlichen mit Kopfschmerzen können von regelmäßiger körperlicher Aktivität und einem geringeren Konsum von alkoholischen Getränken profitieren. Zusätzlich sollte jugendlichen Patienten mit Migräne ein Verzicht auf Kaffee empfohlen werden. Interventionsstudien müssen zeigen, ob die Verhaltensweisen, die mit Kopfschmerzen assoziiert sind, und Kopfschmerzen selbst durch psychologische Trainings beeinflussbar sind.

\section{DGKJ-PV-186}

Einfluss einer stationären Rehabilitation auf Symptome und krankheitsbezogene Lebensqualität bei Jugendlichen mit Asthma bronchiale, Neurodermitis und Adipositas

H. Burmester', U. Tiedjen', S. Kiera², F. Petermann², R. Stachow ${ }^{1}$ 'Fachklinik Sylt für Kinder und Jugendliche der DRV Nord, ${ }^{2}$ Universität Bremen

Fragestellung: Die vorliegende Arbeit untersucht diagnosebezogen an einem Kollektiv jugendlicher Patienten, die eine 4- bis 6-wöchige stationäre Rehabilitation durchführten, die Veränderungen der Symptomausprägung sowie der krankheitsbezogenen Lebensqualität im Verlauf der Rehabilitation und bei einer 1-Jahres-Katamnese.

Material und Methoden: Im Rahmen eines Forschungsprojektes erfolgte in den Jahren 2007 und 2008 bei 250 Patienten der Fachklinik Sylt für Kinder und Jugendliche im Alter von 13 bis 18 Jahren die Erhebung somatischer Messgrößen zur Erfassung von Krankheitssymptomen sowie einer Vielzahl psychometrischer Daten, jeweils bei Antritt der Rehabilitation (to), bei Entlassung (t1) und ein Jahr später ( $\mathrm{t} 2$ ). Die somatischen Parameter, die Gegenstand dieser Untersuchung sind, waren im einzelnen: bei Patienten mit Asthma bronchiale die Symptomkontrolle anhand des ACT (Fragebogen zur Asthmakontrolle), bei Patienten mit Neurodermitis der Hautzustand anhand des SCORAD und bei wegen Adipositas behandelten Patienten der BMI-SDS. Die diagnosebezogene Lebensqualität wurde mit den entsprechenden Modulen des KINDL-R-Fragebogens zur Lebensqualität (Ravens-Sieberer \& Bullinger) ermittelt. Es wurden jeweils die Werte von to und t1 sowie von to nach t 2 in Form gepaarter Stichproben verglichen.

Ergebnisse: Alle Diagnosegruppen erreichen während der stationärern Rehabilitation eine signifikante Verbesserung ihrer Krankheitssymtome und der krankheitsbezogenen Lebensqualität. Deutliche Unterschiede zeigen sich dagegen bei der 1-Jahres-Katamnese. Insbesondere haben Patienten mit Neurodermitis bei t2 einen deutlich höheren Symptomscore als bei t1, was sich aber nicht in ihrer krankheitsbezogenen Lebensqualität widerspiegelt (Tabelle).

\begin{tabular}{|c|c|c|c|c|c|}
\hline \multirow{2}{*}{$\begin{array}{l}\text { Parameter } \\
\text { (N) }\end{array}$} & \multicolumn{3}{|c|}{ Mittelwerte (Std. Abw.) } & \multicolumn{2}{|c|}{ p (T-Test) } \\
\hline & to & $\mathrm{t} 1$ & t2 & t0-t1 & t0-t2 \\
\hline ACT (88) & $19,1(4,4)$ & $20,2(3,9)$ & $20,9(4,1)$ & 0,027 & 0,001 \\
\hline $\begin{array}{l}\text { LQ Asthma } \\
\text { (90) }\end{array}$ & $50,2(7,4)$ & $52,4(6,4)$ & $52,1(6,9)$ & 0,002 & 0,017 \\
\hline SCORAD (30) & $\begin{array}{l}36,5 \\
(21,3)\end{array}$ & $17,8(13,5)$ & $29,2(20,5)$ & $<0,001$ & 0,060 \\
\hline $\begin{array}{l}\text { LQ Neuroder- } \\
\text { mitis(80) }\end{array}$ & $45,9(8,4)$ & $49,5(7,0)$ & $50,3(6,7)$ & $<0,001$ & $<0,001$ \\
\hline BMI-SDS (39) & $\begin{array}{l}2,36 \\
(0,61)\end{array}$ & $2,11(0,61)$ & $2,06(0,79)$ & $<0,001$ & $<0,001$ \\
\hline $\begin{array}{l}\text { LQ Adipositas } \\
\text { (84) }\end{array}$ & $54,1(8,5)$ & $60,3(8,6)$ & $59,1(9,4)$ & $<0,001$ & $<0,001$ \\
\hline
\end{tabular}

Schlussfolgerung: Bei Jugendlichen, die an Asthma bronchiale, Neurodermitis oder Adipositas erkrankt sind, kommt es im Verlauf einer 4bis 6-wöchigen stationären Rehabilitation zu einer signifikanten Verbesserung der Krankheitssymptome und der diagnosebezogenen Lebensqualität. Während im weiteren Verlauf über 1 Jahr bei Asthmaund Adipositaspatienten das erreichte Niveau für objektive Befundparameter und für krankheitsbezogene Lebensqualität stabil blieb, zeigen Neurodermitispatienten eine Wiederzunahme der Symptome, die sich offenbar nicht auf die (krankheitsbezogene) Lebensqualität auswirkt.

\section{DGKJ-PV-187}

Mit welchen Beschwerden gehen jugendliche Jungen und Mädchen zum Arzt? Erste Ergebnisse einer Schülerbefragung in Sachsen.

B. Schumacher, P. Peschel, J. Kugler

Medizinische Fakultät Carl Gustav Carus

Fragestellung: Der vorliegende Beitrag beschäftigt sich mit den Gründen, die Jugendliche zu einem Arztbesuch bewegen sowie der Anzahl der Arztbesuche Jugendlicher.

Material und Methode

Sachsenweit sind per Zufallsstichprobe 6. 525 Schüler der 8. und 10. Klassen schriftlich befragt worden. Die Rücklaufquote betrug $25,9 \%$. In der Stichprobe kamen 35,2\% aus Städten, 57,1\% waren Mädchen. Ein Gymnasium besuchten 62,0\% der Jugendlichen und 61,8\% waren in der 8. Klasse.

Ergebnisse: Der von allen Jugendlichen am häufigsten genannte Besuchsgrund war „Erkältung, grippaler Infekt“ (57,5\%) gefolgt von "Impfungen“ (54,4\%) und „Schmerzen“ (25,1\%). Der Vergleich zwischen den Geschlechtern zeigt einen signifikanten Unterschied in der Häufigkeit verschiedener Erkrankungen als Besuchsgrund beim Arzt $(\mathrm{p}<0,05)$. Mädchen gaben häufiger an, wegen Schmerzen, Impfungen, Hautproblemen, Augenbeschwerden, Hals- sowie Blasenentzündung beim Arzt gewesen zu sein als Jungen. „Pollenallergie“ und „motorische Überaktivität“ hingegen wurde häufiger von Jungen angegeben. Bei anderen Erkrankungen zeigten sich keine Unterschiede.

Diskussion: Jungen im Jugendalter nahmen laut den vorliegenden Daten seltener einen Arzt in Anspruch als gleichaltrige Mädchen. Auch im Erwachsenenalter nehmen Männer seltener Hilfe in Anspruch als Frauen. Außerdem sind jugendliche Mädchen deutlich unzufriedener mit ihrem Gesundheitszustand als gleichaltrige Jungen. Dies könnte häufigere Arztbesuche der Mädchen erklären.

Mädchen im Jugendalter unterscheiden sich von den Jungen in den Gründen einen Arzt aufzusuchen. Die in dieser Untersuchung gefundenen Differenzen in den Besuchsgründen bestätigen frühere Ergebnisse. Aufgrund der für Mädchen zwischen 12 und 17 Jahren empfohle- 
nen HPV-Impfung könnten Mädchen häufiger zum Impfen einen Arzt aufgesucht haben als Jungen.

Schlussfolgerung: Andere Studien haben gezeigt, dass bis zum Beginn der Pubertät Jungen häufiger einem Arzt vorgestellt werden als Mädchen. Im Jugendalter bildet sich ein eigenes Körperbewusstsein aus und Arztbesuche finden zunehmend eigenverantwortlich statt Die vorliegenden Ergebnisse zeigen deutlich, dass jugendliche Mädchen häufiger und aus anderen einen Arzt aufsuchen als gleichaltrige Jungen. Eine einstellungs- und bedürfnisgerechte Versorgung der jugendlichen Mädchen und Jungen erscheint daher von besonderer Bedeutung.

\section{DGKJ-PV-188}

Psychiatrische Komorbidität, der Einfluss von Heißhungerattacken und aktiven Maßnahmen zur Gewichtsreduktion auf die psychiatrische Morbidität bei adipösen Kindern und Jugendlichen

\section{A. Bürger', F. Hammerle' ${ }^{1}$, J. Oepen ${ }^{2}$, M. Huss ${ }^{1}$}

${ }^{1}$ Klinik und Poliklinik für Kinder- und Jugendpsychiatrie und -psychotherapie, Universitätsmedizin der Johannes Gutenberg-Universität, ${ }^{2}$ Viktoriastift

Adipöse Kinder und Jugendliche gelten als Risikogruppe für die Entwicklung psychiatrischer Störungen. Während sich in Feldstudien kein Einfluss der Adipositas auf die psychiatrische Komorbidität zeigt (Lamertz et al. 2002), verweisen klinische Untersuchungen auf eine zweifach erhöhte Erkrankungshäufigkeit affektiver Störungen als auch Angsterkrankungen im Vergleich zu gesunden Kontrollprobanden (Britz et al. 2000). Vor allem die Entwicklung von regelmäßigen Heißhungerattacken mit Kontrollverlust aber auch gesundheitsschädigende gegensteuernde Maßnahmen zur Gewichtsreduktion scheinen einen deutlichen Einfluss auf eine erhöhte psychiatrische Morbidität zu nehmen (Hilbert \& Czaja 2007).

Das Ziel der Studie war es die psychiatrische Komorbidität und das Auftreten psycho- pathologischen Essverhaltens sowie deren Einfluss auf die Morbidität zu untersuchen. Die 168 adipösen Kinder und Jugendlichen (12 - 18 Jahre) befanden sich in einer stationären Reha-Behandlung und wurden sowohl mit strukturierten Interviews (K-SADS, ChEDE) als auch mit Selbstbeurteilungsbögen (SCL-9o-R, EDI-2, BSQ, BIAQ) untersucht.

Bei über 30\% der adipösen Patienten zeigte sich eine komorbide psychiatrische Erkrankung. Bei 12\% der Patienten kam es zu regelmäßigen Heißhungerattacken mit Kontrollverlust bei gut $11 \%$ zu aktiven Maßnahmen zur Gewichtsreduktion. Bei Patienten mit psychopathologisch auffälligem Essverhalten jedoch ohne Essstörungsdiagnose erhöhte sich die psychiatrische Komorbidität auf 50\%.

Zusammenfassend zeigt sich, dass die psychiatrische Morbidität von adipösen Kindern und Jugendlichen insbesondere mit einem pathologischen Essverhalten deutlich erhöht ist. Die Ergebnisse untermauern die Notwendigkeit psychodiagnostischer Maßnahmen, um eine Binnendifferenzierung vornehmen zu können und so die Effizienz der Behandlung von adipösen Kindern und Jugendlichen zu verbessern.

\section{DGKJ-PV-189}

Mischintoxikation mit Metoclopramid-Dyskinesien und anticholinergem Delir: eine therapeutische Wanderung zwischen Skylla und Charybdis

K. Schuster' ${ }^{1}$ S. Senn ${ }^{2}$, N. Kühle², U. Stedtler' ${ }^{1}$, M. Hermanns-Clausen ${ }^{1}$

'Zentrum für Kinder- und Jugendmedizin, Universitätsklinikum Freiburg,

2Bruder-Klaus-Krankenhaus

Einleitung: Medikamentenintoxikationen gehören zu den häufigen und wichtigen Pathologien im Kindes- und Jugendalter. Wir berichten hier über eine höchst eindrucksvolle Klinik und komplizierte Therapie nach Mischintoxikation mit Metoclopramid und Dimenhydrinat. Metoclopramid ist dafür bekannt, speziell im Kindesalter Dystonien auszulösen. Dimenhydrinat fungiert als frei verkäufliches und häufig angewendetes Antiemetikum und Hypnotikum.

Anamnese: Die 14 Jahre alte und $65 \mathrm{~kg}$ schwere Patientin hatte im Rahmen einer Konfliktsituation $120 \mathrm{mg}$ Metoclopramid sowie $1250 \mathrm{mg}$
Dimenhydrinat eingenommen. Zwei Stunden später sprach sie plötzlich wirr und zusammenhangslos. Der Mutter fielen dann ihre ziellos umherwandernden Pupillen auf, ebenso eine gelegentliche Blickstarre. Untersuchung: Bei Aufnahme wirkte die junge Patientin akinetisch und verlangsamt. Sie war zeitlich und örtlich desorientiert und hatte optische und akustische Halluzinationen mit Schwindelgefühl. Die Vitalparameter waren bis auf eine Tachykardie mit 108 bpm unauffällig. Die neurologische Untersuchung zeigte Augendyskinesien und eine deutliche Artikulationsschwäche. Es bestand eine Mydriasis mit Akkomodationsschwäche und Fixationsstörung. Auffällig war zudem eine ophistotone Körperspannung mit Tremor.

Therapie: Zunächst erhielt die Patientin $5 \mathrm{mg}$ Biperiden, wodurch die Dyskinesien wie auch der Schwindel insgesamt rückläufig waren und sie rasch wieder kommunikationsfähig wurde. Im Verlauf standen dann jedoch die Halluzinationen sowie eine ausgeprägte Übererregbarkeit und Agitation im Vordergrund, welche eine Behandlung mit Diazepam notwendig machten. Nach 24-stündiger Überwachung waren die Symptome schließlich insgesamt rückläufig, so dass die junge Patientin zur Weiterbehandlung in die Psychatrie überwiesen werden konnte.

Diskussion: Dimenhydrinat kann im Überdosisbereich klassischerweise eine anticholinerge und zentralnervöse Symptomatik mit Halluzinationen bewirken. Kinder und Jugendliche reagieren empfindlicher als Erwachsene auf dieses Medikament und können auch im therapeutischen Dosisbereich bereits heftige Nebenwirkungen entwickeln. Nach toxischen Dosierungen von Metoclopramid sind Agitation, Delir und extrapyramidal-motorische Störungen (EPMS) zu erwarten, für welche Dimenhydrinat auch als Antidot eingesetzt wird. Biperiden, ein zentral wirkendes Anticholinergikum, wird ebenfalls als Antidot zur Therapie der EPMS eingesetzt, verstärkt jedoch seinerseits die Wirkung von Dimenhydrinat, insbesondere die Halluzinationen. Das therapeutische Vorgehen muss daher an die jeweils klinisch vorherrschende Symptomatik angepasst werden mit dem Risiko einer Wirkungsverstärkung der weiteren beteiligten Substanz.

Schlussfolgerung: Die hier vorgestellte Mischintoxikation mit zwei zentral wirksamen Pharmaka resultierte bei der Jugendlichen in einer eindrucksvollen Klinik. Eine symptomorientierte Therapie wurde dabei aufgrund des Synergismus zwischen Antidot und toxischer Subs$\tan z$ verkompliziert.

\section{DGKJ-PV-190}

Sehr adipöse (XXL), extrem (XXXL) undextremst (XXXXL) adipöse Kinder und Jugendliche in der multizentrischenAPV-Datenbank: Ist das Risiko weiblich?

S. Wiegand' ', U. Hoffmeister ${ }^{2}$, W. Siegfried ${ }^{3}$, C. Denzer ${ }^{4}$, I. Gellhaus ${ }^{5}$, K. Widhalm ${ }^{6}$, G. Clausnitzer ${ }^{7}$, T. Hermann ${ }^{8}$, R. Stachow ${ }^{9}$, K. Ullrich ${ }^{10}$, R. Holl ${ }^{2}$ ${ }^{1}$ Charite Kliniken f. Kinderheilkunde und Kinderchirugie, ${ }^{2}$ Universität UIm, ${ }^{3}$ Adipositas Zentrum Insula, ${ }^{4}$ Universitäts-Kinderklinik, ${ }^{5}$ Praxis für Ernährungsmedizin, ${ }^{6}$ Institut für Ernährungsmedizin, ${ }^{7}$ Spessart-Klinik Bad Orb, ${ }^{8} \mathrm{Hochgebirgsklinik}$ Mittelberg, ${ }^{9}$ Fachklinik Sylt, ${ }^{10} \mathrm{HELIOS}$ Kreiskrankenhaus

Fragestellung: Adipositasprävention und verhaltenstherapeutische Behandlung übergewichtiger und adipöser Kinder und Jugendlicher wird zunehmend als Aufgabe von Kinder- und Jugendärzten erkannt. Die spezifischen Probleme extremst adipöser Kinder und Jugendlicher sind bisher selten berücksichtigt. In Deutschland wird kindliche Adipositas als ein BMI über der 97. Percentile basierend auf den AGA-Referenzwerten definiert, wobei Patienten über der 99. 5 Percentile als extrem adipös (XXL) eingestuft werden. Diese Gruppe entspricht einem $\mathrm{BMI}>32 \mathrm{~kg} / \mathrm{m}^{2} \mathrm{im}$ Erwachsenenalter. In der aktuellen Auswertung wird zusätzlich die Gruppe der Patienten über der 99. 9. Perzentile (XXXL, entsprechend Erwachsenen-BMI von ca $35 \mathrm{~kg} / \mathrm{m}^{2}$ ) und der Patienten über der 99. 95 Percentile (XXXXL, entsprechend einem Erwachsenen$\mathrm{BMI}>4 \mathrm{O} \mathrm{kg} / \mathrm{m}^{2}$ ) gesondert dargestellt.

Patienten und Methoden: Die APV-Software ermöglicht eine standardisierte, prospektive Dokumentation pädiatrischer und internistischer Patienten mit Adipositas, basierend auf den Leitlinien der Fachgesellschaft (AGA = Arbeitsgemeinschaft Adipositas bei Kindern und 
Jugendlichen). Zweimal jährlich werden anonymisierte Verlaufsdaten im Korrekturlauf überprüft, anschließend wird ein Benchmarking relevanter Indikatoren der Prozeß- und Ergebnisqualität erstellt. Aktuell beteiligen sich 161 spezialisierte Adipositaszentren in Deutschland und Österreich an der Initiative, darunter 27 Reha-Zentren. Der anonymisierte APV-Gesamtpool steht für versorgungsepidemiologische Auswertungen zur Verfügung. Es wurden jeweils die Daten bei Erstvorstellung ausgewertet.

Ergebnisse: Aktuell umfasst die APV-Datenbank 57058 Patienten (mittleres Alter 12,53 Jahre, mittlerer BMI-SDS +2,43). 9032 Patienten waren nur übergewichtig ( $52 \%$ weiblich), 24175 adipös ( $50 \%$ weiblich). 15595 fielen in die XXL-Gruppe (BMI-SDS +2,8, 53 \% weiblich), 3193 in die XXXL-Gruppe (BMI-SDS +3,2, $61 \%$ weiblich) und bei 5063 Patienten lag der BMI über der 99. 95. Percentile (XXXXL, BMI-SDS +3,75, $69 \%$ weiblich). Der Zusammenhang zwischen Geschlecht und Adipositaskategorie war hoch signifikant $\left(\mathrm{X}^{2}\right.$-Test, $\mathrm{p}<0$. 0oo1). Extremst adipöse Patienten trugen ein massives Komorbiditäts-Risiko: bei 50 $\%$ bestand eine Hypertension. In der logistischen Regressionsanalyse ergab sich ein OR von 4.78 [3. 91, 5. 84] gegenüber den normalgewichtigen Patienten. 18 \% der XXXXL-Patienten zeigten ein HDL-Cholesterin unter $35 \mathrm{mg} / \mathrm{dl}$, bei $13 \%$ lag das LDL-Cholesterin über $130 \mathrm{mg} / \mathrm{dl}$, bei $16 \%$ die Triglyceride über $150 \mathrm{mg} / \mathrm{dl}$.

Diskussion: Die Behandlung extrem und extremst adipöser Kinder und Jugendlicher stellt eine große Herausforderung dar. Mit zunehmender Extrem-Adipositas überwiegen in spezialisierten Therapieangeboten weibliche Patienten deutlich - ein Faktum das bisher kaum beachtet wurde und bezüglich therapeutischer Konsequenzen weiterführend analysiert werden sollte. Mögliche Gründe sind ein höherer Leidensdruck bei weiblichen Patientinnen und/oder eine schlechtere therapeutische Erreichbarkeit männlicher Patienten.

\section{Review of the Year}

\section{DGKJ-SY-070}

Stammzelltransplantation - Entwicklungen und Perspektiven

P. Bader

Klinik für Kinder- und Jugendmedizin

Ende der sechziger Jahre wurde von der Gruppe um RA Good in Minneapolis die erste erfolgreiche allogene Transplantation bei einem Kind mit einem Immundefekt durchgeführt. Diese Transplantation begründete die "moderne Ära“ der Stammzelltransplantation (SZT). Ein Jahr später wurde in Seattle erstmals einem Leukämiepatienten Knochenmark eines Geschwisters übertragen. Seither hat sich die allogene SZT zu einem sehr wertvollen Therapieverfahren in der Behandlung von vielen Patienten mit malignen und nichtmalignen Erkrankungen entwickelt.

Trotz großer Fortschritte in der Transplantationsmedizin bleibt die allogene SZT eine einschneidende Therapieform mit vielen akuten Komplikationsmöglichkeiten und auch der Gefahr von Langzeitfolgen wie beispielsweise Wachstums- und Fertilitätsstörungen. Diese Komplikationen sind zumeist der hoch dosierten Chemo-/Radiotherapie geschuldet; aber auch immunologische Komplikationen wie die T-zellvermittelte „Transplantat versus Empfängererkrankung“ (engl: graft versus host disease; GvHD) sind geeignet, langfristige Beeinträchtigungen zu hinterlassen. Gerade im Kindesalter sind Langzeitfolgen von besonderer Bedeutung; es sollten alle Anstrengungen unternommen werden, Langzeitfolgen zu verhindern, die die Kindern stigmatisieren und eine altersgerechte Entwicklung unmöglich machen. Da nur etwa 10-20\% aller Patienten über einen HLA-identischen Spender in der Familie und weitere 50\% über einen passenden unverwandten Spender verfügen, ist es ein zentrales Ziel, den Spenderpool zu erweitern. Vor allem im pädiatrischen Bereich stellt dabei der Einsatz von haploidentischen Eltern als Spender einen wesentlichen Fortschritt dar. Lange Zeit wurde zur erfolgreichen Behandlung von Patienten mit bösartigen Erkrankungen eine hochintensive Chemo-/Radiotherapie für erforderlich gehalten, wobei der Stammzellersatz eine nachgeordnete Rolle spielte.

Die Beschäftigung mit den immunologischen Auswirkungen der Übertragung großer Mengen von Stammzellen zeigte die Bedeutung der immunologischen Wirkungsweise des Transplantats selbst, was $\mathrm{zu}$ einem Paradigmenwechsel führte. So spielen NK-Zellen im Transplantat eine entscheidendere Rolle bei der Überwindung von malignen Erkrankungen als die der Transplantation vorausgehende Chemo-/ Radiotherapie.

Damit können allogene Transplantationsverfahren und insbesondere die haploidentische Transplantation als immunologische Plattform verstanden werden, die eine sorgfältige Auswahl und Präparation des Transplantats selbst und eine vielfältige Kombination mit zellulären Therapien nach der Transplantation erlaubt.

Dies eröffnet eine Perspektive, die allogene Transplantationsverfahren in Zukunft mit reduzierten Konditionierungen ohne wesentliche Gewebsschädigung oder sogar mit ausschließlich immunologischen Vorbereitungen des Empfängers denkbar macht. Spezifische Zelltherapieelemente sollen dabei zielgerichtet gegen die zugrunde liegende maligne Erkrankung eingesetzt werden, ohne eine allogene GVHD auszulösen.

\section{Genetisch bedingte Erkrankungen des Knochens}

\section{DGKJ-SY-074}

Genetik, Diagnostik und Therapie der Osteogenesis imperfecta

E. Schönau, O. Semler

Universitäts-Kinderklinik Köln

Osteogenesis imperfecta (OI) ist eine angeborene Kollagensynthesestörung des Kollagen Typ I. Sie beruht in den meisten Fällen auf Mutationen in den kodierenden Genen COL1A1 oder COL1A2. Inzwischen sind mehr als 1000 Mutationen gefunden, die zu dem klinischen Krankheitsbild der OI führen. Verschiedene Untersuchungen haben versucht eine Korrelation zwischen Genotyp und Phänotyp zu finden. Es konnte gezeigt werden, dass leichtere Verlaufsformen überwiegend auf StopMutationen zurück zu führen sind, während die typischen Glycinmutationen häufig mit schwereren Verlaufsformen verbunden sind.

Therapeutisch ist die Anwendung von Bisphosphonaten als Standardtherapie anzusehen. Bei den schweren Verlaufsformen (Typ III und IV) werden diese als intravenöse Therapie appliziert. Die Weiterentwicklung der Bisphosphonate in der Therapie der Altersosteoporose hat zu neuen Bisphosphonat-Wirkstoffen geführt, deren Wirksamkeit in der Pädiatrie überprüft werden muß. Vorteil dieser neuen Präparate ist eine Reduktion der stationären Aufenthalte der Patienten. Zusätzlich wurde die Wirkung oraler Bisphosphonate bei Kindern mit leichten Verlaufsformen untersucht (Typ I) und es konnte eine Zunahme der Knochenflächendichte unter Therapie gezeigt werden.

Ergänzend zu den medikamentösen und orthopädischen Therapiemöglichkeiten gewinnen Rehabilitationsprogramme immer mehr an Bedeutung in der Therapie von Kindern und Jugendlichen mit OI. In Zukunft muß untersucht werden, welche Rolle z. B. neue Methoden des Ausdauertrainings, oder auch der Einsatz der Ganzkörpervibrationstherapie in einem interdisziplinären Behandlungskonzept spielen können. Mit einem solchen multimodalen Rehabilitationskonzept kann bei Kindern und Jugendlichen mit OI eine Verbesserung der motorischen Fähigkeiten, sowie eine Steigerung der Mobilität erreicht werden.

Zusammenfassend ermöglicht die Kombination aus orthopädischer, medikamentöser und physiotherapeutischer Behandlung eine bessere Versorgung der Patienten, als sie noch vor 10 Jahren möglich war. Insbesondere sollte darauf geachtet werden, die Patienten in einem interdisziplinären Zentrum zu versorgen, um die Therapieelemente gut aufeinander abstimmen zu können. 


\section{Lysosomale Speichererkrankungen}

\section{DGKJ-SY-076}

Forschungsförderung im Bereich der "orphan diseases" am Beispiel der Neuronalen Ceroid-Lipofuszinosen (NCL)

F. Stehr

NCL-Stiftung

Die Neuronalen Ceroid Lipofuszinosen zählen - wie auch 5. 000 - 7. ooo andere schwere Krankheiten - zu den sog. „orphan diseases“, den Waisenkindern der Medizin. Sie alle teilen das gleiche Schicksal. Häufig werden sie erst sehr spät oder gar nicht erkannt. Mitunter kommt es zu Fehldiagnosen, die sogar zu Fehlbehandlungen führen können. Aufgrund der Seltenheit erfolgt keine Forschung durch Pharma- und Biotechfirmen, da diese sich nach der Größe eines Marktes orientieren. Um Patienten und Angehörigen eine Hoffnung auf Heilung zu geben, muss die Forschung im Bereich der Seltenen gezielt intensiviert werden. Internationale Kraftanstrengungen sind hierfür notwendig, um z. B. aussagekräftige klinische Studien starten zu können.

Einige Patienten-Organisationen und Stiftungen, die im Bereich der seltenen Krankheiten tätig sind, fördern bereits die Forschung. Häufig sind es sogar die alleinigen Unterstützer. Es werden im Vortrag konkrete Maßnahmen der Forschungsförderung am Beispiel einer einzelnen Einrichtung, der NCL-Stiftung, veranschaulicht. Darüberhinaus werden auch punktuell Beispiele anderer Organisationen vorgestellt, die entweder krankheitsspezifisch oder krankheitsübergreifend im Bereich der „orphan diseases“ agieren.

Die gemeinnützige NCL-Stiftung betreibt kooperative Forschungsförderung. Aufgrund einer kontinuierlich durchgeführten „Marktanalyse“ der NCL-Forschungslandschaft werden gezielte Maßnahmen abgeleitet. Unterstützend wirken ein international besetzter Wissenschaftlicher Beirat, direkte Besuche einzelner Labore sowie persönliche Besuche von verschiedenen wissenschaftlichen Veranstaltungen.

Die NCL-Stiftung unterstützt international ausgerichtete Projekte mit Doktorandenstipendien. Um Wissenschaftler angrenzender Fachgebiete anzusprechen, wird jährlich der NCL-Forschungspreis ausgelobt. Ein weiterer Schwerpunkt der Stiftungsarbeit liegt in der Vernetzung von Forschern unterschiedlicher Disziplinen. Zu den indirekten Maßnahmen der Forschungsförderung zählen $u$. a. verschiedene Fortbildungsmaßnahmen, wie Vorträge halten, Fortbildungen organisieren, Artikel publizieren und eine gemeinsame Lobby-Arbeit mit anderen Patienten-Organisationen. Es findet ein kontinuierlicher Austausch mit verwandten NCL-Fördereinrichtungen statt, um doppelte Förderungen zu vermeiden und ggf. auch Projekte zu identifizieren, die gemeinsam gefördert werden können.

Ziel der NCL-Stiftung ist es, durch konkrete Anschubförderungen und Beratung einzelne Gruppen in die Lage zu versetzen, eigene Drittmittel einzuwerben.

\section{DGKJ-SY-079}

Therapie lysosomaler Speichererkrankungen: M. Beck

Universitätsmedizin, Zentrum für Kinder- und Jugendmedizin

Gesetzlich geregelte Förderungsmaßnahmen sowohl in den USA als auch in Europa bedeuteten für pharmazeutische Firmen einen Anreiz, auch für seltene Krankheiten (Orphan diseases) Medikamente zu entwickeln. So sind in den letzten Jahren Enzym-Präparate für den M. Gaucher, den M. Fabry, die Mukopolysaccharidosen Typ I, II und VI und den M. Pompe entwickelt worden. Die Wirksamkeit dieser Medikamente wurde durch randomisierte, Plazebo-kontrollierte Studien belegt; die Präparate sind in der Lage, den Krankheitsverlauf aufzuhalten oder wenigstens abzuschwächen. Verschiedene Faktoren sind dafür verantwortlich zu machen, dass durch eine Enzymersatz-Therapie eine vollständige Heilung einer lysosomalen Speicherkrankheit nicht möglich ist: Zum einen ist bei Beginn einer Therapie der Krankheitsprozeß oft schon so weit fortgeschritten, dass bereits irreversible Organschäden aufgetreten sind. Viele Organsysteme wie zum Beispiel Knor- pel oder das Zentralnervensystem werden durch die intravenös verabreichten Enzyme kaum oder gar nicht erreicht. Weiterhin wird die Wirksamkeit der Enzymersatz-Therapie durch die Bildung von neutralisierenden Antiköpern beeinträchtigt. Derzeit werden Verfahren entwickelt, um die Effektivität dieser Medikamente zu erhöhen. Durch Modifizierung der Enzyme kann zum Beispiel die Aufnahme in den Knorpel oder in die Muskulatur verbessert werden. Durch eine intrathekale Injektion wird eine Wirksamkeit auch auf das Zentralnervensystem erwartet. Für einige lysosomale Speicherkrankheiten wie die Mukopolysaccharidose Typ I Hurler ist weiterhin die KnochenmarksTransplantation die Behandlung der ersten Wahl wenn bestimmte Kriterien wie Alter und Zustand des Patienten erfüllt sind.

Ganz neue Therapie-Ansätze werden mit der Entwicklung von Medikamenten verfolgt, deren Wirksamkeit auf verschiedenen physiologischen Prinzipien beruht. Für den M. Gaucher und den M. NiemannPick Typ C steht eine Substanz zur Verfügung, die nicht die Aktivität des lysosomalen Enzyms erhöht, sondern die Menge des gespeicherten Substrates vermindert (Substrat-Hemmung). Auch werden Substanzen untersucht, die das Substrat so verändern, dass es leichter abgebaut werden kann (Substrat-Optimierung). Wenn der Defekt von Enzymen auf Mutationen beruht, die die Konformation des Proteins, jedoch nicht das katalytische Zentrum verändern, können sogenannte Chaperone zu einer Erhöhung der Aktivität führen. Als stop-codon read-through wird ein therapeutisches Prinzip verstanden, das darauf beruht, bei Gen-Veränderungen, die zu einem Stop-Codon führen, das Ablesen der messenger RNA trotz dieser Mutation zu ermöglichm, so dass ein vollständiges, katalytisch wirksames Protein synthetisiert wird. So beruhen etwa $20 \%$ aller Gen-Veränderungen bei Mukopolysaccharidose Typ I auf einer Stop-Codon Mutation.

Derzeit ist ein Entwicklungsprozeß in Gang gekommen, der erwarten läßt, das in Zukunft für lysosomale Speicherkrankheiten Medikamente entwickelt werden, die auf unterschiedlichen Ebenen der pathophysiologischen Kaskade ansetzen.

\section{Management, Ökonomie und Zukunftsperspektive von Kinderkliniken}

\section{DGKJ-SY-080}

Anfragen durch den medizinischen Dienst der Krankenkassen (MDK) Von der Diagnose zur Therapie

M. Meyer

Vestische Kinder- und Jugendklinik Datteln - Universität Witten/Herdecke

Ausgaben- und Einnahmenseite im deutschen Gesundheitswesen klaffen für die vollstationäre Versorgung immer weiter auseinander. Die Medien berichten zunehmend über zu hohe Krankenhausrechnungen und systematischen Abrechnungsbetrug durch die Leistungserbringer. Dies ist Ausfluss einer Prüfquote von mehr als 1o Prozent durch die Kostenträger und zugleich Anlass für weitere Einzelfallprüfungen nach $\$ 275$ SGB V. Davon bleibt auch die Kinder- und Jugendmedizin nicht ausgespart. Die Anzahl der durch die Krankenkassen induzierten MDK-Prüfungen steigt trotz der im KHRG festgelegten Aufwandspauschale von 300 Euro pro Anfrage ohne resultierende DRG-Änderung an. Die Anfragehäufigkeit in der Pädiatrie liegt unter dem bundesdeutschen Mittel.

Hauptprüfgründe sind auch in der Kinder- und Jugendmedizin nicht die komplexen Schweregradzuordnungsmechanismen der G-DRG-Logik, sondern die obere und die untere Grenzverweildauer (Prüfung auf sekundäre Fehlbelegung). Dies wird durch den aus pädiatrischer Sicht begrüßenswerten „Linksruck“ im DRG-Katalog 2010 zusätzlich forciert.

Auch die OPS-Komplexbehandlungskodes werden aufgrund ihrer Gruppierungs- bzw. Erlösrelevanz zunehmend hinterfragt. Hier gilt es aus Sicht des Krankenhauses mit möglichst geringem bürokratischem Aufwand eine umfassende Dokumentation anzulegen, die auch der 
MDK-Prüfung standhält. Dies wird an Beispielen demonstriert und durch einzelne, aktuelle Rechtsentscheidungen ergänzt.

Insgesamt erfordert die nicht unerhebliche Zahl von MDK-Prüfungen auf Seiten der betroffenen Kinderklinik bzw. -abteilung neben der medizinsch-fachlichen Qualifikation eine gute Kenntnis des DRG-Algorithmus, der Rechtslage und eine detaillierte und verbindliche Festlegung der Zuständigkeiten im Umgang mit den Anfragen.

\section{DGKJ-SY-081}

Ist die Unterfinanzierung der Spezialambulanzen gelöst?

J. Scheel

GKinD, c/o DRK-Kinderklinik Siegen

Seit dem Frühjahr 2009 existiert mit der Einführung des Absatzes 1a in $\$ 120$ Sozialgesetzbuch V eine gesetzliche Regelung, die erstmals eine kostendeckende Finanzierung ambulanter Leistungen an Krankenhäusern ermöglicht. Es handelt sich um eine spezifische Regelung für an kinder- und jugendmedizinischen, kinderchirurgischen und kinderorthopädischen sowie insbesondere pädaudiologischen und kinderradiologischen Fachabteilungen von Krankenhäusern erbrachte ambulante Leistungen. Das Krankenhaus hat damit die Möglichkeit, neben der EBM-Vergütung eine oder mehrere ambulante Fallpauschalen mit den Kostenträgern zu verhandeln.

Theoretisch ist damit eigentlich das Problem der Unterfinanzierung von Spezialambulanzen gelöst. Leider sieht dies bis dato in der Praxis vollkommen anders aus. Nicht nur die Kostenträger stellen Hürden auf - auch aus den eigenen Reihen gibt es Störfeuer bei den diesbezüglichen Verhandlungen der Kinderkrankenhäuser und -abteilungen.

\section{DGKJ-SY-082}

„Eltern als Unternehmensberater von Kliniken für Kinder und Jugendliche?!" - Aktuelle Ergebnisse und Therapievorschläge

W. Kölfen

Elisabeth Krankenhaus Rheyd

Die Kinderkliniken müssen in ihren Leistungen besser sein als Organfächer. Wer seine Patienten/Eltern behalten will bzw. Neue hinzugewinnen möchte braucht eine aktive Strategie.

Anhand der neuesten Daten der Picker-Studie werden die Stärken und Schwächen von Kinderkliniken aufgezeigt. In der Picker-Studie haben über 6. ooo Eltern sehr differenzierte Beurteilungen über ihren stationären Aufenthalt abgegeben. Ähnliche Befragungen liegen auch zu den Organfächern vor, sodass Vergleiche hergestellt werden können.

Die Ergebnisse zeigen, dass Kinderkliniken in der Beratung der Eltern nicht überzeugen. Defizite in der Kommunikation, Klärung der Zuständigkeiten und die Beratung für zuhause sind dringend verbesserungsnotwendig. Neben der Darstellung der Schwachstellen werden auch Therapieempfehlungen ausgesprochen um bei den Eltern besser zu punkten.

\section{Habilitationsarbeiten im Fokus}

\section{DGKJ-SY-084}

Erkrankungen bei Frühgeborenen - Bedeutung genetischer, immunologischer und klinischer Einflussfaktoren

C. Härtel

Universitätsklinikum Schleswig-Holstein, Klinik für Kinder- und Jugendmedizin

Einleitung: Es war Ziel der Untersuchungen, genetische, immunologische und klinische Einflussgrößen der Immunantwort von Früh- und Neugeborenen zu determinieren, und deren Bedeutung für die Morbidität der Frühgeborenen zu charakterisieren.

Methoden: Die Untersuchungen wurden mit Hilfe von verschiedenen Patientenkollektiven durchgeführt: a) unizentrische Studien mit Früh- und Reifgeborenen (Universität Lübeck) und b) Kohorten von Frühgeborenen mit einem Geburtsgewicht von < $1500 \mathrm{~g}$ und ihren Müttern, die im Rahmen einer deutschlandweiten multizentrischen Zusammenarbeit rekrutiert wurden. Als Methoden wurden PCR (Genotypisierung) sowie für funktionelle Untersuchungen ELISA und Durchflusszytometrie eingesetzt.

Ergebnisse: Hypothese 1 - Polymorphismen der angeborenen Immunantwort und des Gerinnungssystems sind potentielle Risikofaktoren für Frühgeburtlichkeit und Erkrankungen des Frühgeborenen. In unserem Studienkollektiv waren sowohl der mütterliche 174 G>C IL6-Polymorphismus als auch der mütterliche 323 del/ins Faktor VII-Polymorphismus als unabhängige Risikofaktoren mit Frühgeburtlichkeit assoziiert. Erstmalig konnte ein Zusammenhang zwischen dem 34 Val $>$ Leu Faktor XIII-Polymorphismus und Inzidenz der Sepsis bei VLBW-Frühgeborenen beschrieben werden.

Hypothese 2 - der 159 C > T Polymorphismus des CD14-Rezeptor-Gens hat eine funktionelle Bedeutung für die angeborene Immunantwort von Neugeborenen. In einem In-vitro-Modell für gramnegative Sepsis mit Nabelschnurblutkulturen zeigte sich, dass Träger des CD14-159 T Allels höhere Messwerte für lösliches CD14 und IL6 aufwiesen als Träger des CD14-159 C Allels. Der Bedarf an normativen Daten zur quantitativen Immunantwort bei Früh- und Neugeborenen als Antwort auf verschiedene mikrobielle Pathogene führte zu

Hypothese 3, die eine Abhängigkeit der Zytokinproduktion vom Gestationsalter vermutete. Es konnte festgestellt werden, dass die lymphozytäre Produktion von Zytokinen der TH1-Antwort einem altersabhängigen Reifungsprozess unterliegt, ebenso wie die Wirt/ErregerInteraktion zwischen Früh- bzw. Neugeborenen mit einem der wichtigsten Erreger nosokomialer Infektionen, Staphylococcus epidermidis. Schließlich wird vermutet, dass sich die Bedeutung der Immunantwort von Frühgeborenen durch das Wechselspiel mit beeinflussbaren klinischen Risikofaktoren, wie z. B. zentrumsspezifische Unterschiede in der Behandlung (Hypothese 4), ergibt. Unsere Beobachtungen legen nahe, dass zentrumsspezifische Unterschiede in der Dauer des enteralen Nahrungsaufbaus einen wichtigen Einfluss auf die Morbidität von VLBW-Frühgeborenen, wie z. B. die Inzidenz der nosokomialen Sepsis, haben.

Schlussfolgerungen: Die Zusammenschau der Ergebnisse zeigt das Potential von klinisch-epidemiologischen Untersuchungen und modernen Laborverfahren für die langfristige Erstellung von individuellen Risikoprofilen von Frühgeborenen. Prospektive, multizentrische Studien sind notwendig, um einen wirksamen Beitrag zur Prävention von Frühgeburtlichkeit und deren Komplikationen zu erbringen.

\section{DGKJ-SY-085}

Die Lebertransplantation im Säuglingsalter unter Berücksichtigung spezieller Krankheitsbilder - Ergebnisse des Hamburger Transplantationsprogramms

E. Grabhorn

Pädiatrische Hepatologie und Lebertransplantation

Entgegen früherer Erkenntnisse kann die Lebertransplantation im Säuglingsalter bei entsprechender Erfahrung der Transplantationszentren mit einer sehr zufriedenstellenden Kurz- und Langzeitprognose verbunden sein, vergleichbar mit den Ergebnissen bei älteren Kindern. Dies gilt nicht nur für Patienten mit einem chronischen Leberversagen, zum Beispiel im Rahmen einer Gallengangsatresie, sondern auch in Fällen von einem akuten postnatalen Leberversagen mit rascher Verschlechterung des klinischen Zustandes und der Notwendigkeit einer sogenannten Notfall-Lebertransplantation. Die guten Ergebnisse beziehen sich neben dem Transplantat- und Patientenüberleben auch auf die postoperative psychomotorische Entwicklung.

Typische Komplikationen nach einer Lebertransplantation im Säuglingsalter sind ein primäres Transplantatversagen, Galleleckagen, Thrombosen im Bereich der neuen Gefäßanastomosen und Infektionen. Aufgrund eines initial oftmals durch Ischämie und das Operationstrauma geschwollenen Organs sowie einem häufig bestehenden 
Missverhältnis zwischen Lebervolumen des Spenders und der Empfängergröße kommt es regelmäßig zu einer sogenannten „Large-for-size"-Situation. Im Hamburger Transplantationszentrum wird daher bei knapp der Hälfte der lebertransplantierten Säuglinge ein sekundärer Bauchdeckenverschluss durchgeführt.

Die Rate an akuten und chronischen Abstoßungen ist bei Säuglingen vermutlich aufgrund eines physiologisch vorherrschenden Th2-Zytokinprofils niedriger als bei älteren Kindern. Darüber hinaus hat die Einführung einer Induktionstherapie mit dem Anti-Interleukin-2-Rezeptor-Antikörper Basiliximab seit 1998 zu einer deutlichen Reduktion früher akuter Abstoßungen in allen Altersklassen bei sehr guter Verträglichkeit geführt. Die Anwendung von Basiliximab war dabei sowohl im Kurzzeit- als auch im Langzeitverlauf effektiv und nebenwirkungsfrei.

Indikationen für eine Lebertransplantation im Säuglingsalter sind neben der extrahepatischen Gallengangsatresie, der neonatalen Hepatitis und dem akuten Leberversagen auch hereditäre Hepatopathien, wie das Alagille-Syndrom und die progressive familiäre intrahepatische Cholestase. Hier bestehen jedoch oftmals schwierige Entscheidungssituationen in den Fällen, in denen keine Leberzirrhose oder eine chronische Leberinsuffizienz vorliegen, sondern vor allem eine eingeschränkte Lebensqualität durch starken cholestasebedingten Juckreiz oder Kleinwuchs. Während es bei den Patienten mit progressiver familiärer intrahepatischer Cholestase meist zu einem deutlichen Aufholwachstum nach einer Transplantation kommt, trifft dies auf Patienten mit einem Alagille-Syndrom nicht typischerweise zu, da hier der Kleinwuchs auch aus der Grunderkrankung und nicht nur aus der chronischen Cholestase resultieren kann. Daher stellt für diese Patienten der Kleinwuchs keine Indikation für eine Lebertransplantation dar.

Fragliche Indikationen für eine Lebertransplantation sind nach wie vor bestimmte Stoffwechselerkrankungen (zum Beispiel Mitochondriopathien) und das schwere infantile hepatische Hämangioendotheliom, der häufigste vaskuläre Lebertumor im Kindesalter. Oftmals müssen hier bisher sehr individuelle Entscheidungen hinsichtlich einer Transplantation getroffen werden.

\section{DGKJ-SY-086}

\section{Zelluläre und molekulare Mechanismen der Interaktion von Bakte-} rien mit Blut- Hirn und der Blut-Liquor-Schranke in vitro

T. Tenenbaum

Universitätsklinikum Mannheim, Klinik für Kinder- und Jugendmedizin, Pädiatrische Infektiologie

Ein entscheidender Schritt während der Pathogenese der bakteriellen Meningitis ist das Eindringen von Erregern in das zentrale Nervensystem (ZNS). Als Eintrittspforte in das ZNS wird neben der bereits gut untersuchten Blut-Hirn-Schranke (BHS) ebenso die Blut-LiquorSchranke (BLS) diskutiert. An humanen mikrovaskulären Endothelzellen (HBMEC), welche ein Modell für die BHS darstellen, konnte gezeigt werden, dass Virulenzfaktoren von Streptococcus agalactiae (S. agalactiae) sowohl die Adhäsion, am Beispiel des Fibrinogenbindenden Proteins FbsA, als auch die Invasion mit Hilfe des Laminin-bindenden Proteins Lmb fördern (Tenenbaum et al. 2005, Tenenbaum et al. 2007). Wie Bakterien und Phagozyten mit den Epithelzellen des Plexus choroideus, der strukturellen Basis der BLS, interagieren, ist dagegen bisher nicht näher wissenschaftlich bearbeit worden. In eigenen Untersuchungen konnte erstmalig in einem in vitro-BHS-Modell gezeigt werden, dass der schweine- und humanpathogene Erreger Streptococcus suis (S. suis) die Barrierefunktion von porcinen choroidalen Plexusepithelzellen (PCPEC) beeinträchtigen kann (Tenenbaum et al. 2005). Dabei wird die Barrierefunktion der PCPEC aufgrund von Veränderungen der zellulären Integrität kompromittiert, die einerseits durch Zelltodmechanismen (Nekrose oder Apoptose), anderseits durch Affektion von Tight junctions herbeigeführt werden. In diesem Zusammenhang konnte für Dexamethason, welches bereits klinisch während der Behandlung der bakteriellen Meningitis eingesetzt wird, eine protektive Wirkung am Plexusepithel demonstriert werden (Tenenbaum et al. 2006, Tenenbaum et al. 2008). Welche bakteriellen Komponenten und Wirtsfaktoren die Invasion und Translokation von S. suis durch die BLS begünstigen, konnte mit Hilfe eines neu etablierten „Umkehrkultur"-Modells im Transwell-Filtersystem gezeigt werden (Tenenbaum et al., 2009). In diesem Modell wurde erstmalig die Keim-Wirt-Interaktion von der pathogenetisch besonders relevanten basolateralen Seite des Plexusepithels („Blutseite“) analysiert. Es konnte gezeigt werden, dass Invasion und Translokation von S. suis durch das Plexusepithel bevorzugt von der basolateralen Seite und abhängig von dem Virulenzfaktor Kapsel erfolgt. Die Inhibition des $\mathrm{PI}_{3} \mathrm{~K}$-Signalweges, welcher die Zytoskelettveränderungen im Rahmen des bakteriellen Internalisierungsprozesses reguliert, verhinderte dabei die Invasions- und Translokationsrate signifikant. Diese Untersuchungen ermöglichen zum einen neue grundsätzliche Einblicke in die Pathogenese der Meningitis, eröffnen zum anderen aber auch Perspektiven für therapeutische, diagnostische und präventive Strategien.

\section{DGKJ-SY-087 \\ Quantitative sensorische Testung (QST) - eine neue neurophysiologi- sche Methode bei Kindern und Jugendlichen}

M. Blankenburg

Vestische Kinder-und Jugendklinik Datteln

Die quantitative sensorische Testung (QST) nach dem Protokoll des Deutschen Forschungsverbundes Neuropathischer Schmerzen (DFNS) ist ein standardisiertes Verfahren, mit dem alle somato-sensorischen Modalitäten und die Funktion unterschiedlicher peripherer Nervenfasertypen ( $A ß, A d, C)$, sowie zentraler Mechanismen erfasst werden. Wir haben das Verfahren bei gesunden Kindern und Jugendlichen ( $\mathrm{n}=176$, Alter: 6-17 Jahre) an sechs Körperregionen validiert und Referenznormwerte generiert (Blankenburg et al. 2010). Darüber hinaus haben wir Ergebnisse der QST bei juvenilen Patienten (Alter 6-17 Jahre) mit einer peripheren Neuropathie (Diabetes mellitus $>2$ Jahre, $\mathrm{n}=45$ ) und einer Erkrankung des ZNS (Cerebralparese, $\mathrm{n}=30$ ) mit den Ergebnissen herkömmlicher neurophysiologischer Methoden (NLG, SSEP) verglichen. Nach unseren Ergebnissen ist das QST Protokoll des DFNS mit leichten Modifizierungen der Untersuchungsinstruktionen und des Schmerzratings bei Kindern ab dem 6. Lebensjahr valide anwendbar. Die Referenzwerte junger Kinder (6-8 Jahre) unterscheiden sich deutlich von den Referenzwerten bei älteren Kindern (9-12 Jahre) und Jugendlichen (13-17 Jahre) sowie bei Erwachsenen. Jüngere Kinder sind weniger empfindlich für thermische und mechanische Detektionsreize, aber empfindlicher für alle thermischen und mechanischen Schmerzreizen als ältere Kinder und Jugendliche. Geschlechtsunterschiede waren statistisch gering, Mädchen sind nur empfindlicher für thermische Detektions- und Schmerzreize als Jungen. Das Gesicht ist empfindlicher für alle Detektions- und Schmerzreize als die Hand und/oder der Fuß. Bei juvenilen Patienten mit einem Diabetes mellitus Typ 1 findet sich eine hohe Korrelation zwischen abnormen mechanischen Detektionsschwellen (42\% der Patienten) und NLG's ( $37 \%$ der Patienten; $r=0.700 ; \mathrm{p}<0.001)$ und bei Patienten mit einer Cerebralparese eine hohe Korrelation zwischen abnormen mechanischen Detektionsschwellen (90\% der Patienten) und SSEP's (70\% der Patienten; $r=0.910 ; p<0.001)$. Zusammenfassend ist das QST Protokoll des DFNS bei Kindern ab dem 6. Lebensjahr anwendbar und valide. Die Referenzwerte sind abhängig vom Alter und von der Untersuchungsregion. Sowohl bei Patienten mit einer peripheren, als auch bei Patienten mit einer zentralen Neuropathie findet sich eine hohe Übereinstimmung von QST-Parametern mit herkömmlichen neurophysiologischen Methoden. Möglicherweise finden sich Veränderungen der mechanischen Detektionsschwellen früher als Veränderungen der NLG's bzw. SSEP`s. Die QST ist im Vergleich zu herkömmlichen neurophysiologischen Untersuchungen einfach durchführbar, schmerzlos für die Patienten und kosteneffektiv. Lit.: Blankenburg M, Boekens H, Hechler $\mathrm{T}$, et al. Reference values for quantitative sensory testing in children and adolescents: Developmental and gender differences of somatosensory perception. Pain 2010;149: 76-88 
DGKJ-SY-088

Molekulare Grundlagen und klinische Präsentation kongenitaler Erythrozytosen und der Polycythaemia vera im Kindes- und Jugendalter H. Cario

Universitätsklinik für Kinder- und Jugendmedizin

Erythrozytosen bilden bei Patienten ohne kardiale oder pulmonale Grunderkrankungen eine sehr seltene, heterogene Gruppe von Erkrankungen. Es gibt nur wenige systematisch erhobene Daten zu Grundlagen, Präsentation und Behandlung dieser ätiologisch in vielen Fällen ungeklärten Krankheitsbilder, ebenso wie zur Polycythaemia vera bei pädiatrischen Patienten. Wir untersuchten 16 Patienten mit primärer kongenitaler Erythrozytose hinsichtlich genetischer Veränderungen im EPOR-Gen. Bei einer Patientin wurde eine bisher nicht beschriebene, sporadische Mutation EPOR Trp439Stop identifiziert. Eine Mutation EPOR Tyr426Stop, wurde bei drei zu einer Familie gehörenden Patienten mit sehr variablem klinischem Phänotyp nachgewiesen. Die Mutationen führen zu einer Verkürzung des Erythropoietin-Rezeptors um 70 bzw. 83 Aminosäuren mit konsekutiver Hypersensitivität der erythroiden Zellen gegenüber zirkulierendem Erythropoietin. Bei 96 Patienten mit kongenitaler sekundärer Erythrozytose führten wir eine Sequenzanalyse des VHL-Gens durch. Sie erbrachte bei sechs Patienten den Nachweis einer homozygoten, bei drei Patienten den einer heterozygoten Mutation VHL Arg2ooTrp, die die sogenannte Chuvash-Polyzythämie verursacht. Zwei der drei heterozygoten Patienten zeigten eine nahezu ausschließliche mRNA-Expression des mutierten VHLAllels. In der VHL-Haplotyp-Analyse konnten wir zeigen, dass die Chuvash-Mutation zwar in der Mehrzahl der Fälle auf einen gemeinsamen Ursprung zurückzuführen ist, in Einzelfällen aber auch unabhängig davon entstanden sein muss. Außerdem wurde bei einer Patientin eine neue, heterozygote Mutation VHL Gly104Val identifiziert. In einer internationalen Kooperation gelang es, klinische und molekulargenetische Daten von acht pädiatrischen Patienten mit Polycythaemia vera (PV) zu erheben. Die Auswertung der klinischen Daten sowie von publizierten Fällen ergab einige für die PV bei pädiatrischen Patienten charakteristische Besonderheiten, u. a. die bemerkenswert häufige Entwicklung eines Budd-Chiari-Syndroms. Molekulargenetische Analysen ergaben bei sechs unserer Patienten eine somatische Mutation JAK2 Val617Phe. Bei zwei Patienten wurden Mutationen im Exon 12 des JAK2-Gens entdeckt. Durch Untersuchung einer Familie mit zwei an PV erkrankten Patienten konnten wir früh zeigen, dass es sich bei der 2005 erstmals beschriebenen Mutation JAK2 Val617Phe nicht um eine prädisponierende, angeborene Mutation handelt und dass trotz des mit dem JAK2-Haplotyp 46/1 assoziierten allgemeinen Risikos für eine JAK2 Mutation auf diesem Allel bei entsprechender PV-Prädisposition auch unabhängig davon eine JAK2 Mutation akquiriert werden kann. Viele Fragen zu den kongenitalen Erythrozytosen sind offen. Frühzeitige Diagnosestellung und Ursachenklärung sind notwendig, um einen möglichst komplikationslosen Langzeitverlauf zu gewährleisten. Die PV spielt in der pädiatrischen Hämatologie zwar hinsichtlich der Patientenzahl nur eine geringe Rolle, stellt aber gerade aufgrund der Seltenheit eine besondere diagnostische und therapeutische Herausforderung dar. Die Aufklärung der pathogenetischen und klinischen Besonderheiten pädiatrischer Patienten kann zum besseren Verständnis der Pathogenese der PV insgesamt beitragen.

\section{DGKJ-SY-089}

Dynamische Veränderungen des podozytären Aktin-Zytoskelett im Rahmen des Nephrotischen Syndroms

J. Oh

Universitätsklinikum Hamburg-Eppendorf, Klinik für Kinder- und Jugendmedizin

Podozyten sind elementare Bestandteile der glomerulären Filtrationsbarriere und damit essentiell für eine intakte glomeruläre Funktion. Die Podozyten besitzen eine einzigartige, hochkomplexe Architektur: Ihr Zellkörper ragt in den Bowmanschen Kapselraum hinein, von ihm gehen mehrere Primärfortsätze ab, die sich in Sekundärfortsätze (Fußfortsätze) verzweigen. Die Fußfortsätze umgreifen interdigitierend die Kapillarschlingen und sind über a3ß1-Integrine und Dystroglykan3 Komplexe in der glomerulären Basalmembran verankert. Ihr Zytoskelett besteht u. a. aus zahlreichen Aktin-Filamenten. Die Fußfortsätze benachbarter Podozyten sind durch einen Filtrationsschlitz voneinander getrennt, dieser wird von der Schlitzmembran überbrückt. Sie stellt die einzige Verbindung zwischen den benachbarten Podozyten dar. Die hochspezialisierte Struktur der Podozyten ist zudem dynamisch - bei einigen proteinurischen Erkrankungen kommt es zu einer Fußfortsatzverschmelzung, hierbei handelt es sich um eine rasche und reversible Konformationsänderung auf Ebene des Aktin-Zytoskelett. Werden Podozyten gestresst, so zeigen sie durch eine gesteigerte Zellmigration das Bild der Fußfortsatzfusion, dem morphologischen Korrelat des nephrotischen Syndroms (NS). Dies erfolgt u. a. durch das Zusammenspiel von Cathepsin L und Integrin alpha. Durch diese Veränderungen wird die komplexe renale Filtrationsbarriere gestört, und es kommt zu einer Proteinurie, bei persistierender Schädigung sogar zu irreversiblen Veränderungen im Sinne einer fokal-segmentalen Glomerulosklerose (FSGS). Infolge der schweren Zellschädigung durch exogene Noxen und sekundärer Hyperfiltration übrig gebliebener Glomeruli kommt es dann zum Untergang der Podozyten durch Apoptose. Bei der Initiation und Manifestation der chronischen Niereninsuffizienz spielt die Apoptose daher eine bedeutende Rolle. Dies wird zum Teil durch Modulation der intrazellulären Calciumkonzentration (TRPC6 und CalciumSensing-Rezeptoren) gesteuert, die als second messenger Signale auf das Zytoskelett überträgt und für die Regulation der mitochondrialen Apoptosevorgänge mitverantwortlich ist. Diese Veränderungen führen zu einer irreversiblen fokal-segmentalen Glomerulosklerose (FSGS) bzw. chronischen Niereninsuffizienz. Die bekannten etablierten engen Beziehungen (in neuronalen Zellen, Pilzen) zwischen filamentärem Aktin, Mikrotubuli, Apoptose und mitochondrialer Funktion, Lokalisation und Morphologie legen nahe, dass Mitochondrien auch in Podozyten eine wesentliche Rolle in der Entwicklung der chronischen Niereninsuffizienz spielen. In den letzten Jahren zeigte sich weiterhin, dass nicht nur die Immunmodulation als Ursache der podozytären Schädigung in Frage kommt, sondern diese Zelle selber, durch Bindung an spezifische Rezeptoren (B7-1) direktes Ziel zahlreicher extrazellulärer Noxen ist. Hier bei sind Zytokine, Entzündungsmediatoren (aktiviertes Protein C), Hormone (Östrogene) und Toxine (LPS) hervorzuheben. Diese können durch die Bindung an die Podozyten die Aktin-Organization direkt negativ beeinflussen und Krankheitsschübe auslösen. Eine Verhinderung dieser direkten Beinflußung stellt einen völlig neuen therapeutischen Ansatz für die Behandlung der nephrotischen Syndroms dar.

\section{DGKJ-SY-090}

Antigen-spezifische T-Zellen zur adjuvanten Therapie gegen bösartige Erkrankungen des Kindes- und Jugendalters

M. Wölfl

Pädiatrische Tumorimmunologie, Universitätskinderklinik

Die Immuntherapie stellt neben den klassischen Therapiemodalitäten der Chirurgie, Chemotherapie und Strahlentherapie eine weitere Säule der onkologischen Therapie dar. T-Zell-vermittelte Therapien haben sich für einige Tumorentitäten bereits als hochspezifisch und effektiv erwiesen. In eigenen Arbeiten konnten Grundlagen zur Immunogenität pädiatrischer Tumoren erarbeitet werden, sowie wichtige Tumor escape Mechanismen untersucht werden. Um solche inhibitorischen Mechanismen zu umgehen, konnten wir zeigen, dass eine T-Zell-Antwort verstärkt werden, indem T-Zellen ex vivo unter optimierten Bedingungen stimuliert und expandiert werden. Solche T-Zellen können dann als hochselektive T-Zell-Präparate eingesetzt werden. Dabei konnten wir herausarbeiten, dass die Kulturbedingungen wesentlich sowohl die Stärke der resultierenden T-Zell-Antwort, als auch die Funktionalität der T-Zellen beeinflussen. Durch Verwendung von Interleukin-21, IL-7 und IL-15 bei der Stimulation hochaufgerei- 
nigter naiver T-Zellen, ist es gelungen ein robustes Protokoll zu erstellen, das die Kurzzeit-Expansion antigenspezifischer T-Zellen erlaubt. In einer 10-tägigen Kulturzeit kommt es zur starken Expansion multifunktioneller T-Zellen, die durch die Produktion mehrerer Zytokine, die Expression von Homing Rezeptoren sowie auf Grund ihres Phänotyps, sog. „,central memory“ T-Zellen ähneln. Die Verwendung solcher Kurzzeit-kultivierten T-Zellen ist auch im klinischen Kontext gut umsetzbar und könnte eine effektive Verstärkung der Anti-Tumor-Antwort bewirken. Diese Arbeiten werden unterstützt durch die Kind-Philipp Stiftung sowie durch das BayImmunet

\section{DGKJ-SY-091}

Komplementäre und alternative Behandlungsmethoden in der Pädiatrie

S. Gottschling

Universitatesklinikum des Saarlandes

Die Anwendungshäufigkeit komplementärer und alternativer Behandlungsmethoden (CAM) hat in den letzten Jahren deutlich zugenommen. Bei 1071 befragten Familien fanden wir Anwendungsraten bei deren Kindern zwischen $20 \%$ und 70\% je nach Erkrankung. Die Erwartungshaltung gegenüber CAM ist hoch, die subjektive Einschätzung der Methoden ist sehr positiv. Homöopathie und Akupunktur gehören zu den am häufigsten angewandten Methoden. Obwohl Homöopathie bei allen untersuchten Erkrankungen die höchste Anwenderrate hat, gibt es keine wissenschaftliche Grundlage, die die Anwendung im pädiatrischen Bereich stützt. Von 25 publizierten randomisierten, kontrollierten Studien, erbrachten lediglich 2 Studien höherer methodischer Qualität Hinweise für eine mögliche spezifische Wirksamkeit von Homöopathika. Unsere Studien zur Akupunktur bei den Indikationen Prävention von Übelkeit und Erbrechen unter Chemotherapie bei Kindern und Laserakupunktur von Kindern mit chronischen Kopfschmerzen, erbrachten signifikant positive Ergebnisse für die Akupunktur, bezogen auf die untersuchten Zielparameter. Für eine mögliche Integration bestimmter CAM in die konventionelle Medizin ist zum einen ein unvoreingenommener Dialog mit dem Patienten und zum anderen eine intensivierte Grundlagenforschung und vor allem klinische Forschung auf hohem qualitativen Niveau notwendig.

\section{DGKJ-SY-092}

Das Antikörper-Repertoire während B-Zell-Reifung, Ontogenese und Immunantwort

M. Zemlin

Universitätsklinikum Gießen und Marburg GmbH, Standort Marburg

Das Immunsystem kann eine nahezu unbegrenzte Antikörper-Vielfalt produzieren. Unklar ist, wie die Produktion schädlicher und unnützer Antikörper vermieden wird. Wir haben Mechanismen der Diversifikation und Restriktion des Antikörper-Repertoires während der Ontogenese, B-Zell-Reifung und Immunantwort untersucht. Mittels Sequenzierung von RNA-Transkripten der schweren Immunglobulinkette aus Nabelschnurblut und postnatalen Blutproben konnten wir zeigen, dass die Diversifikation des Antikörper-Repertoires während der Ontogenese einer Regulation unterliegt, die während der zweiten Schwangerschaftshälfte zu einer exponentiellen Zunahme der Antikörper-Vielfalt führt. Während die Entwicklung des primären Antikörper-Repertoires (IgM) bereits beim Feten beginnt, diversifiziert das sekundäre Antikörper-Repertoire (IgG und IgA) erst postnatal. Beim Frühgeborenen beginnt der Klassenwechsel vorzeitig, nicht jedoch die die Bildung somatischer Mutationen während der Keimzentrumsreaktion. Daher unterscheiden sich die Antigen-Bindungsstellen der IgG- und IgA-Antikörper von Früh- und Reifgeborenen in ihrer Vielfalt (ca. 0,25\% bzw. $5 \%$ der Diversität Erwachsener) und Struktur erheblich. Die bei Frühgeborenen überwiegenden kuhlenförmigen Antigen-Bindungsstellen mit intakten Wasserstoffbrücken und wenigen somatischen Mutationen verursachen wahrscheinlich die typische Polyreaktivität und geringe Antigenaffinität ihrer Antikörper. Als einen zentralen Mecha- nismus zur sekundären Korrektur unerwünschter (z. B. autoreaktiver) Immunglobuline haben wir den VH-Gen-Ersatz erstmalig beim Menschen nachgewiesen und seinen molekularen Mechanismus aufgeklärt. Im Mausmodell fanden wir Hinweisen dafür, dass ein Defekt derartiger Selektionsmechanismen bereits während der frühen, Antigen-unabhängigen B-Zellentwicklung zur Autoimmunerkrankung prädisponieren kann. Um die Auswirkungen einer gestörten Selektion des primären Antikörper-Repertoires zu untersuchen, haben wir mit gene targeting eine Mauslinie mit veränderten Genen der schweren Immunglobulinkette hergestellt. Vergleiche dieser Mauslinie mit Wildtyp-Mäusen zeigten, dass sich die B-Zell-Subpopulationen von Knochenmark, Milz, Peyer-Plaques und Peritonealhöhle in ihrem Repertoire an AntigenBindungsstelle unterscheiden. Dies stützt die Hypothese, dass B-Zellen anhand ihrer Antigen-Bindungseigenschaften in die Subpopulationen rekrutiert werden. Mit unserer Mauslinie konnten wir im Asthma-Modell zeigen, dass die allergische Reaktion auf Ovalbumin entgegen der ursprünglichen Hypothese eine klassische, Affinitäts-abhängige Immunantwort und nicht eine Superantigen-Antwort ist. Zusammenfassend konnten wir zeigen, dass die Entwicklung des primären und sekundären Antikörper-Repertoires während der Ontogenese nicht zufällig verläuft, sondern strikten genetisch determinierten Regulationsmechanismen unterliegt und dass eine Störung dieser Regulationsmechanismen im Mausmodell zu einer veränderten B-Zell-Entwicklung und Immunantwort führen kann.

\section{Sonntag, 19. September 2010}

\section{Tropenpädiatrie}

\section{Ein Update}

\section{DGKJ-PV-177}

Das Tanzania Telemedicine Network: Unterstützung der pädiatrischklinischen Versorgung in abgelegenen Krankenhäusern in Tansania C. Krüger', M. Niemi²

${ }^{1}$ St. Franziskus-Hospital, ${ }^{2}$ ELCT Health Department

Einleitung: In abgelegenen Krankenhäusern im ländlichen Afrika sind in der Regel keine Pädiater für die Versorgung der erkrankten Kinder verfügbar. Der Einsatz von telemedizinischen Netzwerken kann daher sowohl der theoretischen Ausbildung des medizinischen Personals vor Ort als auch der konkreten Behandlung von Patienten mit problematischen Erkrankungen dienen. Wir berichten hier über unsere bisherigen Erfahrungen mit dem Tanzania Telemedicine Network.

Material und Methode: Das Tanzania Telemedicine Network wurde Anfang 2008 von der zentralen Gesundheitsabteilung der EvangelischLutherischen Kirche in Tansania aufgebaut, um nicht nur die eigenen Krankenhäuser, sondern auch andere Gesundheitseinrichtungen im Land zu unterstützen. Dazu wurde das frei verfügbare iPATH-System auf dem Server der Universität Basel benutzt, und alle beteiligten Krankenhäuser erhielten die notwendige technische Ausstattung. Klinische Experten aus verschiedenen Ländern, die meisten mit eigener Erfahrung in Tansania, beantworten die eingehenden Anfragen. Wir stellen die bisherigen Ergebnisse im Bereich der pädiatrischen Konsultationen vor.

Ergebnisse: Mehr als 400 Konsultationen gingen bisher von den beteiligten Institutionen ein, davon mehr als 120 im pädiatrischen Bereich (Stand 15. 05. 2010). Einige wenige Anfragen behandelten eher generelle Fragen zu Impfungen und anderen Themen, die meisten betrafen schwierige Verläufe bei erkrankten Kindern. Einige typische Beispiele werden im Vortrag demonstriert werden. In $72 \%$ der Fälle erfolgte die erste Antwort durch den Spezialisten innerhalb von 24 Stunden, da meist rasche Entscheidungen erforderlich waren. Zwei Pädiater beant- 
worteten 58\% aller Anfragen, die restlichen wurden von Spezialisten aus der Chirurgie, Dermatologie, Inneren Medizin und Radiologie beantwortet.

Diskussion: Das Tanzania Telemedicine Network bietet eine praktikable Möglichkeit für medizinisches Personal in abgelegenen Krankenhäusern in Tansania, bei schwierigen Krankheitsverläufen Diagnostikund Therapiehinweise von Spezialisten zu erhalten und somit die Versorgungsqualität zu verbessern. Besonders zu betonen ist, dass dieses System auch in Regionen mit schlechter Internetverbindung funktioniert. Schwierigkeiten liegen noch in der relativ niedrigen Nutzerrate und einer niedrigen Rückmeldequote über den Verlauf der Patienten. Schlussfolgerung: Das Tanzania Telemedicine Network bietet nach den bisherigen Erfahrungen sowohl die technischen als auch fachlichen Voraussetzungen, die Qualität der pädiatrischen Versorgung auch in abgelegenen Gesundheitseinrichtungen Tansanias deutlich zu verbessern.

\section{DGKJ-SY-124}

Malaria: Prophylaxe, Diagnose und aktuelle Therapie R. Kobbe

Department of Pediatrics, University Medical Centre Hamburg-Eppendorf

Gerade im Kindesalter muss bei Reisen in Malariaendemiegebiete eine gewichts-adaptierte medikamentöse Malariaprophylaxe und eine Expositionsprophylaxe gewissenhaft durchgeführt werden. Kinder machen einen bedeutenden Anteil aller - meist aus dem tropischen Afrika - nach Europa importierten Malariafälle aus. Eine Erkrankungshäufung tritt jedes Jahr nach der Ferienzeit auf. Durch einen steigenden Trend zu Auslandsreisen und Immigration von Familien aus Ländern, in denen die Malaria endemisch ist, sowie die daraus resultierenden Heimatbesuche, müssen Kinderärzte in der Praxis immer häufiger mit importierter Malaria rechnen und gute Reiseanamnesen erheben. Aufgrund des potenziell lebensbedrohlichen Verlaufs der Malaria tropica sollte bei jeder Fiebererkrankung die 6 Tage bis zu 1 Jahr nach der Rückkehr aus einem Endemiegebiet auftritt, unabhängig von der Einnahme einer medikamentösen Prophylaxe, eine unverzügliche Diagnostik eingeleitet werden. Unspezifische Symptome wie Kopfund Gliederschmerzen, Schüttelfrost, Abgeschlagenheit, Appetitverlust und Durchfall, sowie ein Sklerenikterus, eine Anämie oder eine tastbar vergrößerte Milz müssen auch ohne hohes Fieber, gerade bei immigrierenden Kindern oder Patienten unter medikamentöser Prophylaxe, an eine Infektion mit Plasmodien denken lassen. Die medikamentöse Behandlung der Malaria tropica im Kindesalter erfolgt unter stationären Bedingungen mit effektiven, im Kindesalter erprobten Substanzen. Es muss dabei vordringlich geklärt werden, ob eine respiratorische Insuffizienz, eine Schocksymptomatik oder Zeichen einer zerebralen Beteiligung vorhanden sind. Komplizierte Verlaufsformen erfordern eine intravenöse antiinfektive Therapie unter intensivmedizinischem Bedingungen.

\section{DGKJ-SY-126}

Was kann die Kinder- und Jugendmedizin in Deutschland von Strategien der internationalen Kindergesundheit lernen?

S. Nolte

Kinder- und Jugendarzt, Neonatologie-Psychotherapie-Homöopathie-Palliativmedizin, Lehrbeauftragter der Philipps-Universität Marburg

Dadurch, dass von internationalen Regierungs- und Nichtregierungsorganisationen Bemühungen zu Kindergesundheit im weltweiten Kontext diskutiert und vor allem praktisch implementiert werden, ergeben sich auch für die Pädiatrie in Deutschland Anstöße, die bislang wenig in die Ausbildung oder in den Alltag integriert sind. Neben der zugrundeliegenden gesellschaftlichen und ärztlichen Grundhaltung ist die tägliche Frage „Was brauchen wir wirklich?" im globalen Kontext besser zu beantworten als in unseren lokalen, oft historisch definierten Strukturen.
An einigen Punkten soll dies illustriert werden: angefangen von den basalen, bei uns wegen ihrer Selbstverständlichkeit unterschätzten Voraussetzungen von Hygiene und Ernährung, dem UNICEF Programm GOBI-FFF (Growth monitoring, oral rehydration, breast-feeding, immunization, food security, female education, family spacing) bis hin zu Algorithmen der Notfallerkennung und Behandlung, wie das IMCI (Integrated Management of Childhood Illness) Programm oder der ETAT (Emergency Triage Assessment and Treatment) Kurs der WHO, der Bedeutung der bei uns gescheiterten Positivliste wichtiger und notwendiger Medikamente (Essential drugs), der Qualitätssicherung und des Qualitätsmanagements bis hin zu einem besseren Verständnis für die Lebensbedingungen von Kindern in Krisensituationen (Flucht, Bürgerkrieg, Vertreibung). Der „brain drain“, die Fachkräfteabwanderung, liegt auch an der praxisfernen Ausbildung, die westliche Gastländer ausländischen Medizinern bieten.

An Beispielen, wie Diagnose und Therapie der Pneumonie, HIV und Stillen usw. wird gezeigt, welche Auswirkungen konkrete Forschungsergebnisse der internationalen Kindergesundheit für die tägliche Pädiatrie haben können.

Im Rahmen des Berufsfelderkundungspraktikums finden diese Punkte seit 15 Jahren im Medizinstudium in Marburg wenigstens eine Erwähnung, eine Ausweitung und Integration in die Ausbildung wäre wünschenswert und wird in einigen bescheidenen Ansätzen realisiert.

\section{Genetik und Rheumatologie}

\section{DGKJ-PV-191}

Rezessive Osteogenesis imperfecta durch eine neue LEPRE1-Mutation in einer konsanguinen Familie

J. Hartung' ${ }^{1}$, K. Hörtnagel ${ }^{2}$, M. Rogalski ${ }^{3}$, S. David', P. Degenhardt' ${ }^{1}$, D. Schnabel', G. Schwabe'

${ }^{1}$ Charite Kliniken f. Kinderheilkunde und Kinderchirugie, ${ }^{2}$ Pränatal Medizin München, ${ }^{3} \mathrm{HELIOS}$ Klinikum Berlin-Buch

Osteogenesis imperfecta (OI) ist eine genetisch bedingte Erkrankung des Knochens, die durch eine verminderte Knochendichte und erhöhte Knochenfragilität gekennzeichnet ist. In der Regel wird OI autosomal dominant vererbt und durch Mutationen in den pro-1 oder pro-2 Ketten des TypI-Kollagens (COL1A1; COL1A2) hervorgerufen. Rezessiv vererbte Formen der Osteogenesis imperfecta, die ungefähr 5 bis $7 \%$ aller Osteogenesis imperfecta-Formen ausmachen, werden durch Mutationen in Proteinen verursacht, die bei der posttranslationalen Hydroxylierung oder Prozessierung der COL1A1- oder COL1A2-Ketten bedeutsam sind. Wir beschreiben eine konsanguine Familie türkischer Herkunft mit zwei an einer rezessiven Osteogenesis imperfecta erkrankten Kindern. Bei der 15-jährigen Tochter waren bis zum jetzigen Zeitpunkt über 6o Frakturen aufgetreten, sie benötigt eine Gehhilfe oder Rollstuhl und ist kleinwüchsig $(20 \mathrm{~cm}<3$. P). Aufgrund rezidivierender Frakturen erfolgte eine Stabilisierung der Ober- und Unterschenkel mit Bailey-Dubow-Teleskop-Marknägeln. Bei der jüngeren ebenfalls kleinwüchsigen 2 7/12 Jahre alten Tochter wurden beide stark gebogen und mehrfach frakturierten Femora mit Fassier-Duval-Nägeln versorgt. Im Unterschied zu den klassischen Bailey-Dubow-Nägeln bleibt den Kindern damit eine Eröffnung des Kniegelenkes mit den Nachteilen intarartikulärer Irritationen, Verwachsungen und Bewegungseinschränkungen erspart. Bei beiden Kindern konnte eine neue homozygote c. 446T $>\mathrm{G}$ (p. L149R) Mutation im LEPRE1-Gen nachgewiesen werden. LEPRE1 bildet zusammen mit CRTAP und CyclophilinB (CyPB) den Kollagen-Prolyl-3-Hydroxylierungs-Komplex im Endoplasmatischen Retikulum (ER), der für die Hydroxylierung eines einzelnen Prolinrests, Prog86 der 1(I) and 1(II) Kollagenketten verantwortlich ist. Diese durch LEPRE1-Mutation gekennzeichnet Form, die dem OI Typ III nach der Sillence-Klassifikation ähnelt, wird auch als OI Typ VIII bezeichnet. 
DGKJ-PV-192

Die Array-CGH, eine neue Technik in der molekularen Zytogenetik: Indikationen, Ergebnisse, Ausblick

D. Horn, E. Klopocki

Institut für Medizinische Genetik

Methode: Dargestellt werden die Grundlagen und die Technik der Array-CGH („,comparative genomic hybridization“), eine gesamtgenomische Analysemethode, die Informationen über Verluste oder Gewinne von genetischem Material eines Patienten in nur einem Experiment ergibt. Im Vergleich zur konventionellen Chromosomenanalyse als „Suchtest“ am genetischen Material hat sie eine etwa 1oofach feinere Auflösung und ermöglicht den Nachweis von submikroskopischen Veränderungen.

Ergebnisse: Es werden klinisch erkennbare und molekular neu charakterisierte Mikrodeletions- und Mikroduplikationssyndrome vorgestellt wie das 22q13 Deletionssyndrom und die Mikroduplikation Xq28. An anderen Beispielen werden Grenzen der Methode und auch Probleme der Befundinterpretation erläutert.

Diskussion: Die in der Literatur vorgeschlagenen und unsere eigenen Indikationskriterien für die Anwendung der Array-CGH werden besprochen. Diese Methode trägt überzeugend zur ursächlichen Klärung von mentaler Retardierung und von Dysmorphie- und Fehlbildungssyndromen bei. Die Array-CGH leitet eine neue Ära des genetischen Suchtestes ein.

\section{DGKJ-PV-192a}

Klinisches Spektrum ausgewählter Mikrodeletionssyndrome: Deletion 22q11.2, 1p36 und 17p (Smith-Magenis Syndrom)

L. Graul-Neumann

Medizinische Genetik, Charité, Campus Virchow-Klinikum, Universitätsmedizin

Methode: Die Auflösungsgrenze der Routinechromosomenanalyse liegt bei 450-550 Banden pro Haplosatz, entsprechend liegt die Auflösungsgrenze bei ca 5-7 Megabasenpaaren, d. h. kleinere Deletionen können nicht erkannt werden. Sie werden durch die Methode der FISH (Fluoreszenz-In-Situ-Hybridisierung) erkannt. Die Deletionsgröße bei den meisten Mikrodeletionssyndromen beträgt 1-5 Megabasenpaare. Der Phänotyp der Mikrodeletionssvndrome wird in der Regel durch mehre Gene, die in dem deletierten Bereich liegen beeinflusst. Die Erkrankungen werden daher auch als "Contiguous Gene Syndrome" bezeichnet, weil mehrere benachbarte Gene die Symptomatik bewirken. Es werden Patienten mit verschiedenen Mikrodeletionssyndromen vorgestellt.

Ergebnisse: Mikrodeletion 22q11. 2: Vorkommen 1: 4000; die Patienten haben eine Gaumenspalte in $10 \%$, Herzfehler (besonders conotrunkale, nasale Sprache (velopharyngeale Insuffizienz),Kleinwuchs, Hypocalcämie in 60\%, und Entwicklungsretardierung; Fazies häufig: Hypertelorismus, hypoplastische Nasenflügel, ' overfolded Helices" , schlanke lange Finger, häufig rezidivierende Infekte im Kindesalter, auch Vorkommen von renalen und skelettären Fehlbildungen, später in $\mathbf{2 2} \%$ Schizophrenie.

Mikrodeletion 1p36: Vorkommen 1: 10 ooo; die Patienten zeigen im Allgemeinen eine Wachstumsretardierung, Microcephalie, große vordere Fontanelle, gerade Augenbrauen, tiefliegende Augen, pointiertes Kinn, Cardiomyopathie, Krampfanfälle, später häufig Adipositas. Das Prader-Willi Syndrom stellt dann eine Differentialdiagnose dar.

Mikrodeletion 17p11. 2: Vorkomme ca 1: 25 ooo Smith-Magenis Syndrom Patienten weisen eine verzögerte Sprachentwicklung, Schwerhörigkeit, gestörten Tag/Nachtrhythmus auf sowie Durchschlafstörungen, Aggression oder Autoaggression,faziale Dysmorphien wie ansteigende Lidachse, evertierte Oberlippe, Mittelgesichtshypoplasie sind häufig vorhanden, ebenfalls eine helle Komplexion.

Diskussion: Es gibt hinweisende Symptome für o. g. Mikrodeletionssyndrome. Das Spektrum ist jedoch variabel. Klinisches Erkennen vorausgesetzt lässt sich die Diagnose nachfolgend durch eine FISH Unter- suchung kostengünstig validieren. Daraus ergeben sich häufig Konsequenzen für das Management der Patienten, Präzisierung des Wiederholungsrisikos für eventuelle weitere Kinder bzw. die Möglichkeit einer pränatalen Diagnostk.

\section{DGKJ-PV-193}

Mutationen im VANGL1-Gen sind eine seltene, aber medizinisch relevante Ursache von Spina bifida und Hydrocephalus

O. Bartsch', A. Thiede', S. Lechno', G. Kutschke1, S. Florian², H. Gocan², P. Percsi' ', T. Haaf ${ }^{3}$, U. Zechner' ${ }^{1}$, L. Sabova ${ }^{4}$, F. Horn ${ }^{4}$

${ }^{1}$ Klinikum der Johannes-Gutenberg Universität, ${ }^{2}$ University of Cluj-Napoca, ${ }^{3}$ Universität Würzburg, ${ }^{4}$ University of Bratislava

Fragestellung: Neuralrohrverschlussstörungen sind die zweithäufigsten angeborenen Fehlbildungen nach Herzfehlern, die Prävalenz beträgt 1-2 auf 1. ooo Neugeborene. Als Ursache werden häufig (>70\%) multifaktorielle (umweltbedingte und genetische) Ursachen angenommen, aber in jüngster Zeit wurden auch folsäure-unabhängige Veränderungen in Entwicklungsgenen als eine andere, seltenere Ursache erkannt. Forscher aus Montreal fanden bei 810 Patienten aus zwei großen Spina-Bifida-Zentren (Genua und Chicago) in acht Fällen Veränderungen in VANGL1 (van Gogh-like 1), einem Gen für die Zellpolarität (Kibar et al. 2007 und 2009). Ziel der vorliegenden Untersuchung war die Bestätigung dieser Ergebnisse an einem anderen Patientenkollektiv.

Material und Methode: Wir untersuchten bisher 140 Patienten der Geburtsjahrgänge 1972-2009 (85\%: 1991-2009) aus Spina-Bifida-Zentren in Mainz (Rheinland-Pfalz), Bratislava (Slowakei) und Cluj (Rumänien). Durchgeführt wurde eine direkte Sequenzierung aller kodierenden Abschnitte des VANGL1-Gens einschließlich der Exon-IntronÜbergänge mit einem Beckman CEQ8ooo Genetic Analysis System.

Ergebnisse: Wir konnten bei zwei Patienten relevante Sequenzvarianten im VANGL1-Gen nachweisen, c. 518G >A (p. Arg173His) und c. $613 \mathrm{G}>\mathrm{A}$ (p. Gly205Arg). Beide Varianten verändern evolutionär konservierte Aminosäuren und sind mit hoher Wahrscheinlichkeit krankheitsrelevant. Beide Sequenzvarianten sind zudem neu. Sie wurden bisher weder bei gesunden Kontrollen noch bei anderen Patienten beschrieben.

Diskussion: Die Sequenzveränderung p. Arg173His wurde bei einem jungen Mann aus der Slowakei vorgefunden. Dieser Austausch ist konservativ, weil beide Aminosäuren hydrophil und basisch sind, aber Arginin ist erheblich stärker geladen (pKa 12,5) als Histidin (pKa 7,6) und die Position Arg173 ist evolutionär vollständig konserviert (auch bei Fischen/Tetraodon, Fruchtfliege/Drosophila und Würmern/C. elegans). Zudem sind bereits zwei ähnliche Veränderungen bekannt, p. Arg175Gln und p. Arg181Gln (Kibar et al. 2009). Die Sequenzvariante p. Gly205Arg wurde bei einem nicht verwandten slowakischen Patienten mit einer sporadischen lumbosakralen Myelomeningocele nachgewiesen. Diese Veränderung ersetzt im Protein ein Glycin durch ein Arginin (nicht-konservativer Austausch) und bewirkt eine schwerwiegende Veränderung einer in allen bekannten Spezies (einschließlich Tetraodon, Drosophila und C. elegans) als unpolar konservierten Aminosäure. Somit stellen diese beiden neu entdeckten Sequenzvarianten sehr wahrscheinlich pathogene Mutationen dar.

Schlussfolgerung. Unsere Ergebnisse bestätigen, dass Spina bifida und Hydrocephalus in 1-2\% der Fälle auf einem Defekt im Entwicklungsgen VANGL1 beruhen. In diesen Familien ist das Wiederholungsrisiko bei weiteren Kindern höher als die allgemein geltenden 3 Prozent und kann bis etwa 50\% betragen. Unser Angebot der VANGL1-Mutationsanalyse wird besonders von Familien mit weiterem Kinderwunsch sehr gerne angenommen.

Kibar et al. 2007. N Engl J Med 356: 1432-1437.

Kibar et al. 2009. Hum Mutat 7: E706-715. 


\section{DGKJ-PV-194}

Aufklärung genetisch bedingter Entwicklungsstörungen mittels Array- CGH am Beispiel von 3 Patienten

J. Seidel' ', I. Graneß', B. Thamm-Mücke², O. Bartsch' ${ }^{3}$ J. Kohlhase ${ }^{4}$

${ }^{1}$ SRH Wald-Klinikum Gera, ${ }^{2}$ Labor Reising-Ackermann, ${ }^{3}$ Institut für Humangenetik Mainz, ${ }^{4}$ Praxis für Humangenetik

Zielstellung: Ziel des Beitrages ist die Demonstration der Effizienz der Array-CGH in der genetischen Diagnostik von frühkindlichen Entwicklungsstörungen, die keinem spezifischem Syndrom zugeordnet werden können oder Syndrom-spezifische genetische Veränderungen aufweisen, die mittels konventioneller molekular- zytogenetischer und molekulargenetischer Methoden nicht nachweisbar sind.

Material und Methode: Wir demonstrieren am Beispiel von 3 Patienten bei denen trotz umfangreicher Vordiagnostik mittels konventioneller Diagnostik erst durch den Einsatz der Array-CGH die Ursache frühkindlicher Entwicklungsstörungen aufgeklärt werden konnte.

Ergebnisse: Bei Patient 1, einem 5-jährigen Knaben, stehen neben einer psychomotorischen Entwicklungsverzögerung mit Betonung der Sprachentwicklung ein Hyperkinetisches Syndrom und ein vermindertes Schmerzempfinden im Vordergrund. Chromosomenanalyse, FISH-Diagnostik auf Mikrodeletionssyndrome und Subtelomerscreening, molekulargenetische Untersuchungen auf FraX-Syndrom und des $\mathrm{MeCP}_{2}$-Gens waren unauffällig. Erst in der Array-CGH zeigte sich eine heterozygote Duplikation am Chromosom 17 / dup(17)(p13. 3) unter Einbeziehung des Lis1-Gens, das im Falle von Deletionen zur Lissencephalie (Miller-Dieker-Syndrom) führt.

Patientin 2, aktuell 13 Jahre alt, zeigte frühzeitig das klinische Bild eines Rett-Syndroms mit Entwicklungsverzögerung, Epilepsie und typischen "hand-washing movements“.

Chromosomenanalyse, Subtelomerscreening und Mutationsdiagnostik des $\mathrm{MeCP}_{2}$-Gens ergaben unauffällige Befunde. In der CGH-Array zeigte sich eine Mikrodeletion am langen Arm des Chromosoms 1 (1943-1944) mit Deletion von $228 \mathrm{kB}$, beinhaltend 12 Gene, u. a. das $\mathrm{AKT}_{3}$-Gen, das als Kandidatengen für Hirnfehlbildung und cerebrale Funktionsstörungen gilt.

Patient 3, ein aktuell 3,5 jähriger männlicher Patient weist ein „neues“ genetisch bedingtes Syndrom auf das als Lubs-X-linked - Retardierungssyndrom bezeichnet wird, das ähnlich dem Prader-Willi-Syndrom primär durch eine neonatale Hypotonie auffällt und im Verlauf seinen Phänotyp ändert. Diese beruht beim Patienten auf Duplikation des $\mathrm{MeCP}_{2}$-Gens und weiterer benachbarter Gene und konnte mittels Array -CGH bestätigt werden. Bei unserem Patienten sind insgesamt 13 Gene dupliziert.

Diskussion und Schlussfolgerungen: Mittels der Array-CGH lassen sich zusätzlich zum Einsatz konventioneller genetischer Methoden bei bis zu 20 \% von Kindern mit frühkindlicher Entwicklungsstörung kausale genetische Veränderungen nachweisen.

Dennoch ist auch zukünftig differenzialdiagnostisches Denken notwendig, da auch die Array -CGH nicht alle krankheitsrelevanten genetischen Veränderungen erfasst.

\section{DGKJ-PV-195}

Costello Syndrom als Ursache einer schweren Fütterungsstörung bei einem weiblichen Säugling

N. Züfle', M. Radke' ${ }^{1}$ K. Kutsche' ${ }^{2}$, G. Gaedicke ${ }^{3}$, D. Horn ${ }^{4}$

${ }^{1}$ Klinikum Ernst v. Bergmann, ${ }^{2}$ Institut für Humangenetik, Universitätsklinikum Hamburg-Eppendorf, ${ }^{3}$ Klinik für Allgemeine Pädiatrie, Charité, ${ }^{4}$ Institut für Medizinische Genetik, Charité

Fallbericht: Wir berichten über einen weiblichen Säugling, der uns im Alter von 4 Monaten mit einer Gedeihstörung verbunden mit persistierendem Erbrechen nach nahezu jeder Mahlzeit vorgestellt wurde. Das erste Kind nicht konsanguiner Eltern kaukasischer Abstammung war nach unauffälliger Schwangerschaft in der 37. Schwangerschaftswoche hypertroph geboren worden und hatte anschließend eine mangelhafte Gewichtszunahme gezeigt. Verschiedenste Untersuchungen (Labor,
Sonographie Abdomen, Stoffwechsel u. a.) waren unauffällig, verschiedene Differentialdiagnosen (z. B. Pylorusstenose, gastroösophagealer Reflux) wurden ausgeschlossen. Das Mädchen zeigte jedoch einen auffälligen Phänotyp (grobe Gesichtszüge, großer und breiter Mund, Hypertelorismus, Trichterbrust, tief gefurchte Hand- und Fußsohlen), der zur Verdachtsdiagnose Costello-Syndrom führte; diese wurde molekulargenetisch durch den Nachweis einer Mutation im HRAS-Gen bestätigt. Die Behandlung der Gedeihstörung gestaltete sich schwierig und wurde schließlich durch eine hyperkalorische, langsame nächtliche Dauersondierung gebessert.

Diskussion: Das Costello-Syndrom lässt sich in eine Gruppe mit anderen Erkrankungen wie das Noonan-, cardio-fazio-cutane (CFC)- und LEOPARD-Syndrom einordnen, die klinische Überschneidungen zeigen. Dem Costello-Syndrom liegt eine Keimbahnmutation im Protoonkogen $H R A S$ zugrunde. Diese Mutation führt unter anderem zu einem erhöhten Risiko für Tumoren (Neuroblastome, Rhabdomyosarkome und im späteren Verlauf Blasenkarzinome). Darüber hinaus kommen eine hypertrophe Kardiomyopathie und Tachykardien gehäuft vor, die über die Lebenserwartung entscheiden können. Den regelmäßigen gezielten Vorsorgeuntersuchungen kommt daher eine besondere Bedeutung zu. Ausgeprägte Fütterungsstörungen sind charakteristisch für das Costello-Syndrom und stellen neben dem typischen klinischen Bild ein frühes Diagnosekriterium dar. Sie persistieren meist mehr oder weniger therapieresistent bis zum Alter von 3-4 Jahren und sistieren dann häufig spontan. Verschiedene Ansätze bis hin zur Dauersondierung in kleinsten Portionen oder auch operative Eingriffe sind beschrieben worden. Aufgrund des hohen Leidensdrucks für die Eltern besteht hier in den ersten Lebensjahren ein besonderer therapeutischer und Beratungsschwerpunkt. Es sollte daher sicherlich ein Ziel darstellen, bisherige therapeutische Ansätze für diese Problematik weiter zu verbessern und gegebenenfalls neu zu entwickeln.

\section{DGKJ-PV-196}

Knöcherne Fehlbildungen der oberen Extremitäten als Leitsymptome eines 49, XXXXY Syndroms beim Neugeborenen

A. Kidszun', A. Fuchs', A. Russo', R. Engel', V. Beyer², O. Bartsch², E. Mildenberger $^{1}$

${ }^{1}$ Klinikum der Johannes-Gutenberg Universität, ${ }^{2}$ Klinikum der Johannes-Gutenberg Universität Mainz

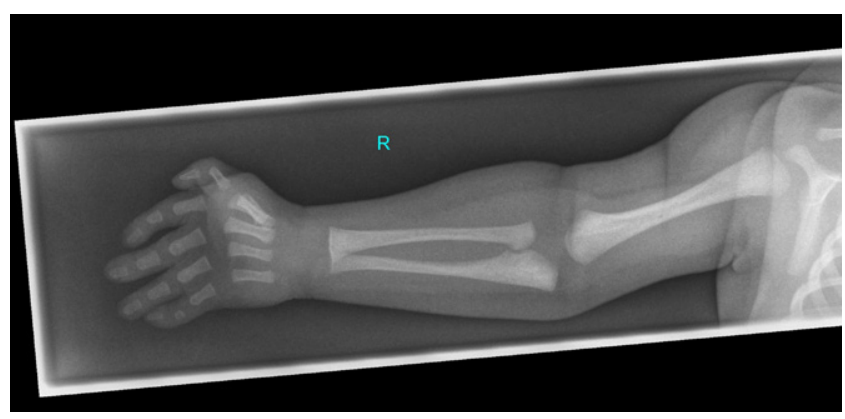

Abb. 1 Röntgenaufnahme des rechten Arms

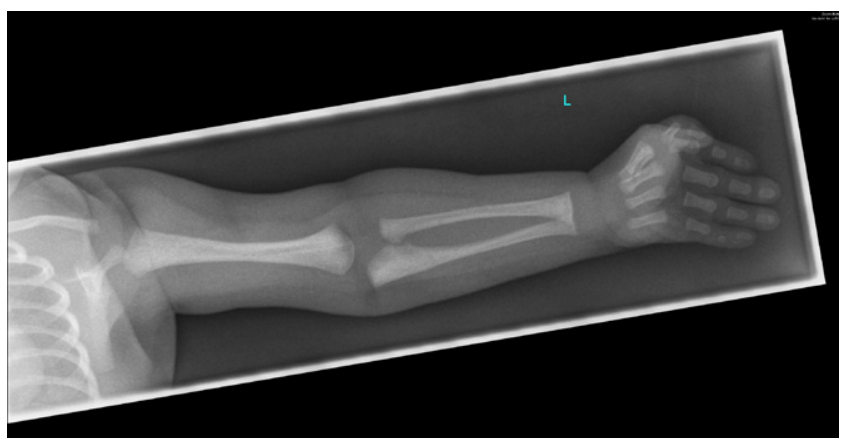


Abb. 2 Röntgenaufnahme des linken Arms

Einleitung: Das 49, XXXXY Syndrom ist eine seltene Sonderform des Klinefelter Syndroms. Die Inzidenz wird mit 1: 85. ooo - 100. ooo angegeben. Die etwa 100 vorliegenden Fallberichte beschreiben vielmals die Symptomtrias aus deutlicher psychomotorischer Retardierung, Hypogonadismus und radioulnarer Synostose. Etwa 15-20\% der Kinder werden mit einem strukturellen Herzfehler geboren, zudem treten im Säuglings- und Kleinkindesalter schwere respiratorische Infekte und Krampfanfälle gehäuft auf. Eine verzögerte Sprachentwicklung und Verhaltensauffälligkeiten sind weitere typische Symptome. Die Diagnose wird jedoch oft erst weit nach Ablauf der Neonatalzeit gestellt, so dass insbesondere bezüglich der Prognose der mentalen Entwicklung von einem nicht unbedeutenden Erfassungsfehler auszugehen ist.

Fallbericht: Wir berichten über ein reifes, eutrophes, männliches Neugeborenes. Der Schwangerschaftsverlauf der 37-jährigen Mutter war unauffällig. Ein älterer Bruder im Kleinkindesalter ist klinisch unauffällig. Das Neugeborene wurde initial bei Blässe, Tachypnoe und muskulärer Hypotonie stationär aufgenommen. Der anfängliche Infektionsverdacht erhärtete sich im Verlauf nicht und die klinische Symptomatik verschwand rasch. In der körperlichen Untersuchung fielen eine symmetrische Varusstellung der Arme mit Supinationseinschränkung, eine beidseitige Klinodaktylie und eine dezente faziale Dysmorphie mit Hypertelorismus und flachem Nasenrücken sowie tiefsitzende Ohren mit einem rechtsseitigen Präaurikularanhängsel auf. Röntgenologisch zeigte sich beidseits eine inkomplette proximale radioulnare Synostose. Der Gelenkspalt war noch minimal erkennbar. Im Rahmen der erweiterten röntgenologischen, sonografischen und echokardiografischen Diagnostik fanden sich keine weiteren Fehlbildungen. Im Karyogramm wurde ein 49, XXXXY Syndrom diagnostiziert. Der Patient konnte die Klinik am 12. Lebenstag in gutem Allgemeinzustand verlassen. Engmaschige interdisziplinäre Verlaufskontrollen wurden mit den Eltern vereinbart.

Diskussion und Schlussfolgerung: Wir beschreiben die frühzeitige Diagnosestellung eines 49, XXXXY Syndroms. Diagnostisch weg-weisend waren die beschriebenen knöchernen Auffälligkeiten. Bei Skelettanomalien der oberen Extremität, insbesondere bei einer radioulnaren Synostose sollte gerade im Neugeborenenalter an diese seltene Erkrankung gedacht werden. Mit der Diagnosesicherung des Syndroms wird eine Entwicklungsstörung insbesondere im sprachlich-mentalen Bereich sehr wahrscheinlich. Daher kann nun durch optimierte Frühförderungversucht werden, dieEntwicklung der Betroffenen positiv zu beeinflussen. Eventuelle endokrinologische Probleme können frühzeitig erkannt und behandelt werden. Inwieweit dies tatsächlich gelingt, werden die langfristigen Verlaufsuntersuchungen zeigen.

\section{DGKJ-PV-197}

\section{Waardenburg Syndrom Typ II: Erstbeschreibung einer Deletion des kompletten MITF-Gens}

G. Wildhardt', J. Trübenbach', J. Bruch', J. Wechtenbruch², M. Suckfüll², D. Steinberger ${ }^{1}$, D. Steinberger ${ }^{3}$

'bio.logis, ${ }^{2}$ Klinikum Großhadern, ${ }^{3}$ Justus-Liebig-Universität

Das Waardenburg-Syndrom (WS) ist durch eine uni- / bilaterale kongenitale Innenohrschwerhörigkeit und Pigmentierungsstörungen der Iris, Haare und Haut charakterisiert. Je nach ursächlicher Genveränderung, Symptomatik und Kombination mit weiteren Funktionsstörungen und Fehlbildungen lassen sich vier Typen des WS unterscheiden. Das für WS 1 als charakterisch angesehene Symptom ist der vergrößerte Abstand der inneren Lidwinkel (Dystopia canthorum). WS2 ist charakterisiert durch das Fehlen der Dystopia canthorum. Beim WS 3 (syn.: Klein-Waardenburg-Syndrom) treten neben den typischen WS1-Symptomen zusätzlich Extremitätenfehlbildungen auf. Beim seltenen WSTyp 4 (syn.: Sha-Waardenburg-Syndrom) besteht eine WS1-Symptomatik in Kombination mit einem Morbus Hirschsprung.

Die verschiedenen Formen des WS sind mit Mutationen in unterschiedlichen Genen assoziiert. Für WS 1 und $\mathrm{WS}_{3}$ sind Mutationen im $P_{1} X_{3}$-Gen ursächlich. WS2 ist mit Mutationen im MITF-Gen assozi-

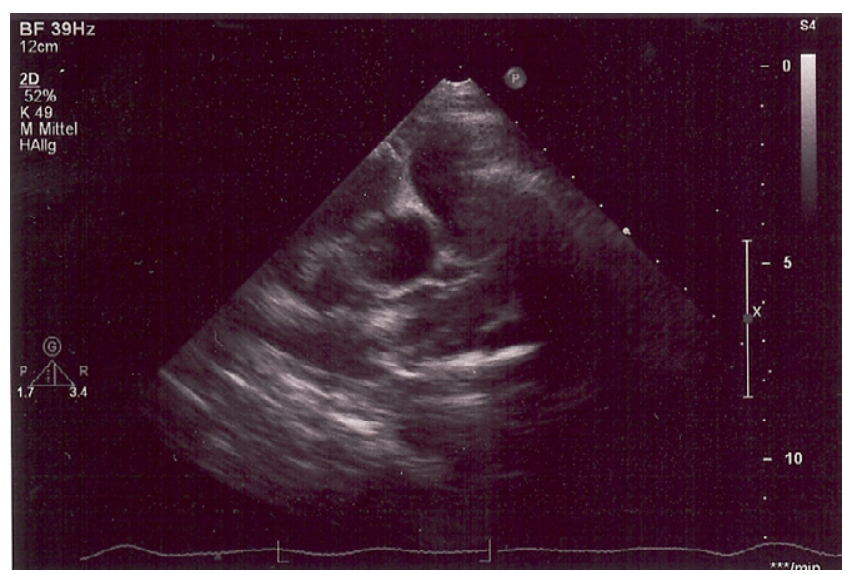

Abb. 1: CAA LAD prox., Diameter $5 \mathrm{~mm}$

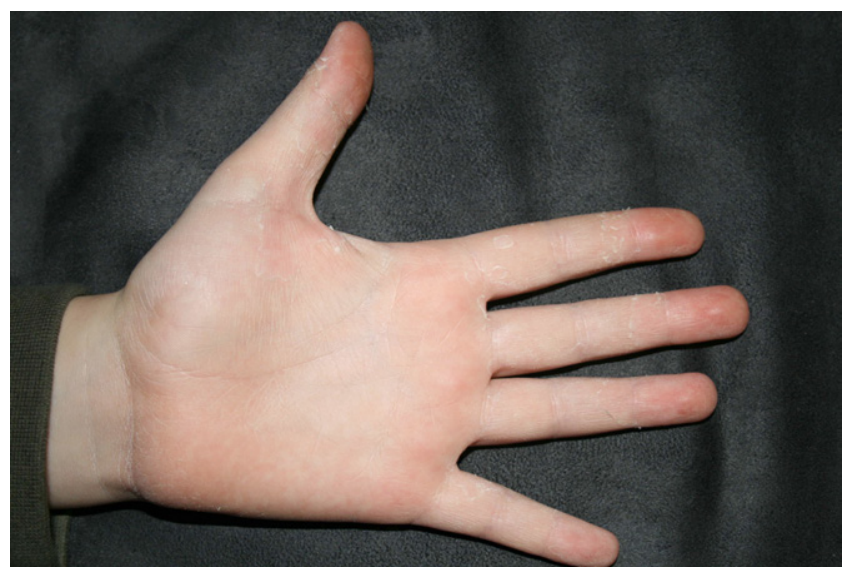

Abb. 2: Palma li

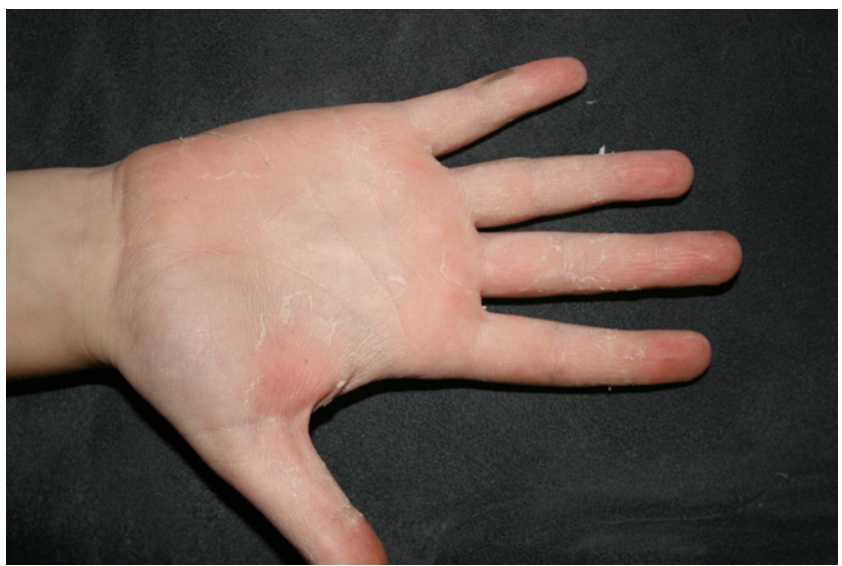

Abb. 3: Palma re.

iert und bei WS 4 sind Mutationen in den Genen $E D N_{3}, E D N R B$ und SOX10 nachweisbar.

Wir stellen das Ergebnis der molekulargenetischen Analyse eines 21/2 Jahre alten Jungen und dessen Familie vor. Der Junge fiel durch eine beidseitige Gehörlosigkeit und Heterochromia iridis auf. Weitere klinische Zeichen oder Symptome eines Waardenburg Syndroms bestanden nicht. Bei dem Jungen wurde die Gehörlosigkeit mit 2 ${ }^{1} / 2$ Jahren diagnostiziert und er wurde dann simultan bilateral mit einem Cochlea Implantat versorgt. 
Bei dem Indexpatienten wurde mittels MLPA (multiplex ligation-dependent probe amplification) eine Deletion des kompletten kodierenden Bereichs des MITF-Gens nachgewiesen. Umschriebene intragenische Mutationen sind in der Literatur bisher nur in Assoziation mit einem Waardenburg Syndrom Typ 1 beschrieben worden und betrafen die $P A X_{3}$-Genregion. Aus den erhobenen Befunden kann für die molekulargenetische Diagnostik des Waardenburg Syndrom Typ2 abgeleitet werden, dass bei unauffälligem Ergebnis der Sequenzierung von MITF die Durchführung einer Deletionsdiagnostik mittels MLPA indiziert ist.

\section{DGKJ-PV-198}

\section{Genotyp-Phänotyp Korrelationen bei M. Pompe}

A. Herzog, R. Hartung, E. Mengel, P. Hermanns, H. Runz, S. Gökce, J. Pohlenz, M. Beck

Zentrum für Kinder- und Jugendmedizin der Universitätsmedizin

Fragestellung: Morbus Pompe ist eine autosomal rezessive lysosomale Speichererkrankung. Der Mangel an saurer a-Glukosidase führt zu einer Glykogenakkumulation, die sich in einem breiten Spektrum klinischer Phänotypen manifestiert. Alle Betroffenen zeigen eine progressive Skelettmuskelschwäche, die zu einer Einschränkung lokomotorischer und respiratorischer Funktionen führt. Darüber hinaus ist die infantile Form charakterisiert durch das Auftreten einer hypertrophen Kardiomyopathie. c.-32-13T $>\mathrm{G}$ ist die häufigste Mutation bei nicht-infantilen Patienten. Sie führt zu einem Splicedefekt von Exon 2, bei dem etwa $10 \%$ normales Produkt gebildet werden.

In dieser Studie sollte die Abhängigkeit der Phänotypen von den Genotypen bei 3 Patienten mit infantilem und 37 Patienten mit nicht-infantilem M. Pompe untersucht werden.

Methode: Neben der klinischen Evaluation der Patienten wurden ihre Enzymaktivität in Lymphozyten gemessen und die Mutationen durch direkte Sequenzierung des GAA-Gens bestimmt.

Ergebnisse: Die infantilen Patienten trugen schwere Mutationen. Ihre Restaktivitäten lagen bei o. 25, 0. 96 und $1.2 \mathrm{mU} / \mathrm{mg}$ (Normbereich 8 . 95-42. $14 \mathrm{mU} / \mathrm{mg}$ ). Die Aktivitäten der nicht-infantil Betroffenen lagen zwischen 0.22 und $4.93 \mathrm{mU} / \mathrm{mg}$. Dreißig von ihnen waren compound heterozygot und ein Patient war homozygot für c.-32-13T $>$ G. Vier Patienten trugen jeweils zwei andere Mutationen.

Die Träger von c.-32-13T $>G$ wurden zwischen o und 56 Jahren symptomatisch mit einem Median von 21. 5 (3. o / 33. 8) Jahren. Die nichtinfantilen Träger anderer Mutationen hatten alle bereits in der Kindheit Symptome, die mit einem medianen Alter von 5.3 (1. 5/ 12. o) Jahren einsetzten. Eine mildere Beeinträchtigung der Patienten mit c.-32$13 \mathrm{~T}>\mathrm{G}$ zeigte sich auch an ihrer Mobilität. Ein Drittel von ihnen $(31 \%)$ konnte frei rennen und 51\% waren in der Lage Treppen ohne Zuhilfenahme des Geländers zu steigen. Dies wurde von keinem der Patienten mit anderen Mutationen erreicht. Zwei von ihnen konnten Treppen nur mit Geländer steigen, wohingegen zwei weitere nicht mehr laufen konnten. Darüber hinaus hatten die c.-32-13 $\mathrm{T}>\mathrm{G}$ compound heterozygoten Patienten mit einem Median von 72\% (50/98) höhere forcierte Vitalkapazitäten. Bei den anderen lagen die Vitalkapazitäten bei $32 \%$, $50 \%$ and $56 \%$, während eine Patientin eine dauerhafte invasive Beatmung benötigte.

Diskussion: Die Studie bestätigt die primäre Abhängigkeit der enzymatischen Restaktivitäten sowie der klinischen Phänotypen von den Genotypen. Die häufige Mutation c.-32-13T $>\mathrm{G}$ ist mit einem milderen nicht-infantilen Verlauf assoziiert. Die große Variabilität der Enzymaktivitäten und der Phänotypen bei Patienten mit dieser Mutation konnte nicht durch die Mutation auf dem zweiten Allel erklärt werden.

Schlussfolgerung: Neben der primären Determination durch den Genotyp existieren wahrscheinlich noch weitere die Enzymaktivität und den klinischen Verlauf modifizierende Faktoren.

Anmerkung: Diese Studie enthält Teile der Inauguraldissertation von A. Herzog.
DGKJ-PV-199

Ein kleinwüchsiges Geschwisterpaar - oder mehr?

E. Müller, S. Eberle, C. von Schnakenburg

Klinikum Esslingen

Enleitung: Diese Fallvorstellung zeigt, dass eine ausführliche Anamnese und eine gute klinische Untersuchung mit der ganzheitlichen Betrachtung des Patienten und seiner Familie mehr über seine Erkrankung verrät als das isoliert betrachtete Symptom.

Kasuistik 1: 16 11/4 - jähriger kleinwüchsiger, dystropher Adoleszent , Körperhöhe 143,7 cm (-5 SD, $20 \mathrm{~cm}<3$. Perzentile), Gewicht $33 \mathrm{~kg}(13 \mathrm{~kg}$ $<3$. Perzentile). Anamnestisch keine weiteren gesundheitlichen Probleme. Körperliche Untersuchung: auffällig dystropher Habitus mit kräftigen Waden, ausgeprägten Cubita valga beidseits mit eingeschränkter Extensionsfähigkeit, Nageldysplasien v. a. der 1.-3. Finger beidseits. Im Röntgenbild der Ellenbogengelenke zeigten sich Radiusköpfchenluxationen beidseits.

Kasuistik 2: 14 10/12 - jähriger, kleinwüchsiger, dystropher Adoleszent, Bruder des o. g. Patienten, Körperhöhe 145,2 cm $(-3,4$ SD, $9 \mathrm{~cm}<3$. Perzentile), Gewicht $32,5 \mathrm{~kg}(9 \mathrm{~kg}<3$. Perzentile). Anamnestisch rezidivierende Patellaluxationen. Körperliche Untersuchung: auffälliger Habitus genau wie der ältere Bruder. Nageldysplasien v. a. der 1.-2. Finger beidseits.

Mutter der Jungen: Hat dieselben Nagelveränderungen und die gleichen Veränderungen an beiden Ellenbogengelenken wie der ältere Junge, auch ihre Schwestern und ihre Mutter leiden unter ähnlichen Problemen. Aufgrund der Veränderungen der Ellenbogen sind bereits mehrere operative Eingriffe erfolgt, die Nägel wurden seit der Kindheit mit unterschiedlichen Tinkturen behandelt. Ein Zusammenhang zwischen den verschiedenen Problemen wurde bisher noch nie hergestellt. Verdachtsdiagnose: Nail-Patella-Syndrom (NPS)

Diagnostik: Kleinwuchsdiagnostik in üblichem Umfang, zusätzlich schrittweise molekulargenetische Diagnostik bezüglich des Nail-Patella-Syndroms

Molekulargenetischer Befund (Labor Dr. Mato Nagel, Weiswasser) identisch bei allen 3 Individuen: Mutation: LMX 1 B Exon 2, Codon 86, IVS $_{2}+1 \mathrm{G}>\mathrm{A}$, DNA: $2257+1 \mathrm{G}>\mathrm{A}$, heterozygot.

Beurteilung: Somit hat sich das Nail-Patella-Syndrom als autosomaldominant vererbte Grunderkrankung für die mütterliche Seite der Familie bestätigt. Viele Fragen, die sich die Familie über Jahrzehnte über Nageldysplasien, Patellaluxationen und vermeintlich traumatisch verletzte Ellenbogengelenke gestellt hat, konnten beantwortet werden. Wichtig ist für alle betroffenen Familienmitglieder die regelmäßige ophatalmologische Untersuchung zum Ausschluß eines Glaukoms, sowie die jährliche Untersuchung der Nierenfunktion, da 30-50\% aller NPS mit einer Nierenbeteiligung einher gehen, wovon 3-5\% im Nierenversagen enden.

Kleinwuchs: Die Körperhöhe von Patienten mit Nail-Patella-Syndrom ist gegenüber einem Normalkollektiv etwas reduziert, was jedoch den ausgeprägten Kleinwuchs beider Patienten weit unterhalb des elterlichen Zielgrößenbereiches nicht erklärt. Bei beiden Patienten konnte zusätzlich noch je eine weitere Ursache des Kleinwuchses (Patient 1: geboren als SGA Neugeborenes, Patient 2: partieller STH-Mangel) gefunden werden.

\section{DGKJ-PV-200}

Case Report: Sehr frühe Koronararterienaneurysmen (CAA) bei Mycoplasma pneumoniae (MP)-assoziiertem Kawasaki-Syndrom (KD)

M. Kuntz, C. Kampmann, W. Mannhardt-Laakmann

Klinikum der Johannes-Gutenberg Universität

Fragestellung: Ist eine sehr frühe intravenöse Immunglobulingabe (IVIG) ein isolierter Risikofaktor (RF) für CAA?

Methode: Literaturrecherche anhand eines Falles.

Ein 9-jähriger Junge wurde 3 Tage nach Fieberbeginn mit inkomplettem KD ohne Konjunktivitis vorgestellt. Die Mutter befand sich in der Woche zuvor mit einer MP-Pneumonie in Behandlung. 
Am Folgetag erhärtete sich der Verdacht durch den UKG Befund eines $5 \mathrm{~mm}$ messenden CAA in der prox. LAD (Abb. 1). Die laborchemischen Parameter mit Leukozytose $21.700 / \mu \mathrm{L}$ und Neutrophilie $68 \%$, BSG 65/110 mm n. W., CRP $13 \mathrm{mg} / \mathrm{L}$, Hyponatriämie131 mmol/L und Leberwerten (?GT 192 U/L, GOT 392 U/L) waren mit einem KD vereinbar.

Es wurden $2 \mathrm{~g} / \mathrm{kg}$ IVIG in $12 \mathrm{~h}$ und ASS $30 \mathrm{mg} / \mathrm{kg} / \mathrm{d}$ verabreicht. Der AZ, die Symptome, die Laborchemie und das CAA besserten sich. Serologie: akute Infektion mit MP.

In der 3. Woche trat eine Schuppung der Palmae auf (Abb. 2+3).

Das CAA persistierte bei $3,5 \mathrm{~mm}$.

Ergebnisse, Diskussion: Die Ursache des KD ist nicht bekannt. Pathogenetische Assoziationen viraler und bakterieller Infektionen und Superantigenen sowie genetischer Polymorphismen wurden vielfach gezeigt. Die beobachtete Assoziation des KD mit einer MP-Infektion wurde in wenigen Fällen beschrieben.

Das KD hat bei inkompletter klinischer Erscheinung aufgrund der Therapieverzögerung eine schlechtere Prognose. Eine Affektion der CA liegt bei allen Erkrankten vor. Die Gabe von IVIG senkt die CAA-Rate von ca. $25 \%$ auf $2-5 \%$. Die Mortalität steigt auf $41 \%$ bei vorliegenden CAA. Hochrisiko-Kinder haben durch eine Kombination von IVIG und Prednisolon ein besseres Outcome (CAA, Nonresponse). Die Stratifizierung erfolgt mittels Score (2 Punkte für $\mathrm{Na}<134 \mathrm{mmol} / \mathrm{L}$, Fieberdauer bis 4 Tage vor IVIG-Gabe, GOT $>100 \mathrm{U} / \mathrm{L},>80 \%$ Neutrophile; 1 Punkt für Thrombozyten < 30. 00o/ $\mu \mathrm{L}$, CRP >100 mg/L, Alter $<12$ Monate. Hochrisiko für Nonresponse ab 5 Punkten). Die Diagnose ist bis zum Auftreten von CAA unsicher. Die Datenlage ist hinsichtlich des optimalen Behandlungszeitpunktes unbefriedigend. Es liegen Ergebnisse von Tse SM et. al., 2003 vor, die zeigen, dass eine Behandlung mit IVIG innerhalb der ersten 5 Tage die Rate von CAA nach 1 Jahr reduziert und die Dauer klinischer Symptome verkürzt. Andererseits wurde von Tremoulet AH et. al. 2008 gezeigt, dass unter IVIG-refraktären Kindern die CAA-Rate höher ist und grenzwertig signifikant viele dieser innerhalb der ersten 3 Tage diagnostiziert wurden.

Schlussfolgerung: Unsere Beobachtungen unterstützen die Theorie einer infektiös-getriggerten, immun-vermittelten Genese des KD, speziell durch MP.

Auch bei inkomplettem KD kann eine kardiale Beteiligung vorliegen, u. U. mit CAA. Die Applikation von IVIG erst ab dem 5. Fiebertag zur Senkung der CAA-Rate kann angesichts o. g. Falles nicht zielführend sein. Eine sehr frühe Therapie scheint indiziert. Ob die frühe Therapie ein isolierter RF für CAA ist oder letzteres auf eine höhere entzündliche Aktivität zurückzuführen ist muss analysiert werden. DGKJ-PV-201

In-vitro-Einfluss von TNF- $a$ - und IL-1-Antagonisten auf das ZytokinNetzwerk bei Patienten mit oligoartikulärer juveniler idiopathischer Arthritis

L. Strothmann, M. Kirchner, V. Umlauf, W. Mannhardt-Laakmann Universitätsmedizin der Johannes Gutenberg-Universität Mainz

Einleitung: Proinflammatorische Zytokine zählen zu den Hauptmediatoren autoinflammatorischer Erkrankungen wie der juvenilen idiopathischen Arthritis. Während zwischen pro- und antiinflammatorischen Zytokinen im Gesunden ein Gleichgewicht herrscht, ist dieses in der Pathogenese der JIA zu Gunsten der proinflammatorischen Zytokine verschoben. Moderne Therapiestrategien mit Biologicals verfolgen daher das Ziel der selektiven Blockade der Wirkung einzelner profinflammatorischer Zytokine.

Ziel der Studie: Es soll untersucht werden, wie sich die in-vitroBlockade eines proinflammatorischen Zytokins auf das übrige Zytokinnetzwerk auswirkt.

Material und Methoden: Aus Vollblut von 10 Patienten mit persistierender oligoartikulärer JIA (OA) und 15 gesunden Kontrollen wurden periphere mononukleäre Zellen mit Hilfe der Ficoll-Dichtezentrifugation separiert und in kombinierte Kulturen gebracht: Der Negativ-Ansatz wurde mit LPS, die weiteren mit LPS und je einem Zytokinantagonisten Adalimumab (humanisierter monoklonaler Antikörper gegen
TNF- $\alpha$ ), Etanercept (TNF- $\alpha$-Rezeptor-Fusionsprotein) oder Anakinra (humaner IL-1-Antagonist) angesetzt. Nach 24 Stunden wurden aus den Überständen mittels eines "multiplex fluorescent bead immunoassay” (FlowCytomix human Th1/Th2 11plex BMS81oFF; Human IL-17A FlowCytomix BMS82017FF, Bender MedSystems, Wien, Österreich) die Zytokine IL- $1 \beta,-2,-4,-5,-6,-8,-10,-12$ p70, $-17 \mathrm{a}$, IFN- $\gamma$ und TNF- $\alpha$ durchflusszytometrisch bestimmt.

Ergebnisse: Nach selektiver Zytokinblockade sanken bei gesunden Kontrollen die Konzentrationen aller proinflammatorischen Zytokine (IL-1 $\beta$, IL-2, IL-6, IL-8, TNF- $\alpha$ und IFN- $\gamma$ ) ab. In den Kulturen von OA mit Adalimumab bzw. Anakinra fiel erwartungsgemäß die Konzentration der Zielzytokine (TNF- $\alpha$ bzw. IL-1 $\beta$ ) ab. Für Etanercept und TNF- $\alpha$ konnte dies jedoch nicht gezeigt werden. Unter den Blockaden sanken zudem die Konzentrationen der proinflammatorischen Zytokine IL- $1 \beta$ und IFN- $\gamma$. Ein Abfall von IL- 6 war nur mit Anakinra und Etanercept zu erzielen. Bei OA fanden wir nach Blockade von TNF- $\alpha$ bzw. IL-1 in allen drei Ansätzen Konzentrationssteigerungen des proinflammatorischen IL-8 sowie des antiinflammatorischen IL-4. Die Zytokine IL-5, IL-12p7o und IL-17 konnten nach LPS-Stimulation in Gesunden wie auch bei OA nicht nachgewiesen werden.

Diskussion: Bei OA werden neben dem Zielzytokin nur vereinzelte andere proinflammatorische Zytokine blockiert. Die selektive antiinflammatorische Medikamentenwirkung wird vielmehr durch eine Erhöhung von IL-4 unterstützt. Mit einer gleichzeitigen Konzentrationssteigerung von IL-8 scheint das Zytokinnetzwerk jedoch zu versuchen die Autoinflammation aufrecht zu erhalten. Dies könnte ein Erklärungsversuch für die Pathogenese therapieresistenter Krankheitsverläufe unter Biological-Therapie sein. In Zukunft könnte daher auch der Einsatz von humanisierten Antikörpern gegen IL-8 (z. B. ABX-IL8) in der Therapie der JIA eine Rolle spielen.

\section{DGKJ-PV-202}

Nicht-bakterielle Osteitis und bakterielle Osteomylitis - Ergebnisse einer ESPED Erhebung

V. Grote, A. Voigt, A. Jansson

Klinikum der Universität München

Hintergrund: Eine nicht-bakterielle Osteitis (NBO) und eine bakterielle Osteomyelitis $(\mathrm{BO})$ sind klinisch und diagnostisch häufig nicht $\mathrm{zu}$ unterscheiden. Während erstere meist nur eine Therapie mit nichtsteroidalen Antiphlogistika bedürfen, muss eine BO über einen längeren Zeitraum mit Antibiotika therapiert werden.

Studienziel: Schaffung einer Datengrundlage zur besseren klinischen und diagnostischen Differenzierung der beiden Krankheitsbilder.

Methode: Die Daten wurden im Jahr 2009 mittels der ESPED (Erhebungseinheit für seltene Kinderkrankheiten in Deutschland) erhoben, in der alle Kinderkliniken und -stationen sowie - für diese Studie zusätzlich alle pädiatrisch-othopädischen Schwerpunktabteilungen in Deutschland monatlich nach neu diagnostizierten Fällen befragt werden. Es sollten immungesunde Kinder und Jugendliche ohne möglicherweise auslösende penetrierende Verletzung, Fraktur oder Operation mit einem Alter über 17 Monate und jünger als 18 Jahre mit radiologischem Nachweis mindestens einer Knochenläsion gemeldet werden. Die detaillierte Erhebung erfolgte mittels Fragebogens.

Ergebnisse: Für das Jahr 2009 gingen 269 Meldungen bei der ESPED ein. 33 Meldebögen wurden nicht beantwortet; dies entspricht einer Antwortrate von $88 \%$. Unter den Meldungen waren 39 Fehl- (meist Alter $<18$ Monate oder falsche Diagnose) bzw. Doppelmeldungen. Von den insgesamt 197 Fragebögen sind bisher 143 vollständig in der Datenbank erfasst worden: 116 bakterielle Osteomyelitiden und 27 nicht-bakterielle Osteitiden.

Jungen hatte häufiger eine BO (63\%) während Mädchen eher eine NBO $(56 \%)$ hatten. BO Kinder waren im Median (25., 75. Perzentile) etwas jünger (9. 4 Jahre; 3. 7, 12. 8) als Kinder mit NBO (11. 2; 7. 7, 12. 3). Das MRT wurde in beiden Entitäten als häufigste Bildgebung (95\%) eingesetzt; die Szintigraphie (54\% versus 17\%) und das konventionelle Röntgen $(88 \%$ vs. $71 \%)$ wurden beide bei NBO Patienten häufiger zur Dia- 
gnostik verwendet. Erwartungsgemäß hatten vier Fünftel aller BO Patienten unifokale Läsionen, während es bei NBO Patienten nur ein Drittel waren; jedoch hatten $8 \%$ der BO Kinder mehr als 2 Knochenläsionen. Schmerzen waren bei fast allen Kinder das Leitsymptom (95\%). Kinder mit einer BO zeigten häufiger Fieber, Inappetenz sowie eine lokale Rötung. Laborchemisch waren die Entzündungsparameter Blutbild, CRP und Blutsenkung wesentlich häufiger in den $\mathrm{BO}$ als in den NBO Patienten auffällig: $95 \%$ versus $59 \%$.

Ein Keim wurde in 53 (46\%) der 116 Kinder mit BO isoliert; in 45 der 53 Isolate handelte es sich um Staph. aureus, ohne Meldung eines MRSA. Die antibiotische Therapie erfolgte in zwei Drittel der BO Fälle zwischen 15 Tagen und 6 Wochen und in etwa 30\% für länger als 6 Wochen. In $29(26 \%)$ BO Patienten erfolgte eine chirurgische Sanierung.

Schlussfolgerung: Patienten mit BO und NBO unterscheiden sich in einigen Faktoren wie Klinik und Laborparameter wesentlich. Die Fortsetzung der ESPED Erhebung bis 2011 und die Erreichung höherer Fallzahlen, wird die Entwicklung eines diagnostischen Scores zur verbesserten Differenzierung der beiden Krankheitsbilder ermöglichen.

\section{Immunologie und Nephrologie}

\section{DGKJ-PV-204}

Zur Verträglichkeit von Octagam ${ }^{\circledast} \%$ bei Kindern und Jugendlichen mit angeborenem Immundefekt: Ein intravenöses ImmunglobulinPräparat in der Langzeitbeobachtung

T. Rothoeft' ${ }^{1}$, C. Schultz ${ }^{2}$, O. Randerath ${ }^{2}$, E. Hamelmann', U. Schauer

${ }^{1}$ Klinik für Kinder- und Jugendmedizin St.Josefs-Hospital, ${ }^{2}$ Octapharma $\mathrm{GmbH}$, Abt. Medizin

Fragestellung: Mit der Zulassung von Octagam ${ }^{\circ} 5 \%$, einem intravenösen Immunglobulin vom Menschen, im Februar 1995 wurde eine nichtinterventionelle Studie (NIS) in Form einer offenen und prospektiven Anwendungsbeobachtung (AWB) initiiert. Ziel dieser AWB ist es, zusätzlich zu dem gesetzlich vorgeschriebenen Spontanerfassungssystem von Nebenwirkungen Informationen über die Verträglichkeit von Octagam $^{\bullet} 5 \%$ bei der Anwendung in der täglichen Praxis zu erhalten. Da Behandlung von Kindern und Jugendlichen eine besondere Herausforderung darstellt und Daten in klinischen Studien vor Zulassung nicht strukturiert erfasst wurden, soll in dieser Subgruppenanalyse die Verträglichkeit von Octagam ${ }^{\circ} 5 \%$ bei Kindern und Jugendlichen mit angeborenem Immundefekt (primary immunodeficiencies, PID) untersucht werden.

Material und Methode: In einer nicht-interventionellen, offenen, prospektiven, multizentrischen AWB werden seit 02/1995 Daten zur Verträglichkeit von Octagam ${ }^{\circ} 5 \%$ in der täglichen Praxis generiert. Die Patienten werden nach individueller therapeutischer Entscheidung behandelt. In die Subgruppenanalyse wurden PID-Patienten einbezogen, die zwischen Februar 1995 und Februar 2009 zum Zeitpunkt der Erstbehandlung unter 18 Jahre alt waren.

Ergebnisse: Von 02/1995 bis 02/2009 wurden in 455 deutschen Zentren bei insgesamt 9671 Patienten 147. 789 Infusionen von Octagam $^{\circledR} 5 \%$ dokumentiert. Davon erhielten 86 Kinder mit angeborenem Immundefekt, die zum Zeitpunkt der Erstbehandlung unter 18 Jahre (Durchschnitt: 6,4 Jahre, Median: 5 Jahre) alt waren, insgesamt 2. 608 Infusionen Octagam ${ }^{\circledR} \%$.

Der Behandlungszeitraum in dieser Subgruppe lag zwischen 1 und 4. 471 Tagen (Durchschnitt: 869 Tage, Median: 183 Tage). Es wurden zwischen 1 und 186 Infusionen pro Patient verabreicht (Durchschnitt: 30 Infusionen, Median: 6 Infusionen).

6 der 86 PID-Patienten $<18$ Jahren $(6,98 \%)$ zeigten bei 12 der 2.608 Infusionen (o,46 \%) eine Nebenwirkung. Die häufigsten Nebenwirkungen waren Fieber, Erbrechen und Kopfschmerzen. Alle aufgetretenen Nebenwirkungen wurden als Non-serious eingestuft und waren von milder bis moderater Intensität.
Diskussion und Schlussfolgerung: Insbesondere vor dem Hintergrund laufender Diskussionen zur medizinischen Behandlung von Kindern stellt eine nicht-interventionelle Studie ein wichtiges Instrument dar, um Daten aus der täglichen Praxis zu gewinnen. Darüber hinaus sind die Informationen zur Verträglichkeit über die Meldung von Nebenwirkungen deutlich häufiger im Vergleich zum Spontanmeldesystem.

Die Ergebnisse dieser Subgruppenanalyse belegen die sehr gute Verträglichkeit von Octagam $^{\circ} 5 \%$ in der Behandlung von Kindern und Jugendlichen mit angeborenem Immundefekt.

\section{DGKJ-PV-205}

\section{Hyper-IgE Syndrome: PHÄNOTYP, IMMUNOLOGIE UND GENOTYP BEI} 80 PATIENTEN MIT EKZEM UND ERHÖHTEM SERUM IGE

L. Schimke', J. Sawalle-Belohradsky', A. Langenbeck', A. Wollenberg², T. Kusuma', J. Roesler', M. Senn', B. Hagl', A. Jansson', G. Notheis', J. Reichenbach $^{4}$, T. Niehues ${ }^{5}$, R. Seger ${ }^{4}$, V. Wahn ${ }^{6}$, M. Borte ${ }^{7}$, H. Hill ${ }^{8}$, M. Albert ${ }^{1}$, T. Torgerson ${ }^{9}$, H. Ochs ${ }^{9}$, B. Belohradsky', E. Renner ${ }^{1}$

'Universitäts- Kinderklinik, ${ }^{2}$ Universitätsklinik Dermatologie, ${ }^{3}$ Universitätsklinikum Carl Gustav Carus Kinderklinik, ${ }^{4}$ Universitäts- Kinderspital, ${ }^{5}$ Klinikum Krefeld, ${ }^{6}$ Charite Kliniken $\mathrm{f}$. Kinderheilkunde und Kinderchirugie, ${ }^{7}$ Städtisches Klinikum St. Georg Kinderklinik, ${ }^{8}$ University of Utah, ${ }^{9}$ Seattle Children's and University of Washington

Hyper-IgE Syndrome (HIES) sind Immundefekte mit autosomal dominantem oder rezessivem Erbgang, die durch Ekzem, StaphylokokkenHautabszesse, rezidivierende Pneumonien und erhöhte Serum-IgE Werte charakterisiert sind. Nachdem eine homozygote Tyk2 Mutation bei einem Patienten mit einer autosomal rezessiven HIES Variante (ARHIES) nachgewiesen wurde, konnten in der Folge heterozygote STAT3 Mutationen als Ursache für das autosomal dominante HIES (ADHIES) identifiziert werden. Ende 2009 wurde außerdem der Zusammenhang zwischen DOCK8 Mutationen und dem 2004 von uns erstbeschriebenen AR-HIES aufgeklärt.

Um die Prävalenz und die klinische Korrelation der STAT3 und DOCK8 Mutationen bei HIES festzustellen, haben wir bei einer Kohorte von 80 Patienten mit HIES oder HIES-ähnlichem Phänotyp das $\mathrm{STAT}_{3}$ Gen sequenziert, die Sequenzierung von DOCK8 begonnen, den klinischen Phänotyp bewertet und die TH17 Zellen nach PMA/Ionomycin Stimulation quantitativ bestimmt. Eine heterozygote STAT3 Mutation konnte bei den meisten Patienten mit HIES Phänotyp (NIH-Score > 40) und/ oder $\mathrm{TH}_{17}$ Zellzahl $<0,2 \%$ von $\mathrm{CD}_{4}+\mathrm{T}$-Zellen nachgewiesen werden. Bisher gelang bei 2 von 4 Patienten mit NIH-Score $>40$ der Nachweis einer DOCK8 Mutation. Während bei AD-HIES missense-Mutationen und in-frame Deletionen eine Expression von verändertem $\mathrm{STAT}_{3}$ Protein erfolgt und damit eine STAT3-Funktionsänderung verursachen, bewirken DOCK8 Mutationen einen Mangel des DOCK8 Proteins. Die TH17 Zellzahl war bei einem Patienten mit DOCK8 Mutation verringert, jedoch zeigten weitere DOCK8-HIES Patienten normale Th17 Zellzahlen. Pneumatozelen und andere HIES charakteristische Symptome wie Skoliose, charakteristisches Gesicht und pathologische Knochenbrüche traten hauptsächlich bei STAT3-HIES Patienten auf. Eine T- Zelldefizienz mit rezidivierenden viralen Infektionen und verminderter in vitro Mitogen Stimulierbarkeit der Lymphozyten wurden bei DOCK8 Genotyp Patienten identifiziert.

Somit sind weitere Fortschritte in der genetischen Differenzierung der Hyper-IgE Syndrome gelungen. Diese Studie beschäftigt sich in einer großen Patientengruppe mit dem klinisch- immunologischen Phänotyp und der molekularen Basis der HIES. Neben der Frage wie genetische Defekte zum klinischen Bild der HIES-Patienten führen, ist ein weiteres Ziel die Abgrenzung zur atopischen Dermatitis und eine frühe Diagnosesicherung der HIES. 


\section{DGKJ-PV-206}

Atypical familial hemophagocytic lymphohistiocytosis associated with mutations in UNC13D and STXBP2

J. Rohr ${ }^{1}$, K. Beutel ${ }^{2}$, A. Maul-Pavicic ${ }^{3}$, T. Vraetz ${ }^{3}$, J. Thiel ${ }^{4}$, K. Warnatz ${ }^{3}$, I. Bondzio $^{3}$, U. Gross-Wieltsch ${ }^{5}$, M. Schündeln ${ }^{6}$, B. Schütz ${ }^{7}$, H. Wagner ${ }^{8}$, A. Groll ${ }^{9}$, B. Walz ${ }^{10}$, C. Speckmann ${ }^{3}$, B. Strahm ', G. Janka ${ }^{2}$, U. zur Stadt ${ }^{2}$, S. Ehl ${ }^{3}$ 'Zentrum für Kinderheilkunde und Jugendmedizin, Universitätsklinikum, ${ }^{2}$ Klinik und Poliklinik für Pädiatrische Hämatologie und Onkologie, Universitätsklinikum, ${ }^{3}$ Centrum für Chronische Immundefizienz (CCl), Universitätsklinikum, ${ }^{4}$ Centrum für Chronische Immundefizienz (CCl), Universitätsklinikum und Medizinische Klinik VI - Rheumatologie und Klinische Immunologie, Universitätsklinikum, ${ }^{5}$ Pädiatrie 5 - Onkologie, Hämatologie und Immunologie, Klinikum Stuttgart/Olgahospital, 'Klinik für Hämatologie und Onkologie, Zentrum für Kinderheilkunde, Universitätsklinikum, ${ }^{7}$ Pädiatrische Hämatologie und Onkologie, Zentrum für Kinderheilkunde, Universitätsklinikum, ${ }^{8}$ Zentrum für Kinder und Jugendmedizin, Universitätsklinikum, ${ }^{9}$ Pädiatrische Hämatologie und Onkologie, Klinik für Kinder und Jugendmedizin, Universitätsklinikum, ${ }^{10}$ Medizinische Klinik 1, Klinikum Ludwigsburg

Familial hemophagocytic lymphohistiocytosis (FHL) is a group of genetically determined disorders of lymphocyte cytotoxicity. FHL usually presents within the first two years of life with a life-threatening hemophagocytic syndrome (HLH), but later onset with atypical features has been described, in particular in patients with missense mutations in Perforin. We report on 6 patients with mutations in STXBP2and 2 patients with mutations in $U_{N C_{13} D}$ presenting with $\mathrm{HLH}$ as late as 32 years of age, in many cases following an atypical clinical course that included chronic active EBV infection, granulomatous hepatitis, pulmonary and cerebral vasculitis, susceptibility to bacterial infections or lymphoma. Most patients had antibody deficiency, reduced memory B cells, activated CD8-positive T cells and reduced or absent NKT cells. In comparison to patients with early-onset HLH, NK and CTL degranulation was impaired to a similar extent, but NK cell degranulation could be partially reconstituted by IL-2 stimulation and CTL cytotoxicity was less impaired in late-onset patients. Our observations show that hypomorphic mutations in $U_{N} C_{13} D$ or $S T X B P_{2}$ can result in combined immunodeficiency and must therefore be considered in a variety of clinical presentations. Degranulation assays are more sensitive than cytotoxicity assays in the early identification of affected patients.

\section{DGKJ-PV-207}

Diagnostic evaluation for disorders of lymphocyte cytotoxicity Y. Bryceson' ', D. Pende' ${ }^{2}$ A. Maul-Pavicic ${ }^{3}$, K. Gilmour ${ }^{4}$, S. Chiang' ${ }^{1}$, J. Rohr ${ }^{3}$, M. Menager ${ }^{5}$, D. Walshe ${ }^{4}$, J. Henter', G. Janka ${ }^{6}$, M. Arico ${ }^{7}$, G. de Saint-Basile ${ }^{3}$, S. Ehl ${ }^{3}$

${ }^{1}$ Centre for Infectious Medicine, Karolinska Instituet, Stockholm, ${ }^{2}$ Institute for National Cancer Research, Genova, ${ }^{3}$ Centre for Chronic Immunodeficiency, University of Freiburg, ${ }^{4}$ Camelia Botnar Laboratories, Great Ormond Street Hospital for Children, London, 5 Institute of Research on Developemental Immunology, ${ }^{6}$ Univ.-Kinderklinik Eppendorf, ${ }^{7}$ Pediatric Hematology and Oncology, Children Hospital A O U Meyer

Congenital defects in lymphocyte cytotoxicity can result in life-threatening hyperinflammatory hemophagocytic syndromes. Rapid diagnosis based on a set of clinical and laboratory criteria is essential to initiate appropriate therapy. Recently, new assays have been developed that not only have the potential to aid in the diagnosis of the syndrome, but also to help in the differential diagnosis of the molecular cause and to assist in the decision of whether hematopoietic stem cell transplantation is required. In order to define user-friendly, robust, and standardized protocols, a consensus conference evaluated the current experience of 5 European laboratories regularly involved in the diagnosis of patients with hemophagocytic syndromes. As a result from this conference, we present a series of optimized protocols for the diagnostic evaluation of perforin expression in lymphocyte subsets as well as of NK cell and cytotoxic $\mathrm{T}$ cell degranuation and cytotoxicity. We discuss the potential and limitations of each assay and propose a diagnostic algorithm for prospective evaluation in order to improve the diagnostic criteria for familial hemophagocytic syndromes.

\section{DGKJ-PV-208}

Severe immune dysregulation in two patients with 22 11 deletion syndrome

M. Hufnagel' ${ }^{1}$, A. Stackelberg' ${ }^{2}$, P. Shivachev ${ }^{3}$, C. Speckmann ${ }^{4}$, P. Fisch ${ }^{4}$, S. Ehl ${ }^{4}$

'Zentrum für Kinderheilkunde und Jugendmedizin, ${ }^{2}$ Hämatologie/Onkologie, Charite, ${ }^{3}$ Department of Pediatric Cardiology, Medical University,

${ }^{4}$ Centre of Chronic Immunodeficiency

22 q11 deletion syndrome is a complex genetic disorder which also affects thymus development. Severe T cell deficiency requiring thymus transplantation occurs in less than $1 \%$ of patients. About $5 \%$ of patients show partial $\mathrm{T}$ cell deficiency leading to a clinically relevant susceptibility to infections and sometimes to immune dysregulation. We report two patients with 22q11 deletion syndrome presenting with an unusual phenotype. Both patients developed massive hepatosplenomegaly and severe poly-autoimmune cytopenia at 3 and 4 years of age and were referred for exclusion of autoimmune lymphoproliferative syndrome. Both patients were pancytopenic, had raised immunoglobulins, but lacked specific antibodies. T cell counts were normal or significantly elevated. The T cells were oligoclonal and expressed high levels of activation markers; $\mathrm{sCD} 25$ was highly elevated. Naive T cells and regulatory $\mathrm{T}$ cells were almost absent. A microbial trigger for the lymphoproliferative disease could not be identified. Both patients received immunoglobulin substitution, cellcept and steroids and responded rapidly with a stabilization of the cytopenias and a significant decrease in hepatosplenomegaly. However, more than one year after the initiation of treatment, the T cell compartment remains highly activated, indicating that the immune dysregulation has not been fully controlled.

\section{DGKJ-PV-209}

Clinical and immunological overlap between autoimmune lymphoproliferative syndrome and common variable immunodeficiency

A. Rensing-Ehl', K. Warnatz' ', M. Schlesier' ${ }^{2}$, U. Salzer', R. Draeger ${ }^{3}$, I. Bondzio',

S. Fuchs', Y. Joos', A. Janda', M. Gomes ${ }^{1}$, M. Abinun ${ }^{4}$, S. Hambleton ${ }^{4}$, A. Cant ${ }^{4}$, F. Shackley ${ }^{5}$, T. Flood ${ }^{5}$, C. Waruiru ${ }^{5}$, K. Beutel ${ }^{6}$, K. Siepermann ${ }^{7}$, G. Dueckers ${ }^{7}$, T. Niehues ${ }^{7}$, T. Wiesel $^{8}$, V. Schuster ${ }^{9}$

${ }^{1}$ Centre of Chronic Immunodeficiency, University Medical Center, ${ }^{2}$ Centre of Chronic Immunodeficiency, University Medical Center and Department of Rheumatology and Clinical Immunolology, University Hospital, ${ }^{3}$ Department of Rheumatology and Clinical Immunolology, University Hospital, ${ }^{4}$ Children's Department Newcastle General Hospital, ${ }^{5}$ Sheffield Children's Hospital, ${ }^{6}$ Pediatric Hematology and Oncology, University Medical Center, ${ }^{7}$ Department of Paediatrics, HELIOS-Klinikum Krefeld, ${ }^{8}$ Vestische Kinderund Jugendklinik Datteln, University Witten / Herdecke, ${ }^{9}$ Hospital for Children and Adolescents, University of Leipzig

Autoimmune lymphoproliferative syndrome (ALPS) is caused by defects in the CD95 pathway and presumably other pathways of lymphocyte apoptosis. Raised $\mathrm{CD}_{3}+\mathrm{TCR} a \mathrm{~b}+\mathrm{CD}_{4}-\mathrm{CD} 8$ - double negative $\mathrm{T}$ cells and impaired $\mathrm{T}$ cell apoptosis are hallmarks of the disease. In contrast, the B cell compartment has been less well studied. We found an altered distribution of B cell subsets with raised transitional B cells and reduced marginal zone $B$ cells, switched memory $B$ cells and plasma blasts in most of 22 analyzed ALPS patients. Moreover, 5 out of 66 ALPS patients presented with low IgG and susceptibility to infection showing a significant overlap between ALPS and common variable immunodeficiency (CVID). In patients presenting with lymphoproliferation, cytopenia, hypogammaglobulinemia and impaired B cell differentiation, determination of Vitamin B12, sCD95L and IL-10 levels is helpful to distinguish between these two disorders. This study suggests a role for the CD95 pathway in the differentiation of human B cells. 
DGKJ-PV-210

Patientenzufriedenheit und Migrationshintergrund in einer universitären kindernephrologischen Ambulanz

Q. Uwe', D. Züllich', M. Zimmering ${ }^{1}$, T. Keil ${ }^{2}$

${ }^{1}$ Charite Kliniken f. Kinderheilkunde und Kinderchirugie, ${ }^{2}$ Universitätsklini-

kum Charité Med.Fakultät d.Humboldt-Univ.

Hintergrund: Messungen der Patientenzufriedenheit werden zunehmend durchgeführt, aber nur selten wissenschaftlich ausgewertet. Über diese Thematik ist bei Kindern und Jugendlichen mit Migrationshintergrund noch wenig bekannt, obwohl solche Daten für eine zukünftige gesundheitspolitische Planung wichtig erscheinen.

Ziel: Erhebung von Daten zur finanziellen und sozialen Situation, Bildung und Patientenzufriedenheit von Kindern und deren Familien Unter Berücksichtigung des Migrationshintergrundes.

Methoden: Durchführung einer Querschnittstudie an 348 Kindern und deren Familien im Alter von o-19 Jahren, die in der kindernephrologischen Ambulanz der Charité (CVK) 2008 behandelt wurden. Mit einem detaillierten Fragebogen wurden epidemiologischen Basisinformationen erhoben und eine standardisierte Bewertung der Patientenzufriedenheit durchgeführt. Hierfür wurde ein modifizierter ZUF-8 Fragebogen verwendet; hierbei handelt es sich um einen Datensatz aus 8 einfachen Fragen, der die globale Patientenzufriedenheit ermittelt und insbesondere in der Rehabilitationsmedizin breite Verwendung findet (Gesellschaft für Qualität im Gesundheitswesen).

Resultate: Ein Migrationshintergrund fand sich bei 131 Patienten (38\%). Diese Familien kamen aus 20 verschiedene Nationen, vor allem aus der Türkei, dem ehemaligen Jugoslawien, Russland, Polen, Vietnam, Irak und dem Libanon, und sprachen insgesamt 22 verschiedene Sprachen. Im Vergleich zu deutschen Familien zeigten sich signifikante Unterschiede in zahlreichen demographischen Variablen, darunter Arbeitslosigkeit (50\% vs. 22\%). Die Patientenzufriedenheit (auf einer Skala von 8-40) war signifikant höher in Familien ohne $(32.9+4.6)$, als in Familien mit Migrationshintergrund $(30.8+4.7$; $\mathrm{p}<0$. ooo1). Die Patientenzufriedenheit war nicht signifikant assoziiert mit der Höhe des Einkommens, Bildung (Schulabschluss der Eltern) oder dem religiösem Hintergrund. In einer Multivarianzanalyse war die Patientenzufriedenheit signifikant assoziert mit den Variablen "Vertrauen in den Arzt", „Freundlichkeit der Ärzte“, „Einfluss der Erkrankung auf das Kind“ und „Einfluss der Erkrankung auf die Familie“.

Schlussolgerungen: Die Patientenzufriedenheit wird wesentlich vom Migrationshintergrund beeinflusst. Die Messung mit dem modifizierten ZUF-8 Fragebogen ist ein geeignetes Instrument zur Beurteilung der Patientenzufriedenheit.

\section{DGKJ-PV-211}

Kongenitale und erworbene Refluxnephropathie bei Kindern mit primärem vesiko-uretero-renalen Reflux (VUR)

C. Schütze' ${ }^{1}$ J. Misselwitz ${ }^{2}$ U. John ${ }^{2}$

${ }^{1}$ Universitäts-Kinderklinik, ${ }^{2}$ Friedrich Schiller Universität Klinik f. Kinder-u. Jugendmed.

Fragestellung: Die Prognose des VUR wird hauptsächlich durch die Entwicklung der irreversiblen Nierenparenchymschädigung (Refluxnephropathie, RNP) bestimmt, welche entweder nach Harnwegsinfektionen (HWI) entsteht oder bereits kongenital vorliegt. In dieser Studie wurde untersucht, wie kongenitale Refluxe charakterisiert sind, mit welcher Häufigkeit und Schweregrad RNP auftritt und welche Rolle diese für die Prognose der Refluxkrankheit spielt. Dazu wurden Kinder mit VUR ohne HWI in der Anamnese mit Kindern verglichen, bei denen erst nach dem Auftreten einer HWI ein VUR diagnostiziert wurde. Materialien und Methoden: Es konnten 177 Patienten in die Studie aufgenommen werden, die zwischen dem 1990 und 2005 an der Kinderklinik der Friedrich-Schiller Universität Jena mit einem primärem VUR diagnostiziert wurden. Die Erfassung der Parenchymschäden erfolgte mittels 99mTc-DMSA Szintigrafie der Nieren und der Einteilung der Schweregrade nach Piepsz. Die Beobachtungsdauer betrug im Median 4,1 Jahre. Ergebnisse: Bei 44 Patienten wurde die Diagnose eines primären VUR ohne einen Hinweis auf eine HWI in der Anamnese gestellt, während 133 Kinder nach dem Auftreten einer HWI diagnostiziert wurden. In der ersten Gruppe waren signifikant mehr Jungen betroffen $(52 \%)$ als in der zweiten Gruppe (78\%), zudem waren sie signifikant jünger als Kinder mit HWI (5,5 zu 18,1 Monaten). In der Gruppe der Kinder ohne HWI traten 57\% der Refluxe bilateral und häufiger hochgradig auf (Grad III-V: $70 \%$ ), während bei Kindern mit HWI der unilaterale Reflux mit 56\% und Grad I+II mit 57\% überwog. In beiden Patientengruppen wurde in $41 \%$ der Refluxeinheiten (RE) eine RNP gefunden. Diese war bei Kindern ohne HWI in 82 \% schwergradig, bei Kindern mit HWI dagegen nur in $67 \%$ der Fälle. Eine Korrelation der Schwere der Nierenschäden mit dem Refluxgrad konnte nur bei Kindern mit HWI nachgewiesen werden. In der Verlaufsbeobachtung fand sich in der Gruppe der Kinder ohne HWI keine Verschlechterung im Score nach Piepsz, bei Kindern mit HWI dagegen in $28 \%$ der RE. Die spontane Rückbildungsrate des VUR zeigte sich abhängig vom Schweregrad des VUR. Nach 5 Jahren lagen die Rückbildungsraten für Grad I bis V bei $100 \%$ bis $67 \%$,, wobei sich Refluxe von Kindern ohne HWI langsamer zurückbildeten (im Median 2,9 zu 2,1 Jahren). Schlussfolgerung: Die kongenitale RNP ist mindestens genauso häufig wie eine nach HWI erworbene RNP. Kongenitalen Schäden sind jedoch schwergradiger und betreffen vorwiegend Kinder im Säuglingsalter mit hochgradigen, oft bilateralen Refluxen. Obwohl Mädchen und Jungen gleich häufig einen neonatalen hochgradigen Reflux und eine RNP aufweisen, zeigen Jungen schwergradigere Parenchymschäden. Die spontane Rückbildungsrate ist gut, jedoch bei Refluxen, die ohne vorherige HWI diagnostiziert werden schlechter, als bei Kindern mit HWI in der Anamnese. In zukünftigen Therapiestudien bei Kindern mit HWI und VUR muss das Vorliegen potenzieller kongenitaler RNP unbedingt berücksichtigt werden.

\section{DGKJ-PV-212}

Intra- undextrazelluläre Magnesiumkonzentrationen bei Patienten mit renalenMagnesiumverlust

A. Laumeier', G. Klaus² ${ }^{2}$ K. Schlingmann', S. Irle ${ }^{3}$, M. Enders ${ }^{4}$

${ }^{1}$ Phillips Universität Zentrum für Kinderheilkunde, ${ }^{2} \mathrm{KfH},{ }^{3}$ Institut für Medizinische Biometrie und Epidemiologie der Philipps-Universität Marburg, ${ }^{4}$ Labor Enders \&amp; Partner

Hintergrund: Renale Magnesium (Mg)-Verlusterkrankungen sind eine wichtige Ursache zur Entwicklung eines Mg-Mangels. Der Großteil des Mg im Blut liegt intrazellulär vor. Klinisch besteht der Eindruck, dass Symptome des Mg-Mangels nicht streng mit den SerumMg-Konzentrationen assoziiert sind. Routinemäßig messbar sind aber nur die Serum-Mg-Werte.

Frage: Gibt es einen direkten Zusammenhang zwischen intrazellulärem- und Serum-Mg? Gibt es eine Korrelation zwischen intra- und/ oder extrazellulärem Mg und Mg-Mangelsymptomen? Bestehen Unterschiede in der intraerythrozytären Mg-Konzentration bei Patienten mit angeborenem vs. Cyclosporin A (CSA)-assoziiertem Mg-Verlust?

Design: Bei (gesunden) Kontrollprobanden ohne Anhalt für eine Nieren- oder Elektrolytstörung $(n=26)$, Patienten mit angeborenen Salzverlusttubulopathien mit ( $\mathrm{n}=7$ Bartter-Gitelman-Syndrom GS/cBS) und ohne ( $\mathrm{n}=12$ Patienten mit antenatalem Bartter-Syndrom: $6 \mathrm{x}$ ROMK- und 6 x NKCC2- Mutation) Mg-Verlust und 18 Patienten mit CSA-assoziiertem Magnesiummangel wurden sowohl das intraerythrozytäre Mg mittels Flammen-Atom-Absorptionspektroskopie, sowie das Serum-Mg gemessen. Außerdem wurden alle Patienten mittels Fragebogen zu potentiellen Magnesiummangelsymptomen befragt.

Ergebnisse: Das intraerythrozytäre Mg korreliert mit dem Serum$\mathrm{Mg}$ sowohl bei den Kontrollen $(\mathrm{r}=0,5 \mathrm{O})$ als auch bei allen Probanden $(r=0,53, p<0,05)$, wobei eine intrazelluläre Sättigungsfunktion des $\mathrm{Mg}$ bei steigenden Serumkonzentrationen nicht statistisch signifikant abgelehnt werden konnte. Im gemessenen Bereich sind die Sättigungs- und die lineare Funktion fast deckungsgleich. GS/cBS-Patienten haben sowohl intra- als auch extrazellulär niedrigere Magnesium- 
werte als alle anderen Gruppen ( $\mathrm{p}<0,05)$. CSA-induzierter Mg-Mangel führt zu niedrigeren Serumwerten als in der Kontrollgruppe $(\mathrm{p}<$ $\mathrm{o}, 05$ ), wobei die intrazellulären Werte im Normalbereich blieben. In der internen Kontrollgruppe der antenatalen Salzverlusttubulopathien war, wie erwartet, kein Unterschied in beiden Mg-Konzentrationen zur Kontrollgruppe festzustellen.

GS/cBS-Patienten zeigen von allen Gruppen die meisten potentiellen Mg-Mangelsymptome. Sowohl die Patienten mit dem antenatalen Bartter-Syndrom als auch die mit dem CsA-induzierten Mg-Mangel zeigten Symptome, allerdings gaben die Patienten verschiedene Schwerpunkte an.

Schlussfolgerung: Die intraerythrozytären Mg-Spiegel korrelieren mit der extrazellulären Mg-Konzentration, wobei eine Sättigungsfunktion nicht ausgeschlossen werden konnte. Angeborene renale Mg-Verlusterkrankungen, nicht aber CyA-Behandlung führen $\mathrm{zu}$ erniedrigten intraerythrozytären $\mathrm{Mg}$-Spiegeln. Magnesiummangelsymptome korrelieren am stärksten mit einem sowohl intra- als auch extrazellulär vorhandenen Mg-Mangel.

\section{DGKJ-PV-213}

\section{Abdominalschmerzen als Hauptsymptom bei zwei Mädchen mit Tran-} sitionalzell-Karzinom der Blase

V. Umlauf', W. Coerdt', I. Leuschner' ${ }^{2}$, A. Schröder', R. Stein', R. Beetz ${ }^{1}$

'Universitätsmedizin der Johannes Gutenberg-Universität Mainz, ${ }^{2}$ Universitätsklinikum Schleswig-Holstein, Campus Kiel

Einleitung: Transitionalzell-Karzinome der Blase sind im Kindes- und Jugendalter äußerst selten und präsentieren sich in der Regel als „low grade, low stage“-Tumoren. Bislang sind etwa 50 pädiatrische Patienten im Alter bis 16 Jahre beschrieben, wobei hierunter nur 10 Mädchen sind. In der Regel fallen die Patienten klinisch mit einer schmerzlosen Makrohämaturie und/oder Symptomen einer Harnwegsinfektion (HWI) auf. Wir beschreiben hier zwei weitere Mädchen, 6 und 11 Jahre alt, mit Transitionalzell-Karzinomen der Blase.

Kasuistik 1: Die 6-jährige Patientin mit unauffälliger Vorgeschichte klagte seit vier Monaten über rezidivierende periumbilikale Bauchschmerzen. Es bestand keine Hämaturie, keine Dysurie. In der Abdomensonografie fiel eine kleine intravesikale papilläre Raumforderung mit singulärer Gefäßversorgung auf, die sich auch über die folgenden Wochen sonografisch nicht veränderte. In der Urethrozystoskopie stellte sich ein in der Nähe des linken Ostiums gelegener papillärer Tumor dar, welcher in toto entfernt werden konnte. Der postoperative Verlauf gestaltete sich ebenso wie die Nachsorgeuntersuchungen über die folgenden 6 Jahre komplikationslos.

Kasuistik 2: Eine 11-jährige Patientin klagte seit drei Monaten über rezidivierende Bauschschmerzen. Eine Hämaturie trat nur einmalig zum Beginn der Bauchschmerzsymptomatik auf. Dysurie oder andere Zeichen einer HWI bestanden nicht. In der Sonografie stellten sich rechts lateral des Ostiums zwei polyzyklisch begrenzte, echoreiche, breitbasig auf der dorsalen Blasenwand aufsitzende $7 \mathrm{~mm}$ bzw. $5 \mathrm{~mm}$ breite papilläre Formationen dar. In der Urethrozystoskopie konnten die beiden Tumoren komplikationslos in toto reseziert werden. In den bislang knapp drei Jahren Nachbeobachtungszeit ist kein Rezidiv aufgetreten. Pathologische Untersuchung: Makroskopisch fand sich bei beiden Patientinnen baumartig verzweigtes papilläres bräunliches Gewebe. Histologisch stellte sich in beiden Fällen ein Urothelpapillom mit fokalem Übergang in ein hoch differenziertes Urothelkarzinom, pTa, G1, dar. Die Diagnosen konnten in einer Zweitbegutachtung am Kindertumorregister in Kiel bestätigt werden.

Zusammenfassung und Diskussion: Wir beschreiben hier zwei 6 und 11 Jahre alte Patientinnen mit Transitionalzell-Karzinom, welches in dieser Altersgruppe äußerst selten auftritt. Bei länger rezidivierenden Bauschmerzen, und erst recht im Rahmen einer Makrohämaturie, sollte immer eine Sonografie des Abdomens einschließlich der Blase und des oberen Harntraktes durchgeführt werden. Unklare intravesikale Raumforderungen bedürfen einer zystoskopischen Inspektion und Gewebeprobenentnahme. Bislang sind im publizierten pädiatrischen
Kollektiv 3 unmittelbar karzinombedingte Todesfälle beschrieben worden. Langfristige Verlaufskontrollen sind daher auch nach erfolgreicher Tumorresektion ratsam.

\section{DGKJ-PV-214 \\ Aktuelle evidenzbasierte Therapie der arteriellen Hypertonie (HTN) im Kindes- und Jugendalter}

R. Eyermann

Dr. Richard Eyermann

Problem: HTN bewirkt schon bei Kindern kardiovaskuläre Schäden, korreliert mit Herzzunahme, Koronarsklerose u. IMT-Zunahme. Potenzierend auf juveniles Risiko wirken weitere CVRF, v. a. Adipositas, Dyslipidämie, Inaktivität u. Rauchen sowie iGTs bis zu DM2.

Ergebnis: Häufigkeit juveniler HTN heute gesteigert auf 4-5\%. Indikation zur Therapie besteht, wenn systolischer u./o. diastolischer RR dauerhaft (bei $>3$ Messungen an verschiedenen Tagen) > 95. Pc. für Körpergröße u. Alter liegt. Primär nicht-medikamentöse Maßnahmen: Lebensstiländerung mit Gewichtsreduktion durch Nahrungsmodifikation mit Reduktion von $\mathrm{NaCl}-\mathrm{u}$. Fettaufnahme u. Steigerung der Frucht- u. Gemüsezufuhr sowie Erhöhung von körperlicher Aktivität $u$. Reduktion des TV- u. PC-Konsums. Rauchen aufgeben. Körperliche Aktivität v. a. durch zusätzlichen Ausdauersport (Radfahren, Schwimmen, Jogging, etc. ) mindestens 30 , besser 6o, min. oder länger/Tag - erzielter Kalorienverbrauch nicht $<1500-2000 \mathrm{kcal} /$ Woche. Bei Nichtausreichen pharmakologische Maßnahmen indiziert; bis vor Kurzem nicht für Kinder u. Jugendliche zugelassen. Neue EU-Kinderarzneimittelverordnung stimuliert Prüfung von Antihypertensiva in Pädiatrie mit modifizierten Studienprotokollen. Antihypertensiv heute meist mit langwirksamen ACE-Hemmern begonnen (aktuell Enalapril ab 6 J. zugelassen). AT-II-Rezeptorblocker derzeit in Studien bei Kindern geprüft. ß-Blocker - bis vor Kurzem Therapie 1. Wahl - nur noch zurückhaltend einsetzen, da diabetogen (Risiko weiterer Gewichtszunahme u. negative Stoffwechseleffekte) u. physisch leistungslimitierend. Auch Thiaziddiuretika in hohen Dosen negative Auswirkungen auf Lipidprofil.

Aktuelle Listung pädiatrischer Antihypertensiva für ACE-Hemmer (Captopril, Enalapril. Ramipril), Kalziumantagonisten (Amlodipin, Nifedipin ER), Diuretika (HCT, Furosemid), ß-Blocker (Atenolol, Metoprolol, Propranolol).

Therapieziele: Generell: < 90. RR-Pc.; Renale Erkrankungen ohne u. mit Proteinurie 50.-75. bzw. < 50. RR-Pc., jeweils bezogen auf Alter, Geschlecht u. Körperhöhe.

Praktisches Vorgehen: Pathophysiologisch u. klinisch ebM primär ACE-Hemmer (z. B. Enlalapril 2,5 - $20 \mathrm{mg} /$ die), bei Unverträglichkeit AT-II-Rezeptorblocker. Kombinationstherapie: Bei DM1 u. chronischer Niereninsuffizienz mit Proteinurie RR-Senkung auf 50. Pc., um hypertoniebedingte Verschlechterung der Nierenfunktion zu vermeiden, meist nur durch Kombinationstherapie möglich. Kombination immer dann, wenn RR weiter > 90. Pc. bei adäquater Monotherapie, ACEHemmer mit niedrigdosiertem HCT (12,5-25 mg/die) oder zusätzlich Kalziumantagonist, z. B. Amlodipin 2,5-5 mg/die).

Differenzialtherapie: Reno-parenchymatöse HTN: Furosemid, ACEInhibitoren, vermeiden Thiazide; Erhöhte Renin-Aktivität: ß-Blocker, ACE-Inhibitoren, Spironolacton; Obstruktive Atemwegserkrankungen: keine B-Blocker; Diabetes mellitus: ACE-Inhibitoren, vermeiden B-Blocker, Thiazide; Neugeborene: Thiazide, Furosemid, Propranolol.

Kontrolle: Klinik-/Ambulanz-/Praxismessung, 24h-Langzeitmessung, Selbstmessung.

Konklusion: Zunehmendes kardiovaskuläres Risikoprofil unserer Kinder verhält sich gegensätzlich zum weltweiten Trend der Reduktion kardiovaskulärer Morbidität u. Mortalität bei Erwachsenen. Somit juvenile HTN von hoher Praxisrelevanz. Für Ärzte neben Allgemeinmaßnahmen perspektivisch zunehmende Bedeutung von pädiatrisch zugelassenen Antihypertensiva. 


\section{Dosierung Antihypertensiva bei Kindern}

ACE Hemmer

- Captopril Initial 0,3-0,5 mg/kg KG/die; Max. $3,0 \mathrm{mg} / \mathrm{kg} \mathrm{KG} / \mathrm{die}(-150 \mathrm{mg} / \mathrm{die})$

- Enlalapril Initial $0,08 \mathrm{mg} / \mathrm{kg} \mathrm{KG/die;} \mathrm{Max.} 0,6 \mathrm{mg} / \mathrm{kg} \mathrm{KG} / \mathrm{die}(-40 \mathrm{mg} / \mathrm{die})$

- Ramipril Initial $1,5 \mathrm{mg} / \mathrm{m} 2$ (2,5 mg/die); Max. $6 \mathrm{mg} / \mathrm{m} 2$ (-20 mg/die)

\section{B-Blocker}

- Atenolol Initial 0,5-1 mg/kg KG/die; Max. $2 \mathrm{mg} / \mathrm{kg} \mathrm{KG} / \mathrm{die}(-150 \mathrm{mg} / \mathrm{die})$

- Metoprolol Initial $0,5-1 \mathrm{mg} / \mathrm{kg} \mathrm{KG} / \mathrm{die}$; Max. $2 \mathrm{mg} / \mathrm{kg} \mathrm{KG} / \mathrm{die}(-150 \mathrm{mg} / \mathrm{die})$

- Propranolol Initial $1 \mathrm{mg} / \mathrm{kg} \mathrm{KG} / \mathrm{die}$; Max. $16 \mathrm{mg} / \mathrm{kg} \mathrm{KG} / \mathrm{die}(-640 \mathrm{mg} / \mathrm{die})$

\section{Kalziumantagonisten}

- Amlodipin Initial 0,06 mg/kg KG -5 mg/die); Max. 0,6 mg/kg KG (-10 mg/die)

- Nifedipin ER Initial $0,25-0,5 \mathrm{mg} / \mathrm{kg} \mathrm{KG} / \mathrm{die} ; \quad$ Max. $3 \mathrm{mg} / \mathrm{kg} \mathrm{KG}(-120 \mathrm{mg} / \mathrm{die})$

\section{Diuretika}

- HCT Initial $0,5 \mathrm{mg} / \mathrm{kg} \mathrm{KG} / \mathrm{die}$;

Max. $2 \mathrm{mg} / \mathrm{kg} \mathrm{KG/die}(-50 \mathrm{mg} /$ die $)$

- Furosemid Initial $0,5 \mathrm{mg} / \mathrm{kg} \mathrm{KG} / \mathrm{die}$;

Max. $5 \mathrm{mg} / \mathrm{kg} \mathrm{KG} / \mathrm{die}(-200 \mathrm{mg} / \mathrm{die})$

\section{DGKJ-PV-215}

Einnässen im Kindesalter - richtige Diagnosestellung ist wichtig für den Therapieerfolg

C. Persson de Geeter', S. Murgas², S. Wilke ${ }^{3}$

${ }^{1}$ Städt. Kliniken, ${ }^{2}$ Apogepha Arzneimittel $\mathrm{GmbH},{ }^{3}$ Urologische Praxis

Fragestellung: Auswertung einer nicht-interventionellen Studie zur Symptomatik, Verteilung der Diagnosehäufigkeit und Therapie des Einnässens im Kindesalter

Material und Methode: Bei Kindern älter als 5 Jahre wurden die Symptomatik des Einnässens, die Diagnose (kleinkapazitäre/überaktive Blase, wahrscheinlicher ADH-Mangel) und anschließende Therapie je nach Diagnose mit Propiverin oder Desmopressin über 12 Wochen erfasst. Zur Therapiebeurteilung wurden Inkontinenzepisoden/Woche, und bei Kindern mit kleinkapazitärer/überaktiver Blase zudem Miktionsfrequenz und Drangepisoden ausgewertet.

Ergebnisse

Es wurden 491 Kinder (184 Mädchen, 301 Jungen, mittleres Alter: 7,5 Jahre) in die Auswertung eingeschlossen. 295 Kinder (60\%) wiesen in der Anamnese eine reine Nachtsymptomatik, 151 Kinder (31\%) eine kombinierte Tag-/Nachtsymptomatik und 43 Kinder (9\%) eine reine Tagsymptomatik des Einnässens auf. Bei 183 Kindern (37\%) wurde die Diagnose Enuresis nocturna aufgrund eines wahrscheinlichen ADHMangels gestellt, bei 119 Kindern (24\%) wurde eine überaktive, bei 99 Kindern (20\%) eine kleinkapazitäre Blase diagnostiziert. Die Tabelle zeigt die Altersverteilung.

\begin{tabular}{|llll|}
\hline Tab. & & & \\
\hline & $\begin{array}{l}<7 \text { Jahre } \\
\text { (N: 192) }\end{array}$ & $\begin{array}{l}\text { 7-8 Jahre } \\
\text { (N: 151) }\end{array}$ & $\begin{array}{l}\text { > 8 Jahre } \\
\text { (N: 134) }\end{array}$ \\
\hline Kleinkapazitäre/überaktive Blase [\%] & 60,8 & 52,9 & 45,5 \\
\hline Wahrscheinlicher ADH-Mangel [\%] & 31,8 & 39,7 & 46,3
\end{tabular}

Differenz zu 100\%: Kombination der Diagnosen

Kinder mit wahrscheinlichem ADH-Mangel wurden zu 92\% mit Desmopressin, Kinder mit kleinkapazitärer Blase zu 81\% mit Propiverin und $16 \%$ mit Desmopressin und Kinder mit überaktiver Blase zu $87 \%$ mit Propiverin und 8\% mit Desmopressin behandelt. Bei der Therapie der kleinkapazitären (A) und überaktiven (B) Blase mit Propiverin konnte eine signifikante Senkung der Inkontinenzepisoden/Woche (A: -5,9; B: -7,5), der Drangepisoden/24h (A: -3,1; B: -4,3) und der Miktionsfrequenz/24 h (A: -2,8; B: -3,4) erreicht werden. Die nächtlichen Inkontinenzepisoden/Woche wurden bei Kindern mit wahrscheinlichen ADH-Mangel unter Desmopressin signifikant gesenkt $(-4,7)$.

Diskussion: Bei $60 \%$ der Kinder wurde anamnestisch eine reine Nachtsymptomatik des Einnässens erfasst, die Diagnose wahrscheinlicher ADH-Mangel wurde allerdings nur bei $37 \%$ der Kinder gestellt.
Dies zeigt die Bedeutung der Begleitsymptomatik (Drangsymptome, erhöhte Miktionsfrequenz, nicht altersgerecht entwickelte Blasenkapazität) für die richtige Diagnosestellung. In dem untersuchten Kollektiv sind kleinkapazitäre und überaktive Blase häufiger als ein wahrscheinlicher ADH-Mangel. Aufgrund der gestellten Diagnose wurde in der Mehrzahl der Fälle indikationsgerecht therapiert, die überaktive/kleinkapazitäre Blase mit Propiverin und ein wahrscheinlicher ADH-Mangel mit Desmopressin.

Schlussfolgerung: Für die richtige Diagnosestellung des Einnässens ist nicht nur der Zeitpunkt des Einnässens, sondern auch die Begleitsymptomatik und Bestimmung der Blasenkapazität von Bedeutung. Bei einer indikationsgerechten Therapie mit Propiverin bzw. Desmopressin werden sehr gute Therapieerfolge erzielt.

\section{DGKJ-PV-216}

\section{EMG-fMRT unter akustischen Prepulse-Startle-Stimuli bei Kindern} mit Enuresis nocturna

D. Wunberg' ${ }^{1}$ S. Schulz-Jürgensen', S. Wolff', P. Eggert ${ }^{1}$, M. Siniatchkin ${ }^{3}$ ${ }^{1}$ Universitätsklinik für Allgemeine Pädiatrie, ${ }^{2}$ Physiologisches Institut der Universität, ${ }^{3}$ Universitätsklinik für Neuropädiatrie

Einleitung: Die primäre monosymptomatische Enuresis (PME) wird zunehmend als eine Reifungsstörung des ZNS mit gestörter Inhibition des Miktionsreflexes angesehen. Studien zeigen eine verminderte Prepulse-Inhibition (PPI) des akustischen Startle-Reflexes bei Kindern mit PME. Die Identifizierung von an der PPI beteiligten kortikalen Strukturen ist mittels funktioneller MRT (fMRT) unter Präsentation akustischer Stimuli möglich. In der vorliegenden Studie wurden die an der PPI beteiligten Strukturen bei Kindern mit PME untersucht.

Patienten und Methoden: 9 Kinder mit PME (Median 12. 4 Jahre, 2 Mädchen) und 10 gesunde Kinder (Median 12. o Jahre, 6 Mädchen) wurden unter Aufzeichnung eines EMG am M. orbicularis oculi im fMRT untersucht (Philips Achieva, 8-Kanal SENSE Kopfspule, TR = $2500 \mathrm{~ms}, \mathrm{TE}=35 \mathrm{~ms}$, 30 Schichten, $64 \times 64$ Matrix, Schichtdicke $=3$. $5 \mathrm{~mm}, \mathrm{FOV}=200 \mathrm{~mm}$, flip angle 900). Dabei wurden einzelne Startle-Stimuli („white noise bursts“, $50 \mathrm{~ms}$, ca. $105 \mathrm{~dB}$, Startle-alone-Bedingung, $\mathrm{n}=25$ ) und Startle-Stimuli mit jeweils einem $120 \mathrm{~ms}$ (PPI-Bedingung, $\mathrm{n}=25$ ) oder einem 48oms (Kontroll-Bedingung, $\mathrm{n}=25$ ) zuvor zu hörenden Prepulse ( $1000 \mathrm{~Hz}$ - Töne, $30 \mathrm{~ms}$, ca. $75 \mathrm{~dB}$ ) in pseudorandomisierter Reihenfolge im Abstand von 8-12 sec über Kopfhörer präsentiert. Nach Artefakt-Korrektur der EMGs wurde die PPI als der prozentuale Rückgang der mittleren Startle-Amplitude der PPI-Bedingung gegenüber der Startle-alone-Bedingung bestimmt. Die Auswertung der fMRT-Daten erfolgte mittels SPM-5 (Realignment, Smoothing $6 \mathrm{~mm}$ gaussian kernel, multipler Regression mit Bewegungs-Parametern als "regressors of no interest" und parametrischer Modulation unter Anwendung der Startle-Amplituden als Parameter, sowie „random effect" Gruppenanalysen, $\mathrm{p}<$ o. oo1 unkorrigiert für alle Ergebnisse).

Ergebnisse: Weder Patienten noch Gesunde zeigten eine PPI. In beiden Gruppen führten Startle-Stimuli zu Aktivierungen im akustischen, medialen präfrontalen und orbitofrontalen Kortex. Es zeigte sich bei den Gesunden im Gegensatz zu den Enuretikern eine positive Korrelation von Startle-Amplitude und Hirnaktivität im Gyrus cinguli anterior. Diese Aktivierung zeigt sich auch für die PPI-Bedingung. Zusammengefasst war unter Inhibitions-Stimuli der präfrontale Kortex bei den gesunden Kindern stärker aktiviert als bei den Kindern mit PME. Diskussion: Die Studie zeigt zum einen methodische Probleme der PPI-Messung im MRT auf (Signal-to-noise-ratio, Beeinflussung durch Emotion). Andererseits konnte jedoch erstmalig die Bedeutung des Kortex in der Pathogenese der PME nachgewiesen werden. Es liegt nahe anzunehmen, dass, wenn im Schlaf die kortikale Kontrolle fehlt, die von der Blase ausgehenden Signale die inhibitorischen MiktionsZentren im Hirnstamm nicht erreichen.

Literatur: Ornitz, E. M. (1999), 'Prepulse inhibition of startle and the neurobiology of primary nocturnal enuresis', Biological Psychiatry, vol. 45, pp. 1455-1466. 
Schulz-Jürgensen, S. (2008), 'Effect of 1-desamino-8-D-arginine vasopressin on prepulse inhibition of startle supports a central etiology of primary nocturnal enuresis', Journal of Pediatrics, vol. 151, pp. 571-574. Campbell,L. E. (2007), 'Primary and secondary neural networks of auditory prepulse inhibition: a functional magnetic resonance imaging study of sensorimotor gating of the human acoustic startle response', European Journal of Neuroscience, vol. 26, pp. 2327-2333.

\section{Pneumologie und Diabetes}

\section{DGKJ-PV-217}

Die Versorgungssituation von Kindern und Jugendlichen im Disease Management-Programm Asthma bronchiale in der Region Nordrhein S. Groos, B. Hagen, J. Kretschmann, L. Altenhofen

Zentralinstitut für die kassenärztliche Versorgung

Fragestellung: Asthma bronchiale stellt eine der häufigsten chronischen Erkrankungen im Kindes- und Jugendalter in Deutschland dar. Der Kinder- und Jugendgesundheitssurvey (KiGGS) des Robert-KochInstituts ermittelte für o bis 17-Jährige eine Lebenszeitprävalenz von 4. 7 \% für diese Erkrankung. Im Jahr 2009 waren in der Region Nordrhein über 14. ooo Kinder und Jugendliche im Disease ManagementProgramm (DMP) Asthma eingeschrieben. Vor diesem Hintergrund ergibt sich die Frage nach der aktuellen Versorgungssituation dieser DMP-Patienten.

Material und Methode: Datengrundlage bildeten die Daten, welche im Rahmen der DMP-Dokumentation erhoben wurden. Untersucht wurden Angaben zur Pharmakotherapie, dem Auftreten stationärer Notfälle, der Häufigkeit von Asthma-Symptomen sowie zu verschiedenen nicht-medikamentösen Maßnahmen. Es erfolgten deskriptive querschnittliche Betrachtungen für das Jahr 2009 sowie eine deskriptive Längsschnitt-Analyse der Entwicklung der medikamentösen Therapie der Patienten für den Zeitraum 2006 bis 2009.

Ergebnisse: In den analysierten Dokumentationen erfolgten keine Angaben zum Schwere- oder Kontrollgrad der Asthma-Erkrankung. Jedoch lagen Informationen zur Auftretenshäufigkeit der Asthmasymptome vor: 10 \% bzw. $21 \%$ der Kinder und Jugendlichen litten unter täglichen bzw. wöchentlichen Symptomen, bei 59 \% traten die Symptome seltener als wöchentlich auf und $11 \%$ waren aktuell symptomfrei. Die Betrachtung der medikamentösen Therapie ergab, dass 29 \% der Patienten SABA als Bedarfsmedikation erhielten, $26 \%$ wurden mit SABA bei Bedarf und ICS als Dauermedikation behandelt und $13.5 \%$ benötigten eine Kombinationstherapie mit SABA bei Bedarf sowie ICS und LABA dauerhaft. Individuelle Verlaufsanalysen zeigten eine Abnahme der Verordnungshäufigkeit von ICS im Laufe der DMP-Teilnahme von 73 auf $60 \%$.

Stationäre Notfallbehandlungen innerhalb der letzten 6 Monate waren mit $1.6 \%$ sehr selten. Bei $80 \%$ der Patienten erfolgte eine Überprüfung der Inhalationstechnik. $86 \%$ der Patienten verfügten über einen Selbstmanagementplan. $64 \%$ der Kinder und Jugendlichen wurde vom behandelnden Arzt eine Schulung empfohlen und $45 \%$ nahmen im Anschluss an diese Empfehlung eine solche Schulung wahr.

Diskussion und Schlussfolgerung: Die Betrachtung der DMP-Daten der Region Nordrhein erlaubt erstmalig eine differenzierte Darstellung der Versorgungsrealität von Asthma-Patienten im Kindes- und Jugendalter, basierend auf einer großen Patientenpopulation. Vor dem Hintergrund der betrachteten Daten erweisen sich die Anteile der Patienten, welche über einen Selbstmanagementplan verfügen bzw. deren Inhalationstechnik überprüft wurde, bereits als erfreulich hoch. Hingegen erscheinen die Quoten der Wahrnehmung einer Asthma-Schulung nach Empfehlung noch steigerungsfähig. Hier ist jedoch auch grundsätzlich der weitere Ausbau von Schulungsangeboten erforderlich.

\section{DGKJ-PV-218}

Ein interdisziplinäres Konzept zur möglichen Prävention und frühen Therapie des Obstruktiven Schlafapnoesyndroms (OSAS) bei Säuglingen mit Trisomie 21

M. Bacher', W. Buchenau'2, A. Linz'ㄹ, G. Iven ${ }^{3}$, P. Brockmann², M. Urschitz², W. Baden', G. Göz', C. Poets ${ }^{2}$

'Zentrum für Zahn-, Mund- und Kieferheilkunde, ${ }^{2}$ Eberhard-Karls-Universität Universitätsklinik für Kinderheilkunde und Jugendmedizi, ${ }^{3}$ Therapiezentrum Iven, ${ }^{4}$ Eberhard-Karls-Universität Universitätsklinik für Kinderheilkunde und Jugendmedizin

Hintergrund: Das Obstruktive Schlafapnoesyndrom (OSAS) ist bei ca. 50\% der Patienten mit Trisomie 21 als Begleiterkrankung beschrieben. Mit dem Ziel der orofazialen Funktionsverbesserung wird ein von Castillo Morales entwickeltes Therapiekonzept eingesetzt. Dieses beinhaltet bei Kindern mit starker Zungenprotrusion eine tagsüber stundenweise eingesetzte Stimulationsgaumenplatte (SGP). Die frühzeitige und nächtliche Therapie mit einer SGP ist bislang nicht üblich. Es existieren keine Untersuchungen bezüglich eines möglichen Effektes der Castillo Morales-Therapie auf die Prävention bzw. Therapie eines OSAS. Methode: Zur schlafmedizinischen Evaluation unseres Therapiekonzepts aus kieferorthopädischer und funktioneller Therapie (modifiziertes Castillo Morales Konzept) führten wir im Rahmen einer prospektiven Studie bei konsekutiv aufgenommenen Neugeborenen und Säuglingen mit Trisomie 21 Polygrafien (PG) durch. Verglichen wurde die Häufigkeit (Index) gemischter und obstruktiver Apnoen/Std. (MOAI) vor Therapiebeginn (PG1) und unter Therapie mit ca. 3, 6 und 12 Monaten (PG2, $\left.\mathrm{PG}_{3}, \mathrm{PG}_{4}\right)$. Bei einem MOAI >1 erfolgte die Diagnosestellung eines OSAS. Bei einem MOAI $>5$ unter Therapie wurde intensivierte kieferorthopädische Therapie (vergleichbar dem Tübinger Therapiekonzept bei Pierre Robin Sequenz, d. h. Gaumenplatte mit verlängertem „Sporn“ [Buchenau et al., J Pediatr 2007]) eingesetzt. Ergebnisse: 28 Säuglinge mit Trisomie 21 konnten zwischen 2003 und 2007 in die Studie eingeschlossen werden. Im Verlauf der Untersuchungen wurde bei 20 Säuglingen die Diagnose eines OSAS gestellt. Unter Therapie kam es zur Reduktion des MOAI. Medianer (Minimum-Maximum) MOAI für PG1 (n=28): 2 (o-13), PG2 $(n=28): 0,7(0-15,4), \mathrm{PG}_{3}(\mathrm{n}=17)$ : o,1 (o-2,9) und bei PG4 $(\mathrm{n}=8)$ : o $(0-1,5)$. Bei 5 Kindern mit abnormen Befunden trotz Castillo Morales-Therapie und SGP kam es unter intensivierter kieferorthopädischer Therapie zur Befundbesserung (PG1: 7,9 (2-13), PG2: 8,8 (6,8-15,4), PG3: o,4 (o-2,9), PG4: o (o-o,2)). Schlussfolgerung: OSAS war bei den eingeschlossenen Säuglingen mit Trisomie 21 häufig. Durch unser Therapiekonzept aus kieferorthopädischer und funktioneller Therapie konnte die Häufigkeit gemischter und obstruktiver Apnoen im Schlaf reduziert werden. Das bestehende Behandlungskonzept von Castillo Morales konnte sinnvoll modifiziert und um eine Indikationsstellung erweitert werden. Bei ausgeprägtem Befund steht ein für die Pierre Robin Sequenz bereits als wirksam erwiesenes Behandlungskonzept zur Verfügung. Hinsichtlich der möglichen langfristigen Prävention eines OSAS durch frühe funktionelle und kieferorthopädische Therapie bei Trisomie 21 sind weitere Studien nötig.

\section{DGKJ-PV-219}

Chronischer Husten: Es muss nicht immer Asthma sein!

K. Stirner, A. Jung, I. Heinrichs, C. Geidel, R. Lauener

Hochgebirgsklinik Davos

Einleitung: Ungenügend kontrolliertes Asthma bronchiale bei chronisch-rezidivierender Hustensymptomatik stellt eine häufige Indikation für eine Rehabilitationsbehandlung dar.

Kasuistik 1: 14-jähriges Mädchen, zwischen dem 3. und 6. LJ rezidivierende Pneumonien, im 5. LJ Diagnose nicht-allergisches Asthma bei chronischem Husten, über 12 Monate kombinierte Therapie mit ICS/ LABA, seit dem 6. LJ pulmonal beschwerdefrei. Ab dem 13. LJ erneut trockener bitonaler Husten, im Verlauf 2 weitere Pneumonien bei linksbasaler Zeichnungsvermehrung im Röntgenthorax, hochdosierte ICS + SABA bei kombiniert restriktiv-obstruktiver Ventilationstörung, dar- 
unter persisitierende Hustensymptomatik. In der Bronchoskopie V. a. externe Kompression des linken Hauptbronchus, ein Thorax-MRT zeigt eine seitendifferente Lumeneinengung links $>$ rechts der Hauptbronchien bei forcierter Expiration. Stationäre Aufnahme zur Rehabilitation, hier Methacholinprovokation, EIA-Belastungstest, FeNO, pHMetrie und Allergiediagnostik unauffällig. Erneute Bronchoskopie mit Nachweis eines partiellen Tracheal- und vollständigen Bronchialkollaps links während Hustenstössen. Diagnose: Selbstperpetuierender chronischer Husten bei kongenitaler Tracheobronchomalazie mit konsekutiv rezidivierenden Pneumonien. Procedere: Hustendisziplin, SABA-Inhalationen bedarfsorientiert zur Verbesserung der mukoziliären Clearance, PEP-Training, bei Persistenz nächtliche CPAP-Beatmung, ggfs. Stent-Einlage.

Kasuistik 2: 9-jähriges Mädchen, seit Kleinkindalter rezidivierende Infekte der Atemwege mit obstruktiven Atemwegssymtpomen, nach Einschulung Diagnose eines nicht-allergischen Asthma bronchiale bei häufigen pulmonalen Infekten und chronischem Husten mit nächtlichen Dyspnoeanfällen. Therapieeinstellung mit ICS/LABA und LTRA, darunter Persistenz der Hustenbeschwerden. Stationäre Aufnahme zur Rehabilitation, hier Ausschluss von alpha-1-Antitrypsinmangel, Immundefekt, Allergien. Methacholinprovokation, EIA-Belastungstest, FeNO, Bodyplethysmographie und nasales NO unauffällig. In der 24-h-pH-Metrie Anhalt für nächtliche Mikroaspirationen, daraufhin Therapiebeginn mit Omeprazol. Sistieren der Hustensymptomatik innerhalb von 48 Stunden, Beschwerdefreiheit auch nach stufenweisem Absetzen der antiasthmatischen Therapie. Diagnose: Chronischer Husten bei gastro-ösophagealem Reflux. Procedere: Vorstellung in gastroenterologischer Sprechstunde.

Schlussfolgerung: Verschiedene respiratorische und nicht-respiratorische Erkrankungen können die Ursache chronisch-rezidivierender Hustensymtpome sein. Die Differenzialdiagnose zum Asthma bronchiale kann sich schwierig darstellen, insbesondere bei einer Anamnese von obstruktiven Atemwegssymtpomen im Kleinkindalter. Ein Rehabilitationsaufenthalt kann durch weiterführende differenzierte Diagnostik und Langzeitbeobachtung des Patienten bei der Diagnosestellung und bei einer konsekutiven Therapieeinleitung hilfreich sein.

\section{DGKJ-PV-220}

\section{Bronchogene Zyste beim Säugling}

U. Walther, H. Rupprecht, J. Klinge

Klinikum Fürth

Kasuistik: Wir berichten über einen 8 Wochen alten Säugling, bei dem bereits präpartal der Verdacht einer mediastinal, unterhalb des Aortenbogens gelegenen Zyste bestand. Die intrauterine Lungenentwicklung verlief unauffällig, Kompression der Lunge oder der Gefäße bestand nicht. Ein postnatal angefertigtes Röntgenbild des Thorax war unauffällig, ebenso der klinische Verlauf. Im Alter von 6 Wochen wurde das Kind mit ausgeprägten Dyspnoezeichen aufgenommen, im Thorax-CT zeigte sich die mediale Zyste links direkt unterhalb der Carina mit massiver Kompression des linken Stammbronchus und Überblähung der linken Lunge. Rechts bestand eine Teilatelektase des rechten Oberlappens und Teilatelektase des Unterlappens. Aufgrund des Ventilmechanismus und der bereits bestehenden Mediastinalverlagerung wurde die Zyste am gleichen Tag reseziert. Histologisch konnte die Diagnose einer bronchogenen Zyste bestätigt werden. Das Kind wurde unmittelbar postoperativ extubiert und konnte nach 13 Tagen aus der stationären Behandlung entlassen werden. Die bronchoskopische Kontrolle 8 Wochen später zeigte einen unauffälligen Befund.

Bronchogene Zysten entstehen durch abnorme Knospung während der Embryonalentwicklung des Tracheobronchialbaumes aus dem Vorderdarm in der 4.-6. Fetalwoche. Die Lokalisation hängt von dem Entstehungszeitraum ab. Mediastinale Zysten entstehen früher während der Gestation und kommunizieren nur selten mit dem Tracheobronchialsystem. Die Zysten sind dünnwandig und mit zilientragendem Epithel ausgekleidet. Die Symptomatik ist variabel und altersabhängig, im Säuglingsalter steht die Atemnot im Vordergrund, bei größeren Kin- dern und Erwachsenen sind brochogene Zysten oft ein Zufallsbefund und asymptomatisch. Neben pulmonalen Symptomen können auch Dysphagie (durch Kompression des Ösophagus) oder Kompression der großen Gefäße auftreten. In der konventionellen Röntgenaufnahme sind bronchogene Zysten nicht immer nachweisbar (20-70\%), vor allem im Mediastinum gelegene Zysten werden erst durch das Computertomogramm diagnostiziert. Die Therapie besteht in der operativen Entfernung der Zyste, um die Diagnose zu sichern und Komplikationen (Infektion, bronchiale Kompression) zu vermeiden.

\section{DGKJ-PV-221}

Inflammasomaktivierung in neutrophilen Granulozyten als pathogenetischer Faktor bei zystischer Fibrose

S. Burdi, A. Hector, V. Marcos, E. Wiedenbauer, I. Mack, C. Strohmeyer, P. Bufler, M. Griese, D. Hartl

Klinikum der Universität München

Einleitung und Fragestellung: Die zystische Fibrose (CF) ist die am häufigsten auftretende, rezessiv vererbbare Erkrankung bei Kaukasiern. Sie ist charakterisiert durch eine Neutrophilen-dominierte, chronischprogressive Inflammation der Atemwege. Neben dem Chemokin Interleukin-8 (IL-8) (CXCL8) ist vor allem das IL-1 $\beta$ am pulmonalen Ort der Entzündung erhöht exprimiert. Das mature IL-1 $\beta$ entsteht nach Aktivierung des sog. Inflammasoms nach proteolytischer Spaltung durch die Caspase-1.

Ziel dieser Studie war es, molekulare Mechanismen zu analysieren, welche die Inflammasomaktivierung und IL-1 $\beta$ Sekretion in Neutrophilen steuern, und deren Relevanz für die Pathogenese der CF-Lungenerkrankung zu beurteilen.

Methoden: Neutrophile Granulozyten wurden mit der Ficoll-Methode aus Vollblut isoliert und mit verschiedenen Inflammasom-induzierenden Stimulanzien behandelt. Im Durchflusszytometer wurde die Aktivierung der Neutrophilen gemessen (CD62L). Die IL-1 $\beta$-Sekretion wurde mittels ELISA gemessen.

Ergebnis: Die Inflammasomaktivierung - z. B. durch ATP - von Neutrophilen resultierte in einem Dosis-abhängigen Abfall der CD62L-Expression, was für eine Aktivierung der Zellen spricht. Übereinstimmend mit dieser Beobachtung führte die Behandlung mit Inflammasomaktivatoren zu einer gesteigerten Sekretion von IL-1 $\beta$.

Diskussion und Schlussfolgerung: Neutrophile Granulozyten stellen eine Schlüsselkomponente in der Pathophysiologie bei der CF-Lungenerkrankung dar. Unsere Ergebnisse zeigen, dass sie in der Lage sind, nach Inflammasomaktivierung IL-1 $\beta$ zu sezernieren, was sehr wahrscheinlich bedeutend zur chronisch-progressiven Inflammation in den CF-Atemwegen beiträgt. Im Folgenden werden a) weitere Inflammasomaktivatoren, die bei der CF eine Rolle spielen könnten, und b) die Wirkung von IL-1 $\beta$ auf Atemwegszellen untersucht. Dies könnte neue therapeutische Möglichkeiten eröffnen.

\section{DGKJ-PV-222}

YKL-40 als möglicher Biomarker und therapeutisches Target bei pädiatrischen Lungenerkrankungen

I. Mack', A. Hector', P. Latzin², E. Kieninger², V. Marcos' ', E. Wiedenbauer', S. Burdi' ${ }^{1}$, C. Strohmeyer' ${ }^{1}$, M. Griese ${ }^{1}$, D. Hartl ${ }^{1}$

${ }^{1}$ Klinikum der Universität München, ${ }^{2}$ Inselspital der Universität von Bern

Einleitung und Fragestellung: YKL-4O $\left(\mathrm{CHI}_{3} \mathrm{~L} 1\right.$, gp39), ein Chitinase-ähnliches Protein ohne enzymatische Aktivität, gehört der Familie der evolutionär konservierten 18-Glykosyl-Hydrolasen an. Vorausgegangene Studien fanden erhöhte YKL-4o Serumspiegel bei Patienten mit Asthma bronchiale mit einer positiven Korrelation zwischen YKL-40 Serumspiegel und dem Erkrankungsschweregrad (Chupp et al. NEJM, 2007). Außer diesen Studien ist über die Expression und Regulation von YKL-4o bei Lungenerkrankungen wenig bekannt. Das Ziel dieser Studie war es, YKL-4O-Konzentrationen in der Zirkulation und den Atemwegen von Patienten mit pädiatrischen Lungenerkrankungen zu quantifizieren, um zu evaluieren, ob YKL-40 als möglicher Biomar- 
ker für eine Subgruppe pädiatrischer Lungenerkrankungen von Relevanz ist.

Methoden: Proteinkonzentrationen von YKL-40 wurden mittels ELISA in bronchoalveolären Lavagen (BAL), induzierten Sputen und Serumproben von repräsentativen Kohorten mit Asthma bronchiale, zystischer Fibrose, Pneumonie und Bronchitis sowie von gesunden Kontrollen quantifiziert.

Ergebnis: Die YKL-40-Konzentrationen waren signifikant erhöht in den Atemwegen von Patienten mit pädiatrisch-inflammatorischen Lungenerkrankungen im Vergleich zu gesunden Kontrollen. Es waren höhere YKL-4O-Spiegel in induzierten Sputumproben gegenüber BAL messbar. Krankheits-Stratifizierungen zeigten Inflammations-abhängige Muster der YKL-40 Expression.

Diskussion und Schlussfolgerung: Diese Ergebnisse legen nahe, dass YKL-40 nicht nur bei allergischen Atemwegserkrankungen wie Asthma bronchiale, sondern auch bei nicht-allergischen pädiatrischen Lungenerkrankungen eine entscheidende Rolle spielen könnte.

\section{DGKJ-PV-223}

\section{Mutationen in zwei CCDC-Genen sind für die Mehrzahl der PCD-Fälle} mit tubulärer Disorganisation verantwortlich

A. Becker-Heck', N. Loges ${ }^{2}$, H. Olbrich ${ }^{2}$, I. Zohn ${ }^{3}$, A. Merveille ${ }^{4}$, A. Lequarré4, M. Georges ${ }^{4}$, R. Burdine ${ }^{5}$, H. Omran ${ }^{2}$

'Universitäts - Kinderklinik, ${ }^{2}$ Westf. Wilhelms-Univ.- Kinderklinik, ${ }^{3}$ Children's National Medical Center, ${ }^{4}$ University of Liège, ${ }^{5}$ Princeton University

Primäre Ciliäre Dyskinesie (PCD) ist eine autosomal rezessiv vererbbare Krankheit mit einer Inzidenz von 1/20. ooo. Aufgrund einer Dysfunktion von motilen Zilien kommt es zu einem komplexen klinischen Phänotyp charakterisiert durch chronische Atemwegserkrankungen und Randomisierung der Rechts-Links-Asymmetrie der Körperachse. Motile Zilien bestehen aus spezifischen Proteinstrukturen, wie die äußeren Dyneinarme (ODA), die inneren Dyneinarme (IDA), den Zentraltubuli (CP), dem „dynein regulatory complex“ (DRC) und den Radialspeichen (RS). Wir identifizierten eine neue Untergruppe von Patienten, die fehlende Radialspeichen, sowie eine Reduktion der inneren Dyneinarme und eine Delokalisierung der Zentraltubuli aufweist. Hochfrequenzvideomikoskopische Analysen zeigen typischerweise ein steifes Schlagmuster der Zilien. In der immunfluoreszenz-mikroskopischen Analyse fehlen das innere Dyneinarm Protein DNALI1 sowie das "dynein regulatory complex" (DRC)-Protein GAS11, wohingegen $\mathrm{DNAH}_{5}$, eine Komponente des äußeren Dyneinarms, ein normales Verteilungsmuster in den Zilien aufweist. Mit Hilfe genomweiter Kopplungsanalysen von mehreren konsanguinen Familien konnten wir eine genetische Heterogenität in dieser Patientengruppe nachweisen. Weitere genetische Analysen identifizierten zwei Gene, deren Proteine eine entscheidende Rolle im Aufbau der Zilien spielen. Mittels DNA-Sequenzierung konnten wir bei 21 von 31 Patienten dieser spezifischen Untergruppe Mutationen in zwei Genen, die für CCDC-Proteine kodieren, identifizieren.

\section{DGKJ-PV-224}

Deletionen und Punktmutationen im LRRC50-Genführen zu PCD mit Defekten der äußeren und inneren Dyneiarmen

N. Loges' ${ }^{1}$ H. Olbrich'², A. Becker-Heck', H. Karsten', A. Heer', C. Reinhard',

M. Schmidts ${ }^{1}$, A. Kispert ${ }^{3}$, M. Zariwala ${ }^{4}$, M. Leigh ${ }^{4}$, M. Knowles ${ }^{4}$, H. Zentgraf ${ }^{5}$, H. Seithe ${ }^{6}$, G. Nürnberg ${ }^{7}$, P. Nürnberg ${ }^{7}$, R. Reinhardt ${ }^{8}$, H. Omran ${ }^{2}$

${ }^{1}$ Universitäts - Kinderklinik, ${ }^{2}$ Westf. Wilhelms-Univ.- Kinderklinik, ${ }^{3}$ Medizinische Hochschule Hannover, ${ }^{4}$ University of North Carolina at Chapel Hill, ${ }^{5}$ Deutsches Krebsforschungszentrum, ${ }^{6}$ Zentrum für Neugeborene, Kinder und Jugendliche, Klinikum Nürnberg, ${ }^{7}$ University Of Cologne, ${ }^{8}$ Max Planck Institute for Molecular Genetics

Als Primäre Ciliäre Dyskinesie (PCD) bezeichnet man eine heterogene Gruppe von Erkrankungen, die durch eine Dysmotilität von Zilien und Flagellen charakterisiert ist. Genetische Defekte, die die Motilität von Zilien und Flagellen beeinträchtigen, führen zu chronischen Atem- wegserkrankungen, Randomisierung der Rechts-Links-Asymmetrie der Körperachse und zu männlicher Infertilität. Motile Zilien haben ein 9+2 Muster: In der Mitte der Zilie befinden sich zwei Zentraltubuli, die von neun Doppeltubuli umgeben sind. Die Doppeltubuli sind miteinander durch Dyneinarme verbunden. Dyneinarme sind große Multiproteinkomplexe, welche eine wichtige Funktion bei der Durchführung und Steuerung des Zilienschlages haben. Die häufigsten Defekte betreffen die äußeren (ODA) und inneren Dyneinarme (IDA). Um neue Kandidatengene für PCD zu identifizieren, haben wir eine genomweite Kopplungsanalyse mittels SNP-Array (Single Nucleotide Polymorphism) bei sieben konsanguinen Familien mit kombinierten ODA- und IDA-Defekten durchgeführt. In einer Familie wurden Kandidatengenorte auf Chromosom 10, 11, 16 und 17 identifiziert. $L R R C_{50}$ lokalisiert auf Chromosom 16 und wurde in Betracht gezogen, da bereits beschrieben wurde, dass Mutationen in den orthologen Genen in der Grünalge Chlamydomonas reinhardtii und Zebrafisch Danio rerio zu ODA- und IDA-Defekten führen. Die Mutationsanalyse der 12 Exone von $L R R C_{50}$ des Betroffenen zeigte eine homozygote „loss-of-function“-Mutation, die zum vorzeitigen Abbruch der Translation führt. Bei der Mutationsanalyse von weiteren 58 Familien mit ODA-Defekten konnten wir insgesamt 3 Deletionen und eine "nonsense“-Mutation mit vorzeitigem Abbruch der Translation in zwei Familien identifizieren. Mittels quantitativer Polymerase-Ketten-Reaktion konnten wir zudem zeigen, dass in einer Familie der Betroffene eine 11kb große Deletion von der Mutter und eine ca. $64 \mathrm{okb}$ große Deletion vom Vater geerbt hat. Beim Betroffenen der zweiten Familie konnten wir eine heterozygote Deletion von ca. $220 \mathrm{~kb}$ und eine „nonsense“-Mutation feststellen. Expressionsanalysen von $L R R C_{50}$ mittels in situ-Hybridisierung in Mausembryonen haben ergeben, dass $L_{R R C} 50$ sowohl in den zilientragenden Zellen des Knotens als auch in respiratorischen Epithelzellen exprimiert wird. Hochgeschwindigkeitsvideomikroskopie-Analysen des Zilienschlages von respiratorischen Zilien der Betroffenen ergaben dass die Zilien unbeweglich sind. Die Analyse der Zilienstruktur in elektronenmikroskopischen Schnitten von Zilien der Betroffenen bestätigte die Abwesenheit von ODA- und IDA-Komplexen. Die hochauflösende Immunfluoreszenzanalyse der ODA-Komponenten $\mathrm{DNAH}_{5}$, DNAH9 und DNAI 2 sowie der IDA-Komponente DNALI bestätigte diese Ergebnisse und ergab, dass alle untersuchten Komponenten im ziliären Axonem betroffener Patienten fehlen.

\section{DGKJ-PV-225}

Vergleich der krankheitsspezifischen Belastung bei Familien mit jungen Kindern mit Typ - 1 Diabetes in Abhängigkeit von der Therapieform (Pumpe versus ICT)

C. Kasper, P. Khalighy, A. Galler, R. Thalemann, K. Raile

Pädiatrische Diabetologie, Virchow Klinikum - Charité Universitätsmedizin

Ziel: Untersuchung der krankheitsspezifischen Belastung bei Kindern unter 7 Jahren und deren Eltern mittels $\mathrm{KINDL}^{\mathrm{R}}$-Fragebogen und Kinderinterview in Abhängigkeit davon, ob eine Insulinpumpentherapie oder eine intensivierte Insulintherapie durchgeführt wird.

Material und Methoden: Durchführung einer unizentrischen Querschnittstudie an einem Diabeteszentrum für Kinder und Jugendliche. Mittels DPV-Datenbank wurden Kinder im Alter bis zu 6 Jahre und einer Diabetesdauer von $>=2$ Monate ausgewählt. Die Health-related Quality of Life (HRQOL) wurde mittels KIDDY - KINDL ${ }^{\mathrm{R}}$ - Fragebogen ( für Eltern) und - Interview (für Kinder) erfasst. Der Sozialstatus und Migrationshintergrund der Familien wurde mit 18 selektierten Items aus dem KIGGS - Fragebogen erfasst.

Ergebnisse: Insgesamt wurden 22 Kinder (12 Jungen, 10 Mädchen, Alter $=5,6 \pm 0.89$ Jahre, Diabetesdauer $=2,71 \pm 1$. 45 Jahre [Mittelwert \pm Standardabweichung]) und deren Eltern befragt. Kinder mit der CSII erreichten im „Erkrankungs“-Modul signifikant ( $\mathrm{p}=0,04)$ höhere Scores $(90,45 \pm 8,95)$ als die mit der MDI $(78,79 \pm 15,08)$. Die Eltern von CSII-therapierten Kindern erreichten auch höhere Scores $(87,05 \pm$ $12,54)$ als die mit MDI (79,55 \pm 8$)$, jedoch nicht signifikant $(\mathrm{p}=0,11)$. Im Total Quality of life ergaben sich unabhängig der Therapieformen: Kin- 
der CSII: 78,18 \pm 14,47 und MDI: 82,95 $\pm 11,7 \mathrm{p}=0$ 0,41, Eltern CSII: 75,05 $\pm 8,62$ MDI: 76,48 $\pm 6,74 \mathrm{p}=0,67$ ähnliche Werte. Die Diabetes-spezifische Lebensqualität, die im speziellen die Lebensqualität der Eltern mit dem Diabetes mellitus des Kindes widerspiegelt, erbrachte Werte für CSII: $66,59 \pm 12,59$ und MDI: 60,19 $\pm 10,87 \mathrm{p}=0,22$. Die Scores der Kinder korrelierten mit denen der Eltern im „chronisch-generischen/ Erkrankungs“ Modul des $\mathrm{KINDL}^{\mathrm{R}}$ um $\mathrm{R}^{2}=0,302$ und für die „Total Quality of life" um $\mathrm{R}^{2}=0,286$.

Schlussfolgerungen: Eine Insulinpumpentherapie ist mit besserer „erkrankungs“-spezifischer Lebensqualität der jungen Kinder assoziiert. Der KINDL ${ }^{\mathrm{R}}$ - Fragebogen hat sich in dieser Pilotuntersuchung als geeignetes Testinstrument erwiesen, um mit hoher Sensitivität die krankheitsspezifische Belastung bzw. die Lebensqualität bereits in dieser Altersgruppe zu messen.

\section{DGKJ-PV-226}

Psychosoziale Risikoindikatoren für eine schlechte Stoffwechseleinstellung bei Jugendlichen mit Typ-1 Diabetes während der Pubertät P. Khalighy, C. Kasper, A. Galler, R. Thalemann, K. Raile Pädiatrische Diabetologie, Virchow Klinikum, Charité - Universitätsmedizin Berlin

Fragestellung: Während der Pubertätsentwicklung liegt der HbA1cWert um ca. $1 \%$ höher als in den Altersgruppen vor dem 12. Lebensjahr. Wir hatten in dieser Arbeit untersucht, welche Risikoindikatoren mit einer schlechten Stoffwechseleinstellung (HbAic > 9\%) im Alter zwischen 12 und 17 Jahren assoziiert sind.

Methodik: Unizentrische Querschnittsstudie in einem ambulanten Diabeteszentrum an Jugendlichen mit Typ-1 Diabetes (Alter 12-17 Jahre) und einem Elternteil bzw. Hauptversorger. Die Jugendlichen füllten standardisierte Fragebögen zur allgemeinen und Diabetes-spezifischen gesundheitsbezogenen Lebensqualität (GBLQ; KINDLFragebogen) sowie zum innerfamiliären Konfliktpotenzial (Diabetes Family Conflict Scale, DFCS) aus. Nahestehende Begleitpersonen erhielten den zugehörigen KINDL-Elternbogen, den DFCSFragebogen und den KIGGS-Bogen zum Sozialstatus. Die Jugendlichen wurden anhand ihres mittleren $\mathrm{HbAic}$ der vorausgegangen acht Monate in eine Fallgruppe ( $\mathrm{HbA1c} \geq 9,0 \%)$ und eine geschlechts- und altersgematchte Kontrollgruppe (HbA1c $<9,0 \%)$ eingeteilt.

Ergebnisse 74 Jugendliche mit Typ-1 Diabetes im Alter von 12-17Jahren (39 Mädchen, 35

Jungen, mittleres Alter 15,17 - 1,91 Jahre, Mittelwert \pm SD) und 48 Hauptversorger haben

teilgenommen. Die Fallgruppe zeigte in fast allen Bereichen geringere Punktescores für die GBLQ

und höhere Punktescore für die DFCS als die Kontrollgruppe. Die GBLQ bei chronisch-generischen

Erkrankungen im Allgemeinen $(\mathrm{p}=0,018)$ und Diabetes im Speziellen $(\mathrm{p}=0,009)$ zeigen signifikant geringere Werte, die DFCS $(\mathrm{p}=0,033)$ signifikant höhere Werte bei der Fallgruppe im Vergleich zur

Kontrollgruppe. Die Antworten der Elternteile zur gesamten GBLQ ihres Kindes ( $\mathrm{r} 2=0,207)$, zur

GBLQ bei chronisch-generischen Erkrankungen ihres Kindes $(\mathrm{r} 2=0,203)$ und zur DFCS $(\mathrm{r} 2=0,299)$

zeigten jeweils mittelstarke, positive Korrelationen zu den Antworten der Jugendlichen.

Schlussfolgerung: Die Ergebnisse zeigen, dass eine sog. „Pubertätskrise" mit längerfristiger und relevanter Erhöhung des HbA1c-Wertes mit geringerer, gesundheitsbezogener Lebensqualität und erhöhten, innerfamiliären Konflikten um das Thema Diabetes assoziiert ist. Die Korrelation der Angaben von Eltern und betroffenen Jugendlichen zeigt, dass auch nahe stehende Bezugspersonen gut in der Lage sind, zuverlässige Angaben zu den Bereichen innerfamiliäres Konfliktpotenzial und gesundheitsbezogene Lebensqualität zu machen. Daher ist die Herausforderung in der kontinuierlichen Betreuung von Jugendlichen mit Typ-1 Diabetes, auch krankheitsspezifische Belastungsfaktoren und innerfamiliäre Konflikte reduzieren zu helfen. Ein multidisziplinärer
Teamansatz unter psychologischer Mitarbeit und Supervision könnte in der Betreuung dieser Familien weiterhelfen.

DGKJ-PV-227

„Moderne" versus „,konservative“ Insulintherapie im Kindesalter: Wie gut ist das „Kölner Modell“?

O. Seewi' ', K. Oster' ${ }^{1}$, G. Even ${ }^{1}$, A. Stockmann-Schulz'1 , R. Holl², E. Schönau'

'Univ.-Kinderklinik, ${ }^{2}$ Universitäts-Kinderklinik

Hintergrund: Die moderne Insulintherapie mit hohem Behandlungsaufwand (intensive Insulintherapie ICT mit 4-6 Injektionen täglich, Verwendung von Pen/Pumpe und Insulinanaloga statt Spritze und Humaninsulin) brachte bei Kindern mit Typ-1 Diabetes mellitus keinen signifikanten Fortschritt bei Stoffwechselqualität und Hypoglykämien in Deutschland und Österreich (Wagner et al., Eur J Pediatr 2008;167: 241-2). In Dänemark waren 1997 bis 2008 weder Insulinanaloga noch die Zahl täglicher Injektionen mit einer Verbesserung des HbAic von 9 $\%$ auf $8.2 \%$ assoziiert, sondern die Zahl täglicher Blutzuckerkontrollen und Therapieanpassungen ( Svensson et al., Pediatric Diabetes 2009;10: 461-7). Die Kinderklinik der Uniklinik Köln (KUK) präferiert seit Jahren als einziges Behandlungszentrum im DPV-Verbund die konservative Insulintherapie mit 1-2 Injektionen täglich und der bedarfsgerechten Anpassung von (in der Spritze frei gemischter Normal- und Basal) Insulindosierung, Ernährung und körperlicher Aktivität an die Blutzuckerlage. Wie gut ist diese konservative Insulintherapie in der KUK („Kölner Modell“)?

Material und Methode: Datenbasis ist die anonymisierte Vergleichsauswertung der QS-DPV-Daten des Jahres 2009; die Ergebnisse der KUK wurden mit dem Durchschnitt sämtlicher 202 DPV-Zentren verglichen.

Ergebnisse: Angegeben werden die Mediane der KUK-Befunde [in Klammern die aller DPV-Zentren]. Regelmäßig betreut wurden in der KUK 219 [81] Patienten unter 21 Jahren mit Typ-1 Diabetes mellitus im Alter von 12. 7 [12. 8] Jahren. Mit konservativer Insulintherapie wurden 61. $2 \%$ [1. 6\%] behandelt, und mit moderner ICT 38. 8\% [98. 4\%]. Mit einer Insulinpumpe wurden 7. 3\% [29. 8\%] behandelt, mit schnellwirkenden Insulinanaloga wurden 1. 6\% [53. 8\%] behandelt, mit langwirkenden Insulinanaloga 0. 5\% [54. 2\%]. Der bezüglich Alter, Diabetesdauer, Geschlecht und Migrationshintergrund adjustierte HbA1c-Wert betrug 7. 9\% [7. 9\%]. Hypoglykämien mit Fremdhilfe gab es 5. 2/100 Patientenjahre [9. 5/10o Patientenjahre] und mit Koma 1. 7/10o Patientenjahre [1. 8/10o Patientenjahre]. Wegen hyperglykämischer Entgleisungen wurde 4 [2] mal pro Zentrum stationär behandelt.

Diskussion: die Ergebnisse der konservativen Insulintherapie in der KUK -einem der größten Zentren im DPV-Verbund- sind ebenso gut wie der Durchschnitt der modernen ICT, bei vergleichbarer Patientenpopulation. Das „Kölner Modell“ ist bei Kindern und Jugendlichen mit Typ-1 Diabetes beliebt: in den letzten 12 Jahren sind ca. 60\% der Patienten in der KUK der konservativen Insulintherapie treu geblieben, während im Durchschnitt der DPV-Zentren dieser Anteil auf 1. 6\% gesunken ist.

(Die DPV-Initiative wird unterstützt vom Bundesgesundheitsministerium, DDS, NAFDM, Dr. Bürger-Büsing-Stiftung, BÄK, Firma NovoNordisk, Kompetenznetz Diabetes mellitus)

\section{DGKJ-PV-228}

\section{Gestörte Glukosetoleranz bei familiärer Aniridie}

T. Grimm', J. Decker², M. Radke

${ }^{1}$ Klinikum Ernst v. Bergmann, ${ }^{2}$ Bioscientia Zentrum für Humangenetik

Wir berichten über eine jetzt 19 jährige Patientin mit familiärer Aniridie, die wiederholt über mehrere Jahre eine gestörte Glukosetoleranz im oralen Glukosetoleranztest zeigte. Diabetesspezifische-Autoantikörper waren nicht nachzuweisen. Die Patientin war normalgewichtig und es fanden sich keine Hinweise für eine Insulinresistenz.

Die Kindesmutter, die ebenfalls an der Aniridie erkrankt ist, zeigte keine Hinweise für eine gestörte Glukosetoleranz. 
Die molekulargenetische Ursache der familiären Aniridie besteht in Mutationen im PAX6-Gen (paired box 6 Gen). Wir führten eine Mutationsanlyse des Exon 13 des PAX6-Gens auf die Mutation c. $1268 \mathrm{~A}>\mathrm{T}$ durch und fanden diese Mutation (p. X423LeufsX15) heterozygot bei Mutter und Tochter bestätigt. Neuere Untersuchungen zeigen, dass das PAX6-Gen nicht nur eine wichtige Rolle bei der Entwicklung des Nervensystem und des Auges, sondern auch bei der Entwicklung des endokrinen Pankreas spielt. PAX6 scheint für die korrekte Differenzierung der Betazelle notwendig zu sein. Es ist essentiell für die normale Insulinexpression und die Regulation des Glukosestoffwechsels. PAX6 Mutationen sind verantwortlich für eine fehlerhafte Prozessierung von Proinsulin.

Wir vermuten daher einen Zusammenhang zwischen der von uns beschriebenen PAX6 Mutation und der gestörten Glukosetoleranz bei unserer Patientin. Natürlich sind weitere umfangreiche Untersuchungen erforderlich, um diese Hypothese zu beweisen.

\section{DGKJ-PV-229}

Ausgeprägte Transaminasenerhöhung und neu aufgefallene Hepatomegaliebei einem Jugendlichem mit bekanntem Typ 1 Diabetes und akuter Ketoazidose

D. Thomas' ${ }^{1}$ W. Burger ${ }^{1}$, A. von Moers' ${ }^{1}$, M. Herr', M. Schmitt ${ }^{2}$

'DRK Kliniken Westend, ${ }^{2}$ Ev. Kreiskrankenhaus

Anamnese: Ein 13 Jahre alter Jungen mit seit 10 Jahren bestehendem Typ 1 Diabetes und offenbar länger bestehender ungünstiger Stoffwechsellage (HbA1c 11,5\%) wurde wegen einer Ketoazidose stationär behandelt. Dabei fielen eine ausgeprägte Hepatomegalie und eine Transaminasenerhöhung (GOT 464 U/l, GPT 473 U/l) auf. Zur weiteren diabetologischen Behandlung und Abklärung erfolgte nach Behandlung der Ketoazidose die Verlegung in unsere Klinik. Der Junge hatte in den letzten Wochen einen zunehmenden Bauchumfang, Drücken im Oberbauch sowie allgemeine Schwäche und Probleme beim Einatmen bemerkt. 4 Wochen zuvor habe er einen fieberhaften Infekt gehabt.

Befund: Geschwächt wirkender Jugendlicher in stabilem Allgemeinzustand, fahl-graues Hautkolorit, kein Ikterus, kein Fieber, ausgeprägte Hepatomegalie mit bis in den linken Unterbauch palpabler Leber. Sonst unauffälliger klinischer Befund. Kein Minderwuchs, Größe mit $154 \mathrm{~cm}$ zwischen der 25. und 50. Perzentile, perzentilenkonformes Wachstum. Diagnostik: Die Abdomensonographie zeigte eine massiv vergrößerte Leber (Länge $23 \mathrm{~cm}$ in MCL) mit stark angehobener Echogenität ohne Splenomegalie oder Aszites. Die Transaminasen waren weiter stark angestiegen (GOT 3564 U/l, GPT 1898 U/l) bei unauffälligen Leberfunktionsparametern (Gerinnung, Albumin, CHE, Ammoniak). Die Fettstoffwechsellage war gestört (Triglyceride $274 \mathrm{mg} / \mathrm{dl}$, Cholesterin 397 mg/dl, LDL-Cholesterin 323 mg/dl, HDL-Cholesterin 19 mg/dl). $\mathrm{CrP}, \mathrm{BB}+$ Diff. und Hepatitis-Serologien ergaben keinen Hinweis auf eine akute Infektion. Die laborchemische Abklärung hinsichtlich Autoimmunhepatitis, weiteren Autoimmunerkrankungen, a1-AT-Mangel, Morbus Wilson und anderen Stoffwechselstörungen zeigte keine Auffälligkeiten. Bei der Suche nach weiteren hepatotropen Viren (CMV, EBV) zeigte die EBV-Serologie eine Konstellation wie bei einer ausklingenden oder kürzlich abgelaufenen Infektion (IgM und IgG positiv, EBNA positiv).

Nach Optimierung der Insulintherapie gelang zügig eine befriedigende metabolische Kontrolle. Obwohl die Hepatomegalie unverändert blieb, konnten wir den Jungen bei gebessertem Allgemeinzustand in die ambulante Betreuung entlassen. Bei der Kontrolle der Transaminasen nach 1 Woche waren diese bereits auf etwa die Hälfte reduziert und im Verlauf weiter abfallend, sonographisch und klinisch war auch die Hepatomegalie rückläufig.

Diskussion: Wir bewerten die beschriebene Befundkonstellation als nicht alkoholische Steatohepatitis (NASH) bei lange bestehendem Typ 1 Diabetes und hyperglykämer Stoffwechsellage, welche im Rahmen einer EBV-Infektion und möglicherweise zusätzlich durch eine Ketoazidose akut exazerbiert war.
Die Diagnose einer NASH bei Diabetes mellitus Typ 1 und ungünstiger Stoffwechsellage ist nicht ungewöhnlich und wurde in Kombination mit Minderwuchs bisher häufig als Mauriac-Syndrom bezeichnet. Diese Konstellation findet sich aber häufiger bei Typ 2 als Typ 1 Diabetes. Da in diesem Fall, nicht passend zur NASH, eine akute Progredienz und ungewöhnlich stark erhöhte Transaminasen zu finden waren, erfolgte eine umfangreiche differentialdiagnostische Abklärung. Anhand dieser Kasuistik könnte postuliert werden, dass Patienten mit Typ 1 Diabetes und NASH anfälliger für hepatotoxische oder infektiöshepatotrope Einflüsse sind, wie in diesem Beispiel eine EBV-Infektion.

\section{Autoinflammatorische Syndrome - Schwerpunkt periodische Fiebersyndrome}

\section{DGKJ-SY-096}

Daten aus dem deutschen Register für Autoinflammatorische Erkrankungen (AID)

U. Neudorf', E. Lainka', M. Bielak', V. Hilger' , O. Basu', H. Wittkowski², D. Holzinger ${ }^{2}$, J. Roth², T. Niehues ${ }^{3}$, D. Foell ${ }^{2}$

${ }^{1}$ Uniklinikum Essen, ${ }^{2}$ UKM Münster, ${ }^{3}$ Helios-Kliniken Krefeld

Einleitung: AID (= auto-inflammatory diseases) sind charakterisiert durch eine unkontrollierte Antwort des angeborenen Immunsystems und eine rekurrierende selbstlimitierende systemische Inflammation. Ziel: langfristige Dokumentation von epidemiologischen, genetischen, klinischen und prognostischen Daten über ein Register, um neue AID zu definieren und Therapiekonzepte und -verläufe zu verstehen.

Material und Methode: 2009 wurde ein Online-Register für AID (http: //aid-register. uk-essen. de oder http: //prst. gpoh. de/aid/) im Rahmen des Forschungsnetzwerkes (AID-Net) initiiert. Einschlusskriterien sind: 1. Genetisch definierte AID mit krankheitsassoziierter Mutation für HPF (Hereditäre periodische Fiebersyndrome) $o$ 2. klinisch definierte AID mit $>3$ selbstlimitierenden Fieberepisoden $>38,5$ ${ }^{\circ} \mathrm{C}$ und hohen Entzündungswerten $o$ 3. PFAPA o 4. SoJIA. Die Patienten werden longitudinal dokumentiert und einmalig DNA für eine Mutationsanalyse sowie im Verlauf Serum für Entzündungsparameter (z. B. S1ooProteine) in zwei Biobanken asserviert. Dieser klinische Forschungsteil wird durch 5 Grundlagenforschungsprojekte zur Pathophysiologie im AID-Net ergänzt.

Ergebnisse: In den ersten 12 Monaten wurden 162 Patienten (90 m, 72 $w$, Alter 1-21 Jahre) als FMF $(n=115)$, HIDS $(n=1)$, TRAPS $(n=8)$ und CAPS $(n=2)$, klinisch definierte AID $(n=5)$, SoJIA $(n=30)$ und PFAPA $(n=1)$ klassifiziert und Follow-up Daten eingegeben. 150 Blutproben von 18 Patienten wurden in den Biobanken bereits deponiert.

Schlussfolgerung: Durch die Vernetzung von Register, Biobanken und Grundlagenforschung innerhalb von AID-Net können in Zukunft neue Erkenntnisse in den Bereichen Genetik, Klinik, Biomarker und Pathogenese von AID die diagnostischen und therapeutischen Möglichkeiten und damit die Prognose dieser heterogenen Krankheitsgruppe verbessern.

Das AID-Register und AID-Net werden über das BMBF (o1GMo8104) gefördert. 


\section{Importierte und heimische parasitäre Hauterkrankungen}

DGKJ-SY-097

Skabies bei Kindern: ein diagnostisches und therapeutisches Problem A. Keysers

Asklepios Klinikum Teupitz

Die Infestation mit Sarcoptes scabiei kommt weltweit vor. In Entwicklungsländern ist die Ektoparasitose endemisch. Bei uns tritt sie meist sporadisch oder in Form von Kleinepidemien in Institutionen auf. Die korrekte Diagnose der Skabies ist eine Herausforderung: Das klinische Bild ist variabel und hängt von zahlreichen Faktoren ab. Die Verdachtsdiagnose stützt sich auf die Präsenz stark juckender Effloreszenzen an charakteristischen Prädilektionsstellen sowie einer ausführlichen Familien- und Umgebungsanamnese. Der Nachweis von Milbengängen ist pathognomonisch, gelingt aber selten. Die Liste der Differentialdiagnosen ist lang. Der Nachweis von Milben erfolgt in Kurettagematerial (Hautgeschabsel), mit Hilfe eines Klebestreifen-AbrissTests oder mittels Dermatoskopie. Die diagnostische Aussagekraft der Methoden hängt stark von der Erfahrung des Untersuchers ab. Immunologische Verfahren haben sich bisher nicht etabliert.

Die Therapie der Skabies erfolgt topisch oder per os. In Deutschland eingesetzte topische Substanzen sind Permethrin und Benzylbenzoat. Beide Substanzen müssen auf den gesamten Körper appliziert werden. Die Konzentration von Permethrin muss dem Alter des Kindes angepasst werden. Permethrin hat einen neurotoxischen Wirkmechanismus, geht in die Muttermilch über und kann eine Allergie auslösen. In Ermangelung besserer Alternativen gilt Permethrin als das Mittel der Wahl bei Kleinkindern. Die Behandlung mit Benzylbenzoat ist zeitintensiv (mehrere Wiederholungsbehandlungen in vorgegebenen Intervallen). Die Substanz wirkt stark hautirritierend. Beide Faktoren beeinträchtigen die Compliance. Ivermectin ist ein Breitspektrumantihelminthikum mit einer guten Wirksamkeit auf Krätzemilben und Läuse. Die Dosierung ist, 200 $\mathrm{gg} / \mathrm{kg}$ KG oral mit einer Wiederholung nach 8-10 Tagen. Es ist kontraindiziert bei Kindern unter fünf Jahren bzw. $15 \mathrm{~kg}$ KG, Schwangeren und Stillenden. Ivermectin ist in Deutschland für die Indikation Skabies nicht zugelassen und muss im Rahmen eines Heilversuches von einer Apotheke aus dem Ausland importiert werden.

DGKJ-SY-098

Epidemiologische und sozialmedizinische Aspekte des Kopflausbefalls in Deutschland

C. Jahnke

Gesundheitsamt der Stadt Braunschweig

Kenntnisse zur Epidemiologie, Wertigkeit der diagnostischen Methoden und Morbidiät der häufigsten Parasitose im Kindesalter sind vergleichsweise rudimentär. Für Deutschland gibt es keine Daten aus bevölkerungsbasierten Studien.

Im Rahmen der Schuleingangsuntersuchung der Stadt Braunschweig wurden alle Kinder des Einschulungsjahrgangs $2008(\mathrm{~N}=1890)$ auf die Präsenz von Kopfläusen und kopflausassoziierter klinischer Pathologie untersucht. Das Wissen der Erziehungsberechtigten über die Pediculosis capitis und die Krankheitsperzeption wurde mithilfe eines Fragebogens erfasst. Durch die Korrelation mit sozialdemografischen Daten, die routinemäßig bei der Schuleingangsuntersuchung erhoben werden, konnten sozialräumliche und familiäre Risikofaktoren analysiert werden. In einer separaten Studie wurde die Sensibilität der visuellen Inspektion im Vergleich mit feuchtem Auskämmen bestimmt und die Auswirkungen auf Prävalenzschätzungen berechnet. Unter Berücksichtigung der Verkaufszahlen von Pedikuloziden pro Kalenderwoche und Meldedaten aus dem Braunschweiger Gesundheitsamt konnte die Hypothese der saisonalen Schwankung des Kopflausbefalles überprüft werden.

Unsere Studien erbrachten erstmals für Deutschland zuverlässige Daten über Prävalenz, Inzidenz und Risikofaktoren der Pediculosis capitis im
Kindesalter und sind die Grundlage für eine evidenzbasierte Planung von Interventionsmaßnahmen.

\section{DGKJ-SY-099}

Neue therapeutische Ansätze bei der Pediculosis capitis

J. Heukelbach

Department of Community Health, School of Medicine/Federal University of Ceará

Die Pediculosis capitis ist die häufigste Parasitose im Kindesalter. Wird die Infestation nicht rasch diagnostiziert und therapiert, entwickeln sich pathologische Veränderungen der Kopfhaut. Eine Crux in der pädiatrischen Praxis sind Kinder mit rezidivierendem Kopflausbefall, die mehrfach vom Besuch einer Einrichtung ausgeschlossen wurden. In den letzten Jahren hat sich ein neues Therapiekonzept zur Behandlung der Pediculosis capitis auf der Basis von Dimeticonen durchgesetzt. Dimeticone sind biochemisch inerte, atoxische Silikonöle mit hervorragenden Kriech- und Spreiteigenschaften.

Dimeticone dringen in weniger als einer Minute in das Tracheensystem der Läuse ein, verdrängen die dort vorhandene Luft und inhibieren die Sauerstoffdiffusion. Das physikalische Wirkprinzip und der rasche Wirkungseintritt machen die Entwicklung resistenter Parasitenpopulationen unwahrscheinlich. Lege artis durchgeführte klinische Studien zeigten eine Wirksamkeit von 70-95\% auf Kopfläuse. In Abhängigkeit von ihren Kriech- und Spreiteigenschaften können Dimeticone auch die Eihülle (Nisse) durchdringen und Lausembryonen abtöten.

\section{DGKJ-SY-100}

Cutane larva migrans und Tungiasis - exotische Prasitosen mit zunehmender Bedeutung

H. Feldmeier

Charité University Medicine Berlin, Campus Benjamin Franklin

Cutane larva migrans (Hautmaulwurf) und Tungiasis (Sandflohkrankheit) sind Ektoparasitosen, bei denen sich der Erreger vorübergehend in der Epidermis aufhält, in situ abstirbt und nach einigen Monaten eliminiert wird. Beide Krankheiten sind ihrer Natur nach Zoonosen. Die Ektoparasitosen sind bei Reisenden aus Endemiegebieten nicht selten, werden aber häufig verkannt. Die Diagnose wird klinisch gestellt. Das klinische Bild der Tungiasis hängt stark vom Krankheitsstadium ab. Die häufig präsenten Kratzexkoriationen sind eine Eintrittspforte für pathogene Bakterien. Die Therapie der Tungiasis ist chirurgisch. Die cutane larva migrans wird mit Ivermectin oder Albendazol per os behandelt. Das Repellent Zanzarin ${ }^{\star}$ schützt zuverlässig vor einer Tungiasis. Die Prävention der cutanen larva migrans gelingt nur durch Vermeiden der Exposition.

\section{Thema Impfen: Antworten auf häufige Fragen in der kinderärztlichen Praxis}

DGKJ-SY-107

Epidemiologie und Impfprävention von Meningokokkenerkrankun-

gen

M. Knuf

Dr. Horst Schmidt Kliniken Wiesbaden

Invasive Meningokokkeninfektionen zählen zu den bedrohlichsten Krankheitsbildern in der Pädiatrie. Im Jahr 2009 betrug die bundesweite Inzidenz 486 Fälle oder o,6 Fälle pro 100. ooo Einwohner. Das klinische Bild der Meningokokkeninfektion hat eine breite Spannbreite von foudroyanter tödlicher Sepsis über eitrige Meningitis bis hin zur fast asymptomatischen Bakteriämie. Das Verständnis für diese Unterschiede ist noch rudimentär, dagegen liegen sehr detailierte Forschungsergebnisse vor über Pathogenitätsmechanismen und Virulenzfaktoren des Erregers selbst. Um eine vergleichende Analyse von mole- 
kularen Virulenzfaktoren einerseits und klinischen Verläufen andererseits in Deutschland herzustellen, werden über das BMBF-geförderte Projekt „MENINGOKOKKEN-NETZ“ Krankheitsfälle bei Kindern und Jugendlichen in Deutschland erfasst, wesentliche klinische Daten erhoben und mit Erregermerkmalen korreliert, die über das Nationale Referenzzentrum für Meningokokken (NRZM) in Würzburg analysiert werden.

Das MENINGOKOKKEN-NETZ hat in einer retrospektiven und prospektiven Erhebung seit dem Jahr 2007214 Patienten entsprechend 33\% aller Fälle im Alter zwischen o und 18 Jahre erfasst. Für die anonymisierten Meldungen konnten in $97 \%$ der Fälle ein Match mit der Datenbank des NRZM hergestellt und so patientenspezifische mit erregerspezifischen Daten verbunden werden. Bei 14\% der Fälle wurde ein fulminanter Verlauf beobachtet, bei 8,7\% mit letalem Ausgang. 16\% der Verläufe waren septisch ohne Meningitis und ohne Multiorganversagen, bei $70 \%$ der Fälle kam es zu einer meningealen Beteiligung. Ohne Folgeschäden überlebt haben drei Viertel der Patienten. Bei etwa 15\% der Patienten kam es zu Folgeschäden. Bei etwa einem Drittel derjenigen Patienten, bei denen Blutproben zur weiteren immunologischen Diagnostik eingesandt wurden, ergaben sich Hinweise für einen partiellen Immundefekt.

Nach Angaben des NRZM wurden 2009379 Meningokokken-Isolate und damit ca. $78 \%$ der an das RKI gemeldeten Fälle durch das NRZM untersucht. Der Anteil der Serogruppe C Erkrankungen blieb mit 22,0\% gegenüber dem Vorjahr gleich, während der Anteil der Serogruppe B Erkrankungen mit 67,8\% leicht abfiel. Meningokokken der Serogruppe Y und W-135 verursachten im Jahr 2009 6,6\% bzw. 3,2\% aller invasiven Erkrankungen und stiegen somit leicht gegenüber dem Vorjahr an. Von 308 untersuchten Stämmen waren 100\% sensitiv gegenüber Rifampicin und Ciprofloxacin. Es wurde ein Penicillin-resistenter Stamm aus einem nichtinvasiven Material (Sputum) beobachtet. Phänotypisch Penicillin-intermediäre Stämme stiegen im Jahr 2009 leicht auf 18,5\% $(\mathrm{n}=57)$ an. Der Anteil der Stämme mit typischen Mutationen im penAGen lag mit 18 von 57 Stämmen bei $32 \%$.

Zur Impfprävention stehen in Deutschland heute mehrere Impfstoffe zur Verfügung. Etabliert und von der STIKO empfohlen sind Meningokokken-Serogruppe C-Konjugatimpfstoffe für Kleinkinder zu Beginn des zweiten Lebensjahres, sowie für Kinder und Jugendliche bis einschließlich 17. Lebensjahr. Ab dem 11. Lebensjahr ist seit diesem Jahr nun auch ein Konjugatimpfstoff gegen die vier Serogruppen A, C, Y, W135 zugelassen. Impfstoffe gegen die Serogruppe B sind in Entwicklung, allerdings bisher in Deutschland nicht verfügbar. Die moderne Methode der "Reverse Vaccinology“ könnte für die Zukunft neue Perspektiven gezielter Impfprävention auch für Meningokokken eröffnen.

\section{Eisenmangel im Kindes- und Jugendalter - Verbreitung, Ursachen, Auswirkungen und Maßnahmen \\ DGKJ-SY-109}

Verbreitung von Eisenmangel im Kindes- und Jugenalter - Ergebnisse aus dem Kinder- und Jugendgesundheitssurvey (KiGGS)

K. Bergmann, R. Bergmann, M. Schlaud

Klinik für Geburtsmedizin Charité Universitätsmedizin

Vorbemerkungen: Eisenmangel ist der weltweit häufigste Nährstoffmangel. Da es Deutschland keine Eisenanreicherung von Grundnahrungsmitteln gibt und eine Fülle von Risikofaktoren sein Auftreten begünstigen, etwa ungünstige Ernährungsgewohnheiten, Blutverluste, niedriger Sozial- und Bildungsstatus aber auch die Weitergabe von Eisenmangel der Mutter an ihr Neugeborenes und Störungen des Eisenstoffwechsels und da Eisenmangel sich auf Wachstum und mentale Entwicklung von Kindern auswirken kann, verdient das Thema die Aufmerksamkeit der Kinderheilkunde und der Epidemiologie.
Methoden: Im Kinder- und Jugendgesundheitssurvey, der ersten repräsentativen Studie zur Gesundheit von Kindern und Jugendlichen in Deutschland, wurden von über 14. ooo Kindern und Jugendlichen Indikatoren der Eisenversorgung wie Hämoglobin, Erythrozyten, Hämatokrit, Eisen, Ferritin und löslicher Transferrinrezeptor gemessen, dazu Indikatoren zu Gesundheit, Entwicklung, Sozial- und Bildungsstatus, Migration, Verhalten, Lebensqualität, Schulleistungen u. a., so dass eine differenzierte Deskription und die Analyse von Zusammenhängen möglich ist. Die Ergebnisse sind für Deutschland gültig, deshalb lassen sich damit neue Normwerte und die Verteilung „gesunder" Blutbild- und Eisenwerte definieren.

Ergebnisse und Schlussfolgerungen: Auch nach Ausschluss eines Eisenmangels verbleiben starke Einflüsse von Alter und jenseits von 11 Jahren des Geschlechts auf Median und Verteilung der Normwerte für das rote Blutbild und die Parameter der Eisenversorgung. Die Häufigkeiten von Anämie und speziell von Eisenmangelanämie unter den verschiedenen Risikobedingungen und deren mögliche Auswirkungen werden präsentiert. Eisenmangelanämie kommt danach auch unter unseren Lebensbedingungen vor. Es gibt Hinweise, dass sie sich ungünstig auf Entwicklung und Verhalten auswirkt. Die routinemäßige $\mathrm{Hb}$ - Bestimmung erscheint besonders bei Kindern unter 3 Jahren, bei lange gestillten Kleinstkindern, bei über 11 -jährigen Mädchen, bei Kindern und Jugendlichen mit Migrationshintergrund, bei niedrigem Sozial - und Bildungsstatus, bei fleischfreier Ernährung und dies vor allem in größeren Städten sinnvoll.

\section{DGKJ-SY-110}

Eisenmangel in der Schwangerschaft und im Kindesalter: Auswirkungen auf das Kind

R. Bergmann, K. Bergmann

Charité, Campus Virchow-Klinikum, Klinik für Geburtsmedizin

Nach dem WHO-Bericht von 2008 sind neben Kindern und weiblichen Jugendlichen schwangere Frauen die Bevölkerungsgruppen mit dem häufigsten Vorkommen eines Eisenmangels und einer Anämie (1). Weltweit leiden danach etwa $40 \%$ der Schwangeren an einer Anämie, in Europa wird mit etwa 25\% gerechnet, mindestens die Hälfte davon bedingt durch Eisenmangel, der meist schon zu Beginn der Schwangerschaft besteht (1). Für eine genauere Ermittlung der Prävalenz von Eisenmangel werden von der WHO neben der Bestimmung des $\mathrm{Hb}$ die des Ferritins und des löslichen Transferrinrezeptors (sTfR) empfohlen (2). Für den Eisenbedarf in der Schwangerschaft werden insgesamt über $1000 \mathrm{mg}$ veranschlagt. Bei der geringen Bioverfügbarkeit von unter $20 \%$ lässt sich eine angemessene Zufuhr über die Ernährung kaum erreichen; deshalb werden Eisen-Supplemente empfohlen. Nach unseren eigenen Untersuchungen hatten in Berlin 14\% der Schwangeren vor der Entbindung einen Hb. -Wert unter $11 \mathrm{~g} / \mathrm{dl}$, 19\% ein Ferritin $<12 \mu \mathrm{g} / \mathrm{dl}$ und $41 \%$ einen hohen sTfR-Wert (3). Bei 5\% der Mütter einjähriger Kinder in Berlin wurde ein $\mathrm{Hb}<12 \mathrm{~g} / \mathrm{dl}$, bei 13\% ein Serumferritin $<12 \mu \mathrm{g} / \mathrm{dl}$, bei $10 \%$ ein erhöhter sTfR -Wert gefunden. Eisenmangel und besonders Eisen-mangelanämie belasten nicht nur Schwangere sondern wirken sich auch auf deren Kinder aus: Neugeborene kommen dann mit geringeren Eisenreserven zur Welt, was selbst nach einem Jahr noch nachweisbar ist. Zahlreiche Studienergebnisse, auch aus eigener Arbeit und aus Tierexperimenten, legen es nahe, dass sich Eisenmangel während des Hirnentwicklung nachhaltig auf mentale Leistungen auswirkt; nach neueren Ergebnissen scheint eine Eisenmangelanämie der Mutter oder des Säuglings die Mutter-Kind-Interaktion noch jahrelang zu beeinträchtigen $(4,5)$. Auf eine optimale Eisenversorgung ist deshalb bereits während der Schwangerschaft und im Säuglingsalter zu achten.

1) World Health Organization (WHO), Centers for Disease Control and Prevention (CDC). In: de Benois B, McLean E, Egli I, Cogswell M (eds) Worldwide prevalence of anemia 1993-2005. A global database on anemia. Geneva: WHO 2008 
2) World Health Organization (WHO), Centers for Disease Control and Prevention (CDC): Assesing the iron status of populations. $2^{\text {nd }} \mathrm{ed}$. Geneva: WHO 2007

3) Bergmann RL, Gravens-Müller L, Hertwig K, Hinkel J, Bergmann KE, Dudenhausen JW: Iron deficiency is prevalent in German pregnant women at delivery. Eur J Obstet Gynecol 2002: 102: 155 - 60 4) Armony-Sivan R, Kaplan-Estrin M, Jacobson SW, Lozoff B: Iron-deficiency anemia in infancy and mother-infant interaction during feeding. J Dev Behav Pediatr 31 (4) 326-32 May 2010

5) Bergmann RL, Bergler E, Bergmann E, Lachmann E, Bergmann KE: Prävention von Eisenmangel bei gestillten Säuglingen durch geeignete Beikost. Eine prospektive, kontrollierte Studie. Monatsschr. Kinderheilkd. 137 (1989), 775-779

\section{Jugendbildung und Jugendcoaching: Ein Update}

\author{
DGKJ-SY-113 \\ Interdisziplinäre Schnittstellen in der Jugendbetreuung: Die Aufgabe \\ des Jugendarztes als Lotse und Coach \\ E. Friederichs \\ Schwerpunktpraxis für Entwicklung und Lernen
}

Jugendgesundheit soll aus verschiedenen Sichtweisen - a) Forschung b) Bildung und c) Coaching betrachtet werden. Jugendgesundheit ist eine interdisziplinäre Aufgabe, an der Jugendliche selbst, Kinder- und Jugendmediziner, Kinder- und Jugendpsychiater sowie Pädagogen wissenschaftlich und in der Anwendung gleichermaßen beteiligt sind. Verbindendes Glied ist die Neurobiologie.

Zunehmende gesundheitliche Probleme und ansteigende Risikofaktoren machen deutlich, dass zusätzliche Maßnahmen zur Gesundheitsförderung bzw. -prävention besonders im Kindes- und Jugendalter dringend notwendig sind. Chronische Erkrankungen, psychische Störungen, Suchterkrankungen aber auch Essstörungen (von der Magersucht bis zum Übergewicht) haben bei Kindern und Jugendlichen im letzen Jahrzehnt deutlich zugenommen. Ursachen sind u. a. in höheren schulischen Anforderungen, in veränderten Essgewohnheiten und verändertem Essverhalten, Zunahme der Medien, Bewegungsarmut etc. zu sehen. Man spricht auch von den neuen Morbiditäten.

Präventionsmaßnahmen sollen Kindern und Jugendlichen gesundheitsbezogene Kenntnisse und Fähigkeiten vermitteln, um sich bewusst für eine gesunde Lebensweise zu entscheiden Es gibt unterschiedliche Settings in denen Prävention verwirklicht werden kann. Während bisher die Familie der wichtiges Ansprechpartner war, kommen vor allem Vorund Schulbereich mehr in den Blickpunkt präventiver Maßnahmen. Der Jugendarzt muss als Lotse und Coach fungieren, um in diesem interdisziplinären Feld zu agieren. Hierzu muss er sich in Zukunft neuen Herausforderungen stellen. Welche Anforderungen an den Jugendarzt in Zukunft gestellt werden, soll in dem Symposium vermittelt werden.

\section{DGKJ-SY-114}

\section{Jugendgesundheit als Ziel pädagogischen Handelns}

Es ist wohl unumstritten, dass zwischen steigendem Zeitdruck in den täglichen Arbeits- und Lebensbedingungen auf der einen Seite und der steigenden Anzahl von Personen mit sozialen oder gar existenziellen Ängsten auf der anderen Seite ein Zusammenhang besteht. Auf der Suche nach möglichen Auswegen wird aus Sicht der Erziehungswissenschaft zunehmend in Frage gestellt, dass die heutige Form unserer sowohl strukturell als auch ideell relativ stabilen Bildungslandschaft dazu geeignet ist, möglichst vielen Beteiligten die Aussicht auf eine annähernd „gesunde“ Zukunft zu ermöglichen. Dem Vortrag liegt ein Gesundheitsbegriff in erziehungswissenschaftlicher Akzentuierung zugrunde, der nicht auf seine physiologische und psychologische Bedeutung reduziert bleibt, sondern um spirituelle, ökonomische und kulturelle Parameter erweitert wird. Basierend auf einer derart ausbalancierten und umfassenden Sichtweise wird „Jugendgesund- heit" als wesentliche bildungspolitische Aufgabe skizziert, die ein relatives Optimum aller zu berücksichtigenden Dispositionen und Zielsetzungen anstrebt. Voraussetzung hierzu ist nicht nur die Expertise aus verschiedenen mehr oder weniger isolierten Fachwissenschaften, sondern es braucht darüber hinaus eine Vernetzung in gemeinsamen Forschungsprojekten, denn nur so kann vermieden werden, dass z. B. die Neurowissenschaft - basierend auf Ergebnissen von Lernexperimenten - Lehrpersonen Empfehlungen für die Gestaltung von Unterricht abgibt, denen diese und die Unterrichtsforschung mit einer gewissen Skepsis gegenüberstehen. Im Vortrag soll anhand von konkreten Beispielen aus der Lehr-Lern- Forschung in realen Settings gezeigt werden, wie in gegenläufigen Prozessen von Orientierungssicherheit und Leidensdruck gleichzeitig die Problemlösefähigkeit und die emotionale Befindlichkeit positiv beeinflusst werden können.

\section{DGKJ-SY-115}

Neurobiologische Grundlagen von Lernen und Schulleistung K. Folta

Universität Hildesheim

In den vergangenen Jahrzehnten haben uns die modernen Methoden der Hirnforschung einen faszinierenden Einblick in die komplexen Informationsverarbeitungsprozesse des lernenden Gehirns geben können. Diese Erkenntnisse erlauben dem Hirnforscher heute eine sehr präzise neurobiologische Beschreibung, wie individuelle Lernerfahrungen zum Aufbau von neuronalen Wissensrepräsentationen und Handlungskonzepten beitragen, die eine bedeutende Grundlage für motiviertes, aufmerksames und zielgerichtetes Verhalten darstellen. Dieser Fachvortrag will auf unterhaltsame Weise die aktuellsten Erkenntnisse zur Neuroanatomie und Neurophysiologie des Lernens vermitteln. Dabei soll aufgezeigt werden, wie sich die Gewichtung und Plastizität von neuronalen Lernmechanismen im Verlauf der normalen Entwicklung (vom Kleinkindalter bis ins hohe Erwachsenenalter) verändert und welche Lernkontexte (in der Familie, der Kita, im Kindergarten oder in der Schule) neuroplastische Veränderungen günstig oder nachteilig beeinflussen. In diesem Zusammenhang sollen auch die möglichen Diskrepanzen zwischen pädagogischen Anforderungsprofilen und prozessualen Abläufen im Gehirn aufgezeigt und diskutiert werden.

\section{DGKJ-SY-116}

Jugendgesundheit aus der Sicht von Jugendlichen mit chronischen Erkrankungen

R. Schmid

Kindernetzwerk e.V.

Jugendliche fühlen sich in der Regel eher gesund. Dass dieses Empfinden mit der Realität häufig nicht übereinstimmt, belegen die Zahlen aus dem Kinder- und Jugendgesundheitssurvey, die seit 2006 vorliegen und nun immer wieder fortgeschrieben werden. Aus diesen Zahlen geht deutlich hervor, dass Jugendliche bundesweit bei weitem nicht so gesund sind, wie dies in der (Fach-)Öffentlichkeit immer wieder dargestellt wird. Erhebliche Defizite gibt es vor allem bei der psychosozialen Versorgung von Kindern und Jugendlichen bis in das Erwachsenenalter hinein. Dies geht aus repräsentativen Ergebnissen hervor, die das Kindernetzwerk bei Selbsthilfeorganisationen in Deutschland erhoben hat.

Um sich all diesen Themen konkret zu stellen, ist im Kindernetzwerk ein bundesweit einmaliger Arbeitskreis "Jugendliche/Junge Erwachsene“ ins Leben gerufen worden, der aus rund 30 jungen Menschen in der Alterspanne zwischen 15 und 28 Jahren besteht und in dem sich Betroffene mit rund 10 höchst unterschiedlichen Erkrankungen oder Beeinträchtigungen zusammenfinden. Bei den Treffen erörtern die Jugendlichen nicht nur den Status ihrer Gesundheit aus der eigenen Perspektive heraus, sondern unterbreiten auch selbst konkrete Lösungsvorschläge, wie sie ihre Situation praktisch verbessern können. Dabei geht es u. a. um die Themen Schule, Ausbildung und Beruf, den Themenkomplex 
Transition (Übergang vom Jugendlichen in das Erwachsenenalter) oder auch um solche Themen wie Mobbing.

Über die bisher erzielten Ergebnisse aus dieser besonderen Arbeitsgruppe junger Menschen soll auf dem Symposium der DGKJ am 19. September im Potsdam berichtet werden. Schließlich sollen auch von Seiten des Kindernetzwerks Wünsche artikuliert werden, wie die Situation von Jugendlichen mit besonderen Bedürfnissen in Zukunft verbessert werden kann.

\section{DGKJ-SY-117}

\section{Jugendgesundheit aus Sicht der Jugendlichen}

S. Bischoff, S. Mirsch

Gymnasium im Stift Neuzelle

Unter der Überschrift „Jugendgesundheit aus Sicht des Jugendlichen“ beschäftigte sich unsere Arbeitsgemeinschaft mit jugendmedizinischen Themen am Gymnasium im Stift Neuzelle. In unserem Beitrag möchten wir vor allem auf die Interessen und Bedürfnisse der Schülerinnen und Schüler in Bezug auf Jugendmedizin eingehen. Zunächst haben wir einen Fragebogen erstellt, um bei allen Schülerinnen und Schülern der Sekundarstufe I zu erfragen, inwieweit sie mit medizinischen Aspekten im Unterricht bzw. im Schulalltag konfrontiert werden. Dabei haben wir uns am brandenburgischen Rahmenlehrplan orientiert und uns auf folgende Schwerpunkte festgelegt:

- Gesunde Ernährung / Essstörungen

- Krankheiterreger und Immunsystem

- Drogen und Süchte

- Sexualität und Fortpflanzung

- Erbkrankheiten

Weiterhin galt unser Interesse der Methodik: Sollten sensible Themen, wie zum Beispiel „Sexueller Missbrauch“ im Rahmen des Unterrichts oder in anderer Art und Weise behandelt werden? Sollten jugendmedizinische Themen von einem Lehrer oder von Fachleuten (Jugendarzt, Psychologe) vermittelt werden? Die Ergebnisse auf diese und weitere Fragen sollen zusammenfassend dargestellt und Konsequenzen für die Unterrichtsgestaltung abgeleitet werden.

\section{DGKJ-SY-118}

\section{Macht die Schule Lehrer und Schüler krank - und was will die Schule} vom Jugendarzt?

Mai 2010, in der Praxis des Kinder- und Jugendarztes, Dr. Simonson $^{*}{ }^{\star}$ Name geändert) herrscht großes Gedränge, Mütter mit ihren überwiegend 8-13jährigen - füllen das Wartezimmer: Kopfschmerzen, Schlafstörungen, Niedergeschlagenheit, starke Magenbeschwerden... Simonsonkennt das: „in 8 Wochen gibt's Zeugnisse, Blaue Briefe gab's vorletzte Woche!" Nicht nur, dass

kinderärztliche Inanspruchnahme mit Schulterminen wie Versetzung, Blaue Briefe, anstehenden Klassenarbeiten korreliert, diese "gefühlte" Bedingungsbeschreibung ist längst per wissenschaftlicher Studien untermauert: Nach Ergebnissen eines bundesweiten Kinderund Jugendgesundheitssurveys des Robert-Koch-Instituts 2007 sind 22\% der Kinder und Jugendlichen zwischen 7 und 17 Jahren psychisch auffällig und 10\% manifest psychisch krank. Frau Professor Beate Herpertz-Dahlmann, damalige Präsidentin der Deutschen Gesellschaft für Kinder- und Jugendpsychiatrie, legte dies auf einem Kongress in Berlin dar. Störungen des Sozialverhaltens, Aggressivität. Lügen, Schuleschwänzen treten bei 10\% auf, Ängste bei 7,6\% und Depressionen bei $5,4 \%$ der Kinder und Jugendlichen. Als bedeutenste Risikofaktoren für psychische Krankheiten und Auffälligkeiten gelten neben sozioökonomischen Fakten in besonderem Maße schulische Bedingungen, die vom Kind als belastend wahrgenommen werden. „Kinder, die so aufwachsen, sind schon sehr früh extremen Stressfaktoren ausgesetzt", so Herpertz-Dahlmann.

Macht die Schule Lehrer und Schüler krank? In meinem Kurzvortrag werde ich versuchen Licht in dieses Bedingungsgeflecht zu bringen: Was rechtfertigt eine solche Frage?
- Gibt es institutionelle, innerschulische, außerschulische Rahmenbedingungen, die zu einer somatischen/psychosomatischen, am Ende krankmachenden Belastung für Schüler und Lehrer führen?

- Lehrerausbildung, Erziehungswissenschaft und Lehrerpersönlichkeit: Wie sind Lehrer auf ihren Beruf vorbereitet?

- Gibt es Auswirkungen auf Lehrer- und Schülergesundheit.

- Medien-Familiensituation- elterliche Erziehung- erweisen sie sich als Faktoren der Stabilisierung oder Destabilisierung des Kindes im Schulalter?

- Welche Kinder sind besonders gefährdet?

- Gibt es praktische Entlastungskonzepte in der konkreten Schul- und Unterrichtsgestaltung?

- Kann - und falls ja, wie - der Jugendarzt zur situativen Entlastung von Schülern und Lehrern beitragen?

\section{Nephrotisches Syndrom: Aktuelle Diagnostik und Therapie}

\section{DGKJ-SY-119}

Wachtum und Endgröße beim steroid-sensiblen Nephrotischen Syndrom

D. Haffner

Universitäts-Kinder- und Jugendklinik Rostock

Die Behandlung des steroid-sensiblen nephrotischen Syndroms (SSNS) stellt für den Pädiater eine große Herausforderung dar. Obwohl diese Erkrankung in der Regel im Erwachsenenalter ausheilt, verläuft sie häufig schubhaft und über viele Jahre. Die Behandlung richtet sich nach den Leitlinien der Gesellschaft für Pädiatrische Nephrologie (GPN). Patienten, die unter einer vierwöchigen Standardtherapie mit Prednison eine komplette Remission zeigen (negative Albustix-Probe im Morgenurin an drei aufeinanderfolgenden Tagen), leiden per definitionem an einem SSNS. Auch wenn es bei einigen Patienten, insbesondere in der Adoleszenz, zu einer kurzfristigen Beeinträchtigung des Längenwachstum unter der Prednisontherapie nach GPN-Schema kommen kann, zeigen Patienten mit nur einem einzelnen Schub der Erkrankung oder solche mit seltenen Rezidiven (weniger als 2 Rezidive innerhalb von 6 Monaten nach Ansprechen auf Prednison) ein komplettes Aufholwachstum nach Absetzen von Prednison und erreichen eine normale Endgröße. Im Gegensatz hierzu haben Patienten mit häufigen Rezidiven (mehr 2 bzw. 4 Rezidive innerhalb von 6 bzw. 12 Monaten nach primärem Ansprechen auf Prednison), sowie steroidabhängige Patienten (2 aufeinanderfolgende Rezidive, die bereits unter einer Standardrezidivbehandlung mit Prednison oder innerhalb von 2 Wochen nach Absetzen aufgetreten sind) ein hohes Risiko für ein gestörtes Längenwachstum mit reduzierter Erwachsenengröße. Patienten, die eine langdauernde bzw. häufige Prednison-Behandlung auf Grund eines steroid-abhängigen-/rezidivierenden NS benötigen, weisen im Mittel ein Größendefizit zwischen 0,5 und 1,5 Standardabweichungen mit entsprechend reduzierter Endgröße auf. Dies trifft insbesondere auf Patienten zu, bei denen eine wiederholte Prednisontherapie in der Adoleszenz zu einem verzögert einsetzenden und reduzierten pubertären Wachstumsschub führte. Durch den Einsatz von Cyclosporin A und Mycophenolat Mofetil (MMF) kann bei Patienten mit häufig-rezidivierendem-/ steroidabhängigen NS die Steroid-bedingte Störung des Wachstums vermieden oder zumindest reduziert werden. Allerdings müssen die potentiellen Langzeitnebenwirkungen dieser Immunsuppressiva, wie Nephrotoxizität, arterielle Hypertonie, Leukopenie und Hypertrichose sorgfältig beachtet werden. Darüber hinaus erfordert die Behandlung mit Cyclosporin A und MMF ein entsprechendes Drug-Monitoring (Talspiegel bzw. Kurzkinetik). Zusammenfassend kann man sagen, dass heutzutage Patienten mit SSNS eine normale Wachstumsprognose haben. Vorraussetzung hierfür ist aber, dass Patienten mit häufigen Rezidiven und/oder Steroidabhängigkeit an einem kindernephrologischen Zentrum behandelt werden, um langfristige Nebenwirkungen der Immunsuppressiva zu vermeiden. 
DGKJ-SY-120

Neue Therapieoptionen beim steroidabhängigen Nephrotischen Syndrom

J. Dötsch

Kinder- und Jugendklinik, Uniklinik Köln

Die Studienlage ist beim steroidresistenten nephrotischen Syndrom im Kindes- und Jugendalter aufgrund einer langen Studientradition günstig. Gründe hierfür sind die relative Häufigkeit des Krankheitsbildes im Kindesalter sowie eine seit vielen Jahren gut aufgestellte Studiengruppe in der Gesellschaft für Pädiatrische Nephrologie.

Höchster Evidenzgrad besteht für die initiale Prednisontherapie, die bei ca. $90 \%$ der Kinder anspricht. Entscheidend ist eine adäquat lange Dauer der Initialtherapie von insgesamt 3 Monaten. Dennoch rezidivieren 50\% der Kinder mindestens 1-mal. Beim Rezidiv spielt die Therapiedauer keine entscheidende Rolle, so dass diese zur Vermeidung von Steroidtoxizität deutlich kürzer als die Initialtherapie ist.

Bei 4 Rezidiven innerhalb eines Jahres spricht man von häufigen Rückfällen, kommt es innerhalb von 2 Wochen nach Beendigung der Prednisontherapie zu Rezidiven liegt ein steroidabängiges nephrotisches Syndrom vor. Die in diesem Zusammenhang am besten untersuchte Therapie basiert auf Cylophosphamid, wenngleich die Substanz aufgrund ihrer Gonadentoxizität zunehmend in die Kritik gerät. Weniger toxisch scheinen Cyclosporin A und Mykophenolatmofetil zu sein, wenngleich die Studienlage weniger sicher und die Rückfallquote nach Therapieende höher ist.

Ein großes Problem sind nach wie vor diejenigen steroidsensiblen Patienten, die trotz immunsuppressiver Therapiezyklen immer wieder Rezidive zeigen. In diesem Zusammenhang könnte die Therapie mit dem monoklonalen Antikörper Rituximab oder ähnlichen Biologika eine zukünftige Möglichkeit der Rescuetherapie bedeuten. Allerdings fehlen derzeit noch kontrollierte Studien sowie Langzeitdaten zu Nebenwirkungen.

Zusammenfassend lässt sich sagen, dass trotz einer historisch guten Studienlage zur Therapie des steroidsensiblen nephrotischen Syndroms im Kindesalter die Entwicklung neuer vielversprechender Medikamente und die zunehmenden Bedenken um die Nebenwirkungen der alten Medikamente Anlass zur Evaluierung neuer Behandlungsmöglichkeiten gibt.

DGKJ-SY-122

Aktueller Therapievorschlag zum steroidresistenten Nephrotischen Syndrom

\section{DGKJ-SY-123}

Elternschulung beim Nephrotischen Syndrom

M. Benz

Pädiatrische Nephrologie, Kinderklinik und Kinderpoliklinik im Dr. von Haunerschen Kinderspital, LMU München

Das nephrotische Syndrom im Kindesalter verläuft in über 50\% der Fälle rezidivierend und persistiert in bis zu 30\% über die Adoleszenz hinaus. Die Chronizität mit Rezidiven und die Unsicherheit über die individuelle Prognose führen zu erhöhter psychosozialer Belastung und zur Beeinträchtigung der Lebensqualität in den betroffenen Familien. Schulungsprogramme im Sinne von pädagogisch-psychologischen Interventionen mit medizinischen Inhalten für Patienten und deren Familien helfen, Eigenverantwortung zu übernehmen und die Erkrankung besser in den Alltag zu integrieren. Während für häufige chronische Erkrankungen des Kindes- und Jugendalters evaluierte Schulungsprogramme existieren, sind Schulungen für seltene pädiatrische Krankheitsbilder rar. Ziele der entwickelten Familienschulung nephrotisches Syndrom (Pipilotta und der Nierendetektiv) sind die Vermittlung von Wissen über die Erkrankung, die Verringerung der psychosozialen Belastung und damit die Akzeptanz des nephrotischen Syndroms als chronisch-rezidivierende Erkrankung mit Krankheitsbewältigung im Familiensystem (empowerment).
Die ganztägige Familienschulung nephrotisches Syndrom, zu der jeweils 4-5 betroffene Kinder sowie deren Eltern und Geschwister eingeladen werden, wird durch ein interdisziplinäres Schulungsteam (Ärzte, Pädagogen/Psychologen, Krankenschwestern) modular unter Berücksichtigung der entwicklungspsychologischen Alterstufen standardisiert gestaltet.

Zur Evaluation wurden vor und 6 Monate nach der Intervention validierte Fragebögen verwendet. Die Auswertung der in den Jahren 2007 und 2008 durchgeführten Familienschulungen nephrotisches Syndrom (41 Kinder und deren Familien (20 Mädchen, 21 Jungen), 5 drop outs (12\%)) zeigt eine signifikante Verringerung der psychosozialen Belastung der Kinder (Child Behaviour Check List) mit nephrotischen Syndrom und deren Eltern (Brief Symptom Inventory). Zudem lassen sich Tendenzen in der Verbesserung der Lebensqualität nachweisen. Mütter, Väter und Kinder denken im Alltag weniger an die Krankheit.

Mit der Familienschulung nephrotisches Syndrom steht ein neuer Baustein im Konzept der Therapie des nephrotischen Syndroms im Kindesalter zur Verfügung.

\section{Psychosomatik komplexer Erkrankungen}

\section{DGKJ-SY-130}

\section{Vitium Cordis als Schicksal}

U. Neudorf

Zentrum für Kinder- und Jugendmedizin

Knapp unter $1 \%$ aller Neugeborenen haben einen „Herzfehler“. In Deutschland werden zur Zeit noch die Daten der neuesten Erhebung (PAN-Studie) ausgewertet. Zum Glück sind viele der Herzfehler, wie Kammerscheidewanddefekte harmlos und bedürfen keiner Therapie. Viele der „Löcher im Herzen“ wachsen sogar zu.

Bei komplexen Herzfehlern ist die Situation anders und oft sind die Schicksale sehr individuell.. Oftmals sind junge Menschen, die sich auf ihr Kind freuen, von dieser einschneidenden Situation betroffen und das sowieso fragile Konstrukt „Familie“ steht unter enormer Belastung. Emily hatte einen komplizierten Herzfehler, der keine Totalkorrektur ermöglichte. Eine totale cavopulmonale Anastomose war die Palliation. Dazu waren 3 Operationen am Herzen nötig. Emily wurde ein sehr selbstbewusstes Kind, was mit seinen Eigenarten manchmal auch nicht einfach zu ertragen war. Sie lebte keine 10 Jahre und starb zu Hause und hat vorher mit uns über ihr Sterben gesprochen.

Bis dahin war die Ehe der Eltern gescheitert und es gab viele Konflikte unter den verschiedenen Erwachsenen.

Situationen wie diese stellen eine maximale Belastung da und führen oft zu Grenzsituationen, zumal, wenn der Herzfehler nicht „heilbar“ ist. Damit gibt es automatisch auch Komponenten über das rein hämodynamische hinaus, die auch der Arzt berücksichtigen muss, und es nicht an z. B. Selbsthilfegruppen delegieren kann.

\section{DGKJ-SY-131}

\section{Brandverletzung als Trauma: D. Kunert}

Gesundheit Nordhessen - Kinderkrankenhaus Park Schönfeld

Schwere thermische Verletzungen gehören zu den schmerzhaftesten Erfahrungen, die ein Mensch machen kann. Die Überlebensrate selbst bei schwersten Verletzungen ist in den letzten Jahrzehnten dank verbesserter Behandlungsmöglichkeiten stark gestiegen. Auch in der Behandlung von Kindern und Jugendlichen stellt sich daher oft nicht die Frage, $o b$ ein Patient überlebt, sondern wie er überlebt. Unsere Erfahrungen zeigen, dass der Rehabilitationsverlauf nach schweren thermischen Verletzungen bei Kindern und Jugendlichen wesentlich von psychosozialen Faktoren abhängig ist. Daher sollte schon in der Akutphase der Behandlung die psychosoziale Medizin einbezogen werden.

Psychosoziale Interventionen in den verschiedenen Phasen der Behandlung werden dargestellt, auch unter dem Aspekt der Verhinderung psychischer Traumata. 


\section{Abstracts der 48. Jahrestagung der Deutschen Gesellschaft für Kinderchirurgie (DGKCH)}

\section{Freitag, 17. September 2010}

\section{Minimalinvasive Kinderchirurgie}

\author{
DGKCH-FV-04 \\ Indikation und Nutzen des thorakoskopischen Verschluss bei der \\ angeborenen Zwerchfellhernie \\ K. Reinshagen, K. Zahn, S. Maier, T. Schaible, L. Wessel \\ Klinikum Mannheim
}

Einleitung: Seit ca. 10 Jahren werden angeborene Zwerchfelldefekte $(\mathrm{CDH})$ mittels minimalinvasiven Techniken (MIC) operativ versorgt. Dabei hat sich der thorakoskopische Verschluss aufgrund der besseren Übersicht und der höheren Erfolgsrate gegenüber dem laparoskopischen Verfahren durchgesetzt. Wir haben in unserem Zentrum 2008 begonnen, Zwerchfellhernien thorakoskopisch zu verschließen. Ziel unserer prospektiven Studie ist es, Indikation und Nutzen zu evaluieren.

Patienten und Technik: Patienten mit einer CDH werden nach Stabilisierung ab dem 3. Lebenstag operativ versorgt. Ausschlusskriterien für eine minimalinvasive Korrektur der $\mathrm{CDH}$ sind rechtsseitige Hernien, die Notwendigkeit von ECMO, (NO) Beatmung und Herniation des linken Leberlappens.

Technisch erfolgt der Verschluss mittels $3^{*} 3 \mathrm{~mm}$ Trokare, die in der mittleren Axillarlinie, in der Verlängerung der Skapulaspitze und parasternal links eingebracht werden. Der Primärverschluss erfolgt mittels nicht resorbierbarer Einzelknopfnähte. Ein notwendiger Patch wird über eine Trokareintrittsstelle eingebracht und mittels fortlaufender nicht resorbierbarer Naht am Zwerchfell fixiert. Dorsolateral erfolgt die Fixierung mittels pericostalen Einzelknopfnähten.

Ergebnisse: Seit 2008 wurden 100 Neugeborene an unserer Klinik aufgrund einer $\mathrm{CDH}$ operativ versorgt. $42 \%$ benötigten ECMO. $76 \%$ hatten einen sehr großen Defekt und wurden mit einem Patch operiert. 9/10o Neugeborenen erfüllten die notwendigen Kriterien in unserem Zentrum für einen thorakoskopischen Verschluss der CDH. Zweimal musste konvertiert werden zur Laparotomie. Einmal aufgrund des kompletten Fehlens einer dorsalen Muskelleiste und einmal zeigte sich überraschend eine Herniation des linken Leberlappens. Die Implantation eines Patches war in einem Fall notwendig. Die Operationszeit betrug im Schnitt 143 min versus 99 min gegenüber einem gematchten Kontrollkollektiv. Der stationäre Aufenthalt betrug 24,12 Tage versus 26,25 der Kontrolle. Ein Frührezidiv zeigte sich bisher bei keinem Patienten.

Zusammenfassung: Bei Patienten mit einer linksseitigen CDH ohne höhergradige respiratorische Einschränkung ist ein thorakoskopischer Zwerchfellhernienverschluss problemlos möglich. Dabei ist die Notwendigkeit eines Patches bei großem Zwerchfelldefekt keine Indikation zur Konversion. Die MIC reduziert dtl. die Narbenbildung und führt zu einem hervorragendem kosmetischen Ergebnis. Die Krankenhausverweildauer ändert sich durch MIC nicht signifikant. Die Rezidivrate nach MIC wird in der Literatur mit bis zu $25 \%$ beschrieben. Ob mit einer Verbesserung der Technik und einer sorgfältige Selektionierung der Patienten die geringe Rezidivrate von 8,2\% unseres CDH Gesamtkollektivs auch mittels MIC erreicht werden kann und ob Komplikationen wie der gastroösophageale Reflux oder der Bridenileus signifikant seltener werden, ist derzeit noch nicht absehbar.

\section{DGKCH-FV-05}

Frühelektive videoassistierte Thorakoskopie (VATS) bei Pleuraempyem bei Kindern und Jugendlichen

M. Dürsch, B. Reingruber

Klinik für Kinderchirurgie - Sankt Hedwig

Ziele: Der Behandlungs-Algorithmus beim postpneumonischen Pleuraemypem ist Gegenstand einer fortwährenden Debatte. Nach einer anfänglichen antibiotischen Therapie wurden in dieser Fallserie die korrekte Verfahrenswahl und der optimale Zeitpunkt für eine invasive Behandlung evaluiert. Die grundlegende Frage war, wann man eine VATS durchführen sollte, in der Anfangsphase der fibrösen Exsudation oder in der Spätphase mit bereits eingetretener konstriktiver Plaquebildung und Verschwartung. Patienten: In den letzten 4 Jahren wurden sieben Patienten mit einem Pleuraempyem in der Klinik für Kinderchirurgie in Regensburg behandelt. Bei vier Patienten wurde nach April 2007 eine frühzeitige VATS (early-VATS), wohingegen im vorherigen Zeitraum bei drei Patienten eine späte chirurgische Intervention (lateVATS) durchgeführt wurde. Diese 3 Patienten dienten bei vergleichbaren Erkrankungsbildern als Kontrollgruppe. Ergebnisse: In der earlyVATS Gruppe war keine Konversion erforderlich, wohingegen bei allen late-VATS Patienten eine Konversion zur offenen Thorakotomie erforderlich war. Bei einem late-VATS Patienten musste eine Mittellappenresektion durchgeführt werden. Die postoperativen Verläufe und Langzeitverläufe waren bei allen early-VATS Patienten komplikationslos mit kompletter Remission der anfänglichen Pleuraverdickung. In der lateVATS Gruppe traten prolongiertes Fieber, längere postoperative Beatmungsdauern, respiratorische Insuffizienz und Atelektasen des Mittellappens auf. Diskussion: Die vorliegende Serie bestärkt unseren Eindruck, dass VATS bereits in der Frühphase des Pleuraempyems bei unzureichendem Ansprechen auf antibiotische Therapie durchgeführt werden sollte. Ob eine VATS generell bereits zum Zeitpunkt und kombiniert mit einer indizierten Thoraxdrainageanlage erfolgen sollte, bleibt Gegenstand der Diskussion. In Anbetracht der Tatsache, dass im kindlichen Patientengut eine Thoraxdrainage in der Regel in Allgemeinnarkose angelegt wird, erhöht die kombinierte VATS die diagnostische Sicherheit, wenn sonographisch ein hyperechogener Erguss ein beginnendes Empyem anzeigt. Wir sehen für dieses Vorgehen klare Vorteile, da sich in der Frühphase Fibrinbeläge sehr gut lösen und mittels Pleuralavage entfernen lassen, außerdem können die Drainagen gezielt und unter Sicht platziert werden. Aufwendige und risikoreichere Spätthorakotomien sowie Komplikationen wie Lungenparenchymverletzungen, insuffiziente Drainagen bei fibrinösen Membranen und deren Spätfolgen wie Dystelektasenbildung durch segmentale Minderbelüftungen oder Verlust der Elastizität der Lunge mit dauerhafter Verminderung der Vitalkapazität können hierdurch weiter reduziert werden. Andere 
Therapieoptionen wie pleurale Fibrinolyse sollten ebenfalls nur unter kontrollierten thorakoskopischen Bedingungen erfolgen.

\section{DGKCH-SY-03}

Laparoskopische versus offene Appendektomie bei Kindern mit perforierter Appendizities

T. Luithle, P. Szavay, J. Fuchs

Eberhard-Karls-Universität Universitätsklinik für Kinderheilkunde und Jugendmedizin

Einleitung: Die laparoskopische Appendektomie bei Kindern mit unkomplizierter Appendizitis hat sich als Standardverfahren etabliert. Das laparoskopische Vorgehen bei perforierter Appendizitis hingegen wird kontrovers diskutiert. Ziel der Studie ist ein Vergleich der Ergebnisse von laparoskopischer und offener Appendektomie.

Material und Methoden: Retrospektiv wurden die Krankenakten aller Kinder ausgewertet, die zwischen Juli 2002 und Oktober 2008 in unserer Klinik mit perforierter Appendizitis operiert wurden. Die demographischen Daten, Werte für Leukozyten- und C reaktives Protein (CRP), Aufenthaltsdauer, Operationszeit und Komplikationen wurden verglichen.

Ergebnisse: Es wurden 548 Patienten mit Appendizitis operiert. Bei $82(15 \%)$ Kindern war eine Perforation zu verzeichnen. Achtundvierzig Appendektomien bei perforierter Appendizitis wurden laparoskopisch (LA) durchgeführt wobei in 6 Fällen auf ein offenes Verfahren umgestiegen wurde. Bei 34 Kindern wurde primär eine offene Appendektomie (OA) durchgeführt. Es gab keine signifikanten Unterschiede bezüglich Alter, Geschlechtsverteilung, Leukozytose, CRP, Länge des Krankenhausaufenthaltes oder der Operationszeit zwischen den beiden Gruppen ( $p>0,05)$. Die Anzahl der postoperative Komplikationen unterschied sich mit 9 Fällen in der LA Gruppe (18\%) und 6 Fällen in der OA Gruppe (17,6\%) nicht signifikant. Intraabdominelle Abszesse stellten die häufigste Komplikation in beiden Gruppen dar.

Schlussfolgerung: Die laparoskopische Appendektomie ist eine sichere Behandlungmethode der perforierten Appendizitis bei Kindern. Bei den von uns operierten Patienten konnte kein erhöhtes Risiko für postoperative Komplikationen nachgewiesen werden. Deshalb empfehlen wir bei allen Patienten mit perforierter Appendizitis die laparoskopische Appendektomie.

\section{DGKCH-SY-04}

Funktionellen Ergebnisse bei Kindern nachlaparoskopischer Nierenbeckenplastik

P. Szavay, T. Luithle, G. Seitz, P. Haber, J. Fuchs

Eberhard-Karls-Universität Universitätsklinik für Kinderheilkunde und Jugendmedizin

Einleitung: Die laparoskopische oder retroperitoneoskopische Nierenbeckenplastik bei Ureterabgangsstenose oder Obstruktion durch ein aberrierendes Polgefäß beim Kind sind mittlerweile Standardprozeduren. Ziel dieser Untersuchung war es, die funktionellen Ergebnisse bei Kindern nach laparoskopischer Nierenbeckenplastik zu evaluieren.

Material und Methoden: Zwischen März 2004 and Oktober 2008 wurden 70 Kinder einer laparoskopischen Nierenbeckenplastik unterzogen. Das mediane Follow-up betrug 24 Monate (11-48). Wir untersuchten die Nierenpartialfunktion, sowie den Abfluss aus dem operierten Nierenbecken mittels Isotopennephrografie unter forcierter Diurese 3 bzw. 12 Monate postoperativ. Die Ultraschalluntersuchung wurde zur Beurteilung des Hydronephrosegrades prä- und postoperativ wiederholt durchgeführt.

Ergebnisse: Das mediane Alter der Patienten zum Zeitpunkt der Operation betrug 20 Monate (1-178). Die mediane Operationszeit betrug 140 Minuten (95-220). Die durchschnittliche Nierenpartialfunktion konnte ohne signifikanten Unterschied zwischen prä- und postoperativ erhalten werden ( $p>0.05)$. Alle Patienten zeigten eine signifikante Verbesserung der Abflussdynamik auf der operierten Seite ( $\mathrm{p}$ o. 0001). Im Ultraschall zeigte sich ein Trend zur Abnahme des Hydro- nephrosegrades von Grad III prä-, auf Grad II postoperativ, jedoch war dies nicht signifikant $(\mathrm{p}=0.657)$.

Schlussfolgerung: Im Sinne eines Erhalts der Nierenpartialfunktion ist das laparoskopische Operation gleich effektiv wie die offene Vorgehensweise. Die Abflussdynamik nach laparoskopischer Nierenbeckenplastik ist signifikant verbessert. Die Operationszeiten bei laparoskopischer Nierenbeckenplastik sind mittlerweile kompetitiv. Wir schlussfolgern, dass die laparoskopischer Nierenbeckenplastik beim Säugling und Kind eine anspruchsvolle Operation darstellt. Sie könnte die bisher konventionelle, offene Operation als Gold Standard bei der Behandlung der Ureterabgangsstenose ersetzen.

\section{Freie Vorträge}

\section{DGKCH-FV-06}

Die Hochregulation von UCHL1 korreliert mit einer Reduktion von vitalen Neuroblastomzellen durch die Kombination von Fenretinid und Doxorubicin

S. Kuehnel', G. Cernaianu' ', K. Stühler' ${ }^{2}$, H. Meyer ${ }^{2}$, A. Bufe², M. Köller ${ }^{3}$, B. Sitek², R. Tröbs

${ }^{1}$ Kinderchirurgische Klinik im Marienhospital, ${ }^{2}$ Ruhr-Universität Bochum, ${ }^{3}$ BG Kliniken Bergmannsheil

Hintergrund: DisseminierendeNeuroblastome (NB) benötigen eine intensive zytotoxische Chemotherapie. Studien belegen die Effektivität von Retinsäurederivaten als differenzierende Agenzien bei NB. Wir untersuchten die Wirkung des synthetischen Retinoids Fenretinid (Fen) und des Zytostatikum Doxorubicin (Dox) auf die Zellvitalität der humanen NB Zelllinie SH-SY5Y bei Einzel- sowie Kombinationsgabe. Methoden: SH-SY5Y-Zellen wurden über 6 Tage mit der zu 50\% die Vitalität reduzierende Konzentration von Fen und Dox inkubiert. Versuchsgruppen: Kontrolle, Fen, Dox, Fen+Dox. Im Anschluss wurde die Vitalität mit dem MultiTox-Fluor Multiplex Cytotoxicity Assay bestimmt. Differenziell regulierte Proteine wurden mittels $2 \mathrm{D}$-Differenz Gelelektrophorese (2D-DIGE) und Massenspektrometrie identifiziert. Die real time PCR (RT-PCR) diente zur Aufklärung der Regulationsebene dieser Proteine sowie der Expressionsprofile von Zellzyklusregulatoren und bekannter Apotose- und Differenzierungsmarker. Ergebnisse: Die 6tägige Einzel- bzw. Kombinationsgabe von Fen und Dox führte zu folgenden Vitalitätsraten bei SH-SY 5 Y-Zellen: Fen $60 \pm 2$.

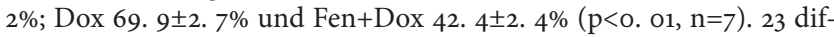
ferenziell regulierte Proteine $(\mathrm{p}<0$. 05; Average ratio $<-2$ or $>2 ; n=6$ ) konnten identifiziert werden. Davon waren UCHL1, KHSRP, ENO2, TPM2, MAPRE1 und GRB2 von besonderem Interesse. Die RT-PCR bestätigte eine Hochregulation von UCHL1 durch alle Behandlungsgruppen und eine Reduzierung von TPM2 durch Dox. Fen+Dox führten zu einer Hochregulation von Cyclin D1, p21 und dem Apoptosemarker Caspase 3. Die neuronalen Marker SNAP25 und Neurofilament waren erhöht, während die Schwannzellmarker GFAP und SiooB nicht beeinflusst wurden.

Zusammenfassung: Retinoide werden allgemein als differenzierende Agenzien betrachtet, die die Aktivität von Zytostatika inhibieren. Im Gegensatz dazu reduziert das neue synthetische Retinoid Fen in Kombination mit dem Zytostatikum Dox die Vitalität von SH-SY 5 Y-Zellen und induziert neuronale Differenzierung. Beide Substanzen alleine und in Kombination verändern die Genexpression auf Protein- und mRNAEbene. Die Hochregulation von UCHLı konnte als selektives Ziel der Kombinationstherapie von Fen und Dox identifiziert werden. 


\section{DGKCH-FV-07}

Nikotin erhöht das Risiko von Insuffizienzen an Darmanastomosen

G. Frongia', C. Mogler'², A. Semaan'1, B. Campos³ , P. Romero' ', S. Holland-

Cunz ${ }^{1}$

${ }^{1}$ Chirurgische Universitätsklinik, ${ }^{2}$ Pathologisches Institut, ${ }^{3}$ Neurochirurgische Klinik

Einleitung und Fragestellung: Die Angiogenese ist ein wichtiger Faktor der Wundheilung von Darmanastomosen und wird durch eine Balance aus pro- und anti-angiogenetischen Einflüssen reguliert. Das Alkaloid Nikotin wirkt proangiogenetisch durch die Stimulation von nicht-neuronalen Acetylcholin-Rezeptoren, wird jedoch als Bestandteil von Tabakrauch auch mit Wundheilungsstörungen in Zusammengang gebracht. Ziel dieser Studie war es die Nikotin-Effekte auf die Angiogenese und Heilung von Dünndarm-Anastomosen im Tiermodell zu untersuchen.

Material und Methoden

Mittels subkutan-implantierter osmotischer Pumpen wurden SD-Ratten kontinuierlich mit Nikotin $(6 \mathrm{mg} / \mathrm{Kg} / \mathrm{Tag})$ (Medikamentengruppe) bzw. mit $\mathrm{NaCl}$ 0,9\% (Kontrollgruppe) behandelt. In standardisierter Nahttechnik wurde das distale Ileum anastomosiert. Nach 3 und 10 Tagen wurden aus beiden Gruppen jeweils $n=5$ Tiere getötet und die intraabdominelle Adhäsionen bestimmt sowie mittels Messung der Bursting-Pressure die mechanische Stabilität der Anastomose gemessen. Nach histologischer Aufarbeitung und Immunfärbung wurden zur Quantifizierung der Angiogenese im Anastomosen-Bereich $\mathrm{CD}_{31}$, Ki67, VEGF und VEGF-Rezeptor 1 und 2 positiven Gefäße bestimmt. Ergebnisse: Die Gruppen waren homogen bezüglich Gewicht der Tiere und Operationsdauer. In der Nikotin-Gruppe waren am 10. Tag die Anzahl CD31-positiver Gefäße signifikant erniedrigt $(\mathrm{p}=0,031)$ und die Bursting-pressure der Anastomosen vermindert $(\mathrm{p}=0,13)$. Die intraabdominellen Adhäsionen waren sowohl am 3. als auch am 10. Tag in der Nikotingruppe vermehrt ( $\mathrm{p}=0,12$ bzw. $\mathrm{p}=0,57)$.

Die weiteren Parameter ergaben keine signifikanten Unterschiede ( $\mathrm{p}>0,05)$.

Diskussion: Aufgrund nachgewiesener proangiogenetischer Effekte könnte Nikotin von therapeutischer Bedeutung an Darmanastomosen sein. Diese Effekte gilt es gegenüber ebenfalls nachgewiesenen heilungshemmenden Effekten dieses Alkaloids abzuwägen. An Darmanastomosen liegen bisher keine Untersuchungen zur Nikotinwirkung vor. Unsere Ergebnisse dieser Pilotstudie zeigen eine durch Nikotin signifikant erniedrigte Anzahl an CD31-positiven Gefäßen im Anastomosenbereich als auch reduzierte Bursting-pressure der Anastomose sowie die vermehrte Tendenz zur Bildung von intraperitonealen Adhäsionen. Trotz geringer Fallzahl konnte beobachtet werden, dass perioperatives Nikotin assoziiert ist mit einer Beeinträchtigung der Angiogenese und Reduzierung der mechanischen Reissfestigkeit der Darmanastomose. Weitere postoperative Komplikationen sind durch die zunehmend gebildeten intraperitoneale Adhäsionen möglich.

Schlussfolgerung

Nikotin zeigt im Tiermodell wundheilungshemmende Effekte auf die Darmanastomose und kann zu vermehrten postoperativen Komplikationen führen.

\section{DGKCH-FV-08}

\section{Risiken und Nebenwirkungen der Propranolol - Therapie juveniler} Hämangiome.

E. Lau', S. Schoof ${ }^{2}$, M. Sinnig' ', J. Kuebler', B. Ludwikowski', B. Ure'2 , C. Engelmann $^{2}$

${ }^{1}$ Kinderkrankenhaus auf der Bult, ${ }^{2}$ Kinderklinik der Med. Hochschule

Fragestellung: In den letzten zwei Jahren wurde die Therapie juveniler Hämangiome durch die Verwendung von Propranolol revolutioniert. Trotz spärlicher Datenlage hat die enorme Effektivität zu einer allgemeinen Verbreitung dieser Behandlung geführt. Die Behandlung mit Propranolol gilt als sicher und nebenwirkungsarm. Der Fokus die- ser Arbeit liegt auf den potentiellen Nebenwirkungen der Propranololtherapie.

Material und Methode: Im Zeitraum von Nov. 2008 bis Feb. 2010 wurden 35 Patienten mit juvenilem Hämangiom mit Propranolol behandelt. Das Behandlungsschema beinhaltete eine stufenweise Erhöhung der Dosis über 2 Tage mit einer Enddosis von $2 \mathrm{mg} / \mathrm{kg} / \mathrm{d}$. In dieser Zeit wurden die Patienten mittels Monitor, RR-Kontrollen, Herzecho, Langzeit-EKG und wiederholten Blutzuckerbestimmungen überwacht. Die auftretenden Komplikationen wurden retrospektiv analysiert. Als Nebenwirkungen wurden rezidivierende Bradykardien unter $60 / \mathrm{min}$, EKG-Veränderungen insbesondere Reizüberleitungszeiten, Blutdruckabfall mit MAD unter $40 \mathrm{mmHg}$ sowie allgemeine Veränderungen im Verhalten definiert.

Ergebnisse: Die beobachteten Nebenwirkungen (bei 7 Patienten) umfassten Bradykardien in einem Fall, arterielle Hypotension in einem Fall, AV Blöcke unterschiedlicher Ausprägung in 4 Fällen, sowie Appetitlosigkeit und Unruhe in einem Fall, woraufhin die Eltern die Therapie abbrachen. Durch ein Langzeit-EKG wurde ein durch Propranolol induzierter, intermittierend auftretender $\mathrm{AV}$-Block $\mathrm{III}^{\circ}$ mit assoziierter 2sec. Asystolie bei einer ansonsten unauffälligen Patientin diagnostiziert, der einen Abbruch der Therapie bedingte. Die anderen Nebenwirkungen sistierten nach Dosisreduktion bzw. Adaptationsphase.

Diskussion: Die meisten Kinder tolerierten die Therapie mit Propranolol ohne signifikante Nebenwirkungen. Dennoch müssen die möglichen Nebenwirkungen beachtet werden. Aufgrund unserer Erfahrungen empfehlen wir, vor Beginn der Therapie und im Rahmen der Dosissteigerung mögliche kardiale Rhythmusstörungen durch ein LangzeitEKG zu erfassen.

Schlussfolgerung: Trotz hoher Effektivität, einfacher Anwendung und geringen Nebenwirkungen erscheint die Propranololtherapie nur sicher, wenn potentielle Risikopatienten erkannt werden.

\section{DGKCH-FV-09}

Wertigkeit des MCU in der Refluxdiagnostik - Gibt es einen Zusammenhang zwischen dem Grad des Refluxes im MCU und der Aufspülbarkeit des Ostiums?

M. Schäfer, H. Beyer

Cnopfsche Kinderklinik

Einführung: Die endoskopische Unterspritzung des Vesicorenalen Refluxes (VRR) nach radiologischer Diagnostik mittels MCU ist das etablierte Standardvorgehen bei dieser Erkrankung. Das Auftreten von rezidivierenden Harnwegsinfekten bei Patienten mit unauffälligem MCU führte zur Einführung des Begriffes „okkulter Reflux“, der sich durch das Auftreten eines VRR im zystoskopisch gesteuerten, direkt auf das Ostium gerichteten Spülstrahl zeigte, bei dem sich das Ostium regelhaft aufspülen ließ. (Rubenstein et al. 2003, Edmondson et al. 2006). Die Behandlung dieses „okkulten“ Refluxes mittels Unterspritzung zeigte eine signifikante Reduktion von fieberhaften Harnwegsinfekten und somit eine klinische Relevanz (Hagerty et al. 20o8). Es stellt sich die Frage, ob die Aufspülbarkeit des Ostiums (engl.: hydrodistention) eine bessere Diagnostik des VRR ermöglicht. Daher wurde die Aufspülbarkeit standardisiert (Kirsch et al. 2008), indem nach vereinheitlichter Durchführung eine Einteilung der Aufspülbarkeit in die Grade o - 3 vorgenommen wurde. Ein Zusammenhang der Aufspülbarkeit mit dem Grad des VRR im MCU wurde nachgewiesen (Kirsch et al. 2009). Diese Studie untersucht die Frage, ob sich die Aufspülbarkeit des Ostiums bei Patienten mit „okkultem“ Reflux signifikant von der Aufspülbarkeit bei Patienten mit nachgewiesenem Reflux im MCU unterscheidet.

Methoden: Im Zeitraum von 01/o9 bis 04/10 wurden bei allen Patienten, die wegen im MCU nachgewiesenem Reflux (43 Patienten mit insgesamt 54 refluxiven renoureteralen Einheiten (RUE)) und „okkultem“ Reflux (44 Patienten) einer Zystoskopie mit konsekutiver Unterspritzung zugeführt wurden, die Aufspülbarkeit der Ostien in der Gradeinteilung nach Kirsch bestimmt. Das durchschnittliche Alter betrug bei 
Patienten mit MCU-Reflux 5,3 Jahre (0,2 - 22,2 Jahre), bei Patienten mit „okkultem“ Reflux 6,4 Jahre (1,4-16,8 Jahre).

Ergebnisse: Der durchschnittliche Grad der Aufspülbarkeit der refluxiven Ostien bei Patienten mit MCU-Reflux 2,18. Bei nicht refluxiven Ostien betrug der durchschnittliche Grad der Aufspülbarkeit 1,25. Die verschiedenen Grade des MCU-VRRs unterschieden sich nicht signifikant im Grad der Aufspülbarkeit (VRR I': 2,11; VRR II': 2,20; VRR III $^{*}$ : 2,27; VRR IV ${ }^{\star}: 2,00$; VRR V ${ }^{\star}: 2,33$ ). Der durchschnittliche Grad der Aufspülbarkeit aller Ostien bei Patienten mit „okkultem“ Reflux betrug 2,13 .

Schlussfolgerungen: Eine Korrelation von Aufspülbarkeit des Ostiums mit dem Vorhandensein eines VRR im MCU konnte bestätigt werden. Die Aufspülbarkeit ist auch bei geringen VRR-Graden ähnlich hoch wie in hohen VRR-Graden, so dass eine Korrelation zum Grad des VRR nur als sehr schwach anzunehmen ist. Bei Patienten mit „okkultem" Reflux, bei dem per definitionem alle Ostien betrachtet wurden (im Unterschied zu Patienten mit MCU-Reflux, bei denen nur die refluxiven Ostien betrachtet wurden!), zeigte sich kein signifikanter Unterschied.

Diese Ergebnisse deuten darauf hin, dass das MCU in der Refluxdiagnostik das Auftreten eines klinisch bedeutsamen VRR unterschätzt und zu falsch-negativen Ergebnissen führen kann, was wiederum zu einer längeren Dauer bis zur erfolgreichen Behandlung der rezidivierenden Harnwegsinfekte führen könnte (höheres Alter der Patienten mit „okkultem“ 'Reflux zum Zeitpunkt der Zystoskopie!). Auf der anderen Seite ist davon auszugehen, dass die alleinige Beurteilung der rezidivierenden Harnwegsinfekte nach der Aufspülbarkeit des Ostiums zu einem „overtreatment" führt.

\section{DGKCH-FV-10}

Behandlung juveniler und aneurysmatischer Knochenzysten bei Kindern mit dem Gravitational Platelet Separation (GPS) ${ }^{\circledR}$ - System

M. Kaiser, M. Rapp

Universitätsklinikum Schleswig-Holstein

Einleitung: In der Behandlung juveniler und aneurysmatischer Knochenzysten existieren verschiedenste Therapiekonzepte, welche mit einer unterschiedlich hohen Rezidiv- und Persistenzrate vergesellschaftet sind. In Einzelfällen konnte die Kombination der elastisch stabilen intramedullären Nagelung (ESIN- Osteosynthese) mit einem künstlichen Knochenersatz (Orthoss ${ }^{\star}$ ) und autologem thrombozytenreichen Plasma (GPS ${ }^{\bullet}$ - System) sehr gute radiologische und funktionelle Ergebnisse nachweisen. Die vorliegende Studie zeigt die langfristigen Behandlungsergebnisse bei Kindern auf.

Methode: Prospektiv wurde allen Kindern mit Knochenzysten (juvenil oder aneurysmatisch) nach pathologischer Fraktur oder frustraner vorheriger Behandlung die Kombinationstherapie mit elastisch stabiler intramedullärer Nagelung (zwei Titannägel der Firma Santech Nord), künstlichem Knochenersatz (Orthoss ${ }^{\circledR}$ der Firma Geistlich) und autologem thrombozytenreichen Plasma, hergestellt mit dem kommerziell erhältlichen Gravitational Platelet Separation (GPS) ${ }^{\circledR}$ - System der Firma Biomet Merck Biomaterials, angeboten.

Radiologische Kontrollen waren nach einem und sechs Monaten bis zur Metallentfernung geplant und wurden nach Capanna klassifiziert. Die Auswertung der Patientendaten beinhaltete vorherige Behandlungen, peri- und postoperative Komplikationen, weitere operative Eingriffe, die Dauer bis zur Metallentfernung sowie die funktionellen Nachuntersuchungsergebnisse.

Ergebnisse: Seit Februar 2007 wurden 14 Kinder (5 Mädchen, 9 Jungen) mit einem mittleren Alter von 11,8 Jahren (7-15 Jahre) in die Studie eingeschlossen, dabei handelte es sich um zehn juvenile und vier aneurysmatische Knochenzysten. Fünf Patienten wiesen eine frustrane vorherige Behandlung nach pathologischer Fraktur mit intramedullärer Nagelung und Kürretage oder künstlichem Knochenersatz auf, die anderen neun stellten sich mit akuten pathologischen Frakturen (sieben Humerus- und zwei Femurfrakturen) vor. Perioperative Komplikationen wie Infektion oder Revisionseingriffe traten nicht auf. Die radiolo- gischen Kontrollen zeigten nach sechs Monaten bei neun Patienten eine vollständige Heilung (Capanna I), bei zweien verblieb eine minimale Restzyste (Capanna II). Bei einem Patienten steht die radiologische Kontrolluntersuchung nach sechs Monaten noch aus. Die Metallentfernung konnte bei bisher zwölf Patienten nach sechs bis neun Monaten erfolgen, in einem Fall wünschte ein vierzehn jähriger Junge (Capanna II) eine simultane erneute GPS-Applikation um eine vollständige Ausheilung zu erreichen, eine weitere Metallentfernung ist bereits terminiert. Alle Patienten werden weiter klinisch nachuntersucht und zeigen gute funktionelle Ergebnisse. Refrakturen oder Rezidivzysten sind bisher nicht aufgetreten.

Schlussfolgerung: Autologes thrombozytenreiches Plasma (GPS) ${ }^{\circ}$ verbessert im Vergleich mit eigenen historischen Daten die Behandlung von Knochenzysten bei Kindern. Zur Therapieoptimierung trägt die verkürzte Behandlungsdauer mit Verzicht auf die komplizierten wachstumsbedingten Wechsel der intramedullären Nägel bei. Technisch scheint die Kürretage und vollständige Füllung der Knochenzyste mit künstlichem Knochenersatz z. B. Orthoss ${ }^{\circledR}$ und autologem thrombozytenreichem Plasma entscheidend zu sein. Aufgrund der vorliegenden Ergebnisse kann

diese Kombinationstherapie als ein Behandlungsarm im Rahmen einer Multi-Center-Studie eingesetzt werden.

\section{DGKCH-FV-11}

In-vivo-Regeneration von Dünndarm durch Biomaterialien und ZellMatrix-Konstrukte

K. Tafazzoli, Z. Gao, L. Wünsch

Universitätsklinikum Schleswig Holstein, Campus Lübeck

Hintergrund Ein ausgedehnter Verlust von Dünndarmgewebe führt zum Kurzdarm-Syndrom, dessen Morbidität und Mortalität unverändert hoch ist. Seit 1998 gibt es Versuche, Darmwand mit den Methoden des Tissue engineerings zu generieren. Besondere Probleme sind die schwierige Kultivierung intestinaler Zellen und das Fehlen geeigneter Biomaterialien. Die Regeneration kleinerer Defekte konnte durch die alleinige Verwendung von Biomaterialien erreicht werden. Die Behandlung größerer Defekte basiert auf der Herstellung von Zell-Matrix-Konstrukten, da die bislang verwendeten Materialien erheblich schrumpfen. Ziel unserer Untersuchungen ist die Identifikation geeigneter Biomaterialien. In einem zweiten Versuchsschritt soll gezeigt werden, ob die Besiedlung dieses Materials mit mesenchymalen Stammzellen zu eine besseren Regeneration der Darmwand führt. In einer ersten Versuchsserie werden unbesiedelte Matrizes gegeneinander verglichen. In einer 2 Versuchsserie werden unbesiedelte Biomaterialien mit Matrix-Stammzellkonstrukten verglichen. Vergleichsparameter sind die Regeneration des Wandaufbaus und die Schrumpfung. Methoden Versuch 1 Bei Wistar-Ratten erfolgte eine Laparotomie und das Ausschalten einer Jejunalschlinge aus der Darmpassage. Diese Darmschlinge wird in der Mitte durchtrennt und eine tubularisierte Matrix in die Mitte implantiert (s. Abb. 1). Es erfolgte jeweils eine Anastomose der Matrix mit einem gut durchbluteten Darmanteil an beiden Enden, und die Ausleitung der Jejunalschlingen als Enterostomata in die Bauchhaut. Es wurden 4 verschiedene Biomaterialen (Chondro-Gide, Matriderm, Integra und SIS) verwendet. Nach 4, 8 und 12 Wochen wurden die Tiere getötet und die Jejunalschlinge mit dem Darmregenerat entnommen, gemessen und immunhistochemisch und histologisch untersucht. Es erfolgte ein Nachweis der 4 verschiedenen Darmepithelzelltypen (Becherzellen, Enterocyten, Paneth-Zellen und enteroendokriner Zellen),von Stromazellen ( Fibroblasten) und immumkompeten Zellen (Makrophagen, T-Zellen und B-Zellen). Abbildung 1. Versuch 2 Die mesenchymalen Stammzellen werden aus dem Knochenmark gewonnen. Nach Aspiration des Knochenmarkes erfolgt eine Isolierung mittels Dichtegradienten- Zentrifugation und Zellkultur. Nach Besiedlung des Biomaterials erfolgt die Implantation des Zell-Matrix-Kostruktes analog wie bereits zuvor beschrieben. Nach 8 Wochen werden die Tiere getötet und die Jejunalschlinge mit dem Darmregenerat entnommen und histologisch untersucht. Erwartete Ergebnisse und Schlussfolge- 
rungen Aus anderen Anwendungen des tissue engineering ist bekannt, dass die Biomaterialien erhblichen Einfluss auf die Qualität der Regeneration haben. Versuch 1 sollte Unterschiede zwischen den getesteten Materialien aufzeigen. Versuch 2 sollte zeigen, ob die Besiedlung der Matrix mit mesenchymalen Stammzellen zu einer im Vergleich zum unbesiedelten Material verminderten Schrumpfung und verbesserten Regeneration führt. Beide Ergebnisse sollten zu einer Optimierung des inestinalen tissue engineerings führen.

\section{DGKCH-FV-12}

Reptilienassoziierte Salmonella Worthington-Infektion als Ursache einer abszedierenden Periorchitis bei einem Neugeborenen

K. Schwab, S. von Bismarck, B. Tillig

Vivantes Klinikum Neukölln

Kasuistik: Bei einem voll gestillten 10 Tage alten Neugeborenen mit einem geschwollenen, druckdolenten und sonographisch hyperperfundierten rechten Hoden sowie Trinkunlust wurde unter dem Verdacht auf eine Orchidoepididymitis eine i. v. antibiotische Therapie mit Ampicillin und Gentamycin eingeleitet. Nach initialer Besserung erfolgte wegen einer erneuten Befundzunahme eine operative Hodenfreilegung. Diese zeigte eine eitrige Periorchitis. Im Abstrich konnten als Erreger Salmonellen vom seltenen Serotyp Worthington nachgewiesen werden. Die Periorchitis heilte im Weiteren unter einer resitogrammadaptierten Behandlung mit einem Cephalosporin der III. Generation komplikationslos ab.

Bei gezielter Befragung gaben die Eltern an, zuhause in einem Terrarium mehrere Reptilien, darunter auch Bartagamen, zu halten. Im Kot einer der Bartagamen konnten ebenfalls Salmonellen vom Serotyp Worthington nachgewiesen werden. Die Reptilien wurden aus dem Haushalt entfernt.

Diskussion: Reptilienassoziierte Salmonelleninfektionen bei Kleinkindern, vorwiegend Säuglingen, sind selten, konnten in den letzten Jahren allerdings zunehmend nachgewiesen werden. Im deutschen Referenzzentrum wurden in den Jahren 2006-2008 insgesamt 26 Fälle registriert. Hierbei handelte es sich um Infektionen mit Salmonella-enterica-Stämmen höherer Subspezies. Eine Infektion verursacht durch Salmonella enterica vom Subtyp Worthington wurde im Nationalen Referenzzentrum für Salmonellen und andere bakterielle Enteritiserreger (NRZ) am Robert-Koch-Institut zuletzt 2001 registriert und ist in der Literatur besonders im Zusammenhang mit Salmonellenausbrüchen bei Neonaten erwähnt. Reptilienassoziierten Salmonelleninfektionen gehen im Neugeborenen- und Säuglingsalter neben den nicht immer typischen Symptomen einer Gastroenteritis mit einem hohen Risiko für Sepsis, Meningitis oder einer Enzephalopathie einher. Reptilien sind inapperente Salmonellenträger mit einer Durchseuchung von bis zu 90\%. Bei der Übertragung der Salmonellen scheint dabei bereits eine geringe Keimzahl (<100 Keim) ausreichend zu sein, so dass schon ein indirekter Kontakt insbesondere bei Neonaten zu einer Infektion führen kann. Nur wenige Fälle von durch Salmonellen hervorgerufenen Orchitiden im Säuglingsalter sind in der Literatur bekannt, ein hämatogener Infektionsweg wird vemutet.

Schlussfolgerung: Bei Abszedierungen im Neugeborenen- und Säuglingsalter ist in der differentialdiagnostischen Abklärung auch die Möglichkeit einer Salmonelleninfektion zu erwägen und als mögliche Infektionsquelle Kontakt zu Reptilien anamnestisch zu erfragen. Auch ein nur indirekter Kontakt zwischen Neonaten und Reptilien ist unbedingt $\mathrm{zu}$ vermeiden. Salmonelleninfektionen bedürfen aufgrund der möglichen schweren Verläufe im Säuglingsalter einer resitogrammgerechten i. v. antibiotischen Therapie und ggf. auch einer chirurgischen Intervention.
DGKCH-FV-13

Minimalinvasive Chirurgie bei Ureterabgangsstenose: Retroperitoneoskopische Ureterolyse und Pyeloplastik per Minilap

M. Hunscha, M. Milosevic, R. Bitterlich, K. Riebe

DRK Kliniken Westend

Intention: Als Ursachen der Ureterabgangsstenose werden intrinsische Stenosen und von außen strangulierende Strukturen wie z. B. Gefäße unterschieden. Therapeutisch kommen verschiedene minimalinvasive Operationsstrategien zur Anwendung: die Operationstechniken umfassen die alleinige Ureterolyse mit Verlagerung des Ureters oder strangulierender Gefäße, die Pyeloplastik in transabdominaler Vorgehensweise, aber auch die technisch sehr anspruchsvolle retroperitoneoskopische Darstellung mit Pyeloplastik per Minilap. Studien belegen die Vorteile (kürzere Liegezeiten und geringere Invasivität) und guten Ergebnisse dieser laparoskopischen Operationstechniken gegenüber der offenen Pyeloplastik. Wir beschreiben die postoperativen Resultate der Pyeloplastik per Minilap sowie der reinen retroperitoneoskopischen Ureterolyse bei Ureterabgangsstenosen gemessen am sonografischen Verlauf.

Methoden: Zwischen November 2004 und Oktober 2009 führten wir an unserer Klinik aufgrund einer Ureterabgangsstenose 11 Pyeloplastiken per Minilap ( 5 Jungs, 6 Mädchen; Alter: 2-8 Jahre; mittleres Alter: 5 Jahre) sowie 13 retroperitoneoskopische Ureterolysen ohne Pyeloplastik (8 Jungs, 5 Mädchen; Alter: 2-15 Jahre; mittleres Alter: 7 Jahre) durch. Bei allen 13 der Ureterolysen sowie bei 4 der 11 Minilap-Patienten zeigte sich ursächlich ein abberrantes Polgefäß. Sonografisch präsentierten alle der insgesamt 24 Patienten präoperativ eine Hydronephrose mit NBKS Dilatation III.-IV. ${ }^{\circledR}$, der Verlauf wurde nach 1, 3, 6 und 12 Monaten sonografisch dokumentiert.

Resultate: Nach einem Jahr zeigten sich bei den 11 per Minilap operierten Patienten bei 8 ein deutlicher Rückgang der NBKS Dilatation, bei 3 Patienten zeigte sich die Dilatation intrarenal weiterhin in unverändertem Ausmaß. In einem Fall war im Verlauf eine Korrektur des DJ-Katheters bei Dislokation nötig. Bei den 13 Patienten mit retroperitoneoskopischer Ureterolyse zeigten 5 keine Veränderung des Ausmaßes der NBKS Dilatation, 4 waren deutlich zurückgegangen und 2 zeigten sich progredient dilatiert, so dass in einem Fall ein DJ-Katheter eingelegt werden musste, im anderen eine offene Pyeloplastik erfolgte. Mittlere Liegezeiten betrugen bei beiden Operationen 3-6 Tage.

Diskussion: Die Retroperitoneoskopische Darstellung und Pyeloplastik per Minilap stellt eine erfolgreiche Methode zur Therapie der Ureterabgangsstenose dar. Die Liegezeiten liegen unter denen mit offener Pyeloplastik operierter Patienten und die sonografischen Verläufe zeigen eine langfristige Reduktion der NBKS Dilatation. Eine alleinige retroperitoneoskopische Ureterolyse dagegen scheint weniger erfolgsversprechend zu sein. Ursachen hierfür können bleibende Impressionen am Ureter sein, welche durch eine alleinige Lösung von Gefäß und Ureter nicht behoben werden. Wir empfehlen daher, die Resektion des stenosierten Ureterabschnittes auch, wenn ursächlich „nur“ ein den Ureter komprimierendes Polgefäß vorliegt.

\section{DGKCH-FV-14}

\section{Narbenlose Laparoskopie im Kindesalter}

R. Böhm, R. Wachowiak, U. Bühligen, H. Till

Klinikum der Universität Leipzig AöR

Einleitung: Das Ziel der Single Incision Laparoscopic Surgery (SILS) ist eine annähernd narbenlose Chirurgie, weil die Operation lediglich über eine Inzision im Nabel durchgeführt wird. Die technischen Möglichkeiten reichen heutzutage vom einfachen Single-Port (SP) mit konventionellen, geraden Instrumenten bis zum Multi-Portsystem (MP) mit vorgebogenen Instrumenten. Für die Kinderchirurgie ist bisher weitgehend unbekannt, welche Technologien („tool box“) für welche Operationen sinnvoll erscheinen.

Methodik: Longitudinale Beobachtungsstudie aller SILS Eingriffe (SP und MP) von Januar 2009 bis April 2010. Zur „tool box“ gehör- 
ten: Single-Port System („Ei-Optik“) der Firma Wolf (5mm) mit 3,5mm Arbeitstrokar; Tri-Portsystem der Firma Olympus; unterschiedliche single- und double-bend Instrumente der Firmen Wolf, Olympus und Storz. Ferner retikulierende Dissektoren der Firma Novare. Als Beobachtungsparameter wurden intraoperative Daten (OP-Dauer, Komplikationen, Konversionen) und der postoperative Verlauf (Liegedauer, Komplikationen) berücksichtigt.

Ergebnisse: 17 Patienten wurden mittels SILS operiert, davon 5 mit SP (2 Varikozelenligaturen und 3 Leistenherniotomien) und 12 mit MP (7 Appendektomien, 1 Cholezystektomie, 1 Nierenzystendekortikation, 2 Ovarialzystenfensterungen (hierunter 1 Detorquierung bei stielgedrehtem Ovar), 1 Teratomexstirpation des Ovars.

Das durchschnittliche Alter der Patienten lag bei 13,5 Jahre (6-17 Jahre). Die mittlere Eingriffsdauer betrug: Appendektomien $59 \mathrm{~min}$, Ovarialeingriffe $69 \mathrm{~min}$, CHE und Nierendekortikation $85 \mathrm{~min}$. Keine intraoperativen Komplikationen, keine Konversionen. Als postoperative Komplikationen sahen wir 2 Wundheilungsstörungen am Nabel, welche keine operative Therapie benötigten.

Durchschnittliche Verweildauer: Die Herniotomien sowie die Varikozelenligaturen wurden als ambulante Eingriffe durchgeführt, Appendektomien 3,5 Tage, Ovarialeingriffe 4 Tage, Cholezystektomie und Nierenzystendekortikation 4 bzw. 2 Tage.

Schlussfolgerung: Mit der aktuellen „tool box“ können vor allem bei Schulkindern und Adoleszenten eine Vielzahl von SILS Eingriffen erfolgreich durchgeführt werden. Dabei sollte die Entscheidung zu SP oder MP von der Komplexizität des Eingriffes abhängig gemacht werden, insbesondere, wenn bimanuelle Manipulationen notwendig sind. Bevor die SILS-Technik allerdings auch Kleinkinder oder Säuglinge erreicht, sollte das Instrumentarium auf deren Geometrie angepasst werden. Schlussendlich untermauert diese Beobachtung nur, dass die SILS in der Kinderchirurgie zwar „feasible“ ist, aber noch lange nicht vorteilhaft sein muss. Dazu bedarf es nun kontrollierter Studien.

\section{Fast Track Kinderchirugie}

\section{DGKCH-FV-16}

Ist die primäre Pleuradrainage bei der operativen Korrektur einer kongenitalen Zwerchfellhernie beim Neugeborenen heute noch indiziert?

K. Zahn' ', S. Maier' ', T. Schaible'2, K. Reinshagen', L. Wessel'

'UMM Mannheim, ${ }^{2}$ Klinikum Mannheim

Die postoperative Entwicklung von relevanten Pleuraergüssen und Chylothoraces stellt eine frühe Komplikation nach der operativen Korrektur kongenitaler Zwerchfellhernien im Neugeborenenalter dar. Im Zeitalter der, evidence-based medicine' stellt sich zunehmend auch die Frage über Sinn und Unsinn primärer Pleuradrainagen zum Zeitpunkt des Zwerchfellverschlusses. Im Kinderzentrum Mannheim wurden bis zum Jahr 2005 routinemäßig Pleuradrainagen primär eingelegt. Seit 2006 geschieht dies nur, wenn sich intraoperativ bereits eine ausgeprägte Sekretion zeigt. Ansonsten werden im Bedarfsfall percutane Thoraxdrainagen sonographisch kontrolliert eingelegt.

Es wurden daher die Zeiträume 2000-2005 und 2006-2009 bezüglich der Inzidenz von Pleuraergüssen und Chylothoraces nach Zwerchfellhernienkorrektur sowie mögliche Risikofaktoren für deren Entstehung analysiert.

Im Zeitraum 2000-2005 traten bei 59 von 206 Patienten $(28,6 \%)$ therapiebedürftige Pleuraergüsse oder Chylothoraces auf, im Zeitraum 2006-2009 bei 34 von 190 Neugeborenen (17,9\%). Hierbei ließen sich große Zwerchfelldefekte mit der Notwendigkeit einer ECMO-Therapie und eines Patchverschlusses sowie die Herniation der Leber bei linksseitigen Zwerchfellhernien als signifikante Risikofaktoren identifizieren (ECMO: $p=0,0002$; Patch: $p=0,02$; liver up': $p=0,0002$ ). Das relative Risiko eines therapiebedürftigen Pleuraergusses oder Chylothorax in der ECMO-Gruppe betrug das Doppelte. Die Seite der Zwerchfell- hernie hingegen hatte keinen Einfluß auf das Entstehungsrisiko eines Chylothorax $(p=0,66) .15$ der 93 Patienten mit Chylothorax verstarben $(16 \%)$. Das Therapieschema umfasst die Ergußdrainage, Eiweißund Faktorensubstitution bei hohen Verlustmengen, eine adaptierte enterale bzw. rein parenterale Ernährung, Somatostatingabe und ggf. erneute chirurgische Intervention mit Versuch der Leckabdichtung. Das Einlegen einer primären Pleuradrainage zum Zeitpunkt des Zwerchfellverschlusses ist in der Hochrisikogruppe (ECMO-Therapie, Patchverschluß und intrathorakale Lage der Leber bei linksseitigen Zwerchfellhernien) gerechtfertigt, kann in unserem Haus aber etwa $80 \%$ der Neugeborenen mit kongenitaler Zwerchfellhernie erspart werden.

\section{DGKCH-SY-06}

Fast Track-Kooperationen - Steuerung zur Qualität als Herausforderung im Versorgungsmangagement der Deutschen Krankenversicherung AG

E. Slany

Deutsche Krankenversicherung AG - ERGO-Versicherungsgruppe

Als Nummer 1 in Europa ist die DKV „Das Unternehmen Gesundheit!“ und bietet als erster privater Krankenversicherer die zukunftsweisende Gesamtlösung: Private Krankenversiche-rung, Gesundheitsservice und medizinische Versorgung aus einer Hand. Dieser Idee entspre-chend werden in der Abteilung „Medizinische Beratung“ der DKV auch von Ärzten Projekt-ideen auf den Weg gebracht, Kunden zu einer medizinischen Beratung auf dem neuesten Stand der Wissenschaft zu steuern. Der Bruch mit chirurgischen Traditionen und Ritualen durch systematische Forschung zur Ver-ringerung der perioperativen Stressbelastung und Verbesserung der postoperativen Rekonva-leszenzbedingungen in der Arbeitsgruppe um den dänischen Abdominalchirurgen Henrik Kehlet war Anlass für eine umfasssende Literaturrecherche. Deutsche Studien zur Umsetzung der FT- Idee in Viszeral- und Kinderchirurgie zeigten eine gute Patientenakzeptanz und Ergebnisqualität in FT-Zentren. Umfragen unter deutschen Chirurgen ergaben aber Mängel und Schwächen in der FT-Umsetzung in der Breite der Versorgungskliniken. In einer eigenen Publikation wurden versicherungsmedizinische Aspekte der FT-Konzepte analysiert. Da Vorteile in Prozess- und Ergebnisqualität sowohl für Patieten als auch Versicherer herausgestellt werden konnten, eröff-nete sich für die Abteilung „Strategisches Gesundheitsmanagement" ein neues Thema für die Steuerung von Kunden: „Chirurgie auf der Schnellspur“. Zusammen mit den deutschen Prota-gonisten der FT-Strategien in Viszeral- und Kinderchirurgie, Prof. Schwenk und Prof. Ure, wurden Versorgungsnetzwerke von FT-Abteilungen geschaffen, die bereits in Studien ihre Kompetenz bewiesen hatten bzw. überprüfen wollten.

DKV-Kunden werden über die FT-Behandlung umfassend informiert. Interessierte Kunden werden in der Behandlung in diesen Netzwerken vom Versorgungsmanagement der DKV begleitet. Die DKV unterstützt die Studien zur Qualitätsevaluation in diesen Netzwerken. Konzepte und Parameter der Studien, Steuerungsinstrumente und erste Erfahrungen werden zur Diskussion gestellt.

\section{DGKCH-SY-07}

Evaluation der Relevanz klinischer Parameter für eine optimierte Patientenversorgung durch kinderchirurgische Fast-Track-Verfahren M. Reismann, M. Arar, A. Hofmann, N. Schukfeh, B. Ure

Kinderklinik der Med. Hochschule

Fragestellung: In vorhergehenden Studien konnten wir die ausgezeichnete Eignung von Fast-track (FT)-Verfahren für die Kinderchirurgie zeigen. Das Ziel der aktuellen Studie war die differenzierte Untersuchung der Durchführbarkeit einzelner Fast-track-Parameter im Rahmen unterschiedlicher kinderchirurgischer Eingriffe in der Routine. Material und Methode: Von April 2009 bis April 2010 wurden alle stationären kinderchirurgischen Patienten in unserer Klinik erfasst und nach definierten Kriterien einer Behandlung gemäß unserer FT-Proto- 
kolle zugeführt. Zur Bewertung der Anwendbarkeit der FT-Parameter wurden prospektiv Erfolgskriterien festgelegt: ausreichende Analgesie, vollständiger Nahrungsaufbau, vollständige Mobilisation, Anwendbarkeit minimal invasiver Techniken, Vermeidung von Schläuchen, verkürzte stationäre Verweildauer im DRG-Vergleich, Fehlen von postoperativen Symptomen und Komplikationen, Eltern- und Patientenzufriedenheit. Lediglich Eingriffstypen mit einer Anzahl von mindestens fünf Operationen während des Untersuchungszeitraumes wurden ausgewertet.

Ergebnisse: Es konnten 10 verschiedene Eingriffstypen für 161 FT-Patienten definiert werden: Hypospadiekorektur $(n=29)$, Appendektomie $(n=18)$, Thorax-OP $(n=36)$, Pyeloplastik $(n=10)$, andere laparoskopische Eingriffe $(n=23)$, Tumorresektion $(n=9)$, Durchzug-OP bei M. Hirschsprung $(n=7)$, Kasai-OP bei Gallengangatresie $(n=8)$, Unterspritzung Ureterostium $(n=9)$, Darmeingriff $(n=12)$. Den Zielkriterien wurde im Rahmen nahezu aller Eingriffstypen bei der überwiegenden Mehrzahl der Patienten entsprochen: ausreichende Analgesie (mindestens $75 \%$ der Patienten, Ausnahme Tumorresektion 44\%), vollständiger Nahrungsaufbau (mindestens $62 \%$ ), vollständige Mobilisation (mindestens $80 \%$, Ausnahme Hypospadiekorrektur 31\%), postoperative Symptome (mindestens $78 \%$, Ausnahme Kasai-OP 50\%), Komplikationen (mindestens 75\%). Nachteile durch den Verzicht auf Katheter und Drainagen wurden nicht verzeichnet. Die Befragung der Eltern ergab für alle Gruppen eine ausgezeichnete Beurteilung (100\% mit Behandlung zufrieden bis sehr zufrieden). Die mittlere Verweildauer betrug 5,7 Tage und liegt somit unter dem Durchschnitt im DGR-System.

Diskussion /Schlussfolgerung

Für nahezu alle untersuchten FT-Parameter konnten wir für die in der Studie definierten Eingriffstypen eine gute Anwendbarkeit zeigen. Die rasche Mobilisation ist bei der Hypospadiekorrektur in der Mehrzahl der Fälle nicht realisierbar. Tumorpatienten und Patienten mit Gallengangatresie bedürfen hinsichtlich der analgetischen bzw. der antiemetischen Therapie eines von den verwendeten FT-Protokollen abweichenden Vorgehens.

\section{Samstag, 18. September 2010}

\section{E-Poster}

\section{DGKCH-EP-17}

Falldarstellung: Kongenitale sanduhrförmige Septierung der Gallenblase als Ursache für rezidivierende Gallenkoliken

M. Schäfer', R. Getto' , G. Hammersen', P. Wünsch², H. Beyer' ${ }^{1}$

${ }^{1}$ Cnopfsche Kinderklinik, ${ }^{2}$ Instut für Pathologie, Klinikum Nürnberg

Einführung: Gallenblasenfehlbildungen gehören zu den seltensten Organfehlbildungen. Klare Angaben zur Inzidenz fehlen. Als Begriffsbezeichnungen finden sich die "multiseptate gallbladder", die (einfach) septierte Gallenblase sowie die kongenitale Sanduhrstriktur der Gallenblase.

Methoden: Wir berichten über einen 16-jährigen Jungen türkischer Abstammung, der sich mit akuten kolikartigen Oberbauchbeschwerden vorstellte. Ähnliche Episoden bestanden bereits mehrfach vor ca. zwei Jahren, eine internistische Untersuchung habe damals keine Ergebnisse gezeitigt. Dem Patienten war nahegelegt worden, sich in kinder- und jugendpsychiatrische Behandlung zu begeben. Laborchemisch fanden sich jetzt mäßig erhöhte Cholestaseparameter. Sonographisch zeigt sich eine echoarme zystische Struktur direkt neben der Gallenblase. Unter dem Verdacht einer Choledochuszyste wurde zunächst eine ERCP durchgeführt, die unauffällige Gangverhältnisse des Ductus choledochus und des Ductus cysticus zeiget. Die Gallenblase selbst wies eine zipfelige Ausziehung auf, die aus den Bildern nicht erklärt werden konnte. Weder in der Sonographie noch in der ERCP fanden sich Hin- weise auf Konkremente. In Anbetracht der Klinik wurde die Indikation zur laparoskopischen Cholezystektomie gestellt.

Ergebnisse: Intraoperativ fand sich eine septierte Gallenblase, die auf Grund der Einschnürung wie eine kongenitale Sanduhrgallenblase imponierte. Der distale Teil der Gallenblase war wie nach einer stattgehabten Cholecystitis mit dem Omentum verwachsen, während der proximale Anteil sich reizlos darstellte. Die histologische Untersuchung bestätigte die Diagnose. Konkremente ließen sich nicht finden. Der postoperative Verlauf war unauffällig.

Schlussfolgerungen: Bei sonographisch auffälligen zystischen Strukturen im rechten Oberbauch sollte auch an eine septierte Gallenblase bzw. eine Gallenblasenfehlbildung (Sanduhrgallenblase) gedacht werden. Die Indikation zur laparoskopischen Cholezystektomie, die auch bei dieser abweichenden Anatomie gut durchzuführen ist, besteht bei entsprechender Klinik.

\section{DGKCH-EP-18}

Die PCNL (Perkutane Nephrolitholapaxie) zur Behandlung der Nephrolithiasis auch im Säuglingsalter

W. Kluwe', D. Ackermann²

${ }^{1}$ Inselspital Bern, ${ }^{2}$ Hirslanden-Klinik Aarau

Die Nephrolithiasis im Kindesalter ist mit einer Inzidenz von ca. 1\%o in Europa selten. Dabei sind ca. 50\% der Kinder jünger als 6 Jahre und ca. 10\% im Säuglingsalter.

Es besteht je jünger der Patient eine steigende individuelle wie gesundheitspolitische Bedeutung. Die Rezidivrate beträgt bis zu 60\% und es kommt sehr selten zu Spontanabgängen. Die vergleichsweise hohe Inzidenz an akuten Verschlüssen kann bereits nach Wochen einen Funktionsverlust der betroffenen Niere nach sich ziehen. So sind eine dauerhafte Betreuung und oft lebenslange metaphylaktische Massnahmen notwendig.

Die ESWL ist die Therapie der ersten Wahl. Jedoch muss sie im Säuglings- und Kleinkindalter in Narkose durchgeführt werden und ist durch die langen Bestrahlungszeiten wie auch die wirkende direkte Kraft durch die Stosswellen auf das Nierengewebe durchaus nicht atraumatisch und risikolos.

Gerade beim Säugling können kleine Konkrementbruchstücke schon zu einer akuten Harntransportstörung führen. Die offene Steinentfernung aber auch die PCNL stehen aus diesen Gründen als Alternativmethoden zur Verfügung.

Die PCNL ist die endoskopische Nierensteinentfernung durch transkutane Punktion der Niere. Dabei werden über einen direkten Zugang zur Niere Steine wie bei der URS desintegriert oder im Stück entfernt. Hierbei wird nach ultraschallgezielter Punktion der Niere der Punktionskanal aufgeweitet und über ein starres Endoskop die Steinbehandlung und direkte Entfernung durchgeführt. Nach der Operation wird für einige Zeit eine Nephrostomie (Nierenkatheter) im Nierenbecken belassen.

Im November 2007 führten wir bei einem Mädchen im 12. Lebensmonat bei einer Nephrolithiasis (Konkrement von $1 \mathrm{~cm}$ ) im Pyelon rechts eine PCNL durch.

Der postinterventionelle Verlauf war komplikationslos und bis zur letzten Kontrolle im Frühjahr 2010 zeigte sich kein Rezidiv und ein regelrechtes und symmetrisches Nierenwachstum.

Bei der alleinigen ESWL-Therapie beim Säugling und Kleinkind muss mit dem Verbleib von kleinen Konkrementen als Residuen mit der Notwendigkeit sehr engmaschiger Kontrollen gerechnet werden. Zusätzlich ist eventuell die Einlage einer Harnleiterschienung oder perkutanen Nephrostomie erforderlich. Im Säuglingsalter ist die Durchführung in Narkose und unter radiologischer Kontrolle notwendig und mit eigenen Risiken behaftet.

Im Sinne einer primär definitiven Therapie sollte die PCNL wie die offene operative Steinentfernung inklusive der direkten Korrekturmöglichkeit von Harnwegsanomalien als Alternativmethoden durch die betreuenden Kinderurologen bedacht werden. 
DGKCH-EP-19

Angst- und Schmerzprophylaxe für Kinder im Krankenhaus

R. Ehrentraut

St. Joseph-Stift Bremen

Die Ausgangslage: Kinder erleben ein Krankenhaus oft sehr bedrohlich. Die Größe des Gebäudes, die als unübersichtlich empfundenen Wege zu den Stationen, die Betriebsamkeit des Personals und die von medizinischen Notwendigkeiten geprägte Atmosphäre rufen bei ihnen nicht selten Hilflosigkeit hervor. Dazu kommt mitunter ein von Sorge geprägtes Umfeld (Eltern und Angehörige), deren eigene Nervosität vom Kind aufgenommen und reflektiert wird. So kann ein ungünstiger Ausnahmezustand für alle Beteiligten entstehen - in erster Linie aber für das Kind.

Fragestellungen: Mit welchen möglichst einfach umsetzbaren Methoden können Mitarbeiter einer Klinik bei chirurgischen Eingriffen auf die Befindlichkeiten von Kindern und Eltern vor einer Aufnahme ins Krankenhaus positiven Einfluss nehmen?

- Welche Auswirkungen hat eine gezielte nichtmedikamentöse Angstprophylaxe auf die kindliche Psyche, das Schmerzempfinden und den Genesungsprozess.

- Wie kann ein integratives Gesamtkonzept aussehen, dass den Bedürfnissen der Kinder Rechnung trägt, ihre Compliance verbessert, sowie Eltern vor, während und nach dem Krankenhausaufenthalt unterstützt.

Wissenschaftliche Grundlage: Eine Studie aus den USA belegt, dass nichtmedikamentöse Ansätze Ängste bei Kindern deutlich minimieren und den Genesungsverlauf positiv beeinflussen.

„Imagination reduziert postoperativen Schmerz bei Kindern“ (Huth et al.

). Bei Kindern im Schulalter wurde nach einer Tonsillektomie oder Adenoidektomie eine Verminderung von Schmerz und Angst durch den Einsatz von Imagination erreicht.

Interpretation und Umsetzung

Unter Berücksichtigung der Kernaussagen der Studie wurde das eigenständige, holistische Angst- und Schmerzprophylaxekonzept „DOLORES“ entworfen. Ort der Umsetzung: Ein Akutkrankenhaus (461 Betten), in dem jährlich ca. 550 Kinder überwiegend in der HNO-Abteilung behandelt werden.

Das Konzept beruht auf dem Gedanken der systemischen Wirkungsweise.

Protagonist ist die Figur „Schnobbl“, ein Phantasie-Wesen, das Kinder vor, während und nach Operationen begleitet. Kinder und Eltern werden gezielt mit einem besonderen Hörspiel und Infomaterialien auf den Klinikaufenthalt vorbereitet und mental eingestimmt. In der Klinik wird das Thema wieder aufgegriffen. „Schnobbl“ begleitet die Kinder durch „dick und dünn“. Neben der inhaltlich angepassten Gestaltung der Kinderbereiche, werden auch Teile des Hörspiels sowohl auf den Kinderstationen, als auch im Aufwachraum zur Anxiolyse und Entspannung eingesetzt.

Ergebnisse: Erste Befragungsergebnisse zeigen, dass das Konzept von Kindern und Eltern außerordentlich gut angenommen worden ist und die Zufriedenheit, im operativen Setting gestiegen ist. Im Aufwachraum lässt sich z. B. beobachten, dass die Kinder ruhiger wach werden und insgesamt stressärmer auf die Normalstation zurück verlegt werden können.

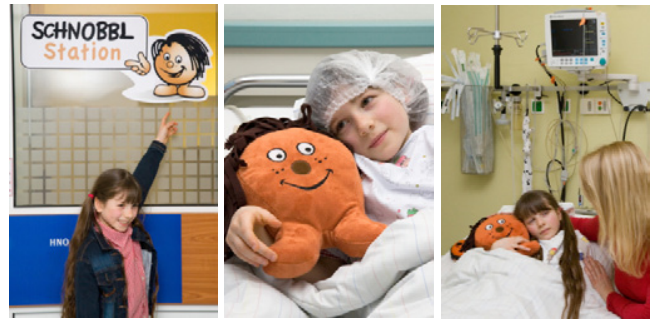

Diskussion: Der Einfluss auf das Schmerzerleben sollte zukünftig mit validen Messinstrumenten erfasst und in ein Qualitätssicherungssystem integriert werden.

Schlussfolgerung: Das „DOLORES“-Konzept lässt sich mit verhältnismäßig geringem Aufwand erfolgreich umsetzen, weil es an die tatsächlichen Bedürfnisse von Kindern und Eltern angepasst ist und darüber hinaus die Mitarbeiter im Klinikalltag unterstützt.

\section{DGKCH-EP-20}

Spinale Dysraphie assoziiert mit OEIS-Syndrom: Aspekte der Diagnose und Behandlung

C. Städtler, R. Cremer, M. Kellner, T. Boemers

Kinderkrankenhaus Amsterdamerstraße, Kliniken der Stadt Köln gGmbH

Neurospinale Dysraphien in Kombination mit urogenitalen Fehlbildungen sind häufig mit einer Analatresie assoziiert. Das Spektrum der begleitenden Fehlbildungen variiert mit dem OEIS-Syndrom als stärkste Ausprägungsform. Das Akronym OEIS steht für Omphalozele, Exstrophie (Blasenexstrophie/ Kloakenexstrophie), imperforierter Anus und spinaler Defekt.

Patienten: Es werden Daten von sechs Patienten mit spinaler Dysraphie (vier mit Myelomeningozele, zwei mit Lipomeningozele) und Analatresie, die in unserer Spina bifida Sprechstunde in Behandlung sind, präsentiert. Zwei dieser Patienten zeigen die kompletten Merkmale des OEIS-Syndroms, zwei weitere haben eine Kloakenexstrophie ohne Omphalozele und wieder zwei andere Patienten haben renale Fehlbildungen. Zwei der sechs Patienten haben einen Hydrozephalus. OEIS-Syndrom-Patienten benötigen häufig anspruchsvolle und wiederholte rekonstruktive Operationen (Blasenaugmentation, Mitrofanoff-Stoma, Colostoma, Durchzugoperationen, Omphalozelenverschluß, neurochirurgische Eingriffe). Insbesondere die Inkontinenzbehandlung ist sehr komplex und umfasst Probleme der Blasenkontinenz und -kapazität sowie der Stuhlkontinenz.

Diskussion: Das OEIS-Syndrom ist eine schwerwiegende Kombination von Anomalien, die zu einem neurologischen Defizit, ähnlich dem bei einer Myelomeningozele führen. Im Gegensatz zu Spina-bifida-Patienten leiden Kinder mit OEIS-Syndrom jedoch zusätzlich an funktionellen Beeinträchtigungen, die auf die Fehlbildungen des Urogenitaltraktes und des Anorektums zurückzuführen sind. Die adäquate Behandlung dieser Patienten erfordert daher ein strukturiertes Management, das bereits pränatal beginnen und in eine lebenslängliche Betreuung münden soll. Priorität muß dabei die Behandlung in spezialisierten Zentren mit multidisziplinären Therapieoptionen haben.

\section{DGKCH-EP-21}

Winkelstabile Implantate in der Kinderorthopädie Welche Indikationen gibt es?

J. Funk, R. Placzek

Charité - Universitätsmedizin Berlin

Einleitung: Moderne winkelstabile Implantate finden zunehmend Anwendung in der traumatologischen und orthopädischen Behandlung Erwachsener. Vereinzelt werden ihre Vorzüge auch in der Kindertraumatologie beschrieben. Bisher gibt es keine publizierten Untersuchungen zur Versorgung mit winkelstabilen Implantaten in der Kinderorthopädie.

Material und Methoden: Das Prinzip der winkelstabilen Platte bzw. des Fixateur interne beruht auf einer Gewindeverankerung der Schrauben in der Platte. Vorteilhaft ist dabei zum einen die höhere Primärstabilität und somit initiale Belastbarkeit und zum anderen die Möglichkeit der Schonung von Weichteilen und Periost, wodurch die biologischen Heilungsabläufe weniger gestört werden.

Anhand von Fallbeispielen aus dem Patientengut zweier kinderorthopädischer Abteilungen werden klinisch und radiologisch verschiedene Indikationen für eine Anwendung von winkelstabilen Platten gezeigt und der Vorteil gegenüber herkömmlichen Osteosynthesen dargestellt. 
Hüftgelenknahe Derotationen bei Patienten mit infantiler Zerebralparese können nach Osteosynthese mit winkelstabilen Implantaten sofort belastet werden, ebenso wie Extensionsosteotomien am Kniegelenk. Damit wird die motorische Entwicklung der Patienten deutlich weniger beeinträchtigt.

Bei ausgeprägtem Übergewicht (12J., 138kg) aufgrund eines POMC-Defekts war die Mobilisation nach fokaler Dome-Osteotomie und winkelstabiler Osteosynthese bei M. Blount sicher möglich, wie auch bei ansonsten gesunden Patienten mit kniegelenknahen Korrekturosteotomien aufgrund von Valgusfehlstellungen und Rotationsfehlern. Nach sprunggelenknaher Extensions- bzw. Derotationsosteotomie und entsprechender Osteosynthese konnte nicht nur bei Klumpfußpatienten sondern auch bei der schlechten Knochenqualität von MMC Patienten sofort mit der Belastung begonnen werden. Auch nach Versagen anderer Osteosynthesen kann mittels winkelstabiler Implantate eine Ausheilung herbeigeführt werden, wie die Versorgung einer Patientin mit PFFD, deren Fixateur externe herausgebrochen war, zeigt.

Ergebnisse: Implantatspezifische Komplikationen sind bei diesen Patienten nicht aufgetreten. Insbesondere wurde kein Implantatversagen beobachtet. Die Mobilisation war in allen Fällen gipsfrei und frühzeitig mit Belastung der Osteotomie innerhalb der ersten Woche möglich.

Diskussion: Winkelstabile Implantate sind nicht nur der Versorgung von Erwachsenen vorbehalten, sondern finden zunehmend Einzug in die Behandlung von Kindern und Jugendlichen. Bei korrekter Operationstechnik profitieren die jungen Patienten von dieser Technik, da sie in allen Fällen eine schnellere Belastung ermöglichen als mit herkömmlichen Platten oder Drähten. Des Weiteren kann auf eine Gipsimmobilisation verzichtet werden. Diese Vorteile sollten bei der Implantatwahl in Betracht gezogen werden insbesondere bei Patienten mit infantiler Zerebralparese, MMC oder anderen systemischen Erkrankungen, die mit verminderte Knochendichte bzw. erschwerter Mobilisation unter Entlastung oder Teilbelastung einhergehen. Klinische Studien müssen zeigen, ob die frühere Mobilisation verbunden mit kürzerer stationärer Behandlung und weniger aufwändiger physiotherapeutischer Nachbehandlung auch bei ansonsten gesunden Patienten die Versorgung mit den teureren winkelstabilen Implantaten rechtfertigen.

\section{DGKCH-EP-22}

Falldarstellung: Multiple Frakturen und wiederholte Episoden von nicht-bakterieller Osteitis bei einem Kind mit HSAN Typ IV - Diskussion der therapeutischen Optionen

M. Schäfer, T. Mika, H. Beyer

Cnopfsche Kinderklinik

Einführung: Die hereditäre sensorische und autonome Neuropathie (HSAN) Typ IV, auch als CIPA (congenital insisivity to pain with anhidrosis) bezeichnet, ist eine seltene autosomal-rezessive Erkrankung. Betroffene Kinder leiden an einer Anhidrosis, einer Schmerzunempfindlichkeit sowie Episoden von Hyperthermie.

Methoden: Wir berichten über den Fall eines sechsjährigen Mädchens mit dieser Erkrankung, die eine Tibiaschaftfraktur erlitt. Die Frakturheilung war extrem verzögert und führte zu einer zunehmenden Inaktivitätsosteoporose. In der Folge trat eine Reihe von weiteren Frakturen der unteren Extremität auf, die mit wiederholten Episoden von nichtbakteriellen Osteitiden einhergingen.

Ergebnisse: Sowohl die operative als auch die konservative Behandlung der Frakturen bei diesem Kind mit HSAN IV erwies sich als sehr schwierig. Die Ruhigstellung im Gips neigte durch die vorhandene Schmerzunempfindlichkeit stets zur Bildung von Druckstellen. Die ersten Episoden der nicht-bakteriellen Osteitis wurden als Osteomyelitis interpretiert und antibiotisch behandelt. Da keinerlei septische Ereignisse auftraten, wurde in der Folge darauf verzichtet.

Schlussendlich führte die Anfertigung spezieller orthopädischer Schienen zu einer zufriedenstellenden Situation, in der keine neuen Frakturen mehr auftraten.
Schlussfolgerungen: Bei Kindern mit HSAN Typ IV und Frakturen sollten die Immobilisationszeiten möglichst gering gehalten werden. Dies kann sich als besonders schwierig erweisen, da die Frakturheilung deutlich verzögert ist und Kinder mit dieser Erkrankung offenbar anfällig für eine Inaktivitätsosteoporose sind - mit der Gefahr von konsekutiven pathologischen Frakturen. Trotz des Risikos von Drucknekrosen sind orthopädische Schienen eine Option zur Verringerung des Frakturrisikos. Es sei zur Diskussion gestellt, ob eine Therapie mit Bisphosphonaten (Neridronat ${ }^{\circledR}$ ) möglicherweise ebenfalls eine Option zur Verringerung des Frakturrisikos ist.

\section{DGKCH-EP-23}

Das diagnostische Dilemma: Atypische mykobakterielle Lymphadenopathie

C. Staufner, M. Chmelnik, S. Holland-Cunz

Universitätsklinikum Heidelberg, Chirurgische Klinik

Die Lymphadenopathia colli ist ein häufiger Befund der pädiatrischen Praxis. Eine wichtige Differentialdiagnose unilateraler Lymphadenopathien ist die atypische Mykobakteriose. Die frühzeitige Diagnosestellung kann sich als schwierig erweisen, ist jedoch für einen komplikationsarmen Verlauf von großer Bedeutung.

Eine fächerübergreifende diagnostische und therapeutische Strategie ist zu fordern. Die Analyse eigener Fälle mit atypischer mykobakterieller Lymphadenopathie $(\mathrm{n}=7)$ zeigt hingegen ein heterogenes Vorgehen, in 5 Fällen war primär eine Inzision und Drainage erfolgt. Das diagnostische Vorgehen sowie die Therapie bei Verdacht auf atypische mykobakterielle Lymphadenopathie werden nach der aktuellen Literatur und anhand der eigenen klinischen Fälle kritisch diskutiert.

Die Lymphadenopathie ist die häufigste Manifestationsform einer atypischen Mykobakteriose im Kindesalter und betrifft vor allem Kleinkinder. Häufig ist die Diagnosestellung verzögert, eine Sicherung der Diagnose gelingt erst durch Gewinnung bioptischen Materials. Als effektivste Therapie hat sich die primäre komplette Exzision bewährt, sie ist der alleinigen antimykobakteriellen medikamentösen Therapie deutlich überlegen. Ein zweizeitiges Vorgehen bringt ein erhöhtes Risiko von Rezidiven, Fisteln und Keloidbildung mit sich. Außerdem ist dann eine antimykobakterielle Therapie mit Tuberkulostatika über mehrere Monate zu empfehlen.

Die Abgrenzung zur unspezifischen bakteriellen Lymphadenopathie kann insbesondere bei aufgetretener Einschmelzung schwierig sein. Eine hohe klinische Achtsamkeit ist bei unilateralen Lymphadenopathien gefragt, um bei Verdacht auf atypische Mykobakteriose frühzeitig die Indikation zur primären kompletten Exzision stellen zu können und eine Inzision und Drainage vermeiden zu können. Dabei sind eine Reihe wichtiger Differentialdiagnosen abzugrenzen, was einen hohen Anspruch an Interdisziplinarität bedeutet. Die Rolle von Bildgebung, Feinnadelbiopsie und Tuberkulin-Haut-Testung werden diskutiert. Es stellt sich die Herausforderung, atypische mykobakterielle Lymphadenopathien frühzeitig zu erkennen und direkt einer kompletten Exzision zuzuführen. Ein entsprechender Algorithmus wird aufgezeigt.

\section{DGKCH-EP-24}

Choledochuszystenresektion - wie früh ist früh genug? Komplikationen einer kongenitalen Choledochuszyste Typ IV a nach Todani nach initialer Teilresektion in der Neonatalperiode

E. Molinger', O. Kollmar², G. Dockter ${ }^{3}$, J. Rädle ${ }^{4}$, C. Meier ${ }^{1}$

${ }^{1}$ Klinik für Allgemeine Chirurgie, Viszeral-, Gefäß- und Kinderchirurgie, ${ }^{2} \mathrm{Kli}-$ nik für Allgemeine, Viszeral-, Gefäß- und Kinderchirurgie, ${ }^{3}$ Unversitätsklinik für Kinder und Jugendmedizin Gebäude 9, ${ }^{4}$ Klinik für Innere Medizin II

Einleitung: Bei der Choledochuszyste handelt es sich um eine seltene Erkrankung, die in der westlichen Welt mit einer Häufigkeit von ca. 1 : 15 ooo Lebendgeborenen auftritt. In den meisten Fällen wird die Diagnose in den ersten Lebenstagen gestellt, in manchen Fällen aber auch verspätet. 
Obwohl die Resektion der Choledochuszyste der Goldstandard der Therapie ist und bleibt, sind auch andere Therapiekonzepte angewendet worden. Diese wurden oft aufgrund der schwierigen anatomischen Verhältnisse bei sehr kleinen Säuglingen als Alternative angesehen.

\section{Fallpräsentation}

Anamnese: Wir präsentieren eine zum jetzigen Zeitpunkt 17jährige Patientin bei der postpartal eine $3,7 \mathrm{~cm}$ große Choledochuszyste Typ IV a nach Todani diagnostiziert wurde. Am fünften Lebenstag wurde die Zystenteilresektion und Rekonstruktion des Ductus choledochus mit Drainage in das Duodenum durchgeführt. Bis zum Alter von 15 Jahren war die Patientin beschwerdefrei. Im Alter von 16 Jahren kam es zu einem akuten Verschlussikterus und Cholangitis, mit massiver Aufweitung des D. choledochus bei Papillenstenose. Es erfolgte eine endoskopische Papillotomie und Stenteinlage in den DHC. Darunter kam es zu einer deutlichen Symptomatikbesserung. Vier Wochen später kam es zu einem erneuten Galleaufstau, es wurde erneut eine endoskopische Papillotomie durchgeführt. Ein Jahr später kam es erneut zu einem Galleaufstau und Papillenstenose. Eine endoskopische Eröffnung der Papille war nicht möglich, daher wurde die Indikation zur Choledochuszystenresektion gestellt.

Intraoperativ: Es findet sich ein deutlich erweiterter Ductus choledochus mit weit bis hinter das Pankreas reichender Choledochuszyste, es wird eine biliodigestive Fistel mit Hepaticojejunostomie nach Roux-Y vorgenommen.

Postoperativ: Der postoperative Verlauf gestaltet sich erfreulich, außer leichtgradig erhöhten Pankreaswerten kam es zu keinerlei Komplikationen, auch die ambulanten Kontrollen zeigen keine Probleme.

Diskussion: Der Goldstandard bei Choledochuszysten ist heutzutage die Zystenresektion mit biliodigestiver Fistel, die meist als Hepatojejunostomie vorgenommen wird. Jedoch gibt es Fälle, in denen die initiale Versorgung nicht unter idealen Bedingungen vorgenommen werden kann, so dass zu anderen Therapieoptionen, wie in dem beschriebenen Fall, gegriffen wird.

Wir stellen die Frage zur Diskussion, welches Vorgehen das Beste ist, falls eine definitive Versorgung der Choledochuszyste bei der initialen Operation nicht möglich ist. Es stellt sich insbesondere die Frage, welches das beste Alter ist, um die Zystenresektion mit biliodigestiver Fistel vorzunehmen. Das Risiko der malignen Entartung darf bei der Debatte natürlich nicht außen vor bleiben.

\section{DGKCH-EP-25}

Congenital Insensitivity to Pain with Anhidrosis (CIPA): Unklarer entzündlichen Prozess im rechten Talus nach Ausheilung einer bilateralen Calcaneus- Osteomyelitis bei einem siebenjährigen Jungen

M. Rapp, J. Spiegler, M. Kaiser

Universitätsklinikum Schleswig-Holstein

Einleitung: CIPA ist eine seltene autosomal rezessive Erkrankung, welche klinisch durch eine fehlende Schweißproduktion und komplette Analgesie bei ansonsten normaler Funktion der peripheren Nerven diagnostiziert und durch eine Mutation im neurotropen Tyrosinrezeptorkinase 1 Gen (NTRK1) verursacht wird. Die Patienten zeigen eine psychomotorische Retardierung, Selbstverletzungen und eine Temperaturregulationsstörung mit rezidivierenden Fieberschüben ohne Focus. Klinisch weisen sie eine deutlich gestörte Fraktur- und Wundheilung mit avaskulären Knochennekrosen und Osteomyelitiden auf. $\mathrm{Ob}$ diese Veränderungen direkt mit dem NTRK1- Defekt oder den vereinzelt beschriebenen zusätzlichen immunologischen Auffälligkeiten in der Ig-Synthese zusammenhängen, ist noch unklar.

Epikrise: Der Patient ist das dritte Kind seiner consanguinen Eltern. Sein jüngerer Bruder und er haben keine messbare Schweißproduktion sowie eine komplette Schmerzunempfindlichkeit, so dass klinisch die Diagnose CIPA gestellt wurde. Die humangenetische Untersuchung ist noch nicht abgeschlossen.

Bei schwerer psychomotorischer Retardierung erlitt der Junge durch massive Selbstverletzungen bisher drei offene Nagelkranzfrakturen, eine dislozierte Epiphysiolyse des proximalen Humerus (K-Draht-Os- teosynthese), mehrere kleinflächige Verbrennungen an den Händen sowie schwer therapierbare beidseitige Cornealulcera mit nachfolgender Sehbeeinträchtigung.

Im vierten und fünften Lebensjahr wurde der Patient wegen einer metachronen bilateralen Calcaneus-Osteomyelitis stationär behandelt. Diese konnte bei massiver Destruktion erst nach mehrfachem Debridement durch eine Kombination aus GPS ${ }^{\circledast}$, Fremdknochen und Spongiosaplastik zur Ausheilung gebracht werden.

Seit einem halben Jahr befindet er sich erneut mit einem unklaren entzündlichen Prozess im rechten Talus in unserer interdisziplinären kinderchirurgisch- immunologischen Behandlung. Neben einem Debridement, lokaler und intravenöser antibiotischer Therapie kam es erst in Kombination mit einer dauerhaften antiphlogistischen Therapie zum Stillstand der Knochendestruktion. Eine umfangreiche immunologische Diagnostik im humoralen und zellulären System konnte bislang keinen Immundefekt als Ursache der rezidivierenden entzündlichen Prozesse bei dem Patienten nachweisen.

Schlussfolgerung: Patienten mit CIPA leiden unter komplexen Beeinträchtigungen. Zur Klärung der veränderten Wundheilungsprozesse kann jedoch bisher nur auf Fallbeschreibungen und molekularbiologische Untersuchungen zurückgegriffen werden. Eine strukturierte interdisziplinäre Behandlung der Patienten durch Pädiater (Immunologie, Neuro- und Sozialpädiatrie), Orthopäden und Kinderchirurgen ist notwendig.

\section{DGKCH-EP-26}

Congenital Insensitivity to Pain with Anhidrosis (CIPA): Hypertrophe Kallusbildung und rezidivierende Weichteilinfektion nach Ellenbogen- und Unterschenkelschaftfraktur bei einem dreijährigen Jungen M. Rapp, J. Spiegler, M. Kaiser

Universitätsklinikum Schleswig-Holstein

Einleitung: CIPA ist eine autosomal rezessive Erkrankung, welche klinisch durch eine fehlende Schweißproduktion und komplette Analgesie bei ansonsten normaler Funktion der peripheren Nerven diagnostiziert und durch eine Mutation im neurotropen Tyrosinrezeptorkinase 1 Gen (NTRK1) verursacht wird. Die Patienten zeigen eine psychomotorische Retardierung, Selbstverletzungen und eine Temperaturregulationsstörung mit unklaren Fieberepisoden. Ebenso weisen sie eine deutlich gestörte Fraktur- und Wundheilung mit hypertropher Kallusbildung und Weichteilinfektionen auf. Die Pathomechanismen dieser Frakturheilungsstörung sind trotz Nachweis von NTRK1 auf knochenbildenden Zellen im Mausmodel nicht hinreichend geklärt.

Epikrise: Der Patient ist das jüngste Kind seiner consanguinen Eltern. Sein siebenjähriger Bruder und er haben keine messbare Schweißproduktion sowie eine komplette Schmerzunempfindlichkeit, so dass klinisch die Diagnose CIPA gestellt wurde. Die humangenetische Untersuchung ist noch nicht abgeschlossen. Die älteste Schwester starb im Alter von einem Jahr, ein neunjähriger Bruder weist bis auf eine massive Verhaltensstörung keine somatische Erkrankung auf.

Im dritten Lebensjahr erlitt der Patient eine geschlossene grob dislozierte Querfraktur des Unterschenkelschafts (ESIN-Osteosynthese) mit Kompartmentsyndrom und nachfolgender verzögerter Knochenheilung und notwendiger Hauttransplantation. Im Verlauf zeigte sich eine massive Kallusbildung des distalen Femurs als sekundäres Frakturzeichen und eine Osteomyelitis der Tibia, welche ebenfalls von einer hypertrophen Kallusbildung begleitet war und weitere operative Interventionen erforderlich machte. Nach wieder gewonnener Lauffähigkeit kam es zu einem unbeaufsichtigten Sturz mit nachfolgender Schwellung des linken Ellenbogens. Nachdem die Fraktur mit K-Drähten versorgt wurde, zog sich der Patient beim ersten Verbandwechsel die K-Drähte selbständig. Die erneute Osteosynthese der Fraktur des Condylus radialis mit Schraube und K-Draht hielt einem weiteren Sturz nicht stand. Intraoperativ stellte sich nun ein ausgedehnter Infekt des Weichteilgewebes dar, welcher eine mehrwöchige VAC- Therapie erforderlich machte. Sechs Monate nach Abschluss der Behandlung im Alter von vier Jahren ist eine eingeschränkte Extension/Flexion des Ellbo- 
gengelenkes von 0-30-90 und der Supination/Pronation mit 20-0-20 die Folge.

Schlussfolgerung: CIPA ist eine seltene aber sehr komplexe Erkrankung. Eine systematische Erfassung der Probleme in der Frakturheilung mit eventuellen Lösungsvorschlägen existiert leider nicht, so das nur auf Fallbeschreibungen und Tierexperimentelle Hypothesen zurückgegriffen werden kann.

Die wichtigste Differentialdiagnose der immer wieder auftretenden Frakturen stellt die Kindesmisshandlung durch Eltern oder ältere Geschwister dar. Aus diesem Grund sollte eine interdisziplinäre Betreuung der betroffenen Familien durch Neuro-/Sozialpädiater und Kinderchirurgen erfolgen.

\section{DGKCH-EP-27}

Nd:YAG-Laseranwendungen in der Kinderurologie

U. Hübner, S. Hirtsiefer

Kinderkrankenhaus Wilhelmstift

Nd: YAG-Laseranwendungen in der Kinderurologie:

Bei einigen Prozeduren am unteren Harntrakt hat sich die Anwendung von Lasern bewährt. Große Vorteile sind die zeitgleiche Blutstillung sowie der geringe Durchmesser von Laserfasern, die auch in Arbeitskanälen kleinster Endoskope anwendbar sind. So muss bei der Schlitzung von Urethralklappen nicht gewartet werden bis ein 9,5 Ch Resektoskop in die kindliche Urethra einführbar ist (bis zu 6 Monate). Ein 6 Ch. Endoskop mit Arbeitskanal erlaubt die Therapie dagegen direkt postpartal. Die genannten Vorteile beziehen sich auch auf die Eröffnung von Ureterocelen, die wir in 8 Fällen durchgeführt haben. Urethralklappen wurden bei 6 Kindern reseziert. Auch Urethrastrikturen (5), vasculäre Malformationen (1) und Blasenwand-Polypen (!) konnten erfolgreich mithilfe des Lasers behandelt werden. Wir stellen unsere Erfahrungen mit dieser Technik vor, zeigen die Anwendung und berichten über klinische Verläufe.

\section{DGKCH-EP-28}

Multifokaler inflammatorischer myofibroblastischer Tumor-Kasuistik C. Müller, W. Barthlen

Ernst-Moritz-Arndt-Universität

Wir berichten über einen 17jährigen Knaben der in der Diagnostik unspezifischer Oberbauchschmerzen in der Bildgebung solide Tumoren im Oberbauch, Pankreaskorpus und -schwanz sowie am Oberpol der linken Niere zeigte. Die Histologie der PE erbrachte einen ALK-1negativen inflammatorischen myofibroblastischen Tumor. Nach 4 Blöcken Chemotherapie mit Vincristin, Actinomycin D und Cyclophosfamid konnten im PET-CT eine deutliche Tumorregression und Verringerung der Stoffwechselaktivität nachgewiesen werden. Im Rahmen der second-look Operation konnten der mesenteriale Tumor und der Nierentumor organerhaltend versorgt werden. Aus dem makroskopisch unauffälligem Pankreas erfolgten Biopsien, welche histologisch deutlich regressive Veränderungen bzw. Fibrosen zeigten. In den po. Verlaufskontrollen über 18 Monate fand sich bisher kein Rezidivanhalt.

\section{DGKCH-EP-29}

Abdominoskrotale Hydrozelen (Hydrozele permagma) im Kindesalter - direkte OP-Indikation?

K. Kretschmer, H. Trenkner, R. Bitterlich, K. Riebe

DRK Kliniken Westend

Seit der Erstbeschreibung von Hydrozelen permagma im Jahre 1834 wird hin und wieder von Einzelfällen berichtet. Diese Form der Hydrozele zeigt unterschiedlichste Symptomatiken und ist zudem recht komplikationsträchtig, was wir anhand dreier Fallbeispiele verdeutlichen möchten.

Fall 1: 4-Monate alter Patient, welcher zunächst mit dem Verdacht auf einen bestehenden zystischen Tumor vorstellig wurde. Neben den beidseitigen Hydrozelen permagma, konnte intraoperativ außerdem eine deutlich hypoplastische Gonade dargestellt werden. Fall 2: 8-Monate alter Junge mit einseitiger abdominoskrotaler Hydrocele und Lymphödem des ipsilateralen Beines. Fall 3: 6-Monate alter Patient mit deutlich progressiven Hydrozelen beidseits und unilateral ausgeprägter Ausbreitung.

In der Literatur wurde neben beträchtlichen Schädigungen der Hoden z. B. auch von ipsilateral sekundär auftretenden Hydroureteronephrose berichtet.

Fazit: Aufgrund der geschilderten Komplikationen mit teilweise rasanter Progression und bisher nicht beschriebener Spontanregressionen empfehlen wir die sofortige, möglichst komplette Hydrozelen-Exstirpation über einen inguinalen Zugang als Mittel der Wahl.

\section{DGKCH-EP-30}

Intrauteriner Volvulus ohne Malrotation - Eine Gegenüberstellung E. Molinger ${ }^{1}$, G. Dockter ${ }^{2}$, G. Meyberg-Solomayer ${ }^{3}$, C. Meier ${ }^{1}$

${ }^{1}$ Klinik für Allgemeine Chirurgie, Viszeral-, Gefäß- und Kinderchirurgie, ${ }^{2}$ Unversitätsklinik für Kinder und Jugendmedizin Gebäude $9,{ }^{3}$ Klinik für Frauenheilkunde, Geburtshilfe und Reproduktionsmedizin

Einleitung: Ein intrauteriner Volvulus ist eine lebensbedrohliche Erkrankung. Ursachen hierfür sind vielfältig. Eine Kombination mit Malrotation ist häufig, ein Volvulus ohne Malrotationen ist jedoch selten. Eine weniger häufige Ursache ist ein Mekoniumileus bei Mukoviszidose. Dies kann zu intrauterinem Fruchttod oder zu vorzeitigen Wehen und Frühgeburtlichkeit führen. Wir stellen hier zwei Fälle gegenüber, in denen wir den Verlauf zweier Kinder mit intrauterinem Volvulus vergleichen. Bei Fall 1 handelt es sich um ein Mädchen mit kongenitalem Volvulus ohne Mukoviszidose, bei Fall 2 um einen Jungen mit nachgewiesener Mukoviszidose.

Fallpräsentation

Fall 1: Reifes weibliches Neugeborenes. Postpartal fiel ein deutlich überblähtes peritonistisches Abdomen mit reduziertem Allgemeinzustand des Kindes auf, es wurde blutiges Mekonium abgesetzt.

Sonographisch zeigte sich eine Raumforderung im rechten Unter-Mittelbauch ohne eindeutige Begrenzung durch die Darmwand, daneben multiple aufgeweitete mit Flüssigkeit gefüllte Darmschlingen und Pendelperistaltik. Laborchemisch waren die Entzündungswerte erhöht. Es zeigte sich volvulierter Darm Dünndarm mit Perforation, die Perforation war bereits alt. Darm wurde reseziert und ein Stoma angelegt. Der postoperative Verlauf zeigte sich regelrecht, es traten keine Probleme auf, das Mädchen konnte am 9. postoperativen Tag in ein peripheres heimatnahes Haus verlegt werden.

Fall 2

Im pränatalen Schall war in der 30. SSW eine Dünndarmdilatation aufgefallen, eine Kontrolle in der 33. SSW zeigte eine Volvulierung, Aszites sowie Polyhydramnion. Nach Sectio zeigte sich ein männliches Frühgeborenes in schlechtem Allgemeinzustand mit vorgewölbtem Abdomen und Peritonismus.

Es erfolgte die notfallmäßige Laparotomie, hier zeigte sich eine Mekoniumzyste bei einer Dünndarmvolvulierung von mindestens $40-50$ $\mathrm{cm}$ bis ca. $4 \mathrm{~cm}$ vor die Ileo-Zökalklappe. Es erfolgt die Resektion des nekrotischem Gewebes und die Anlage eines doppelläufigem Dünndarmstomas.

Der initiale postoperative Verlauf war regelrecht, es konnte jedoch eine Mukoviszidose nachgewiesen werden. Im Rahmen des Kostaufbaus kam es zu einer akuten Enterokolitis mit massivem Abgang blutiger Stühle über das Stoma, dieses war konservativ beherrschbar. Im Alter von 3 Monaten kam es erneut zu einer Ileussymptomatik, diesmal musste eine chirurgische Revision vorgenommen werden. Intraoperativ zeigten sich massive Adhäsionen und Darmwandverdickungen. Die Adhäsiolyse führte zu einer Besserung der Symptomatik und der postoperative Verlauf war regelrecht.

Diskussion: Der kongenitale Volvulus ist eine seltene Erkrankung. Als Ursachen kennt man die Malrotation, idiopathischen Volvulus, Darmwandveränderungen und Veränderungen der Mesenterialgefäße und auch die Mukoviszidose. Hier wurden zwei Fälle nebeneinander 
gestellt, in Fall 1, ein neugeborenes Mädchen mit idiopathischem Volvulus ohne Malrotation, in Fall 2, ein Volvulus durch Mekoniumileus. In beiden Fällen konnte eine rasche Diagnose gestellt werden und die notwendige chirurgische Therapie eingeleitet werden. Da der kongenitale Volvulus bei Mukoviszidose auch mit schwereren Verläufen assoziiert ist, sollte im Falle eines intrauterinen Volvulus immer auch an eine Mukoviszidose gedacht werden, insbesondere, wenn der Verlauf kompliziert wird.

\section{DGKCH-EP-31}

Intravaginales Rhabdomyosarkom: Iokale Spätfolgen und Therapieoptionen

M. Kapapa, D. Henne-Bruns, C. Leriche

Klinik für Allgemein-, Viszeral- und Transplantationschirurgie

Fragestellung: Das seltene vaginale Rhabdomysarkom im Kindesalter führt im Verlauf zu deutlicher Einschränkung der Lebensqualität u. a. durch Strahlenschäden, Verwachsungen und Vaginalen Stenosen. Wir stellen den Fall einer erfolgreichen Neo Vagina Anlage mit Spalthaut im Erwachsenenalter vor.

Material und Methode

Eine 30 Jahre alte verheiratete Patientin, welche im Alter von 3 Jahren wegen eines vaginalen Rhabdomysarkoms behandelt wurde, stellte sich wegen rezidivierender Neo-Vaginalstenosen vor. Im Kindesalter erfolgte die lokale Bestrahlung, sowie 4x VACA Zytostase. Im Verlauf kam es zu Strahlenschäden mit Kolitis und narbiger Stenose der Vagina. Es erfolgten auswärts mehrfache frustrane Versuche der Vaginalen Rekonstruktion: u. a. 2002 ein Transpositionslappen und 2006 die Anlage einer Kolon Neo- Vagina mit einer hoch- anterioreren Kolonanastomose. Bei erneuter Stenose und verminderter Lebensqualität erfolgte 2010 die Entfernung der Kolon- Neovagina und die Anlage einer Neo- Vagina mit Spalthautentnahme von Gesäß. Intraoperativ erfolgte die Einlage eines Silimed VaginalStent ${ }^{\circledR}$ und nach 5 Tagen wurde bei zweizeitigem Vorgehen die Stententfernung und die Introitusplastik durchgeführt. Wir leiteten die Patientin im selbstständigen Bougieren mit Hegarstiften und bei der Durchführung von vaginalen Spülungen an. Die Entlassung nach Hause erfolgte nach 14 Tagen.

Ergebnisse: Funktionell und kosmetisch ansprechendes Ergebnis, welches zur vollen Zufriedenheit der Patientin geführt hat. Das selbstständige Bougieren mit Hegarstiften bis Größe 30 ist problemlos möglich und in der klinischen Kontrolle zeigte sich ein reizloses Abheilen der Hautentnahmestellen. Die Kompressionsbehandlung mit Maßkleidung und Scar FX Silikonpflaster wurde begonnen.

Diskussion

Da die präoperative Vorbereitung und die langfristige klinische Nachbetreuung für den Behandlungserfolg entscheidend sind, sollte die Durchführung einer Korrekturoperation wie die Neo-Vagina Anlage Kliniken vorbehalten sein, die sich auf diese Art der Operationen spezialisiert haben.

Schlussfolgerung: Die Anlage einer Neo Vagina aus Spalthaut ist auch nach bereits mehrfachen operativen Korrekturen möglich. Das operative Vorgehen ist stets an die Patientin individuell anzupassen, abhängig vom Alter, Compliance und Anzahl der Voroperationen. Die regelmäßige postoperative Bougierung mit Hegarstiften ist für den dauerhaften Behandlungserfolg essentiell, da es ansonsten zu erneuten Stenosen kommt.

\section{DGKCH-EP-32}

Managment schwerer kindlicher Weichteilverletzungen

K. Bodenschatz, B. Hülße

Klinikum Nürnberg

Einführung: Ausgeprägte Weichteildefekte im Kindesalter sind oft Folge von Verkehrs- oder Maschinenunfällen. Auch gemeinsam mit gravierenden nichttraumatischen Knochen- und Weichteilinfekten sind keine hohen Fallzahlen zu erreichen. Grundlegende Erstmaßnahmen, wie Wundreinigung und -desinfektion, sowie chirurgisches
Débridement, Gefäß-, Nerven- und Frakturversorgung werden durch weitergehende Therapien wie z. B. Vakuum-Pumpenbehandlung, freie Lappenplastik, biologische Wundreinigung und Hauttransplantation ergänzt.

Fallbeispiele: 6-jähriges Mädchen, Polytrauma, osteosynthetische Versorgung des linken Beines bei Oberschenkelfraktur, Kompartementspaltung, Osteosynthese. Anschließende VAC Therapie, Hautdeckung. Nach Abschluss Derotationsosteotomie bei Rotationsfehlstellung. 7-jähriges Mädchen Teilamputation des Calcaneus und Abtrennung von Haut und Gewebe im Bereich des Fußes und des Unterschenkels. Im Verlauf Osteosynthese, Replantation, freier microvasculärer Lappen und Hauttransplantation.

Überrolltrauma eines 9-jähriges Mädchen mit Frakturen und massiven Decollement der Fußsohle. Amputation von D2-5, Osteosynthese, Weichteilersatz mit Integra und anschließender Spalthautdeckung. 1-jähriges Mädchen mit Meningokokkensepsis, ausgedehnte Nekrosen des Vorfußes und der Haut. Behandlung: Grenzzonenamputation, Vakuum-Pumpen-Behandlung, biologischen Wundreinigung, Hautdeckungen.

Die Bedeutung der raschen adäquaten kindgerechten Vorgehensweise wird eingehend dargestellt.

Heilverläufe werden komplett abgebildet.

\section{DGKCH-EP-33}

Das Popliteale Pterygium Syndrom - Fallbericht eines seltenen Syn-

droms

S. Höhne', K. Gerlach' ${ }^{1}$, R. Finke', D. Wand ${ }^{2}$

${ }^{1}$ Martin-Luther-UNiversität, ${ }^{2}$ Martin-Luther-Universität

Das Popliteale Pterygium Syndrom (PPS) ist eine seltene autosomaldominant vererbte Erkrankung ausgeprägter Variabilität und inkompletter Penetranz.

Ursache ist, ebenso wie beim Van der Woude Syndrom eine Mutation des IFR6 Gens. IFR6 gehört zu einer Familie von neun verschiedenen Transkriptionsfaktoren, die die Differenzierung und Proliferation von Keratinozyten regulieren.

Phäntotypische Merkmale des PPS sind orofaziale Fehlbildungen, muskuläre Störungen und Anomalien des Skelettsystems und der Genitalregion.

Die Häufigkeit dieses Syndroms wird in der Literatur mit 1: 300 ooo Geburten angegeben. Genitalfehlbildungen treten in ca. 50 \% der Fälle auf.

Wir möchten drei Patienten mit diesem Syndrom und begleitender Affektion des Genitalbereiches vorstellen, die in unserer Klinik behandelt wurden.

Dabei handelt es sich um ein Geschwisterpaar, die Schwester zeigte eine Aplasie der Labia majora, der Bruder litt unter einer Skrotumaplasie, einem Leistenhoden und einem intracruralen Pterygium. Der dritte Patient erhielt einen plastisch-chirurgischen Skrotalaufbau bei Skrotumaplasie.

Alle Patienten wiesen weitere Fehlbildungen wie ausgeprägte Pterygien, Syndaktylien und eine Lippen-Kiefer-Gaumenspalte und andere Dysmorphien auf.

Trotz der verschiedenen Missbildungen ist die Gesamtprognose dieser Patienten als gut einzustufen, die auftretenden Fehlbildungen können operativ mit einem guten kosmetischen und funktionellem Ergebnis versorgt werden, die mentale Entwicklung ist fast nie beeinträchtigt. Erst in kürzerer Zeit wurde der genetische Hintergrund dieser Erkrankung geklärt, obwohl sich auch in der älteren Literatur zahlreiche Beschreibungen dieses Syndrom finden.

Mit der Entschlüsselung eines ursächlichen Gens ist der Grundstein einer möglichen kausalen Therapie in der Zukunft gelegt. 
DGKCH-EP-34

QUIPSInfant - Qualitätssicherung in der postoperativen Schmerztherapie bei Kindern

T. Chaudhary', C. Lipinski', S. Wolke' ', S. Mescha ${ }^{2}$, W. Meissner ${ }^{2}$, F. Eckoldt ${ }^{1}$

${ }^{1}$ Friedrich Schiller Universität, ${ }^{2}$ Anästhesiologie- und Intensivmedizin

Einleitung: QUIPS (Qualitätssicherung in der postoperativen Schmerztherapie) ist ein multizentrisches, interdisziplinäres Benchmar-Projektzur Verbesserung der postoperativen Schmerztherapie bei Erwachsenen. QUIPSI ist ein Modul, welches aus dem Qualitätssicherungsprojekt bei Erwachsenen entwickelt wurde. Jährlich werden 100. ooo Kinder in Deutschland operiert. Postoperativ klagen 50-70\% aller Kinder über mäßige bisstarke Schmerzen. Postoperative Schmerzen beeinflussen sowohl das Operationsergebnis als auch die Patientenzufriedenheit. Deswegen ist eine systematische Evaluation der Schmerztherapie notwendig, um anhand der erhobenen Daten eine Verbesserung zu erzielen. Aktuell fehlt es jedoch an standisierten, evluierten Testinstrumenten für das Kindesalter.

Methoden: Zunächst wurde ein Fragebogen entworfen, mit dem alle Kinder im Alter von 4 bis 18 Jahren an einer chirurgischen Klinik am ersten postoperativen Tag befragt und relevante Prozessparameter erhoben wurden. Hier sollen die Ergebnisse der Pilotstudie vorgestellt werden.

Ergebnisse: Die Auswertung der ersten 200 Fragebögen zeigt, dass ca. 50\% aller Kinder mäßige bis starke Schmerzen angeben. Weitehin zeigte sich, dass bereits das bewusste Erheben von Schmerzdaten zu einer Verbesserung der Schmerztherapie führte.

Diskussion: Die Ergebnisse bestätigen einerseits die insuffiziente postoperative Schmerztherapie, zeigen aber auch, dass mit dem QUIPSIFragebogen ein solides Instrument zur Evaluation der Schmerztherapie im Kindesalter vorhanden ist. Interessant ist jetzt der Klinikvergleich.

\section{DGKCH-EP-35}

\section{Postoperative Bauchdeckenwicklung nach Nabelherniotomie: Sinn oder Unsinn? \\ E. Molinger, K. Lorch, C. Meier \\ Klinik für Allgemeine, Viszeral-, Gefäß- und Kinderchirurgie}

Einleitung: Die Behandlung einer Nabelhernie kann konservativ oder operativ erfolgen. Nach einer operativen Therapie des Nabelbruchs wird die Wunde von der Mehrzahl der Chirurgen nach dem Eingriff mit einem zirkulären Bauchdeckenverband versorgt. Durch diesen Verband soll die Entstehung von Rezidiven, Hämatomen, Seromen und anderen Komplikationen verhindert werden. Der Nutzen eines solchen postoperativ angelegten Verbandes ist jedoch durch keinerlei Daten gesichert und bewiesen. Auf Grund dessen wird in dieser Studie die Wirkung des postoperativ angelegten Bauchdeckenverbandes untersucht.

Material und Methoden: Für diese Analyse wurden zwei Patientenkollektive gebildet: ein Patientenkollektiv, bestehend aus 59 Patienten $(n=59)$, welches postoperativ mit einem Bauchdeckenverband und ein zweites Patientenkollektiv, bestehend aus 36 Patienten $(n=36)$, welches ohne Verband versorgt wurde. Diese beiden Fraktionen wurden im Hinblick auf den postoperativen Heilungsverlauf und entstehenden Komplikationen untersucht und miteinander verglichen. Hierfür wurden Daten von Krankenakten, Angaben einer telefonischen Patienten- beziehungsweise Elternbefragung und Aussagen von Kinderärzten anhand von Fragebögen ausgewertet.

Ergebnisse: Während dieser Studie trat in der Gruppe mit postoperativem Bauchdeckenverband bei einem Patienten eine erneute Schwellung im Nabelbereich auf. Im Patientenkollektiv ohne Verband entwickelte sich kein Rezidiv. Der Vergleich der beiden Patientengruppen im Hinblick auf das Auftreten von postoperativen Beschwerden, wie Schmerzen, Erbrechen, Obstipation und Komplikationen, wie Hämatom oder Serom, erbrachte keinen signifikanten Unterschied. Ferner wurde durch die Patienten-, beziehungsweise Elternbefragung, deut- lich, dass von einer Vielzahl der Eltern die Anwendung des Bauchdeckenverbandes in häuslicher Umgebung nicht fortgeführt wurde. Schlussfolgerung: Schließlich zeigen die Ergebnisse unserer Studie, dass ein postoperativ angelegter Bauchdeckenverband keinen nennenswerten Nutzen im Hinblick auf den Heilungsverlauf und das Auftreten von postoperativen Komplikationen mit sich bringt und eine Behandlung mit einem Pflasterverband ausreichend zu sein scheint.

\section{DGKCH-EP-36}

Ungewöhnliche Insassenskalpierungsverletzung bei Verkehrsunfall S. Schäfer, F. Eckoldt

Friedrich Schiller Universität

Einleitung: Unfälle sind die häufigste Todesursache bei Kindern in Deutschland und Europa. Dabei ist die Detektion und Minimierung unfalldisponierender Faktoren die beste Unfallprävention.

Fallvorstellung: Beschrieben wird der Fall eines 5-jährigen Jungen, welcher sich als PKW-Insasse bei einem Verkehrsunfall eine ausgedehnte isolierte Skalpierungsverletzung zuzog. Der Patient saß zum Unfallzeitpunkt angeschnallt in einem altersgerechten Kindersitz auf dem rechten Rücksitz. Auf der Rückseite des Vordersitzes war ein Klapptisch angebracht. Nach operativer Wundversorgung, i. v. antibiotischer Therapie und neurologischem Monitoring konnte der Patient mit primärer Wundheilung und ohne neurologische Auffälligkeiten entlassen werden.

Schlussfolgerung: Eine Evaluation und Veröffentlichung von Verletzungsmechanismen und möglichen Auslösern ist unabdingbar zur Unfallvermeidung, Ursachenbehebung und zum Erreichen von mehr Sicherheit für Kinder.

\section{DGKCH-EP-37}

Pfählungsverletzung mit Rektum-Blasen-Perforation Eine Fallvorstellung

A. Hilpisch

Bürgerhospital Dr. Senckenbergsche Stiftung

Titel: Pfählungsverleztung mit Rektum-Blasenperforation

Anamnese: 5-jähriger Junge, der beim Zubettgehen gestolpert und mit dem nackten Po auf die „Rutsch-Stange“ eines „Playmobil“-Feuerwehrhaues gefallen ist. Die Stange hatte sich ins Rektum gebohrt. Entfernung der Stange durch die Mutter und sofortige Vorstellung in der Klinik wegen massiven peranalen Blutabgangs.

In der Klinik sistierte die Blutung, Miktion o. b., Schmerzen suprasymphysär, Abdomen o. b..

Bildgebung: Röntgen des Abdomens: keine freie Luft, Sono: keine freie Flüssigkeit, Organe o. b..

Behandlung: Antibiose, klinische und sonographische Kontrolle. Im Verlauf Harnverhalt, kein Blutabgang mehr, sonographisch nach wie vor keine freie Flüssigkeit, Blasenwand unauffällig.

nach 12 h: Diagnostik in Narkose: Transurethraler Blasenkatheter: wenig klarer Urin, aber: Urinabgang aus dem Rektum.

Rektoskopie: Perforation an der Rektumvorderwand.

OP von abdominal/extraperitoneal und transvesikal: Blasennaht, Rektumnaht von rektal

Unkomplizierter Verlauf, primäre Wundheilung, Zwei Wochen poststat. noch erhöhte Miktionsfrequenz, Stuhl normal, Sonographie: V. a. Steinbildung am Nahtmaterial.

Nach 8 Wochen völlige Beschwerdefreiheit, klinisch und sonographisch keine Residuen, Blasenwand glatt. Miktion und Stuhl normalisiert. 


\section{Abstracts}

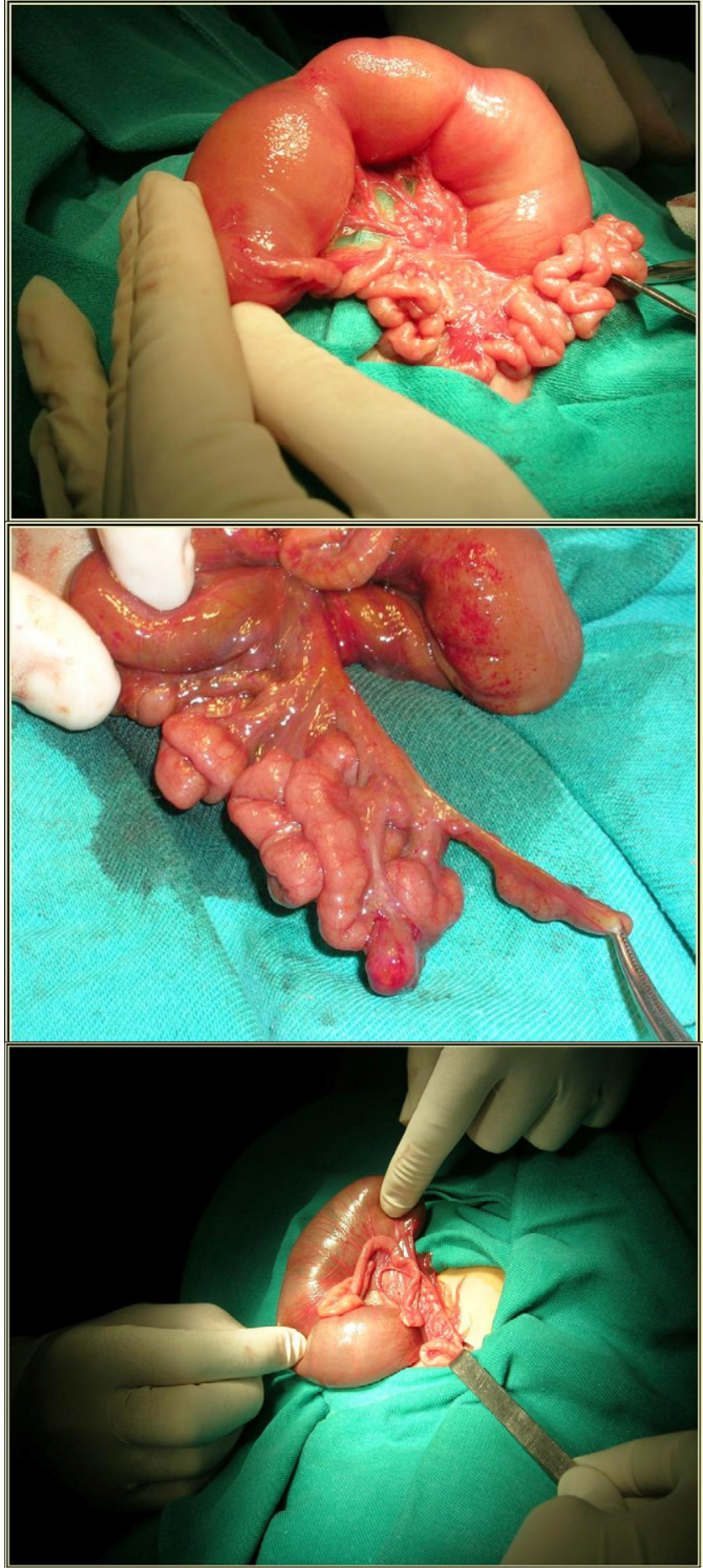

Extreme Umphangsdifferenz Apple-Peel- Syndrom

\section{DGKCH-EP-38}

Prognostische Besonderheiten in der proximalen Jejunumatresie (PJA) im Vergleich zur übrigen Dasrmatresien:

Z. AlAgha', M. Morgan², R. Harithi²

${ }^{1}$ Aleppo Universitaet, Medizinische Fakultaet, ${ }^{2}$ Aleppo Universitaet- Medizinische Fakultaet

Fragestellung: Darmatresien distal des Ligaments von Treiz haben im Allgemeinen eine günstigere Prognose als Duodenalatresien. Da Durch Ihr spätes Geschehen im Intrauterinen Leben, ist es weniger mit Frühgeburt, Chromosomanomalien und Zusatsmissbildungen beglei-

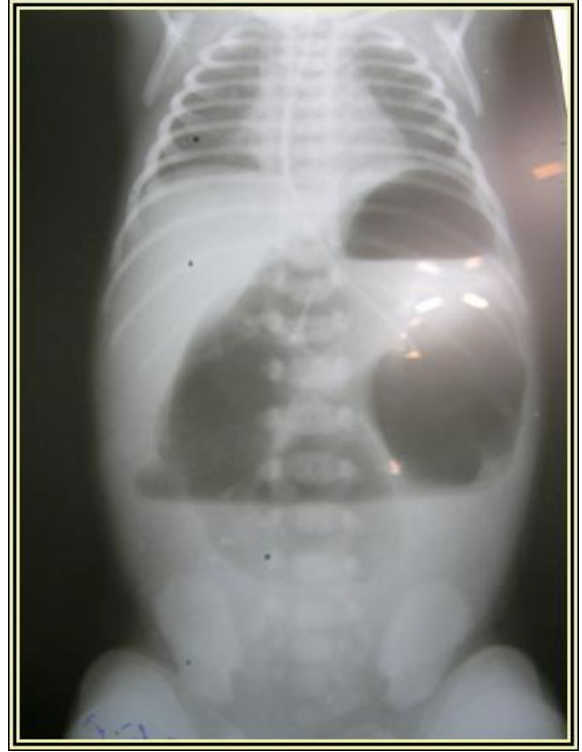

3-4 Spiegel

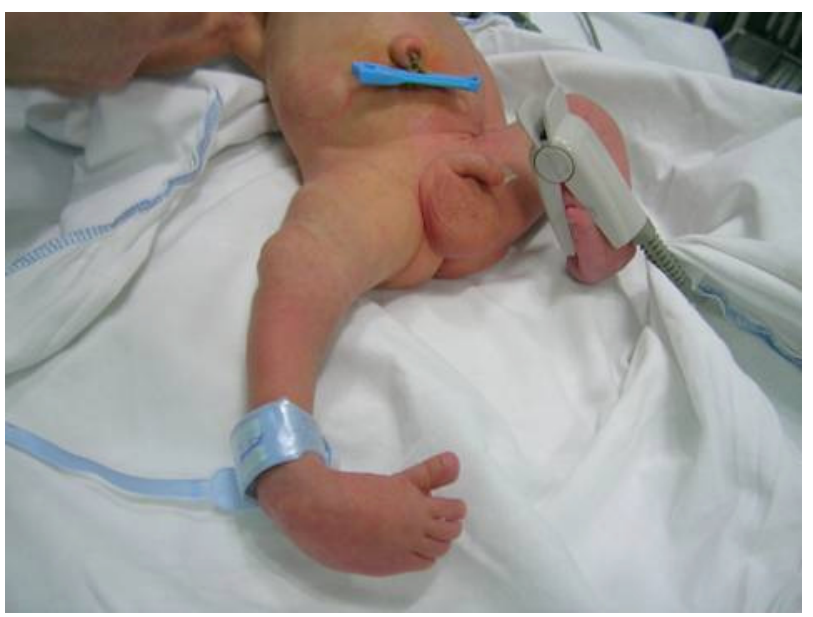

nahezu Fehlen des distalen Duenndarms Zusatzmissbildung

tet. Jedoch haben Wir im proximalen Jejunalatresie (PJA) häufig das Gegenteil getroffen.

Material und Methode: Daten von 24 Fälle mit (PJA) aus Unserer Praxis, die aufs Röntgenbild 3-4 Spiegel zeigten, wurden analysiert; Wir studierten ihre Krankengeschichte, Ihr clinisches Presentation, Ihre begleitende Missbildungen, Ihre operative Befunde, Ihr postoperatives Verlauf und Ihre Complicationen.

Erzielt wurde der Einfluss der Prä- und intraoperativen Befundeauf dem postoperativen Verlauf und auf der Morbidität.

Ergebnisse: Im Vergleich mit eigener Studie über Darmatresien verschiedener localisationen haben Wir in (PJA) das Folgende festgestellt:

- Variable Bauchvorwölbung im ähnlichen Obstruktionsniveau.

- Abwesende bzw. verzögerte Meconium Passage war ausgeprägter als in Fälle mit distalen Atresien.!!

- Frühgeburte, Familiengeschichte ähnlicher Missbildungen, und Begleitende Missbildungen waren in 14 Fälle vorhanden. Keine der Fälle wurde mit Trisomie 21 begleitet.

- Intraoperativ: Ein kurzes und erhaeblich dilatiertes proximales Jejunum in aller Fälle.

- Die Obstruktion war nur in 11 einfach.

- Distale multiple Obstructionen, Beschtimmte Anomalien wie (-apple -peal -Syndrom) und subtotales Fehlen des Dünndarms waren in 13 Fälle getroffen. 
-Postoperativ:

- 7 aus den 24 Patienten sind in durchschnitt in 27 Tage Postoperativ gestorben

( die Todesursache wurden analysiert).

- Der Aufenthalt der überlebende lag zwischen 14-und-56 Tage postoperativ (durchschnittlich: 32 Tage).

Discussion: In Unserem Krankengut hat die PJA wesenttlich höhere Mortalität-und- Komplicationsrate dazu die längste P. O. Verlauf im Vergleich mit der Duodenalatresie. Die merkliche Quote des Frühgeburts und der Begleitmissbildungen in anderen organsystem zeigten einen mässigen Einfluss ueber die Prognose.

Besonders hatte das dilatierte proximale Jejunum und die anatomische Situation des distalen Darms, Die die zukünftige Darmfunction und Darmlänge beeinflussten, die entscheidende Rolle; Eishäzen dieser Situation ist nicht präoperative möglich.

Schlussfolgerung: Häufig unerwünschte Komplicationen wie eine lange postoperative Verlauf und Syndrom des kurzen Darms mit dem folgenden Notwendichkeit der parenteralen Ernährung mit Ihrer potenziellen Nebenwirkungen sind mit PJA zu erwarten. Besonders die extreme

Umphangdifferenzen und die Zusätliche distale Darmmissbildungen, die nur intraoperative festzustellen sind, die ungünstige Prognose im Vergleich zur übrigen Dasrmatresien erklären.

\section{DGKCH-EP-39}

Dünndarmduplikatur beim Säugling-eine seltene Ursache für massives Erbrechen

M. Weber ${ }^{1}$, A. Daniels ${ }^{2}$, W. Steurer ${ }^{3}$

${ }^{1}$ Westpfalz-Klinikum Kaiserslautern, ${ }^{2}$ Westpfalz-Klinikum GmbH, ${ }^{3}$ WestpfalzKlinikum

Anamnese: Ein 5 Monate alter Säugling erscheint mit massivem Erbrechen und Stuhlverhalt. Bis dahin regelrecht geformte Stühle, keine Auffälligkeiten.

Befund: 5 Monate alter männlicher Säugling in altersentsprechendem AZ/EZ. Blasses Hautkolorit, weiches Abdomen, Meteorismus, keine Schmerzreaktion am Abdomen, keine Resistenz. Cor und Pulmo regelrecht, keine seitendifferente Belüftung.

Sono Abdomen: geblähte Dünndarmschlingen, flüssiger Darminhalt, keine erkennbare Peristaltik, regelrechte Darstellung aller parenchymatöser Organe, zystische Struktur im rechten Mittelbauch.

Labor: keine Entzündungszeichen(CRP und Leukocyten normal) Rö Magen Darm Passage: deutlich dilatierte Dünndarmschlingen, kein KM-Transport in distale Darmabschnitte. Stuhluntersuchung negativ.

Therapie: Der Patient wurde daraufhin der OP zugeführt. Es fand sich bei der Laparotomie die sonographisch beschriebene cystische Struktur direkt am terminalen Ileum an der Ileocoecalklappe zum Mesenterium hin gelegen. Der proximal davon gelegene Dünndarm war deutlich dilatiert, das Kolon dagegen normal weit. Zur Sanierung erfolgte eine Ileocoecalresektion mit latero-lateraler Ileoascendostomie. Der postoperative Kostaufbau war komplikationslos und konnte rasch durchgeführt werden. Die Entlassung erfolgte am 5. postoperativen Tag.

Histologie: $1 \mathrm{~cm}$ oberhalb der Ileocoecalklappe liegt ein ausgestülpter blind endender Dünndarmanteil. Der angrenzende Dünndarm zeigt eine deutlichen Wandverdickung. Die Dünndarmschleimhaut in o. g. Areal geht in ein duodenal strukturiertes Epithel über, z. T. mit einer gastralen Metaplasie. Der Befund erinnert an ein Meckel-Divertikel.

Diskussion: Das Meckel-Divertikel ist ein Rest des embryonalen Dottergangs und wird bei ca 4,5\% der Patienten gefunden. Die Differentialdiagnose eines Meckel-Divertikels in der Beurteilung einer akuten Appendicitis ist schwierig. In 30-50\% wird Magenschleimhaut im Divertikel nachgewiesen. Beim menschlichen Neugeborenen liegt das Meckel-Divertikel ca 30-50 cm oralwärts der Ileocoecalklappe.

Die Darmduplikatur ist eine angeborene Fehlbildung des Dünnund Dickdarms, bei der ein Darmteil im Mesenterium doppelt angelegt wurde. Sie kann in Form eines Schlauches oder auch nur als kurzer, rundlicher zystischer Abschnitt ausgebildet sein mit Verbindung zum regulären Darm oder vollkommen isoliert. Makroskopisch ist die Darmduplikatur der normalen Darmwand ähnlich, sie kann aber auch ortsfremdes Gewebe enthalten. Komplikationen sind Erbrechen, Distension des Abdomens und erschwerte Stuhlpassage.

In Zusammenschau aller Befunde muss in dem vorliegenden Fall eine Darmduplikatur im terminalen Ileum zu massivem Erbrechen und einem beginnenden Dünndarmileus geführt haben. Die daraufhin durchgeführte Ileocoecalresektion hat zu sofortiger Beschwerdefreiheit geführt.

\section{DGKCH-EP-40}

ADEPT-Lösung in Prophylaxe und Therapie des kindlichen Adhäsionsileus

C. Müller', N. Hübner' ${ }^{2}$, A. Kramer'2, W. Barthlen'

${ }^{1}$ Ernst-Moritz-Arndt-Universität, ${ }^{2}$ Institut für Hygiene und Umweltmedizin

Wir berichten über 9 Kinder vom Neonaten bis zum Jugendlichen bei denen wir aufgrund des intraoperativen Befundes (Adhäsionen, Rezidivadhäsionen, schwerste entzündliche Veränderungen) ADEPT (4\% Icodextrin-Lsg.) einsetzten. Nach anfänglich alleiniger Lavage erfolgte später die zeitlich begrenzte Instillation 8-24-48 Stunden bis hin zur Instillation ohne Ablassen des ADEPT's. Wir beobachteten primär unkomplizierte po. Verläufe.

Zur Sicherung der Anwendbarkeit wurden zusätzlich quantitative Suspensionsversuche mit typischen Keimen vorgenommen. In diesen wurde keine relevante Wachstumsfördeung gegenüber dem Kontrollmedium verzeichnet.

Aus unserer Erfahrung bietet sich ADEPT als bewährtes Mittel auch für kinderchirurgische Adhäsionsprophylaxe an.

\section{DGKCH-EP-41}

Kardiale Gefährdung und Prävention des plötzlichen Herztodes (SCD) beim Sport unter besonderer Berücksichtigung von Thoraxtraumata R. Eyermann

Dr. Richard Eyermann

\section{Ursachen des plötzlichen Herztodes beim Sport} im jüngeren Alter $(n=207)$

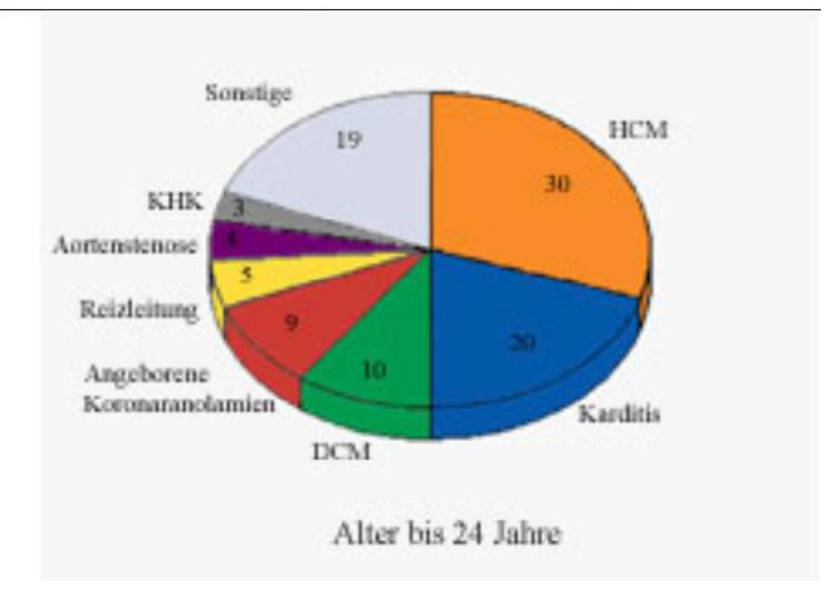


Problem: SCD bei Leistungs- u. ambitionierten Freizeitsportlern immer präsent. Weltweit beispielhaft hat in Italien ein Vorsorgeprogramm 90\% SCD-Rückgang bei jungen Wettkampfsportlern erreicht. Ergebnis: Meist SCD im Sport durch Herzvorschädigung bedingt. Unmittelbare Ursache elektrische Instabilität mit resultierenden schwerwiegenden Dysrhythmien.

Ursachen des plötzlichen Herztodes beim Sport im weiter fortschreitenden Alter $(n=703)$

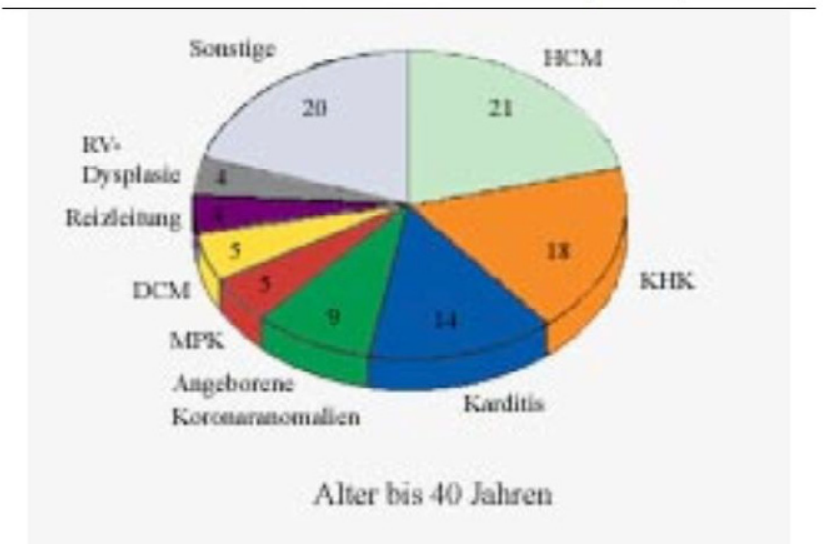

2 dominierende Ursachen:

Bei jüngeren Personen < 35-40 J. meist HCM, auch DCM, mit genetischem Hintergrund.

Studiendaten belegen Ursachenhäufigkeiten für SCD im Sport im jüngeren Alter bis 24 J. $(n=207)$ : HCM 30\%, Karditis 20\%, DCM 10\%, angeborene Koronaranomalien 9\%, Reizleitungsstörungen 5\%, Aortenstenose $4 \%$, KHK $3 \%$ Sonstige $19 \%$.

Jenseits des 35.- 40. Lj. sind bekannte kardiovaskuläre Risikofaktoren, ist KHK, häufigste Ursache.

Studiendaten belegen Ursachenhäufigkeiten für SCD im Sport im zunehmenden Alter bis $40 \mathrm{~J}$. ( $\mathrm{n}=703)$ : HCM 21\%, KHK 18\%, Karditis $14 \%$, angeborene Koronaranomalien 9\%, MKP 5\%, DCM 5\%, Reizleitungsstörungen $4 \%$, ARVC $4 \%$, Sonstige $20 \%$.

Hohe Belastungsintensitäten führen zu größerer Gefährdung. Des weiteren sind v. a. Alter u. mangelnder Trainingszustand von wesentlicher Bedeutung: z. B. ist bei 40- 50j. Sporttreibenden das Risiko 13X u. bei schlechtem Trainingszustand bis 1060x (!) erhöht. Das statistisch höchste Risiko für SCD im Sport haben > 40j. männliche Sporteinsteiger oder Wiedereinsteiger mit $>/=2$ kardiovaskulären Risikofaktoren bei ungewohnt hoher Belastung mit z. T. statischer bzw. Haltearbeit. Risiko SCD im Sport weniger von der betriebenen Sportart als von der individuellen Gefährdung abhängig, daher Sportarten an der Spitze der Mortalitätsstatistiken, die von Männern im mittleren bis höheren Lebensalter am häufigsten betrieben werden, wie Jogging, Tennis u. Kegeln.
Weitere Ursachen des plötzlichen Herztodes beim Sport Sog. „Brückenbildungen des Myokards“ und anomale Koronargefäßverläufe mit Einengung der Koronarien v.a. unter Belastung

\section{HINTEN}

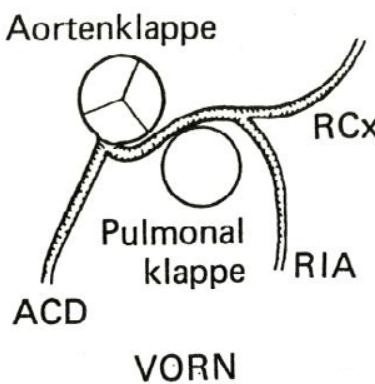

- Ursprung LCA aus re. Sinus Valsalvae mit Gefäßverlauf nach links (1. Einengungsmöglichkeit) u. posterior zwischen Aorta u. rechtsventrikulärem Infundibulum (2. Einengungsmöglichkeit)
Weitere Ursachen des plötzlichen Herztodes beim Sport Traumata, starke stumpfe Schlageinwirkungen, wie z.B. durch einen Zusammenprall mit Spielpartnern, Ball, Puck oder Sturz auf den Thorax können reflexbedingt Koronarspasmen auslösen

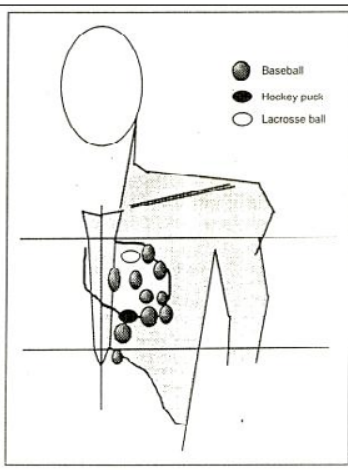

-Kontusionspunkte am Thorax mit dem Ergebnis einer Commotio cordis
Weitere Ursachen für SCD sind sog. „Myokardbrückenbildungen“ mit Einengung der Koronarien v. a. unter Belastung u. pektanginöser Symptomatik ähnlich wie bei KHK.

Traumata, starke stumpfe Schlageinwirkungen, wie z. B. durch einen Zusammenprall mit Spielpartnern, Ball, Puck oder Sturz auf den Thorax können reflexbedingt Koronarspasmen auslösen.

Studiendaten zum SCD von Kindern u. Jugendlichen im Alter von 3-19 J., unmittelbar nach stumpfem, nicht penetrierendem Thoraxtrauma im Sport ohne sichtbare äußere Thoraxverletzungen $(n=25)$, belegen bei der Obduktion weder vorbestehende organische Herzerkrankungen noch akute strukturelle Schädigungen des Herzens. Die Kontusion am Thorax durch Baseballs, Hockey Puck u. Lacrosse Ball führte zur Commotio cordis mit jeweils SCD auf reflektorischer Basis mit ventrikulärer Dysrhythmie.

Konklusion: Risiko SCD beim Sport weniger von betriebener Sportart als von individueller Gefährdung abhängig.

Wichtigste Ursachen für SCD im Sport sind: HCM, Myokarditis, KHK, angeborene Koronaranomalien, MKP, Erkrankungen der Aorta incl. Aortenklappen, Störungen der Reizbildung u. Reizleitung.

Präventivmedizinisch ist auf Prodromi zu achten !

Kardiologische Vorsorgeuntersuchungen sind für Leistungs-u. ambitionierte Freizeitsportler in jedem Lebensalter, also auch $<35$ Jahren, zu fordern.

Beachtung von KI für sportliche Aktivitäten wie bei akuten Erkrankungen sowie von Trainingsempfehlungen v. a. nach längerer physischer Inaktivität hilft Übersterblichkeiten (bis zu 106ox) zu reduzieren. 
Obwohl traumatisch reflexbedingte koronarspastische SCD selten, bei besonders gefährdenden Sportarten Protektoren, wie Brustpanzer, zu empfehlen.

\section{DGKCH-EP-42}

Erfassung postoperativer Schmerzen nach HNO-Eingriffen bei Kindern ab dem 4. Lebensjahr - Ergebnisse nach 6 Monaten "QUIPSI"

A. Schnelle, G. Volk, O. Guntinas-Lichius

Friedrich Schiller Universität HNO-Klinik

Fragestellung

Ist eine standardisierte Erfassung von postoperativen Schmerzen bei Kindern ab dem 4. Lebensjahr bereits möglich? Decken sich die Ergebnisse eines einmaligen postoperativen Fragebogeninterviews mit der klinischen Beobachtung?

Material und Methoden: Die HNO-Klinik des Universitätsklinikums Jena beteiligt sich seit Januar 2010 an der Etablierung eine Qualitätssicherung in der postoperativen Schmerztherapie bei Kindern - QUIPSI. Dazu werden bei allen Kindern ab dem 4. Lebensjahr ein Fragebogeninterview durchgeführt und Prozessdaten erhoben. Dies geschieht bei stationären Patienten am ersten postoperativen Tag, bei ambulanten am Nachmittag des OP-Tages. Das Fragebogeninterview enthält sowohl „Face-Pain-Scales“ nach Hicks et al sowie sechs dichotome Fragen zu Einschränkungen und Nebenwirkungen. Die Prozessdaten beziehen sich auf Details der Narkose, der Prämedikation, der intraoperativen Medikation und der postoperativen Schmerztherapie. Die erhobenen Daten werden webbasiert zentral erfasst. Mit Hilfe dieses Servers lassen sich die eigenen erhobenen Daten unter anderem nach OPS-Ziffern, im zeitlichen Verlauf und im Vergleich zu anderen Zentren betrachten. Ergebnisse: Das Fragebogeninterview wird sowohl von den Patienten als auch von deren Eltern nicht als Belastung empfunden. Durch die klare Festlegung der Abläufe kann eine Erfassungquote von über 90\% erreicht werden. Nach Einarbeitung ist die Datenerhebung in 15 bis 20 Minuten pro Patient möglich. Bei Kindern im 4. Lebensjahr zeigen sich häufig Verständnisschwierigkeiten. Am Beispiel der Adenotomie im Vergleich zur Tonsillektomie zeigen sich Eingriffe-spezifische Schmerzintensitäten.

Diskussion: Die Zwischenbilanz nach 6 Monaten seit Einführung von QUIPSI fällt positiv im Hinblick auf die Durchführbarkeit aus, wobei eine klare Instruktion und Aufgabenverteilung essential für eine standardisierte Datenerhebung sind. Der Zeitaufwand der Befragung pro Patient ist gut kalkulierbar. Sie sollte deshalb integriert mit anderen Stationsroutinen durchgeführt werden um Akzeptanz und Standardisierung zu erhöhen. Bei Kindern im 4. Lebensjahr ist je nach geistigem Entwicklungstand der Fragebogen wenig aussagekräftig aufgrund überwiegender Verständnisschwierigkeiten. Die klinische Erfahrung über die Schmerzintensität am Beispiel der Adenotomie und Tonsillektomie deckt sich gut mit den Ergebnissen der Befragung.

Schlussfolgerung: QUIPSI verspricht nach Abschluss der Evaluierung und Optimierung ein hilfreiches Instrument zur Qualitätssicherung der Schmerzbehandlung bei Kindern zur werden.

\section{DGKCH-EP-43}

Einführung minimal-invasiver Techniken an einer kinderchirurgischen Klinik der Maximalversorgung

K. Bodenschatz, S. Simon

Klinikum Süd, Nürnberg Klinik für Kinder und Jugendliche

An der Klinik für Kinderchirurgie des Klinikums Nürnberg wurden in den letzten drei Jahren gezielt minimal-invasive Techniken etabliert. Es wir dargestellt was in drei Jahren in den verschiedenen Bereichen der Kinderchirurgie erreicht wurde.

Es wurden in den Jahren vorher immer wieder einzelne Eingriffe, wie zum Beispiel die Spenektomie, die laparaskopische gestützte Op n. Dühamel durchgeführt, ein täglicher Einsatz erfolgte nicht.
Die Etablierung der Techniken erfolgte schrittweise, das erste Verfahren stellte die Varicozele gefolgt durch die Apenndektomie dar. So konnten alle Operateure Erfahrung sammeln.

Die minimalinvasive Chirurgie wird zunehmend zum gewünschten Standardverfahren.

Die Verweildauer wurde weiter abgesenkt.

Kinderurologie: Nephrektomie, Heminephrektomie, Varicozele Thoraxchirurgie: Empyem, Zwerchfellhernie, Ösophagusatresie

Viszeralchirurgie: Appendektomie, Leistenhernie, Pylorusstenose, Atresie, Resektion Meckel`sches Divertikel, Volvulus.

DGKCH-EP-44

Nicht akzidentelle Verletzungen: Passen Anamnese und Verletzungsmuster?

M. Kapapa, D. Henne-Bruns, C. Leriche

Klinik für Allgemein-, Viszeral- und Transplantationschirurgie

Fragestellung: Das Erkennen von nicht akzidentellen Verletzungen im Kindesalter und der Umgang zum Schutz des Kindes, sowie das interdisziplinäre Vorgehen stellen für alle Beteiligten eine Herausforderung dar. An Klinken der Grund- , Regel- und Schwerpunktversorgung kann dies schwierig sein. Wir berichten über einen Fall.

Material und Methode

Ein 12 Monate altes Mädchen, die aktuelle Vorstellung erfolgte durch Überweisung eines niedergelassenen Kinderarztes. Das Kind sei am Morgen weinend im Bett aufgefunden worden, ohne dass ein Trauma vorgelegen habe. Die Patientin sei lt. Mutter gesund, kein Hinweis auf Gerinnungsstörungen oder Knochenerkrankungen, die Mutter berichtete von einer Femurfraktur 6 Wochen zuvor. Klinisch zeigte sich eine starke Schwellung des rechten Ellenbogens, mit prall gespannter Haut, ausgeprägtem Hämatom in der Ellenbeuge ohne Durchspießung. Klinisch bestand der V. a. eine suprakondyläre Fraktur oder eine Olekranonfraktur. Ferner konnten weitere Hämatome am linken Oberarm und Ober- und Unterschenkel festgestellt werden, die übrige körperliche Untersuchung verlief ohne pathologischen Befund.

Ergebnisse: Die Röntgen Aufnahmen in 2 Ebenen zeigten eine dislozierte Suprakondyläre Oberarmfraktur rechts mit Rotationsfehler. Sofortige operative Versorgung mit Kirschner- Drähten und Immobilisation im Oberarmgips durch die Unfallchirurgie. Im Verlauf zeigte sich eine gute Konsolidierung der Fraktur und die freie Beweglichkeit im Gelenk. Im Verlauf erfolgte die konsiliarische Betreuung durch die Pädiater und das SPZ. Im Verlauf gab der leibliche Vater schließlich zu, sich in Stresssituationen nicht unter Kontrolle zu haben, und gewalttätig zu werden. Auch die Femurfraktur vor einigen Wochen war auf eine Misshandlung seitens des Vaters zurückzuführen.

Diskussion: Die Schwierigkeiten des adäquaten Umgangs von nicht akzidentellen Verletzungen betreffen alle involvierten Fachdisziplinen. Gerade an Kliniken ohne eigene Pädiatrie stellt eine nicht akzidentelle Verletzung, aufgrund des geringeren Anteils von pädiatrischen Patienten, die Mitarbeiter vor große Herausforderungen. Persönliche Empfinden wie Wut, Entsetzen und den Drang „das Ganze Aufklären zu wollen“ müssen zurückgestellt werden. Die urteilsfreie Anamnese ist essentiell, Aussagen sollten wortgetreu erfasst werden. Emotionale Schuldzuweisungen können zu Arzt- Hopping führen, dies nützt niemandem, dem Kind am wenigsten.

Schlussfolgerung: Das Wohl des Kindes steht immer im Mittelpunkt. Es ist am Wichtigsten an eine nicht akzidentelle Verletzung zu denken. Die aktuellen AWMF Leitlinien geben Anhalt für das weitere Vorgehen im multiprofessionellen Team und ermöglichen somit auch den Mitarbeitern an Kliniken der Grund-, Regel- und Schwerpunktversorgung eine initiale adäquate Versorgung durchzuführen. Im Zweifelsfall sollte die Verlegung des Kindes in eine Klinik für Pädiatrie oder Kinderchirurgie erfolgen, um die Diagnostik zu vervollständigen und das Prozedere festzulegen. 


\section{DGKCH-EP-45}

Tissue Expander Implantation vor Exzision eines 24x8cm großen Nävuszellnävus bei einem 20 Monate alten Mädchen

M. Kapapa, D. Henne-Bruns, C. Leriche

Klinik für Allgemein-, Viszeral- und Transplantationschirurgie

Fragestellung: Die operative Entfernung eines Tierfellnävus stellt im Kindesalter immer eine Herausforderung dar. Dabei hängen das Behandlungsergebnis und die Komplikationsrate sowohl von der Lokalisation, der Größe des Ausgangsbefundes und dem Alter des Kindes ab. Die operative Entfernung eines über $20 \mathrm{~cm}$ großen Tierfellnävus im Kleinkindalter ist selten beschrieben. Wir berichten über einen Fall.

Material und Methode: 20 Monate altes Mädchen, Androgenitales Syndrom mit leichtem Salzverlust, bereits durchgeführte Klitoris-Reduktionsplastik und Vulvaplastik bei genitaler Fehlbildung (Prader IV). Bei dem Kind besteht lumbosakral ein ca. $24 \mathrm{~cm}$ langer Tierfellnävus dreiecksförmig mit der Basis in Höhe von Lendenwirbelkörper 1 und der Spitze, ca. $8 \mathrm{~cm}$ Länge, zur Rima ani reichend, haarig. Nach Vorbehandlung in einer auswärtigen Klinik mit Teilexzision und Schleifung des großen Nävus erfolgte nun die Korrekturoperation bei erneutem Auftreten des Tierzellnävus und narbiger Verziehung im ehemaligen Wundbereich. Zunächst wurde eine Teilresektion und Schleifung durchgeführt, außerdem konnten zwei Selbstquellende Osmoseexpander rechts und links gluteal implantiert werden. Die Osmed Tissue Expander bestehen aus Hydrogel in einer perforierten Silikonhülle, durch Absorption von Körperflüssigkeit wird das Volumen um etwa das 1ofache vergrößert. Das angestrebt finale Volumen von ca. $130 \mathrm{ml}$ pro Expander war nach etwa $5^{1 / 2}$ Wochen erreicht. Danach erfolgt die Resektion des Tierfellnävus in toto und in gleicher Sitzung der primäre Wundverschluss durch zwei Verschiebelappenplastiken nach ausreichender Expander- Dilatation der Haut gluteal beidseits.

Ergebnisse: Initial gutes operatives Ergebnis. Nach etwa 2 Wochen kam es zu einer kleinen $2 \times 3 \mathrm{~cm}$ großen dreiecksförmigen Nahtdehiszenz im Bereich des Zusammentreffens der beiden Verschiebelappen. Progedienz im Verlauf, daher Wunddebridement und Anlage einer portablen Vakuumversiegelung (KCI-Pumpe). Nach 12 Tagen Defektdeckung mit 1: 1,5 gemeshter Spalthaut von der behaarten Kopfhaut. Anschließend problemlose Wundheilung mit komplettem Angehen des Transplantates und sehr guter Wundheilung am Entnahmegebiet.

Diskussion: Vorteil des Osmed Tissue Expanders ist der geringe Implantationszugang und die Volumenzunahme durch Absorption von Körperflüssigkeit ohne zusätzliche Injektionen. Das Risiko einer Infektion wird minimiert.

Schlussfolgerung: Der Richtige Zeitpunkt einer Expander Im- und Explantation mit anschließend korrektiver Operation ist für jedes Kind individuell zu wählen. Auch im Kleinkindesalter ist die Entfernung eines großen Tierfellnävus möglich. Dabei hängt das Ergebnis aber sowohl von der betroffenen Körperregion, als auch dem Alter des Kindes und der Compliance der Eltern ab.

\section{Tissue Engineering}

\section{DGKCH-FV-17}

\section{Erste Schritte zu einem Genitalhautmodel}

\section{Wünsch', J. Kalk1, R. Werner2 ${ }^{2}$, P. Holterhus ${ }^{3}$, O. Hiort ${ }^{2}$}

${ }^{1}$ Klinik für Kinderchirurgie, ${ }^{2}$ Universitätsklinikum Schleswig Holstein, ${ }^{3} U n i-$ versitätskinderklinik

Hintergrund: Die Rekonstruktion von Fehlbildungen des männlichen Genitales ist oft durch fehlende Genitalhaut limitiert. Das Wachstum der Genitalhaut in androgenabhängig, und Genitalhautfibroblasten exprimieren Androgenrezeptoren (AR). Auch ein Genitalhautersatz sollte einen funktionierenden Androgenrezeptor aufweisen. Wir besiedelten eine Integra ${ }^{-}$-Matrix mit Genitalhaut-Fibroblasten und untersuchten die Stimulierbarkeit durch Dehydrotestosterone (DHT). Die molekularen Mechanismen der Androgenresistenz sind weitgehend ungeklärt. Da sich in den üblichen Zellkulturen keine Androgen-responsiven Gene finden ließen, haben wir in unserem Genitalhaut-Modell nach solchen Genen gesucht.

Patienten und Methoden: Genitalhaut-Fibroblasten wurden von 11 gesunden Jungen angezüchtet. Die Zellen wurden in Petri-Schalen oder in der Intergr ${ }^{\oplus}$-Matrix kultiviert. Nach Stimulation mit DHT wurde die AR-Rezeptorexpression immunhistochemisch und im WesternBlot untersucht. Ein screening auf androgen-abhängige Gene wurde durch einen c-DANN-chip-Array durchgeführt und die Ergebnisse mittels RT-PCR überprüft.

Ergebnisse: Die in der Integra ${ }^{\circ}$-Matrix kultivierten Genitalhautfibroblasten zeigten nach DHT-Stimulation eine vermehrte AR-Expression. Im Screening auf androgenabhängige Gene wurden das IGFBP2-Gen sowie das Apo-D-Gen als neue Kandidaten identifiziert.

Schlussfolgerung: Die Besiedlung einer Integra ${ }^{\circ}$-Matrix ist ein sinnvoller erster Schritt zu einem Genitalhautmodell. Die Stimulierbarkeit durch Androgen bleibt erhalten und bietet somit ein gute Potential für Wachstum in der Pubertät. Unser Modell ist auch für die Charakterisierung der Androgenresistenz von Interesse, da neue, androgenabhängige Gene identifiziert werden können.

\section{Posterforum}

\section{DGKCH-PV-01}

Nationales Register für kongenitale uro-rektale Fehlbildungen (CURENet)

E. Jenetzky ${ }^{1}$, H. Reutter ${ }^{2}$

${ }^{1}$ Klinische Epidemiologie und Alternsforschung, ${ }^{2}$ Abteilung Neonatologie, Institut für Humangenetik

Hintergrund: Anorektale Malformationen (ARM) und der Ekstrophie-Epispadie-Komplex (EEK) repräsentieren die schwersten Formen des kongenitalen uro-rektalen Fehlbildungsspektrums. Jährlich werden in Deutschland etwa 280 Kinder geboren, entsprechend einer Häufigkeit von 1 auf 2. 500 Lebendgeburten. Das Verständnis der molekularen Mechanismen, die zu ARM und zum EEK führen, ist rudimentär. Die bisherige Erforschung der Krankheitsbilder lässt eine Reihe wichtiger Fragen unbeantwortet, da die vorliegenden Studien zu Therapieergebnissen fast ausschließlich auf retrospektiv erhobene Daten einzelner Zentren mit zum Teil unterschiedlichen Klassifikationen der jeweiligen Fehlbildungen zurückgreifen.

Fragestellung: Das vom Bundesministerium für Bildung und Forschung (BMBF) geförderte Netzwerk für kongenitale uro-rektale Malformationen (CURE-Net) hat ein Nationales Register zur anonymen Erfassung betroffener Neugeborener geschaffen. Es werden lediglich standardisierte Angaben zur Diagnose, Begleiterkrankungen, Prognose und Behandlung gespeichert.

Material und Methode: Im Vorfeld wurden standardisierte Klassifikationsbögen entwickelt, die sich am Krickenbeck-Konsens und nach der Klassifikation von Gearheart und Jeffs orientieren. Begleitfehlbildungen werden anhand der London Dysmorphology Database erfasst. Zur Ursachenerforschung werden Blut- oder Speichelproben und pränatale Einflussfaktoren erhoben. Hierbei werden die etablierten EUROCAT-Items der generischen Fehlbildungsregister verwendet. Behandelnde Ärzte können seit November 2009 Säuglinge (< 12 Lebensmonate zum Zeitpunkt der Erfassung) mit ARM oder EEK in das CURENet Register einschließen. Mit Hilfe eines durch die TMF-zertifizierten, online (www. cure-net. de) verfügbaren PID-Generators (Patient Identifier) kann der Arzt die Säuglinge verschlüsseln. Patientenidentifizierende Daten werden getrennt vom Register asserviert. Erfassungsbögen können kostenfrei angefordert werden. Der Aufwand wird mit 50 $€$ pro Patient vergütet. Die molekulargenetischen Analysen der gesammelten Blut- oder Speichelproben erfolgt im Institut für Humangenetik in Bonn. 
Ergebnisse und Diskussion: Innerhalb der ersten 6o Tage nach Eröffnung des Registers haben sich über 40 operierende Kliniken registriert und damit begonnen betroffene Neugeborene anonym in das Register einzuspeisen. Durch die einrichtungsübergreifende Rekrutierung können notwendige Stichprobengrößen erreicht werden. Die unterschiedlichen Analysen dienen dem eingehenden Verständnis der Ursachen und molekularbiologischen Zusammenhänge angeborener uro-rektaler Fehlbildungen und tragen dazu bei, einen evidenzbasierten und krankheitsspezifischen Nachsorge-Pass für Patienten zu formulieren. Die zentrale Datenbank des Registers stellt eine einzigartige überregionale Informationsquelle für eigenständige Forschungsprojekte dar. Schlussfolgerung: Der Erfolg des Registers ist auf die aktive flächendeckende Teilnahme neonatologischer und pädiatrischer Intensivstationen angewiesen.

\section{DGKCH-PV-02}

Harnblasensteine als Komplikation nach minimal invasiver Harnleiterunterspritzung mit Polydimethylsiloxan

M. Milosevic, M. Hunscha, R. Bitterlich, K. Riebe

DRK Kliniken Westend

Intention: Die endoskopisch minimal invasive Harnleiterunterspritzung (1984) ist eine etablierte und effektive Methode zur Behandlung des vesicoureteralen Refluxes (VUR). Dafür stehen verschiedene Substanzen zur Verfügung, Polydimethylsiloxan (Macroplastique •) bestehend aus reinem Silikonelastomer, weist in Studien die höchsten Sanierungsraten ( $80 \%$ ) bei VUR auf und gehörte in der Vergangenheit zu den beliebtesten und am meisten gebrauchten Substanzen. Wir berichten über 4 Fälle mit Entstehung von Harnsteinen als Spätkomplikation nach minimal invasiver Harnleiterunterspritzung bedingt durch Polydimethylsiloxan.

Material and Methode: In den Jahren 1997 bis 2002 wurden 4 Kinder, 1 Mädchen und 3 Jungen, mit Polydimethylsiloxan aufgrund rezidivierender hochfieberhafter Harnwegsinfektionen (HWI) und kindlicher Harninkontinenz bei VUR II- ${ }^{\odot} \mathrm{III}^{\oplus}$, uni- sowie bilateral und in 2 Fällen mehrfach behandelt .

Resultat: Postoperativ wurden die Kinder durch Unterleibs- und dysurische Beschwerden, Makrohämaturien, Harnwegsinfektionen und rezidivierende Steinabgänge symptomatisch. In den postoperativ durchgeführten sonographischen Kontrollen gab es nie Hinweise auf eine Nephrolithiasis, jedoch Darstellung von Konkrementen in der Harnblasenwand mit dorsaler Schallauslöschung in Höhe der Harnleitermündungen oder Harnblase.

Die bei allen Kindern durchgeführten diagnostischen Urethrozystoskopien zeigten zum Teil exophytisch herausragende Konkremente aus den Injektionspunkten, sowie frei flotierende inkrustierte Polydimethylsiloxanteilchen.

Der Nachweis erfolgte histopathologisch und durch Steinanalysen.

Fazit: Aufgrund der Komplikation von Harnsteinbildung und daraus resultierenden sekundären Komplikationen, die weitere operative Eingriffe bei Kindern notwendig machen, halten wir Polydimethylsiloxan für die minimal invasive Harnleiterunterspritzung nur in Ausnahmefällen und nach genauer Risikoabwägung indiziert.

\section{DGKCH-PV-03}

S2 Leitlinien zur Therapie des Hodenhochstands Alter bei der Operation und praeoperative Hormontherapie Eine prospektive Multicenterstudie niedergelassener Kinderchirurgen

\section{G. Hrivatakis' ${ }^{1}$ W. Astfalk ${ }^{2}$}

${ }^{1}$ Kinderchirurgische Gemeinschaftspraxis G. Hrivatakis, Dr. Th. Heim, ${ }^{2}$ Chirurgische Gemeinschaftspraxis Dr. Fuhrer, H. Nonnenmacher, Dr. Astfalk, Dr. Fauser

Fragestellung: Seit Einführung der S2 Leitlinien sollte die Therapie des Hodenhochstands am Ende des 1. Lebensjahres abgeschlossen sein. Außerdem sollte eine Hormontherapie nach dem 1. Lebensjahr nicht mehr durchgeführt werden. Es stellt sich die Frage, inwieweit diese Leitlinien bereits in die alltägliche Praxis umgesetzt wurde.

Materialien und Methoden: In einer prospektiven Studie wurden die Daten aller Patienten aus fünf kinderchirurgischen Praxen erfasst und ausgewertet. Das betraf die Art des Hodenchstands (primärer, sekundärer), das Alter es Kindes zum Zeitpunkt der Operation und die durchgeführte praeoperative Hormontherapie.

Ergebnisse: Vom 01. 01. 2009 bis zum 31. 12. 2009 wurden insgesamt 456 Orchidopexien bei 371 Kindern durchgeführt. Davon handelte es sich bei 275 Kindern um einen primären Hodenhochstand. Bei diesen 275 Kindern wurden 336 Orchidopexien durchgeführt.

Die Kinder, bei denen ein primärer Hodenhochstand vorlag, wurden in drei Gruppen eingeteilt:

- Gruppe I: bis zum 12. LM zum Zeitpunkt des Eingriffes

- Gruppe II: 13-24 LM zum Zeitpunkt des Eingriffes

- Gruppe III: > 24 Monate alt zum Zeitpunkt des Eingriffes

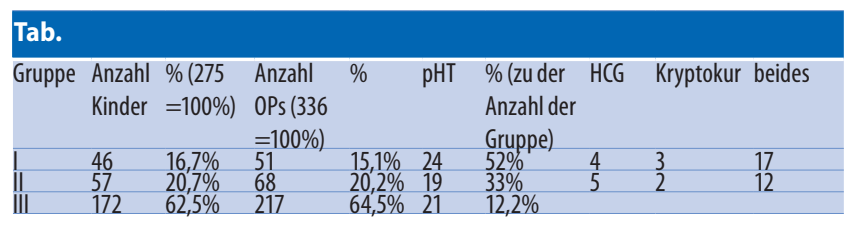

Von den 46 Kindern aus Gruppe Imit prim. HH hatten 24 eine Hormontherapie à $52 \%$

Fazit: Beim überwiegenden Anteil der Kinder mit primärem Hodenhochstand $(>80 \%)$ erfolgte die operative Therapie jenseits des ersten Lebensjahres und nur bei 16,7\% wurde der Hodenhochstand im ersten Lebensjahr operiert.

Schlussfolgerung: Um die S2 Leitlinien umsetzen zu können sollte in der Zukunft intensivere Aufklärung vor allem der Kinderärzte und in ländlichen Gebieten der Hausärzte erfolgen.

\section{DGKCH-PV-04}

Diagnostik, Therapiemanagement und Outcome von Übergangsfrakturen am Sprunggelenk

T. Lehnert, U. Bühligen, M. Weisser, W. Hirsch, H. Till

Universitätsklinikum Leipzig AöR

Einleitung: Aufgrund fortschreitender Verknöcherung der Wachstumsfuge findet man bei Verletzungen im Bereich der distalen Tibiaepiphyse spezifische Übergangsfrakturen (ÜGF). Dabei differenziert man Two-Plane, Triplane-I und -II-Frakturen.

Fragestellung: Welchen Stellenwert hat die CT-Diagnostik hinsichtlich Therapiemanagement und funktionellem Outcome bei ÜGF am Sprunggelenk?

Material und Methode: Retrospektive Analyse von 04/2001-12/2008 aller Pat. mit ÜGF. Operationsindikation bei CT-morphologischer Fragmentdislokation $>2 \mathrm{~mm}$ oder Stufenbildung im Gelenk.

Ergebnisse: 5Two-PF,14Tri-PF-I, 13Tri-PF-II im Alter von 14. 1 Jahren (range 11. 7-17). Nach CT-Durchführung Änderung des Therapieverfahrens bei 18/32 Patienten (Indikation zur Schraubenosteosynthese bei 12/18, modifizierte Operationsstrategie bei 6/18). Insgesamt wurden 29/32 Pat. mittels Schraubenosteosynthese versorgt (24/29 minimalinvasiv), bei $3 / 32$ Pat. erfolgte die geschlossene Reposition. Alle mit Gipsretention für median 5. 6 Wochen. Teilbelastung ab $4.6( \pm 1$. 5) Wochen, Vollbelastung ab $6.5( \pm 1.6)$ Wochen. Materialentfernung nach 12. $4( \pm 5.1)$ Wochen postoperativ. Sportfreigabe ab $4.9( \pm 1.5)$ Monaten. Follow-up nach 2. 5 bis 28 Monaten. Dabei zeigten sich 2 Pat. mit Knick-Senk-Füßen. Keine Beobachtung von Wachstumsstörungen oder Beweglichkeitseinschränkung.

Schlussfolgerung: Die konservative und operative Therapie der ÜGF führt dann zu funktionell guten Ergebnissen, wenn das Ausmaß der Fraktur exakt bestimmt wurde. Hier bringt die CT-Diagnostik in der Mehrzahl der Fälle zusätzliche Information. 


\section{DGKCH-PV-05}

Antegrade Sklerosierung des Plexus pampiniformis

H. Trenkner, K. Kretschmer, R. Bitterlich, K. Riebe

DRK Klinik Westend

Ziel der Studie war es die Durchführbarkeit und Effektivität von antegrader Sklerosierung im kindes- und jugendlichen Alter zu evaluieren.

Von Januar 2000 bis Dezember 2009 führten wir bei 85 Kindern im Alter von 9 bis 16 Jahren eine antegrade Sklerosierung einer Varikozele durch. Die Indikation für die Operation wurde gestellt bei einem hohen Schweregrad der Varikozele (nach Dubin und Amelar II-III gradig), bei Hodenatrophie sowie bei Beschwerden.

Die Diagnose wurde sowohl klinisch als auch durch Dopplersonografie gesichert.

Die Durchführung der Operation erfolgte entweder unter Lokalanästhesie oder mit einem Caudalblock. Nach skrotaler Inzision und Punktion einer Vene des Plexus Pampiniformis erfolgte die Injektion von Kontrastmittel. Unter Röntgenkontrolle wurde der korrekte Abfluss über die Vena testicularis dokumentiert. Erst dann erfolgte die antegrade Sklerosierung mit Instillation eines Sklerosierungsmittels in eine Vene des Plexus Pampiniformis.

Nach 3 und 6 Monaten fand eine klinische und sonografische Nachuntersuchung statt.

Wir beobachteten keine schweren Komplikationen wie Beckenvenenthrombosen, Beckenwandnekrosen oder Hodenatrophie. Bei 13 Patienten trat postoperativ eine Hydrocele auf, bei 4 kam es zu einer Schwellung des Samenstrangs, die sich spontan zurückbildete. Die Rezidivrate lag bei $7 \%$.

Die antegrade Sklerosierung ist eine risikoarmes minimalinvasives Verfahren, das sich gut durchführen läßt, um Varikozelen im kindes- und jugendlichen Alter effektiv zu behandeln.

\section{DGKCH-PV-06}

Postoperative Blasen- und Rektumfunktion bei Kindern mit Steißbeinteratom

M. Stehr, M. Berger, M. Heinrich, M. Lacher, J. Hubertus, D. von Schweinitz Klinikum der Universität München

Steißbeinteratome sind Keimzelltumoren und sind insgesamt selten. Nach chirurgischer Entfernung zielt die onkologische Nachsorge vor allem auf die Erkennung von Rezidiven. Das Risiko einer postoperativen Blasen- und Rektumfunktionsstörung ist offensichtlich, allerdings gibt es diesbezüglich keine klaren Leitlinien für die postoperative Nachsorge solcher Kinder. Das Ziel dieser Untersuchung war es, Kinder mit Steißbeinteratom postoperativ bezüglich ihrer Blasen- und Rektumfunktion zu untersuchen. Es wurde eine retrospektive Analyse von den 25 Kinder (6 Jungen, 19 Mädchen) mit Steißbeinteratom durchgeführt, die in den letzten 11 Jahren an unserem Klinikum operiert wurden. Eine funktionelle Analyse erfolgte an Hand der klinischen Untersuchung, Rektomanometrie und Zystomanometrie. Eine Blasenfunktionsstörung wurde definiert als entweder zu schwacher Harnstrahl, Inkontinenz, Restharn und/oder rezidivierende Harnwegsinfekte; eine Rektumfunktionsstörung als klinisch relevante Obstipation oder Stuhlinkontinenz. Die Daten von 21 Kindern konnten in die Untersuchung eingeschlossen werden. Von den 21 Kindern hatten 7 (33\%) einen malignen und 14 (67\%) einen benignen Tumor. 3 Kinder (15\%) starben nach einem mittleren Überleben von 63 Monaten an den Folgen ihres fortgeschrittenen, malignen Tumors. 2 Kinder mit gutartigem Tumor erlitten ein Rezidiv, beide früh im Verlauf. Jedoch lebten alle 14 Kinder mit gutartigem Tumor und waren tumorfrei zum Zeitpunkt der Nachuntersuchung (mittleres Lebensalter 94 Monate). 11 der 21 Kinder (52\%) entwickelten eine klinisch relevante Blasenfunktionsstörung (6 der 7 (86\%) Kinder mit malignem Tumor und 5 der 14 (36\%) Kinder mit benignem Tumor). Alle 11 Kinder zeigten pathologische Auffälligkeiten in der Zystomanometrie, 7 Kinder zeigten in dieser Untersuchung eine neurogene Blase. Im Gegensatz dazu fanden wir keine Rektumfunktionsstörungen in diesen Kindern. Blasenfunktionsstörungen stellen ein erhebliches Risiko bei Kindern mit Steißbeinteratom dar und können mittels Zystomanometrie aufgedeckt werden. Deshalb sollte zusätzlich zu bestehenden Leitlinien die Zystomanometrie als Standardverfahren in der postoperativen Nachsorge von Kindern mit Steißbeinteratom etabliert werden.

\section{DGKCH-PV-07}

Single Inzision Laparoscopic Surgery (SILS) Cholezystektomie and intraoperative Cholangiographie - technisch machbar und sicher M. Dürsch, B. Reingruber

Klinik für Kinderchirurgie - Sankt Hedwig

Ziele: In unserer kinderchirurgischen Klinik führen wir seit ca. 1 1/2 Jahr Single-Port-Operationen durch. In dieser Zeit haben wir bis dato 38 SILS-Operationen durchgeführt, davon 3 SILS-Cholecystektomien mit intraoperativer Cholangiographie. Wir berichten über unsere Erfahrungen und Vorgehensweise. Patientenselektion: Bei Patienten mit symptomatischer Cholecystolithiasis mit intra- oder extrahepatischer Cholestase wird zunächst eine ERCP durchgeführt. Bei unklaren Befunden führen wir eine intraoperative Cholangiographie durch, um das Vorliegen eines Choledochuskonkrementes nachzuweisen oder auszuschließen. Diese Cholangiographie führen wir vor der Cholezystektomie laparoskopisch durch. Vorgehensweise: Wir verwenden den SILS-Port sowie die Rotikulator-Instrumente von Covidien. Nach der Darstellung des Gallenblasenhilus und sicherer Identifikation des Ductus cysticus wird dieser gallenblasenwärts geklippt. Anschließend führen wir eine kleine Inzision in mittleren Drittel des Dct. cysticus durch und führen den Cholangiographiekatheter mit der Cholangiographiekatheter-Einführzange von Storz ein. Mit dieser Zange kann das distale Ende des Dct. cysticus so verschlossen werden, dass die Cholangiographie mit ausreichend Druck zur Entfaltung der Gallenwege durchgeführt werden kann, ohne dass Kontrastmittel in die freie Bauchhöhle austritt. Am Ende wird das System mit NaCl-Lösung gespült und die Cholezystektomie in üblicher Weise beendet. Diskussion: Die dargestellte Vorgehensweise der SILS-Cholangiographie ist technisch problemlos durchführbar und führt zu exzellenten Ergebnissen, die wir vorstellen werden.

\section{DGKCH-PV-08}

Sonomorphologie und Outcome bei Hodentorsionen im Säuglingsund Kindesalter

M. Chmelnik', J. Schenk'², U. Hinz' ', S. Holland Cunz', P. Günther'

${ }^{1}$ Chirurgische Universitätsklinik Heidelberg, ${ }^{2}$ Radiologische Universitätsklinik Heidelberg

Einführung: Die perinatale Hodentorsion (PHT) stellt neben der Hodentorsion (HT) bei älteren Kindern eine eigene Krankheitsentität mit Besonderheiten in Diagnostik und Therapie dar. Die klinische Evaluierung ist im Neugeborenenalter oft schwierig, sodass PHTen häufig protrahiert diagnostiziert werden. Die Dopplersonographie ermöglicht zwar den Nachweis einer Perfusionsstörung, gibt aber keine Hinweise auf die Dauer der Ischämiezeit und der daraus folgenden Dringlichkeit der chirurgischen Intervention - bei lang zurückliegendem Torsionsereignis mit bereits eingetretener Hodennekrose ist keine notfallmäßige Exploration notwendig. Ziel der vorgestellten Studie war es, sonomorphologische Parameter zur Beurteilung des Ischämieschadens zu evaluieren, um v. a. für die PHT einen Behandlungsalgorithmus zu erarbeiten.

Material und Methoden: Über einen Zeitraum von 7,5 Jahren wurden 25 konsekutive Fälle von PHT $(n=9)$ und HT $(n=16)$ retrospektiv ausgewertet. Alle Patienten wurden präoperativ sonographisch untersucht. Neben der Dopplersonographie zur Beurteilung der Perfusion wurden folgende sonomorphologischen Parameter ausgewertet und mit dem postoperativen Outcome korreliert: Normale Echogenität, diffuse Hyper-/Hypoechogenität, fokale Hyper-/Hypoechogenität. 
Ergebnisse: Für beide Gruppen (PHT + HT) zeigte sich die signifikant höchste Hypotrophie-/Atrophierate bei sonomorphologisch heterogenem Hodenparenchym mit fokaler Hyper-/Hypoechogenität.

Diskussion: Sonomorphologische Parameter geben in allen Altersgruppen wichtige Hinweise auf den Schädigungsgrad bzw. die Ischämizeit des Hodenparenchyms und die sich daraus ergebende Prognose für das testikuläre Outcome. Ein Behandlungsalgorithmus für PHT und HT wird vorgestellt. Bei dopplersonographisch gesicherter PHT zeigt ein sonomorphologisch heterogener Hoden eine fortgeschrittene Hodenschädigung an, so dass keine notfallmäßige Exploration angezeigt ist.

\section{DGKCH-PV-09}

Endoskopie bei unklarer peranaler Blutung im Kindesalter. Kinderchirurgische Sicht

R. González-Vásquez, G. Cernaianu, J. Engert, R. Tröbs

Stiftung Katholisches Krankenhaus Marienhospital Herne Kinderchirurgische Klinik der Ruhr-Universität Bochum

Fragestellung: Ermittlung der diagnostischen Effizienz der Dickdarmendoskopie im Kindesalter anhand einer single institution-Serie.

Material und Methode: Wir analysieren die auswertbaren Endoskopien zwischen 1994 und 2009, die in unserer Kinderchirurgischen Klinik durchgeführt wurden. Bei 408 Patienten wurden 459 Endoskopien des unteren Darmtraktes durchgeführt, davon 348 wegen peranaler Blutung.

Ergebnisse: Wir führten 311 flexible Koloskopien und 37 starre Rektoskopien durch. In 220 Fällen erfolgten Biopsieentnahmen.

Es ergaben sich folgende Diagnosen: Kolitis 98 (unspezifisch 70, CED 17, allergisch 11), Polypen 73 (17 oral des Sigmabereichs), Analrhagaden bzw. Perianalekzem 25, massive Blutung 9 (Meckel'sches Divertikel 6, sonstige 3), Rektalulkus 6, lymphatische Hyperplasie 6, Z. n. Sigmavolvulus 3, sonstige Befunde 13, kein pathologischer Befund 112.

Das Komplikationsspektrum umfasste bei 3 Kindern Bauchschmerzen und Meteorismus sowie bei 2 Kindern schwerere Komplikationen (1 Aspirationspneumonie, 1 postoperative Anurie). Es gab keine postoperative Blutung oder Perforation.

Zusätzliche diagnostische Maßnahmen: Meckelszintigraphie 25, RöKM-Studie 14, andere 3, Kontroll-Koloskopie 19, Rektoskopie 4.

Es erfolgten 14 Laparotomien, 5 Laparoskopien und eine intraoperative Endoskopie im Anschluss.

Diskussion: Die Abklärung der unklaren peranalen Blutung führt häufig zur Koloskopie. Diese wird gut toleriert. In fast $2 / 3$ der Fälle wird eine Ursache nachgewiesen, meist Kolitiden und Polypen. Viele Polypen liegen proximal des Sigma, was die Notwendigkeit der totalen Koloskopie unterstreicht. Bei unklarem Befund oder Rezidiv sind die Meckelszintigraphie oder die Wiederholung der Endoskopie notwendig. Massive Blutungen können die anschließende Laparotomien bzw. Laparoskopien erfordern.

Schlussfolgerung: Kolitiden und Polypen sind die häufigsten Befunde bei den Endoskopien des unteren Darmtraktes bei Kindern, die uns zur Abklärung zugewiesen wurden. Die Dickdarmendoskopie besitzt eine hohe Treffsicherheit zur Diagnose bzw. Ausschluß einer Blutungsursache im Darm.

\section{DGKCH-PV-10}

\section{Das Swyer Syndrom: Die Rolle der Kinderchirurgie}

\section{Kapapa' ${ }^{1}$ D. Henne-Bruns ${ }^{2}$, C. Leriche ${ }^{1}$}

${ }^{1}$ Sektion Kinderchirurgie, ${ }^{2}$ Klinik für Allgemein-, Viszeral- und Transplantationschirurgie

Fragestellung: Das Swyer Syndrom ist für Kind und Eltern eine familiäre Herausforderung. Bei Verdacht auf Streakgonaden sollte die komplette Diagnostik in kurzer Zeit erfolgen und die prophylaktische Gonadektomie wegen des erhöhten Entartungsrisikos schnellstmöglich durchgeführt werden. Wir berichten über einen Fall.
Material und Methode: Ein 14 Jahre altes Mädchen, welches zunächst eine altersgerechte Entwicklung zeigte, erscheint äußerlich unauffällig. Im Pubertätsalter entwickelten sich typische Symptome mit primärer Amenorrhoe, ausbleibender Thelarche und einem sonographisch auffälligen inneren Genitale. Das MRT erbrachte den Verdacht auf Streakgonaden und die Chromosomenanalyse ergab einen XY- Karyotyp, Die diagnostische Urethrozysto- und Vaginoskopie mit anschließender Laparoskopie zeigte intraoperativ eine typische Streakgonade rechts und eine Gonade mit Tumorverdacht links sowie eine Leistenhernie rechts. Es erfolgte die komplette Gonadektomie und die inguinale Herniotomie rechts. Postoperativ erfolgte ein Ganzkörper PET CT und ein CT Thorax zur Tumorsuche. Bei unauffälliger Bildgebung erfolgen weitere Kontrollen.

Ergebnisse: Histologisch konnte eine typische Streakgonade mit ovariellem Stroma und Verkalkungen ohne Primordialfollikel nachgewiesen werden. Die tumorös veränderte linke Seite zeigte ausgedehnte Verbände eines in Nekrose stehenden malignen Keimzelltumor, eines Dysgerminoms. Tuben- und Fimbrienanteile wurden auf beiden Seiten mit entfernt, es konnte eine Ro Resektion erreicht werden.

Diskussion: In der 7./8. Embryonalwoche Veränderung durch den fehlenden/ mutierten Hoden-determinierende Faktor (TDF). Das Protein, welches von dem SRY-Gen codiert wird, entscheidet über die Entwicklung von zunächst indifferenten Gonadenanlagen. Fehlt es, kommt es zur Ausbildung von Klitoris, Labien, Vagina und Uterus. Die Ovarien werden nicht gebildet, an deren Stelle befinden sich sogenannte Streakgonaden. Bei verzögerter Pubertätsentwicklung ist die genaue Familienanamnese ebenso wichtig wie die zügige Diagnostik, da die verzögerte Diagnosestellung eines Swyer- Syndroms eine inkomplette Tumorentfernung sowie Metastasenbildung zur Folge haben kann. Dies hat einen signifikanten Einfluss auf die Lebenserwartung.

Schlussfolgerung: Ab dem 1. Lebensjahrzehnt neigen Streak-Gonaden in 20-30 Prozent dazu maligne zu entarten. Die prophylaktische Entfernung muß umgehend nach Diagnosestellung erfolgen. Die Swyer-Betroffenen sind infertil, daher ist die lebenslange Hormonsubstitution ist unverzichtbar. Der hormonell stimulierte Uterus macht es jedoch theoretisch möglich, ein Kind nach einer Eizellspende auszutragen.

\section{DGKCH-PV-11}

\section{De La Torre auf dem Prüfstein - ein 4-Jahres-Rückblick}

C. Baier ${ }^{1}$, H. Menzel ${ }^{2}$, B. Romeike 3 , F. Eckoldt ${ }^{1}$

${ }^{1}$ Friedrich Schiller Universität, ${ }^{2}$ Abteilung für Kinderradiologie Jena, ${ }^{3}$ Institut für Pathologie

Hintergrund: Eines von 5000 Neugeborenen leidet an einem M. Hirschsprung (Lantiere at al. 2008). Die Klinik reicht vom Ileus des Neugeborenen bis zur chronischen Obstipation des Kleinkindes. Insbesondere Mutationen des RET-Knockout-Gens am Chromosom 10 sind für den menschlichen M. Hirschsprung verantwortlich. (Cass 2000). Gerade bei Aganglionosen bis zum rektosigmoidalen Übergang hat sich in den letzten Jahren die transanale Resektion nach De La Torre durchgesetzt.

Methoden: Wir führten eine Nachuntersuchung unserer Patienten mit M. Hirschsprung der letzten 4 Jahre durch. Dabei wurden Klinik, OPMethoden und postoperative Komplikationen verglichen.

Ergebnisse: Retrospektiv wurden 17 seit 2006 wegen M. Hirschsprung behandelte Patienten untersucht (14/17 männlich). 4/17 Patienten wiesen weiteren Fehlbildungen auf (Trisomie 21, Syndaktylie, etc.). 15/17 Patienten erkrankten schon in den ersten Lebenstagen am M. Hirschsprung. 2/17 Kinder erkrankten erst im 6. Lebensmonat im Rahmen der Nahrungsumstellung. 8/17 Neuerkrankten erhielten einen transanalen Durchzug nach De La Torre. Hierbei lag das Lebensalter der operativen Erstversorgung zwischen dem 2. Lebensmonat und dem 5 Lebensjahr ( $5 \mathrm{x}$ bis 6. Lebensmonat und $3 \mathrm{x}$ im 11-48. Lebensmonat). Ein Enterostoma musste vor der definitiven operativen Versorgung bei 2/8 Kindern angelegt werden (Kind 1: nicht beherrschbarer Ileus am 3. LT, Kind 2: totale Aganglionose des Kolons). Der stationäre Aufenthalt betrug im Durchschnitt 12 Tage. Am 10. postoperativen Tag wurden die Kinder 
regelmäßig in Narkose anal kalibriert. Hierbei musste bei 2/8 Kindern die Anastomosennaht revidiert werden. Ein Kind entwickelte frühzeitig eine Stenose. Im späteren Verlauf litt $1 / 8$ Kindern unter Obstipation, 2/8 Kindern unter Enterokolitis. Diese Verläufe konnten unabhängig vom Operationsalter beobachtet werden. Nur bei Kind 2 (totale Aganglionose des Kolons) war ein Zweiteingriff notwendig. Insgesamt wurde bei den Patienten über 5-11 Monate postoperativ anal kalibriert. 1/17 Patient mit einem ultrakurzen Segment wurde mit einer Sphinktermyektomie nach Lynn versorgt. 3/17 Patienten mit ultrakurzem Segment konnten bisher konservativ geführt werden. 4/17 Patienten hatten schon Jahre zuvor bzw. in anderen Einrichtungen eine operative Versorgung (2xRehbein, 1xDuhamel, $1 \mathrm{x}$ De La Torre) erhalten und wurden aufgrund von Komplikation erneut z. T. unter Stomataschutz operiert. Schlussfolgerung: Die Analyse unserer Daten reflektiert die aus der Literatur bekannten Geschlechterverteilungen und Komorbiditäten. Die primär nach de la Torre operierten Patienten zeigten gute Ergebnisse unabhängig vom Operationsalter. Zweizeitige Operationen konnten weitgehend vermieden werden, wobei wir großen Wert auf die anale Untersuchung und Kalibrierung in Narkose am 10. postoperativen Tag legten. Engmaschige Nachkontrollen bis mindesten 1 Jahr postoperativ und die Anleitung der Eltern vermeiden Spätkomplikationen.

\section{DGKCH-PV-12}

\section{Adjuvante homöopathische Therapie in der Kinderchirugie}

R. Böhm, A. Neugebauer, H. Till

Klinikum der Universität Leipzig AöR

Einleitung: In den Kinderkliniken ist die Homöopathie zunehmend gefragt, wenn sie auch nur in wenigen Einrichtungen angeboten wird. In der Klinik für Kinderchirurgie der Universität Leipzig wird seit Juli 2009 in der posttraumatischen und -operativen Schmerztherapie eine adjuvante homöopathische Medikation als zusätzliche Option bereitgestellt.

Methodik: Nach Commotiones, Extremitätenverletzungen, thermischen Verletzungen und postoperativ wurde eine begleitende homöopatische Therapie angeboten, die Akut-Anamnese, und -Symptome berücksichtigend. Als Arzneien wurden nach standardisiertem Schema aus dem Spektrum der typischen homöopathischen Notfallmedikamente verabreicht: Aconitum, Arnica, Cantharis, Hypericum und Staphisagria,. Nach 2, 4 und 8 bzw. 12 Stunden erfolgte jeweils die Reevaluierung und Dokumentation der Beschwerden.

Ergebnisse: Es wurden insgesamt 135 Behandlungen durchgeführt. In insgesamt 113 Fällen wurde Arnica verabreicht. 23 Kinder mit einer Commotio cerebri, 12 hiervon mit Erbrechen erhielten jeweils eine Einmalgabe. Ein unmittelbare Besserung (2h) trat bei 9 Kindern ein (39\%), im Verlauf (nach 4-8h) bei 9 Kindern (39\%), keine nennenswerte Verbesserung in diesem Zeitraum war bei 5 Kindern (21\%) festzustellen. 33 bzw. 57 Kinder erhielten nach operativer Versorgung von Frakturen bzw. nach sonstigen operativen Eingriffen gleichfalls Arnica mit Besserung nach o. g. Zeitintervall in 22 bzw. 45 Fällen ( 66 bzw. 78\%). Staphisagria wurde nach Schnittverletzungen oder nach Laparotomien bei 8 Kindern verabreicht und Cantharis nach therm. Verletzungen bei 2 Kindern; Aconitum war das Medikament der Wahl bei posttraumatischen Angstzuständen oder vor Verbandswechseln bei 11 Kindern. Die Erfolgsrate lag zwischen 68 und $85 \%$. Konservativ und allopathisch nicht zu beherrschende Phantomschmerzen bei einem Pat. nach traumatischer Amputation waren nach einer Einmalgabe von Aconitum und in der Folge Hypericum innerhalb weniger Stunden abgeklungen. Diskussion und Schlussfolgerung: Unsere Studie will als eine Summe von standardisiert dokumentierten Einzelbeobachtungen adjuvanter homöopatischer Therapie nach Verletzungen und nach Operationen verstanden werden. Ausschlaggebend für die Bewertung war der Eindruck der Pflegekräfte, der Eltern sowie der an dieser Erhebung mitwirkenden ärztlichen Kollegen nach einem festen Zeitschema. Während die genannten Commotiones keine weitere Schmerz-Medikation erhielten, erfolgte die Anwendung in den anderen Fällen zusätzlich zu einem festen Basis-Analgesie Konzept - dies muss in der Bewertung berücksichtigt werden. Trotzdem haben unsere Erfahrungen gezeigt, dass die adjuvante homöopathische (Schmerz)-Therapie in einem definierten Zeitintervall nach Gabe zu einer Besserung der Befindlichkeit in $66-85 \%$ der Fälle beiträgt. Dies ermutigt uns, unser Evaluationskonzept auf kontrollierte Studienbedingungen auszuweiten.

\section{DGKCH-PV-13}

Thymus in der Thyroidea - Kasuistik bei unklarem solitärem Schilddrüsenknoten

C. Staufner, S. Holland-Cunz

Universitätsklinikum Heidelberg, Chirurgische Klinik

Schilddrüsenknoten sind im Kindesalter selten, als bisher wenig bekannte Ursache kann intrathyroidal gelegenes Thymusgewebe vorliegen.

Die Indikationsstellung zur histologischen Abklärung mittels offener Biopsie kann nicht unmittelbar aus den Empfehlungen der Erwachsenenmedizin abgeleitet werden.

Anhand des klinischen Falls eines 8 jährigen Mädchens mit einem solitären Schilddrüsenknoten werden die Indikation zur Biopsie, sowie der ungewöhnliche Befund diskutiert. Die Patientin war asymptomatisch, laborchemisch ergab sich kein pathologischer Befund, insbesondere keine erhöhten Tumormarker. Der solitäre Knoten zeigte sich in regelmäßigen Verlaufskontrollen sonographisch leicht größenprogredient, so dass bei unklarer Dignität des Prozesses sowie schlechter Abgrenzbarkeit die Indikation zur sparsamen Hemithyroidektomie gestellt wurde. Es zeigte sich histologisch intrathyroidales Thymusgewebe.

Bisher sind erst sehr vereinzelte Fallbeschreibungen hierzu bekannt, die Mehrzahl davon im Kindesalter. Zervikales ektopes Thymusgewebe ist ein relativ häufiger Befund, der jedoch meist unentdeckt bleibt. Intrathyroidales Thymusgewebe ist als Relikt aberranter Thymuswanderung embryologisch zu erklären.

Bei unklarem solitärem Schilddrüsenknoten im Kindesalter ist die Enukleation beziehungsweise sichere offene Gewebegewinnung angezeigt. Differentialdiagnostisch sollte auch an intrathyroidales Thymusgewebe gedacht werden, uns ist jedoch keine diagnostische Maßnahme bekannt, die dies ohne histologische Aufarbeitung klären kann.

\section{DGKCH-PV-14}

Workflow-Analysen zur statistischen Beurteilung neuer laparoskopischer Techniken und neuer Instrumente.

U. Bühligen', R. Wachowiak', R. Böhm', T. Woller', M. Weißer', H. Till' , T. Neumuth $^{2}$, S. Schumann ${ }^{2}$, B. Kaschek ${ }^{2}$

${ }^{1}$ Klinik und Poliklinik für Kinderchirurgie, Universität Leipzig, ${ }^{2} I C C A S$ (Innovative Center Computer Assisted Surgery)

Statistisch gesicherte Aussagen zu verschiedensten Abläufen von operativen Vorgängen und Arbeitsschritten können Workflowanalysen liefern. Unter Verwendung eines definierten Modellaufbaus haben wir diese Prinzipien angewandt, um laparoskopische Techniken und laparoskopisches Instrumentarium zu testen und mit statistischen Analysen zu vergleichen.

Material und Methode: Unter standardisierten Bedingungen führten wir drei verschiedene Arbeitsschritte aus:

1. Schneiden (= resezierendes Verfahren)

2. einfache Naht fortlaufend (= verschließendes Verfahren)

3. Anastomosennaht fortlaufend (= rekonstruktives Verfahren).

Die laparoskopische Technik beinhaltete:

- konventionelle gerade Instrumente in konventioneller Technik (3 Trokarpositionen)

- konventionelle gerade Instrumente in SILS Technik (1 Tripeltrokarposition im Nabel)

- TEM- Instrumente gekröpft in konventioneller Technik (3 Trokarpositionen)

- TEM- Instrumente gekröpft in SILS Technik (1 Tripeltrokarposition im Nabel).

(TEM $=$ Transanale Endoskopische Mikrochirurgie) 
Jeder Arbeitsschritt wurde pro Testperson fünfmal vorgenommen, so dass je 15 Durchläufe für eine laparoskopische Technik analysiert und statistisch ausgewertet werden konnten. Damit standen pro Person insgesamt 6o Datensätze zur Verfügung (bei 10 Personen entspricht das 600 Datensätzen).

Ergebnisse: 1 . In konventioneller 3-Trokar-Technik ist die Arbeit mit gekröpften Instrumenten (TEM) 4mal schneller (=signifikant) als mit geraden Instrumenten, bei gleicher Qualität.

2. Das Absolvieren der Übungen dauerte mit gekröpften Instrumenten (TEM) in 1-Trokar-Technik ca. 3mal länger (=signifikant) als mit geraden Instrumenten in konventioneller 3-Trokar-Technik. Dabei gibt es keinen signifikanten Unterschied in der Qualität.

3. In 1-Trokar-Technik ist die Zeitdauer mit gekröpften Instrumenten (TEM) deutlich geringer (=signifikant) als mit geraden Instrumenten, bei gleicher Qualität der Leistung.

Schlussfolgerungen: Die Workflowanalyse unter standardisierten Bedingungen kann ausreichend Daten für die Beurteilung laparoskopischer Arbeitsgänge erheben. Sie erlaubt sichere, statistisch fundierte Aussagen über alle registrierten Parameter. Damit erhalten wir objektive Ergebnisse, die konventionelle und neu entwickelte laparoskopische Operationsverfahren und Instrumente in ihrer Effektivität und Qualität vergleichbar einschätzen können.

\section{DGKCH-PV-15}

\section{Die dislozierte distale Unterarmfraktur im Kindesalter nach der} Reposition: - K-Draht oder nicht ?

D. Großmann, C. Müller, W. Barthlen

Ernst-Moritz-Arndt Universität Greifswald

Einleitung: Nach Reposition einer dislozierten Unterarmfraktur im Kindesalter stellt sich die Frage, ob das Repositionsergebnis mit einer K-Drahtosteosynthese gesichert werden sollte oder eine Ruhigstellung im Gips ausreichend ist.

Patienten und Methode: Retrospektive Krankenblattstudie an Jugendlichen, die von 1998 - 2007 behandelt wurden. Der Altersdurchschnitt lag bei 11 Jahren, das Verhältnis von Jungen zu Mädchen war $2: 1$.

Ergebnisse: Der linke Arm war mit 54,5\% häufiger betroffen als der Rechte $(43,6 \%)$, sieben Kinder $(1,9 \%)$ hatten doppelseitige Frakturen. Insgesamt wurden 215 Frakturen versorgt. In 27,44\% ( $n=59)$ der Fälle handelte es sich um isolierte Radiusfrakturen, bei 71,63\% ( $n=154)$ lag zusätzlich eine Fraktur im Bereich der Ulna vor. Epiphysäre Läsionen des Radius wurden bei 30,7\% ( $n=66)$ der Frakturen beobachtet.

Bei $37,67 \%(n=81)$ Frakturen erfolgte eine primäre osteosynthetische Versorgung. Davon 35,35\% ( $n=76)$ mit Kirschnerdrähten, o,93\% $(n=2)$ mit ESIN und 1,4\% $(n=3)$ mit ESIN und Kirschnerdrähten kombiniert. Dislokationen nach erfolgter osteosynthetischer Stabilisierung traten nicht auf. Als postoperative Komplikation traten bei 2 Patienten leichte Pintrakt- Infektionen der K-Drähte auf, die nach der Metallentfernung folgenlos abheilten.

$62,8 \%(n=134)$ der Frakturen wurden lediglich reponiert und im Oberarm-Gips ruhiggestellt. Bei 17 Patienten aus diesem Kollektiv (12,7\%) kam es zur erneuten Dislokation. Nach Re-Reposition wurde bei einem Patienten eine erneute Gipsruhigstellung vorgenommen. Bei den verbleibenden 16 Patienten wurde das Re-Repositionsergebnis mit einer Osteosynthese fixiert (ESIN $\mathrm{n}=1$, Kirschnerdraht $\mathrm{n}=13$, ESIN und Kirschnerdraht $\mathrm{n}=2$ )

Schlussfolgerung: Aufgrund der beträchtlichen Rate an sekundären Re-Dislokationen und der geringen Rate an operativen Komplikationen erscheint eine großzügige Indikationsstellung zur Osteosynthese nach Reposition einer dislozierten distalen Unterarmfraktur im Kindesalter angebracht. Die perkutane Kirschnerdrahtfixation ist dabei das von uns bevorzugte Verfahren.
DGKCH-PV-16

Weichteildefektdeckung bei Kindern: R. Grabs, P. Chatzopoulos, M. Ghods

Klinikum Ernst v. Bergmann

Fragestellung: Haut- Weichteildefekte mit freiliegenden funktionellen Strukturen an den Extremitäten stellen eine große Herausforderung für den Chirurgen dar. Besonders bei Kindern ist der Erhalt der Funktionalität sehr bedeutsam. Hierbei ist ein besonderes Augenmerk auf die Narben in Bezug auf das Wachstum und die Vermeidung von Kontrakturen zu legen. Aus diesem Grund ist neben einem Hautersatz auch ein Weichteilersatz erforderlich. An den Extremitäten ist die Möglichkeit lokaler Lappenplastiken begrenzt, weswegen freie mikrovaskulär anastomosierte Lappenplastiken auch bei Kindern ihren Stellenwert haben.

Material und Methode: In den letzten 12 Monaten haben wir 4 Kinder und Jugendliche zwischen 4 und 16 Jahren mit Defekten der Extremitäten operativ behandelt. Die Ursachen der chronischen Wunden waren in 2 Fällen Dekubitalulcera $(n=2)$ und in 2 Fällen instabile Narben mit Gelenkkontrakturen nach Verbrennung $(n=2)$. Ein Kind erheilt eine lokale Rotationslappenplastik von der Fußsohle auf die Ferse, eins einen fasziokutanen Tensor fasciea latea Lappen. Ein weiteres Kind erheilt einen gestielten Leistenlappen auf die Hand und eins eine mikrovaskulär anastomosierte Perforator-Lappenplastik (ALT-Lappen) auf den Fuß.

Ergebnisse: Wir hatten weder vollständige noch teilweise Lappenverluste zu beklagen. Alle Lappenplastiken heilten primär ein und verschlossen den jeweiligen Defekt vollständig.

Die funktionellen Ergebnisse waren durchweg gut.

Diskussion: Defektdeckungen an den Extremitäten von Kindern stellen eine große Herausforderung dar. Bei geeigneter Indikationsstellung, optimaler Operationsplanung und operativer Erfahrung besteht die Möglichkeit Extremität und Funktionalität zu erhalten. Sobald funktionelle Strukturen freiliegen ist eine Defektdeckung durch Lappenplastiken erforderlich. Insbesondere aufgrund des Wachstums ist eine gute Weichteildeckung mit entsprechend gelegten Narben erforderlich um spätere Gelenkkontrakturen beziehungsweise Wachstumsstörungen zu vermeiden. Unsere bisherigen Ergebnisse zeigen, dass neben einer guten operativen Behandlung auch die postoperative Betreuung mit entsprechender Pflege und krankengymnastischer Übungsbehandlung von großer Bedeutung ist.

Schlussfolgerung: Tiefe Defektwunden an den Extremitäten sind eine interdisziplinäre Herausforderung. Hierbei sollten zum Erhalt der Funktionalität neben Kinderärzten, Kinderchirurgen, Intensivmedizinern auch Plastische Chirurgen in die Therapieplanung mit einbezogen werden. 


\section{Jahrestagung der Deutschen Gesellschaft für Sozialpädiatrie und Jugendmedizin}

\section{Freitag, 17. September 2010}

\author{
Postersitzung \\ DGSPJ-P0-01 \\ Kenntnisstand von Zahn- und Kinderärzten zu oralen Auswirkungen \\ von Kindesvernachlässigung und -misshandlung \\ R. Schilke, I. Finke, W. Geurtsen \\ Medizinische Hochschule Hannover
}

Fragestellung: In einer repräsentativen Befragung sollte vergleichend der Kenntnisstand und die Erfahrungen von Zahnärzten und Kinderärzten zu Kindesvernachlässigung und -misshandlung ermittelt werden.

Methode: Von März bis November 2009 wurde ein Fragebogen an 1000 allgemeinzahnärztliche $(Z), 260$ schwerpunktmäßig kinderzahnärztliche $(\mathrm{K})$ sowie 260 pädiatrische Praxen $(\mathrm{P})$ zweimalig bundesweit versandt.

Ergebnisse: Die Rücklaufquote betrug 37,4\% (Z), 49,2\% (K) und 30,8\% (P). Das mittlere Alter der Antwortenden betrug 45,2 $\pm 9,2$ (Z), 40,8 $\pm 6,6$ $(\mathrm{K})$ und 52,0 $\pm 7,8(\mathrm{P})$ Jahre. $63,2 \%(\mathrm{Z}), 15,1 \%(\mathrm{~K})$ bzw. 59,5\% (P) waren

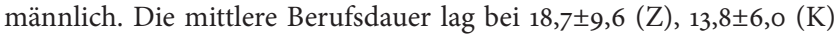
und 22,3 $\pm 9, \mathrm{O}(\mathrm{P})$ Jahren.

Vernachlässigung (Z: 67,1\%, K: 86,6\%, P: 96,2\%) und Misshandlung (Z: 49,3\%, K: 73,2\%; P: 86,1\%) werden als relevante Themen für den Beruf gesehen. 68,9\% (Z), 75,0\% (K) bzw. 78,2\% (P) sind der Ansicht, dass sie in einer guten Position sind, Kindesvernachlässigung aufzudecken. 68,6\% (Z), 74,2\% (K) bzw. 94,4\% (P) fühlen sich in der Lage, Anzeichen von Kindesvernachlässigung zu erkennen (Misshandlung: 52,2\% (Z), 48,7\% (K), 91,4\% (P)). 77,1\% (Z), 83,3\% (K) bzw. 63,9\% (P) sehen einen direkten Zusammenhang zwischen oraler und allgemeiner körperlicher Vernachlässigung. 36,1\% (Z), 26,2\% (K) bzw. 32,5\% (P) sind der Ansicht, dass orale Vernachlässigung keine Art von Kindesmisshandlung ist. Dass wiederholte Erkrankungen oder Verletzungen der Zähne ein Anzeichen für Vernachlässigung oder Misshandlung sein können, wurde von $89,2 \%(\mathrm{Z}), 84,8 \%$ (K) bzw. 93,4\% (P) bejaht. 87,8\% (Z), 80,3 (K) bzw. 93,5\% (P) halten ein Kind für vernachlässigt, bei dem trotz ärztlicher Aufklärung über bestehende kariöse Läsionen und orale Entzündungen eine zahnärztliche Konsultation und Behandlung unterbleibt. 48,2\% (Z), 69,3\% (K) bzw. 93,7\% (P) hatten bereits den Verdacht, dass Kindesvernachlässigung vorgelegen hat (Misshandlung: 16,7\% (Z), $35,4 \%(\mathrm{~K}), 87,3 \%(\mathrm{P})$ ). In diesen Fällen haben $23,4 \%(\mathrm{Z}), 13,8 \%(\mathrm{~K})$ bzw. 2,9\% (P) nichts Weiteres unternommen (bei Misshandlung: 21,4\% (Z), $18,6 \%(\mathrm{~K}), \mathrm{o} \%(\mathrm{P}))$.

10,1\% (Z), 5,5\% (K) und 39,2\% (P) gaben an, dass Vernachlässigung oder Misshandlung (Z: $11,5 \%, \mathrm{~K}: 7,9 \%$, P: $51,3 \%$ ) während des Studiums thematisiert wurden. 75,0\% (K) bzw. 86,3\% (P) haben nach Studienabschluss eine Fortbildung zu diesen Themen besucht (Z: 6,2\%). Über Bücher oder Zeitschriften haben sich 96,3\% (P) über diese Themen informiert (Z: 61,6\%, K: 71,9\%). 87,7\% (Z), 95,3\% (K) bzw. 81,3\% (P) würden es begrüßen, wenn mehr Informationen zu diesen Themen zur Verfügung stünden.

Schlussfolgerungen: Kinderärzte zeigen eine höhere Sensibilisierung und Sicherheit im Erkennen von sowie im Umgang mit Kindesvernachlässigung und -misshandlung. Wie in der pädiatrischen Ausbildung sollten beide Themen sowohl in das zahnmedizinische Curriculum als auch in die Fortbildungsangebote aufgenommen und zusätzlich weitere Informationsquellen angeboten werden. Unterstützt durch Nationales Zentrum Frühe Hilfen (Projekt 1. 4).

\section{DGSPJ-PO-02}

Führt die verbesserte Technik des kranialen MRT auch zu einer erhöhten Aussagekraft der Befunde?

P. Streibert ${ }^{1}$, W. Piroth ${ }^{2}$, P. Borusiak ${ }^{3}$

'Universität Witten/Herdecke, ${ }^{2} \mathrm{HELIOS}$ Klinikum Wuppertal, ${ }^{3}$ Klinikum

Wuppertal GmbH Zentrum f. Kinder- u. Jugendmedizin

Fragestellung: Die MRT-Diagnostik wurde in den vergangenen Jahren durch die Erweiterung der untersuchten Sequenzen incl. zusätzlicher Dünnschichttechniken bei Routineuntersuchungen verbessert. Ziel unserer Untersuchung war die Klärung, ob dies auch im klinischen Alltag einen relevanten Informationsgewinn bringt. Von besonderem Interesse war die Gruppe der Kinder, bei denen die Indikation „Kopfschmerzabklärung“ vorlag, wobei dies nach den Leitlinien in den allermeisten Fällen keine klare medizinische Indikation darstellt und die Untersuchung überwiegend aus Angst vor einem Tumor durchgeführt wird.

Methode: Retrospektiv wurden die MRT von 1004 Untersuchungen an Kindern zwischen 1 und 17 Jahren (MW= 8,23 J.; $\mathrm{SD}=5,06 \mathrm{~J}$.) ausgewertet $(538 \mathrm{~m}, 466 \mathrm{w})$. Die Indikationen betrafen u. a. Kinder mit Epilepsien, Entwicklungsstörungen und Kopfschmerzen, sowie Diagnostik bzw. Verlaufskontrollen bei Kindern mit Hirntumoren und Hydrocephalus, Die Gruppe der Kinder, die vor der Umstellung der Technik untersucht wurde $(n=419)$, wurde mit derjenigen nach Umstellung auf Dünnschichttechnik incl. neuer Sequenzen verglichen $(\mathrm{n}=585)$. Ferner wurde bei allen Kindern mit den neuen Untersuchungssequenzen eine Reduktion der Bilder auf die alte Technik durchgeführt und die Aufnahmen i. S. einer eigenen Kontrollgruppe verglichen. Als relevant wurden Befunde definiert, die die Symptomatik erklären, weitere diagnostische Maßnahmen nach sich ziehen oder Änderungen im therapeutischen Vorgehen bedingen.

Ergebnisse: Mit der alten Untersuchungstechnik waren in der Gesamtgruppe auffällige Befunde bei 248/419 (59,2\%) der Kinder festzustellen. Hiervon konnten 100/248 (40,3\%) als relevant eingeordnet werden, bei $148 / 248$ (59,7\%) wurden die Befunde als Zufallsbefunde ohne Bezug zur klinischen Fragestellung oder pathologischen Wert eingeordnet (z. B. kleine unspezifische Gliosen). Bei den neuen Sequenzen waren bei 410/585 (70,1\%) Das ist ja eine ganze Menge - stimmen die zahlen ware ja schon gut! pathologische Befunde zu diagnostizieren, hiervon 174/410 (42,4\%) mit klinischer Relevanz. Bei Rückführung auf die alten Sequenzen waren 170/174 (97,7\%) der relevanten Befunde ebenfalls in vergleichbarer Qualität erkennbar. In der Untergruppe der Kinder mit 
der Indikation „Kopfschmerzen“ zeigten sich auffällige Befunde bei 114/216 (52,8\%) Kindern der Gesamtgruppe (35/74 bei der alten Untersuchungstechnik und 79/142 bei den neuen Verfahren). Hiervon war keiner der Befunde als klinisch relevant einzuordnen. Bei Reduktion der Bilder der neuen Untersuchungssequenzen auf die alte Technik waren alle Befunde ebenfalls zu erkennen. Bei Kindern mit epileptologischer Fragestellung oder in der (Verlaufs-)Diagnostik bei Tumoren oder Blutungen zeigten sich in den neuen Sequenzen bei 9/183 (4,9\%) Patienten Befunde, die mit der alten Technik nicht darstellbar gewesen wären und einen Erkenntnisgewinn bedeuten.

Schlussfolgerung: In unserer Untersuchung konnten wir keinen wesentlichen Erkenntnisgewinn für die Patienten mit Kopfschmerzen feststellen. Bei Kindern mit anderen Fragestellungen ergaben sich in Einzelfällen Befunde, die mit der alten Untersuchungstechnik nicht feststellbar waren und eine Änderung des klinischen Vorgehens nach sich zogen.

\section{DGSPJ-PO-03}

Neuro- und sozialpädiatrische Aspekte einer Langerhanszell-Histiozytose-Erkrankung - eine Kasuistik

H. Kühne' ${ }^{1}$, R. Schmid' ', I. Schmid² H. Schwarz², N. Arijanto ${ }^{3}$

'Zentrum für Kinder und Jugendliche, ${ }^{2}$ Klinikum der Universität München, ${ }^{3}$ Kreiskrankenhaus Alt-Neu-Ötting

Bei der Langerhanszell-Histiozytose (LCH) können verschiedenste Organe befallen sein. Bei ZNS-Befall werden in bis zu 70\% neurodegenerative Veränderungen v. a. im Kleinhirn beschrieben. Besonders zum Vorgehen bei neurodegenerativen Veränderungen bestehen Unsicherheiten. Hirnmorphologische Umwandlungen und klinische Folgen verlaufen im unterschiedlichen Tempo. Welchen Stellenwert haben neben Bildgebung $u$. a. Maßnahmen regelmäßige neurologische, entwicklungsdiagnostische Untersuchungen für das therapeutische Vorgehen und welche Schlussfolgerungen leiten sich für die sozialpädiatrische Betreuung ab?

Material und Methode: Anhand der Kasuistik eines 11-jährigen Mädchens mit Langerhanszell-Histiozytose werden der mehrdimensionale Krankheitsverlauf mit speziellem Blick auf die neurologische Problematik beschrieben und die Therapie- bzw. Testergebnisse vorgestellt.

Ergebnisse: Onkologischer und endokrinologischer Verlauf:

Bei dem seinerzeit 6-jährigen Mädchen erfolgt nach Diagnosesicherung von ossären Veränderungen eine systemische Chemotherapie mit Cladribine. Kontrolluntersuchungen zeigen danach keine LCH-Aktivität, aber zunehmende neurodegenerative Veränderungen speziell im Kleinhirn. Ein sich seit dem 4. Lebensjahr entwickelnder Panhypopituitarismus macht eine regelmäßige Hormonsubstitution erforderlich. Neuropädiatrischer und neuropsychologischer Verlauf: Zwischen dem 6. und 8. Lebensjahr nehmen bei dem Mädchen neurologische Veränderungen und motorisch-koordinative Schwächen zu. Die neuropsychologische Diagnostik zeigt einen leichten Abfall der Gesamtintelligenz und deutliche Einbußen in der Handlungsintelligenz und Visuomotorik. Im psychoemotionalen Bereich entwickeln sich Auffälligkeiten in der Mutter-Kind-Interaktion.

Diskussion: Bei der Patientin mit einer multisystemischen LCH zeigt sich ein als prognostisch günstig einzuschätzendes Ansprechen auf eine systemische Chemotherapie. Der Panhypopituitarismus ist gut steuerbar. In Übereinstimmung mit der Literatur scheinen neurodegenerative Veränderungen therapeutisch weniger gut beeinflussbar. Die Testergebnisse zeigen eine anfänglich rasche, aktuell geringere Zunahme neurologischer Auffälligkeiten. Die eingeleiteten Therapien (medikamentöse Therapie, Ergotherapie, Krankengymnastik, Psychotherapie) werden dementsprechend modifiziert. Das Outcome ist unsicher.

Schlussfolgerungen: Der Krankheitsverlauf widerspiegelt die aktuelle Behandlungsproblematik von neurodegenerativen Veränderungen bei LCH. Die Verlaufsergebnisse stützen die in den Leitlinien geforderten regelmäßigen neurologischen/neuropsychologischen Untersuchungen. Die sozialpädiatrische Betreuung ist weiter notwendig und wird fortgeführt.

\section{DGSPJ-PO-04}

Evaluation der Hautkrebskampagne „Immer auf der Hut“ im Land Brandenburg

U. Sadowski, E. Seidel, G. Ellsäßer

Landesgesundheitsamt Brandenburg

Hintergrund: UV-Strahlung verursacht schon in der Kindheit und Jugend Schäden in der Epidermis. Plattenepithelkarzinom, Basalzellkarzinom oder malignes Melanom können im späteren Leben auftreten, wenn entsprechende genetische Prädispositionen und bestimmte Expositionsmuster vorliegen. Die Gesundheitsbehörden müssen deshalb ihre Bemühungen verstärken, die Öffentlichkeit - und insbesondere Kinder und Jugendliche - über einen gesundheitsbewussten Umgang mit natürlicher und künstlicher UV-Strahlung aufzuklären. Auch Kindergärtner/-innen und Erzieher/-innen haben eine besondere Verantwortung und Vorbildfunktion, wenn es um den Sonnenschutz geht. Für das Land Brandenburg wurden vom Ministerium für Arbeit, Soziales, Gesundheit und Familie und dem Landesgesundheitsamt im Jahr 2007 verschiedene „Maßnahmen zur Prävention von Hautkrebs" vorgeschlagen. Die Umsetzung dieses Programms begann 2008 mit einer Aktion unter dem Motto „Immer auf der Hut.“. Diese ist eine Gemeinschaftsaktion mit dem Verband der Ärzte des Öffentlichen Gesundheitsdienstes der Länder Berlin und Brandenburg e. V. und wird in Kooperation mit dem Netzwerk Gesunde Kita und der AOK Brandenburg durchgeführt. Wichtigste Zielgruppe sind Kinder im Vorschulalter in Kindereinrichtungen. Sie wendet sich ebenso an die für die Erziehung verantwortlichen Personenkreise (Eltern, Kindergärtner/-innen, Erzieher/-innen) mit dem Ziel, dass diese angeregt werden, das Thema Sonnenschutz in der pädagogischen Arbeit aufzugreifen und Sonnenschutzmaßnahmen zu einem festen Bestandteil im Alltag zu machen. Dabei soll auf die altersgerechte Vermittlung der drei wichtigsten Maßnahmen der Primärprävention von Hautkrebserkrankungen - Vermeidung erhöhter UV-Exposition durch vernünftiges Verhalten und strukturelle Veränderungen, wie z. B. Schaffung von Schattenplätzen im Freien, textiler Sonnenschutz und Anwendung von Sonnenschutzmitteln - besonderes Augenmerk gerichtet werden.

Material und Methoden: Externe summative Evaluation (Ergebnisbezogene Ex-Post - Erhebung), Quantitatives Vorgehen /Erhebung über Fragebögen. Auswertung des standardisierten Fragebogens über Statistikprogramm/ SPSS.

Ergebnisse/Diskussion: Ziel der Evaluation ist die Ermittlung der tatsächlichen Inanspruchnahme/Verteilung der Flyer + Mützen durch die Gesundheitsämter (KJGD) und der Koordinierungsstelle „Netzwerk Gesunde Kita“ an die Kindertagestätten im Land Brandenburg (Phase 1). Aufbauend auf der Phase 1 soll in einem zweiten Evaluationsteil untersucht werden:

. ob die Aufklärungsbroschüre eine altersgerechte Information darstellt und wie diese von den Eltern und Erzieher/innen bewertet wird,

- ob eine Verhaltensveränderung bei der Zielgruppe stattgefunden hat, - ob der Sonnenschutz in die pädagogischen Alltagsroutinen der Erzieher/innen und der Eltern integriert wurde,

- welche strukturellen Schutzmaßnahmen in der Kita initiiert wurden.

\section{DGSPJ-PO-05}

\section{Einstellungen zum Stillen bei Müttern deutsche und türkischer Her-} kunft

A. Hilbig, L. Stahl, Ö. Avci, J. Dinter, M. Kersting

Forschungsinstitut für Kinderernährung

Hintergrund: Stillen ist ein zentrales Thema in der Säuglingsernährung. Empfohlen wird ausschließliches Stillen in den ersten 4-6 Lebensmonaten und anschließendes Teilstillen neben einer altersgemäßen Beikost. Die letzte bundesweite Erhebung zu Stillquoten (SuSe) 1997/98 zeigte, dass etwa ein Drittel der Säuglinge mit 4 Monaten vollgestillt wurde. Einstellungen und Motive von Müttern unterschiedlicher ethnischer Herkunft zum Stillen wurden in Deutschland bisher kaum untersucht. 
Methode: Für diese Auswertung wurden 10 leitfadenzentrierte Interviews durchgeführt, um Einstellungen und Verhaltensweisen zu Ernährung und Gesundheit von Säuglingen und Kleinkindern bei deutschen $(n=5)$ und türkischstämmigen $(n=5)$ Eltern zu erfassen. Der Leitfaden umfasste u. a. die Themenbereiche Stillen und Beikost. Die Interviews wurden nach Transkribierung und Übersetzung mittels qualitativer Inhaltsanalyse ausgewertet.

Ergebnisse: Alle interviewten Mütter fanden Stillen wichtig und hatten ihre Kinder auch gestillt. Die Meinungen über die optimale Stilldauer gingen zwischen deutschen und türkischen Müttern auseinander. Unabhängig vom kulturellen Hintergrund wurde Voll- und Teilstillen vielfach nicht eindeutig unterschieden. Im Vergleich zu deutschen Müttern hielten türkische Mütter eine längere Stilldauer für empfehlenswert und sie stillten ihre Kinder auch über das erste Lebensjahr hinaus noch eher weiter.

Die Motive für das Stillen waren vielfältig. Für türkischstämmige Mütter standen die gesundheitlichen Vorteile des Stillens im Vordergrund. Zusätzlich waren für deutsche Mütter soziale und praktische Gründe wichtig.

Wurde die von den Müttern genannte optimale Stilldauer als „Norm“ verstanden, so führte bei den meisten Müttern das Nichteinhalten dieser „Norm“ zu inneren Konflikten. Sowohl bei türkischen als auch bei deutschen Müttern äußerte sich dieser innere Konflikt in Unsicherheit und Rechtfertigungen u. a. für das - früher als geplante - Einführen von Flaschennahrung oder Beikost. Subjektive Gründe für das vollständige oder teilweise Abstillen waren u. a. zu geringe Milchmenge, gesundheitliche Beschwerden der Mutter, aber auch der Wille nach mehr Unabhängigkeit. Nur zwei der zehn Mütter waren mit ihrer Stillsituation voll zufrieden.

Schlussfolgerung: Trotz unterschiedlicher Motive und Einstellungen scheint das Nichteinhalten der Stillempfehlung als vermeintliche „Norm“ für Mütter deutscher und türkischer Herkunft mit inneren Konflikten verbunden zu sein. Diesen ersten Ergebnisse eines qualitativen Forschungsansatzes muss in weiteren Untersuchungen nachgegangen werden. Bis dahin ist es für die Still- und Ernährungsberatung angezeigt, Empfehlungen als Rahmen für eine gesunde Ernährung ohne Dogmatismus zu vermitteln, um Müttern eine ausgeglichene Stillzeit zu ermöglichen.

Mit finanzieller Förderung durch den Europäischen Integrationsfonds (EIF) via Bundesamt für Migration und Flüchtlinge (BaMF)

\section{DGSPJ-PO-06}

Verstehen Familien die allgemein üblichen Begriffe in der Säuglingsernährung? - Qualitative Analyse leitfadenzentrierter Interviews bei Müttern deutscher und türkischer Herkunft

A. Hilbig, L. Stahl, Ö. Avci, J. Dinter, M. Kersting

Forschungsinstitut für Kinderernährung

Hintergrund: Die Essgewohnheiten von Kindern werden durch soziale und kulturelle Rahmenbedingungen geprägt. Die derzeitigen ernährungsbezogenen Präventionskonzepte in Deutschland („, Der Ernährungsplan für das 1. Lebensjahr") nehmen aber keine Rücksicht auf kulturell bedingte Einstellungen. Somit stellt sich die Frage, inwieweit Migranten mit den herkömmlichen Informationsangeboten zur Kinderernährung erreicht werden. Ziel dieser Arbeit war es u. a. zu überprüfen, ob allgemein übliche Begrifflichkeiten der Säuglingsernährung (Flaschennahrung, Beikost) für deutsche bzw. türkische Familien verständlich sind.

Methode: Für diese Auswertung wurden 10 leitfadenzentrierte Interviews durchgeführt, um Einstellungen und Verhaltensweisen zu Ernährung und Gesundheit von Säuglingen und Kleinkindern bei deutschen $(n=5)$ und türkischstämmigen $(n=5)$ Eltern zu erfassen. Der Leitfaden umfasste $u$. a. die Themenbereiche Flaschennahrung und Beikost. Die Interviews wurden nach Transkribierung und Übersetzung mittels qualitativer Inhaltsanalyse ausgewertet.

Ergebnisse: Bei türkischen Müttern wurde Flaschennahrung häufig als „mama“ oder „Flaschenmama“ bezeichnet. Unklar blieb, ob neben industriell hergestellter auch selbst hergestellte Milch unter den Begriff fällt. Besonders für türkische Mütter gehörte Flaschennahrung nicht zu einer gesunden Ernährung. Gründe hierfür waren „Zugaben“ oder die lange Lagerzeit. Flaschennahrung wurde als künstlich und nachteilig für die Entwicklung der Kinder betrachtet. Für deutsche Mütter gehörte Flaschenahrung - wenn nicht gestillt werden kann - zur gesunden Ernährung dazu. Sie wurde als Alternative, aber nicht gleichwertig wie Muttermilch gesehen.

Abweichend vom deutschen Sprachgebrauch bedeutet Beikost für türkische Mütter „Bei-“ oder „Zusatznahrung“ oder Nahrung zwischen den Mahlzeiten. Türkische Mütter unterschieden selbst hergestellte und fertig gekaufte Breinahrung in den Begrifflichkeiten. Als „Löffelbrei“, „Löffelmama“ oder „Beimama“ wurden die kommerziellen Breie bezeichnet. Ähnlich wie Flaschennahrung wurden kommerzielle Breie eher kritisch bewertet. Zusätzlich gab es im türkischen Sprachgebrauch „Suppe“ oder „Püree“, was dem deutschen Gemüse-Kartoffel-FleischBrei entspricht. Alle Lebensmittel, die für die Selbstherstellung von Brei genutzt wurden, wurden unabhängig vom Alter des Kindes unter dem Oberbegriff „Essen“ zusammengefasst.

Schlussfolgerung: Die unterschiedliche Verwendung von Standardbegrifflichkeiten der Säuglingsernährung lässt erwarten, dass die derzeitigen deutschsprachigen Empfehlungen für türkische Familien nur schwer verständlich und damit auch schwer umsetzbar sind. Für Beratungskräfte in der Säuglingsernährung erscheint es wichtig, verständliche Begriffe für türkischstämmige Familien zu wählen.

Mit finanzieller Förderung durch den Europäischen Integrationsfonds (EIF) via Bundesamt für Migration und Flüchtlinge (BaMF)

\section{DGSPJ-P0-07}

„Binge-Eating“ Störung - Eine Modediagnose oder eine psychiatrische Erkrankung?

A. Bürger', F. Hammerle' ${ }^{1}$, M. Huss' 1 , J. Oepen ${ }^{2}$

${ }^{1}$ Klinik und Poliklinik für Kinder- und Jugendpsychiatrie und -psychotherapie, ${ }^{2}$ Viktoriastift

Einzelnen Berichten zu Folge leiden Untergruppen adipöser Kinder und Jugendlicher an regelmäßigen Essattacken und einer erhöhten Psychopathologie. Obwohl in den letzten Jahren mehrere Untersuchungen im Bereich der „Binge-Eating“ Störung (BES) durchgeführt wurden (Hilbert 2009, Tanofsky-Kraff 2009, Mirch 2006), wird die Diagnose in Deutschland von vielen Klinikern in Frage gestellt oder ist noch unbekannt. Der Vortrag soll einen Überblick über den derzeitigen Forschungsstand der BES im Kindes- und Jugendalter geben und eine kritische Reflexion der bisherigen DSM-IV Forschungskriterien beinhalten.

Zentrales Augenmerk liegt in der Überprüfung der klinischen Validität der BES-Kriterien. Dabei werden vier Prüfsteine diskutiert, die bei der Beantwortung hilfreich sein sollen. Erstens werden die Diagnosekriterien gegenüber normalem Essverhalten und adipösem Essverhalten abgegrenzt. Zweitens werden die Lebensqualität und das Funktionsniveau eingeschätzt mit denen von gesunden Kindern und Jugendlichen verglichen. Drittens wird der Frage nachgegangen, ob Kinder und Jugendliche mit einer BES sich von Kindern und Jugendlichen mit Adipositas oder Bulimia nervosa unterscheiden. Viertens wird dargestellt, inwieweit die BES durch bisherige psychotherapeutische Behandlungsmaßnahmen verändert werden kann. Diese Fragen werden durch aktuelle Studienbefunde unterlegt und sollen die Notwendigkeit aufzeigen, die BES in der Diagnostik und Behandlung bei adipösen Kindern und Jugendlichen stärker zu berücksichtigen. 
DGSPJ-PO-09

Adipositas-Prävention in Geraer Kitas - Ergebnisse einer Befragung zur Ernährungs- und Bewegungssituation von 30 Kitas in Ostthüringen

A. Liebmann' ${ }^{1}$, I. Funke' ${ }^{1}$, J. Seidel ${ }^{2}$

${ }^{1}$ Friedrich-Schiller-Universität Jena, ${ }^{2}$ SRH Wald-Klinikum Gera

Einleitung: Zur Schuleingangsuntersuchung 2007/2008waren in Gera und Umland $12 \%$ der 6-7 jährigen Kinder übergewichtig und $4 \%$ davon adipös. Deshalb kommt der Präventionsarbeit auch in den Kitas Ostthüringens eine große Bedeutung zu.

Zielstellung der Befragung war die Erfassung von Ernährungs- und Bewegungsgewohnheiten sowie eine Bedarfsermittlung von ProjektHilfen und finanzieller Förderung über das Netzwerk zur Adipositasprävention bei Kindern und Jugendlichen in Gera (GAP).

Ergebnisse: An der Befragung nahmen 30 von 39 angeschriebenen Kitas teil (77\%) aus allen 13 privaten sozialen Trägern teil. Der überwiegende Teil der befragten Einrichtungen gehört zu den 2 größten Trägern, der Volkssolidarität und der AWO. Der soziale Status der betreuten Kinder im Alter von 6 Monaten bis 7 Jahren setzt sich folgendermaßen zusammen: $21 \%$ aus sozial gut gestellten Familien; $20 \%$ alleinerziehenden Eltern; 19,5\% Familien mit Sozialhilfe-Unterstützung, 15\% finanziell benachteiligten Familien, 12 \% Familien mit Migrationshintergrund, 5,5 \% Isoliert lebende sowie 6,5\% gesundheitlich belastete Familien.

Über 80\% der Einrichtungen werden ausschließlich durch Caterer versorgt, nur $13 \%$ bereiten das Essen selbst zu. Der Einfluss auf die Caterer-Auswahl durch die Leiterinnen (40\%) der Einrichtungen überwiegt deutlich gegenüber dem Elterneinfluss (27\%). Entscheidende Kriterien der Caterer-Auswahl sind die Qualität; der Preis und das Preis-Leistungsverhältnis (je $20 \%$ ), während die Größe der Caterer-Firma und die Firmenphilosophie eher von untergeordneter Bedeutung $(<7,5 \%)$ sind. Spezielle Ernährungsprogramme werden in nur $20 \%$ der Kitas umgesetzt, Bewegungs-Programme demgegenüber in $1 / 3$ der Kitas. Insgesamt wird ein großes Interesse (63\%) an einer Unterstützung von Projekten durch das Geraer Netzwerk zur Adipositasprävention im Kindes- und Jugendalter (GAP; www. Gera. de; Gesundheit/Sport; Netzwerk GAP) angegeben.

Diskussion und Schlussfolgerungen: Die noch geringe Anzahl von Ernährungs-und Bewegungsprojekten in den Geraer Kitas stellt eine wesentliche Chance zur Verbesserung der Präventionsarbeit dar. Weiterhin zeigt sich, dass eine größere Einbeziehung der Eltern notwendig ist. Das GAP-Netzwerk steht den Einrichtungen zur Projektetablierung und -begleitung zur Verfügung. Die personelle und finanzielle Projektförderung wird über das Netzwerk in direkter Zusammenarbeit mit den regionalen Krankenkassen, dem „Rotary Club Gera“ und weiteren privaten Förderern getragen. Auch erste gute Erfahrungen in der Elternarbeit können über das GAP-Netzwerk vermittelt werden.

\section{DGSPJ-PO-10}

EMDR als hilfreiches Therapiemodul in einem salutogenetisch orientierten psychosomatischen Therapieprozess bei Kindern und Jugendlichen

C. Johannsen ${ }^{1}$, M. Meusers ${ }^{2}$, A. Längler ${ }^{1}$

${ }^{1}$ Gemeinschafts-Krankenhaus, ${ }^{2}$ Gemeinschaftskrankenhaus Herdecke

Seit mehr als einem Jahr wird auf der Station für pädiatrische Psychosomatik in der Abteilung für Kinder und Jugendmedizin im Gemeinschaftskrankenhaus Herdecke EMDR (Eye Movement Desensitization and Reprocessing) als optionales Therapiemodul eingesetzt. In diesem Zeitraum kam in 15 von 134 Fällen EMDR zur Anwendung. Die Behandlungsdiagnosen reichten von Enuresis über dissoziative Krampfanfälle bis hin zu Schulvermeidung bei V. a. Frühtraumatisierung.

In der qualitativen Auswertung der Therapieverläufe ergab sich zusammenfassend, dass EMDR bei richtiger Indikationsstellung eine äußerst effektive Methode ist, die sich gut in das salutogenetisch-lösungsorien- tierte Therapiekonzept mit kurzen Verweildauern (Mittlere Verweildauer: 22 Tage) einfügt.

Das im EMDR-Prozess neben der Begegnung mit dem Trauma vermittelte Menschenbild, „dass Menschen ein angeborenes Streben nach Gesundheit und Anpassung eigen ist“ (Shapiro 2002,68), ist für die Patienten im Therapieprozess direkt erfahrbar. Die Patienten erleben sich in diesem Verfahren unmittelbar als Hauptakteure: der Patient macht und kontrolliert den Prozess, der Therapeut bietet dafür Struktur und Rahmen. Sie erleben dadurch direkt Selbstwirksamkeit und Koherenzgefühl. Dies führt im weiteren zum positiven Gefühl der Beeinflussbarkeit der eigenen Situation und der Möglichkeit eine positivere Zukunft für sich zu gestalten.

Die mit dem Patienten in der EMDR-Therapie erarbeiteten traumatherapeutischen Techniken der Stabilisierung („Sicherer Ort“), Ressourceninstallation, der Distanzierung (Innerer Beobachter) und das vor der bifokalen Stimulation notwendige exakte Isolieren der Belastungenssituationen - Teilen der Gesamtbelastung (Traumatisierung) in bearbeitbare („verdauliche“) Untereinheiten - bleiben den Kindern und Jugendlichen als salutogenetisch wirksame Kompetenzen über den stationären Aufenthalt hinaus erhalten.

Der gesamte Therapieprozess erhält dadurch positive Impulse, so dass EMDR in unserer Behandlung ein selbstverständliches Modul geworden ist.

Anhand von 3 der genannte 15 Fälle werden im Vortrag die Indikation, die EMDR-Therapie und die Ergebnisse im psychosmatischen Setting vorgestellt.

15-jähriger Junge mit Hauptdiagnose Enuresis nocturna

14-jähriger Junge mit chronischen Kopfschmerzen

13-jähriges Mädchen mit dissoziativen Synkopen

\section{DGSPJ-PO-11}

Integratives Therapiekonzept der Enuresis nocturna im stationären psychosomatischen Setting

C. Johannsen'1, M. Meusers², A. Längler'

${ }^{1}$ Gemeinschafts-Krankenhaus, ${ }^{2}$ Gemeinschaftskrankenhaus Herdekce

Die Enuresis nocturna ist ein gängiges Krankheitsbild der kinderärztlichen Praxis. Mit zunehmendem Alter der Patienten steigt der Leidensdruck, so dass bei frustranen ambulanten Therapieversuchen die stationäre psychosomatische Behandlung indiziert ist.

In unserer Klinik behandeln wir seit $3 \frac{1}{2}$ Jahren Patienten mit diesem Krankheitsbild in einem multimodalen psychosomatischen Therapiesetting unter Verwendung von systemischen und verhaltenstherapeutischen Ansätzen erweitert durch therapeutische Maßnahmen der anthroposophischen Medizin.

Zentraler Punkt unseres Ansatzes ist die Auffassung, dass der monosymptomatischen Enuresis nocturna in der Regel eine Reifunsverzögerung zugrunde liegt. Dies wird in der Psychoedukation den Patienten und ihren Familien vermittelt und führt bereits im Aufnahmegespräch oft zur Entlastung und Entschuldung der Familien, die durch die Sympotmatik sekundär psychisch belastet und beinträchtigt sind. Die im psychosomatischen Setting mögliche ausführliche Anamnese ermöglicht eine umfassende Wahrnehmung des Patienten und seines Umfelds. Subtile Hinweise für die Reifungsverzögerungen lassen sich häufig auch in anderen Bereichen finden: z. B. ein gestörter Wärmehaushalt (Leiden an kalte Extremitäten), motorische Koordinationsprobleme, altersunangemessene Verträumtheit oder Intellektualität u. a.. Neben den symptombezogenen Heilmitteln ergeben sich anhand des individuellen Profils der Stärken (Qualitäten) und Schwächen (Schwierigkeiten) des Patienten konstituionelle spezifische Medikamente aus dem homöopathischen und phytotherpeutischen Arzneimittelfundus der Anthroposophischen Medizin ergänzt durch künstlerische Therapien wie Mal-, Musiktherapie oder Heileurythmie.

Diese Maßnahmen unterstützen die Motivation und Kooperation der Kinder und Jugendlichen bei der Strukturierung des Trink- und Toilettenverhaltens tagsüber und beim verhaltenstherapeutisch orientierte Wecktraining des Nachts. Einerseits wird dadurch ein trocken Bett 
erreicht, andererseits eine positive Gewohnheitsbildung für die Schlafrhythmik. In den „gefährlichen“ Zeiten kommte es im Verlauf zu einem leichteren Schlaf. Den Kindern und Jugendlichen und ihren Familien wird damit eine klare Methode an die Hand gegeben die Zusammenhänge und die Möglichkeiten für ein trockenes Bett in ihrem individuellen Fall zu erfahren. Die Optionen der Klingelhose/ Matte als weiteres Trainingsmodul und das ADH als „Sicherheitsgurt“ bei Klassenfahrten werden mit den Familien erörtert.

In den meisten Fällen ist ein Verschwinden der Symptomatik oder eine deutliche Verringerung der „nassen Nächte“ erreicht worden. Mit den Informationen und Erfahrungen der stationären Therapie entstand in jedem Fall für die Familien eine Grundlage die ambulanten Therapie mit geringerer Belastung, angepasst an die Entwicklungsgegebenheiten ihres Kindes, fortzusetzen.

Im Vortrag/Poster wird das psychoedukative Konzept unserer Klinik mit Wecktraining und die eingesetzten Heilmittel der Anthroposophischen Medizin dargestellt.

\section{DGSPJ-PO-12}

Wieviel wissen Eltern über Säuglingspflege - „Babyführerschein“ ja oder nein?

B. Lehner' ${ }^{1}$, R. Kerbl ${ }^{2}$

'Univ. Klinik für Kinder- und Jugendheilkunde, ${ }^{2}$ Landeskrankenhaus Leoben-Eisenerz

Fragestellung: Wieviel wissen Eltern über Säuglingspflege - „Babyführerschein" ja oder nein?

Methodik: Mittels Fragebogen für Eltern (mit Kindern von einem Alter bis zu zwei Jahren) und eines Fragebogens für KinderärztInnen, wurde das Wissen von 94 Eltern und die Einschätzung dessem durch 88 KinderärztInnen eruiert.

Für ordinalskalierte Daten wurden Median und Spannweite, Mittelwert und Standardabweichungberechnet. Die Signifikanztests, mit denen die Kontrollgruppen Kinderklinik vs. kinderfachärztliche Praxis, InländerInnen vs. MigrantInnen und höhere Bildung vs. niedrige Bildung verglichen wurden, wurden mit SPSS mittels Mann-Whitney-U-Test und dem $\mathrm{CHI}_{2}$-Test berechnet.

Ergebnisse: Gute Kenntnisse zeigen Eltern in den Bereichen Ernährung und Pflege, allerdings Wissens-defizite in den Bereichen Schlafen (SIDS), Impfungen sowie Kinderkrankheiten und deren Behandlungsmöglichkeiten. Dies wird von KinderärztInnen ähnlich eingeschätzt. Wissensdefizite in den Bereichen SIDS und Impfungen sind signifikant häufiger bei MigrantInnen, Eltern aus der Praxis als auch bei Eltern mit niedriger Bildung zu finden als in ihrer Kontrollgruppe.

Die größten Defizite sehen KinderärztInnen in einer Falsch/Überinformation, in der Einschätzung des Schweregrades der Erkrankung, Ernährung, Fieber, Erziehung, Hautpflege und banale Infekte. Hauptprobleme bei MigrantInnen sehen sie in der Sprachbarriere, Ernährung und Überfütterung, sowie den geringeren Hygienestandard.

49 Prozent der KinderärztInnen wünschen einen verpflichtenden Säuglingsvorbereit-ungskurs, jedoch nur ein Drittel der befragten Eltern.

Diskussion: Studien aus England und Schweden zeigen, dass junge, alleinerziehende Frauen mit einer anderen Muttersprache als der Landessprache am schwersten für eine Teilnahme an Elternbildungsveranstaltungen zu erreichen sind.

Um die Gesundheit von Kindern mit Migrationshintergrund zu verbessern, ist ein Abbau von sprachlichen und kulturellen Kommunikationsbarrieren notwendig, da diese Kinder häufiger von Adipositas, Entwicklungsstörungen (allen voran Sprachentwicklungsstörungen), Karies, einer höheren Säuglingssterblichkeit und einer höheren Gewaltbereitschaft betroffen sind als Kinder ohne Migrationshintergrund.

Um auch diese Elterngruppe besser erreichen zu können, wäre ein niederschwelliges Beratungskonzept von Vorteil, z. B durch eine Kooperation von Kinderärzten/ Allgemeinmedizinern mit Mutter-Kind-Spielgruppen, Kinderflohmärkten und/ oder mit Sprachkursveranstaltungen für Migranteneltern.
Um eine Stigmatisierung einzelner Elterngruppen zu vermeiden, wäre die Integration von Elternbildung am Arbeitsplatz ein Lösungsvorschlag.

Schlußfolgerung: Zusammenfassend betrachtet wäre eine verpflichtende Schulung werdender Eltern, insbesondere an die Mutter-KindPass-Untersuchungen und den Erhalt des Kinderbetreuungsgeldes geknüpft, in mancher Hinsicht sicher vorteilhaft, sie lässt sich aber sowohl juristisch als auch emotional vermutlich nicht leicht umsetzen.

\section{„neues musik forum" - Musik als Begegnung}

\section{DGSPJ-SY-08 \\ Musikphysiologie vom Kindesalter an}

Die Sensomotorik des Musizierens ist einzigartig: neben anspruchsvollen koordinativen Fertigkeiten, feinmotorischer Präzision und geschultem Körpergefühl ist eine Integration verschiedener Sinneswahrnehmungen erforderlich, zudem bestehen ausgeprägte emotionale Kopplungen. Professionelles Musizieren erfordert also eine jahrzehntelange, äußerst komplexe Tätigkeit, permanent auf höchstmöglichem Niveau und von Außenstehenden in ihrer technischen und künstlerischen Qualität bewertet.

Musikphysiologische Zusammenhänge und eine Schulung der Körperwahrnehmung müssen daher bereits im frühen Instrumentalunterricht berücksichtigt werden - sowohl unter dem Aspekt der Prävention physischer und psychomentaler Überlastung, als auch unter dem Aspekt der leichteren Entfaltung musikalischer Potentiale.

\section{DGSPJ-SY-10}

Synchronisation - ein relevantes Moment nicht nur in der Musiktherapie

Inhalt: Sich zeitlich und emotional auf einen anderen Menschen einstellen und genau abstimmen zu können, hat "synchrone Momente" zur Folge. Diese Erfahrung spielt sowohl beim Musizieren wie bei der Behandlung von schwer beziehungsgestörten Menschen eine Rolle. Anhand von videographierten Sequenzen aus der musiktherapeutischen Arbeit mit tiefgreifend entwicklungsgestörten Kindern und Ausschnitten aus Herbert von Karajans Probenarbeit und Aufführungspraxis wird das Thema veranschaulicht.

Kurzvita: Karin Schumacher, Prof. Dr. rer. sc. mus., studierte an den Musikuniversitäten Wien und Salzburg Musiktherapie und Elementare Musik- und Bewegungserziehung. Heute lehrt sie an der Universität der Künste Berlin und der Musikuniversität Wien und ist als Musiktherapeutin und Kinder- und Jugendlichenpsychotherapeutin in freier Praxis tätig.

\section{DGSPJ-SY-11}

Transfereffekte des Musizierens bei Kindern

Durch den „Mozart-Effekt" wurde die Aufmerksamkeit der Öffentlichkeit auf vermeintlich intelligenzfördernde Wirkungen des Hörens bestimmter Musik gelenkt. Obwohl sich diese Behauptung nicht bestätigen ließ, bleibt offen, welche anderen Auswirkungen das Hören von Musik aber auch das Erlernen eines Musikinstruments auf die kindliche Entwicklung haben kann. Der Vortrag gibt einen kurzen Überblick über den Stand der Erkenntnisse und diskutiert verschiedene Antwortmöglichkeiten. Hierbei werden kognitive, soziale und affektive Kompetenzen einbezogen.

\section{DGSPJ-SY-9}

Musik und Emotion aus Perspektive der sozial-affektiven Neurowissenschaft

Ein Grund, weshalb uns Musik so viel Spaß macht, ist, dass Musik soziale Funktionen aktivieren und fördern kann. Z. B. haben wir beim Musizieren Kontakt mit anderen Menschen (und wir empfinden uns nicht allein, selbst wenn wir nur Musik hören), wir aktivieren unsere „soziale Kognition“ (d. h., wir beschäftigen uns z. B. damit, was 
andere Menschen uns durch die Musik mitteilen möchten), wir empfinden ähnliches wie die Musiker/innen bzw. die Mitspieler/innen, wir kommunizieren über Musik, koordinieren unsere Bewegungen beim Musizieren oder Tanzen, handeln beim Musizieren oder beim Tanzen kooperativ und erfahren, dass sich soziale Bindungen dadurch stärken. Dieser Vortrag beschreibt den Zusammenhang zwischen Musik und sozialen Funktionen und geht dabei auch darauf ein, wie Musik in unseren Gehirnen verarbeitet wird.

\section{Samstag, 18. September 2010}

\author{
Internationale Klassifikation der \\ Funktionsfähigkeit: WHO-Kriterien im \\ Praxiseinsatz \\ DGSPJ-SY-13 \\ ICF in der praktischen Anwendung in der Kinderrehabilitation \\ J. Oepen \\ Viktoriastift Bad Kreuznach
}

Die Rehabilitation von Kindern und Jugendlichen ist im stationären Bereich strukturiert durch die Anforderungen des Sozialgesetzbuchs V (für die gesetzlichen Krankenkassen) und des Sozialgesetzbuch VI für die Deutsche Rentenversicherung.

Das grundsätzliche Denken des SGB IX das die ICF als übergreifendes Gesetzbuch kann dabei als gesetzliche Form der ICF angesehen werden. Dabei sind die Regelungen des SGB IX über die funktions-bezogene Ermittlung des Leistungsbedarfs sowie die mit der medizinischen Rehabilitation verfolgten Ziele auch unmittelbar geltendes Recht für die Erbringung von Leistungen der Krankenbehandlung, bei denen besonderen Belangen behinderter und chronisch kranker Menschen Rechnung zu tragen ist.

Im stationären Bereich hat die Bundesarbeitsgemeinschaft für Rehabilitation (BAR) 2008 ein „Gemeinsames Rahmenkonzept der Gesetzlichen Krankenkassen und der Gesetzlichen Rentenversicherung für die Durchführung stationärer medizinischer Leistungen der Vorsorge und Rehabilitation für Kinder und Jugendliche" herausgegeben, das die Prinzipien der ICF als Grundlage der Vorgehensweise festlegt.

In diagnosebezogenen Leitlinien der Deutsche Gesellschaft für Pädiatrische Rehabilitation und Prävention (DGPRP seit 2001) und „Rahmenempfehlungen ambulante Rehabilitation Kinder und Jugendliche" (DGSPJ und DGPRP 2007) ist ebenfalls die Zielorientierung und Orientierung an Aktivitäten und teilhabe als verbindliche Grundlage der Rehaplanung festgelegt worden.

Die Umsetzung der ICF in der konkreten Rehabilitations-Arbeit mit Kodierung ist dagegen nur punktuell und sehr unterschiedlich erfolgt, z. B. in der "Verordnung von medizinischer Rehabilitation“ (Formular „61/ 63"), neuropädiatrische Rehabilitation) - hierfür gibt es verschiedene Begründungen, die im Ansatz diskutiert werden sollen. funktionsbezogene Feststellung des Leistungsbedarfs im Sinne der ICF, die Zielorientierung der Leistungen sowie die Erbringung bzw. Ausführung von Leistungen nach anderen Sozialleistungsgesetzen, insbesondere die Krankenversorgung im Bereich der gesetzlichen Krankenversicherung sowie von Leistungen der Pflege und der Pflegeversicherung setzt.
DGSPJ-SY-15

ICF aus Sicht der Kostenträger am Beispiel der sozialmedizinischen

Nachsorge

T. Mandel, A. Niedling

GKV-Spitzenverband

Der Vortrag befasst sich mit der sozialmedizinischen Begutachtung von Kindern und Jugendlichen am Beispiel der sozialmedizinischen Nachsorge nach $₫ 43$ Abs. 2 SGB V

unter Berücksichtigung der ICF und erläutert die leistungsrechtlichen Hintergründe

dieser Leistung.

Seit 01. 01. 2004 können die Krankenkassen sozialmedizinische Nachsorgemaßnahmen erbringen. Mit dem GKV-OrgWG sind zum 18. 12. 2008 Änderungen der Rechtsvorschriften der sozialmedizinischen Nachsorgemaßnahmen ( $\$ \$ 43$ Abs. 2 und 132 C SGB V) in Kraft getreten. Die gesetzlichen Krankenkassen erbringen aus medizinischen Gründen in unmittelbarem Anschluss an eine Krankenhausbehandlung nach $₫ 39$ Abs. 1 SGB V oder stationäre Rehabilitation erforderliche sozialmedizinische Nachsorgemaßnahmen für chronisch kranke oder schwerstkranke Kinder und Jugendliche, die das 14. Lebensjahr, in besonders schwerwiegenden Fällen das 18. Lebensjahr, noch nicht vollendet haben. Voraussetzung für die Inanspruchnahme dieser Leistung ist, dass die Nachsorge wegen der Art, Schwere und Dauer der Erkrankung notwendig ist, um den stationären Aufenthalt zu verkürzen oder die

anschließende ambulante ärztliche Behandlung zu sichern.

Im Vordergrund dieser als Beipiel dienenden sozialmedizinischen Begutachtung von Kindern und Jugendlichen stehen dabei nicht die Diagnosen nach ICD 10, sondern die altersrelevanten Beeinträchtigungen der Aktivitäten und Teilhabe mit den daraus resultierenden Interventionsnotwendigkeiten.

Fazit: Bei der sozialmedizinischen Nachsorge handelt es sich nicht um eine medizinische Behandlung, sondern um eine (koordinierende) Maßnahme, die den Zugang zu einer adäquaten medizinischen Leistung erleichtern oder ermöglichen soll.

Die sozialmedizinische Begutachtung dieser Leistung basiert auf der ICF-Nomenklatur.

\section{Sonntag, 19. September 2010}

\section{Freie Vorträge}

\section{DGSPJ-FV-2}

Outcome bei pränatal diagnostizierter Agenesie des Corpus callosum V. Raile, J. Stupin, L. Urbrock, H. Freitag, W. Henrich, T. Michael Charité Campus Virchow

Fragestellung: Postnatale Entwicklung von Kindern mit pränatal sonographisch diagnostizierter Agenesie des Corpus Callosum (ACC) und damit Implikationen für die pränatale Beratung.

Methoden und Kohorte: Untersucht wurden Kinder, bei denen im Zeitraum 2000-2007 im pränatalen Ultraschall die Diagnose ACC gestellt wurde, die Bestätigung erfolgte durch eine prä- oder postnatale MRT-Untersuchung. Ausgeschlossen wurden Fälle mit weiteren ZNSFehlbildungen, ausgenommen Hydrocephalus. Bei $n=21$ wurde pränatal eine ACC diagnostiziert, in einem Fall wurde die Diagnose postnatal nicht bestätigt. Lebend geboren wurden $\mathrm{n}=16$ Kinder, 2 Kinder starben im Alter von 3 Tagen bzw. 19 Monaten, 4 Familien konnten nicht rekrutiert werden, somit wurden $n=9$ Kinder entsprechend des Protokolls nachuntersucht. Die Nachuntersuchung erfolgte im Alter von 2,4-8, o Jahre mit: neuropädiatrischem Status, Intelligenz- oder Entwicklungs- 
tests(Bayley Scales, HAWIVA, SON-R, HAWIK IV), Adaptivem Verhalten (Vineland Adaptive Behavior Scales (VABS II)).

Ergebnisse: Ein isolierter Balkenmangel wurde bei 3 Kindern im MRT bestätigt, davon entwickelte 1 Kind einen shunt-pflichtigen Hydrocephalus in den ersten 6 Lebensmonaten. Motorische Entwicklung: Motorisch altersgerecht: 2 Kinder, leichte Koordinationsstörung der Grob- u. Feinmotorik: 6 Kinder (freies Laufen ohne Hilfsmittel möglich), schwere körperliche Beeinträchtigung: 1 Kind. Kognitive Entwicklung: IQ $\geq 85: 4$ Kinder, IQ 70-84: 1 Kind, IQ 50-69: 1 Kind, IQ <50: 3 Kinder. Ein assoziierter Hydrocephalus wirkte sich nicht negativ auf die kognitive Entwicklung aus. Im Gegenteil: die Kinder mit einem shunt-pflichtigen Hydrocephalus erreichten tendentiell höhere IQ-Werte als die Kinder mit isoliertem Balkenmangel. Bei $n=7$ Kindern traten im klinischen Verlauf weitere Komorbiditäten auf: Dystrophie/ Sondenernährung, Sehbehinderung, Sprachstörung, Epilepsie, dilat. Kardiomyopathie mit Herztransplantation.

Zusammenfassung: Die Entwicklung von Kindern mit pränatal diagnostiziertem Balkenmangel zeigt eine große Bandbreite. Motorisch zeigen die Kinder in unserem Kollektiv bis auf 1 Kind keine oder nur dezente Auffälligkeiten. Kognitiv auffällig sind 5 von 9 Kindern, hiervon 3 mit einer schweren geistigen Behinderung. Die in der Literatur beschriebene mögliche altersgerechte Entwicklung bei isoliertem Balkenmangel konnten wir in unserem Kollektiv nicht bestätigen. Damit lassen sich aus unserer Sicht aufgrund der rein morphologischen pränatalen Diagnostik keine Rückschlüsse auf das postnatale Outcome ziehen.

\section{DGSPJ-FV-3}

\section{Psychische Störungen bei Kindern mit Infantiler Zerebralparese (ICP)} und Spina bifida

K. Kohleis, M. Storck

Ostfalia Hochschule für Angewandte Wissenschaften

Fragestellung: Zur psychosozialen Adaption von Kindern mit zerebralen Bewegungsstörungen liegen nur relativ wenig kontrollierte Studien vor. Unser Beitrag gibt einen Überblick über den aktuellen Forschungsstand.

Zerebrale Bewegungsstörungen sind ein Risikofaktor für die Entwicklung komorbider Verhaltensauffälligkeiten. Im Vergleich zu gesunden Kindern liegen die Prävalenzraten psychopathologischer Symptome bis zu fünfmal höher (McDermott et al., 1996). Nach Parkes et al. (2008) zeigen ca. $42 \%$ der Kinder mit ICP im Alter von 8-12 Jahren grenzwertige/ auffällige Gesamtsymptomwerte in der Strength and Difficulties Questionnaire (SDQ). Am häufigsten treten dabei Probleme mit Gleichaltrigen, Hyperaktivität und Unaufmerksamkeit auf.

Bei Kindern und Jugendlichen mit Spina bifida stehen insbesondere internalisierende Störungen, ein niedriges Selbstwertgefühl, Passivität und sozialer Rückzug im Vordergrund (z. B. Lavigne et al., 1988; Holmbeck et al., 2003).

Insgesamt scheinen die psychopathologischen Symptome sich früh zu manifestieren und stabil über die Zeit zu erhalten (Goodman, 1998). Schon Kleinkinder zeigen Schwierigkeiten in den Bereichen Anhänglichkeit und Weinen, Schlaf und Angst (Elternurteil). Die Ergebnisse der Untersuchungen verdeutlichen ebenfalls, dass die psychischen Probleme der Kinder und Jugendlichen oft unbemerkt mit den körperlichen Beeinträchtigungen einher gehen, obwohl sie das Alltags- und Familienleben stark beeinträchtigen können.

Schlussfolgerung: Die genaue Kausalitätskette für die erhöhten Prävalenzraten psychischer Störungen ist bislang ungeklärt. Biologische Faktoren (z. B. IQ, Funktionsstatus, neurologische Begleitstörungen) sowie familiäre- und Umweltfaktoren (z. B. sozioökonomischer Status, familiäre Belastungen) interagieren und beeinflussen den Entwicklungsprozess der Kinder. Die zum Teil stark differenzierten Störungsprofile der ICP- Subtypen und Spina bifida scheinen aber einen signifikanten Einfluss der Ätiopathogenese zu belegen.

\section{DGSPJ-FV-4}

Prävalenz von Kopfschmerzen bei Kindern im Vorschulalter

H. Gärtner, F. Ebinger

Klinikum d.Ruprecht-Karl- Universität

Fragestellung: In den letzten Jahrzehnten war ein starker Anstieg der Kopfschmerzhäufigkeit von Schulkindern und Jugendlichen zu beobachten. Die wenigen existierenden Studien zur Epidemiologie von Kopfschmerzen bei Vorschulkindern zeigen dieselbe Tendenz. Die Ursachen dieser Zunahme sind unklar.

Wir führten eine Studie zur Prävalenz von Kopfschmerzen im Vorschulalter, zur näheren Charakterisierung dieser Kopfschmerzen und zur Identifikation möglicher Ursachen oder Risikokonstellationen durch.

Methoden: In 21 Arztpraxen für Kinder- und Jugendmedizin im Stadtund Landkreis Heidelberg wurden Eltern, die mit ihrem Kind zu den Vorsorgeuntersuchungen U8 oder U9 (43.- 48. Lebensmonat [LM] bzw. 6o.- 64. LM) kamen, um das Ausfüllen eines Fragebogens gebeten. Darin wurden Erfahrungen des Kindes mit Kopfschmerzen und deren genaue Charakterisierung erfragt. Zudem wurden Angaben zu Alter und Geschlecht, zur sonstigen Gesundheit und zur Betreuungssituation des Kindes sowie Daten zum Sozial- und Migrationsstatus der Familie erhoben.

Ergebnisse: In einem Zeitraum von 12 Monaten wurden 630 Fragebögen ausgefüllt. 32,6 \% aller Kinder hatten schon einmal Kopfschmerzen, dabei besteht kein signifikanter Geschlechtsunterschied.

Mit dem Alter steigt die Häufigkeit der Kopfschmerzerfahrungen, von $25,4 \%$ aller Kinder im 4. Lebensjahr (LJ) (37.- 48. LM) über $26,7 \%$ aller Kinder im 5. LJ (49.- 60. LM) bis auf 41,1\% aller Kindern im 6. LJ (61.72. LM).

Ungefähr ein Viertel aller Kinder (24,8\%) hatte innerhalb der letzten 6 Monate Kopfschmerzen.

Als vermutete Auslöser wurden bei der Hälfte der Kinder Infekte angeben, bei 50\% wurden jedoch KEINE bzw. NICHT NUR Infekte als Ursache angesehen.

Kinder, die nur den halben Tag in Kindergarten oder Kindertagesstätte verbringen, hatten signifikant weniger häufig Kopfschmerzerfahrungen als Kinder, die dort den ganzen Tag verbringen (28,6\% gegen $43,0 \%$ ). Dieser Unterschied ist nicht durch eine unterschiedliche Altersstruktur beider Gruppen erklärbar, da sie sich in ihrer Altersverteilung stark ähneln.

Diskussion: Die Ergebnisse unserer Studie zeigen im Vergleich zu anderen Untersuchungen im Vorschulalter (Mortimer 1992, Sillanpäa \& Urponen 1984, Sillanpää et al. 1984, Ellert et al. 2007) eine höhere Häufigkeit von Kopfschmerzen bei Kindern. Erklärung dafür sind sowohl unterschiedliche Methoden möglicherweise aber auch ein Anstieg der Prävalenz, wie er für Schulkinder gezeigt wurde (Bille 1997, Anttila et al. 2006). Um dies zu beantworten, ist von uns eine Folgestudie mit gleicher Methodik geplant.

Schlussfolgerungen: Kopfschmerzen sind auch schon bei Vorschulkindern ein häufiges Problem. Bei vielen Kindern gibt es keinen bzw. nicht ausschließlichen Zusammenhang zwischen Infekten und Kopfschmerzen. Dies gibt Hinweise auf das frühe Auftreten primärer Kopfschmerzen. Die Zuordnung zu Migräne oder Kopfschmerzen vom Spannungstyp ist jedoch häufig nicht möglich. Der Zusammenhang zwischen Betreuungsdauer und Kopfschmerzerfahrungen sollte in weiteren Studien untersucht werden.

\section{DGSPJ-FV-5}

Qualitätsstandards der AGA zur Behandlung adipöser Kinder und Jugendlicher

U. Tiedjen', T. Reinehr ${ }^{2}$, R. Holl ${ }^{3}$

${ }^{1}$ Fachklinik Sylt, ${ }^{2}$ Vestische Kinderklinik, ${ }^{3}$ Universität Ulm

Die Arbeitsgemeinschaft Adipositas im Kindes- und Jugendalter (AGA) hat sich in den letzten Jahren die Schaffung von Qualitätsstandards zur Behandlung adipöser Kinder und Jugendlicher mit zum Ziel 
gesetzt. Es wurden Zertifizierungsrichtlinien für Therapieeinrichtungen, für Adipositas-Trainer sowie für deren Ausbildung in Adipositas-Trainer-Akademien entwickelt. Die Qualität der Behandlung soll dadurch nachhaltig verbessert, die Strukturen für (Fach-)Öffentlichkeit und Kostenträger transparenter gemacht werden.

In der Liste der Therapieanbieter auf der Homepage der AGA (www. a-g-a. de) haben sich mittlerweile bundesweit über 250 Einrichtungen eintragen lassen. Qualitätsanforderungen sind hiermit nicht verbunden. Schon in einer Erhebung 2006 sind große Unterschiede in Struktur- und Prozessqualität der $(\mathrm{n}=118)$ Einrichtungen festzustellen gewesen. Auf der Basis des „Konsensuspapier Patientenschulungsprogramme“ (BMGS, 2004) wurden von der AGA Kriterien zur Zertifizierung von Therapieanbietern verabschiedet. Sie beinhalten Vorgaben zur Strukturqualität (bauliche Ausstattung, Therapiemanual, Personal), zur Konzeptqualität (Kombinationsansatz, Elterneinbindung, Programmdauer), zur Prozessqualität (Einschluss-, Ausschluss und Abbruchkriterien sowie Stellung des behandelnden Arztes) und zur Ergebnisqualität (Abbrecherquote, Verlauf BMI-SDS). Eine eingerichtete Zertifizierungskommission aus unabhängigen Fachleuten begutachtet die Anträge. Die zertifizierten Einrichtungen werden auf der Homepage der AGA hervorgehoben. Zwei Jahre nach Zertifizierungsbeginn sind bereits 20\% der gelisteten Anbieter zertifiziert.

Adipositas- Trainer sollen im jeweiligen Berufszweig die Schulung adipöser Kinder, Jugendlicher und ihrer Eltern durchführen. In der Ausbildung werden dazu nicht nur Fachkenntnisse aus dem eigenen Bereich vertieft, sondern auch Einblicke in die anderen Bereiche eines multidisziplinären Teams erworben werden. Adipositas- Trainer können genau definierte Angehörige der Berufsgruppen Medizin, Ernährung, Sport/Bewegung sowie Psychologie/ Pädagogik mit mindestens einjähriger Erfahrung in der Betreuung von adipösen Kindern und Jugendlichen werden. Die Fortbildungsrichtlinie fordert eine 18-stündige Hospitation, ein 48-stündiges Seminar mit hohem Praxisbezug sowie eine Supervision. Die Trainer-Zertifizierung ist unabhängig davon, an welchem Therapieprogramm sich die Ausbildung orientiert hat. Auch die AGA-zertifizierten Adipositas-Trainer (inzwischen 58) sind in einer Liste auf der AGA-Homepage ersichtlich.

Eine Akademie muss über Dozenten (AGA-Trainer) je Fachrichtung verfügen und mit einer Therapieeinrichtung kooperieren. Die quantitative wie qualitative Einhaltung der Empfehlungen an ein Curriculum wird überprüft. Mittlerweile sind 7 Akademien unterschiedlicher Programmausrichtung nach den AGA-Kriterien zertifiziert (Zahlen per 30. 04. 2010).

Inhalte und Verfahren der Zertifizierungen werden vorgestellt, Aspekte der Rezertifizierung von Therapieeinrichtungen erörtert.

\section{DGSPJ-FV-6}

KIDS - Adipositasschulungsprogramm in Thüringen - Evaluation nach 6 Monaten ( 4 Monate Intensiv-Phase + 2 Monate Grundphase)

A. Schmitt ${ }^{1}$, J. Seidel ${ }^{2}$

${ }^{1}$ Friedrich-Schiller-Universität Jena, ${ }^{2}$ SRH Wald-Klinikum Gera

Hintergrund: Das interdisziplinäre KIDS- Adipositaschulungsprogramm ist ein einjähriges, ambulantes Interventionsprogramm zur Behandlung übergewichtiger und adipöser Kinder und Jugendlicher. Es werden die vorläufigen Ergebnisse einer sechsmonatigen Evaluation (Ernährungswissen, Ernährungszustand) an 3 Standorten in Thüringen vorgestellt.

Methoden: Bei 30 Kindern (19 Mädchen, 11 Jungen) wurden zu Schulungsbeginn und nach 6 Monaten (4 Mo Intensiv-Phase+ 2 Mo Grundphase) Körpergröße, Körpergewicht gemessen, der jeweilige BMI berechnet und das Körperfett mittels Bioimpedanzanalyse $\left(\mathrm{FM}_{\mathrm{BIA}}\right)$ ermittelt sowie das Ernährungswissen mittels Fragebogen erfasst. Die Kinder waren durchschnittlich $11,1( \pm 2,8)$ Jahre alt. Die Drop- out Rate betrug $16,7 \%$.

Ergebnisse: Das Ernährungswissen konnte signifikant verbessert werden ( $\mathrm{p}<0,001)$. Die Anzahl der Kinder in der BMI-Klasse > 99,5 P. verringerte sich um 23,4 \%; $77 \%$ der Kinder wiesen im Verlauf einen gerin- geren BMI-SDS auf. Dieser reduzierte sich im Mittel signifikant um $0,16(p=0,001)$. Die FM $(n=20)$ sank signifikant um $2 \%(p=0,001)$. Diskussion und Schlussfolgerungen: DieWirksamkeit des KIDS- Schulungsprogramms konnte für die ersten 6 Monate bestätigt werden. $\mathrm{Ob}$ die positive Entwicklung, die bei den meisten Teilnehmern ermittelt wurde, nachhaltig ist, sollte Inhalt zukünftiger Studien sein. Die aktuellen Daten ermutigen uns zu einer Fortsetzung der wissenschaftlichen Programmbegleitung und weiteren regionalen Etablierung des KIDSAdipositasschulungsprogramms in Ostthüringen.

\section{DGSPJ-FV-7}

\section{Migration und Gesundheit. Kulturelle Kompetenz im Kinder- und Jugendgesundheitsdienst - MIKKI NRW \\ E. Sievers' ${ }^{1}$ A. Dietrich², S. Greis 1}

${ }^{1}$ Akademie für öffentliches Gesundheitswesen, ${ }^{2}$ Institut für interkulturelle Kommunikation und Konfliktmanagement

Fragestellung: Fachkräfte im Kinder- und Jugendgesundheitsdienst (KJGD) haben eine Schlüsselfunktion für die transkulturelle Ausrichtung der Angebote für Kinder in ihrer Kommune. Berufsausbildungen berücksichtigen diesen Aspekt bisher nur in Ausnahmefällen. Kann ein Fortbildungskonzept zur Förderung der kulturellen Kompetenz implementiert und flächendeckend umgesetzt werden?

Methoden: In einer Kooperation der Akademie für öffentliches Gesundheitswesen in Düsseldorf mit dem Institut für interkulturelle Kommunikation, Essen, wurde ein dreistufiges Schulungskonzept von 3X2 Tagen erarbeitet: Interkulturelle Kommunikation im KJGD. Das Ziel ist, mit unterschiedlichen didaktischen Lehrmethoden eine Stärkung der kulturellen Kompetenz zu erreichen und ein evaluiertes Fortbildungsangebot nachhaltig einzuführen.

Schwerpunkte werden hierbei in drei Bereichen gesetzt: 1.) Sensibilisierung für mögliche Besonderheiten der interkulturellen Kommunikation, 2.) Bestandsaufnahme der Umsetzung der interkulturellen Öffnung der KJGDs der Teilnehmer, 3.) Unterstützung bei der Erarbeitung von Handlungsoptionen sowie die Vertiefung besonderer Fragestellungen der Teilnehmer.

In NRW wurde im Rahmen des Projekts MIKKI NRW durch Förderung des Ministeriums für Arbeit, Gesundheit und Soziales NRW ein flächendeckendes Angebot als Inhouse-Fortbildung auf der Ebene der Stufe 1 (Grundkurse) möglich.

Ergebnisse: Insgesamt konnten durch Lehrangebote der Akademie seit 2008 über 589 Mitarbeiter/innen der KJGDs der Trägerländer in 47 Fortbildungen (FB) auf Stufe 1 in Gruppen von $\leq 16$ Teilnehmer/innen) erreicht werden, 81 auf Stufe $2(n=7$ FB) und 22 auf Stufe $3(n=1 F B)$. Ca. $75 \%$ der Kinder- und Jugendgesundheitsdienste in NRW erhalten 2009/2010 ein Inhouse - Angebot .

In der begleitenden Evaluation der FB erfolgte neben einer ergänzenden Befragung zum Fortbildungsbedarf eine Bewertung von 8 Items auf einer 6stufigen Skala („Schulnoten“). Alle Mittelwerte für die FB auf Stufe 1 lagen $<2$,o, insbesondere auch für die Aussage „Gemessen am zeitlichen und organisatorischen Aufwand hat die Teilnahme am Kurs sich für mich gelohnt“. Über $30 \%$ der Teilnehmer hielten ein Kursangebot von insgesamt $>40$ bis 60 Std. für notwendig. In den FB wurden einige Problembereiche durch die Teilnehmer besonders häufig thematisiert: 1. Wahrnehmung von Förder- oder Therapieangeboten im Alter von o-3 Jahren, 2. Optimierungsmöglichkeiten der Organisation der Einschulungsuntersuchungen sowie 3. erhöhte Anteile der Kinder mit Migrationshintergrund im Haupt- und Förderschulbereich.

Schlussfolgerungen: Seit 2008 konnte ein Fortbildungsangebot zur Förderung der kulturellen Kompetenz im KJGD etabliert und 2009/2010 in NRW auf der Stufe 1 flächendeckend angeboten werden. Die Ausweitung entsprechender berufsgruppenübergreifender Angebote für den KJGD und andere pädiatrische Berufsfelder ist für die transkulturelle Ausrichtung der Pädiatrie von großer Bedeutung. 
DGSPJ-FV-8

Chronisch kranke Kinder \&amp; Jugendliche im Land Brandenburg-

Datenlage und Handlungsempfehlungen

U. Sadowski, G. Ellsäßer

Landesgesundheitsamt Brandenburg

Hintergrund: Repräsentative Studien zur Prävalenz somatischer Erkrankungen im Kindes- und Jugendalter existieren für Deutschland bislang nur für einige Erkrankungen. Die Ergebnisse internationaler Studien können nicht ohne weiteres auf Deutschland übertragen werden. Neueren Untersuchungsergebnissen (KiGGS-Studie,2003-2006) zufolge kann davon ausgegangen werden, dass ca. $39 \%$ der untersuchten Kinder und Jugendlichen an einer chronischen Erkrankung leiden [Pressemitteilung RKI Juni 2008]. Die 6 Monats - Prävalenzrate psychischer Störungen im Kindes- und Jugendalter liegt bei $17,2 \%$. Das Zusatzmodul der KiGGS-Studie, die sogenannte Bella-Studie Befragung zur seelischen Gesundheit - zeigt, dass bei 21,8 \% der Kinder und Jugendlichen deutliche Hinweise auf eine psychische Auffälligkeit vorliegen. Vor dem Hintergrund einer zunehmenden Prävalenz chronischer somatischer und psychischer Erkrankungen im Kindes- \& Jugendalter und der damit verbundenen erhöhten Inanspruchnahme von Versorgungsleistungen erhalten adäquate Versorgungskonzepte, die neben den klassischen diagnostischen Kriterien die Konsequenzen (Funktions- und Teilhabestörungen) sowie die durch die Erkrankung hervorgerufenen Belastungen (gesundheitsbezogenen Lebensqualität) in den Blick nehmen einen immer höheren Stellenwert.

Material und Methoden: Die Darstellung der aktuellen Datenlage zur Prävalenz somatischer und psychischer chronischer Erkrankungen im Kindes- und Jugendalter basiert auf den Daten der Krankenhausdiagnosestatistik (Statistik 2008/09) und den Abrechnungsdaten der KV-Brandenburg/Berlin (2008/2009) sowie auf den durch den ÖGD / Kinder- und Jugendgesundheitsdienst (KJGD) erhobenen Daten zur Schuleingangs- und Schulabgangsuntersuchung und Kitauntersuchung (2008/09). Ergänzend zur quantitativen Darstellung und Analyse der Prävalenz chronischer Erkrankungen wird vom Landesgesundheitsamt (LGA) im Sommer 2010 in Abstimmung mit dem Ministerium für Umwelt, Gesundheit und Verbraucherschutz (MUGV) eine qualitative Studie zur Explikation subjektiver Bedarfe/Bedürfnisse durchgeführt. Ziel der Studie ist es, möglichst viele subjektive Hinweise aus der Betroffenen und Versorger-Perspektive zu gewinnen, um auf dieser Grundlage wichtige Aspekte für eine an den Bedürfnissen und Erfordernissen orientierten ganzheitlichen Versorgungsstruktur für chronisch kranke Kinder und Jugendliche ableiten zu können. $\mathrm{Zu}$ diesem Zweck wurden mit Eltern, Kinder, Jugendlichen und Betreuungs- Versorgungspersonen, die in den unterschiedlichen Lebensräumen von chronisch kranken Kindern und Jugendlichen von Bedeutung sind, Leidfadengestützte Interviews geführt und mittels einer qualitativen Inhaltsanalyse [Mayring 2000] ausgewertet.

Ergebnisse/Diskussion:

Datenlage: Prävalenz spezifischer (somatischer u. psychischer) chronischer Erkrankungen im Kindes- und Jugendalter/Darstellung des Behandlungsaufkommens chronischer Erkrankungen der Zielgruppe im ambulanten und stationären Versorgungssystem im Land Brandenburg.

Handlungsempfehlungen: Qualitative Daten zu den Bedarfen/ Bedürfnissen von Betroffenen und Versorgern der Zielgruppe in Hinblick auf relevante Aspekte für eine ganzheitliche, interdisziplinäre an den Bedürfnissen der Zielgruppe orientierte Versorgung.

\section{DGSPJ-FV-9}

Berufsorientierung in der Rehabilitation chronisch kranker Jugendlicher

R. Stachow ${ }^{1}$, S. Kiera ${ }^{2}$, U. Tiedjen'1, F. Petermann ${ }^{2}$

'Fachklinik Sylt für Kinder und Jugendliche, ${ }^{2}$ Universität Bremen

Einleitung: Für chronisch kranke Jugendliche stellt die richtige Berufswahl eine besondere Herausforderung dar. Potentielle Risiko- oder
Triggerfaktoren des zukünftigen Berufsumfeldes mit ungünstiger Auswirkung auf die Erkrankung müssen bei der Entscheidung berücksichtigt werden. Die Jugendrehabilitation erscheint geeignet berufsorientierende Hilfestellung geben zu können.

Methode: Im Rahmen eines durch die DRV-Nord geförderten Projektes zur Optimierung der Jugendrehabilitation, wurden modular (je $45 \mathrm{~min}$ ) aufgebaute Schulungseinheiten zur Berufsorientierung in den Rehaprozess eingeführt und in einem kontrollierten Design evaluiert. Im Modul 1 wurde als Einstieg in das Thema die Auseinandersetzung mit eigenen, potentiell berufsbezogenen Neigungen und Ressourcen gefördert. Im Modul 2 lernten die Jugendlichen sich Informationen und Tätigkeitsbeschreibungen über verschiedene Berufe zu verschaffen. Im 3. Modul wurden Konfliktfelder zwischen potentiellem zukünftigem Beruf und der chronischen Erkrankung erarbeitet und ggf. Wege zum Suchen von Alternativen aufgezeigt.

Ergebnisse: 388 Jugendliche (Alter 13,3-20,8 J, Diagnoseverteilung: Adipositas (Adi) 108, Asthma (AB) 110, Neurodermitis (ND) 97, Diabetes (DM) 64, Sonstige 9) nahmen an der Untersuchung teil. 199 Jugendliche partizipierten an dem optimierten Jugendrehaverfahren. Diese äußerten im Vergleich zu den Kontrollpatienten sich signifikant mehr mit der Berufswahl beschäftigt haben $(\mathrm{p}=$. ooo), dass die Reha ihnen sign. besser in Bezug auf die Berufswahl geholfen habe ( $\mathrm{p}=$. oo1), sie signifikant besser gelernt haben, welche Berufe für sie aufgrund der Erkrankung nicht geeignet sind $(\mathrm{p}=$. ooo) bzw. welche Berufe für sie trotz der Erkrankung geeignet sind $(\mathrm{p}=$. 004). In diesem Sinne profitierten besonders die Patienten mit $\mathrm{AB}, \mathrm{ND}$ und $\mathrm{DM}\left(\mathrm{Chi}^{2}=14,09, \mathrm{df}=3\right.$, $\mathrm{p}=0,003)$ sowie die Mädchen ( $\mathrm{p}=$. 024). Für verschiedene Altersgruppen $(<15,5 \mathrm{~J}\rangle)$ bzw. die Art der besuchten Schule ergaben sich keine Unterschiede. Diese Effekte der Berufsorientierung korrelierten nicht mit der Selbsteinschätzung zur Rehamitarbeit oder zur selbst wahrgenommenen gesundheitlichen Verbesserung während der Reha.

Schlussfolgerung: Eine kurze berufsorientierende Schulungsintervention bestehend aus 3 Modulen findet bei Jugendlichen mit Atemwegs- und Hauterkrankung sowie Diabetes eine positive Resonanz und erscheint einen Bewusstwerdungsprozess im Hinblick auf die spätere, krankheitskompatible Berufswahl zu fördern.

\section{Armut als Risiko für die Kinderentwicklung?}

\section{DGSPJ-SY-18}

Zukünftige Konzepte einer Salutogenese für Kinder

H. Straßburg

Universitäts-Kinderklinik, Sozialpädiatrisches Zentrum „Fühdiagnosezentrum"

$80 \%$ der Kinder in Deutschland sind nach den jüngst durchgeführten profunden epidemiologischen Erhebungen gesund, bei den $20 \%$ der Kinder mit chronischen Gesundheitseinschränkungen und Behinderungen werden einerseits eine zunehmend große Zahl von $z$. T. sehr speziellen, z. B. genetisch bedingten Ursachen festgestellt. Die häufigsten Diagnosen sind aber die sog. „neuen Morbiditäten“, worunter Verhaltens-und Lernstörungen im weitesten Sinne, emotionale Störungen, Übergewichtigkeit sowie Allergien subsummiert werden können. Die wichtigste Ursache hierfür ist nach übereinstimmender Erkenntnis die Armut, nicht nur materiell, sondern auch in einem umfassenderen Sinn. Auf der Grundlage des von A. Antonovsky entwickelten Konzeptes der Salutogenese, nach dem es das Wichtigste ist, seinem Leben Sinn zu geben („sense of coherence“) haben A. Sen und M. Nussbaum den "Capability-Ansatz" der 6 C's formuliert, der wesentliche Grundlage für körperliches, seelisches und soziales Wohlbefinden ist. Danach müssen vor allem Ausbildung (competence und character), die Bereitschaft zur Sorge für andere und die Pflege von Verbindungen (caring und connections), Vertrauen (confidence) und Beiträge für die Gemeinschaft bzw. Partizipation (contribution) gefördert werden. Dies kann für die Kinder- und Jugendmedizin nur in einer konstruktiven inter- und mul- 
tidisziplinären Zusammenarbeit mit Pädagogen, Psychologen, Therapeuten, Soziologen und Gesundheitswissenschaftlern, aber auch Ökonomen und vor allem der Politik stattfinden. Eine wesentliche Plattform hierfür kann und sollte die Sozialpädiatrie sein. Eine Förderung entsprechender Projekte in Deutschland ist dringend notwendig. 


\section{Gemeinsame Sitzung: Freitag, 17. September 2010}

\section{Kolorektale Motilitätsstörungen}

\section{DGKCH-FV-01}

Das Enterische Nervensystem (ENS) am Modell der Dünndarmatresien im Hühnerembryo: Morphologie un d Reversibilität der Veränderungen

C. Oetzmann v. Sochaczweski ${ }^{1}$, H. Fiegel ${ }^{2}$, R. Metzger ${ }^{3}$, K. Wenke $^{4}$, H. Till ${ }^{3}$, D. Kluth ${ }^{3}$

${ }^{1}$ Kinderklinik der Med. Hochschule, ${ }^{2}$ Klinikum der J.W.Goethe-Univ. Zentrum der Kinderheilkunde, ${ }^{3}$ Universitätskinderklinik, ${ }^{4}$ Univ.-Kinderklinik Eppendorf

Fragestellung: Motilitäts- und Malabsorbtionsstörungen nach operativer Korrektur von Dünndarmatresien sind die Ursache für die hohe Mortalität im Neugeborenenalter. Morphologisch lassen sich Alterationen am ENS nachweisen. Ziel der vorliegenden Studie ist die Erfassung der Veränderungen am ENS nach fetaler Induktion einer Dünndarmatresie und deren mögliche Reversibilität der pathologischen Verhältnisse nach Korrektur der induzierten Ligatur.

Material und Methode: Am Entwicklungstag (embryonic day, ED) 11 wurde der Dünndarm von Hühnerembryonen mikrochiurgich in ovo ligiert $(\mathrm{n}=100)$. Proximal und distal der Ligatur wurden Darmproben sequenziell an den Tagen ED 12 bis 19 von je 10 Embryonen entnommen $(n=80)$ Bei 20 Hühnerembryonen wurde die Ligatur nach 4 Tagen (ED15) entfernt und die Darmproben am ED 19 entnommen. Das ENS wurde mittels Acetylcholinesterasefärbung (AChE), Versilberungstechnik nach Spaethe, Immunhistochemie (Vasointestinales Peptid, VIP) und der Elektronenmikroskopie untersucht.

Ergebnisse: Die experimentell induzierten Dünndarmatresien entsprechen den klinisch beschriebenen Typen I bis IV nach Louw und Barnard. Bereits 4 Tage nach Ligaturinduktion (ED15) zeigt sich eine deutliche Dilatation im proximalen Segment mit Rarefizierung des Nervengeflechtes. Es zeigt sich eine verminderte AChE- Reaktiviät bei ebenfalls verminderter VIP- Expression. Morphologisch zeigt sich eine reduzierte Ganglienzahl bei prinzipiell erhaltener Darmwandarchitektur un deine deutliche Abnahme der kommunizierenden Nervenfasern zwischen den Plexus myentericus. Nach lösen der Ligatur am ED 15 bildeten sich die beschriebenen Veränderungen nahezu vollständig zurück. Die Anzahl der Ganglien, die nervale Vernetzung, Aktivität von AChE und die VIP- Expression sind mit den gesunden Kontrollen gleichen Alters vergleichbar.

Schlußfolgerung: Für die experimentelle Dünndarmatresie im Hühnerembryo gilt, dass die morphologisch fassbaren Veränderungen der Darmwandarchitektur und des ENS durch eine frühe fetale Intervention reversibel sind. Weitere Untersuchungen sind zur Evaluation der funtionellen Auswirkugen erforderlich.

\author{
DGKCH-FV-02 \\ Implantation von enterischen neuronalen Vorläuferzellen in das Rek- \\ tum von NOD-SCIDIL2R-/IL2R-Mäusen \\ F. Obermayr ${ }^{1}$, H. Dettmann ${ }^{1}$, R. Mohr ${ }^{2}$, J. Fuchs ${ }^{1}$, L. Just ${ }^{2}$ \\ 'Universitätsklinik für Kinder- und Jugendmedizin, ${ }^{2}$ Anatomisches Institut
}

Hintergrund: Das Potential neuronaler Stamm- und Vorläuferzellen des enterischen Nervensystems (ENS) als mögliche Quelle für eine zellbasierte Therapie neurogastrointestinaler Erkrankungen soll evaluiert werden.

Material und Methoden: Murine und humane enterische Vorläuferzellen wurden aus postnatalen Darmproben isoliert, in vitro proliferiert und differenziert. Die Zellen wurden auf einem biokompatiblen Kollagen-Zellträger (CCC) in das Rektum von NOD-SCID IL2R-/IL2R- Mäusen implantiert. Die Charakterisierung der isolierten und implantierten Zellen erfolgte immunhistochemisch.

Ergebnisse: ENS Vorläuferzellen konnten sowohl aus murinem als auch aus humanem postnatalen Darm isoliert, in vitro proliferiert und in Zellen mit einem neuronalen Phänotyp differenziert werden. Nach Implantation in das Rektum von NOD-SCID IL2R-/IL2R- Mäusen zeigt sich ein Überleben und ein konstanter Phänotyp der Zellen.

Diskussion: Die vorläufigen Ergebnisse zeigen die Möglichkeit einer Implantation von ENS Vorläuferzellen als möglichen Therapieansatz neurogastrointestinaler Erkrankungen auf. Die Integration der Zellen, sowie die daraus resultierenden funktionellen Folgen bleiben noch im Detail zu untersuchen.

\section{DGKCH-FV-03}

Ultraschallkontrolliertes Bowel management zur Therapie der Inkontinenz

S. Märzheuser, S. David, F. Grauel, K. Rothe

Charite Kliniken f. Kinderheilkunde und Kinderchirugie

Einleitung: Zahlreiche Untersuchungen belegen, dass, trotz adäquater chirurgischer Therapie einer anorektalen Fehlbildung, eine Stuhlentleerungsstörung entstehen kann. Die Form der Kontinenzstörung ist unterschiedlich. Je nach Art der Malformation stehen Inkontinenz oder Obstipation im Vordergrund des klinischen Beschwerdebildes.

Fast $50 \%$ der Patienten haben bei klinischen Nachuntersuchungen keine altersentsprechende Darmfunktion. 30 \% der Patienten klagen über schwerwiegende Probleme bei der Darmentleerung.

Durch Anwendung eines bowel managements können Kinder und Jugendliche mit absoluter Inkontinenz für Stuhl eine soziale Kontinenz erreichen. Bowel management bedeutet, dass mit Hilfe einer kontrollierten Darmspülung idealerweise das gesamte Kolon entleert wird, so dass der Patient anschließend für einen Zeitraum von 24-48 Stunden frei von unwillkürlichem Stuhlverlust ist. 
Für ein effektives bowel management ist eine gute Vorbereitung des Patienten erforderlich. Das benötigte Flüssigkeitsvolumen muss abgeschätzt und ein adäquates Spülprogramm initiiert werden.

Wir berichten über unsere Erfahrungen mit Hilfe der Hydrosonographie ein Spülprogramm bei 20 Patienten mit absoluter Stuhlinkontinenz zu etablieren.

Material und Methode: Die Hydrosonographie des Kolons ist eine Ultraschalluntersuchung, bei der das Kolon von rektal mit Flüssigkeit aufgefüllt wird. Diese Flüssigkeit dient als Kontrastmedium und soll ermöglichen das erforderliche Flüssigkeitsvolumen für das Spülprogramm zu bemessen. Für die Untersuchung wird der Analkanal mit einem geblockten Katheter verschlossen. Die Spülflüssigkeit läuft über eine elektrische Pumpe (Braun Irrimatic) mit konstanter Geschwindigkeit in das Darmlumen. Der Progress der Flüssigkeit wird sonographisch verfolgt. Sobald die Flüssigkeit das Zökum erreicht hat, wird die Pumpe arretiert und die Flüssigkeitsmenge, die benötigt wurde, bestimmt.

Wir untersuchten 20 Patienten im Alter von 4- 17 Jahren. In die Studie eingeschlossen wurden nur solche Patienten, die eine absolute Inkontinenz für Stuhl hatten (Krickenbeck Klassifikation Gruppe 2, Grad 3). Alle Patienten wurden mit einer orthograden Spülung mit Polyethylenglykol (Macrogol) auf die Untersuchung vorbereitet. Die Untersuchungsdauer betrug zwischen 10 und 15 Minuten.

Resultate: 18 Patienten waren bei Kontrolluntersuchungen sechs und zwölf Monate nach Beginn des Spülprogramms vollständig beschwerdefrei und berichteten über keinen unwillkürlichen Stuhlverlust oder Stuhlschmieren. Zwei Patienten beendeten das Spülprogramm nach sechs Monaten und benötigten wieder Windeln oder Einlagen.

Schlussfolgerung: Die Hydrosonographie des Kolons ist eine den Patienten wenig belastende Untersuchungsmethode, die die Bestimmung des adäquaten Flüssigkeitsvolumens für ein effektives Bowel management ermöglicht.

\section{DGKJ-GEM-33}

\section{Organische Ursachen für Obstipationen}

A. Ballauff

Kinderklinik HELIOS-Klinikum Krefeld

Die Obstipation im Kindesalter ist ein häufiges Problem. Nahrungsumstellung, geringe Trinkmenge, Infektionen oder perianale Läsionen können zu einer akuten Obstipationsepisode durch Eindicken des Stuhls oder Einhalten führen. Hieraus kann sich bei fehlender Besserung eine funktionelle chronische Obstipation mit und ohne Überlaufenkopresis entwickeln. Bei weniger als $5 \%$ aller Kinder ist eine chronischer Obstipation durch eine andere organische Erkrankung bedingt. Meist finden sich anamnestische Hinweise (Obstipationssymptome seit Geburt oder nach Abstillen, später Mekoniumabgang als Hinweis für eine Innervationsstörung, andere nicht gastrointestinale Symptome als Hinweis für eine Allgemeinerkrankung, Medikamenteneinnahme) oder auffällige Untersuchungsbefunde (ektoper Anus, rektale Stenose, perianale Läsion, neurologische Auffälligkeiten).

Organische Ursachen für eine chronische Obstipation

Darmerkrankungen: M. Hirschsprung, andere Innervationsstörungen (MEN 2b)

Angeborene Enddarmfehlbildungen (Analatresie, ektoper Anus, Analstenose)

Erworbene Stenosen (z. B. Lichen sclerosus, M. Crohn)

Allgemeinerkrankungen: Raumforderung im kleinen Becken (Teratom)

Neurologische Erkrankungen, Muskelerkrankungen

Neurogene Mastdarmlähmung (Spinale Läsion, Meningomyelocele, Tethered Cord)

Endokrinologische Erkrankungen (Hypothyreose)

Hypercalciämie, Hypokaliämie

Mukoviszidose: Zöliakie, Kuhmilchallergie bei Säuglingen

Medikamente (z. B. Schmerzmittel, Antiepileptika)

Intoxikationen ( Blei, Vit D )
Organische Ursachen der Inkontinenz

Neurogene Mastdarmlähmung (Spinale Läsion, Meningomyelocele, Tethered Cord)

Muskelerkrankungen: Periphere Neuropathien (selten)

Sphincterläsion nach Verletzung, nach Operation, bei Fisteln (M. Crohn)

Bei Säuglingen mit Obstipation kann ein Therapieversuch mit kuhmilchfreier Ernährung erfolgen, insbesondere bei schwerer Symptomatik, bei geblähtem Abdomen oder Erbrechen sollte ein M. Hirschsprung durch eine Rektumsaugbiopsie ausgeschlossen werden, ebenso bei älteren Kindern mit Therapieresistenz. Außerdem wird der Ausschluß einer Hypothyreose und einer Zöliakie empfohlen. Nur selten sind weitere diagnostische Maßnahmen zum Ausschluss oben genannter Erkrankungen und nur bei speziellen Fragestellungen Ganzwandbiopsien, Kolonkontrasteinlauf, Defäkografie, Kolontransitzeitmessung nach Einnahme von röntgendichten Markern, eine anorektale Manometrie oder eine Oberflächenelektromyographie notwendig.

\section{DGKJ-GEM-34}

Funktionelle Obstipation: M. Claßen

Klinik für Kinder- und Jugendmedizin, Klinikum Links der Weser

Funktionelle Störungen sind ganz überwiegend (>95\%) die Ursache für eine chronische Obstipation im Kindesalter. Typisch ist der Beginn der Obstipation zwischen dem 1. und 3. Lebensjahr. Konstitutionelle und genetische Faktoren (z. B. langsamer Transport im Colon, Reifungsverzögerung des enterischen Nervensystems) könnten einen Beitrag leisten, sind aber bislang ungenügend definiert.

Oft wird die Obstipation durch ein äußeres Ereignis als Störfaktor ausgelöst (zum Beispiel schmerzhafte Defäkation bei perianaler Entzündung, Analfissuren oder schmerzhafte Manipulationen am Anus. In der Folge vermeiden die Kinder alle unangenehmen Sensationen am Anus und unterdrücken die Darmentleerung. Daraufhin erweitert sich das Rektum, das Stuhlkaliber wird größer, so dass die nächste Stuhlpassage erneut zu schmerzhaften Erfahrungen führt. Schließlich verselbstständigt sich diese Sequenz dann im Sinne eines Circulus vitiosus, auch wenn der Auslöser längst beseitigt ist. Für die Stuhlinkontinenz stellt wiederum die chronische Obstipation die häufigste Ursache dar.

Mithilfe manometrischer Techniken konnte gezeigt werden, dass bei einem hohen Prozentsatz der Kinder mit funktioneller Obstipation ein paradoxes Defäkationsverhalten vorliegt. Während des Pressens zur Defäkation spannen die Betroffenen den Sphinkter externus und den M. puborektalis an, statt diese zu entspannen. So gelingt es durch die Bauchpresse nicht, den Darm effektiv oder komplett zu entleeren.

In der Diagnostik der Kinder mit V. a. funktionelle Obstipation muss mit Anamnese und problemorientierter klinischer Untersuchung nach Hinweisen auf eine organische Genese gesucht werden. Ergänzend kann eine Ultraschall-Untersuchung erfolgen. Invasive Untersuchungen sind in typischen Fällen entbehrlich. Allerdings sollte nach psychiatrischen und nephrologischen Komorbiditäten (Harninkontinenz) gesucht werden.

Die Therapie der funktionellen Obstipation sollte rasch und effektiv durchgeführt werden, um den Circulus vitiosus von schmerzhafter Defäkation und Stuhlretention zu unterbrechen. Zunächst sollten die Eltern ausführlich geschult und informiert werden, ggf. auch ältere Kinder. Die Säulen der Therapie sind eine orale stuhlweichmachende Therapie unterstützt durch eine Ernährungsoptimierung und bei älteren Kindern auch einer Verhaltenstherapie. Selten werden Biofeedbacktechniken benötigt. Die Therapie muss ausreichend lange durchgeführt werden und der Effekt der Therapie regelmäßig ärztlich überwacht werden. 


\section{Hämangiome}

\section{DGKJ-GEM-01}

\section{Klassifikation und Kryotherapie von Hämangiomen}

Hämangiome sind gutartige Gefäßtumoren (VTs). Mit einer Häufigkeit von 5-10 \% sind sie die häufigsten gutartigen Tumoren des Kindesalters. Dabei gibt es sehr unterschiedliche Verlaufsformen, deren Kenntnis für alle therapeutischen Überlegungen unentbehrlich ist.

A] die „Klassischen Hämangiome

1) lokalisierte Hämangiome (LHs)

Die lokalisierten Hämangiome sind definiert als von einem zentralen Fokus ausgehende gutartige Tumoren des Gefäßendothels. Sie bilden die mit Abstand größte Gruppe aller Hämangiome. Sie sind meist rundlich begrenzt und glatt. Die meisten LHs sind überwiegend oberflächlich.

2) Segmentale Hämangiome (SHs)

Als „segmental“ werden flächige Hämangiome bezeichnet, welche sich im Schädelbereich ganz oder teilweise einem Entwicklungs-Segment zuordnen lassen. Es kommt bei ihnen häufiger zu Komplikationen, die Behandlung ist schwieriger und langwieriger und Assoziationen mit neurologischen, cardialen und opthalmologischen Anomalien sind möglich. (Phaces-Syndrom). Dies gilt vor allem bei Sitz im Kopfbereich.

Bei Lokalisation im „Bart-Bereich“ und bei Mitbeteiligung der Mund/ Rachenschleimhaut findet sich nicht selten auch einetracheale Beteiligung. (Hinweisend ist ein inspiratorischer Stridor). Hier ist dann zur weiteren Diagnostik unbedingt eine Sonographie, MRT und auch eine Bronchoskopie erforderlich.

Es gibt auch segmentale Hämangiomen im Stamm/Extremitätenbereich

3) nicht determinierte Hämangiome

Alsnicht determiniertwerden solche Hämangiome bezeichnet, welche weder lokalisiert sind (also nicht von einem zentralen Fokus ausgehend) noch - z. B. wegen geringer Ausdehnung - eindeutig den segmentalen Hämangiomen zugeordnet werden können.

4) abortive Formen

In diese Gruppe gehören Hämangiome die im weiteren Verlauf keine wesentliche Wachstumstendenz zeigen und daher in der Regel auch keiner Therapie bedürfen.

$\mathrm{Zu}$ dieser Gruppe gehört ein Großteil der „weißen Hämangiome“ (Hämangiom-Vorläufer),

einige als gruppenförmige Papeln auftretenden Hämangiome sowie die meisten teleangiektatischen Hämangiome.

B] Weitere seltene Formen vaskulärer Tumoren (VTs).

Es gibt eine Reihe seltener Formen vaskulärer Tumoren, welche sich hinsichtlich Verlauf, erforderlicher Diagnostik und erforderlicher therapeutischer Maßnahmen grundsätzlich von den bereits erwähnten Hämangiomformen unterscheiden. In diese Gruppe gehören:

B1) Hämangiome mit abgeschlossener Entwicklung bereits beiGeburt Diese seltenen Hämangiome sind bereits bei Geburt voll entwickelt und zeigen danach kein weiteres Wachstum mehr.

Bei dieser Hämangiom-Art gibt es 2 im weiteren Verlauf unterschiedliche Formen:

a) mit guter Spontanrückbildung ( $\mathrm{RICH}=$ rapid involuting congenital hemangioma). Diese bei Geburt bereits voll entwickelten, tumorartig aussehenden Hämangiome sind häufig von einem weißen Randsaum umgeben, sie bilden sich im Verlauf von 1-2 Jahren spontan zurück b) ohne Spontanrückbildung $(\mathrm{NICH}=$ non involuting congenital hemangioma) Diese sehr selten Hämangiomarten zeigen innerhalb von 2 Jahren keinerlei Rückbildung).

B2) VTs mit histologischen Besonderheiten

Eine Diagnosesicherung ist nur histologisch möglich

a) tufted Angiom können unauffällig klein, aber auch ausgedehnt und mit einem KASABACH-MERRITT-Phaenomen verknüpft sein.

b) Das kaposiforme Hämangio-Endotheliom ist meist schon bei Geburt vorhanden und geht ebenfalls häufig mit einem KASABACH-MERRITT- Phaenomen einher. c) Spindelzell - Hämangio-Endotheliome kommen selten auch im Kindesalter vor. Sie finden sich im Fingerbereich und stellen eine Kombination einer Gefäßfehlbildung mit einem Hämangiom dar.

B3) Hämangiomatosen

(benigne neonatale Hämangiomatose und disseminierte Hämangiomatose).

Die kleinen multiplen LHs bei der benignen neonatalen Hämangiomatose erinnern im Aussehen an eruptive Hämangiome.

Diagnostisch ist prinzipiell eine Sonographie des Abdomen zum Ausschluß der prognostisch dubiösen disseminierten Hämangiomatose mit viszeraler Beteiligung erforderlich.

\section{DGKJ-GEM-04}

Lasertherapie: H. Berlien

Evangelische Elisabeth Klinik Krankenhausbetriebs gGmbH

Da die infantilen Hämangiome eine hohe Rate der Spontanregression zeigen, muss die Indikation zu einer Therapie streng gestellt werden. Andererseits kann exzessives Wachstum abhängig von der Lokalisation zu bleibenden Schäden führen, so dass eine frühzeitige Diagnose und Indikationsstellung erforderlich ist.

Neben dem Stadium sind die Lokalisation und das Wachstumsverhalten für Komplikationen und damit für die Indikation zur Therapie entscheidend. Die wichtigste Untersuchungsmethode, mit der sowohl eine Artdiagnose, exakte Bestimmung des Stadiums und der Ausdehnung möglich ist, ist die farbkodierte Duplexsonographie (FKDS). Sie ist somit die Säule einer adjustierten Hämangiomtherapie.

Von den infantilen Hämangiomen müssen die kongenitalen Hämangioendotheliome, die in unterschiedlichen Verlaufsformen wie dem $\mathrm{NICH}$, dem RICH und den kaposiformen Hämangioendotheliom auftreten, unterschieden werden. Hier bestimmt der Typ und somit die möglichen Komplikationen die Therapieindikation. Bei den kaposiformen Hämangioendotheliomen stellt die Kasabach-Merritt Symptomatik mit disseminierter Koagulopathie die Hauptkomplikation dar. Durch eine frühzeitige Lasertherapie können diese Komplikationen verhindert, zumindest in ihrer Schwere vermindert werden. Entscheidend ist die korrekte Auswahl der Lasertypen und der Laserverfahren. Für oberflächliche rein intrakutane Frühstadien der infantilen Hämangiome mit einer Dicke von weniger $3 \mathrm{~mm}$ ist der Farbstofflaser eine wichtige Behandlungsoption und der Kryotherapie überlegen, da mit ihm auch großflächige infantile Hämangiome behandelt werden können und mit geeigneten Kühlverfahren eine Epithelverletzung vermieden werden kann. Er versagt aber bei allen dickeren und vor allem den subkutanen Hämangiomen. Diese werden mit dem cw-Nd: YAG Laser entweder transkutan mit Eiswürfelkühlung oder mukosal in Impressionstechnik behandelt. Damit sind Hämangiome mit einer Schichtdicke von bis zu $30 \mathrm{~mm}$ sicher, ohne Oberflächenverbrennung einer Therapie zugängig. Voluminösere oder primär tief subkutan gelegene Hämangiome werden nach Farbduplexsonographie gesteuerter Punktion interstitiell behandelt. Insbesondere subglottische und tracheale Hämangiome können endoskopisch so rechtzeitig behandelt werden, dass eine Tracheotomie verhindert werden kann. Jedoch ist bei diesen Hämangiomen, genauso wie bei ausdehnten periorbitalen Hämangiomen immer eine adjuvante kurzzeitige Hochdosis-Prednisolon-Therapie erforderlich. Auch bei kaposiformen Hämangioendotheliomen mit Zeichen einer Kasabach-Merritt Symptomatik ist eine adjuvante Prednisolon-Therapie notwendig. Die interkurrente Lasertherapie, vorzugsweise transkutane Nd: YAG-Laserbehandlung mit Eiswürfelkühlung leitet die Regression ein und verhindert so den Rebound-Effekt nach Absetzen des Prednisolon, so dass auch hier eine kurzzeitige Therapie ausreichend ist.

Anstelle einer Prednisolontherapie wird derzeit eine alleinige oder auch ergänzende Propranololbehandlung diskutiert, da die Nebenwirkungen als geringer eingestuft und ein Reboundeffekt zunächst nicht beobachtet wurde, dies hat sich anhand der ersten klinischen Erfahrungen relativiert. 


\section{DGKJ-GEM-05}

\section{Chirurgische Methoden: R. Grantzow}

Kinderchirurgische Klinik im Dr.v. Haunerschen Kinderspital der Ludwig-Maximilians-Universität München

War vor Einführung der Kryo-, Laser- und jetzt Propranololtherapie noch eine operative Entfernung die einzige Behandlungsmethode von Hämangiomen - neben der systemisch nebenwirkungsreichen Cortisonbehandlung - , so haben sich in den letzten 25 Jahren diesbezüglich die Indikationsbereiche der chirurgischen Therapie von Hämangiomen stark geändert und reduziert. In heutiger Zeit können wir zwischen primären und sekundären Indikationen unterscheiden und die sekundären Eingriffe als Teil einer Kombinationstherapie im Zusammenhang mit anderen vorangegangenen Therapien sehen. Primäre operative Therapie: Große Hämangiome der Augenlidregion, die bei längerem Bestehen eine Amblyopie hervorrufen, müssen primär operativ entfernt oder verkleinert werden. Eine Nd-YAG Lasertherapie ist hier kontraindiziert, da ihre Wirkung zu spät eintritt. Eine weitere klare Indikation stellen Hämangiome im Haarbereich dar. Deren Problem ist die spätere Alopezia areata, die nur chirurgisch behandelt werden kann. Da dies durch die Laser- oder andere Therapieformen nicht beeinflusst wird, sollte hier primär eine Entfernung angestrebt werden. Primäre Operationen im übrigen Gesichtsbereich sind hingegen nicht indiziert. Hämangiome am Rumpf oder den Extremitäten können unter bestimmten Umständen ebenfalls primär operativ entfernt werden, wenn spätere Residuen sicher zu erwarten sind und die Narben unauffällig plaziert werden können. Sekundäre operative Therapie: Große Hämangiome können durch die Nd-YAG Lasertherapie oder neuerdings mittels Propranolol erheblicher rascher involvieren, jedoch bleiben die klassischen Residuen wie narbige und pigmentgestörte Haut und überschüssiges degenerartives Fettgewebe ebenso bestehen, wie nach spontaner Remission. Derartige Residuen können eine Indikation zur operativen Korrektur darstellen. Der Zeitpunkt für solche Eingriffe sollte so gewählt werden, dass die Remission weitgehend beendet ist und damit das Ausmaß der Operation auf ein Minimum reduziert werden kann. Dies ist umso wichtiger, da die meisten Hämangiome im Gesichtsbereich lokalisiert sind und damit überflüssig große Narben vermieden werden können. In der Regel sollten daher derartige Eingriffe erst vor Eintritt in die Schule erfolgen, also im Alter von etwa 5- 6 Jahren. Zusammenfassung: Die operative Therapie von Hämangiomen stellt nur noch bei wenigen Hämangiomen ein primäres Therapieverfahren dar und ist ansonsten als ideale Ergänzung für die Behandlung von Residuen nach vorangegangenen anderen Therapieformen zu sehen.

\section{Perioperatives Management bei Früh- und Neugeborenen}

\section{DGKJ-GEM-09}

Das akute Abdomen des Frühgeborenen - perioperatives Management aus der Sicht des Neonatologen, des Kinderchirurgen und des Kinderanästhesisten

P. Degenhardt', L. Garten', L. Müller-Lobeck²

${ }^{1}$ Charite Kliniken f. Kinderheilkunde und Kinderchirugie, ${ }^{2}$ Klinik für Anästhesiologie mit dem Schwerpunkt operative Intensivmedizin, CVK

Fragestellung: Das akute Abdomen des vlbw-Frühgeborenen stellt an das interdisziplinäre Arbeiten von Neonatologen, Kinderchirurgen und Kinderanästhesisten ganz besonders hohe Anforderungen. Es ist ein gefürchtetes, mit hoher Morbidität und Mortalität verbundenes Krankheitsgeschehen. In unserer gemeinsamen Darstellung möchten wir zum einen auf das perioperative Management auf der neonatologischen Intensivstation, insbesondere auf die Möglichkeiten der Schmerztherapie eingehen, zum anderen die verschiedenen klinischen Aspekte des akuten Abdomens darstellen und die Besonderheiten der kinderanästhesiologische lokalen Therapieoptionen diskutieren.

Neonatologisches Vorgehen: Vorgestellt werden wichtige Behandlungsprinzipien und Fallstricke in der prä- und postoperativen Betreuung von VLBW-Frühgeborenen mit akutem Abdomen. Inhaltliche Schwerpunkte des Vortrages werden sein: Prämedikation zur elektiven Intubation, Kreislaufmanagement, sowie Schmerzerfassung und systemische Analgesie).

Kinderchirurgisches Vorgehen: Methode: In einer vorliegenden single-center Studie haben wir über einen Zeitraum von 01. 01. 1995 bis 31. 12. 2008 alle in der Charité versorgten, ohne intestinale Fehlbildungen geborenen, Frühgeborenen mit einem Geburtsgewicht unter $1500 \mathrm{~g}$ erfasst, die während ihres ersten Klinikaufenthaltes ein akutes Abdomen entwickelten.

Ergebnisse: Insgesamt konnten im Beobachtungszeitraum 141 Kinder in die Studie eingeschlossen werden. Erwartungsgemäß zeigte sich mit 62x eine nekrotisierende Enterokolitis (NEC) als häufigste Ursache, gefolgt von der fokalen intestinalen Perforation (FIP, 27x), dem Mekoniumäquivalent-Ileus $25 \mathrm{x}$ sowie dem Volvulus mit 19 betroffenen Kindern. 8x erfolgte die Indikationsstellung zur Laparotomie unabhängig von den vier großen Indikationsgruppen zur Op, u. a. infolge mehrerer isolierter neonataler Appendicitiden.

Zum Zeitpunkt der Erstbeschreibung der akuten abdominellen Symptomatik zeigten sich für die einzelnen Indikationsstellungen signifikante Unterschiede aber auch im Verlauf und den vorzustellenden Komplikationshäufigkeiten

Kinderanästhesiologischess Vorgehen: Im Vordergrund anästhesiologischen Handelns bei Frühgeborenen mit akutem Abdomen steht die differenzierte Volumen- und Kreislauftherapie sowie deren Überwachung.

Die Auswahl der Anästhesieverfahren (balancierte Anästhesie aus volatilen Anästhetika und Opioiden, oder Kombinationsanästhesie aus volatilen Anästhetika und Kaudalanästhesie) erfolgt unter Berücksichtigung des Volumenstatus und den aus den Anästhesieverfahren resultierenden Beeinträchtigungen (Sympathikolyse bei Kaudalanästhesie etc.) und der Risiko-Nutzen-Analyse (Optimierung der postoperativen Schmerztherapie vs. perioperativem Zeitaufwand).

Das Routinemonitoring des Volumenstatus umfasst den mittleren arteriellen Druck, BGA (zumeist kapillär) mit $\mathrm{Hb} / \mathrm{Hkt}$ und $\mathrm{BE}$, sowie die periphere Sauerstoffsättigung. Invasives hämodynamisches Monitoring ist Ausnahmefällen vorbehalten.

Allgemeine Schlussfolgerungen: Trotz guter Erfolge in der neonatologischen Intensivbehandlung von VLBW-Frühgeborenen stellt das akute Abdomen auch heute noch eine Herausforderung an die im Team arbeitenden Neonatologen, Kinderchirurgen und Kinderanästhesisten dar. Die Vermeidung von Re-Eingriffen, hat auf das Outcome der Kinder einen großen Einfluss, da die Letalität nach Re-Eingriffen deutlich steigt.

\section{Kindergastroenterologie: Chronisch entzündliche Darmerkrankungen}

DGKJ-GEM-16

Indikation und Terminierung von chirurgischen Maßnahmen bei CED - aus kinderchirurgischer Sicht

L. Wessel

Kinderchirurgische Klinik Universitätsmedizin Mannheim, Klinikum Mannheim $\mathrm{GmbH}$

Das Verständnis der Genese der chronisch entzündlichen Darmerkrankungen hat sich in der letzten Zeit grundlegend geändert. Für die Entstehung geht man von einer Barrierestörung der intestinalen Schleimhaut aus, die auf eine mangelhafte Cadherin-Synthese zurückgeführt wird. Vor diesem Hintergrund muss die Indikation von chirurgischen 
Maßnahmen bei chronisch entzündlichen Darmerkrankungen einer kritischen Prüfung unterzogen werden.

Konsens zum chirurgischen Vorgehen besteht beim Auftreten von Komplikationen (Blutung, Perforation, Abszess, enterale Fistel, Stenose, toxisches Megakolon) und Malignomen bei CED. Die therapierefraktäre Entzündung in Verbindung mit Wachstumsverzögerung und erhebliche Gedeihstörungen bedürfen eines intensiven Dialogs.

Anhand eigener Erfahrungen und einer Literaturanalyse werden die gängigen Operationsindikationen und deren Terminierung überprüft. Die akute, $\mathrm{Hb}$-wirksame Blutung sowie eine freie Perforation stellen klassische Notfallindikationen dar. Das gilt ebenso für das konservativ nicht behandelbare toxische Megakolon, das stets die totale Kolektomie erfordert.

Für Abszesse gilt das alte Prinzip: ubi pus, ibi evacua. Lediglich sehr kleine Abszesse lassen sich antibiotisch behandeln. Es muss stets die Möglichkeit der interventionellen Drainage gegen einen operativen Eingriff abgewogen werden. Drainagen bergen die Gefahr einer Fistelbildung in sich.

Entereale Fistelbildung mit der Ausbildung eines funktionellen Kurzdarmsyndroms sollten alsbald der chirurgischen Therapie zugeführt werden. Eine erfolgreiche medikamentöse Therapie der Fisteln wurde bisher nicht publiziert. Das gleiche gilt für die belastenden enterovesikalen bzw. enterovaginalen Fisteln. Allerdings ist die chirurgische Korrektur dieser Fisteln sehr anspruchsvoll und die Rezidivrate beträchtlich.

Analfisteln können häufig mit Infliximab-Therapie zur Ausheilung gebracht werden. Eine wiederholte Resektion einer Analistel birgt die große Gefahr des Rezidivs, eines Fuchsbaus und auf der Dauer der Inkontinenz in sich. Bleiben medikamentöse und alimentäre Therapie ohne Erfolg, so muss eine Fadendrainage indiziert werden.

Der früher sehr gefürchtete Ileus aufgrund Stenosen reagiert exzellent auf die Kombination einer alimentären und Steroidtherapie. Beim therapierefraktären Befund bzw. Konglomerattumor sollte die klassische Resektionstherapie in enger Absprache mit den Gastroenterologen erfolgen werden. Die Strikturoplastik zeigt sich der Resektionstherapie gegenüber überlegen.

Geht die aktive Erkrankung mit erheblicher Gedeihstörung und Wachstumsverzögerung (über 2 Standardabweichungen hinausgehend) einher, so führt die Resektionstherapie in die Remission und wird ein Aufholwachstum erreicht.

Die sehr selten auftretenden Malignome im Jugendalter müssen stets baldmöglichst der operativen Therapie zugeführt werden.

Insgesamt sollte die chirurgische Therapie idealerweise in ständigem Dialog und Konsens mit den pädiatrischen Gastroenterologen indiziert und terminiert werden.

\section{Unfallprävention}

\section{DGKJ-GEM-21 \\ Das WHO-Safe-Community Konzept - Beispiel durch das Land Bran- denburg \\ G. Ellsäßer \\ Landesgesundheitsamt Brandenburg}

Die Safe Communities sind ein internationaler Zusammenschluss von derzeit 180 Städten und Regionen aus aller Welt, die sich zu einer gemeindeorientierten Verletzungsprävention verpflichtet haben. Ziel der Safe Communities-Bewegung ist es, sichere Lebenswelten vor Ort zu schaffen. Die Weltgesundheitsorganisation WHO setzt für die Anerkennung als „Safe Community“ die Erfüllung von sechs Indikatoren voraus:

- Aufbau einer Infrastruktur, die auf Partnerschaft und Zusammenarbeit basiert.
- Durchführung langfristiger und nachhaltiger Programme, die beide Geschlechter sowie alle Altersgruppen umfassen und lebensweltorientiert ausgerichtet sind.

- Durchführung von Programmen für Risikogruppen

- Verletzungsmonitoring: Evaluation der Aktivitäten: Teilnahme am internationalen Safe Community Netzwerk

Am 11. Dezember 2009 wurde das Land Brandenburg als „Safe Region“ im Netzwerk der Safe Communities der Weltgesundheitsorganisation WHO zertifiziert. Das Land Brandenburg ist damit die erste Region in Deutschland, die dieses Label erhält - ein für die regionale Weiterentwicklung der Prävention von Unfällen und Gewalt wichtiger Meilenstein und auch Vorbild für andere Bundesländer oder Kommunen. Mit der Etablierung des Safe Community-Programms in Brandenburg folgt das Land Brandenburg den Empfehlungen des Europäischen Rates vom Mai 2007, die Prävention von Verletzungen durch koordinierte Aktionspläne zu stärken. Der Kurzbericht „Sicheres Brandenburg - auf dem Weg zur Safe Region“" sowie der Antragsbericht enthalten weitere Informationen und stehen unter www. gesundheitsplattform. brandenburg. de (unter „Sicheres Brandenburg“) zum downloaden bereit (1).

In Brandenburg wird die Unfall- und Gewaltprävention auch für besonders gefährdete Bevölkerungsgruppen (Kinder, ältere Menschen, junge Verkehrsteilnehmer, Frauen) nach den Standards der Safe Communities umgesetzt: Die Akteure zur Prävention von Verletzungen wirken in einem verbindlichen Kooperationsnetz zusammen. Eine Steuerungsgruppe auf ministerieller Ebene, 5 ressortübergreifende Arbeitsgruppen und die Geschäftsstelle im Landesgesundheitsamt als Bindeglied zwischen Akteuren und Politik, bilden die strukturelle Grundlage. Diese Struktur ist eine wichtige Voraussetzung für ein planvolles und abgestimmtes Vorgehen.

Eine standardisierte Bewertung von insgesamt 59 Projekten zur Unfallund Gewaltprävention zeigt, dass Maßnahmen im Land Brandenburg seit Jahren zielgruppen- und settingbezogen durchgeführt werden und somit die Kriterien der „safe community“ erfüllen. Schwerpunkte sind u. a. die Verhütung von Unfällen und Gewalt bei Kindern und Jugendlichen, die Prävention von häuslicher Gewalt sowie die Sicherheit von jungen Verkehrsteilnehmern im Straßenverkehr (wie Kinder oder junge Autofahrer).

Das Landesgesundheitsamt beobachtet und bewertet das Verletzungsgeschehen anhand eines kontinuierlichen Verletzungsmonitoring (2). Darüber hinaus wurde am Carl Thiem Klinikum in Cottbus die europäische Injury Data Base (IDB) etabliert, eine standardisierte Erfassung von ambulant und stationär behandelten verletzten Patienten (Verletzungen durch Unfälle, Gewalt und Selbstverletzungen) (3). Das Verletzungsmonitoring und die Ergebnisse werden vorgestellt, da sie die Basis für die Brandenburger Ziele und Maßnahmen in der Unfallprävention von Kindern und Jugendlichen bilden.

Dass regionale oder gemeindeorientierte Ansätze in der Verletzungsprävention hoch wirksam sind, wird durch internationale Forschungsergebnisse bestätigt. Die regionale Verletzungsprävention steht in Deutschland erst am Anfang. Deshalb wäre es sehr zu begrüßen, wenn das Brandenburger Modell auch in anderen Regionen Schule machen würde.

Literatur: 1 Sicheres Brandenburg - auf dem Weg zur Safe Region (2009) Antragsbericht zur Zertifizierung des Landes Brandenburg als Safe Region innerhalb des WHO-Programms "Safe Communities“. Ministerium für Umwelt, Gesundheit und Verbraucherschutz des Landes Brandenburg (Hrsg.)

2 Ellsäßer G, Müller R (2009) Verletzungsgeschehen durch Unfälle und Gewalt bei Kindern und Jugendlichen im Land Brandenburg. Landesgesundheitsamt Brandenburg im Landesamt für Soziales und Versorgung (Hrsg.) !nfaktum Ausgabe 01/o9

3 Erler T, Ellsäßer G (2010) Die Gesichter der Opfer - Auswirkungen von Gewalt bei Kindern und Jugendlichen erkennen. Pädiat. Prax. 75, 387-395 (2010) Hans Marseille Verlag GmbH München 
DGKJ-GEM-22

Die Rolle der European Child Safety Alliance - Bedeutung und Konsequenzen für die medizinischen Gesellschaften

S. Märzheuser

Charité Universitätsmedizin Berlin, Klinik für Kinderchirurgie

Die European Child Safety Alliance (ECSA) ist das europäische Netzwerk zur Prävention von Kinderunfällen und Verbesserung der Kindersicherheit in Europa (EuroSafe). Sie will Kindersicherheit als Querschnittsaufgabe voranbringen, wirksame präventive Maßnahmen verbreiten sowie Qualität und Quantität von Daten und Forschung beeinflussen. Das Programm wird von einem Steuerungsgremium geleitet. Dieses Steuerungsgremium setzt sich aus Repräsentanten aus 30 Mitgliedsländern der Europäischen Union zusammen, zusätzlich haben Beobachter aus EU-Anwärterländern die Möglichkeit an den Sitzungen teilzunehmen.

Kindersicherheit wird in der EU zunehmend als wichtiges Handlungsfeld wahrgenommen. Unfallbedingte Verletzungen sind bei Kindern in Europa die Todesursache Nummer Eins, und die Sicherheitsunterschiede in den Nationen sind groß. So gilt es, koordinierte Aktivitäten zu starten und von den Besten zu lernen. Die EU unterstützt deshalb die ECSA und deren zentrales Projekt den Child Safety Action Plan. Zur Förderung gezielter nationaler Aktionspläne hat die ECSA Sicherheit und Präventionsstrategien in den Mitgliedsländern verglichen, wobei für Deutschland noch Verbesserungsbedarf festgestellt wurde.

In Deutschland werden nicht alle Präventionspotentiale genutzt und unfallpräventive Maßnahmen nicht ausreichend evaluiert. Deshalb sollten die Hochschulen für das Thema Verletzungsprävention interessiert und neue Schwerpunkte in Forschung und Lehre gesetzt werden. Zur Verbesserung der Evidenzbasierung sollten zu der Frage, wie unfallpräventive Maßnahmen wirken und welche Interventionen effektiv sind, Forschungsprojekte angestoßen werden.

Ziel dieser Arbeit soll es sein, in Europa und den individuellen Mitgliedsländern Maßnahmen zu empfehlen, deren Effektivität geprüft und ausreichend evaluiert ist

\section{DGKJ-GEM-24}

Die Europäische Injury Database IDB - Projekt zur Unfallerfassung und Unfallprophylaxe

T. Woller

Universitätsklinikum Leipzig, Klinik und Poliklinik für Kinderchirurgie

Hintergrund: Unfälle sind die häufigste Todesursache bei Kindern, im Schulalter sind sie der häufigste Grund für einen Krankenhausaufenthalt. Im Jahr 2007 wurden in Deutschland ca. 1,7 Millionen Kinder unter 15 Jahren verletzt. Etwa 197. ooo Kinder mussten wegen einer schweren Verletzung im Krankenhaus stationär behandelt werden, 281 Kinder wurden 2007 durch einen Unfall getötet. In Leipzig beträgt der Anteil unfallverletzter Kinder und Jugendlicher ca. 10. ooo pro Jahr. Diese Zahlen sind erschreckend und alarmierend, insbesondere wenn man bedenkt, dass bis zu 95\% der tödlichen Unfälle und $60 \%$ der Unfälle mit Verletzungen verhindert werden könnten. Voraussetzung dafür ist, dass Unfälle systematisch auf ihre Ursachen untersucht und alters- und umgebungsspezifische Präventionsmöglichkeiten ermittelt werden.

Methodik: Seit 2006 beteiligen sich einzelne Krankenhäuser in Deutschland an einem kontinuierlichen Verletzungsmonitoring im Rahmen einer europäischen Datenbank (Injury Database, IDB). Seit 2007 ist auch die Klinik und Poliklinik für Kinderchirurgie Leipzig in dieses krankenhausbezogene Erfassungssystem von Verletzungen implementiert. Im Rahmen der IDB werden kontinuierlich die Daten aller verletzungsbedingt behandelten Kinder und Jugendlichen unter 18 Jahren als Stichprobe an einem Tag in der Woche erhoben. Erfasst werden dabei sowohl soziodemografische Daten als auch das Verletzungsereignis über die Kernmerkmale Intention, Unfallort, Unfallmechanismus, Tätigkeit der verletzten Person und beteiligte Produkte.
Ergebnisse: Die erhobenen Daten ermöglichen detaillierte und bevölkerungsbezogene Aussagen zu Verletzungen durch Unfälle und Gewalt. Die IDB ermöglicht Einblicke in den Verletzungshergang, sie identifiziert verschiedene Verletzungskategorien und altersspezifische Verletzungsmechanismen und informiert über die Vermeidbarkeit von Unfällen. Die Bedeutung von Produkten als Auslöser von Unfällen kann erkannt und direkt in Präventionsempfehlungen umgesetzt werden.

Schlussfolgerung: Die Injury Database ist ein wirksames Instrument zur systematischen Untersuchung von Verletzungsursachen und -mechanismen als Voraussetzung für eine alters- und umgebungsspezifische Unfallprävention.

\section{Kinderbewusstsein Festvortrag mit Verleihung des Stefan-Engel-Preises und Statements der familienpolitischen Sprecher der Fraktionen des Deutschen Bundestages}

\section{DGKJ-GEM-26}

\section{Kinderbewusstsein - Was Kinder wirklich brauchen}

Seit einigen Jahren werden die Kinder und Jugendlichen in ihrem körperlichen und psychischen Wohlbefinden zunehmend beeinträchtigt. So nehmen die Klagen über psychosomatische Störungen und Verhaltensauffälligkeiten, soziale Ausgrenzung und Schulverweigerung, Risikoverhalten, Drogen und Alkohol-Konsum ständig zu. Kinder und Jugendliche leiden unter einer allgemeinen Verunsicherung, die sich in Familie, Schule und Gesellschaft ausgebreitet hat.

Für diese Verunsicherung gibt es zahlreiche Gründe. Einer der wichtigsten ist zweifelsohne, dass Bildung und Erziehung in einer engen Wechselbeziehung mit Gesellschaft, Kultur und Wirtschaft stehen. In den vergangenen 40 Jahren ist es in diesen drei Bereichen zu Umwälzungen gekommen, die wir in ihrem ganzen Ausmaß noch nicht erfasst und schon gar nicht bewältigt haben.

Gesellschaft: Mit der Entwicklung von der Gross- zur Kleinfamilie und weiter zur Scheidungs- und Patchworkfamilie haben sich Betreuung und Erziehung der Kinder tief greifend verändert. Zusätzlich hat sich auch das Rollenverständnis von Frau und Mann und damit dasjenige von Mutter und Vater gewandelt. Der gesellschaftliche Anspruch, dass die Eltern für die alleinige Betreuung der Kinder zuständig sind, kann immer weniger eingelöst werden. Dafür steht die Gesellschaft umso mehr mehr in der Verantwortung.

Kultur: Es besteht eine Kluft zwischen den Generationen. Die Kontinuität der Traditionen können die älteren Menschen, auch wenn sie dies noch so sehr möchten, nicht mehr aufrechterhalten, während die jungen Menschen sich mühelos laufend Neues aneignen, was die älteren wiederum verunsichert. So hat der technische Fortschritt, vor allem im IT-Bereich, und damit die allgemeine Verfügbarkeit von Information die Hierarchie der Generationen zumindest nachhaltig erschüttert, wenn nicht umgedreht. Eltern und Lehrer gehörten einer anderen Zeit an als die Kinder - was das Erziehen und das Unterrichten kompliziert und anspruchsvoll macht.

Wirtschaft: Europa hat sich von einer Industrie- zu einer Dienstleistungs- und Wissensgesellschaften gewandelt, was dem Bildungssystem tief greifende Anpassungen abverlangt. Die Resultate der PISAStudien haben bei Bildungspolitikern und Bildungswissenschaftlern wie auch in der Bevölkerung schwere Zweifel am bestehenden Schulsystem geweckt, was zu überhasteten Schulreformen führte, die Kinder und Eltern unter massiven Druck setzen. Eltern der Mittel- und Oberschicht investieren in ihre Kinder wie nie zuvor. Frühförderung und Nachhilfe stehen auf der elterlichen Agenda ganz oben.

In dem Gemenge der gesellschaftlichen, kulturellen und wirtschaftlichen Umwälzungen drohen die Grundbedürfnisse der Kinder und Jugendlichen unterzugehen. Wir müssen alles daran setzen, um das körperliche und psychische Wohlbefinden der Kinder besser $\mathrm{zu}$ 
gewährleisten, und die Kinder darin zu unterstützen, ihr individuelles Entwicklungspotenzial möglichst gut auszuschöpfen. Nur so können die Kinder zu jenen eigenständigen, kreativen und lernbereiten Individuen zu werden, die sich in dieser zunehmend vielseitigen, dynamischen und anforderungsreichen Gesellschaft der Zukunft erfolgreich behaupten können. Eine kindorientierte Gesellschaft zu schaffen stellt eine grosse gesundheitsmedizinische, pädagogische und politische Herausforderung dar.

\section{Akutes Abdomen - Differentialdiagnostik und Schmerztherapie}

\section{DGKJ-GEM-28}

Die Passagezeit von Mekonium bei Neugeborenen unter $1000 \mathrm{~g}$ Geburtsgewicht - Ein klinischer Marker der gastrointestinalen Funktion

J. Trapp 1 , P. Degenhardt ${ }^{2}$

${ }^{1}$ Klinik für Kinder- und Jugendmedizin, Evangelisches Waldkrankenhaus Spandau, ${ }^{2}$ Klinik und Poliklinik für Kinderchirurgie der Medizinischen Fakultät Charité - Universitätsmedizin Berlin

Hintergrund: ELBW-Frühgeborene können als Symptom ihrer Darmunreife gastrointestinale Passagestörungen, Entzündungen oder Perforationen präsentieren. Klinisch beobachten die Kinderchirurgen der Charité, dass Frühgeborene, die wegen eines akuten Abdomens operationspflichtig werden, häufig im Vorhinein einen verspäteten Mekoniumabgang aufweisen. Ziel: Zu analysieren, inwiefern der Zeitpunkt des Mekoniumabganges ein klinisch anwendbarer Frühmarker der Darmfunktion von ELBW-Neugeborenen ist. Methodik: Retrospektive Fall-Kontrollstudie mit zeitlicher Erfassung von Mekoniumabgängen bei ELBW-Neugeborenen. Die OP-Gruppe bestand aus Kindern, die wegen eines akuten Abdomens operativ an der Charité versorgt wurden. Die Kontrollgruppe wurde aus Kindern ohne akutes Abdomen per Matched Pair System ermittelt. Der Zeitpunkt des ersten dokumentierten Mekoniumabganges wurde als „M1“, der des letzten als „Mlast“ erfasst. Mögliche Konfounder der Passagezeit wurden zur Überprüfung auf Gleichverteilung in beiden Gruppen erhoben. Ergebnisse: Bei 70 verwendbaren ELBW-Fällen - je Gruppe 35 - war der Zeitpunkt von Mlast in der OP-Gruppe mit $172 \mathrm{~h}(29-696 \mathrm{~h})$ signifikant später $(\mathrm{p}=0,033)$ als in der Kontrollgruppe (141 h, $27-269$ h). Der Zeitpunkt von M1 zeigte Gruppenvergleich keinen signifikanten Unterschied: OPGruppe 14 h (1 - 242 h), Kontrollgruppe 9 h $(1-81$ h). Die Faktoren niedriges Gestationsalter und Geburtsgewicht, schlechter CRIB-Score und später Nahrungsaufbau korrelierten mit verzögertem Mekoniumabgang. Schlußfolgerung: ELBW-Kinder mit abdominellen Problemen haben häufig einen verspäteten Mekoniumabgang. Dies drückt sich jedoch nur für Mlast signifikant aus, nicht für M1. Mlast sagt mehr über die Verdauungsaktivität aus als $\mathrm{M}_{1}$, da Mlast als Repräsentant der totalen Mekoniumausscheidung auf die Funktion von Dünn- und Dickdarm hinweisen kann, während $\mathrm{M}_{1}$ lediglich ein Indikator der terminalen Dickdarmfunktion ist. Wir empfehlen vor allem die Erfassung von Mlast bei abdominell auffälligen Kindern unter Berücksichtigung des individuellen Gestationsalters, Geburtsgewichtes, CRIB-Score und Ernährungsform des Kindes.

\section{DGKJ-GEM-32}

Schmerztherapie bei akutem Abdomen, altersspezifische Besonderheiten

Das akute Abdomen ist ein Zustand zwischen lebensbedrohlicher und harmloser Situation, zwischen Operation und spontaner Genesung. Der Schmerz ist Hauptproblem und wichtigstes Symptom.

Immer ist die Frage: Wird der Verlauf durch eine Maßnahme ungünstig beeinflusst?

Als Prinzip gilt je jünger, desto strikter:
1. eine Analgesie ist meist auch eine Sedierung. Atmung und Kreislauf müssen stets überwacht und gesichert werden.

2. das Medikament darf nicht selbst zur Ursache eines akuten Abdomens werden.

3. die Applikation (i. v., rektal, nasal) muss problemarm sein und 4. Schmerzfreiheit heißt nicht Auflösung des „akuten Abdomens“ Auf der anderen Seite wird durch eine Analgesie und ggf. Sedierung erreicht, dass:

1. der Patient einer Untersuchung leichter zugänglich ist,

2. bestimmte diagnostische Eingriffe so überhaupt erst möglich sind

(Sonogramm, Kontrasteinlauf, ...)

3. der Schmerz als Schockursache ausscheidet und

4. Eltern/Begleiter beruhigt sind. Sie können leichter befragt werden. Medikament der Wahl ist das Medikament, mit dem die Person oder das Haus gut umgehen kann. Auf unerwartete Ereignisse wie bei jeder Analgesie/Sedierung muss man vorbereitet sein. Oft ist das etabliert postoperative Therapieprototkoll auch präoperativ, gut weil es allen bekannt ist

In der Hand des Referenten bewährt haben sich:

Dipidolor $^{\oplus}\left(\right.$ Piritramid $\left.^{\circledR}\right)$ i. v., PCA Ketanest ${ }^{\oplus}$ S $\left(\operatorname{Ketamin}^{\circledR}\right)$ i. v., i. $m$.

Dormicum $^{\circledR}$ (Midazolam ${ }^{\circledR}$ ) nasal, i. v. Buscopan ${ }^{\circledR}$ (Butylscopolamin) i. v. Alternativen sind als Kurzinfusion Paracetamol ${ }^{\circ}$ und Metamizol $^{\circ}$ ggf. plus Piritramid ${ }^{\oplus}$ (oder + Tramadol ${ }^{\circledR}$ ).

Ibuprofen ${ }^{\otimes}$ hat ein ungünstiges Profil für diese Indikation.

Manterola et al. Analgesia in patients with acute abdominal pain. Cochrane Database Syst Rev 2007;18: CDoo5660

\section{Migration und Gesundheit}

\section{DGKJ-GEM-37}

\section{Macht Migration krank?}

M. Knipper

Institut für Geschichte der Medizin

Der Zusammenhang zwischen Migration und Krankheit ist komplex. Zum einen aufgrund der vielfältigen mit Migrationsprozessen und dem sozialen Status als „Migrant" verbundenen, positiven wie negativen (und in der Regel nicht für „Migranten“ spezifischen) Einflussfaktoren auf die physische und psychische Gesundheit. Nur selten liegen die Verhältnisse so klar wie etwa bei erblich bedingten Leiden mit deutlichem geographischem Bezug wie im Falle der Sichelzellkrankheiten oder Thalassämien. Der andere Grund besteht in der Vieldeutigkeit und in der Regel mangelhaften Trennschärfe von Begriffen wie „Migrant" und Migrationshintergrund" sowie von ethnischen und Herkunftskategorien. Migration per se ist nicht „pathologisch“, kann jedoch mit verschiedenen Risiken assoziiert sein, die jeweils differenziert zu analysieren sind. Der Vertrag erörtert die Möglichkeiten und Bedingungen für eine angemessene Herangehensweise an die für die ärztliche Praxis, Epidemiologie und Sozialmedizin gleichermaßen relevante Frage, ob bzw. unter welchen Umständen Migration „krank“ macht. Dabei wir die im engeren Sinne medizinische mit einer kulturund sozialanthropologischen Perspektive kombiniert.

\section{DGKJ-GEM-38 \\ Kinder- und Jugendliche mit Migrationshintergrund in der pädiatri- schen Praxis \\ F. Cerci \\ Kinder- und Jugendarzt}

Der Begriff „Kinder und Jugendliche mit Migrationshintergrund“ umfasst nicht nur Ausländer, sondern auch eingebürgerte Migranten sowie Spätaussiedler. Da es sich um eine heterogene Gruppe handelt ist in der Praxis die Information um „welche Migrantenkinder" es sich handelt von Bedeutung. Kinder mit Trauma-Erfahrung oder sonstige gefährdete Kinder benötigen besondere Aufmerksamkeit. Neueinge- 
wanderte Migranten und die hier eingelebte Migranten können medizinisch unterschiedliche Probleme aufweisen. Im Alltag überwiegen meistens wie bei allen anderen Kindern auch die üblichen Krankheiten wie Luftwegsinfekte oder Magen-Darminfekte, sowie Krankheitsmanagement bei chronischen Erkrankungen, und Vorsorgen und Impfungen.

Wir müssen bei unserem ärztlichen Vorgehen je nach der Situation den Migrationskontext beachten und dafür notwendige Kenntnisse besitzen. Bei neu angekommenen Migranten müssen wir eher mit Infektionskrankheiten wie Tuberkulose, Malaria, Hepatitis A und B, Wurmerkrankungen oder aber auch mit Anämien rechnen, die in bestimmten Herkunftsländern häufig vorkommen. Mit der Zeit beeinflussen dann mehr und mehr Lebensverhältnisse und Lebensstil sowie sozioökonomische Faktoren das Krankheitsgeschehen. Manche genetischen Erkrankungen wie Hämoglobinopathien sind bei einigen Migrantengruppen häufiger festzustellen. Seltene autosomal rezessive Erkrankungen kommen bei Verwandtenehen gehäuft vor. Der diagnostische und therapeutische Erfolg und die Arzt-Patientenbeziehung kann einerseits beeinflusst werden von unterschiedlichen Erwartungen an unserem Gesundheitssystem und von medizinisch relevanten Denk- und Verhaltensweisen, sowie andererseits von unseren kommunikativen Fertigkeiten mit diesen Patienten umzugehen, wodurch wir auch die Inanspruchnahme unserer medizinischen Angebote in der Praxis erhöhen können.

Wenn Sprachbarrieren nicht zu überbrücken sind brauchen wir geeignete Dolmetscher.

Bei diesem Vortrag werden Beispiele für die Vorgehensweise in der Praxis genannt.

\section{DGKJ-GEM-39}

\section{Migration - spezieller Risikofaktor in der Entwicklung von Kindern} und Jugendlichen mit Migrationshintergrund?

H. Bode

Universitätsklinikum Ulm

Etwa $30 \%$ der Kinder und Jugendlichen in Deutschland kommen aus Familien mit Zuwanderungshintergrund. 70 \% der Kinder türkischer Eltern und 50 \% der Kinder von Eltern aus den ehemaligen GUS - Staaten leben in sozial schwachen Familien (Mikrozensus 2005).

Seit langem ist der soziale Gradient für Gesundheit und Krankheit bekannt. Der Bildungbericht 2010 belegt dies erneut auch für die schulische Entwicklung.

Sind vermeintliche migrationsbedingte Häufungen von Krankheiten und Entwicklungs- sowie Lernproblemen bei Kindern und Jugendlichen tatsächlich Migrationsfolge oder vielmehr Ausdruck sozialer Schichtung / Benachteiligung?

Die Datenlage lässt für Deutschland bislang hier keine eindeutigen Aussagen zu.

Vor dem Hintergrund eines theoretischen Konzeptes vielfältiger Schutz- und Risikofaktoren für die Entwicklung und Gesundheit von Kindern und Jugendlichen und einiger empirischer Daten aus aktuellen epidemiologischen Untersuchungen soll ein differenzierender Ansatz begründet werden: Genetische Faktoren und Polymorphismen, Gesundheits- und Erziehungsverhalten, innerfamiliäre Beziehungen und das Rollenverständnis, z. B. hinsichtlich der Förderung von Kindern, Gewalt, Medienkonsum, Wohnsituation, soziale Isolation, Heterogenität / Ghettoisierungstendenzen in in Kitas und Schulen, soziale Vorbilder (Aufsteiger vs. mehrgenerationale Hartz IV- Familien), Gründe/ Umstände / Verarbeitung der Migration, Zugangsbarrieren zu Institutionen der Förderung / Bildung / Ausbildung / des Gesundheitswesens seitens der Migrantenfamilien und seitens der Personen und Einrichtungen in Deutschland ( Fremdenfeindlichkeit / Interkulturelle Öffnung) u. a. m. sind zu berücksichtigen.

Migration kann Chance und Risiko für die Entwicklung von Kindern und Jugendlichen sein. Zur Zeit überwiegen für die Migranten als gesamte Gruppe in Deutschland die Risiken.
Wirksame Interventionen zur Verbesserung der Chancen für eine gute Entwicklung und Gesundheit von Kindern und Jugendlichen mit Migrationshintergrund können nur auf dem Boden differenzierter Analysen nach Sozialraum, Herkunftsland, Bildungsstand, Geschlecht, kultureller Prägung, sozialer Lage usf. stattfinden. Sie müssen Migranten aktiv in die Planung und Umsetzung der Interventionen einbeziehen (Dolmetscher, muttersprachliche Pädagogen und medizinisches Personal, Communities, erfolgreiche Migranten als Modelle etc.)

Individuum -bezogene Ansätze erweisen sich dabei aus sozialpädiatrischer Erfahrung oft als relativ frustran für die Betroffenen Familien und die professionellen Helfersysteme.

\section{Samstag, 18. September 2010}

\section{Kooperationsmodelle im Kinderschutz}

\section{DGKJ-GEM-48}

\section{Kooperationsmodell zwischen Jugendamt und Kinderklinik in Stutt-} gart

A. Oberle' ${ }^{1}$ W. Reich ${ }^{2}$

${ }^{1}$ Klinikum Stuttgart - Olgahospital, ${ }^{2}$ Jugendamt der Stadt Stuttgart

Kinderschutz gibt es nicht zum Nulltarif und ist nur in der multiprofessionellen Zusammenarbeit adäquat möglich. Mit dem im Bereich Kinderschutz beispielhaft tätigen (Diagnoseinstrument Kinderschutzbogen) und bundesweit bekannten Jugendamt der Stadt Stuttgart hat die städtische Kinderklinik eine Kinderschutzkonzeption entwickelt. Trotz aktuell schwieriger finanzieller Situation schuf der Gemeinderat die Möglichkeit, 2 feste Stellen sowohl im Pädiatrischen Zentrum des Klinikums Stuttgart - dem Olgahospital - als auch im Jugendamt für diese Kinderschutzarbeit neu einzurichten. Dies eröffnet zukunftsweisende Möglichkeiten. Mitarbeiter des Jugendamts und des Olgahospitals bilden zukünftig ein Kinderschutz-Team im Olgahospital. Die Dienstund Fachaufsicht liegt bei der jeweiligen Organisation, die personalrechtliche und organisatorische Anbindung beim Jugendamt. Der Weg zu diesem "neuen Kooperationsmodell“ wird ausführlich erläutert. Es mussten ungewohnte strukturelle Rahmenbedingungen geschaffen werden und fachliche Verantwortlichkeiten institutionsübergreifend erarbeitet werden. Die 2 wesentlichen Säulen der Aktivitäten sind 1.: Kinderschutz ist eine Aufgabe für Alle in einer Kinderklinik Tätigen, die deshalb eine umfassende, aber auch kontinuierliche Qualifizierung erforderlich macht und 2.: es sind dafür ausschließlich eingesetzte, feste Mitarbeiter erforderlich. Von Anfang an wurde das Prinzip der Multiprofessionalität konsequent verfolgt und deshalb ist im „Startteam" neben den Sozialpädagogen im Olgahospital und Jugendamt, in der Kinderklinik ein Kinder- und Jugendarzt und eine Kinderkrankenschwester fest integriert. Die beiden Referenten werden darüber hinaus auf angestrebte Schritte in nächster Zukunft eingehen und die bisher im Verlauf aufgetretenen Stolpersteine, entstanden aus den Realitäten des Alltags, näher erläutern.

\section{DGKJ-GEM-49}

\section{Kooperationsmodelle im Kinderschutz: T. Erler}

Klinik für Kinder- und Jugendmedizin, Carl-Thiem-Klinikum Cottbus

Verfolgt man die öffentliche Stimmung in unserem Land, die von Medien nicht unwesentlich geprägt wird, so fällt zwangsläufig auf, dass immer wieder und regelmäßig von gravierenden Kindeswohlverletzungen berichtet und dies dann auch öffentlich thematisiert wird. Natürlich ist man dann rasch geneigt, nach verschärften Gesetzen zu rufen, vermeintlich Verantwortliche bestrafen zu wollen, von verkommener Moral zu sprechen, die doch früher so viel besser gewesen sei oder eben „alles anders machen zu müssen“. Mit Sicherheit ist es eine gesamtge- 


\section{Abstracts}

sellschaftliche Aufgabe, sich mit Problemen wie Misshandlung, Vernachlässigung oder sogar Missbrauch auseinander zu setzen. Trotzdem vertritt der Autor die Meinung, dass es keinen Grund gibt, von hoffnungslosen Zuständen zu sprechen oder zu behaupten, die Verwahrlosung oder Gefährdung unserer Kinder würde immer schlimmer. Tagtäglich setzten sich zahlreiche Mitarbeiter von Jugendämtern und Gesundheitsämtern, von Kindertagesstätten und Schulen, ehrenamtliche Helfer, soziale Organisationen und Institutionen usw. aufopferungsvoll für Kinder ein, die in Not geraten sind oder vor scheinbar unlösbaren Problemen stehen. Unsere Gesellschaft hat ein dicht gewebtes Netz, bestehend aus vielfältigen präventiven Maßnahmen, Fürsorgeprojekten, Bildungseinrichtungen, staatlichen Strukturen usw. entwickelt das günstige Entwicklungschancen für alle Kinder und Jugendliche garantieren sollte. Natürlich bedarf dies immer wieder der Belebung durch engagierte Mitarbeiter, die sich auch in regelmäßigen Abständen weiterbilden, die Erfahrungen austauschen und voneinander lernen. Besonders schwierig ist es in einem Flächenland die Vernetzung dieser Kinderschutzakteure zu realisieren. Beispielhafte Strukturen, Veranstaltungen und Aktionen für einen wirksamen Kinderschutz des Landes Brandenburg werden im Sinne eines Erfahrungsberichtes vorgestellt. Das Thema Kinderschutz geht über den Problemkreis des Missbrauchs und der Misshandlung weit hinaus und umfasst auch Bereiche wie z. B. die Unfallprävention im privaten und öffentlichen Leben, die Organisation ärztlicher und hygienischer Versorgung, der allgemeinen Gesundheitsvorsorge, die Bekämpfung von Armut und Hunger, den Kinderschutz vor und unmittelbar nach Geburt (Thema Babyklappen!) sowie den Umgang mit Suiziden, Tötungsdelikten und vermissten Kindern. Unsere Gesellschaft muss erkennen, dass wirkungsvolle Erfolge auf dem Gebiet des Kinderschutzes nur durch konsequente Vernetzung der Strukturen aller Entscheidungsträger erreicht werden kann. 